CARLOS HENRIQUE DA SILVA

\title{
“DEGRADAÇÃO DE UHMWPE E DE POM DEVIDO À AÇÃO TRIBOLÓGICA CONTRA AÇO INOXIDÁVEL E ALUMINA"
}

Tese apresentada à Escola Politécnica da Universidade de São Paulo para a obtenção do título de Doutor em Engenharia.

\section{SÃO PAULO}

2003 


\section{CARLOS HENRIQUE DA SILVA}

\section{“DEGRADAÇÃO DO UHMWPE E DO POM DEVIDO À AÇÃO TRIBOLÓGICA CONTRA AÇO INOXIDÁVEL E ALUMINA”}

Tese apresentada à Escola Politécnica da Universidade de São Paulo para a obtenção do título de Doutor em Engenharia.

Área de concentração: Engenharia Mecânica Orientador: Prof. Dr. Amilton Sinatora

\section{SÃO PAULO}

2003 
Este exemplar foi revisado e alterado em relação à versão original, sob responsabilidade única do autor e com a anuência de seu orientador.

São Paulo, 31 de Julho de 2003.

Assinatura do autor

Assinatura do orientador

FICHA CATALOGRÁFICA

Silva, Carlos Henrique da

Degradação de UHMWPE e de POM devido à ação tribológica contra aço inoxidável e alumina / Carlos Henrique da Silva. -- ed.rev. -- São Paulo, 2003. 294 p.

Tese (Doutorado) - Escola Politécnica da Universidade de São Paulo. Departamento de Engenharia Mecânica..

1. Tribologia 2. Polímeros 3. Aço inoxidável 4. Alumina 5. Fluência dos materiais I. Universidade de São Paulo. Escola Politécnica. Departamento de Engenharia Mecânica. II. t. 


\section{AGRADECIMENTOS}

Ao Professor Doutor Amilton Sinatora, pela orientação, amizade e estímulo para a conclusão desta pesquisa.

Ao Professores Dr. Deniol Katsuki Tanaka e Dr. Roberto Martins de Souza, pela sempre valiosa colaboração na realização deste trabalho.

Ao MSc. Vanderlei Ferreira e a $\operatorname{Dr}^{\mathrm{a}}$ Marcia Marie Maru, pela amizade valiosa e ajuda em todos os sentidos.

Aos integrantes e ex-integrantes do Laboratório de Fenômenos de Superfície LFS: Adelci, Alejandro, Alexandre Martins, Alex Oraggio, Álvaro, Aloísio, André Guimarães, Andréia, Antônio, Argemiro, Carlos Figueroa, Daniel, Diego, Eduardo, Elvys, Felipe, Fran, Giuseppe, Gustavo Cueva, João Telésforo, Jovânio, Júlio Klein, Júlio Aya, Juliano, Juan Vélez-Restrepo, Leandro, Leonardo, Luiz Henrique, Luiz Mari, Marcos Ara, Marcos Manuel, Marcelo Guimarães, Maluf, Michelle, Miguel, Márcio Cuppari, Márcio Matos, Maria Cristina, Ossimar, Paulo Ferrari, Paulo Ferrer, Parada, Rélbis, Ricardo Murilo Dias, Renato, Rui, Sidney, Silene, Silmara, Urbano e Wilson Carlos.

Aos alunos de iniciação científica: Etore Tomaz Frederici Filho, Marcelo Bolsonaro Moura, Eduardo Rigolizzo Ebeling, Murillo Moranza Di Cicco e Ricardo Millego de Castro.

Aos Professores Dr. Marcelo Carvalho Reis e Dr. Sebastião Vicente Canevarolo Jr. pela colaboração nas discussões do trabalho e por todo o apoio.

Ao Professor Dr. Linilson R. Padovese, pela ajuda com o modelamento por redes neurais.

À Fundação de Amparo à Pesquisa do Estado de São Paulo - FAPESP pela bolsa de estudos concedida no processo 91/12620-9.

À equipe do Laboratório de Metalografia do Departamento de Engenharia Metalúrgica e de Materiais da Escola Politécnica da USP, pela colaboração nas discussões e nas análises MEV, em especial ao Professor Doutor André Paulo Tschiptschin. 
À equipe do Laboratório de Polímeros do Departamento de Engenharia Metalúrgica e de Materiais da Escola Politécnica da USP, pela colaboração na realização das análises por calorimetria exploratória diferencial, em especial à $\operatorname{Prof}^{\mathrm{a}} \operatorname{Dr}^{\mathrm{a}}$ Nicole Raymonde Demarquette.

À equipe do Laboratório de Cerâmica e do Laboratório de Processamento de Materiais do Centro de Ciência e Tecnologia de Materiais (CCTM) do Instituto de Pesquisas Energéticas e Nucleares (IPEN), em especial ao Dr. José Carlos Bressiani e a Dr $^{\mathrm{a}}$ Ivana Conte Cosentino.

À equipe do Laboratório de Análises Térmicas de Polímeros do Departamento de Engenharia de Materiais (DEMA) da Universidade Federal de São Carlos (UFSCar), em especial ao Doutorando Nelson Larroca.

À equipe do Laboratório de Plasmas e Aplicações do Departamento de Física e Química da UNESP (Campus de Guaratinguetá), pela colaboração na determinação do trabalho de adesão dos materiais desta pesquisa, em especial ao Dr.Nilson C. Cruz e à $\operatorname{Dr}^{\mathrm{a}}$ Elidiane C. Rangel.

À equipe do Laboratório de Fundição da Divisão de Metalurgia do Instituto de Pesquisas Tecnológicas do Estado de São Paulo - (IPT), em especial ao Dr. Eduardo Albertin, Dr. Mário Bocalini Jr. e Dr. Flávio Beneduce Neto.

Ao Laboratório de Materiais do Centro Tecnológico da Marinha (LabMat CTM) do Ministério da Marinha (ARAMAR).

Às empresas BRASKEM, TICONA, CORMATEC Indústria e Comércio de Plásticos Ltda, MGS Indústria e Comércio de Plásticos Ltda, PLASTECNO Representações e Comércio Ltda, PIRELLI PNEUS S.A., IOCHPE-MAXION Fundição e Equipamentos Ferroviários, a Fundição CAMACAN e a Jaguaré Protótipos. 
"A beleza está em toda a parte. E talvez em cada momento de nossas vidas"

Jorge Luís Borges 


\section{SUMÁRIO}

RESUMO X xi

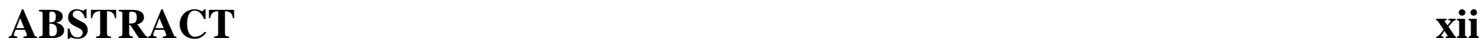

LISTA DE SÍMBOLOS X xiii

ABREVIAÇÕES Xvii

LISTA DE FIGURAS Xviii

LISTA DE TABELAS $\quad$ xxxi

1 . INTRODUÇÃO 1

2. REVISÃO BIBLIOGRÁFICA 3

2.1 Polímeros 4

2.1.1 Classificação dos polímeros 4

2.1.1.1 Tipo de ligações atômicas 4

2.1.1.2 Copolímero e homopolímero 5

2.1.1.3 Desempenho mecânico 6

$\begin{array}{lll}\text { 2.1.2 Físico-química dos polímeros } & 7\end{array}$

$\begin{array}{lll}\text { 2.1.2.1 } & \text { Cristalinidade } & 7\end{array}$

2.1.2.2 Massa molecular 8

$\begin{array}{ll}\text { 2.1.2.3 Densidade de energia coesiva } & 10\end{array}$

$\begin{array}{lll}\text { 2.1.3 Comportamento térmico } & 11\end{array}$

2.1.4 Comportamento mecânico de materiais viscoelástico 13

2.1.4.1 Fluência 13

2.1.4.2 Modelos reológicos diferenciais 15

2.1.4.2.1 O modelo de Maxwell 16

2.1.4.2.2 O modelo de Kelvin-Voigt 17

$\begin{array}{lll}\text { 2.1.4.3 Energia de amortecimento } & 17\end{array}$

$\begin{array}{lll}2.2 & \text { Tribologia dos polímeros } & 20\end{array}$

$\begin{array}{lll}2.2 .1 & \text { Atrito de polímeros } & 21\end{array}$ 
2.2.1.1 Mecanismos de atrito $\quad 21$

2.2.2 Efeito das características do composto polimérico no atrito 24

2.2.2.1 Energia de superfície 24

2.2.2.2 Morfologia das regiões cristalinas 25

2.2.3 Parâmetros do sistema tribológico e o atrito 26

2.2.3.1 Velocidade de deslizamento 26

2.2.3.2 Carga normal aplicada 28

2.2.3.3 Temperatura de contato 28

2.2.3.4 Umidade Relativa 30

2.3 Desgaste dos polímeros 31

2.3.1 Mecanismos de desgaste 33

2.3.1.1 Transferência de filme polimérico 33

2.3.1.1.1 Transferência "normal" 33

2.3.1.1.2 Transferência lamelar $\quad 34$

2.3.1.1.3 Transferência por Fusão 36

$\begin{array}{lll}2.3 .1 .2 & \text { Abrasão } & 37\end{array}$

$\begin{array}{lll}2.3 .1 .3 & \text { Fadiga } & 40\end{array}$

2.3.1.3.1 Fadiga devido às deformações 40

2.3.1.3.2 Fadiga devido à concentração de tensões 42

2.3.2 Efeito da cristalinidade no desgaste 43

2.3.3 Comportamento dinâmico-mecânico e o desgaste 45

2.3.4 Parâmetros do sistema tribológico e o desgaste 47

2.3.4.1 Carga, Velocidade e Condição PV 47

$\begin{array}{lll}\text { 2.3.4.2 Rugosidade } & 48\end{array}$

3. OBJETIVOS

4. MATERIAIS E MÉTODOS 52

$\begin{array}{lll}4.1 & \text { Materiais } & 52\end{array}$

4.1.1 Polímeros $\quad 52$

$\begin{array}{lll}\text { 4.1.1.1 POM } & 52\end{array}$ 
4.1.1.2 UHMWPE 54

4.1.1.3 Pinos de polímeros $\quad 55$

4.1.2 Aço Inoxidável 56

4.1.3 Alumina $\left(\mathrm{Al}_{2} \mathrm{O}_{3}\right) \quad 59$

$\begin{array}{lll}4.2 & \text { Ensaio Tribológico } & 60\end{array}$

$\begin{array}{lll}\text { 4.2.1 O Tribômetro } & 60\end{array}$

4.2.2 Montagem do ensaio $\quad 62$

4.2.3 Coeficiente de atrito e taxa de desgaste 64

4.2.4 Condições de ensaio 65

4.2.5 Temperatura no contato 66

4.2.6 Mecanismos de desgaste $\quad 68$

$\begin{array}{lll}\text { 4.2.7 Ensaio de fluência } & 69\end{array}$

$\begin{array}{lll}\text { 4.3 Caracterização dos corpos-de-prova } & 70\end{array}$

4.3.1 Calorimetria Exploratória Diferencial - DSC 70

4.3.2 Análise Termo-Dinâmico-Mecânica 70

$\begin{array}{lll}\text { 4.3.3 Energia de superfície } & 71\end{array}$

4.3.3.1 Método da gota séssil 71

$\begin{array}{lll}\text { 4.3.4 Densidade de energia coesiva } & 74\end{array}$

$\begin{array}{lll}\text { 4.3.5 Rugosidade } & 74\end{array}$

4.3.6 Ensaio instrumentado de dureza $\quad 75$

$\begin{array}{lll}\text { 4.3.7 Composição química do metal } & 77\end{array}$

$\begin{array}{lll}\text { 4.3.8 Análise metalográfica } & 77\end{array}$

4.3.8.1 Microscopia óptica 77

$\begin{array}{lll}\text { 4.3.8.2 Análise Quantitativa } & 77\end{array}$

$\begin{array}{lll}\text { 4.3.9 Dureza Vickers } & 78\end{array}$

$\begin{array}{lll}\text { 4.3.10 Densidade absoluta } & 78\end{array}$

$\begin{array}{lll}\text { 4.3.11 Difração de raios-X } & 78\end{array}$

5. RESULTADOS E DISCUSSÃO 80

5.1 Caracterização dos corpos-de-prova $\quad 80$

5.1.1 Polietileno de ultra-alto peso molecular - UHMWPE 80

5.1.1.1 Propriedades dinâmico-mecânicas $\quad 81$ 
5.1.1.2 Dureza Vickers $\quad 83$

5.1.1.3 Módulo de elasticidade 83

5.1.1.4 Grau de cristalinidade $\quad 84$

5.1.1.5 Densidade de energia coesiva 84

$\begin{array}{lll}\text { 5.1.1.6 Rugosidade } & 85\end{array}$

5.1.2 Polioximetileno - POM 86

5.1.2.1 Propriedades dinâmico-mecânicas 87

5.1.2.2 Dureza Vickers $\quad 89$

5.1.2.3 Módulo de elasticidade $\quad 90$

$\begin{array}{ll}\text { 5.1.2.4 Grau de cristalinidade } & 90\end{array}$

5.1.2.5 Densidade de energia coesiva 91

5.1.2.6 Rugosidade $\quad 92$

5.1.3 Aço inoxidável 93

5.1.3.1 Composição química 93

5.1.3.2 Análise metalográfica 94

5.1.3.3 Dureza Vickers 95

5.1.3.4 Módulo de elasticidade $\quad 95$

$\begin{array}{lll}\text { 5.1.3.5 Rugosidade } & 96\end{array}$

$\begin{array}{lll}\text { 5.1.4 Alumina } & 97\end{array}$

5.1.4.1 Difração de Raios-X 97

$\begin{array}{lll}\text { 5.1.4.2 Densidade } & 98\end{array}$

$\begin{array}{lll}\text { 5.1.4.3 Rugosidade } & 99\end{array}$

$\begin{array}{lll}\text { 5.2 Trabalho de adesão }-\mathrm{W}_{\mathrm{ab}} & 100\end{array}$

$\begin{array}{lll}5.3 & \text { Medidas de temperatura } & 101\end{array}$

$\begin{array}{lll}5.4 & \text { Ensaios de fluência } & 105\end{array}$

5.5 Determinação da taxa de desgaste 108

5.5.1 Resultados brutos de taxa de desgaste 109

5.5.2 Correção da taxa de desgaste devido à fluência 110

5.5.2.1 Correção dos dados do POM 111

5.5.2.2 Correção dos dados do UHMWPE 113

$\begin{array}{lll}\text { 5.5.3 Resultados corrigidos de taxa de desgaste } & 121\end{array}$

5.6 Análise dos resultados de taxa de desgaste 123 
$\begin{array}{lll}\text { 5.6.1 Desgaste do POM } & 125\end{array}$

5.6.1.1 POM x Alumina R3 125

5.6.1.2 POM x Alumina R4 135

5.6.1.3 Efeito do acabamento superficial no desgaste de POM x Alumina

5.6.1.4 POM x Aço Inox R2 141

5.6.1.5 POM x Aço Inox R3 145

5.6.1.6 Efeito do acabamento superficial no desgaste de POM x Aço Inoxidável

5.6.1.7 Efeito do contra-corpo na taxa de desgaste do POM 149

$\begin{array}{lll}\text { 5.6.2 Desgaste do UHMWPE } & 155\end{array}$

5.6.2.1 UHMWPE x Alumina R3 155

5.6.2.2 UHMWPE x Alumina R4 158

5.6.2.3 Efeito do acabamento superficial no desgaste de UHMWPE x Alumina 161

5.6.2.4 UHMWPE x Aço Inox R2 164

5.6.2.5 UHMWPE x Inox R3 168

5.6.2.6 Efeito do acabamento superficial no desgaste de UHMWPE x $\begin{array}{ll}\text { Aço Inoxidável } & 170\end{array}$

5.6.2.7 Efeito do contra-corpo na taxa de desgaste do UHMWPE 172

5.6.3 Comparação de resultados: POM x UHMWPE 176

5.7 Período de amaciamento (running-in) 180

$\begin{array}{lll}5.8 & \text { Coeficiente de atrito } & 187\end{array}$

5.8.1 Análise dos resultados de coeficiente de atrito 187

$\begin{array}{lll}\text { 5.8.1.1 POM x Alumina } & 190\end{array}$

5.8.1.2 POM x Aço Inoxidável 191

5.8.1.3 UHMWPE x Alumina 192

5.8.1.4 UHMWPE x Aço Inoxidável 193

$\begin{array}{lll}5.8 .2 & \text { Severidade global } & 195\end{array}$

5.9 Consolidação dos fenômenos relacionados ao desgaste 196 
Anexo A

Anexo B

Anexo C

215

Anexo D

239

8. REFERÊNCIAS BIBLIOGRÁFICAS 


\section{RESUMO}

O presente trabalho tem como objetivo estudar o efeito da carga normal aplicada, da velocidade de deslizamento, do acabamento superficial e do tipo de contra-corpo, na degradação dos materiais poliméricos POM e UHMWPE, resultante do contato deslizante contra corpos rígidos. Para tanto, foram realizados ensaios de desgaste em um tribômetro do tipo pino-contra-disco, com os pinos de materiais poliméricos e os discos de alumina e aço inoxidável.

Nos ensaios de desgaste, utilizou-se 3 valores de carga, 3 velocidades de deslizamento e 3 níveis de acabamento superficial do contra-corpo. Para cada condição de ensaio, foram realizadas 3 repetições. Durante os ensaios, foram monitoradas a temperatura na interface dos materiais, a força de atrito e a posição vertical do pino. $\mathrm{O}$ deslocamento vertical do pino devido ao desgaste foi utilizado para a determinação da taxa de desgaste do polímero. A distância percorrida pelos pinos sobre o disco foi de 3.500 metros. Os ensaios foram realizados em ambiente com umidade relativa controlada em $50 \pm 5 \%$.

As análises por microscopia eletrônica de varredura das superfícies de desgaste dos pinos e dos discos indicaram a ocorrência de três tipos de mecanismos de desgaste: a abrasão, a fadiga e a transferência de filme (adesão).

Para analisar o comportamento do desgaste mediante as influências estudadas, um parâmetro de severidade global (PVR/DD) é proposto. No parâmetro PVR/DD, considerou-se a relação entre um fator mecânico (condição de pressão e velocidade, $\mathrm{PV}$ ), um fator topográfico (rugosidade do contra-corpo, R) e um fator térmico (difusividade térmica dos materiais em contato, DD). Verificou-se que os níveis de desgaste dos materiais poliméricos são influenciados pela condição de severidade global do contato; entretanto, o efeito preponderante foi devido ao tipo de material do contracorpo.

Como foi observado que o deslocamento vertical ocorre devido não somente ao desgaste, mas também à fluência do polímero, à atuação de diferentes mecanismos de desgaste e ao fenômeno da fusão, os resultados de cada material de polímero estudado foram organizados na forma de mapas em função da severidade global, salientando as regiões de atuação de cada fenômeno. 


\begin{abstract}
The present investigation aims to study the degradation of polymeric materials resulting from the sliding contact against rigid bodies. The effect of some tribological influences, such as the applied load, the sliding velocity, the surface roughness and the counter-face material, were investigated. Experimental sliding wear tests were performed through a pin-on-disc tribometer, with the pins of polymeric material and the discs of alumina and stainless steel.

The testing conditions of the wear tests encompassed three values of load (normal pressure) and three values of sliding velocity, or PV values, and three ranges of disc surface roughness. Three tests were performed in each condition. The interface temperature between the specimens, the friction force and the vertical position of the pin were monitored along the tests. The vertical displacement of the pin, resulting from the wear, was used for the determination of the polymer wear rate. The total sliding distance was of 3,500 meters. During the tests, the relative humidity of the environment was controlled to $50 \pm 5 \%$.

Analyses on the worn surfaces of pins and discs performed through scanning electronic microscopy indicated the occurrence of three wear mechanisms: abrasion (scratches), fatigue (waves) and adhesion (transfer film).

In order to analyze the wear behavior of the polymer, a parameter of global severity of the contact (PVR/DD) was proposed. This parameter comprised a mechanical factor (the PV values), a topographic factor (the disc roughness) and a thermal factor (the thermal diffusivity of the materials in contact). It was possible to verify that the polymer wear depended on the level of global severity of the contact, where the major effect was due to the counterface material.

It was also observed that the vertical displacement of the pin occurred not only due to the wear phenomena, but also due to the creep and the melting of the polymer, both depending on the testing condition. The creep and the melting phenomena were considered in the polymer degradation behavior, organizing the results of polymeric pin displacement in degradation maps, showing the boundaries of each observed phenomena, in function of the contact global severity.
\end{abstract}




\section{LISTA DE SÍMBOLOS}

A - área aparente de contato

a - raio da área de contato

$\alpha$ - nível de significância

c.d.p. - corpo-de-prova

$\mathrm{Cp}$ - calor específico

D - difusividade térmica

Dd - constante de desgaste

$\mathrm{d}=$ distância percorrida

di - média do comprimento das diagonais da impressão de dureza Vickers

$\delta$ - ângulo de fase

'’ - parâmetro de solubilidade

$\Delta$ - decremento das medidas de amortecimento

$\Delta \mathrm{h}$ - Variação de altura

E - módulo de elasticidade

E* - módulo de elasticidade absoluto ou complexo

E' - módulo de armazenamento

E” - módulo de perda

$\mathrm{E}_{\mathrm{coh}}$ - energia coesiva

E \{ \} - valor da esperança matemática

$\varepsilon_{0}$ - deformação provocada pela tensão pulsante

$\varepsilon$ - deformação específica

$\varepsilon^{\mathrm{e}}-$ deformação específica elástica

$\varepsilon^{\mathrm{v}}$ - deformação específica viscosa

$\dot{\varepsilon}$ - taxa de deformação específica

$\dot{\varepsilon}^{\mathrm{e}}-$ taxa de deformação específica elástica 
$\varepsilon^{\mathrm{v}}$ - taxa de deformação específica viscosa

$F$ - constante de atração molar

$\mathrm{F}$ - porcentagem da distribuição F (Ficher)

$\mathrm{Fa}$ - força de atrito

$\phi$ - alongamento até a ruptura

G - Módulo de cisalhamento

$\mathrm{G}(\mathrm{t})$ - módulo de relaxação de tensão

G'- módulo de cisalhamento em fase

G” - módulo de cisalhamento fora de fase

$\gamma$ - energia superficial

$\gamma^{\mathrm{p}}$ - componente polar;

$\gamma^{\text {sol }}$ liq - energia interfacial entre sólido e líquido;

$\gamma^{\text {vap }}{ }_{\text {liq }}$ - energia de superfície do líquido.

$\gamma^{\mathrm{vap}}{ }_{\text {sol }}$ - energia de superfície do sólido

$\gamma_{\mathrm{a}}$ - energia de superfície do material a;

$\gamma_{\mathrm{ab}}$ - energia interfacial entre as superfícies a e b.

$\gamma_{b}$ - energia de superfície do material b;

$\gamma^{\mathrm{d}}$ - componente de dispersão (não-polar);

$\mathrm{H}$ - dureza

$\mathrm{H}_{0}$ e $\mathrm{H}_{1}$ - Hipóteses

$\mathrm{h}_{\mathrm{c}}$ - profundidade de penetração;

$J(t)$ - função flexibilidade de fluência

$\mathrm{k}$ - número de amostras;

lc - comprimento de corte

lm - comprimento de medição

$\operatorname{lnRz/lnSm~-~parâmetro~de~rugosidade~composto~}$

M - massa molar do mero

MM - massa molecular

$\mu$ - coeficiente de atrito

$\mu_{1}, \mu_{2}, . ., \mu_{\mathrm{k}}-$ médias de medidas 
$\mu_{\mathrm{r}}$ - coeficiente de atrito por rolamento

$\mathrm{N}$ - carga normal aplicada

$\mathrm{n}$ - tamanho de amostras

$\eta$ - viscosidade

P - pressão normal aplicada

PVR/DD - parâmetro de severidade global

Pe - número de PECLET

$\pi$ - constante $\mathrm{Pi}$

Q - Taxa de desgaste

$\mathrm{R}$ ou $\mathrm{r}$ - raio

$\mathrm{R}^{2}$ - coeficiente de correlação

$\mathrm{Ra}$ (CLA) - rugosidade média do perfil de alturas a partir de uma linha média

Rq (RMS) - rugosidade média quadrática

Ry - altura máxima entre pico e vale

RzDIN - média das alturas de pico à vale

$\rho$ - densidade

$s_{1}$ e $s_{2}$ - variância das amostras

Sm - distância média entre cristas

SQE - soma de quadrados entre amostras

SQR - soma dos quadrados residual

SQT - soma de quadrados total

$\sigma-$ tensão

$\sigma^{\prime}$ - tensão pulsante em fase com $\sigma_{0}$

$\tau "$ - tempo de relaxação

$\sigma$ " - tensão pulsante fora de fase com $\sigma_{0}$

$\sigma_{0}$ - tensão pulsante

$\sigma_{\mathrm{dp}}-$ desvio-padrão

$\sigma_{\mathrm{e}}$ - tensão normal de escoamento

$\sigma^{\mathrm{e}}-$ tensão elástica

$\sigma^{\mathrm{v}}-$ tensão viscosa 
$\mathrm{t}$ - tempo

$\mathrm{T}$ - período de oscilação

$\mathrm{Tb}$-Temperatura do volume (bulk)

Tc -Temperatura no contato

$\mathrm{Tg}$ - temperatura de transição vítrea

Tm - temperatura de fusão cristalina

Tme -Temperatura média do volume na região de contato

$\tau_{\mathrm{e}}$ - resistência ao escoamento por cisalhamento

$\tau$ - tensão de cisalhamento

$\tau$ ' - tempo de atraso

$\lambda$ - condutividade térmica

U.V. - raios ultra-violeta

$\mathrm{v}$ - velocidade de deslizamento

$\mathrm{V}$ - volume molar do mero

$v$ - coeficiente de Poisson

w - amplitude de oscilação

$\mathrm{W}_{\mathrm{ab}}$ - trabalho de adesão

$\omega$ - frequiência de pulsação

x e y - coeficientes de inclinação 


\section{ABREVIAÇÕES}

ASTM - American Society for Testing Materials

CR - capacitivo - resistivo

DSC - Calorimetria Exploratória Diferencial

DMTA - Análise Térmica Dinâmico-Mecânica

HDPE - Polietileno de alta densidade

HV - Dureza Vickers

IPEN - Instituto de Pesquisas Energéticas e Nucleares

IPT - Instituto de Pesquisas Tecnológicas

LDPE - Polietileno de baixa densidade

LFS - Laboratório de Fenômeno de Superfície

PA - Poliamida

PEEK - Poli (éter-éter-cetona)

PET - Poli (tereftalato de etileno)

PME-EPUSP - Departamento de Engenharia Mecânica da Escola Politécnica da Universidade de São Paulo

PMT-EPUSP - Departamento de Engenharia Metalúrgica e de Materiais da Escola Politécnica da Universidade de São Paulo

PMMA - Poli(metacrilato de metila)

POM - Polioximetileno

PP - Polipropileno

PPS - Poli (sulfeto de fenileno)

PS - Poliestireno

PTFE - Poli(tetraflúoro-etileno)

PV - pressão-velocidade

PVC - Poli(cloreto de vinila)

U.R. - Umidade Relativa

UHMWPE - Polietileno de ultra-alto peso molecular 


\section{LISTA DE FIGURAS}

Figura 2.1 - Modelo da micela franjeada.

Figura 2.2 - Modelos de estruturas de polímeros semi-cristalinos. (a) estrutura esferulítica, com um esferulito em detalhe, (b) modelo da cadeia dobrada.

Figura 2.3 - Influência da massa molecular (MM) nas propriedades mecânicas dos polímeros.

Figura 2.4 - Representação esquemática do efeito da temperatura no volume específico.

(a) polímero amorfo, (b) polímero semicristalino. ${ }^{9}$

Figura 2.5 - Curvas tensão x deformação de POM copolímero para diversas temperaturas.

Figura 2.6 - Curva esquemática de fluência em ensaio a temperatura constante.

Figura 2.7 - Modelo de Maxwell.

Figura 2.8- Modelo de Kelvin-Voigt.

Figura 2.9 - Variação da tensão e da deformação com o tempo para um material viscoelástico, mostrando o ângulo de fase $\delta$ e a freqüência de oscilação (w).

Figura 2.10 - Representação esquemática da capacidade de amortecimento $(\tan \delta)$ de um polímero semi-cristalino em função da temperatura.

Figura 2.11 - Componentes de um tribossistema.

Figura 2.12 - A origem do atrito associado ao deslizamento de uma aspereza dura deslizando contra uma superfície polimérica. ${ }^{28}$

Figura 2.13 - Coeficiente de atrito por rolamento e fator de perda $\delta / G^{1 / 3}$ em função da temperatura. $^{27}$

Figura 2.14 - Modelo de deslizamento entre as macromoléculas de PE. ${ }^{25}$ 
Figura 2.15 -Comportamento do coeficiente de atrito durante dois passos (1 e 2) de um riscador sobre a superfície de esferulitos de polipropileno.

Figura 2.16 - Comportamento da área real e da tensão de cisalhamento em função da velocidade de deslizamento.

Figura 2.17- Coeficiente de atrito em função da velocidade de deslizamento para polímeros semi-cristalinos.

Figura 2.18 - Relação entre coeficiente de atrito e carga para várias velocidades de deslizamento (poliamida e aço).

Figura 2.19 - Curva de temperatura no contato pelo tempo para condições PV cada vez mais elevadas.

Figura 2.20 - Efeito da rotação na temperatura de contato de PE contra aço inoxidável. 30

Figura 2.21 - Influência da carga e da umidade relativa no coeficiente de atrito de HDPE.

Figura 2.22- Descrição dos mecanismos de dissipação de energia no deslizamento de um polímero contra um contra-corpo rígido.

Figura 2.23 - Mecanismo de transferência normal.

Figura 2.24 - Três modos genéricos de transferência de filme polimérico A, B e C.

Figura 2.25 - Estrutura do PTFE - (a) um bloco cristalino ou 'banda', (b) laminas cristalinas ou 'estrias' e (c) arranjo hexagonal.

Figura 2.26 - Taxa de desgaste em função da carga normal no deslizamento contra aço $(\mathrm{Ra}=0,15 \mu \mathrm{m})$ em ensaio não lubrificado. ${ }^{60}$

Figura 2.27 - Taxa de desgaste da poliamida 6 deslizando sobre aço carbono e vidro.

Figura 2.28 - Micromecanismos de abrasão, para um sistema a dois corpos. 
Figura 2.29 - Taxa de desgaste em função da tenacidade à fratura $\left(\mathrm{K}_{\mathrm{IC}}\right)$ para termorrígidos (resinas epóxies) variando a densidade de ligações cruzadas. ${ }^{72}$

Figura 2.30 - Superfície de desgaste de UHMWPE apresentando morfologia tipo ondas. 40

Figura 2.31 - Ilustração do mecanismo de desgaste que conduz a formação de ondas. (I) zona de compressão (II) zona de estiramento.

Figura 2.32 - Superfície de desgaste de acetábulo de UHMWPE.

Figura 2.33-Diagrama esquemático mostrando a escala relativa entre as superfícies.

Figura 2.34 - Coeficiente de atrito e volume de desgaste em função do grau de cristalinidade do polietileno.

Figura 2.35 - Resistência ao desgaste do PTFE deslizando sobre aço carbono em dois tribômetros (pino-sobre-disco e placa-sobre-anel).

Figura 2.36 - Arranjo esquemático de um corte transversal de fita magnética.

Figura 2.37 - Volume de desgaste em função da velocidade (a) e da pressão de contato

(b) em ensaios tipo pino-contra-anel de POM x Aço Carbono.

Figura 2.38 - Coeficiente de atrito e taxa de desgaste em função da rugosidade para quatro pares aço-polímero (o= PA66, $=\mathrm{PA} 6, \Delta=\mathrm{POM}$ e $\mathrm{x}=\mathrm{PET})$.

Figura 2.39 - Coeficiente de atrito cinético e altura de desgaste do HDPE em função da Rugosidade Ra.

Figura 4.1 - Estrutura química do POM homopolímero e copolímero.

Figura 4.2 - Fórmulas estruturais do Trioxano e do óxido de etileno.

Figura 4.3 - Estrutura química do UHMWPE.

Figura 4.4 - Dimensões dos corpos-de-prova poliméricos (sem escala). 
Figura 4.6 - Dimensões dos discos de aço inoxidável (a). Vista frontal do disco de aço inoxidável montado ao porta-disco e este ao eixo do motor (b).

Figura 4.7 - Esquema do processo de preparação dos discos de alumina.

Figura 4.8 - Esquema do processo de preparação dos discos de alumina.

Figura 4.9 - Dimensões dos discos de alumina, mostrando os chanfros para fixação (a).

Vista frontal do disco de alumina montado ao porta-disco.

Figura 4.10 - Vista frontal (a) e lateral (b) do tribômetro TE-67.

Figura 4.11 - Desenhos ilustrativos dos principais componentes do sistema pino-contradisco. Cabeçote de fixação do pino em corte (a) e em perspectiva (b).

Figura 4.12 - Suporte cônico para fixação do pino na haste do equipamento de desgaste

(a). Suporte cônico roscado e pino travado ao equipamento (b).

Figura 4.13 - Sistema de movimentação do disco (motor-tacômetro-eixo)-(a). Vista frontal do equipamento mostrando os pontos de fixação de disco e pino (b).

Figura 4.14 - Vista lateral do cabeçote do equipamento de desgaste, mostrando as células de carga responsáveis pela medição da carga normal transmitida pelo atuador pneumático e da força de atrito.

Figura 4.15 - Esquema mostrando termopar, pino e disco (a). Fotografia de um pino montado com a ponta do termopar em seu interior.

Figura 4.16 - Corpos-de-prova com recobrimento de ouro para observação em MEV.

Pinos (a), discode alumina (b) e disco de aço inoxidável (c).

Figura 4.17 - Dimensões dos corpos-de-prova para análises DMTA (sem escala).

Figura 4.18 - Balanço de forças em uma gota séssil.

Figura 4.19 - Tela do analisador de imagens mostrando os ângulos de contato da gota com a linha de base dos lados direito e esquerdo. 
Figura 4.20 - Desenho esquemático dos discos e pinos mostrando as regiões e sentidos de medição da rugosidade.

Figura 4.21 - Indicação esquemática dos parâmetros utilizados para cálculo de dureza dinâmica.

Figura 4.22 - Curva típica de dureza dinâmica.

Figura 5.1 - Módulo elástico de armazenamento (E') em função da temperatura.

Figura 5.2 - Módulo elástico de perda (E”) em função da temperatura.

Figura 5.3 - Tangente de delta ( $\tan \square$ ) em função da temperatura.

Figura 5.4 - Curva de potência em função da temperatura para o UHMWPE.

Figura 5.5 - Perfil de rugosidade da superfície dos pinos de UHMWPE.

Figura 5.6 - Módulo elástico de armazenamento (E’) em função da temperatura para o POM.

Figura 5.7 - Módulo elástico de perda (E”) em função da temperatura para o POM.

Figura 5.8 - Tangente de delta (tg $\square$ ) em função da temperatura para o POM.

Figura 5.9 - Pico da temperatura de transição vítrea do POM.

Figura 5.10 - Curva de potência em função da temperatura para o POM.

Figura 5.11 - Exemplo de um perfil de rugosidade do POM.

Figura 5.12 - Microestrutura do aço inoxidável mostrando as microestruturas presentes. Ataque Vilela. Ferrita (clara) e austenita (escura).

Figura 5.13 - Difratograma de raios-x da alumina.

Figura 5.14 - Dependência dos estados físico-mecânicos dos polímeros de acordo com

Tm e Tg em função da massa molecular.

Figura 5.15 - Módulo de armazenamento - E' (a) e de perda - E” (b) dos polímeros na faixa de temperaturas atingidas durante o ensaio. 
Figura 5.16 - Curvas de fluência do UHMWPE sob carga constante de 50, 100 e 200N. 105

Figura 5.17 - Curvas de fluência do POM sob carga constante de 50, 100 e 200N.

Figura 5.18 - Curvas de ajuste linear dos pontos de fluência do POM à temperatura ambiente (50, 100 e $200 \mathrm{~N})$.

Figura 5.19 - Curvas de ajuste linear dos pontos dos ensaios de fluência do POM, corrigidas para temperatura de $100^{\circ} \mathrm{C}$.

Figura 5.20 - Curvas de ajuste dos ensaios de fluência do UHMWPE realizados à temperatura ambiente, para os três níveis de carga.

Figura 5.21 - Taxa de deformação em função do tempo de ensaio de fluência para o UHMWPE, para os três níveis de carga, à temperatura ambiente.

Figura 5.22 - Curvas de fluência para a temperatura de $50^{\circ} \mathrm{C}$ (a), curvas de taxa de deformação para o UHMWPE a $50^{\circ} \mathrm{C}$ (b).

Figura 5.23 - Taxa de deformação devido à fluência em função da temperatura para o UHMWPE.

Figura 5.24 - Regiões do corpo-de-prova polimérico com duas regiões de temperatura diferentes durante os ensaios de desgaste.

Figura 5.25 - Diagrama esquemático das análises da taxa de desgaste em função da condição PV, da temperatura no contato, do acabamento superficial e dos materiais do contra-corpo e do polímero.

Figura 5.26 - Taxa média de desgaste e seus respectivos desvios padrões em função da condição PV dos ensaios com o par POM x $\mathrm{Al}_{2} \mathrm{O}_{3} \mathrm{R} 3$.

Figura 5.27 - Taxa média de desgaste e seus respectivos desvios padrões em função da temperatura medida no pino, par $\mathrm{POM} \times \mathrm{Al}_{2} \mathrm{O}_{3} \mathrm{R} 3$. 
Figura 5.28 - MEV da superfície do pino de POM $\left(\mathrm{Al}_{2} \mathrm{O}_{3} \mathrm{R} 3,0,1 \mathrm{~m} / \mathrm{s}\right.$ e $\left.50 \mathrm{~N}\right)$. Notam-se riscos de abrasão e partículas de desgaste aderidas à superfície.

Figura 5.29 - MEV da superfície de pino de POM $\left(\mathrm{Al}_{2} \mathrm{O}_{3} \mathrm{R} 3,0,1 \mathrm{~m} / \mathrm{s}\right.$ e $\left.200 \mathrm{~N}\right)$. Notamse riscos de abrasão e formação de ondas.

Figura 5.30 - MEV da superfície de pino de POM $\left(\mathrm{Al}_{2} \mathrm{O}_{3} \mathrm{R} 3,0,1 \mathrm{~m} / \mathrm{s}\right.$ e $\left.100 \mathrm{~N}\right)$. Nota-se um aspecto fragmentado da bordas dos riscos e partículas aglomeradas.

Figura 5.31 - MEV da superfície de pino de $\mathrm{POM}\left(\mathrm{Al}_{2} \mathrm{O}_{3} \mathrm{R} 3,0,1 \mathrm{~m} / \mathrm{s}\right.$ e $\left.100 \mathrm{~N}\right)$

Partículas c/ diversos tamanhos e formas (a) aglomeração de partículas (b).

Figura 5.32 - Disco de alumina após a realização do ensaio de desgaste contra POM.

Figura 5.33 - Gênese e características das partículas originadas pelo desgaste.

Figura 5.34 - Taxa média de desgaste e seus respectivos desvios padrões em função da condição PV dos ensaios com o par POM x $\mathrm{Al}_{2} \mathrm{O}_{3} \mathrm{R} 4$.

Figura 5.35 - Taxa média de desgaste e seus respectivos desvios padrões em função da temperatura medida no pino dos ensaios com o par POM x $\mathrm{Al}_{2} \mathrm{O}_{3} \mathrm{R} 4$.

Figura 5.36 - MEV da superfície do pino de $\mathrm{POM}\left(\mathrm{Al}_{2} \mathrm{O}_{3} \mathrm{R} 4,0,5 \mathrm{~m} / \mathrm{s}\right.$ e $\left.50 \mathrm{~N}\right)$ Observase riscos e poucas partículas depositadas.

Figura 5.37 - MEV da superfície do pino de POM $\left(\mathrm{Al}_{2} \mathrm{O}_{3} \mathrm{R} 4,0,5 \mathrm{~m} / \mathrm{s}\right.$ e $\left.50 \mathrm{~N}\right)$. Partículas com aspecto frágil (quebradiço / geométrico).

Figura 5.38 - MEV da superfície do pino de $\mathrm{POM}\left(\mathrm{Al}_{2} \mathrm{O}_{3} \mathrm{R} 4,1 \mathrm{~m} / \mathrm{s}\right.$ e $\left.50 \mathrm{~N}\right)$. Partículas fortemente aderidas ao pino e morfologia tipo ondas.

Figura 5.39 - MEV da superfície de pino de $\mathrm{POM}\left(\mathrm{Al}_{2} \mathrm{O}_{3} \mathrm{R} 4,1 \mathrm{~m} / \mathrm{s}\right.$ e $\left.50 \mathrm{~N}\right)$. Mecanismo de formação de ondas e partículas aderidas ao pino, apresentando a mesma morfologia de desgaste da superfície do pino. 
Figura 5.40 - Taxa média de desgaste e seus respectivos desvios padrões em função da condição $\mathrm{PV}$, par $\mathrm{POM} \times \mathrm{Al}_{2} \mathrm{O}_{3}$.

Figura 5.41 - Taxa média de desgaste e seus respectivos desvios padrões em função da temperatura no contato dos ensaios com o par $\mathrm{POM} \times \mathrm{Al}_{2} \mathrm{O}_{3}$.

Figura 5.42 - Taxa média de desgaste em função do acabamento superficial dos ensaios com o par $\mathrm{POM} \times \mathrm{Al}_{2} \mathrm{O}_{3}$.

Figura 5.43 - Taxa média de desgaste e seus respectivos desvios padrões em função da condição PV dos ensaios com o par POM x Aço inox R2.

Figura 5.44 - Taxa média de desgaste e seus respectivos desvios padrões em função da temperatura medida no pino dos ensaios com o par POM x Aço Inox R2.

Figura 5.45 - MEV da superfície de pino de POM (Aço Inox R2, 0,5 m/s e 50 N).

Observa-se presença de riscos e partículas aderidas e aglomeradas.

Figura 5.46 - MEV da superfície de pino de POM (Aço Inox R2, 0,1 m/s e 100 N).

Observa-se presença simultânea de riscos e de ondas.

Figura 5.47 - MEV da superfície do pino de POM (Aço Inox R2, 0,1 m/s e 100 N).

Observação de um aspecto frágil nas bordas dos riscos.

Figura 5.48 - MEV da superfície do pino de POM (Aço Inox R2, 1 m/s e 50 N).

Observação de filme recobrindo grande extensão da área de contato.

Figura 5.49 - Taxa média de desgaste e seus respectivos desvios padrões em função da condição PV dos ensaios do par POM x Aço inox R3.

Figura 5.50 - Taxa média de desgaste e seus respectivos desvios padrões em função da temperatura medida no pino dos ensaios do par POM x Aço inox R3.

Figura 5.51 - MEV da superfície do pino de POM (Aço Inox R3, 1 m/s e 100 N).

Mecanismo de formação de ondas acompanhando os riscos de abrasão. 
Figura 5.52 - Taxa média de desgaste e seus respectivos desvios padrões em função da condição PV dos ensaios com o par POM x Aço Inox.

Figura 5.53 - Taxa média de desgaste e seus respectivos desvios padrões em função da temperatura no contato dos ensaios com o par POM x Aço Inox.

Figura 5.54 - Taxa média de desgaste em função do acabamento superficial dos ensaios de POM x Aço Inox.

Figura 5.55 - Taxa média de desgaste e seus respectivos desvios padrões em função da condição PV dos ensaios com POM (rugosidade R3).

Figura 5.56 - Taxa média de desgaste e seus respectivos desvios padrões em função da condição PV dos ensaios com POM.

Figura 5.57 - Taxa média de desgaste e seus desvios padrões em função da temperatura no contato dos ensaios com POM (rugosidade R3).

Figura 5.58 - Taxa média de desgaste e seus respectivos desvios padrões em função da temperatura no contato dos ensaios com POM.

Figura 5.59 - Taxa média de desgaste em função do acabamento superficial dos ensaios com POM.

Figura 5.60 - Taxa média de desgaste em função da severidade global dos ensaios de POM contra alumina e aço inoxidável.

Figura 5.61 - Taxa média de desgaste e seus respectivos desvios padrões em função da condição PV dos ensaios com UHMWPE x $\mathrm{Al}_{2} \mathrm{O}_{3} \mathrm{R} 3$.

Figura 5.62 - Taxa média de desgaste e seus respectivos desvios padrões em função da temperatura próxima ao contato dos ensaios com UHMWPE $\mathrm{x} \mathrm{Al}_{2} \mathrm{O}_{3} \mathrm{R} 3$.

Figura 5.63 - MEV da superfície do pino de UHMWPE $\left(\mathrm{Al}_{2} \mathrm{O}_{3} \mathrm{R} 3,0,1 \mathrm{~m} / \mathrm{s}\right.$ e $\left.50 \mathrm{~N}\right)$.

Observam-se riscos de abrasão e formação de ondas, e partículas se destacando. 
Figura 5.64 - MEV da superfície do pino de UHMWPE $\left(\mathrm{Al}_{2} \mathrm{O}_{3} \mathrm{R} 3,0,1 \mathrm{~m} / \mathrm{s}\right.$ e $\left.200 \mathrm{~N}\right)$. A formação de ondas é mais intensa e o riscamento acompanha o formato das ondas. 157

Figura 5.65 - MEV da superfície do pino de UHMWPE $\left(\mathrm{Al}_{2} \mathrm{O}_{3} \mathrm{R} 3\right.$, de $1 \mathrm{~m} / \mathrm{s}$ e $50 \mathrm{~N}$.

Presença de grandes placas de material polimérico aderidas à superfície do pino.

Figura 5.66 - Taxa média de desgaste e seus respectivos desvios padrões em função da condição PV dos ensaios com UHMWPE x $\mathrm{Al}_{2} \mathrm{O}_{3} \mathrm{R} 4$.

Figura 5.67 - Taxa média de desgaste e seus respectivos desvios padrões em função da temperatura próxima ao contato dos ensaios com UHMWPE x $\mathrm{Al}_{2} \mathrm{O}_{3} \mathrm{R} 4$.

Figura 5.68 - MEV da superfície do pino de UHMWPE $\left(\mathrm{Al}_{2} \mathrm{O}_{3} \mathrm{R} 4,0,5 \mathrm{~m} / \mathrm{s}\right.$ e $50 \mathrm{~N} 0$.

Nota-se mecanismo de abrasão e pouca presença de material depositado no pino.

Figura 5.69 - MEV da superfície de pino de UHMWPE $\left(\mathrm{Al}_{2} \mathrm{O}_{3} \mathrm{R} 4,0,5 \mathrm{~m} / \mathrm{s}\right.$ e $\left.100 \mathrm{~N}\right)$.

Atuação concomitante dos mecanismos de abrasão e de formação de ondas.

Figura 5.70 - Taxa média de desgaste e seus respectivos desvios padrões em função da condição PV dos ensaios com o par UHMWPE x $\mathrm{Al}_{2} \mathrm{O}_{3}$.

Figura 5.71 - Taxa média de desgaste e seus respectivos desvios padrões em função da temperatura próxima ao contato dos ensaios com o par UHMWPE x $\mathrm{Al}_{2} \mathrm{O}_{3}$.

Figura 5.72 - Taxa média de desgaste em função do acabamento superficial dos ensaios de UHMWPE x $\mathrm{Al}_{2} \mathrm{O}_{3}$.

Figura 5.73 - Taxa média de desgaste e seus respectivos desvios padrões em função da condição PV dos ensaios com o par UHMWPE x Aço Inox R2.

Figura 5.74 - Taxa média de desgaste e seus respectivos desvios padrões em função da temperatura no contato dos ensaios com o par UHMWPE x Aço Inox R2.

Figura 5.75 - Curva de deslocamento do pino em função da distância percorrida, para o par UHMWPE x Aço Inox R2 ( $50 \mathrm{~N}$ e 1,0 m/s). 
Figura 5.76 -MEV da superfície de pino de UHMWPE (Aço Inox R2, 1 m/s e 50 N).

Filme homogêneo e compacto formado em uma grande região, com alguns riscos.

Figura 5.77 -MEV da superfície de pino de UHMWPE (Aço Inox R2, 1 m/s e $100 \mathrm{~N}$ ).

Observa-se o mecanismo de desgaste do tipo rolled-up wear particules.

Figura 5.78 - Taxa média de desgaste e seus respectivos desvios padrões em função da condição PV dos ensaios com o par UHMWPE x Aço Inox R3.

Figura 5.79 - Taxa média de desgaste e respectivos desvios padrões em função da temperatura próxima ao contato dos ensaios com UHMWPE contra Aço Inox R3.

Figura 5.80 - MEV da superfície de pino de UHMWPE (Aço Inox R3, 0,5 m/s e 100 N). Presença de mecanismo de desgaste por abrasão no filme polimérico.

Figura 5.81 - Taxa média de desgaste e seus respectivos desvios padrões em função da condição PV dos ensaios do par UHMWPE x Aço Inox.

Figura 5.82 - Taxa média de desgaste e seus respectivos desvios padrões em função da temperatura próxima ao contato dos ensaios do par UHMWPE x Aço Inox.

Figura 5.83 - Taxa média de desgaste em função do acabamento superficial dos ensaios de UHMWPE contra aço inoxidável.

Figura 5.84- Taxa média de desgaste e seus respectivos desvios padrões em função da condição PV dos ensaios com UHMWPE (rugosidade R3).

Figura 5.85 - Taxa média de desgaste e seus respectivos desvios padrões em função da temperatura próxima ao contato dos ensaios com UHMWPE (rugosidade R3).

Figura 5.86 - Taxa média de desgaste em função do acabamento superficial dos ensaios com UHMWPE.

Figura 5.87 - Taxa média de desgaste em função da severidade global dos ensaios com UHMWPE contra alumina e aço inoxidável. 
Figura 5.88 - Taxa média de desgaste do POM e do UHMWPE em função da condição PV.

Figura 5.89 - Taxa média de desgaste em função da temperatura no contato. Todos os resultados com POM e UHMWPE (a), separados pelo tipo de contra-corpo (b).

Figura 5.90 - Taxa média de desgaste do POM e do UHMWPE em função do acabamento superficial.

Figura 5.91 - Taxa média de desgaste do POM e do UHMWPE em função da severidade global (PVR/DD).

Figura 5.92 - Taxa média de desgaste em função da severidade global (PVR/DD) dos pares estudados (nuvens de tendência).

Figura 5.93 - Curvas de coeficiente de atrito e deslocamento do pino em função da distância, para o UHMWPE x Aço Inoxidável R2, com P = 50N e v = 0,1 m/s.

Figura 5.94 - Desenho esquemático do aumento da área real de contato com a carga aplicada.

Figura 5.95 - Desenho esquemático da formação das lâminas presentes na superfície dos pinos durante o deslizamento no período de running-in.

Figura 5.96 - MEV da superfície de pino de UHMWPE.(Aço Inox R3, v = 0,5 m/s e 100 N). Presença do mecanismo de desgaste por fadiga + abrasão.

Figura 5.97 - Detalhe da superfície do pino mostrando que o filme polimérico presente na superfície do pino é formado por várias lâminas sobrepostas.

Figura 5.98 - MEV da superfície de pino de UHMWPE (Aço Inox R3, 0,1 m/s e 50 N). Filme formado de camadas mostrando o destacamento de uma lâmina.

Figura 5.99 - MEV da superfície de pino de UHMWPE (Aço Inox R3, 0,1 m/s e 100 N).

Quase todas as marcas de usinagem foram removidas. 
Figura 5.100 - Coeficiente de atrito em função das condições PV (a) e da temperatura no contato (b). (POM x Alumina)

Figura 5.101 - Coeficiente de atrito em função das condições PV e da temperatura no contato (POM x Aço Inoxidável).

Figura 5.102 - Coeficiente de atrito em função das condições PV e da temperatura no contato (UHMWPE x Alumina).

Figura 5.103 - Coeficiente de atrito em função das condições PV e da temperatura no contato do par UHMWPE x Aço Inoxidável, nos dois níveis de acabamentos superficiais estudados.

Figura 5.104 - Coeficiente de atrito em função da severidade global - PVR/DD.

Figura 5.105 - Quadro resumo dos resultados de desgaste dos polímeros, evidenciando as influências em termos percentuais de cada variável estudada.

Figura 5.106 - Mapa do comportamento do UHMWPE.

Figura 5.107 - Mapa do comportamento do POM. 


\section{LISTA DE TABELAS}

Tabela 2.1 - Energia de superfície de polímeros termoplásticos.

Tabela 2.2 - Regiões de transição de polímeros.

Tabela 4.1 - Composição química pretendida para o aço inoxidável nitrogenado ${ }^{99}$.

Tabela 4.2 - Planilha do cálculo de carga do aço inoxidável nitrogenado.

Tabela 4.3 - Informações obtidas no equipamento TE-67.

Tabela 4.4 - Parâmetros dos ensaios de desgaste

Tabela 4.5 - Valores de condição PV para os diversos níveis de carga e velocidade de deslizamento.

Tabela 4.6 - Difusividade térmica dos discos e dos pinos.,

Tabela 4.7- Energia de superfície e as componentes polar e de dispersão a $20^{\circ} \mathrm{C}$

Tabela 4.8 - Contribuições dos grupos químicos para $F$.

Tabela 5.1 - Propriedades físico-químicas, mecânicas e térmicas do UHMWPE.

Tabela 5.2 - Dureza Vickers do UHMWPE.

Tabela 5.3 - Módulo de elasticidade do UHMWPE.

Tabela 5.4 - Características Térmicas do UHMWPE.

Tabela 5.5 - Parâmetro de rugosidade da superfície dos pinos de UHMWPE.

Tabela 5.6 - Propriedades físico-químicas, mecânicas e térmicas do POM copolímero.

Tabela 5.7 - Dureza Vickers do POM.

Tabela 5.8 - Módulo de elasticidade do UHMWPE.

Tabela 5.9 - Características térmicas do POM copolímero.

Tabela 5.10 - Parâmetros de rugosidade da superfície dos pinos de POM.

Tabela 5.11 - Composição química do aço inoxidável.

Tabela 5.12 - Teor de ferrita presente no aço inoxidável. 
Tabela 5.13 - Dureza Vickers do aço inoxidável.

Tabela 5.14 -Módulo de elasticidade da fase ferrítica.

Tabela 5.15 - Aço Inoxidável - Rugosidade Ra desejada $0,05<\mathrm{Ra}<0,2 \square \mathrm{m}$.

Tabela 5.16 - Aço Inoxidável - Rugosidade Ra desejada $0,3<\mathrm{Ra}<0,6 \square \mathrm{m}$.

Tabela 5.17 - Densidade dos discos de alumina e nível de porosidade.

Tabela 5.18 - Alumina - Rugosidade desejada $0,3<\mathrm{Ra}<0,6 \square \mathrm{m}$.

Tabela 5.19 - Alumina - Rugosidade desejada 1,5 $<\mathrm{Ra}<2,0 \square \mathrm{m}$.

Tabela 5.20 - Ângulos de contato e energia de superfície dos materiais estudados.

Tabela 5.21 - Trabalho de adesão médio $\left(\mathrm{W}_{\mathrm{ab}}\right)$ e coeficiente de variação dos pares de materiais estudados.

Tabela 5.22 - Temperatura $\left[{ }^{\circ} \mathrm{C}\right]$ próxima à superfície de contato do UHMWPE.

Tabela 5.23 - Temperatura $\left[{ }^{\circ} \mathrm{C}\right]$ próxima à superfície de contato do POM.

Tabela 5.24 - Deformação específica (\%) por compressão do UHMWPE (UTEC) em função da carga aplicada e da temperatura.

Tabela 5.25 - Deformação específica (\%) do POM (Hostaform®) em função da temperatura e do tempo de ensaio, para carregamento de $10 \mathrm{MPa}$.

Tabela 5.26 - Pares de materiais estudados nesta pesquisa.

Tabela 5.27 - Resultados de taxa de desgaste dos ensaios POM versus $\mathrm{Al}_{2} \mathrm{O}_{3}$.

Tabela 5.28 - Resultados de taxa de desgaste dos ensaios UHMWPE versus $\mathrm{Al}_{2} \mathrm{O}_{3}$.

Tabela 5.29 - Resultados de taxa de desgaste dos ensaios UHMWPE versus Aço Inoxidável.

Tabela 5.30 - Resultados de taxa de desgaste dos ensaios POM versus Aço Inoxidável.

Tabela 5.31 - Taxa de deformação do pino devido a fluência do POM à temperatura ambiente. 
Tabela 5.32 - Taxa de deformação do pino devido a fluência do POM, a $100{ }^{\circ} \mathrm{C}$.

Tabela 5.33 - Taxa de variação de altura de pino devido a fluência em relação ao tempo, à temperatura ambiente, do UHMWPE.

Tabela 5.34 - Taxa de deformação do pino devido a fluência, à temperatura ambiente, do UHMWPE.

Tabela 5.35 - Taxa de deformação do pino devido a fluência, a $50{ }^{\circ} \mathrm{C}$, do UHMWPE.

Tabela 5.36 - Taxa de deformação total dos pinos de UHMWPE nos ensaios contra aço inoxidável R2.

Tabela 5.37 - Taxa de deformação total dos pinos de UHMWPE nos ensaios contra aço inoxidável R3.

Tabela 5.38 - Taxa de deformação total dos pinos de UHMWPE nos ensaios contra alumina R3.

Tabela 5.39 - Taxa de deformação total dos pinos de UHMWPE nos ensaios contra alumina R4.

Tabela 5.40 - Taxa de desgaste final dos ensaios POM versus $\mathrm{Al}_{2} \mathrm{O}_{3}$.

Tabela 5.41 - Taxa de desgaste final dos ensaios POM versus Aço inoxidável.

Tabela 5.42 - Taxa de desgaste final dos ensaios UHMWPE versus $\mathrm{Al}_{2} \mathrm{O}_{3}$

Tabela 5.43 - Taxa de desgaste final dos ensaios UHMWPE versus aço inoxidável.

Tabela 5.44 - Coeficiente de variação médio $\left(\mathrm{CV}_{\mathrm{m}}\right)$ dos resultados finais de taxa de desgaste para os 4 tribossistemas estudados.

Tabela 5.45 - Código de acabamento superficial e parâmetro de rugosidade combinado das superfícies dos discos de alumina e aço inoxidável.

Tabela 5.46 - Resultados de coeficiente de atrito dos ensaios POM versus $\mathrm{Al}_{2} \mathrm{O}_{3}$ 
Tabela 5.48 - Resultados de coeficiente de atrito dos ensaios UHMWPE versus $\mathrm{Al}_{2} \mathrm{O}_{3}$.

Tabela 5.49 - Resultados de coeficiente de atrito dos ensaios UHMWPE versus Inox.

Tabela 5.50 - Coeficiente de variação médio(CV) dos resultados de coeficiente de atrito para os tribossistemas estudados.

Tabela 5.51 - Propriedades térmicas, mecânicas e características físico-químicas dos materiais estudados.

Tabela 7.1 - Disposição prática dos dados para a análise de variância. 


\section{INTRODUÇÃO}

Nas últimas décadas, tem-se observado uma crescente aplicação de materiais poliméricos em substituição a materiais tradicionais, seja na fabricação de itens convencionais como utensílios domésticos e embalagens (plásticos commodities) ${ }^{1}$, seja em aplicações onde um melhor desempenho químico, mecânico e térmico é necessário (plásticos especiais e de engenharia). Dentre os vários motivos da opção pelos polímeros, estão o crescente volume de produção (estima-se para 2004 uma produção mundial de 183 milhões de toneladas de termoplásticos ${ }^{2}$ ) e o desenvolvimento das técnicas de preparação e caracterização dos polímeros, as quais permitem produzir materiais mais adequados às novas aplicações.

O melhor desempenho dos plásticos de engenharia tem alcançado novos setores da indústria em todos os países. Além dos tradicionais ramos da indústria, como os setores automotivo e aeronáutico, também a construção civil, a náutica e a biomecânica têm conseguido encontrar novas aplicações para os polímeros, pois, além dos requisitos técnicos serem satisfatórios, também possuem uma grande capacidade competitiva.

Pensando em substituir os materiais metálicos por polímeros em aplicações mecânicas, além de se procurar obter um material com melhores propriedades mecânicas, como dureza, módulo de elasticidade, tenacidade à fratura e resistência ao impacto, torna-se necessário estudar o comportamento tribológico dos materiais poliméricos nas mais diversas condições de contato.

Os custos envolvidos com o desgaste dos materiais e com a perda de energia em sistemas tribológicos com polímeros podem se tornar críticos, quando se verifica a crescente utilização de polímeros em um vasto número de setores industriais, como na fabricação de rotores de bombas, válvulas, engrenagens, fusos, mancais, freios, cames, anéis de pistão, selos, pisos, em aplicações agrárias e na industria siderúrgica.

A utilização de polímeros em próteses de articulações e válvulas cardíacas artificiais são alguns exemplos da aplicação tribológica destes materiais nas ciências médicas. Para o caso particular de articulações artificiais humanas, o polímero mais utilizado é o polietileno de ultra-alto peso molecular (UHMWPE), no entanto o polioximetileno (POM) também tem sido amplamente estudado para estas aplicações ${ }^{3}$. 
Portanto, o domínio tecnológico das propriedades tribológicas dos polímeros e uma utilização racional dos recursos envolvidos com o projeto, fabricação, utilização e manutenção de equipamentos são fatores de grande interesse para o meio científico e, principalmente, para o setor industrial do país.

Uma das informações mais importantes que obtemos ao estudarmos o comportamento tribológico de qualquer material é que tanto o coeficiente de atrito quanto a resistência ao desgaste são propriedades do sistema como um todo, ou seja, do tribossistema, e não somente do material. Desta forma, quando há, por exemplo, um contato deslizante entre dois materiais, a resposta tribológica de cada material será influenciada não somente pelas propriedades mecânicas, físico-químicas e térmicas dos materiais, mas também pelo meio em que estes materiais estão envolvidos, pelo acabamento das superfícies, pela severidade das condições de contato e pelo modo com que estes materiais estão se tocando, ou seja, pela configuração mecânica do sistema.

Em termos de propriedades tribológicas dos polímeros, entre as mais conhecidas estão a capacidade de alto-lubrificação e a inércia química, que são características quase que exclusivas destes materiais. No entanto, para se prever o que realmente ocorrerá em um dado tipo de contato e conseguir utilizar a potencialidade destes materiais, torna-se necessário uma compreensão dos mecanismos de atrito e de desgaste que atuam no sistema e das relações entre as propriedades mecânicas e físico-químicas com as demais variáveis do tribossistema. 


\section{2 . REVISÃO BIBLIOGRÁFICA}

No Século XX ocorreu um avanço sem igual na elaboração de novos materiais para aplicações domésticas e de uso comum, mas mais pronunciadamente em aplicações de engenharia. Neste contexto os polímeros se apresentam como um material capaz de viabilizar novas aplicações em grande escala, como também, progressivamente substituir materiais tradicionais como metais, madeiras e cerâmicas, em geral apresentando-se muito competitivo quanto aos custos de produção e de matéria-prima e com processos de fabricação bastante diversificados.

As características mecânicas e físico-químicas como: baixa densidade, possibilidade de reciclagem, reprodutibilidade dimensional e resistência a ataques químicos, foram capazes de aumentar uma produção mundial de 350.000 ton/ano nos anos 50, para quase 200 milhões de ton/ano de plásticos, elastômeros e fibras, na virada para o século $\mathrm{XXI}^{4}$.

Características como baixo coeficiente de atrito, resistência à corrosão e autolubrificação são extremamente importantes em aplicações tribológicas como: rotores de bombas, válvulas, engrenagens, fusos, mancais, cames, anéis de pistão, selos, etc. ${ }^{5}$.

Esta revisão bibliográfica irá apresentar alguns conceitos relevantes sobre os termoplásticos, tais como físico-química dos polímeros e propriedades mecânicas, os quais de alguma forma se relacionam com o comportamento tribológico destes materiais. Além disto, com o objetivo de proporcionar um maior embasamento nas discussões sobre o comportamento tribológico dos polímeros, será apresentado uma revisão bibliográfica sobre as influências de diversos parâmetros de ensaios, como carga aplicada, velocidade de deslizamento e acabamento superficial, que afetam significativamente os valores de coeficiente de atrito e taxa de desgaste. 


\subsection{Polímeros}

\subsubsection{Classificação dos polímeros}

Os materiais poliméricos podem ser agrupados de acordo com diversos tipos de classificação, dentre outras pode-se citar: estrutura química, fusibilidade, comportamento mecânico, tipos de aplicação e escala de produção. Dentre as principais formas de classificação dos polímeros, utilizadas pelos engenheiros, serão citadas os tipos de ligações atômicas da macromolécula, o número de diferentes meros presentes no polímero e o seu desempenho mecânico.

\subsubsection{Tipo de ligações atômicas}

Pode-se classificar os polímeros dependendo das ligações atômicas das macromoléculas ${ }^{6}$, da seguinte forma:

a) Polímeros lineares: são aqueles nos quais os monômeros se unem linearmente em cadeias simples. As cadeias adjacentes, porém, se mantêm juntas por ligações secundárias relativamente fracas (forças de Van der Waals);

b) Polímeros ramificados: durante a etapa de polimerização, pequenos ramos crescem a partir da cadeia principal. Estes ramos são considerados partes das cadeias principais resultantes de reações laterais que ocorrem durante a sintetização do polímero;

c) Polímeros com ligações cruzadas: nestes polímeros, as cadeias laterais adjacentes se ligam a outras cadeias em várias posições através de ligações covalentes;

d) Polímeros em rede: os monômeros com três ligações covalentes ativas ou trifuncional, formam polímeros com estrutura tridimensional. Este tipo de estrutura limita fortemente o escorregamento entre as moléculas.

Basicamente esta classificação divide os polímeros em três grandes famílias:

- Termoplásticos (de cadeia linear ou ramificada),

- Elastômeros (borrachas) e

- Termorrígidos (estrutura tridimensional). 


\subsubsection{Copolímero e homopolímero}

A composição de um polímero pode apresentar um único tipo de mero (cadeia homogênea) ou dois ou mais meros (cadeia heterogênea).

Homopolímero: é o polímero constituído por apenas um tipo de unidade estrutural repetida. Se considerarmos A como o mero presente em um homopolímero, sua estrutura será:

$\sim \mathrm{A}-\mathrm{A}-\mathrm{A}-\mathrm{A}-\mathrm{A}-\mathrm{A}-\mathrm{A}-\mathrm{A}-\mathrm{A}-\mathrm{A}-\mathrm{A}-\mathrm{A}-\mathrm{A}-\mathrm{A}-\mathrm{A}-\mathrm{A} \sim$

Copolímero: é o polímero formado por dois ou mais tipos de meros. Supondo que A e B sejam os meros de um copolímero, pode-se dividir os copolímeros em:

a) Copolímero estatístico ou aleatório. Neste caso os meros estão dispostos de maneira desordenada na cadeia polimérica;

$$
\sim \mathrm{A}-\mathrm{A}-\mathrm{A}-\mathrm{B}-\mathrm{A}-\mathrm{A}-\mathrm{A}-\mathrm{B}-\mathrm{B}-\mathrm{A}-\mathrm{B}-\mathrm{A}-\mathrm{A}-\mathrm{B}-\mathrm{A}-\mathrm{A} \sim
$$

b) Copolímero alternado. Os meros estão ordenados de forma alternada na cadeia do copolímero;

$$
\sim \mathrm{A}-\mathrm{B}-\mathrm{A}-\mathrm{B}-\mathrm{A}-\mathrm{B}-\mathrm{A}-\mathrm{B}-\mathrm{A}-\mathrm{B}-\mathrm{A}-\mathrm{B}-\mathrm{A}-\mathrm{B}-\mathrm{A}-\mathrm{B}-\mathrm{A} \sim
$$

c) Copolímero em bloco. O copolímero é formado por uma sequiência de meros iguais de comprimento variável;

$$
\sim \mathrm{A}-\mathrm{A}-\mathrm{A}-\mathrm{B}-\mathrm{B}-\mathrm{B}-\mathrm{A}-\mathrm{A}-\mathrm{A}-\mathrm{A}-\mathrm{B}-\mathrm{B}-\mathrm{B}-\mathrm{B}-\mathrm{A}-\mathrm{A}-\mathrm{A} \sim
$$

d) Copolímero grafitizado (ou enxertado). A cadeia principal do copolímero é formada por um tipo de unidade de repetição, enquanto que o outro mero forma a cadeia lateral (enxertada).

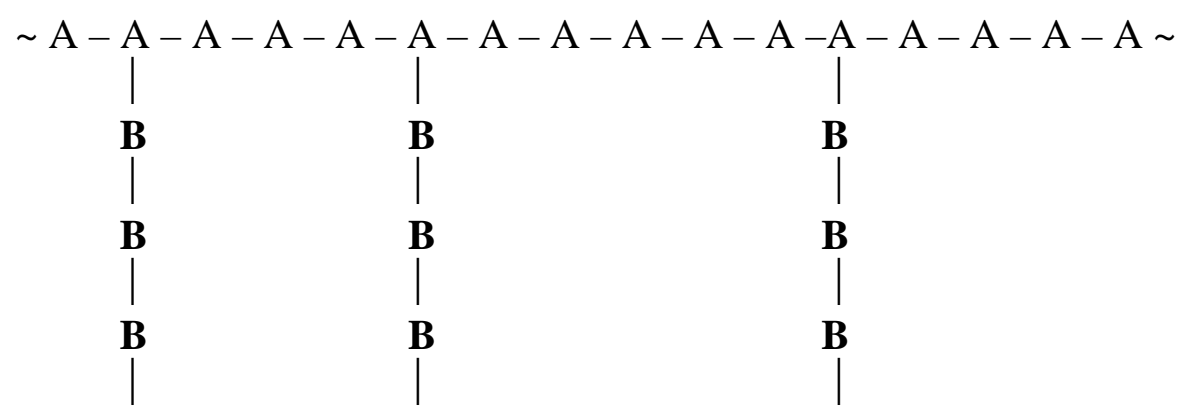




\subsubsection{Desempenho mecânico}

Neste tipo de classificação considera-se o desempenho mecânico do polímero e o tipo de aplicação mais comum ${ }^{7}$. Desta forma, os polímeros podem ser classificados como:

Termoplásticos convencionais. Estes materiais são também chamados de commodities, pelo grande volume de produção ( $90 \%$ da produção mundial) e com baixo custo em relação aos demais tipos de polímeros. Os termoplásticos têm como característica a utilização em peças e utensílios de baixíssimos requisitos de resistência mecânica, química e/ou térmica. Como exemplo, pode-se citar os polietilenos de alta e baixa densidade (HDPE e LDPE), o polipropileno (PP) e o policloreto de vinila (PVC);

Termoplásticos especiais. Estes materiais apresentam algumas características, como a estabilidade térmica e a transparência, sensivelmente superiores aos termoplásticos convencionais, podendo desta forma, serem utilizados em situações mais agressivas. Como exemplo pode-se citar o politetrafluoro-etileno (PTFE) e o polimetacrilato de metila (PMMA);

Termoplásticos de engenharia. Estes materiais são muito utilizados na fabricação de peças para dispositivos mecânicos. Ultimamente tem ampliado seu escopo de aplicações, e muitas vezes substituído os metais, pela sistemática melhoria de propriedades como a resistência mecânica, a tenacidade e a estabilidade dimensional. Como exemplo pode-se citar o polietileno de ultra-alto peso molecular (UHMWPE), as poliamidas (PA) e o polioximetileno (POM);

Termoplásticos de engenharia especiais. São aqueles polímeros especialmente desenvolvidos para trabalharem, de forma ininterrupta, em temperaturas elevadas (acima de $150{ }^{\circ} \mathrm{C}$ ). Como exemplo, pode-se citar o poliéter-éter-cetona (PEEK) e o polissulfeto de fenileno (PPS). 


\subsubsection{Físico-química dos polímeros}

\subsubsection{Cristalinidade}

Uma características muito importante nos termoplásticos semicristalinos é o seu grau de cristalinidade. Regiões cristalinas são formadas quando um número suficiente de cadeias se aproxima uma das outras de forma que as forças de ligação secundárias possam sobrepor o efeito desordenante da energia térmica ${ }^{6}$, estas regiões são chamadas de cristalitos. Cristalitos são regiões ou volumes de matéria em que as unidades estruturais sejam átomos, íons, meros ou moléculas são, arranjadas em um sistema regular geométrico ${ }^{8}$. Os cristalitos são estruturas da ordem de várias centenas de nanômetros.

As cadeias poliméricas são muito maiores que as dimensões de um cristalito, podendo uma cadeia passar de uma região cristalina para uma região amorfa, e atingir novamente uma outra região cristalina. Uma vez que uma cadeia polimérica individual passa aleatoriamente de uma região cristalina para outra, o modelo da micela franjeada (Figura 2.1) explica porque um cristal polimérico perfeito nunca pode ser alcançado 9 .

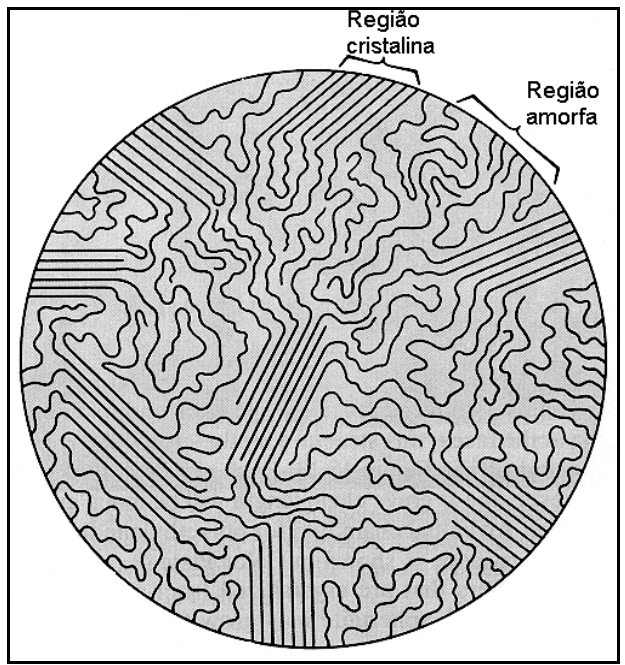

Figura 2.1 - Modelo da micela franjeada. ${ }^{10}$

A literatura ${ }^{11}$ mostra que monocristais de polímeros podem ser desenvolvidos através da cristalização lenta de uma solução polimérica diluída. Estes cristais se apresentam na forma de estrias finas ou lamelas com espessura de cerca de $10 \mathrm{~nm}$. Devido ao fato da espessura da estria ser apenas uma fração do comprimento da cadeia, 
esta última é obrigada a se dobrar para trás e para frente ao longo do cristal. Este modelo de estrutura cristalina é mostrado na Figura 2.2.

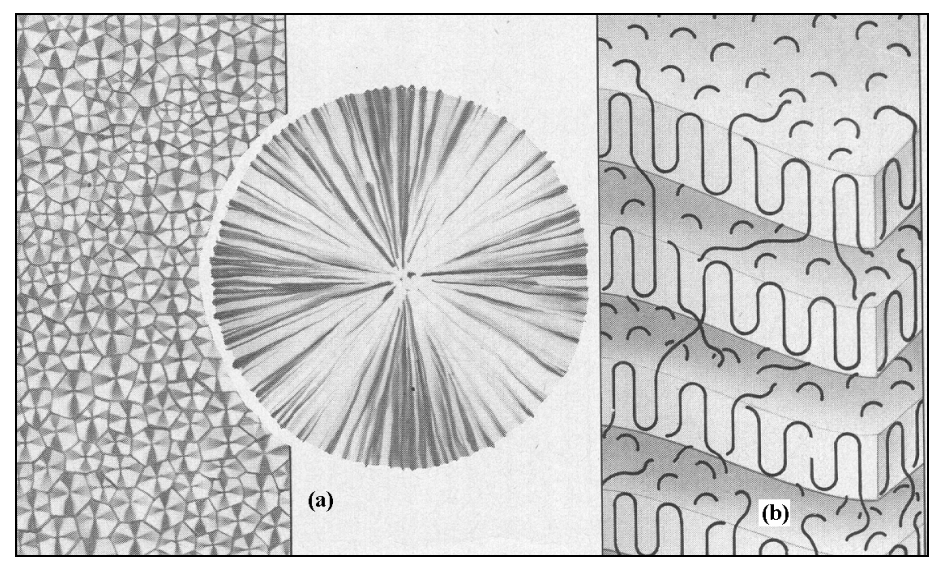

Figura 2.2 - Modelos de estruturas de polímeros semi-cristalinos. (a) estrutura esferulítica, com um esferulito em detalhe, (b) modelo da cadeia dobrada. ${ }^{12}$

Os polímeros podem se cristalizar a partir do estado líquido em uma forma maciça através da formação de esferulitos. Os esferulitos são formados por lamelas de cadeias dobradas, que ao se combinarem, formam uma unidade maior. Eventualmente, os esferulitos tomam formas poliédricas devido a interferência mútua no crescimento, assemelhando-se aos grãos de um material policristalino. Cada esferulito consiste de um grande número de cristalitos, enquanto que cada grão em um metal é um monocristal (Figura $2.2-\mathrm{a})^{12}$.

A cristalinidade possui papel importante no comportamento tribológico dos polímeros, principalmente no sentido de apresentar menores coeficientes de atrito em polímeros cristalinos, como o HDPE, UHMWPE e o POM. A orientação das cadeias moleculares também contribui para o aumento da resistência mecânica e da dureza dos polímeros, características importantes quanto a resistência ao desgaste.

\subsubsection{Massa molecular}

Polímero é uma palavra de origem grega e significa: muitos membros (partes), ou seja, estes materiais possuem moléculas longas constituídas de diversas unidades de repetição ou meros (monômeros) ${ }^{13}$. Sendo os polímeros um material constituído basicamente da união de várias unidades de repetição, é possível definir e/ou determinar a quantidade de monômeros que se combinam para formar as macromoléculas de 
polímeros e com isto definir um parâmetro muito importante que é a massa molecular (MM).

Na realidade, a união de vários monômeros só irá constituir um polímero quando sua massa molecular ${ }^{7}$ atingir valores da ordem de 10.000. Para MM entre 1.000 e 10.000, este material recebe a denominação de oligômero. A massa molecular de um polímero é um parâmetro importante que tem forte influência nas suas propriedades mecânicas $^{7}$ e tribológicas. A Figura 2.3 mostra esquematicamente que com o aumento da massa molecular, para um determinado polímero, ocorre um aumento em suas propriedades mecânicas. No entanto, existe um ponto de saturação onde somente aumentar a massa molecular não irá propiciar aumentos significativos de suas propriedades.

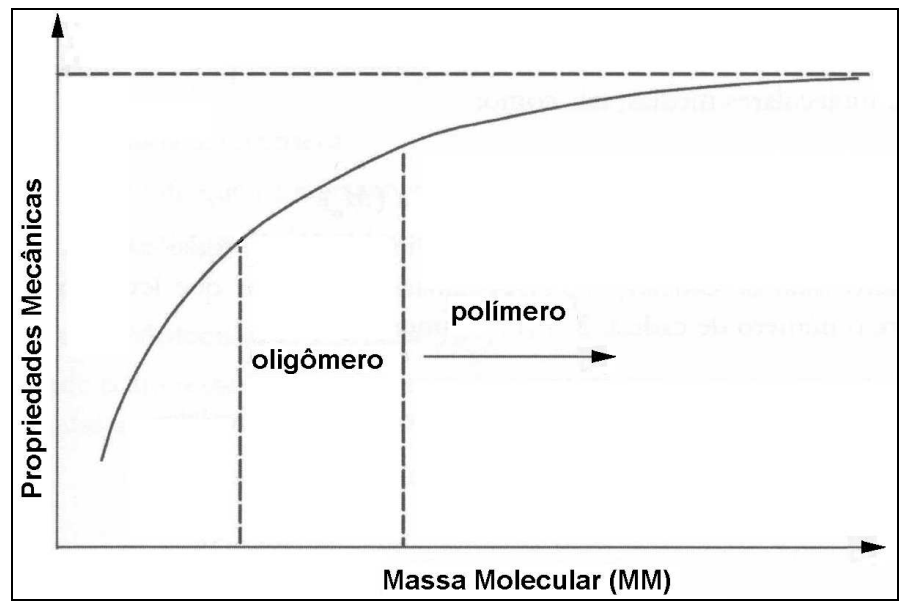

Figura 2.3 - Influência da massa molecular (MM) nas propriedades mecânicas dos polímeros. ${ }^{7}$

O aumento da massa molecular pode também dificultar a formação de regiões cristalinas, pois moléculas mais longas têm maior dificuldade em se arranjarem de uma maneira ordenada. Este fato é característico no caso da comparação entre MM e grau de cristalinidade de HDPE e UHMWPE. Apesar do UHMWPE atingir massa molecular da ordem de $6 \times 10^{6}$ [g/mol], seu grau de cristalinidade não ultrapassa os $45 \%$, enquanto que o HDPE pode atingir até $95 \%$ de cristalinidade com MM de 500.000 [g/mol].

Sabe-se que o aumento da massa molecular para um dado material conduz a um aumento de sua resistência ao desgaste ${ }^{14}$, no entanto ainda não se encontrou um patamar, ou um limite de valores de MM, onde a partir do qual o aumento da massa molecular deixa de ser representativa no seu comportamento ao desgaste. 


\subsubsection{Densidade de energia coesiva}

As propriedades coesivas de um polímero estão diretamente ligadas à sua solubilidade em relação a um líquido orgânico ${ }^{15}$. Ou seja, a densidade de energia coesiva $\left(\varepsilon_{c}\right)$ é uma medida da coesão entre as moléculas e está relacionada com a intensidade das forças intermoleculares (secundárias) ${ }^{7}$.

Pode-se então definir que a densidade de energia coesiva é a energia por unidade de volume requerida para separar completamente os átomos ou as moléculas de um sistema.

Como o objetivo da solubilização de um soluto (polímero) em um líquido (solvente) é promover a separação entre as suas moléculas, nada mais natural que o parâmetro de solubilidade se relacione com a energia coesiva de um polímero.

HILDEBRAND apud VAN KREVELEN ${ }^{15}$ propôs em 1936 a seguinte relação:

$$
\delta^{\prime}=\sqrt{\varepsilon_{\mathrm{C}}}
$$

Equação 2-1

onde

$\delta^{\prime}=$ parâmetro de solubilidade e

$\varepsilon_{\mathrm{c}}=$ densidade de energia coesiva.

A solubilidade e a densidade de energia coesiva são parâmetros que possuem uma forte dependência com as características químicas dos polímeros, desde o tipo de átomos que compõem as unidades monoméricas, até o grau de cristalinidade e a massa molecular.

O estudo dos polímeros em solução é de extrema importância em setores tecnológicos como a indústria farmacêutica, de alimentos, de cosméticos, de tintas e vernizes e de processamento de petróleo.

Em tribologia o estudo da transferência de camadas poliméricas no contato polímero-polímero ou polímero-metal, está diretamente relacionada com a capacidade de formar ligações secundárias fortes ou fracas. BAHADUR ${ }^{16}$ afirma que a transferência de camadas poliméricas ocorre do polímero de menor densidade energia coesiva para o de maior. 


\subsubsection{Comportamento térmico}

Os polímeros são materiais cujo comportamento mecânico depende muito da mobilidade de suas cadeias moleculares e esta mobilidade é função da agitação de suas moléculas e, conseqüentemente, da temperatura em que se encontra o material. As temperaturas de transição vítrea ( $\mathrm{Tg}$ ) e a de fusão cristalina ( $\mathrm{Tm})$ são especialmente importantes para definir o comportamento termomecânico e as características físicas dos polímeros.

Tg é a temperatura na qual a mobilidade das cadeias moleculares se torna restrita pela coesão intermolecular, assim o material torna-se mais rígido. É nesta temperatura que o polímero faz a transição do estado de borracha ou viscoso para o estado vítreo (Figura 2.4). Abaixo da Tg, as moléculas estão em um estado onde os movimentos moleculares como a rotação e a vibração são limitados. Acima de Tg, as moléculas possuem maiores níveis de energia e são possíveis movimentos de segmentos de uma molécula.

A temperatura de fusão cristalina (Tm), na realidade é uma faixa de temperaturas, em que toda a cristalinidade desaparece, onde os cristalitos e esferulitos se desagregam e fundem. Os polímeros amorfos não apresentam Tm, passando diretamente do estado vítreo para o de escoamento viscoso (Figura 2.4 - a), já os polímeros semicristalinos apresentam o estado borrachoso entre Tg e Tm (Figura 2.4 - b).

Assim como a massa molecular afeta as propriedades mecânicas, também a temperatura tem papel fundamental. A maior mobilidade das macromoléculas, provoca alterações substancias nas propriedades mecânicas tradicionais dos polímeros. A Figura 2.5, mostra o efeito da temperatura nas curvas tensão x deformação do polioximetileno (POM) copolímero. Nota-se que a além da redução do módulo de elasticidade, também a tensão máxima tem seu valor reduzindo, em $70 \%$, com uma variação de temperatura de $23^{\circ}$ para $120^{\circ} \mathrm{C}$. 


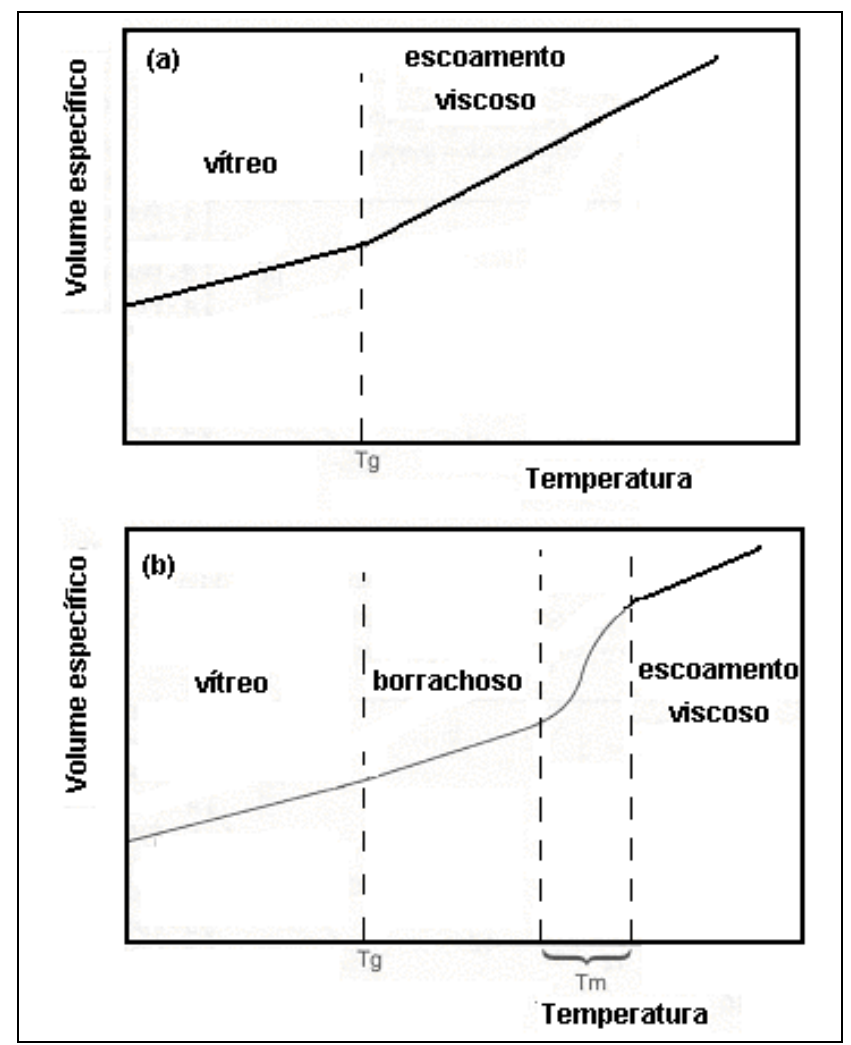

Figura 2.4 - Representação esquemática do efeito da temperatura no volume específico. (a) polímero amorfo, (b) polímero semicristalino.'

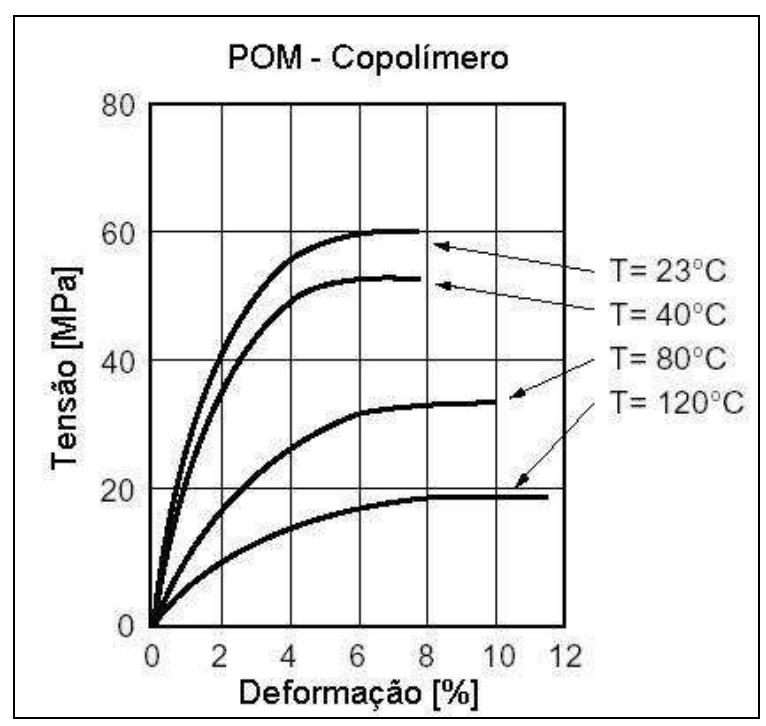

Figura 2.5 - Curvas tensão x deformação de POM copolímero para diversas temperaturas. $^{17}$

Além das propriedades elásticas e dinâmico-mecânicas (seção 2.1.4.3) também as características físico-químicas, como calor específico $(\mathrm{Cp})$, condutividade térmica $(\lambda)$ 
e energia de superfície $(\gamma)$, são influenciadas pela temperatura. A Tabela 2.1 mostra o efeito da temperatura na energia de superfície de alguns polímeros.

Tabela 2.1 - Energia de superfície de polímeros termoplásticos. ${ }^{18}$

\begin{tabular}{lcc}
\hline & \multicolumn{2}{c}{ Energia de Superfície $\times \mathbf{1 0}^{-3}\left[\mathbf{~ J} / \mathbf{m}^{2}\right]$} \\
\hline POLÍMERO & $\mathbf{2 0}{ }^{\circ} \mathbf{C}$ & $\mathbf{1 4 0}{ }^{\circ} \mathbf{C}$ \\
\hline PE & 35,7 & 27,3 \\
PS & 40,7 & 32,1 \\
PTFE & 23,9 & 16,9 \\
PMMA & 41,1 & 32,0 \\
\hline
\end{tabular}

\subsubsection{Comportamento mecânico de materiais viscoelástico}

\subsubsection{Fluência}

Fluência pode ser definida como uma lenta deformação plástica dependente do tempo, que ocorre em certos materiais quando submetidos a um carregamento constante. Entre os materiais que apresentam este comportamento podem ser citados os metais a altas temperaturas, polímeros e concreto. ${ }^{19}$

Um dos ensaios mais simples para se descrever o comportamento viscoelástico de materiais é o ensaio de fluência, no qual um carregamento trativo ou compressivo (constante durante o ensaio) é aplicado instantaneamente no c.d.p. e mede-se a deformação deste corpo em função do tempo. Uma curva esquemática de fluência é mostrada na Figura 2.6.

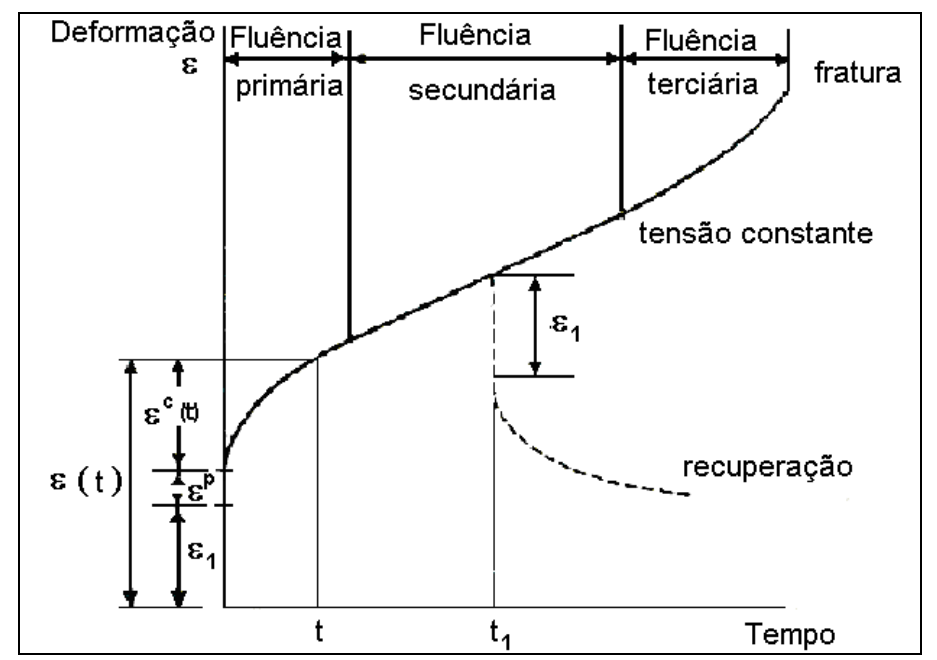

Figura 2.6 - Curva esquemática de fluência em ensaio a temperatura constante. ${ }^{20}$ 
Verifica-se que a deformação inicial tem uma componente elástica $\varepsilon_{1}$ e, no caso da tensão aplicada exceder a tensão de escoamento do material, uma componente plástica $\varepsilon^{\mathrm{p}}$. Com o decorrer do tempo, pode-se observar um aumento na deformação total do corpo $\varepsilon(\mathrm{t})$ devido ao aumento da componente relacionada à fluência do material, $\varepsilon^{\mathrm{c}}(\mathrm{t})$.

Nota-se que a curva de fluência pode ser dividida em três partes distintas. $\mathrm{Na}$ primeira parte da curva, onde se observa uma taxa de deformação de fluência decrescente no tempo, tem-se a região de fluência primária. A componente de deformação $\left(\varepsilon_{2}\right)$ é devida à capacidade de alinhamento das cadeias moleculares quando submetidas a uma tensão.

A parte da curva onde a taxa de deformação tem um valor mínimo e constante é a chamada região de fluência secundária ou regime estacionário (steady-state creep). A componente de deformação $\left(\varepsilon_{3}\right)$ está associada ao comportamento viscoso do material, decorrente do deslizamento entre as moléculas. Finalmente, na terceira região, verificase um aumento na taxa de deformação, causado pela redução da área do c.d.p., até a fratura do material. Essa componente de deformação é denominada por $\varepsilon^{\mathrm{ft}}$.

Desta forma tem-se:

onde:

$$
\varepsilon(\mathrm{t})=\varepsilon_{1}+\varepsilon^{\mathrm{p}}+\varepsilon^{\mathrm{c}}(\mathrm{t}) \quad \text { Equação 2-2 }
$$

$$
\varepsilon^{\mathrm{c}}(\mathrm{t})=\varepsilon_{2}+\varepsilon_{3}+\varepsilon^{\mathrm{ft}} \quad \text { Equação 2-3 }
$$

Para o modelamento do comportamento sob tensão com fluência, a componente de deformação plástica $\left(\varepsilon^{\mathrm{p}}\right)$ e a deformação sofrida na terceira região $\left(\varepsilon^{\mathrm{ft}}\right)$ foram desprezadas e assim, redefiniu-se a deformação total $\varepsilon(\mathrm{t})$ pela soma das três parcelas $\varepsilon_{1}, \varepsilon_{2}$ e $\varepsilon_{3}$, sendo definidas por:

$\varepsilon_{1}=$ deformação elástica instantânea;

$\varepsilon_{2}=$ deformação elástica atrasada;

$\varepsilon_{3}=$ deformação viscosa.

Se o material exibir um comportamento viscoelástico linear, a magnitude das deformações $\varepsilon_{1}, \varepsilon_{2}$ e $\varepsilon_{3}$ será proporcional à magnitude da tensão aplicada. Pode-se então 
ser definida uma função flexibilidade de fluência $J(t)$, a qual será uma função apenas do tempo:

$$
\varepsilon(\mathrm{t}) / \sigma=\mathrm{J}(\mathrm{t})=\mathrm{J}_{1}+\mathrm{J}_{2}+\mathrm{J}_{3}
$$

Equação 2-4

onde: $\mathrm{J}_{1}, \mathrm{~J}_{2}$ e $\mathrm{J}_{3}$ correspondem a $\varepsilon_{1}, \varepsilon_{2}$ e $\varepsilon_{3}$, respectivamente.

A parcela $\mathrm{J}_{3}$ é definida como escoamento viscoso e poderá ser desprezada para os seguintes casos:

- polímeros rígidos a temperatura ambiente;

- polímeros lineares amorfos a temperaturas abaixo de $\mathrm{T}_{\mathrm{g}}$;

- polímeros que apresentam muitas ligações cruzadas;

- polímeros que apresentam alto grau de cristalinidade.

\subsubsection{Modelos reológicos diferenciais}

Para simular o comportamento mecânico dos materiais viscoelásticos, foram criados modelos físicos simples. Sendo que os dois elementos básicos destes modelos são a mola e o amortecedor.

A mola representa o componente elástico do material. No caso particular de um comportamento linear, a relação entre a tensão atuante na mola e sua deformação será:

$$
\sigma=\mathrm{E} . \varepsilon
$$

Equação 2-5

onde: $\sigma=$ tensão normal aplicada;

$\mathrm{E}=$ módulo de elasticidade;

$\varepsilon=$ deformação total específica.

O amortecedor representa o comportamento viscoso do material. Logo, se o comportamento viscoso for Newtoniano, a taxa de deformação $(\dot{\varepsilon})$ e a tensão de cisalhamento $(\tau)$ estão relacionados por:

$$
\tau=\eta \cdot \dot{\varepsilon}
$$

Equação 2-6

onde $\eta=$ viscosidade dinâmica. 
Estes modelos básicos podem ser combinados de diversas maneiras, de modo a tentar simular materiais que não se comportam nem de forma perfeitamente elástica e nem de maneira perfeitamente viscosa.

\subsection{0 modelo de Maxwell}

O modelo de Maxwell resulta da combinação de uma mola e de um amortecedor ligados em série, como mostra a Figura 2.7.

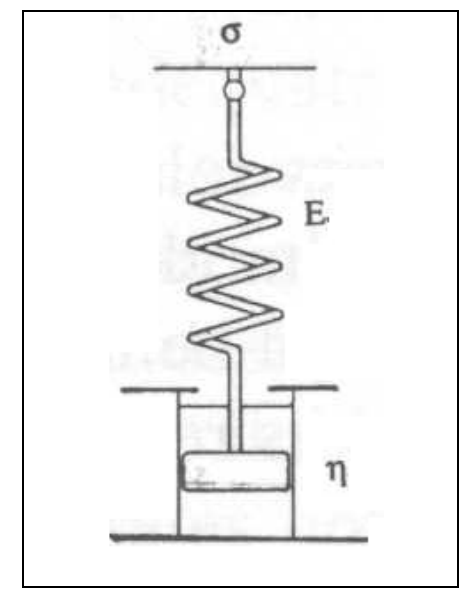

Figura 2.7 - Modelo de Maxwell. ${ }^{6}$

As equações que relacionam a tensão e a deformação em cada um dos elementos são expressas por:

onde:

$$
\begin{array}{ll}
\sigma^{\mathrm{e}}=\mathrm{E} \cdot \varepsilon^{\mathrm{e}}(\text { tensão na mola) } & \text { Equação 2-7 } \\
\sigma^{\mathrm{v}}=\eta \cdot \frac{\mathrm{d} \varepsilon^{\mathrm{v}}}{\mathrm{dt}} \text { (tensão no amortecedor) } & \text { Equação 2-8 }
\end{array}
$$

$\sigma^{\mathrm{e}}$ e $\varepsilon^{\mathrm{e}}$ representam a tensão e a deformação elástica agindo na mola;

$\sigma^{\mathrm{v}}$ e $\varepsilon^{\mathrm{v}}$ representam a tensão e a deformação viscosa agindo no amortecedor.

Para obtermos a equação constitutiva do modelo de Maxwell devemos relacionar a tensão aplica $\boldsymbol{\sigma}$ à deformação total $\varepsilon$. Para isso, notamos que:

$$
\sigma=\sigma^{\mathrm{e}}=\sigma^{\mathrm{v}} \quad \text { e } \quad \varepsilon=\varepsilon^{\mathrm{e}}+\varepsilon^{\mathrm{v}} \quad \text { Equações 2-9 }
$$

Com as relações acima chegamos então a:

$$
\dot{\varepsilon}=\dot{\varepsilon^{\mathrm{e}}}+\dot{\varepsilon^{\mathrm{v}}} \rightarrow \dot{\varepsilon}=\frac{\dot{\sigma^{\mathrm{e}}}}{\mathrm{E}}+\frac{\dot{\sigma^{\mathrm{v}}}}{\eta} \quad \Rightarrow \quad \dot{\varepsilon}=\frac{\dot{\sigma}}{\mathrm{E}}+\frac{\dot{\sigma}}{\eta}
$$


A Equação 2-10 é a equação constitutiva procurada (o ponto representa a derivada parcial da grandeza em questão em relação ao tempo). O modelo de Maxwell é de interesse particular na consideração de ensaios de relaxação de tensões.

\subsection{O modelo de Kelvin-Voigt}

O modelo consiste de uma mola e um amortecedor ligados em paralelo como mostra a Figura 2.8.

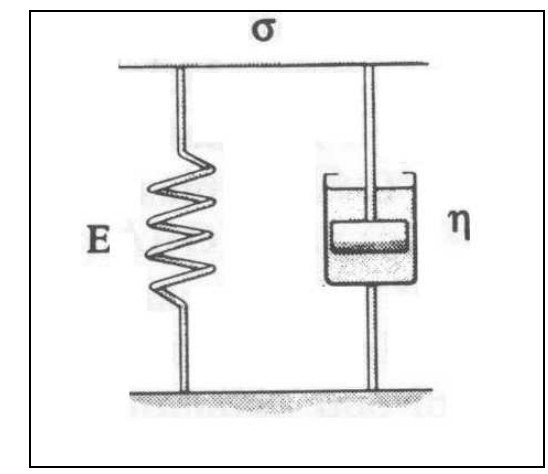

Figura 2.8- Modelo de Kelvin-Voigt. ${ }^{6}$

As relações entre tensão e deformação na mola e no amortecedor são as mesmas dadas pelas Equações 2-7 e 2-8.

Novamente é preciso relacionar a tensão aplicada $\boldsymbol{\sigma}$ com a deformação total $\boldsymbol{\varepsilon}$ para obtermos a equação constitutiva do modelo.

Observamos que neste caso:

$$
\sigma=\sigma^{\mathrm{e}}+\sigma^{\mathrm{v}} \quad \text { e } \quad \varepsilon=\varepsilon^{\mathrm{e}}=\varepsilon^{\mathrm{v}} \quad \text { Equações 2-11 }
$$

com as relações acima e as Equações 2-7 e 2-8 chega-se a:

$$
\sigma=\sigma^{\mathrm{e}}+\sigma^{\mathrm{v}} \quad \rightarrow \sigma=\mathrm{E} \cdot \mathrm{\varepsilon}^{\mathrm{e}}+\eta \dot{\cdot}^{\mathrm{v}} \quad \Rightarrow \quad \sigma=\mathrm{E} \cdot \varepsilon+\eta \cdot \dot{\dot{\varepsilon}} \quad \text { Equação 2-12 }
$$

que é a equação constitutiva procurada para o modelo de Kelvin-Voigt. Este modelo representa bem, o comportamento do material num ensaio de fluência.

\subsubsection{Energia de amortecimento}

Os ensaios dinâmico-mecânicos têm como objetivo o estudo do efeito da estrutura molecular, bem como da morfologia dos polímeros em propriedades como o módulo de elasticidade, tempo de relaxação, além dos mecanismos de dissipação de energia. $^{20}$ 
Quando se solicita um material polimérico com uma tensão senoidal, este responderá a esta solicitação com uma deformação atrasada com relação à solicitação. Este atraso "se deve à necessidade de ocorrer rearranjos moleculares associados a fenômenos de relaxação de cadeias poliméricas ou segmentos desta cadeia"21 ${ }^{\text {. Observa- }}$ se na Figura 2.9 que a deformação $\varepsilon_{0}$ está atrasado em relação a tensão $\sigma_{\mathrm{o}}$ pelo ângulo de fase $\delta$.

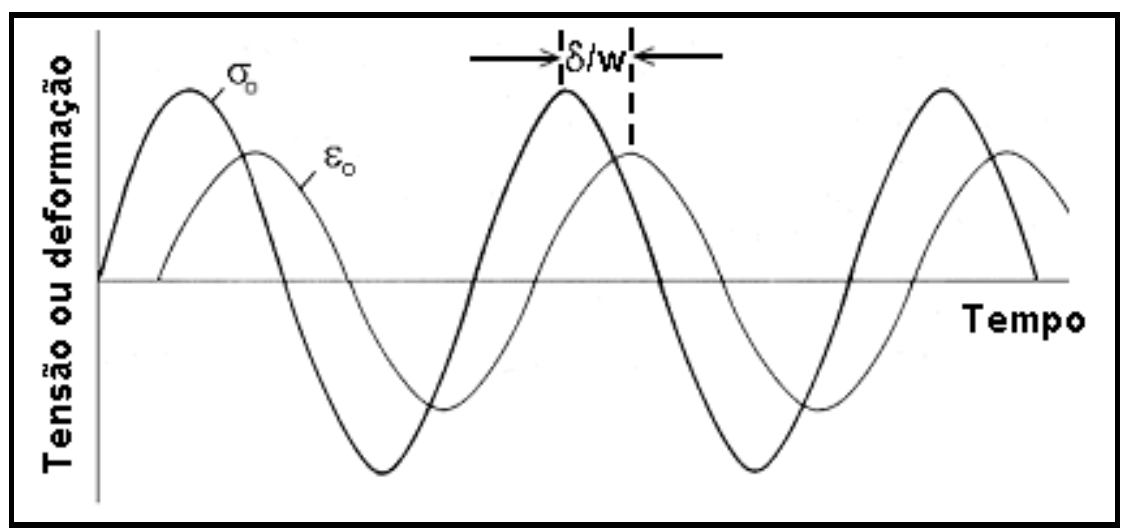

Figura 2.9 - Variação da tensão e da deformação com o tempo para um material viscoelástico, mostrando o ângulo de fase $\delta$ e a freqüiência de oscilação (w). ${ }^{20}$

Separando-se o vetor de tensão em componentes defasadas de $90^{\circ}$, tem-se:

$$
\begin{array}{ll}
\sigma^{\star}=\sigma_{0} \cdot \cos \delta(\text { componente da tensão em fase }) & \text { Equação 2-13 } \\
\sigma^{\star}=\sigma_{0} \cdot \operatorname{sen} \delta(\text { componente da tensão fora de fase }) & \text { Equação 2-14 }
\end{array}
$$

Os correspondentes módulos de elasticidade em fase e fora de fase com a deformação são determinados diretamente das equações 2-13 e 2-14:

$$
\begin{aligned}
& \mathrm{E}^{\prime}=\sigma^{\prime} / \varepsilon_{\mathrm{o}}=\left(\sigma_{\mathrm{o}} / \varepsilon_{\mathrm{o}}\right) \cdot \cos \delta=\mathrm{E}^{*} \cdot \cos \delta \\
& \mathrm{E}^{\prime \prime}=\sigma^{\prime \prime} / \varepsilon_{\mathrm{o}}=\left(\sigma_{\mathrm{o}} / \varepsilon_{\mathrm{o}}\right) \cdot \operatorname{sen} \delta=\mathrm{E}^{*} \cdot \operatorname{sen} \delta
\end{aligned}
$$

onde:

$$
\mathrm{E}^{*}=\text { módulo de elasticidade complexo }=\left(\mathrm{E}^{, 2}+\mathrm{E}^{, 2}\right)^{1 / 2} \text { Equação 2-17 }
$$

O módulo de elasticidade em fase com a deformação (E') reflete a resposta elástica do material, onde as componentes de tensão e deformação estão em fase. E' é chamado de módulo de armazenamento. Esta parte da energia de deformação, é introduzida no sistema pela aplicação de $\sigma_{0}$. Por outro lado, E" descreve a energia de 
deformação que é totalmente dissipada (muitas vezes na forma de calor), por isso é chamado de módulo de perda ${ }^{6}$.

A relação de amortecimento ou de perda de energia do material é dada pela tangente de perda:

$$
\mathrm{E}^{\prime} / \mathrm{E}^{\prime}=\left(\mathrm{E}^{*} \cdot \operatorname{sen} \delta\right) /\left(\mathrm{E}^{*} \cdot \cos \delta\right)=\operatorname{tg} \delta
$$

A Figura 2.10 apresenta a variação do comportamento viscoelástico, ou a capacidade de amortecimento de um homopolímero semi-cristalino em função da temperatura. Os picos de relaxação referentes a transições primárias e secundárias são representados por letras gregas.

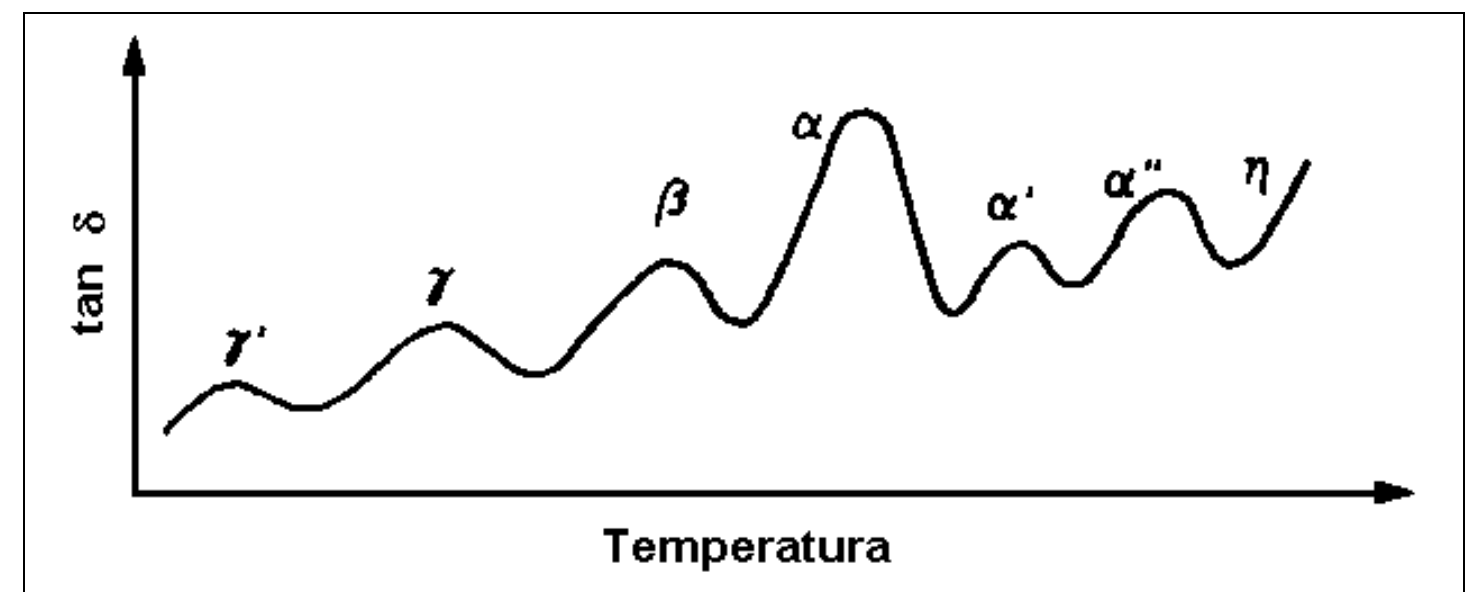

Figura 2.10 - Representação esquemática da capacidade de amortecimento $(\tan \delta$ ) de um polímero semi-cristalino em função da temperatura. ${ }^{22}$

A Tabela 2.2 apresenta uma relação entre os picos de relaxação com movimentos moleculares. No caso de polímeros semicristalinos, é muito difícil explicar o comportamento viscoelástico (posição dos picos de relaxação) devido á complexidade de uma estrutura bifásica.

Tabela 2.2 - Regiões de transição de polímeros. ${ }^{6}$

\begin{tabular}{ll}
\hline Transições & Causa \\
\hline$\gamma^{\prime}$ e $\gamma$ & Movimentos de pequenos grupos de moléculas no estado vítreo \\
$\beta$ & Movimento de 2 - 3 unidades de repetição \\
$\alpha$ & Mov. coordenados de 10 - 20 unidades de repetição - transição vítrea \\
$\alpha^{\prime}$ e $\alpha ”$ & Movimentos de estruturas supermoleculares \\
$\eta$ & Fusão cristalina \\
\hline
\end{tabular}


A seguir serão apresentadas informações importantes para o entendimento da tribologia de polímeros.

\subsection{Tribologia dos polímeros}

A tribologia é definida como a ciência que estuda o atrito, a lubrificação e o desgaste de superfícies de materiais de engenharia, com o objetivo de entender as interações entre os materiais em contato, podendo assim maximizar a sua aplicação ${ }^{23}$.

Parâmetros como coeficiente de atrito estático e cinético e resistência ao desgaste, são considerados propriedades do sistema, ou melhor, do tribossistema (Figura 2.11) e não como uma propriedade intrínseca de um material.

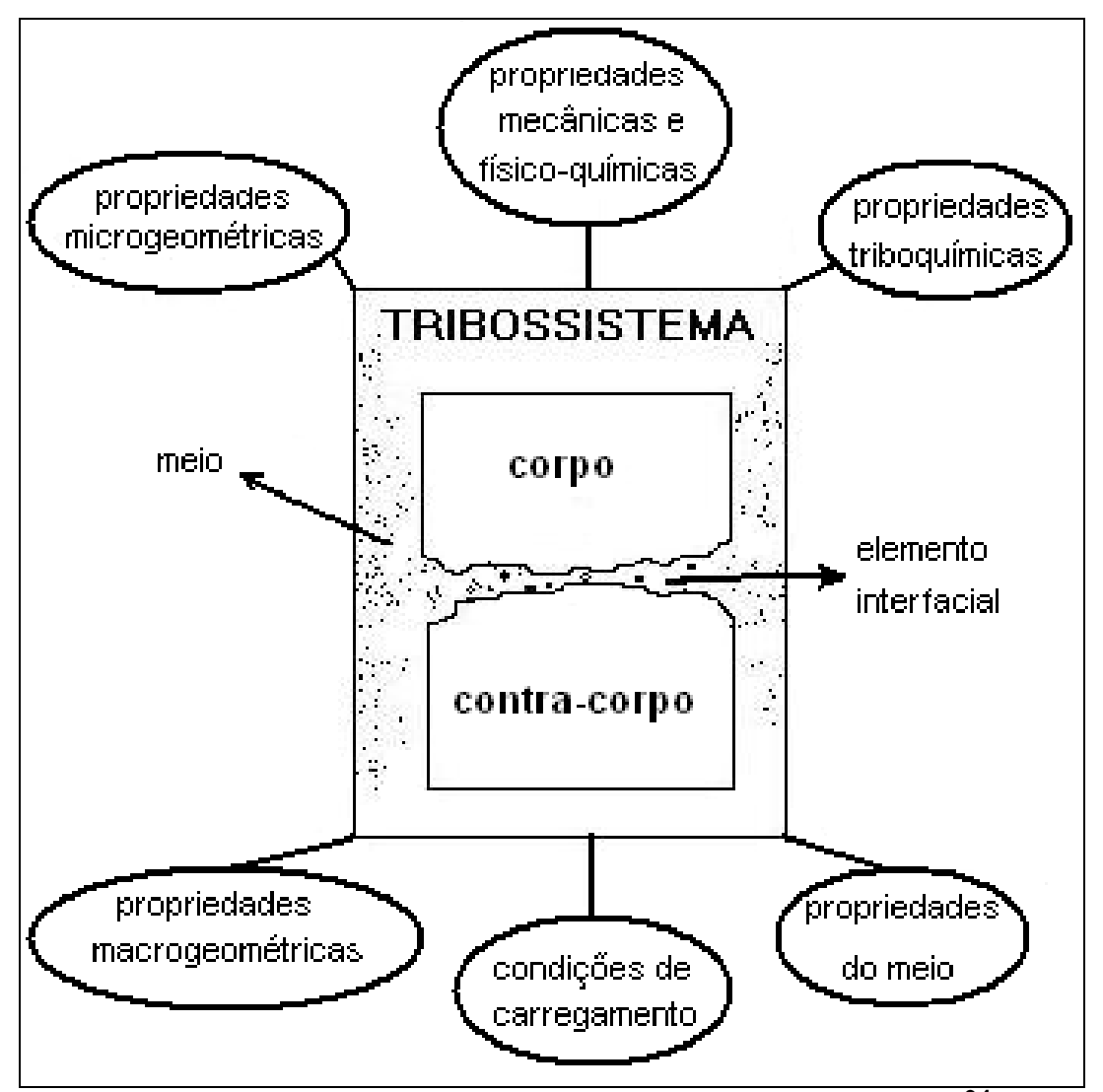

Figura 2.11 - Componentes de um tribossistema. ${ }^{24}$

Observa-se na Figura 2.11 que além dos materiais em contato, denominados usualmente de corpo e contra-corpo, adquirem papel fundamental na resposta tribológica do sistema, também as propriedades mecânicas e físico-químicas destes materiais, as propriedades do meio, as propriedades macro e microgeométricas das duas 
superfícies, as condições de carregamento, propriedades triboquímicas, além da presença de um meio interfacial e/ou resíduos provenientes do próprio processo de desgaste. Desta forma, para se determinar às propriedades tribológicas ou analisar resultados obtidos de ensaios experimentais, é extremamente necessário uma caracterização precisa do sistema tribológico em estudo.

Apesar do tribologista trabalhar com o conceito de interdisciplinaridade, integrando conceitos de física, química, mecânica, termodinâmica e ciências dos materiais, muitas vezes ocorre deste pesquisador se especializar em sistemas tribológicos específicos. No estudo de sistemas tribológicos, onde ao menos um dos corpos em contato é um material polimérico, este fato também pode acontecer.

A própria observação do sistema tribológico e a intuição dos fenômenos que ocorrem na região do contato, sugere uma relação biunívoca entre o coeficiente de atrito e o comportamento ao desgaste dos materiais do sistema. No entanto, tanto os livrostexto sobre tribologia ${ }^{25,22,26,27}$, quanto os artigos técnicos de revisões (review papers $)^{28,29,30,31,32,33}$ apresentam didaticamente, em separado os assuntos de atrito e de desgaste de polímeros. Tal fato se justifica pela complexidade dos assuntos e pela necessidade de um entendimento claro sobre os dois fenômenos, conduzindo assim a uma congruência de conhecimentos e a uma visão global deste ramo da tribologia.

Com o intuito de alcançar este mesmo objetivo, esta maneira de apresentar as informações sobre a tribologia dos polímeros será empregada nas seções a seguir.

\subsubsection{Atrito de polímeros}

Quando os polímeros deslizam sobre outros materiais (metálicos e nãometálicos) chamados rígidos (dureza e módulo de elasticidade muito maiores que os dos polímeros), o atrito tende a ser determinado pelas propriedades do material polimérico. O que não exclui a significativa parcela de contribuição de características de superfície (mecânicas, térmicas e físico-químicas) do contra-corpo rígido. ${ }^{22,28,38}$

\subsubsection{Mecanismos de atrito}

O atrito entre polímeros, assim como para metais, é atribuído a dois mecanismos principais, o de deformação e o de $\operatorname{adesão~}^{34,35}$. A Figura 2.12 mostra, para o deslizamento de uma aspereza dura contra uma superfície polimérica, a região onde 
ocorre mecanismo de deformação (zona coesiva) e de adesão (zona interfacial). Vale a pena ressaltar que a zona interfacial não ultrapassa espessuras de $10 \mathrm{~nm}$ da superfície do polímero. $^{36}$

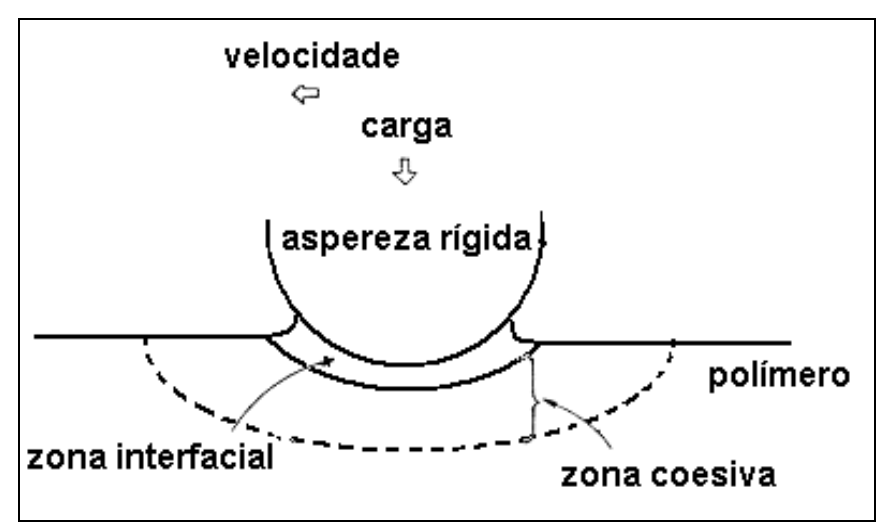

Figura 2.12 - A origem do atrito associado ao deslizamento de uma aspereza dura deslizando contra uma superfície polimérica. ${ }^{28}$

O mecanismo de deformação envolve dissipação completa de energia em volta da área de contato, provocando sulcamento. Este mecanismo possui forte dependência com a rugosidade do contra-corpo.

A Figura 2.13 mostra o coeficiente de atrito por rolamento e um parâmetro relacionado ao fator de perda (representado por $\delta / \mathrm{G}^{-1 / 3}$, onde $\mathrm{G}$ é o módulo de cisalhamento complexo) em função da temperatura, de um ensaio de esfera de aço contra PTFE com $48 \%$ de cristalinidade.

Nota-se na Figura 2.13 uma correlação direta entre o parâmetro $\delta / G^{-1 / 3}$ e o coeficiente de atrito por rolamento do polímero, conseqüentemente, também com a componente de deformação do coeficiente de atrito. 


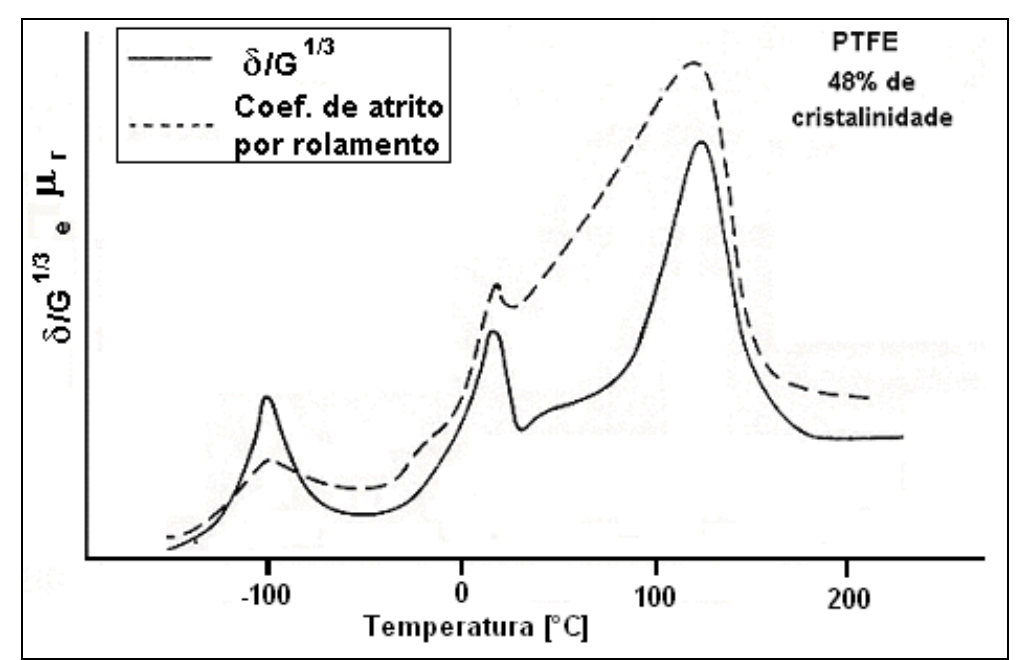

Figura 2.13 - Coeficiente de atrito por rolamento e fator de perda $\delta / G^{1 / 3} \mathrm{em}$ função da temperatura. ${ }^{27}$

No contato entre polímero e contra-corpo, as forças de ligação fracas, tipos Van der Waals e eletrostáticas, presentes na superfície dos polímeros, são responsáveis pela adesão entre os corpos. Desta forma, a componente de adesão relaciona-se com a força necessária para romper (cisalhar) as junções formadas no contato devido à atuação destas forças ou movimentar as cadeias poliméricas em regiões subsuperficiais.

A Figura 2.14 mostra, esquematicamente como se daria o contato entre superfícies de aço e de polietileno $(\mathrm{PE})^{25}$. Neste caso, a resistência ao movimento relativo entre as moléculas A e B do PE, gerado pela imposição de uma tensão de cisalhamento entre A e a superfície do aço, se traduz na componente de adesão do atrito.

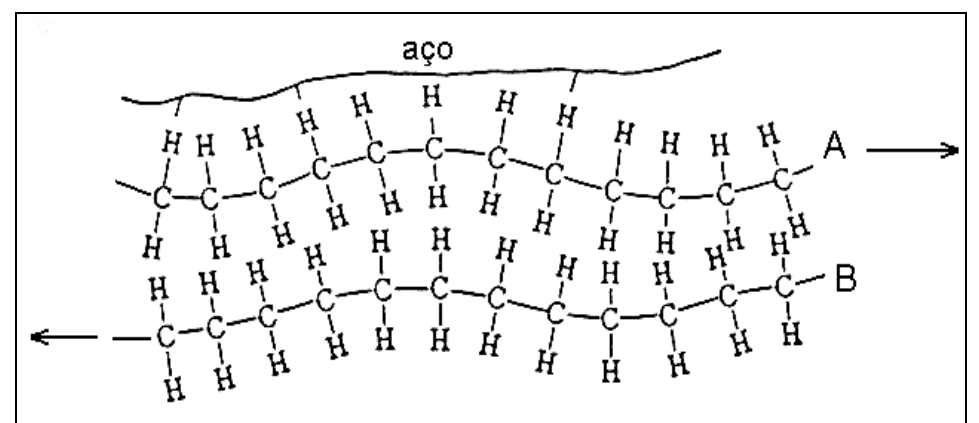

Figura 2.14 - Modelo de deslizamento entre as macromoléculas de PE. ${ }^{25}$

Apesar da Figura 2.14 não representar aspectos importantes das macromoléculas dos polímeros, como a conformação, o encadeamento e a taticidade ${ }^{8}$, YAMAGUSHI busca mostrar que a dificuldade no escorregamento entre as macromoléculas dos polímeros possui uma correlação com os valores de coeficiente de atrito. Quanto mais 
grupos volumétricos a cadeia apresentar e quanto maior o enovelamento destas cadeias, maiores serão os valores de coeficiente de atrito.

\subsubsection{Efeito das características do composto polimérico no atrito}

\subsubsection{Energia de superfície}

No início da década de 60 (século XX) RABINOWICZ ${ }^{37,38,39}$ discutiu a aplicação prática da energia de superfície na resolução de problemas de engenharia envolvendo sistemas tribológicos metálicos e propôs o seguinte modelo de coeficiente de atrito, que considera além da energia de superfície dos materiais também um parâmetro referente ao acabamento superficial:

$$
\mu=\frac{\tau_{\mathrm{e}}}{\mathrm{H}}\left(1+\frac{2 \cdot \mathrm{W}_{\mathrm{ab}} \cdot \cot \Theta}{\mathrm{H} \cdot \mathrm{r}}\right)
$$

onde: $\mathrm{r}$ - raio das asperezas;

$\Theta$ - ângulo de inclinação das asperezas;

$\mathrm{W}_{\mathrm{ab}}$ - trabalho de adesão $\left(\mathrm{W}_{\mathrm{ab}}=\gamma_{\mathrm{a}}+\gamma_{\mathrm{b}}-\gamma_{\mathrm{ab}}\right)$;

$\gamma_{\mathrm{a}}$ e $\gamma_{\mathrm{b}}$ - energia superficial dos materiais a e $\mathbf{b}$;

$\gamma_{\mathrm{ab}}=$ energia interfacial entre as superfícies $\mathbf{a}$ e b.;

$\mathrm{H}$ - dureza do material menos duro;

$\tau_{\mathrm{e}}$ - tensão de escoamento por cisalhamento.

No entanto, a tribologia de polímeros já caminhava nesta mesma direção, desde meados dos anos 50. Principalmente pela preocupação com as propriedades superficiais dos polímeros quando em aplicações como adesivos e/ou tintas.

Se o mecanismo de adesão pode ser considerado como o principal mecanismo de atrito para polímeros deslizando, a seco, sobre uma superfície 'lisa', é razoável crer que as interações eletrostáticas e/ou de Van der Waals que ocorrem no contato tenham papel fundamental para o coeficiente de atrito. No entanto, a compreensão dos fenômenos de adesão e a sua correlação com a energia de superfície (ou trabalho de adesão) fica um pouco mais dificultada quando do deslizamento sobre superfícies 'rugosas', pois a componente de deformação começa a ter papel decisivo no valor do coeficiente de atrito e nos mecanismos de desgaste. 
É importante ter em mente que a componente de deformação pode ser indiretamente afetada pela componente de adesão, pois uma alta aderência entre polímero e contra-corpo, pode reduzir a perda de energia por amortecimento do polímero $^{40}$.

MA apud FOLKES ${ }^{41}$ afirma que a componente de adesão da força de atrito (Fa) consiste da interação de várias componentes, podendo ser expressa da seguinte maneira:

onde:

$$
\mathrm{Fa}=\mathrm{Fa}^{\mathrm{d}}+\mathrm{Fa}^{\mathrm{dip}}+\mathrm{Fa}^{\mathrm{i}}+\mathrm{Fa}^{\mathrm{h}}+\mathrm{Fa}^{\mathrm{e}} \quad \text { Equação 2-20 }
$$

$\mathrm{Fa}^{\mathrm{d}}=$ forças de dispersão;

$\mathrm{Fa}^{\text {dip }}=$ forças dipolo-dipolo;

$\mathrm{Fa}^{\mathrm{i}}=$ forças de indução;

$\mathrm{Fa}^{\mathrm{h}}=$ pontes de hidrogênio;

$\mathrm{Fa}^{\mathrm{e}}=$ forças eletrostáticas.

Principalmente para os contatos polímero-polímero ${ }^{42,43}$, a utilização do conceito de trabalho de adesão $\left(\mathrm{W}_{\mathrm{ab}}\right)$ proposto por DUPRÉ ${ }^{44}$, assume papel predominante no entendimento da influência da energia de superfície tanto no coeficiente de atrito quanto na resistência ao desgaste.

\subsubsection{Morfologia das regiões cristalinas}

A cristalinidade em polímeros consiste no alinhamento de segmentos de cadeias em um arranjo tridimensional. Assim como as maiorias das propriedades físicas, mecânicas e termodinâmicas dos polímeros, também as propriedades tribológicas são afetadas pelo grau de cristalinidade e pela morfologia das regiões cristalinas.

BELY et all $^{45}$ mostram a influência da morfologia de uma estrutura cristalina do tipo esferulitos no coeficiente de atrito. Na Figura 2.15 observa-se que nos contornos dos esferulitos o coeficiente de atrito apresenta seus menores valores $(\mu \approx 0,22)$, por outro lado nas regiões centrais do esferulito o atrito se eleva $(\mu \approx 0,27)$. Estas mudanças de comportamento para diferentes zonas no esferulito são interpretadas pela heterogeneidade das propriedades volumétricas e de superfície devido a natureza complexa desta formação supermolecular com comportamento anisotrópico devido às fibras dos esferulitos. 


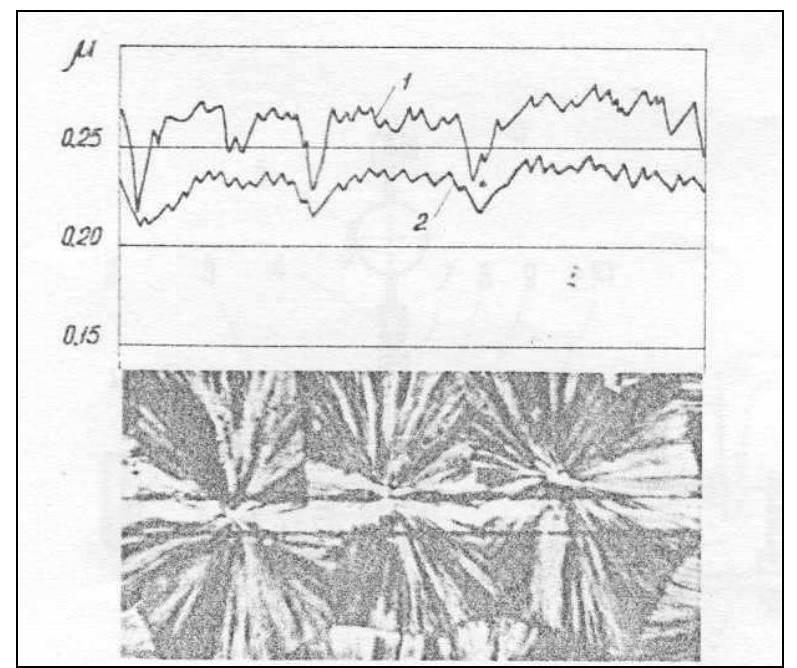

Figura 2.15 -Comportamento do coeficiente de atrito durante dois passos (1 e 2) de um riscador sobre a superfície de esferulitos de polipropileno. ${ }^{45}$

\subsubsection{Parâmetros do sistema tribológico e o atrito}

\subsubsection{Velocidade de deslizamento}

Devido à natureza viscoelástica dos polímeros, a variação na velocidade de deslizamento poderá provocar mudanças significativas nos mecanismos de atrito, principalmente pela sua importância na temperatura desenvolvida na região de contato.

LUDEMA; TABOR ${ }^{34}$ verificaram que o aumento da velocidade de deslizamento provoca um aumento na tensão de cisalhamento. Além disto, da análise do contato entre superfícies rugosas proposta por GREENWOOD; WILLIAMSON ${ }^{46}$, sabe-se que a área de contato é proporcional a $\mathbf{E}^{2 / 3}(\mathbf{E}=$ módulo de elasticidade), e que $\mathbf{E}$ diminui com o aumento da velocidade.

A Figura 2.16 apresenta a análise proposta por LUDEMA; TABOR que utilizam a hipótese de BOWDEN; TABOR para a força de atrito $(\mathrm{Fa})$, onde esta é expressa pelo produto da tensão de cisalhamento aplicada à área real de contato $(\mathrm{Fa}=\tau$. A $)$. 


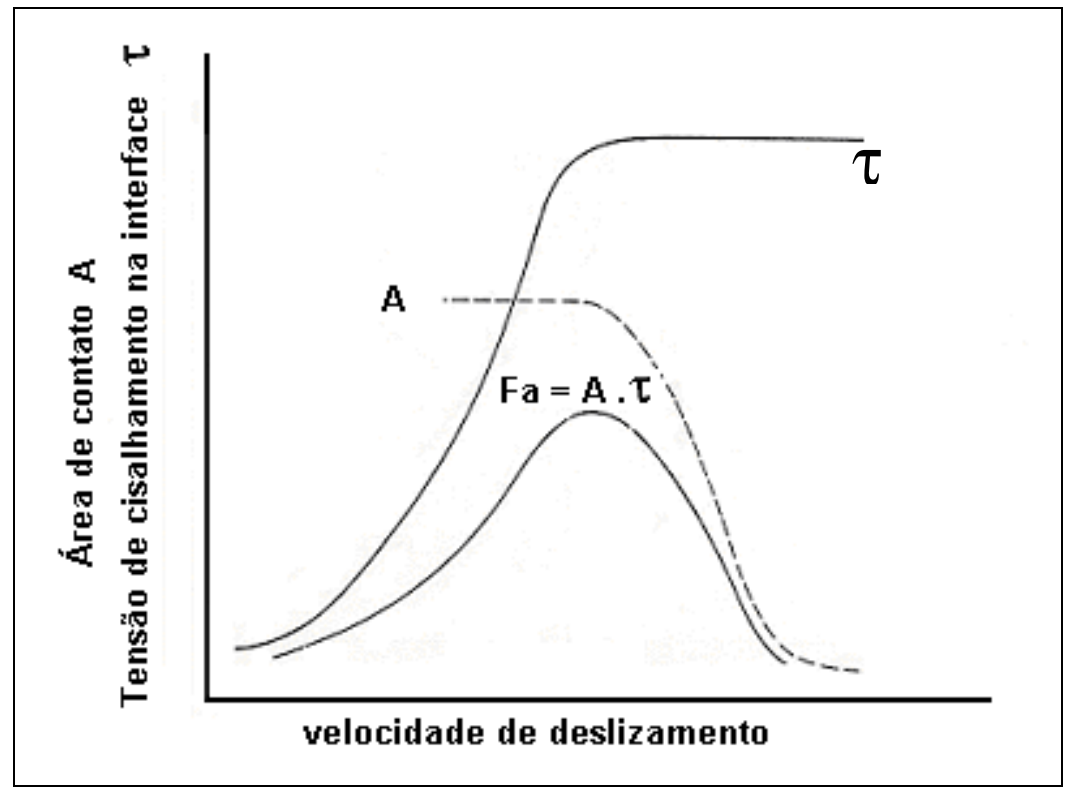

Figura 2.16 - Comportamento da área real e da tensão de cisalhamento em função da velocidade de deslizamento. ${ }^{34}$

A Figura 2.17 mostra o comportamento do coeficiente de atrito em função da velocidade de deslizamento do polietileno de alta e baixa densidade (HDPE e LDPE), o politetrafluoroetileno (PTFE) e poliamida 6 (PA 6).

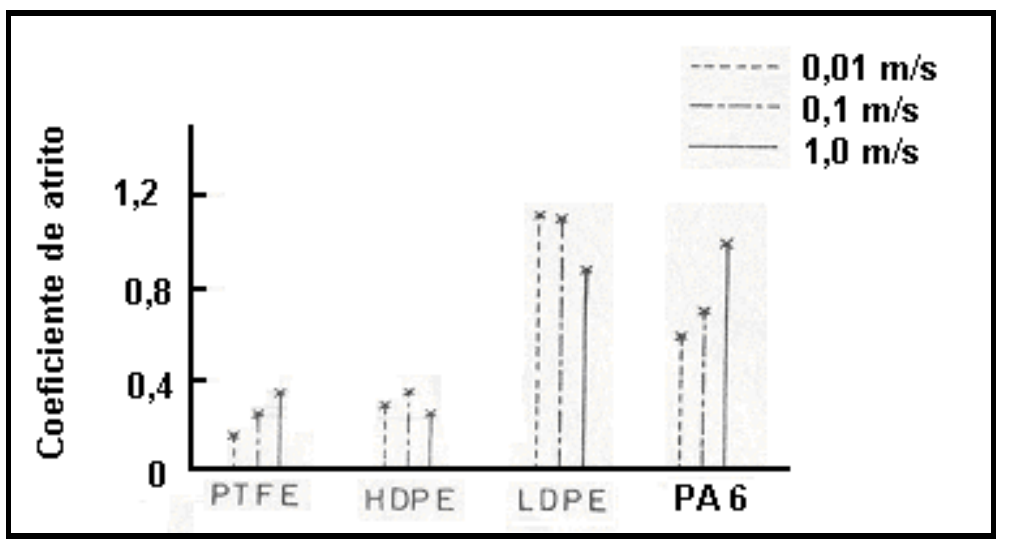

Figura 2.17- Coeficiente de atrito em função da velocidade de deslizamento para polímeros semi-cristalinos. ${ }^{47}$

Portanto, dependendo da velocidade de deslizamento e dos materiais em contato, o coeficiente de atrito será inversa ou diretamente proporcional ao aumento da velocidade de deslizamento dependendo da faixa de velocidade estudada ${ }^{48,49,50}$. 


\subsubsection{Carga normal aplicada}

O estudo do comportamento tribológico dos polímeros em função da carga aplicada tem sido foco de estudo de muitos pesquisadores. SANTNER; $\mathrm{CZICHOS}^{31}$, BRENTNALL; LANCASTER ${ }^{51}$ e CLERICO ${ }^{52}$ observaram que o coeficiente de atrito de polímeros ou compósitos poliméricos, quando atritados contra metais, diminui à medida em que se eleva a carga. Exatamente opostos, foram os resultados obtidos por VINOGRADOV et all $^{53}$. No entanto, YAMAGUCHI ${ }^{25}$ mostra na Figura 2.18 que para o deslizamento entre poliamida e aço, o coeficiente de atrito apresenta uma região de máximo com a variação carga aplicada.

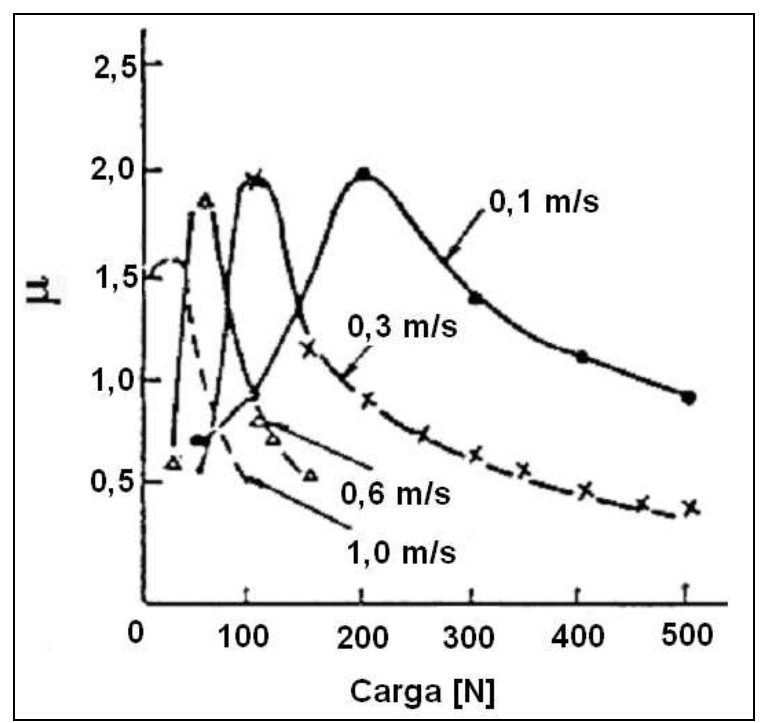

Figura 2.18 - Relação entre coeficiente de atrito e carga para várias velocidades de deslizamento (poliamida e aço). ${ }^{25}$

Com isto, pode-se supor que os resultados onde o coeficiente de atrito é inversamente proporcional a carga aplicada, foram realizados em regiões onde $\mathrm{o}$ comportamento do coeficiente de atrito é decrescente em relação à carga. O mesmo raciocínio pode ser feito para os resultados exatamente opostos.

\subsubsection{Temperatura de contato}

Em aplicações onde o sistema tribológico não está sendo refrigerado, o aumento tanto da carga normal como da velocidade de deslizamento irá provocar um aquecimento na região de contato e, conseqüentemente, um aumento na temperatura. MALAY; BAHADUR ${ }^{54}$, mostram que, para o HDPE deslizando contra aço carbono, o 
aumento da temperatura provoca um crescimento no coeficiente de atrito. Logo, pode-se dizer que a temperatura, e conseqüentemente, o coeficiente de atrito e a taxa de desgaste possuem uma dependência com a condição PV (pressão-velocidade) do sistema tribológico $^{29}$.

$\mathrm{Na}$ seleção de materiais para mancais de rolamento ou deslizamento, um parâmetro de engenharia de grande importância é a condição PV. Esta condição representa o grau de severidade dos esforços na região de contato e limita a utilização dos materiais, de acordo com a condição PV limite de um dado material em um sistema específico. Apesar dos materiais poliméricos apresentarem baixa condutividade térmica, o que dificultaria sua aplicação em mancais, sua característica de autolubrificação a seco permite a utilização destes materiais em aplicações especiais.

A Figura 2.19 mostra que a temperatura no contato estabilizará em patamares cada vez mais elevados quanto mais severas forem as condições PV. A condição PV máx representa a condição em que a temperatura no contato não se estabilizará e o material atingirá temperaturas elevadíssimas, fundindo ou provocando uma intensa oxidação na região de contato. Este valor pode ser chamado de condição PV limite.

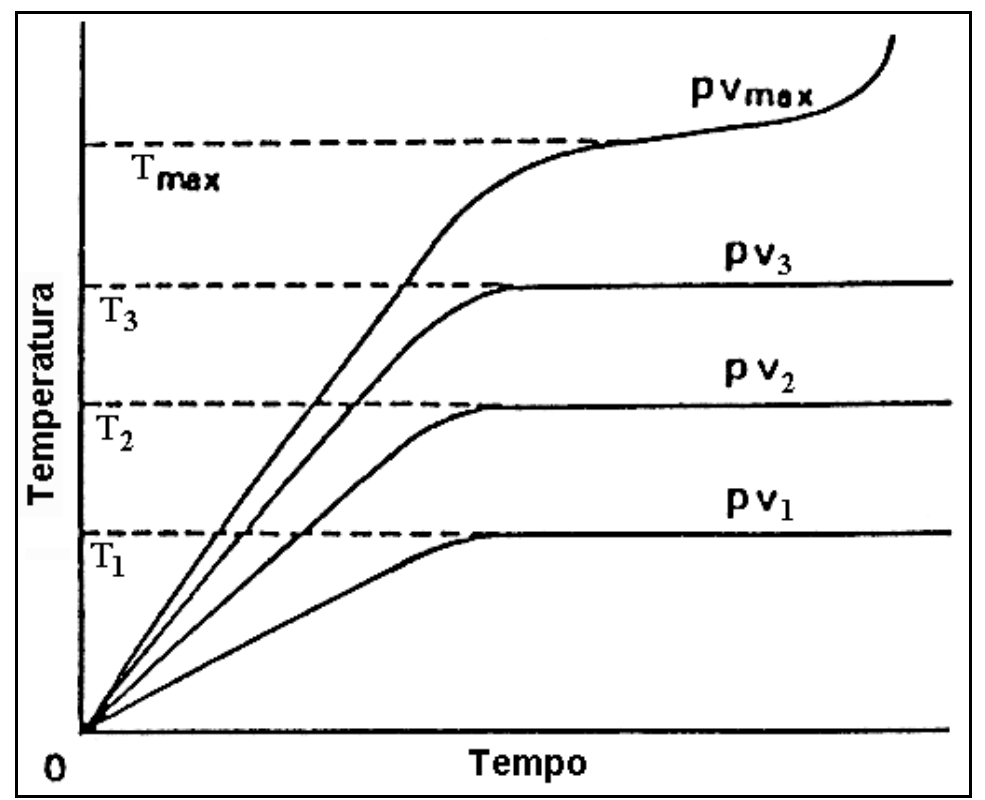

Figura 2.19 - Curva de temperatura no contato pelo tempo para condições PV cada vez mais elevadas. ${ }^{25}$

Um exemplo de determinação da condição PV limite, foi obtido com o aumento da rotação (velocidade), em um ensaio tipo disco-contra-disco, para o deslizamento de polietileno contra aço inoxidável ${ }^{55}$. A Figura 2.20 mostra o efeito da rotação na 
temperatura de contato a medida em que o ensaio de desgaste se desenvolve. Observa-se que para a rotação de $250 \mathrm{rpm}$, a temperatura no contato não se estabiliza.

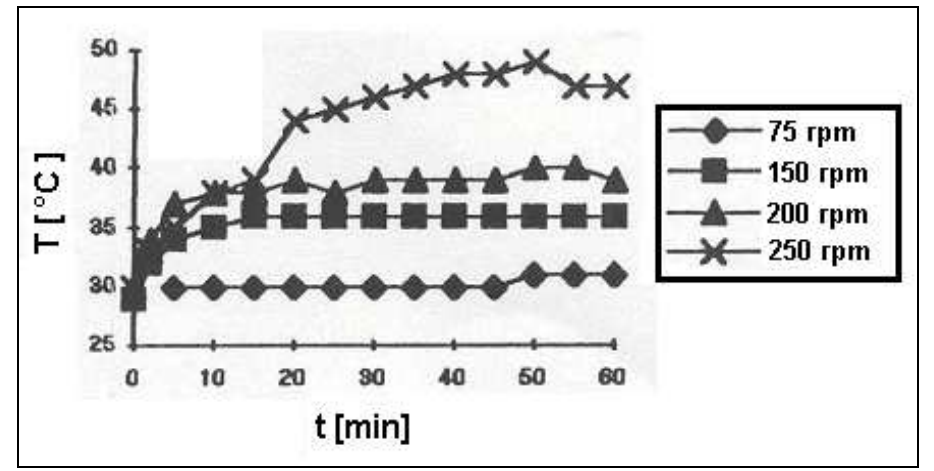

Figura 2.20 - Efeito da rotação na temperatura de contato de PE contra aço inoxidável. ${ }^{55}$

Estes dados mostram que o aumento da temperatura na superfície de contato, provocado tanto pelo aumento da carga aplicada como da velocidade de deslizamento, tem um papel fundamental na resposta tribológica do material.

\subsubsection{Umidade Relativa}

A importância da umidade relativa em sistemas tribológicos pode ser verificada no trabalho de $\mathrm{CZICHOS}^{42}$, onde foi tomado um cuidado especial nas medidas de coeficiente de atrito de termoplásticos contra aço e verificou-se que a capacidade higroscópica dos polímeros afeta substancialmente o seu comportamento quanto ao desgaste. A dependência do coeficiente de atrito em relação à umidade relativa do ambiente, tanto para polímeros quanto para metais e cerâmicas, continua ainda a ser um ponto de discussões e tema de muitas pesquisas ${ }^{56,57,58}$.

SILVA et all ${ }^{59}$ mostram que a umidade relativa do ambiente pode ter seu efeito sobre o coeficiente de atrito reduzido, dependendo da carga aplicada na região do contato. A Figura 2.21 apresenta o efeito da carga aplicada e da umidade relativa sobre o coeficiente de atrito de HDPE, com 3,5\% de negro-de-fumo, deslizando sobre aço galvanizado com rugosidade $\mathrm{Ra}$ de $1,2 \mu \mathrm{m}$, em ensaio pino-contra-disco. 

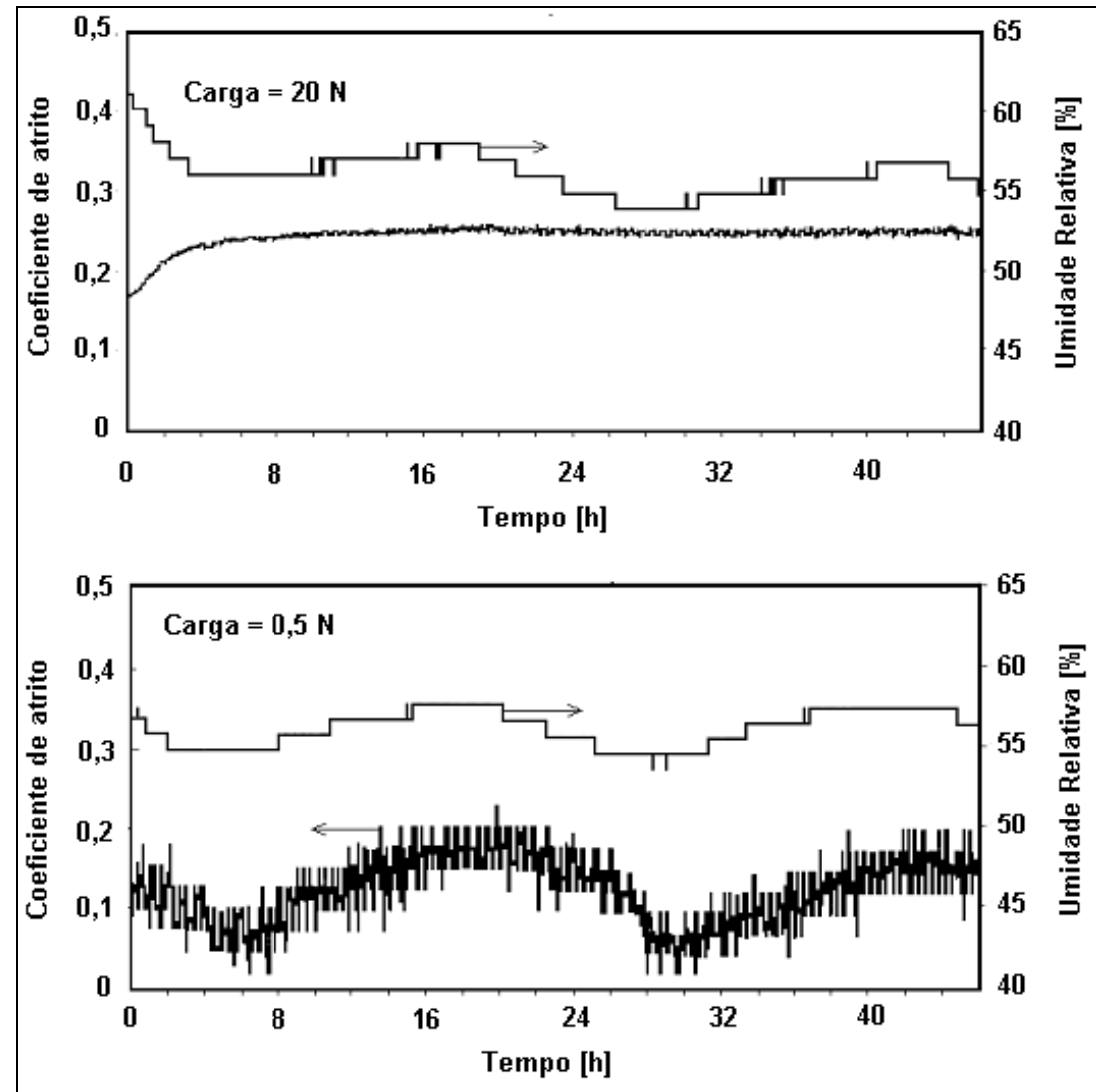

Figura 2.21 - Influência da carga e da umidade relativa no coeficiente de atrito de HDPE. ${ }^{59}$

\subsection{Desgaste dos polímeros}

Assim como no coeficiente de atrito, o fenômeno de desgaste também pode ser analisado de acordo com a forma que a energia imposta no sistema é absorvida e como provoca dano no material. Na Figura 2.22, o contra-corpo é considerado perfeitamente rígido. 


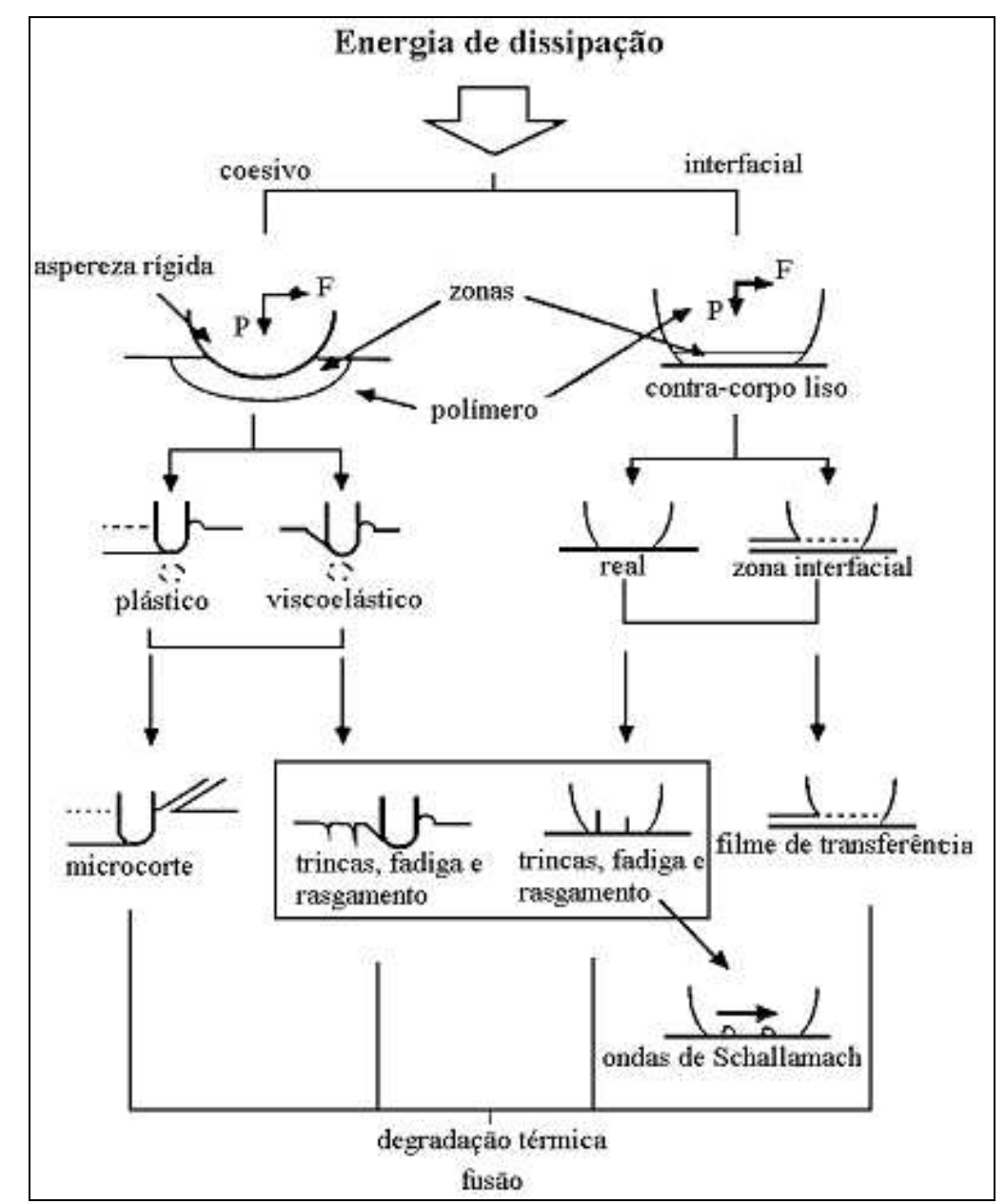

Figura 2.22- Descrição dos mecanismos de dissipação de energia no deslizamento de um polímero contra um contra-corpo rígido. ${ }^{36}$

Uma classe de mecanismos de atrito é proveniente das forças de adesão entre o polímero e o contra-corpo rígido, a qual conduz a um processo de dissipação interfacial de energia. Acredita-se que a componente de adesão possui uma "zona de dissipação de energia primária" normalmente localizada próxima da interface, com uma espessura típica de 2 a $10 \mathrm{~nm}$. A outra componente é chamada de deformação e geralmente inclui volumes que são muito maiores e comparáveis com o comprimento de contato aparente. Estas componentes são responsáveis pelas classes de mecanismos de desgaste que envolvem fenômenos superficiais e sub-superficiais, sendo respectivamente chamados de desgaste por adesão e desgaste por abrasão, processo interfacial e processo coesivo ${ }^{60}$ ou ainda desgaste interfacial e desgaste por deformação volumétrica ${ }^{35}$. 


\subsubsection{Mecanismos de desgaste}

A compreensão dos mecanismos de desgaste que atuam em um tribossistema polimérico tem sido um assunto amplamente estudado na tribologia ${ }^{16,22,23,25,26,27}$. Uma classificação geral de mecanismos depende da combinação dos seguintes fenômenos ${ }^{25}$ :
a) abrasão;
b) desgaste térmico;
c) adesão e transferência;
d) macrocisalhamento;
e) fadiga;
f) fratura superficial;
g) deformação plástica;
h) amolecimento (fusão).

A seguir, serão apresentados os principais mecanismos de desgaste de materiais poliméricos que envolvem processos interfaciais (transferência de filme) e processos coesivos (abrasão e fadiga).

\subsubsection{Transferência de filme polimérico}

Em sistemas tribológico onde ocorre deslizamento de materiais poliméricos, um mecanismo de grande importância é a transferência de filme sobre a superfície do contra-corpo rígido. Algumas condições de deslizamentos promovem a formação de filmes com espessura constante durante os ensaios de desgaste ${ }^{61}$, pois ocorre um balanço entre mecanismos de arrancamento e de deposição, admitindo com isso que apenas as camadas superiores de filme de transferência são removidas.

A estabilidade destes filmes também depende da maior adesão entre estes e o contra-corpo; quanto maior esta adesão, menor será a taxa de desgaste, mais orientadas serão suas cadeia e maior será a cristalinidade do filme depositado ${ }^{81}$, caso o polímero seja recristalizável.

\subsection{Transferência "normal"}

Como a junção entre polímero e contra-corpo é mais forte que as ligações intermoleculares do polímero, a falha do material ocorre por transferência de fragmentos. Repetidos deslizamentos conduzem a uma progressiva transferência de 
camadas, as quais eventualmente se destacam. Estes filmes irregulares têm espessura da ordem de 0,1 a $1,0 \mu \mathrm{m}$.

Este fenômeno é conhecido como "transferência normal" ou "regime de alto atrito", onde o polímero é transferido para o contra-corpo sem significativo rompimento de cadeias e/ou degradação química. É o mecanismo de transferência mais comum entre os polímeros ${ }^{62}$.

Não está bem estabelecido se estes filmes são depositados à mesma taxa em que o material é perdido, ou se os detritos originais formam o filme, o que é mais provável, pois frequientemente encontra-se filme maior que as cavidades de desgaste presentes na superfície dos polímeros.

Existe uma evidência de que os polímeros relutam em transferir filmes para si mesmos e se o filme aderir fortemente ao substrato, a taxa de desgaste tende a reduzir. LANCASTER $^{35}$ e HUTCHINGS ${ }^{60}$ afirmam que este mecanismo está relacionado com um processo de destacamento inter ou policristalino, pois as intensas tensões cisalhantes excedem a resistência das ligações interlamelares ( Figura 2.23).

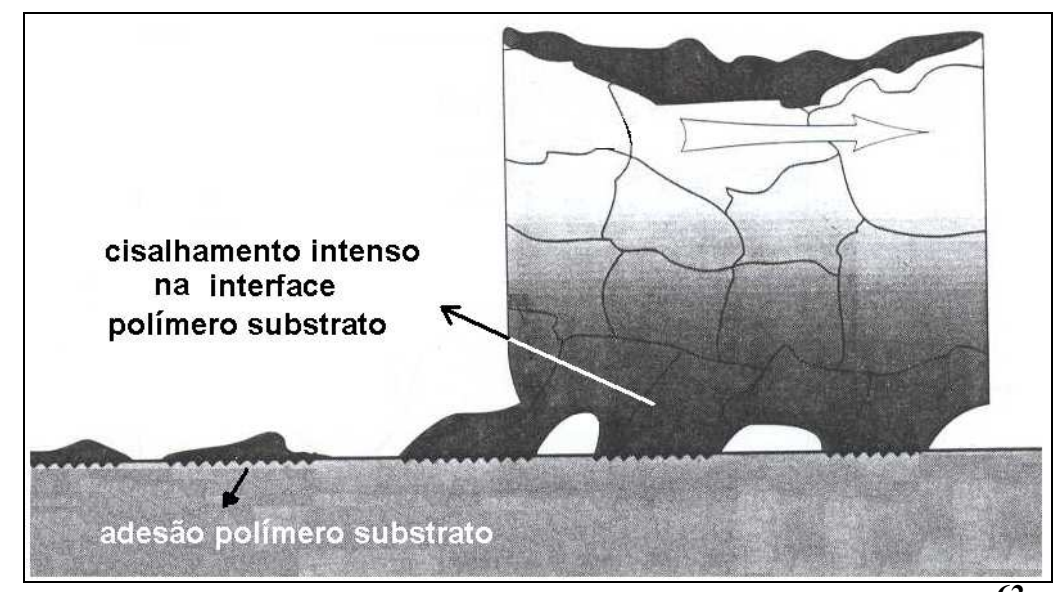

Figura 2.23 - Mecanismo de transferência normal. ${ }^{62}$

\subsection{Transferência lamelar}

Este tipo de mecanismo de transferência também é conhecido como: "regime de baixo atrito", "mecanismo de cisalhamento lamelar" ou " microscopic asperit wear" $\mathrm{Na}$ Figura 2.24, este mecanismo é identificado como processo "a frio" e "não degradativo" (Tipo B). Este mecanismo se refere a um comportamento "especial" de polímeros como o PTFE, POM, HDPE e o UHMWPE ${ }^{36}$. 


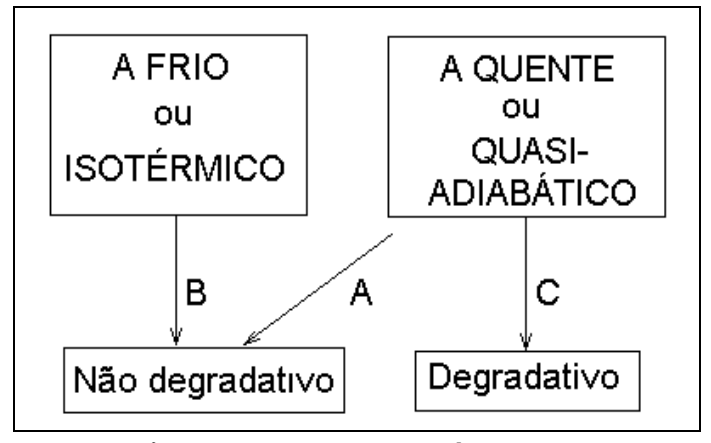

Figura 2.24 - Três modos genéricos de transferência de filme polimérico A, B e C. ${ }^{36}$

Estes polímeros são chamados de "polímeros de perfil molecular plano ou liso" 36,60,63,66, pois suas estruturas moleculares são caracterizadas pela linearidade de suas cadeias e a ausências de grupos do tipo polar ou volumétrico. Estas características conduzem a um alto grau de cristalinidade e ligações intermoleculares fracas. Os filmes lamelares são mais uniformes e diferenciam-se por apresentar espessuras entre 1 e 40 nm.

A Figura 2.25 mostra esquematicamente a estrutura lamelar proposta por SPEERSCHINEIDER ${ }^{63}$ para o PTFE. Embora estes polímeros formem filmes em um contra-corpo duro, subseqüentes deslizamentos na mesma direção tendem a ocorrer na interface entre o corpo polimérico e o filme, conduzindo a uma baixa taxa de desgaste. O coeficiente de atrito assume valores muito baixos e ocorre uma diminuição nas tensões de contato. Além disto, sabe-se que para o PTFE o desgaste é mais influenciado pela largura das bandas do que pela cristalinidade. ${ }^{64}$

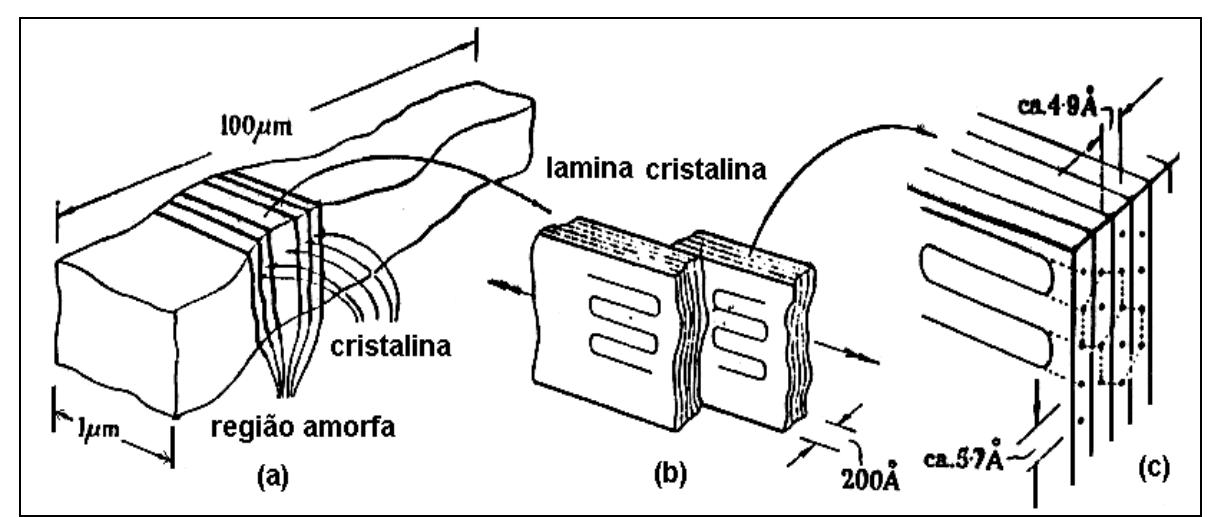

Figura 2.25 - Estrutura do PTFE - (a) um bloco cristalino ou 'banda', (b) laminas cristalinas ou 'estrias' e (c) arranjo hexagonal. ${ }^{63}$

O filme transferido é muito fino e contém cadeias moleculares fortemente orientadas na direção de deslizamento ${ }^{80,81,82,65}$. Porém, a adesão é fraca e o filme é 
altamente deformado e então removido durante os movimentos subseqüentes. Deve ser feita uma distinção entre filme de transferência e detritos de desgaste compactados e deformados, freqüentemente vistos na superfície de desgaste.

\subsection{Transferência por Fusão}

Polímeros têm baixa condutividade térmica ${ }^{66}$ e baixa temperatura de fusão cristalina. Estes fatores conduzem a um amolecimento sob condições de carga e velocidade muito menos severas do que para os metais.

O fenômeno de transferência por fusão é exatamente o mesmo da transição de condição de deslizamento isotérmico para adiabático. Indicando que o rápido aumento da taxa de desgaste que ocorre com o LDPE (Figura 2.26) é devido ao amolecimento. O mesmo efeito pode ser conseguido com um aumento da velocidade. Na Figura 2.24, este mecanismo pode ser classificado como transferência "a quente" e "não degradativa" (Tipo A).

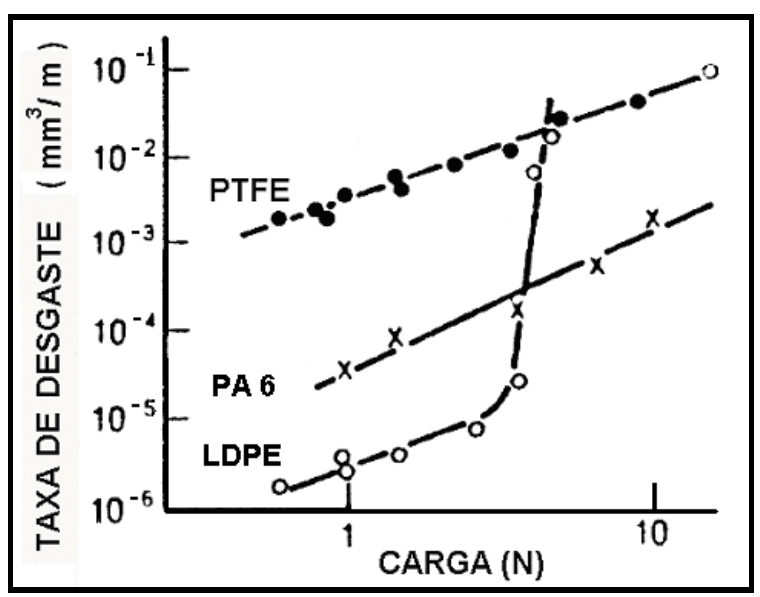

Figura 2.26 - Taxa de desgaste em função da carga normal no deslizamento contra aço $(\operatorname{Ra}=0,15 \mu \mathrm{m})$ em ensaio não lubrificado. ${ }^{60}$

Com o aumento da temperatura, ocorre a destruição dos esferulitos e uma queda da resistência ao cisalhamento; conduzindo a uma amorfização e a um escoamento plástico do material ${ }^{28,67}$. Com a subseqüente elevação da temperatura, este processo pode tornar-se "degradativo", atuando assim, o mecanismo do tipo C (Figura 2.24).

A transferência por fusão também está relacionada à capacidade de dissipação de calor do contra-corpo. TANAKA apud STACHOWIAK; BATCHELOR ${ }^{62}$, mostra na Figura 2.27, que com o aumento da velocidade, a taxa de desgaste da poliamida 6 (PA 
6), permanece constante quando deslizando sobre aço carbono. No entanto, quando desliza sobre vidro nas mesmas condições, a taxa de desgaste se eleva a partir de 1,2 $\mathrm{m} / \mathrm{s}$. Este fato foi relacionado com a menor capacidade de dissipação térmica do vidro em relação ao aço carbono.

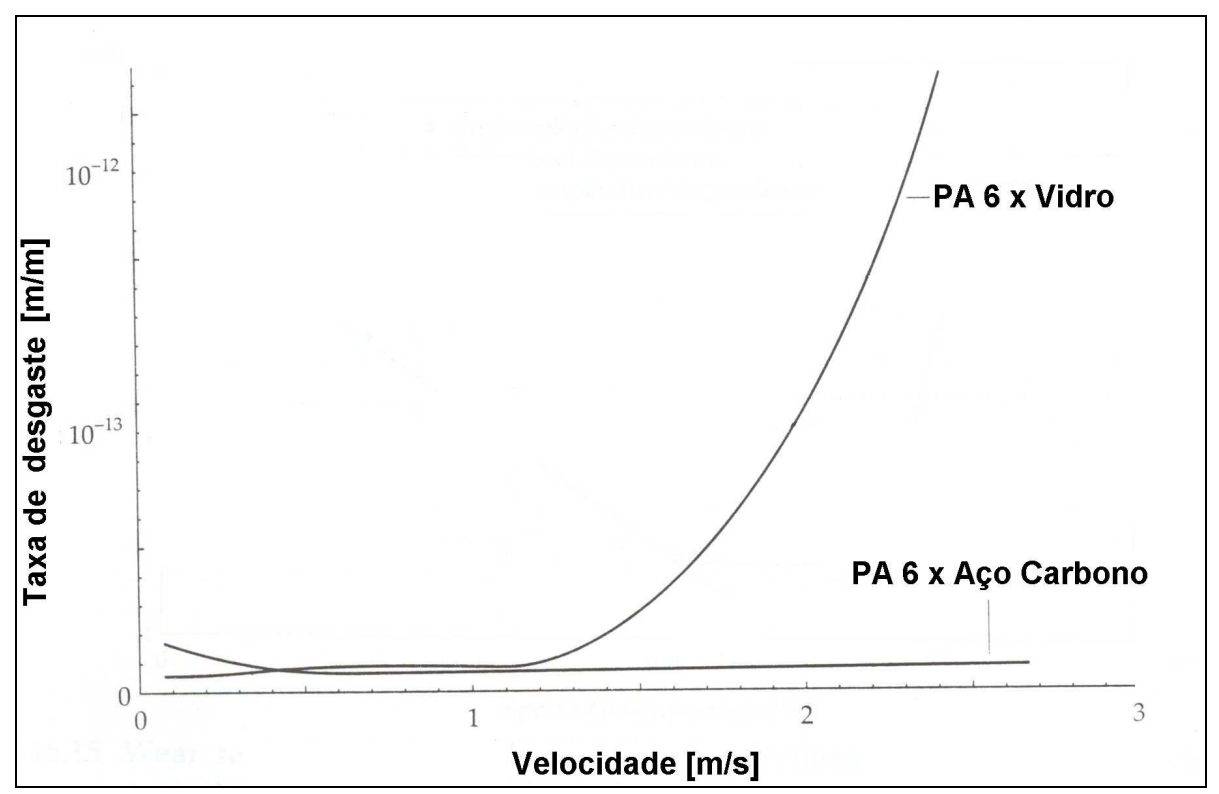

Figura 2.27 - Taxa de desgaste da poliamida 6 deslizando sobre aço carbono e vidro. $^{62}$

\subsubsection{Abrasão}

Em tribologia, uma maneira tradicional de se hierarquizar os tipos de mecanismos de desgaste atuantes em sistemas tribológicos é dividi-los em:

- desgaste por deslizamento e

- desgaste abrasivo.

Sendo que o desgaste abrasivo também pode ser separado em sistemas com abrasão a dois corpos (lixamento, torneamento, retífica, etc.) ou a três corpos (moagem, britagem, etc. $)^{60}$.

O mecanismo de desgaste abrasivo é definido como o desgaste que ocorre pelo destacamento de material da superfície em movimento relativo, causado pela presença de protuberâncias ou pela presença de partículas duras entre as superfícies ou encrustadas em uma delas ${ }^{68}$.

Um fenômeno de abrasão a três corpos pode ocorrer no caso de partículas de desgaste, originadas por outros mecanismos, permaneçam na região de contato, 
provocando o surgimento de uma nova componente abrasiva no desgaste e também modificando o comportamento sob atrito da superfície de contato do polímero ${ }^{69}$.

O mecanismo de desgaste discutido a seguir refere-se a uma componente de abrasão provocada somente pela penetração das asperezas do contra-corpo rígido no polímero e não devido a presença de uma ferramenta ou partícula abrasiva entre os corpos.

RATNER et all apud LANCASTER ${ }^{68}$ sugerem que três estágios consecutivos envolvem o destacamento de uma partícula: a deformação pela penetração de uma aspereza de maior dureza, a resistência ao movimento relativo e, finalmente, o destacamento, o qual envolve trabalho de fratura e mecanismos de microcorte. Estes pesquisadores mostram que a resistência à abrasão dos polímeros possui forte ligação com a "energia de falha" do material, sendo que esta está relacionada com a coesão entre as cadeias poliméricas e é chamada de energia coesiva ${ }^{16,70}$. A vantagem da introdução deste conceito está na possibilidade de relacionar as propriedades de desgaste dos polímeros com a constituição química de suas cadeias ${ }^{71}$.

ZUM-GHAR ${ }^{26}$ mostra que a remoção de material da superfície na abrasão a dois corpos, pode ser divida em quatro micromecanismos (microcorte, microssulcamento, microlascamento e microfadiga de baixo ciclo), como apresentado na Figura 2.28. Para o caso dos polímeros, o microssulcamento e o microcorte são mais fáceis de se identificar, principalmente pela formação de deformações plásticas laterais ao sulco (pile-up), no primeiro caso, e pelo formato das partículas de desgaste no segundo. A microfadiga é um mecanismo que sempre atua, principalmente, quando o sistema tribológico prevê contato contínuo entre as asperezas (ou particulas abrasivas) e a superfície de contato; porém é um mecanismo de difícil observação, principalmente para polímero. O mecanismo de microlascamento (microfratura) tende a ocorrer mais nos materiais frágeis. 


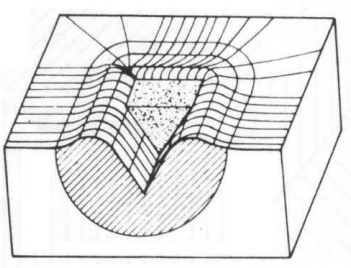

MICROSSULCAMENTO

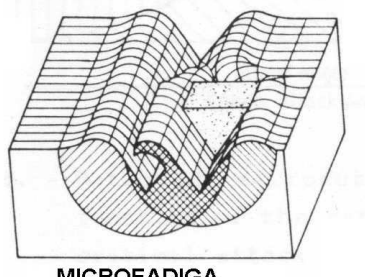

MICROFADIGA

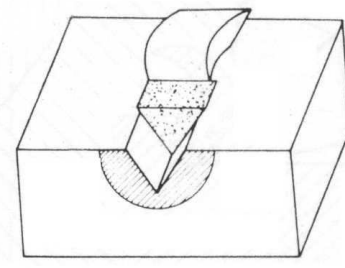

MICROCORTE

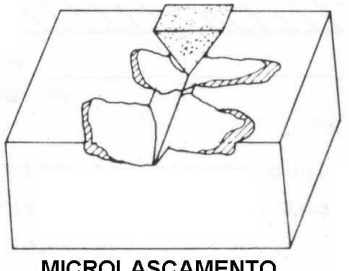

MICROLASCAMENTO

Figura 2.28 - Micromecanismos de abrasão, para um sistema a dois corpos. ${ }^{26}$

OMAR et all $^{72}$ mostram a importância da tenacidade à fratura $\left(\mathrm{K}_{\mathrm{Ic}}\right)$ para o desgaste de polímeros em sistemas abrasivos, buscando correlacionar também mecanismos de fadiga de polímeros com a equação de PARIS e encontrando uma dependência inversamente proporcional do desgaste como o trabalho de fratura de materiais termorrígidos (vide Figura 2.29).

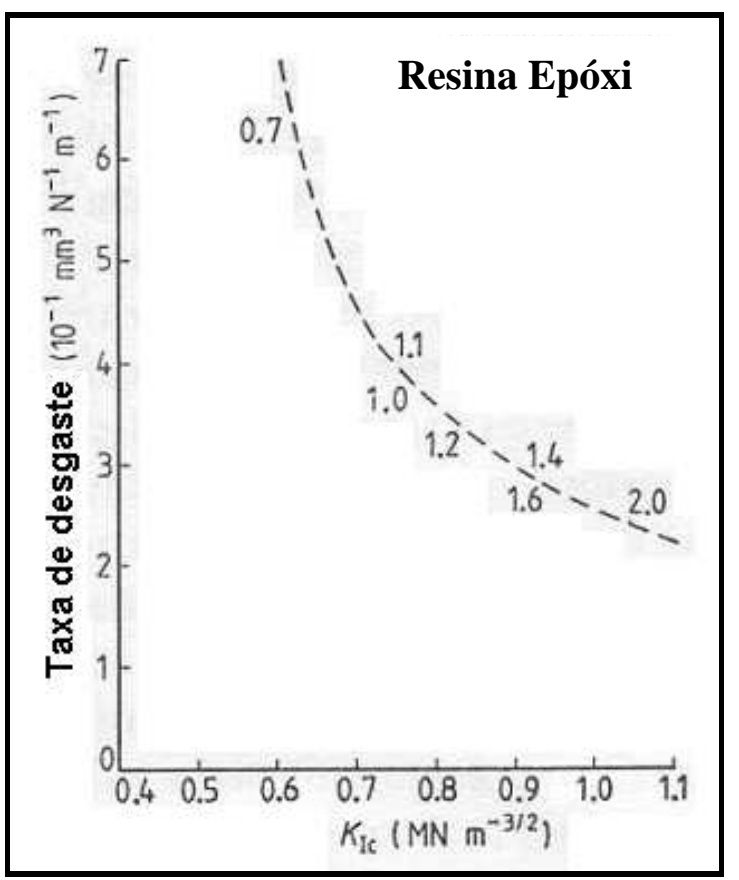

Figura 2.29 - Taxa de desgaste em função da tenacidade à fratura $\left(K_{I C}\right)$ para termorrígidos (resinas epóxies) variando a densidade de ligações cruzadas. ${ }^{72}$

Existem evidências consideráveis sugerindo que durante o deslizamento, as deformações provocadas pelas asperezas do contra-corpo não são suficientes para atingir 
o limite de escoamento dos polímeros e que as partículas se destacam pela ação de mecanismos de fadiga ${ }^{25}$. Sendo assim, será apresentado a seguir o mecanismo de desgaste por fadiga em polímeros, o qual é gerado pelas deformações produzidas em processos abrasivos.

\subsubsection{Fadiga}

\subsection{Fadiga devido às deformações}

Quanto a morfologia de desgaste tipo ondas apresentada na Figura 2.30, há uma certa divergência quanto aos mecanismos de desgaste que as originam (as ondas). Sabese que no deslizamento de termoplásticos contra superfícies com parâmetro de rugosidade $\mathrm{Ra}$ acima de $0,3 \mu \mathrm{m}$, predominam-se os mecanismos de deformação plástica $^{73}$ (abrasivos) em relação aos adesivos. Acredita-se que devido aos altos esforços na superfície de contato, mesmo para baixas cargas, ocorre deformação plástica intensa, a ponto de praticamente escoar o material e provocar este aspecto de ondas. BRISCOE apud BRISCOE $^{74}$ afirma que para polímeros semi-cristalinos, ocorre uma parcial reorganização microestrutural quando sujeito à tensões superficiais. Com a repetição contínua dos esforços, pedaços deste material desprendem-se devido ao mecanismo de fadiga.

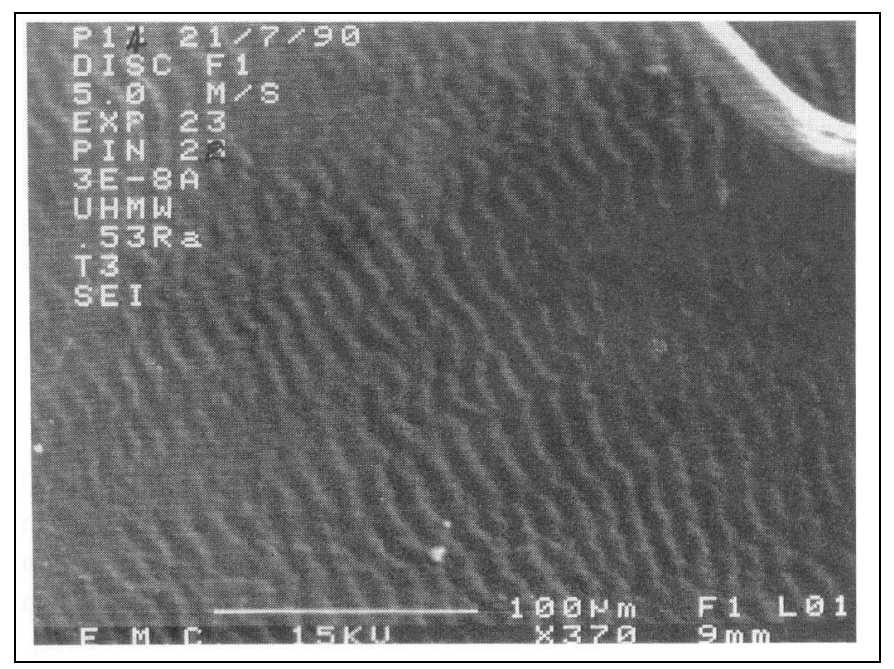

Figura 2.30 - Superfície de desgaste de UHMWPE apresentando morfologia tipo ondas. $^{75}$ 
A relação da morfologia de desgaste tipo ondas, como sendo um fenômeno mais relacionado ao mecanismo fadiga, tem tido um maior concenso ${ }^{22,28,36,73,76}$. BARTENEV; LAVENTREV $^{22}$ mostram que as ondas são formadas devido a uma intensa deformação, a qual pode ser produzida por um penetrador (Figura 2.31 - 1), ou uma aspereza, que desliza sobre a superfície do polímero (Figura 2.31 - 2), e cria uma zona de estiramento posterior à passagem da aspereza, onde surgem microtrincas (healing cracks) ${ }^{77}$. Como em muito casos, esta deformação ocorre novamente quando o identador passar pelo mesmo local, estas trincas se propagarão e o material será então arrancado, deixando o aspecto de ondas na superfície do polímero.

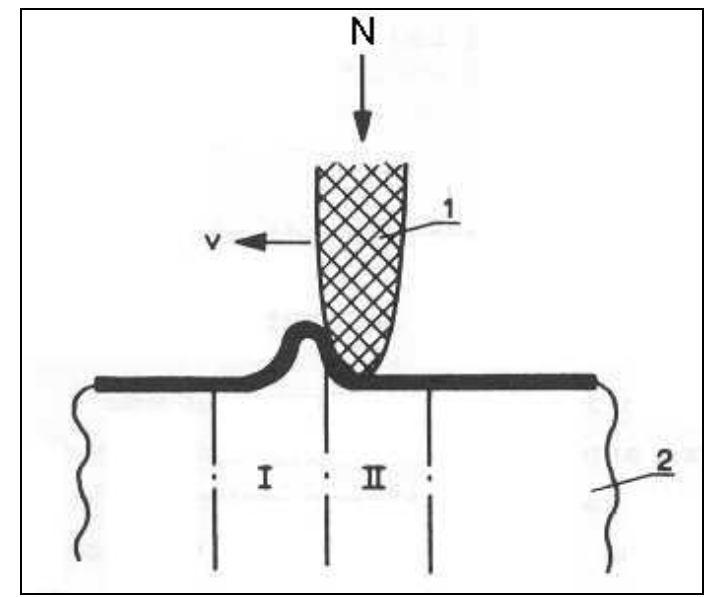

Figura 2.31 - Ilustração do mecanismo de desgaste que conduz a formação de ondas. (I) zona de compressão (II) zona de estiramento. ${ }^{22}$

Este mecanismo também pode ocorrer num meio lubrificado. A Figura 2.32, mostra a superfície de desgaste de um acetábulo de prótese femural feito em UHMWPE, submetido a ensaios de desgaste lubrificado. 


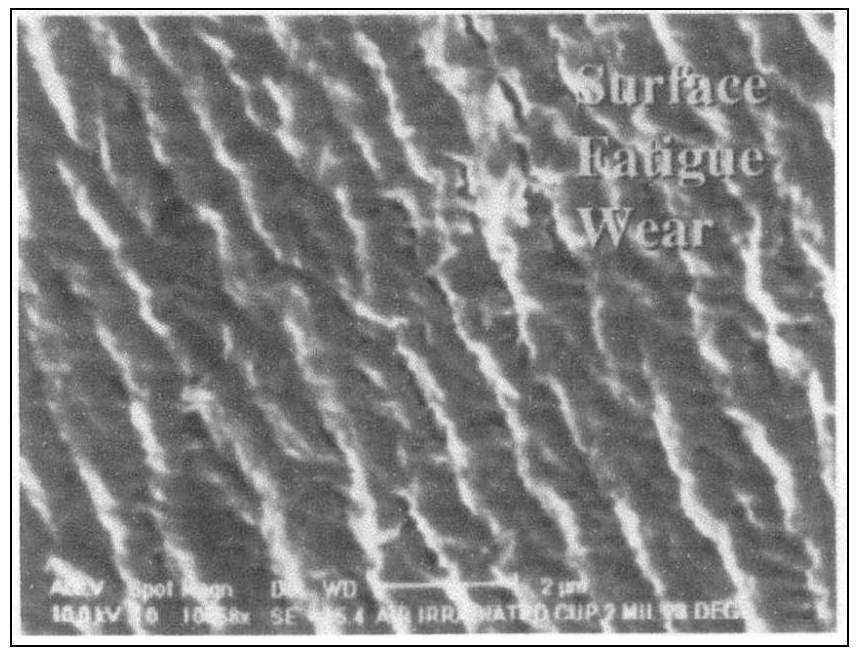

Figura 2.32 - Superfície de desgaste de acetábulo de UHMWPE. ${ }^{76}$

O aspecto superficial tipo ondas, muitas vezes é chamado de 'Schallamach waves' (ondas de Schallamach). SCHALLAMACH ${ }^{78}$ estudou o que ocorre na superfície de elastômeros quando do deslizamento sobre uma superfície lisa. Neste caso, o mecanismo de formação das ondas está relacionado com fenômenos adesivos e interfaciais (vide Figura 2.22). No entanto, o fenômeno principal que provoca a formação das trincas, tanto nas borrachas como nos termoplásticos, é a intensa deformação cíclica superficial.

\subsection{Fadiga devido à concentração de tensões}

Pode-se dividir o fenômeno de fadiga em superfícies poliméricas em dois mecanismos. O primeiro refere-se às deformações cíclicas provocadas pelas asperezas do contra-corpo e outro é chamado por macroscopic polymer asperit wear process ${ }^{36}$ e é descrito pela remoção de material, que sofrem altas deformações devido à concentração de tensão superficial e sub-superficial; geradas pelas altas asperezas da superfície do polímero $^{61}$ (vide Figura 2.33). 


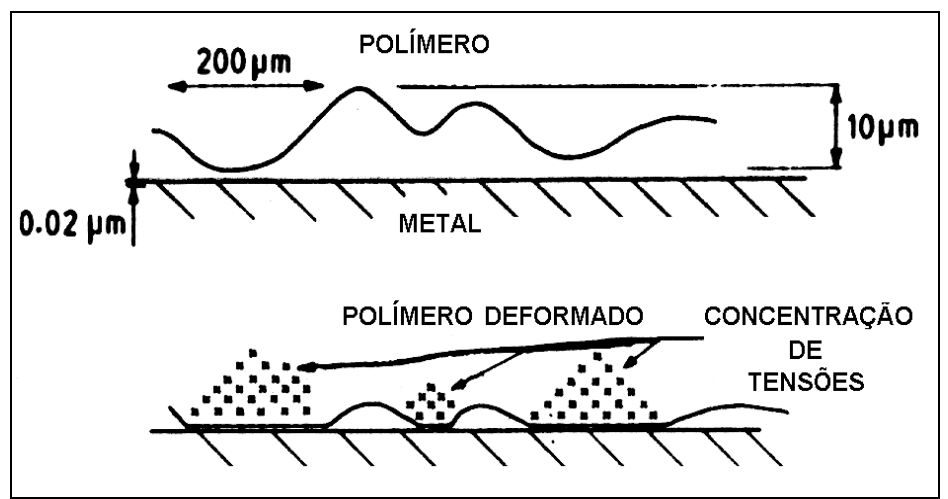

Figura 2.33-Diagrama esquemático mostrando a escala relativa entre as superfícies. $^{61}$

Este tipo de mecanismo de desgaste está associado com:

- baixa severidade, conduzindo a um filme não contínuo ${ }^{35}$;

- deformações residuais de cisalhamento em planos perpendiculares à direção de deslizamento;

- deformação de uma superfície nominalmente plana, pelas interações repetidas com as asperezas microscópicas do contra-corpo ${ }^{61}$.

\subsubsection{Efeito da cristalinidade no desgaste}

O grau de cristalinidade, a mobilidade e a flexibilidade da macromolécula ${ }^{25}$, a capacidade de formação de radicais livres, os grupos funcionais originais e a presença de ligações duplas de carbono, são algumas das características microestruturais que também influenciam o desgaste dos materiais poliméricos ${ }^{26,79,80,81,82}$.

$\mathrm{O}$ aumento da cristalinidade de uma material seja por um estiramento da superfície durante o contato ou alinhamento entre as cadeias por um processo de deslizamento durante o contato, conduzem a uma redução do coeficiente de atrito. YAMAGUCHI $^{25}$ apresenta o efeito do grau de cristalinidade sobre o coeficiente de atrito e o volume de desgaste para o polietileno (Figura 2.34). 


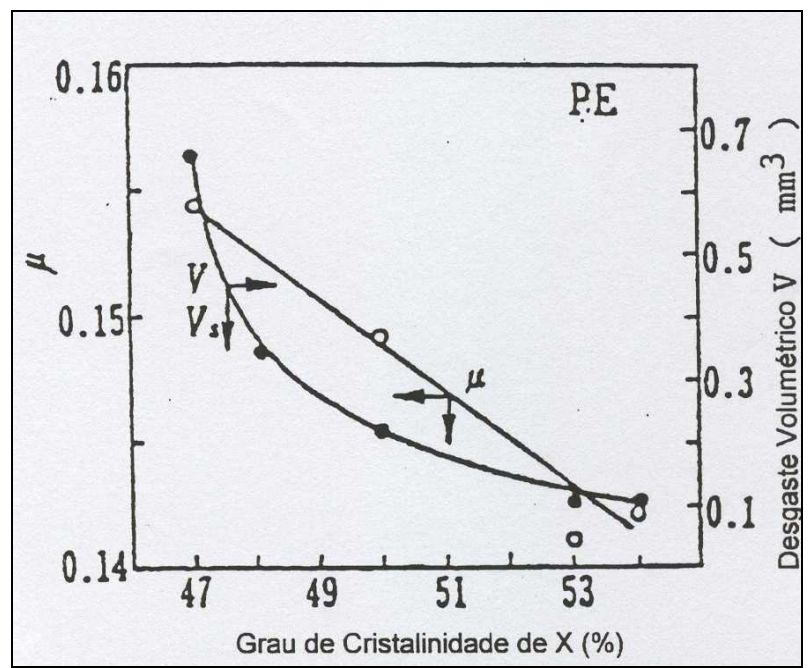

Figura 2.34 - Coeficiente de atrito e volume de desgaste em função do grau de cristalinidade do polietileno. $^{25}$

HU et all apud STACHOWIAK; BATCHELOR ${ }^{62}$ mostram que a resistência ao desgaste dependerá tanto do tipo de polímero quanto da configuração do equipamento utilizado. A Figura 2.35 mostra que o desgaste de PTFE deslizando contra aço carbono em tribômetros diferentes (pino-sobre-disco e placa-sobre-anel) é afetado significativamente pelo configuração geométrica do sistema estudado. TANAKA et all ${ }^{64}$ têm mostrado que mais importante que o grau de cristalinidade do PTFE são as larguras das lâminas cristalinas (Figura 2.25). CLAUSS apud STACHOWIAK; BATCHELOR ${ }^{62}$ e $\mathrm{ZHANG}^{32}$, afirmam que além do grau de cristalinidade, também o tamanho dos esferulitos possuem papel decisivo na resistência ao desgaste dos polímeros. 


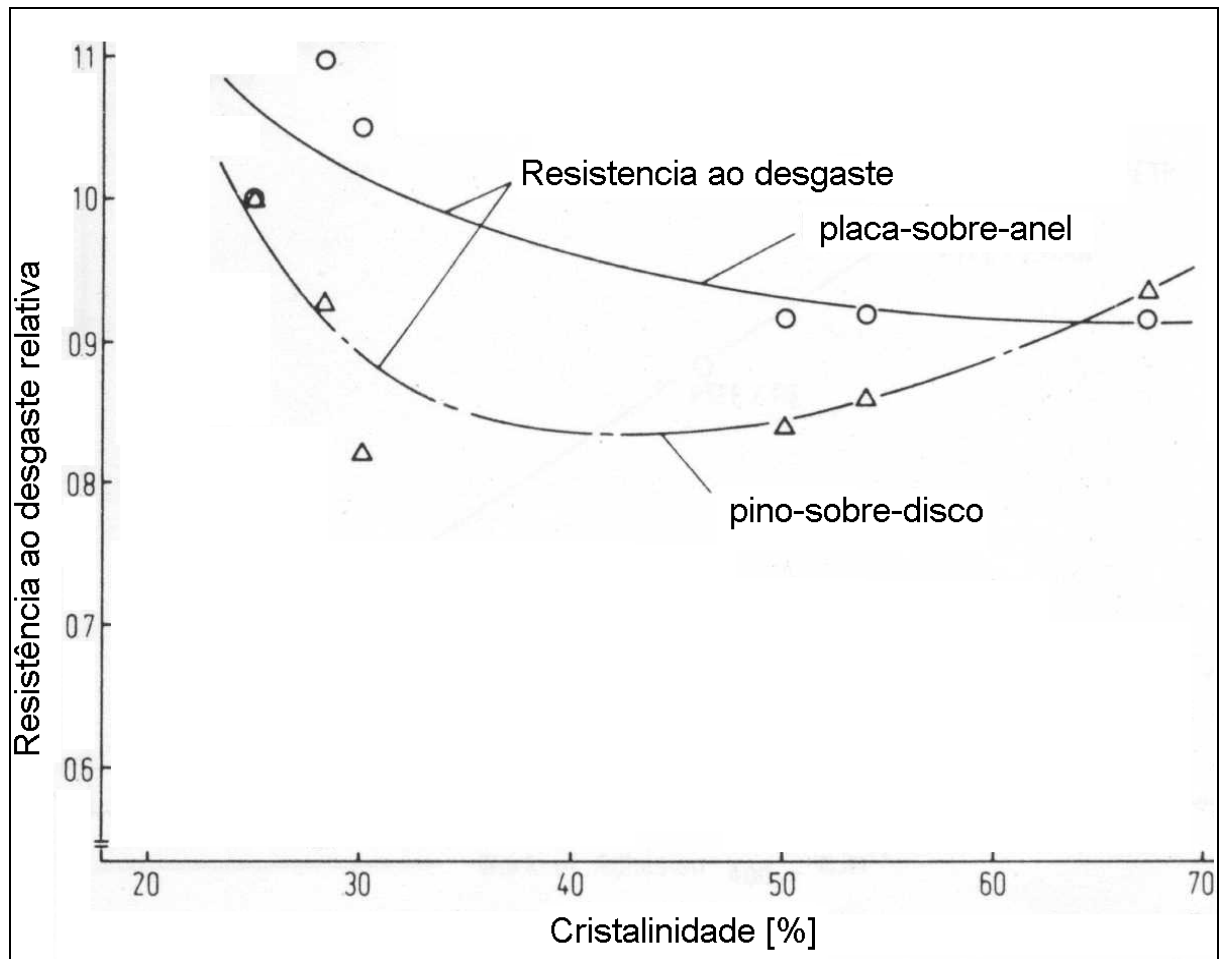

Figura 2.35 - Resistência ao desgaste do PTFE deslizando sobre aço carbono em dois tribômetros (pino-sobre-disco e placa-sobre-anel). ${ }^{26}$

\subsubsection{Comportamento dinâmico-mecânico e o desgaste}

$\mathrm{Na}$ obtenção das propriedades tribológicas de pares de materiais, sejam eles poliméricos ou não, os resultados de coeficiente de atrito e taxa de desgaste, em geral, apresentam uma elevada dispersão, tanto em ensaios laboratoriais como nos ensaios em campo (máquinas e equipamentos).

Uma causa para esta dispersão de resultados é atribuída ao desconhecimento dos aspectos dinâmicos envolvidos no contato e a resposta do material a solicitações dinâmicas. Entre os parâmetros importantes responsáveis por um componente de carregamento dinâmico, pode-se citar: a rugosidade das superfícies, a dinâmica das interações entre as asperezas e as flutuações dinâmicas devido às vibrações provocadas pela excitação das estruturas das máquinas ${ }^{83,84}$.

Neste sentido, o comportamento dinâmico-mecânico dos polímeros assume papel importante na sua resposta tribológica. Mesmo com a evidente influência das propriedades viscoelásticas no coeficiente de atrito e no comportamento quanto ao desgaste dos materiais poliméricos, pouco se tem feito na tentativa de correlacionar, diretamente, propriedades dinâmico-mecânicas com propriedades tribológicas. 
CAIS et all $^{85}$ buscaram compreender a influência de modificações nas propriedades dinâmico-mecânicas de diversos policarbonatos (PC) na resistência à abrasão. Fica clara a importância deste estudo quando se sabe que este material é utilizado na fabricação de papel eletro-fotográfico de alta e média velocidade para copiadoras e impressoras lasers. Os autores acreditam que a presença de moléculas de baixo peso molecular facilita o escorregamento entre as macromoléculas do material, influenciando o coeficiente de atrito e o comportamento quanto ao desgaste.

Atualmente, uma aplicação tribológica de grande importância que está merecendo uma maior atenção quanto a propriedades dinâmico-mecânicas são as mídias magnéticas. WEICK; BRUSHAN ${ }^{86,87}$ estão preocupados em compreender o comportamento dinâmico-mecânico de materiais poliméricos utilizados na fabricação de fitas magnéticas. Além de se tornar uma ferramenta na seleção de materiais para estas fitas, as análises dinâmico-mecânicas fornecem informações sobre desgaste do cabeçote e coeficiente de atrito dos pares fita-cabeçote e fita-fita. A Figura 2.36 mostra que uma fina camada de material magnético é depositada sobre uma fita polimérica (substrato polimérico), portanto o desgaste do cabeçote está relacionado com o contato polímerocabeçote. O contato fita-fita, ou seja, polímero-camada magnética, é importante quanto à potência utilizada para bobinar a fita e, além disto, vencer o atrito entre fita e cabeçote.

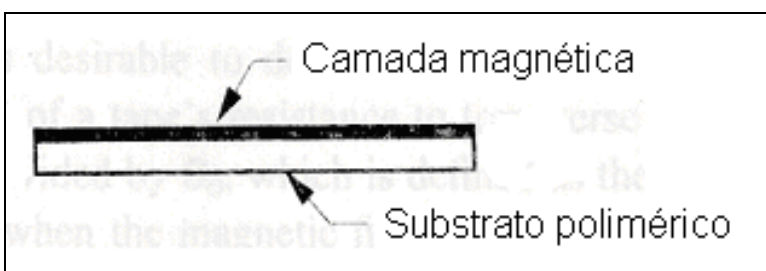

Figura 2.36 - Arranjo esquemático de um corte transversal de fita magnética. ${ }^{87}$

Acredita-se que a capacidade de dano de mecanismos como microfadiga e microcorte devem se alterar, a medida em que a relação entre módulo de perda e de armazenamento é modificada durante o uso ${ }^{87}$. Entretanto, até o momento, não foi possível chegar a conclusões definitivas sobre como modificações físico-químicas, provocadas pela variação na temperatura no contato, alteram as propriedades tribológicas dos materiais poliméricos. 


\subsubsection{Parâmetros do sistema tribológico e o desgaste}

Assim como para o coeficiente de atrito, a intensidade da pressão média de contato $(\mathbf{P})$ e a velocidade relativa entre os corpos (v), definem o parâmetro chamado condição $P V$, o qual tem papel fundamental nos níveis de desgaste de um sistema.

O acabamento superficial, por exemplo, além de controlar a quantidade de partícula a ser formada e a formação de um filme uniforme durante o processo de deslizamento $79^{88}$, também determinará se o mecanismo de desgaste será microscópico ou macroscópico.

\subsubsection{Carga, Velocidade e Condição PV}

Os níveis de carga aplicada e de velocidade de deslizamento, são as condições de carregamento do sistema tribológico que possuem uma importância muito grande quanto aos tipos de mecanismos de desgaste que irão atuar, a intensidade destes mecanismos e as possíveis transições.

A Figura 2.37 (a) mostra, num ensaio tipo pino-contra-anel, que o volume de desgaste apresenta um valor de mínimo em função da velocidade de deslizamento. Este fato relaciona-se com mudanças na estrutura cristalina dos polímeros ${ }^{47}$, com a transferência de filme para a superfície do contra-corpo, com o nível de rugosidade da superfície, com o aumento da área real de contato $^{89}$, etc.. Na realidade, em muitos casos um comportamento inverso é verificado, principalmente quando há um excessivo aquecimento na região de contato e a fusão (amolecimento) do polímero provoca a formação de um filme que acaba por proteger o polímero ${ }^{89}$. Ainda sobre a velocidade, STACHOWIAK; BATCHELOR ${ }^{62}$ afirmam que o acabamento superficial do contracorpo, pode perder sua importância para velocidade de deslizamento elevadas. 


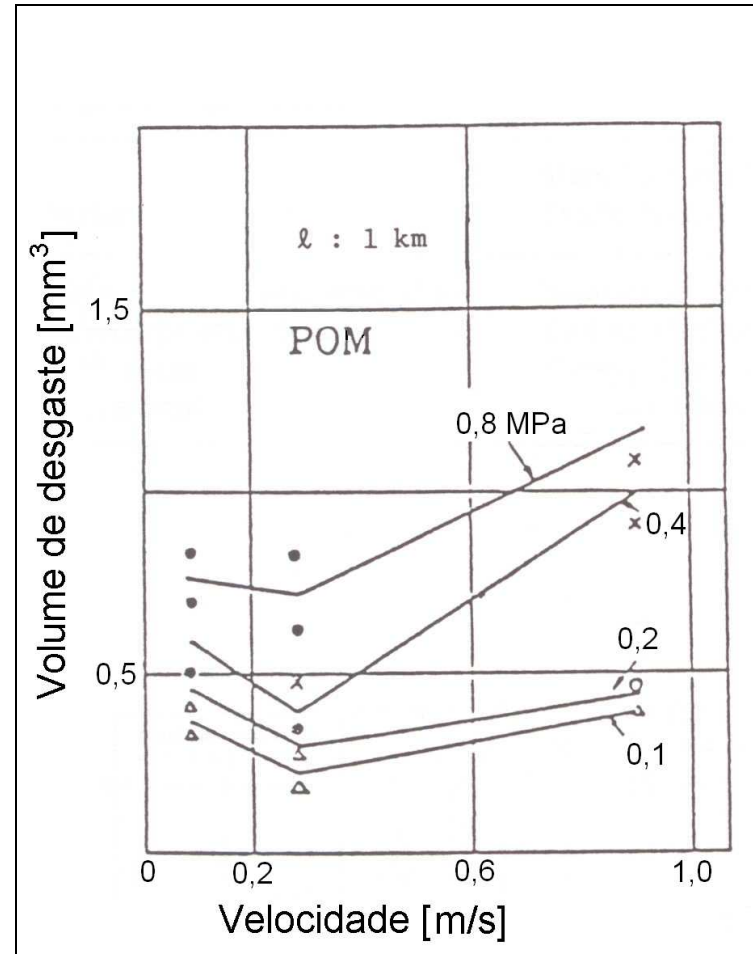

(a)

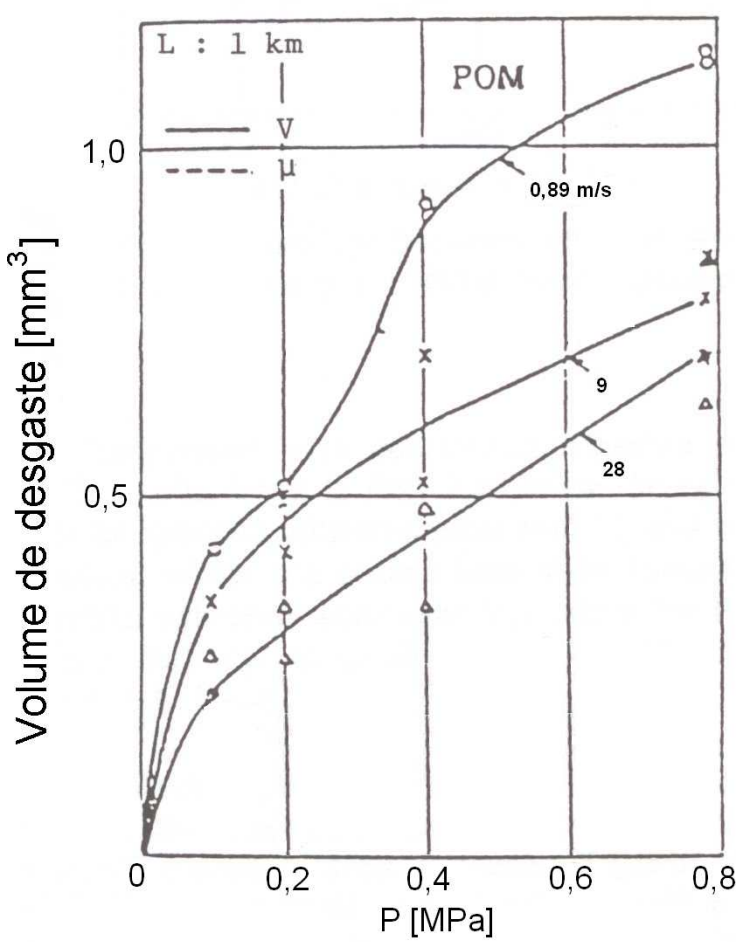

(b)

Figura 2.37 - Volume de desgaste em função da velocidade (a) e da pressão de contato (b) em ensaios tipo pino-contra-anel de POM x Aço Carbono. ${ }^{25}$

A Figura 2.37 (b) apresenta o efeito da elevação da pressão de contato (área normal / área aparente) no volume de desgaste. Observa-se que para uma certa velocidade, pressões maiores conduzem a um aumento no desgaste. Este comportamento está relacionado com o aumento da intensidade de atuação dos mecanismos de desgaste e, logicamente, com o aumento da temperatura no contato.

Assim, como havíamos comentado em relação ao atrito, existe um valor limite para a condição PV, onde a temperatura na interface se estabiliza num dado patamar. Acima desta condição PV limite, o mecanismo de desgaste predominante será a transferência por fusão. Abaixo desta condição limite, os demais mecanismos de desgaste poderão atuar dependendo agora, além dos níveis de carga e velocidade, também da configuração do sistema tribológico, do tipo de material e do acabamento das superfícies.

\subsubsection{Rugosidade}

Sabe-se que quanto menor a rugosidade do contra-corpo, maior será a adesão entre os $\operatorname{corpos}^{26,60}$, porém, quanto mais rugosa a superfície, maior a penetração da 
aspereza do corpo rígido no polímero. Portanto, o efeito da rugosidade depende de mecanismos concorrentes que atuam na determinação do coeficiente de atrito e dos mecanismos de desgaste dos polímeros ${ }^{28}$.

O comportamento quanto ao atrito e ao desgaste de polímeros, em função da rugosidade superficial, apresentado nas Figura 2.38, mostra que o acabamento superficial é mais um parâmetro do sistema tribológico que não apresenta um comportamento linear. Ou seja, dependendo do sistema e do material estudado, uma inversão de comportamento ou uma mudança de mecanismo poderá ocorrer.

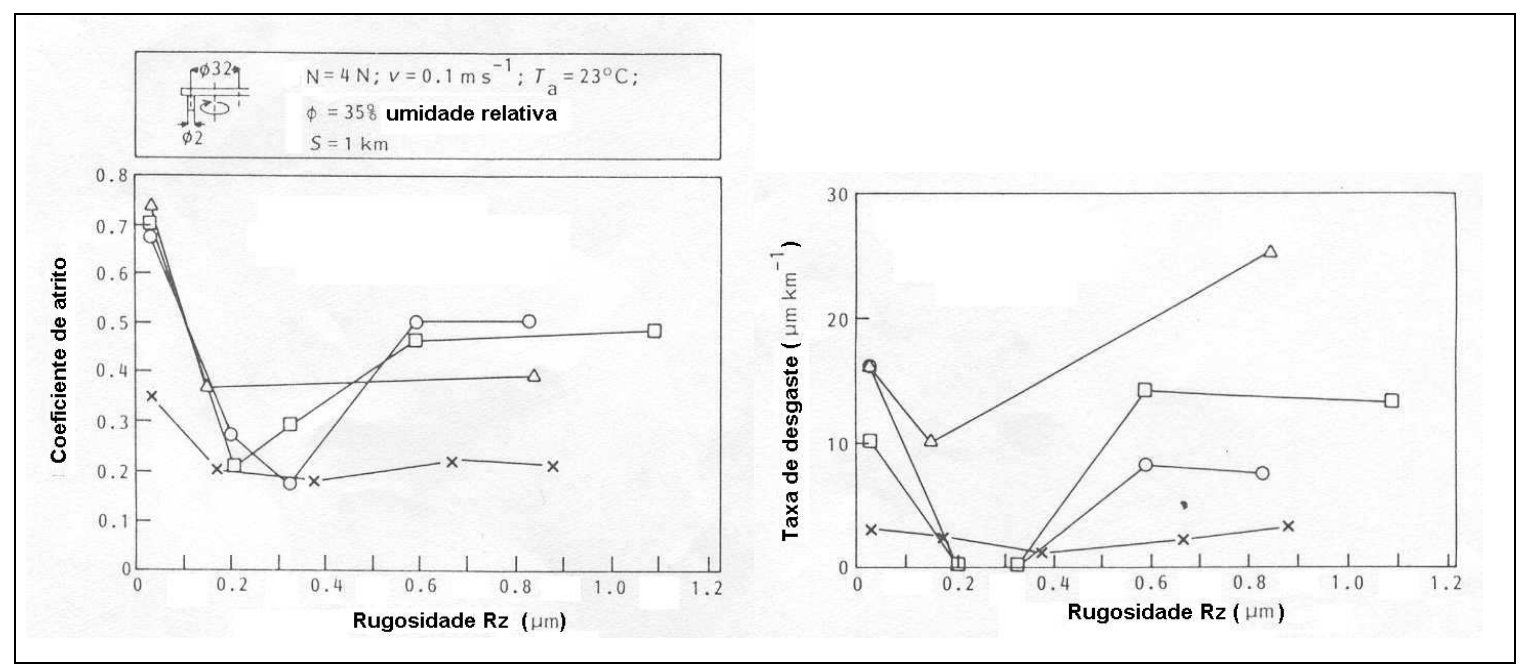

Figura 2.38 - Coeficiente de atrito e taxa de desgaste em função da rugosidade para quatro pares aço-polímero $(0=\mathrm{PA66}, \quad=\mathrm{PA6}, \Delta=\mathrm{POM}$ e $\mathrm{x}=\mathrm{PET}) .^{31}$

SILVA et all ${ }^{90}$ mostraram que além dos parâmetros tradicionais de rugosidade, como Ra, Rz e Sm, também o processo de fabricação das superfícies em contato afeta significativamente a resposta tribológica dos polímeros. A Figura 2.39 apresenta os resultados de coeficiente de atrito e altura de desgaste, em função do parâmetro de rugosidade $\mathrm{Ra}$, para ensaios tipo pino-contra-disco, com pinos de HDPE deslizando sobre discos de aço carbono ABNT 1045, onde a altura de desgaste foi determinada pela pesagem dos pinos de polímeros com diâmetro de $3 \mathrm{~mm}$.

Dos ensaios realizados com discos com superfícies torneadas pode-se dizer que o coeficiente de atrito não apresentou mudanças significativas para a faixa de rugosidade estudada. Entretanto, quanto ao desgaste, foi observado um crescimento deste para a superfície com acabamento mais fino. 


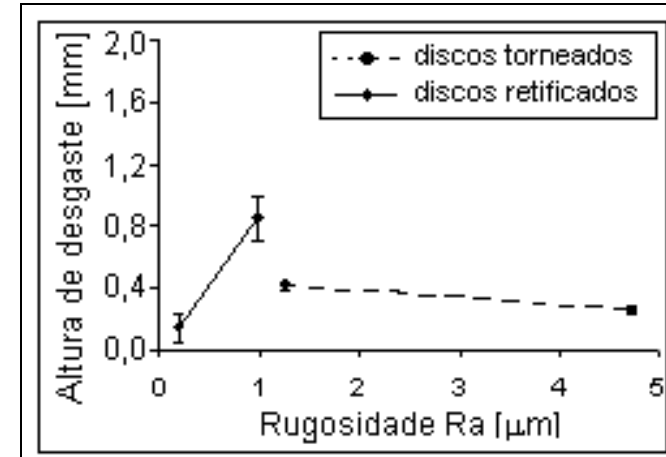

(a)

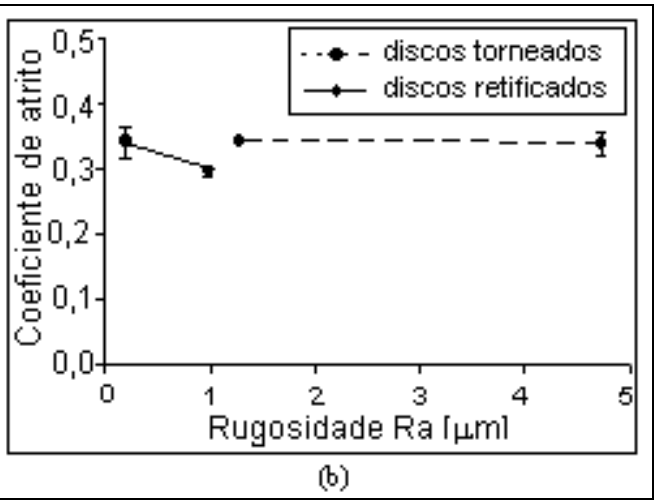

(b)

Figura 2.39 - Coeficiente de atrito cinético e altura de desgaste do HDPE em função da Rugosidade Ra. ${ }^{90}$

Nos ensaios realizados com superfícies retificadas o coeficiente de atrito se elevou com o aumento do parâmetro Ra (rugosidade). Entretanto, quanto ao desgaste, foi observado um decréscimo deste para a superfície com acabamento mais fino. Estes resultados mostram que a utilização dos parâmetros tradicionais de rugosidade, não são suficientes para caracterizar uma superfície ${ }^{91}$.

Atualmente alguns pesquisadores ${ }^{92,93}$ estão utilizando a dimensão fractal de uma superfície como uma informação mais representativa, na caracterização tribológica de uma superfície. GUIMARÃES ${ }^{93}$ conseguiu uma boa correlação entre a dimensão fractal de superfícies e o parâmetro combinado $\mathbf{l n R z} / \mathbf{l n S m}$. Este parâmetro expressa de uma forma combinada, os efeitos de amplitude da rugosidade (parâmetros escalares de altura - Ra, Ry, Rz, etc.) com efeitos de comprimento (parâmetros de separação - Sm).

Por fim, EISS; MILLOY ${ }^{94}$ mostram que informações sobre distribuição de altura de asperezas e raio de curvatura dos picos são de grande importância quanto aos mecanismos de desgaste de polímeros. 


\section{3 . OBJETIVOS}

Esta tese de doutorado tem como objetivo estudar o efeito da carga normal aplicada, da velocidade de deslizamento, do acabamento superficial e do tipo de contracorpo na degradação de polioximetileno (POM) e de polietileno de ultra-alto peso molecular (UHMWPE) pela ação tribológica contra alumina e aço inoxidável num sistema tipo pino-contra-disco. 


\section{MATERIAIS E MÉTODOS}

O capítulo de materiais e métodos será dividido nas seguintes seções:

- Materiais:

§ obtenção e preparação de pinos e discos.

- Métodos:

\$ ensaio tribológico e

$\S$ caracterização dos corpos-de-prova.

\subsection{Materiais}

Os materiais utilizados nesta Tese de Doutorado são:

- Poliméricos

$\$$ polioximetileno copolímero (POM) e

$\S$ polietileno de ultra-alto peso molecular (UHMWPE).

- Metálico

§ aço inoxidável;

- Cerâmico

$\S$ alumina.

\subsubsection{Polímeros}

\subsubsection{POM}

O polioximetileno (POM), também conhecido como poliacetal, é obtido pela técnica de polimerização em solução utilizando como iniciador o chamado ácido de LEWIS (Boro Trifluorado - $\mathrm{BF}_{3}$ ). Existem dois tipos de POM, o homopolímero e o copolímero, os quais são obtidos pela reação de um formaldeído.

Atualmente o POM copolímero é aquele com o maior volume de fabricação mundial, pois apresenta, dentre outras características, melhor estabilidade térmica e química. Esta vantagem do copolímero se dá devido à presença dos grupos -C-C- em sua estrutura química, os quais possuem uma ligação um pouco mais forte que o grupo $-\mathrm{C}-\mathrm{O}$-. 
A Figura 4.1 mostra, de uma forma esquemática a estrutura química dos dois tipos de polioximetileno. O POM copolímero da Ticona, apresenta um grupo -C-C- a cada 100 unidades dos grupos $-\mathrm{C}-\mathrm{O}-{ }^{95}$. No entanto, os grupos -C-C- dificultam a formação de regiões cristalinas no POM, fazendo com que o homopolímero atinja até $85 \%$ de cristalinidade, enquanto que o copolímero não ultrapassa $70 \%$.

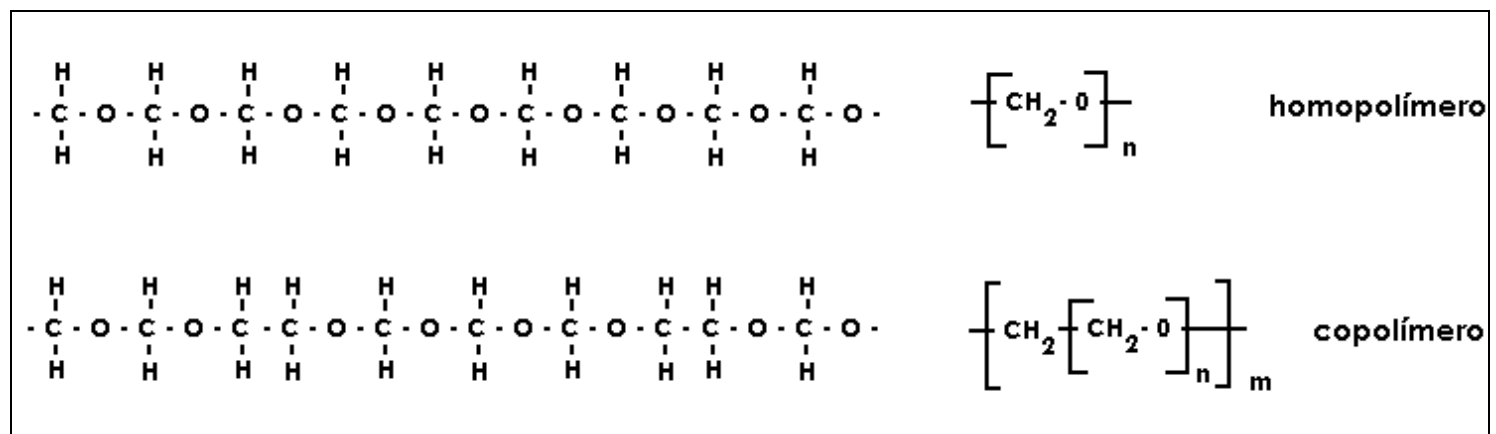

Figura 4.1 - Estrutura química do POM homopolímero e copolímero. ${ }^{18}$

O POM copolímero apresenta esta dupla de carbonos em sua cadeia por utilizar um formaldeído na forma de um trímero cíclico, denominado trioxano e o óxido de etileno como comonômero (Figura 4.2). O Trioxano, além de propiciar melhorias nas características do polímero, também é mais seguro quanto ao manuseio, pois é utilizado na forma líquida. Ainda sobre o formaldeído, vale a pena ressaltar que este é uma matéria-prima que não deriva do petróleo. O gás natural é a principal fonte de matéria prima para o formaldeído, e além de ser mais abundante que o petróleo, é mais distribuído geograficamente.

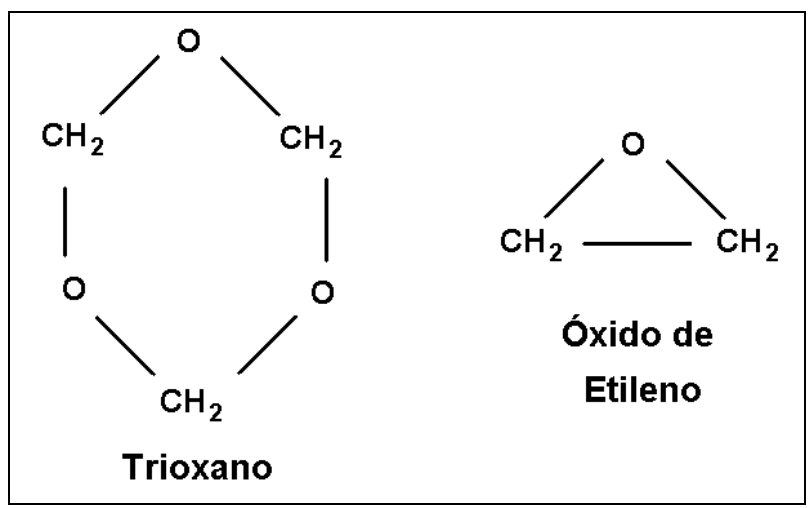

Figura 4.2 - Fórmulas estruturais do Trioxano e do óxido de etileno ${ }^{18}$.

O POM copolímero é um polímero que apresenta diversas características de grande interesse para aplicações de engenharia. Dentre estas, pode-se citar: 
- resistência química;

- estabilidade dimensional;

- estabilidade térmica (resistência à altas temperaturas);

- estabilidade aos raios ultra-violeta (UV) e

- resistência ao desgaste.

Devido á sua estabilidade dimensional combinada com a resistência ao desgaste, o POM apresenta-se como um material ideal para o setor de engrenagens. Sendo o POM um polímero que pode ser moldado por injeção e por sopro e extrudado em forma de placas e perfis $^{96}$, a gama de geometrias em que peças de POM podem ser fabricadas é muito grande, este fato faz com ele tenha um leque de aplicações muito grande. Dentre as aplicações tribológicas do POM, temos: carcaças de bombas, alojamentos, fechaduras, rodas de impressoras, fieiras para extrusão de massa, roldanas, polias, engrenagens, etc..

\subsubsection{UHMWPE}

O polietileno de ultra-alto peso molecular é um polímero da família dos polietilenos, porém com a característica de apresentar massa molecular (MM) entre 2 e 8 milhões de $\mathrm{g} / \mathrm{mol}$. Caracteriza-se também por ter uma cadeia linear, apolar e isenta de ramificações. A Figura 4.3 apresenta a estrutura química do UHMWPE.

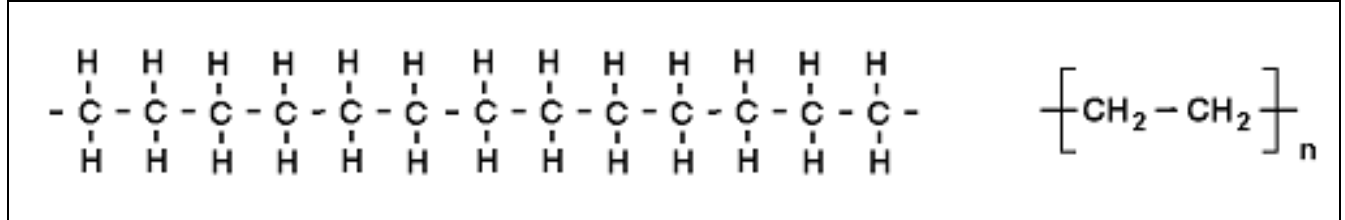

Figura 4.3 - Estrutura química do UHMWPE. ${ }^{8}$

O UHMWPE, fabricado pela BRASKEN, é obtido pelo sistema de polimerização em lama usando catalisadores do tipo Ziegler-Natta, podendo o processo ser em batelada ou contínuo ${ }^{97}$. O UHMWPE é obtido na forma de pó fino (branco e opaco) e devido à sua alta massa molecular, apresenta uma altíssima viscosidade quando fundido, o que dificulta o seu processamento. Desta forma, os processos tradicionais de sopro, injeção e extrusão não podem ser empregados no UHMWPE. Os métodos empregados para a transformação desta resina são: moldagem por compressão e extrusão por pistão. Nos dois casos são obtidos semi-acabados em forma de chapas ou 
tarugos para acabamento posterior em usinagem. Comparado com o POM, este alto índice de fluidez reduz a variedade de geometrias em que se pode fabricar peças de UHMWPE.

Existem peças de UHMWPE que são produzidas por técnicas de sinterização parcial, usando menores temperaturas e diferentes níveis de pressão. O objetivo desta técnica é obter peças porosas para aplicações como separadores e filtros.

Dentre suas propriedades características, destaca-se a estabilidade química (quase totalmente inerte), alta tenacidade (também em temperaturas sub-zero), eficiente isolante elétrico, baixo coeficiente de atrito (efeito auto-lubrificante) e resistência à $\operatorname{abrasão}^{98}$.

A gama de setores para aplicações de peças feitas em UHMWPE, vai desde a indústria alimentícia, passando pela mineração, petróleo e agricultura, até aplicações biomédicas. Dentre as aplicações tribológicas, pode-se citar: bombas centrífugas, dosificadores, placas para filtros, revestimentos para depósitos de minérios, juntas, válvulas, rolos-guias, esteiras transportadoras, mancais, misturadores, roletes; além de artigos esportivos e ortopédicos.

\subsubsection{Pinos de polímeros}

Os materiais poliméricos foram obtidos na forma de barras circulares de $10 \mathrm{~mm}$ de diâmetro. Para adquirirem a forma final, estes foram torneamento nas dimensões apresentadas na Figura 4.4.

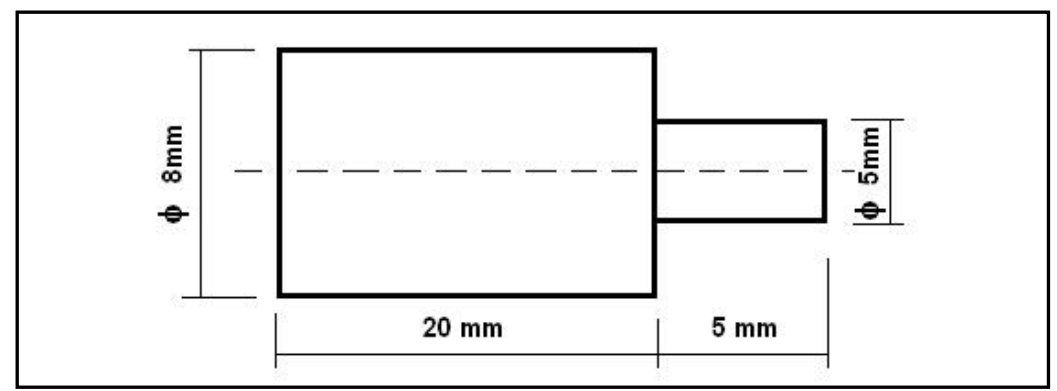

Figura 4.4 - Dimensões dos corpos-de-prova poliméricos (sem escala).

O UHMWPE foi fornecido pela empresa CORMATEC e termoformado (moldagem por compressão) à temperatura de $210{ }^{\circ} \mathrm{C}$, com pressão de 8 [MPa] (80 $\mathrm{kgf} / \mathrm{cm}^{2}$ ) durante 6 horas, utilizando como matéria-prima a resina UTEC-6540 de fabricação BRASKEM. 
O POM copolímero, extrudado pela MGS Indústria e Comércio de Plásticos Ltda com matéria-prima Hostaform ${ }^{\circledR}$, de fabricação TICONA, foi doado pela empresa PLASTECNO Representações e Comércio Ltda.

A superfície de contato dos pinos poliméricos foi faceada em torno, com avanço de $0,16 \mathrm{~mm} /$ rot. Para os dois polímeros, optou-se por uma usinagem longitudinal em relação à direção de extrusão. Este fato faz com que a orientação das macromoléculas sejam as mesmas para os dois materiais poliméricos. A Figura 4.5 apresenta uma fotografia dos pinos de UHMWPE e POM.

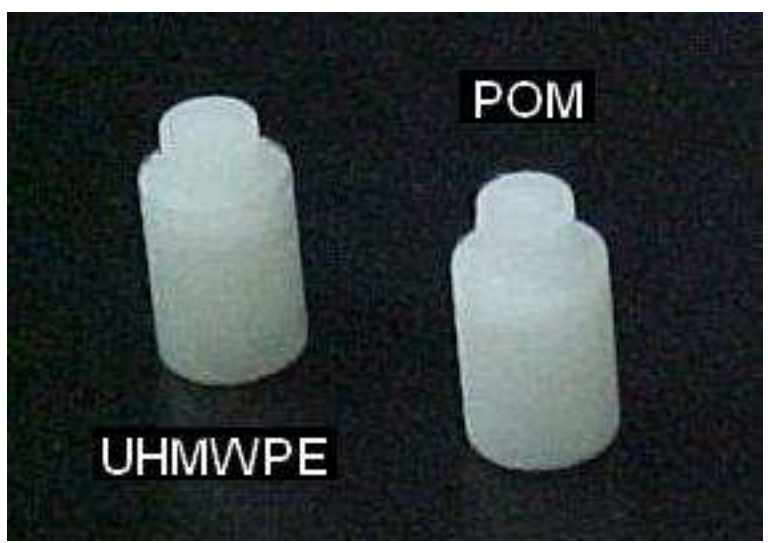

Figura 4.5 - Pinos de UHMWPE e POM, antes dos ensaios de desgaste.

\subsubsection{Aço Inoxidável}

O aço inoxidável nitrogenado isento de cobalto, desenvolvido no PMT-EPUSP apresentou bons resultados como material para fabricação de próteses ortopédicas internas $^{99}$. Sendo as próteses femurais uma das aplicações onde ocorre o contato UHMWPE-AÇO INOXIDÁVEL, optou-se por estudar o comportamento tribológico deste polímero deslizando contra o aço inoxidável nitrogenado. A Tabela 4.1 apresenta a composição química pretendida para o aço inoxidável nitrogenado.

Tabela 4.1 - Composição química pretendida para o aço inoxidável nitrogenado ${ }^{99}$.

\begin{tabular}{ccccccccc}
\hline Elemento & C & Mn & Si & P & S & Cr & Fe & N \\
\hline$\%$ & $\mathbf{0 , 0 2 5}$ & 15 & $\mathbf{0 , 1 9}$ & $\mathbf{0 , 0 0 5}$ & $\mathbf{0 , 0 0 4}$ & 18 & 66,246 & 0,5 \\
\hline
\end{tabular}

A Tabela 4.2 apresenta a planilha de cálculo da carga utilizada na fundição para uma corrida de $5 \mathrm{~kg}$. Foram realizadas três corridas (3 lingotes), no entanto, um lingote foi totalmente descartado devido a grande presença de bolhas e impurezas. 
Para a realização das corridas de fundição do aço inoxidável, o Laboratório de Fundição do IPT não dispunha de liga FeCrN, a qual foi doada pela empresa IOCHPEMAXION Fundição e Equipamentos Ferroviários.

Tabela 4.2 - Planilha do cálculo de carga do aço inoxidável nitrogenado.

\begin{tabular}{|c|c|c|c|c|c|c|c|c|c|c|}
\hline \multirow[b]{2}{*}{$\begin{array}{l}\text { Matéria } \\
\text { Prima }\end{array}$} & \multirow{2}{*}{\multicolumn{2}{|c|}{$\%$ desejada }} & \multicolumn{8}{|c|}{ Elementos químicos } \\
\hline & & & $\begin{array}{c}\mathrm{C} \\
\mathbf{0 , 0 2 5}\end{array}$ & $\begin{array}{c}\text { Mn } \\
15\end{array}$ & $\begin{array}{c}\mathrm{Si} \\
0,19\end{array}$ & $\begin{array}{c}\mathbf{P} \\
\mathbf{0 , 0 0 5}\end{array}$ & $\begin{array}{c}\mathrm{S} \\
\mathbf{0 , 0 0 4}\end{array}$ & $\begin{array}{l}\mathrm{Cr} \\
18\end{array}$ & $\begin{array}{c}\mathrm{Fe} \\
66,246\end{array}$ & $\begin{array}{c}\mathrm{N} \\
0,5\end{array}$ \\
\hline \multirow[t]{2}{*}{ Aço ED } & & $\%$ & 0,01 & 0,03 & 0,03 & & & 0,03 & 99,74 & 0,00 \\
\hline & 3112 & $\mathrm{~g}$ & 1 & 1 & 1 & 0 & 0 & 1 & 3104 & 0 \\
\hline \multirow[t]{2}{*}{ Grafita } & & $\%$ & 100 & 0 & & & & & & \\
\hline & 1 & $\mathrm{~g}$ & 1 & 0 & 0 & 0 & 0 & 0 & 0 & 0 \\
\hline \multirow{2}{*}{$\mathrm{Mn}$} & & $\%$ & & 100 & & & & & & \\
\hline & 749 & $\mathrm{~g}$ & 0 & 749 & 0 & 0 & 0 & 0 & 0 & 0 \\
\hline \multirow[t]{2}{*}{$\mathrm{Cr}$} & & $\%$ & & & & & & 100 & & \\
\hline & 458 & $\mathrm{~g}$ & 0 & 0 & 0 & 0 & 0 & 458 & 0 & 0 \\
\hline \multirow[t]{2}{*}{$\mathrm{CaSi}$} & & $\%$ & & & 51,7 & & & & & \\
\hline & 14 & $\mathrm{~g}$ & 0 & 0 & 7 & 0 & 0 & 0 & 0 & 0 \\
\hline \multirow[t]{2}{*}{$\mathrm{FeCrN}$} & & $\%$ & 0,054 & & 0,32 & & & 65,2 & 30,73 & 3,7 \\
\hline & 676 & $\mathrm{~g}$ & 0 & 0 & 0 & 0 & 0 & 441 & 208 & 25 \\
\hline TOTAL & 5010 & $\%$ & 0,04 & $\overline{15,00}$ & 0,2 & $\overline{\mathbf{0}}$ & $\overline{\mathbf{0}}$ & $\overline{18,00}$ & 66,25 & 0,5 \\
\hline
\end{tabular}

Posteriormente ao processo de fundição, os tarugos de aço inoxidável foram cortados na forma de discos, aquecidos a uma temperatura de aproximadamente de 1200 ${ }^{\circ} \mathrm{C}$ e em seguida passaram por um processo de forjamento unidirecional, num martelo de forja hidráulico, com capacidade de $40 \mathrm{kN}$, pertencentes a empresa CAMACAN, para eliminar a estrutura bruta de fundição.

O tratamento térmico de solubilização e tempera, realizados num forno tipo mufla do LFS-PME-EPUSP, tiveram como objetivo a obtenção de uma matriz austenítica isenta de carbonetos e/ou nitretos. As condições do tratamento de solubilização foram: temperatura de $950{ }^{\circ} \mathrm{C}$, tempo de 3 horas e taxa de aquecimento de $20{ }^{\circ} \mathrm{C} / \mathrm{min}$. A tempera em óleo, sem agitação, foi realizada ao término da $3^{\mathrm{a}}$ hora.

As dimensões finais dos discos foram obtidas mediante processos comuns de usinagem (torneamento e furação). A Figura 4.6 mostra um desenho do esquemático dos discos de aço inoxidável e uma fotografia do disco de aço inoxidável montado, por meio de parafuso, na base rotativa do tribômetro. 


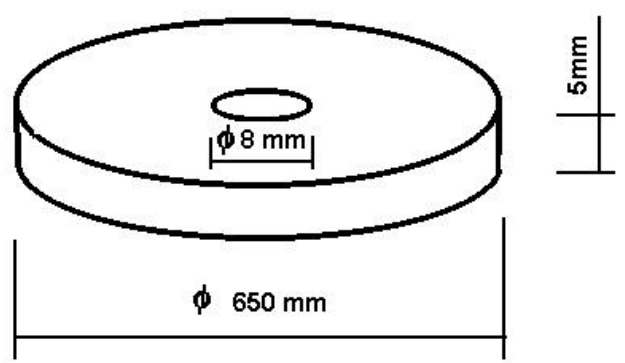

(a)

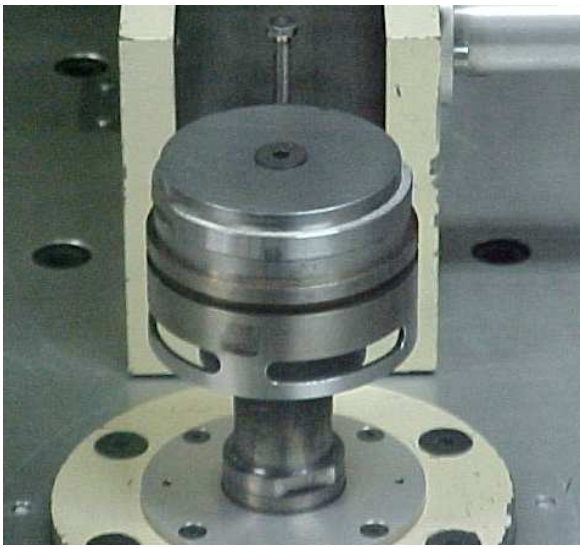

(b)

Figura 4.6 - Dimensões dos discos de aço inoxidável (a). Vista frontal do disco de aço inoxidável montado ao porta-disco e este ao eixo do motor (b).

Os níveis do parâmetro de rugosidade Ra (o qual está sendo utilizado como parâmetro inicial de comparação de acabamento) obtidos e a granulometria do papel abrasivo responsável por este acabamento estão apresentados abaixo:

- $0,05<\mathrm{Ra}<0,2 \mu \mathrm{m}(\operatorname{Lixa} \# 320) \mathrm{e}$

- $0,3<\mathrm{Ra}<0,6 \mu \mathrm{m}(\operatorname{Lixa} \# 180)$.

O processo completo de fabricação dos discos de aço inoxidável está apresentado no diagrama esquemático da Figura 4.7.

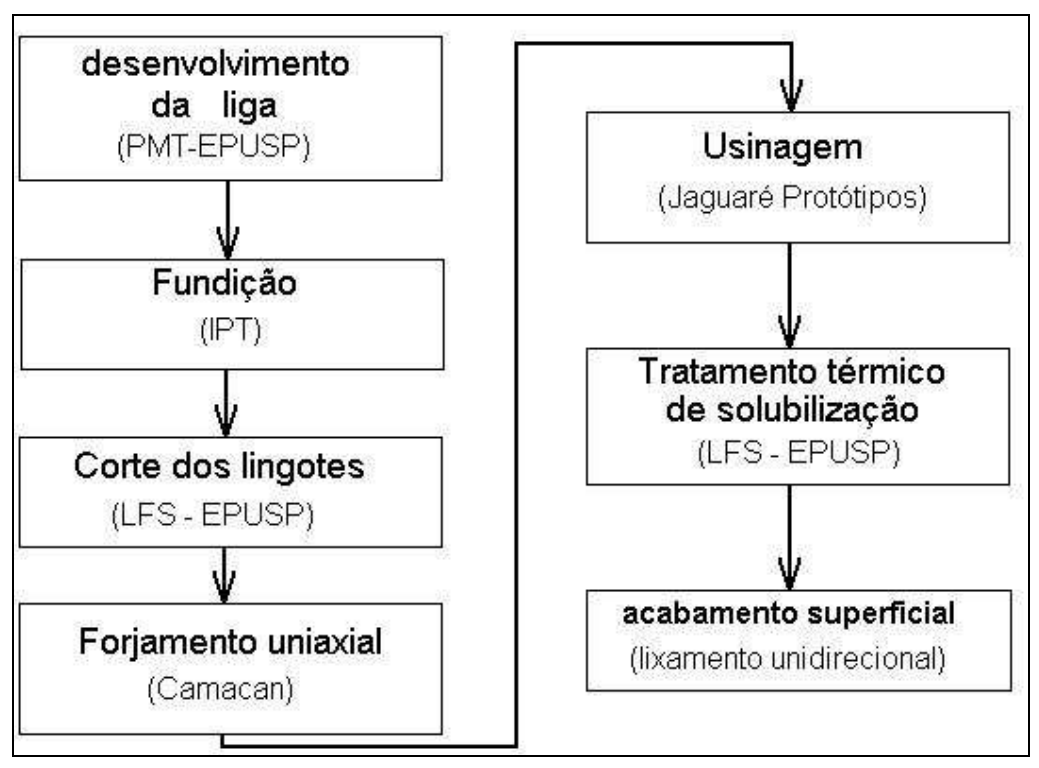

Figura 4.7 - Esquema do processo de preparação dos discos de alumina. 


\subsubsection{Alumina $\left(\mathrm{Al}_{2} \mathrm{O}_{3}\right)$}

Os discos de alumina foram processados pelo Laboratório de Cerâmica do IPEN (Instituto de Pesquisas Energéticas e Nucleares) nas dimensões de $64 \mathrm{~mm}$ de diâmetro e $5 \mathrm{~mm}$ de espessura. O pó de alumina pura A-1000 ALCOA, foi doado pelo Laboratório de Materiais do Centro Tecnológico da Marinha (LabMat - CTM) do Ministério da Marinha (ARAMAR). O processo de fabricação dos discos de alumina está apresentado no diagrama esquemático da Figura 4.8.

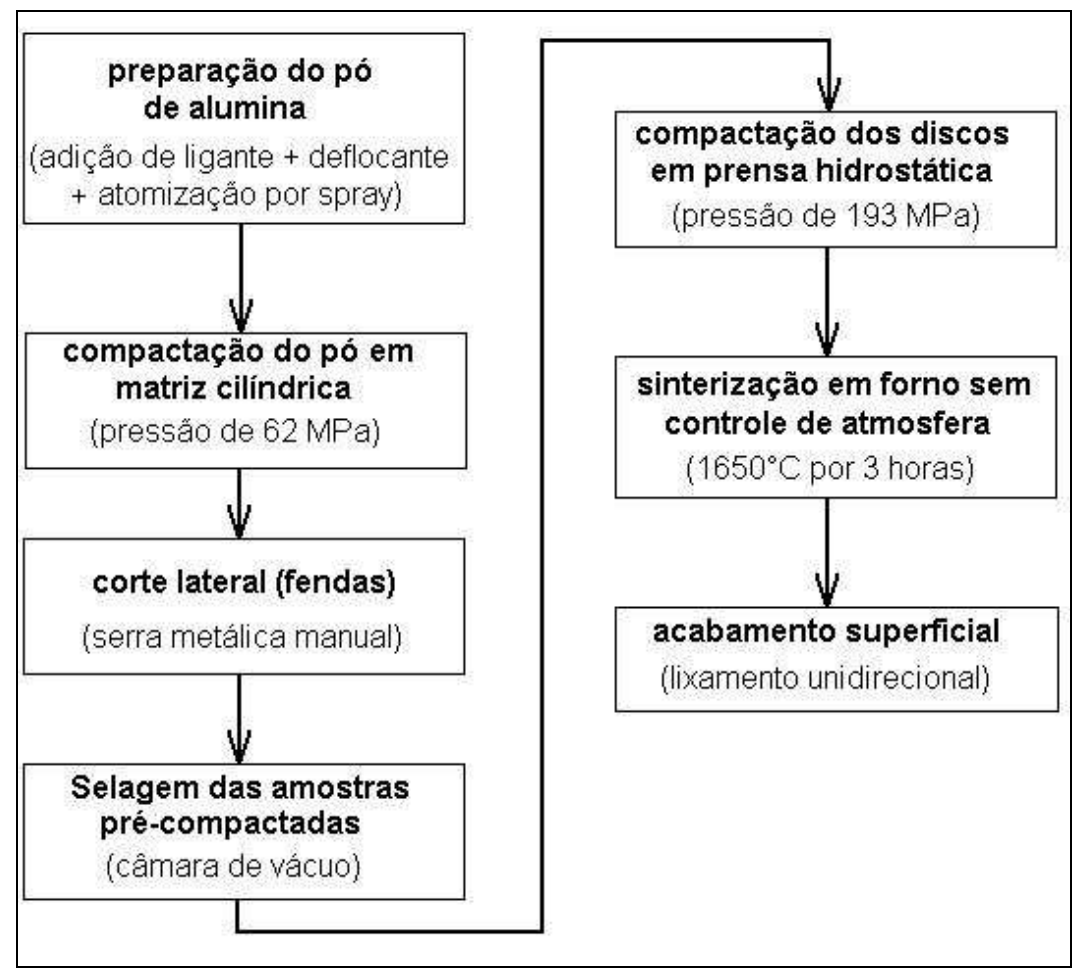

Figura 4.8 - Esquema do processo de preparação dos discos de alumina.

A Figura 4.9 mostra um desenho esquemático dos discos de alumina e uma fotografia do disco montado no porta-amostras do tribômetro. Para fixar o disco de alumina, o qual não poderia ser furado, para ser parafusado na base do tribômetro, foram feitos 3 chanfros laterais nos discos. Estes chanfros eram comprimidos por parafusos e placas de alumínio, impedindo desta forma a rotação dos discos durante os ensaios tribológicos. 


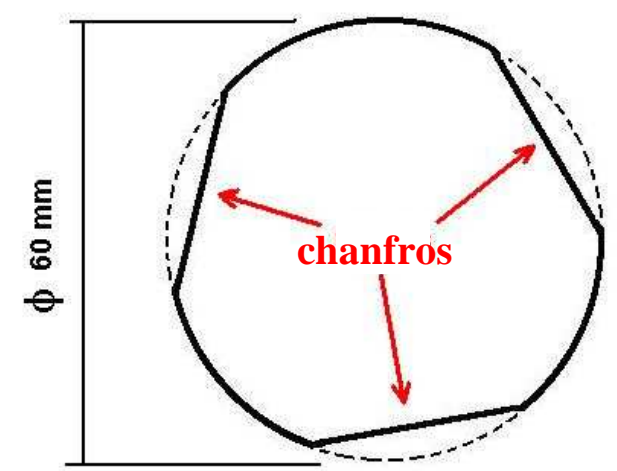

(a)

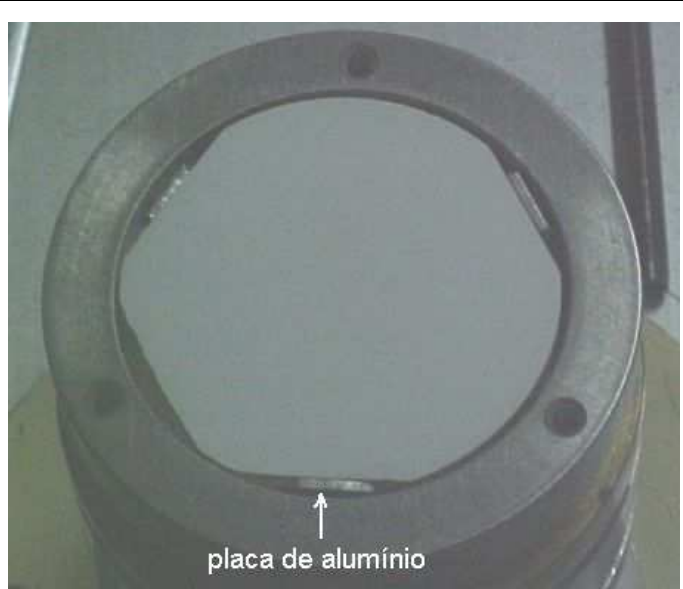

(b)

Figura 4.9 - Dimensões dos discos de alumina, mostrando os chanfros para fixação (a). Vista frontal do disco de alumina montado ao porta-disco.

A preparação das superfícies dos discos de alumina com acabamentos diferenciados foi realizada mediante o processo de lixamento manual unidirecional com lixas de papel abrasivo, com partículas abrasivas de $\mathrm{Al}_{2} \mathrm{O}_{3}$, da marca NORTON, com diversas granulometrias.

Na preparação das superfícies dos discos de alumina foram repetidos os mesmos procedimentos feitos nas amostras de aço inoxidável. Os níveis de rugosidade Ra obtidos e a granulometria das partículas abrasivas, estão apresentados abaixo:

- $0,3<\mathrm{Ra}<0,6 \mu \mathrm{m}($ Lixa \#320) e

- $1,5<\mathrm{Ra}<2,0 \mu \mathrm{m}(\operatorname{Lixa} \# 60)$.

\subsection{Ensaio Tribológico}

\subsubsection{O Tribômetro}

Para se determinar o comportamento tribológico de materiais poliméricos deslizando sobre superfícies de metais e/ou cerâmicas, utilizou-se um tribômetro tipo pino-contra-disco, modelo TE-67 de fabricação PLINT \& PARTNERS LTD, pertencente ao Laboratório de Fenômenos de Superfície do Departamento de Engenharia Mecânica da Escola Politécnica da USP (LFS-PME-EPUSP). A Figura 4.10, apresenta fotografias da vista lateral e frontal do equipamento de desgaste. 
Para a realização dos ensaios de desgaste foram observadas as recomendações da Norma ASTM G-99 ${ }^{100}$. Os requisitos mais importantes desta Norma são:

- promover a limpeza da superfície dos corpos-de-prova antes de cada ensaio;

- a perpendicularidade entre os eixos de centro do disco e do pino de $\pm 1^{\circ}$ deve ser garantida;

- manter o paralelismo entre a superfície de contato do pino com o plano do disco;

- iniciar o ensaio com o pino em contato com o disco;

- deve-se utilizar amostras adicionais quando da repetições de ensaios.

O equipamento de desgaste TE-67 está capacitado a fornecer diversas informações sobre os parâmetros de ensaios, bem como os resultados das medições de seus diversos sensores.

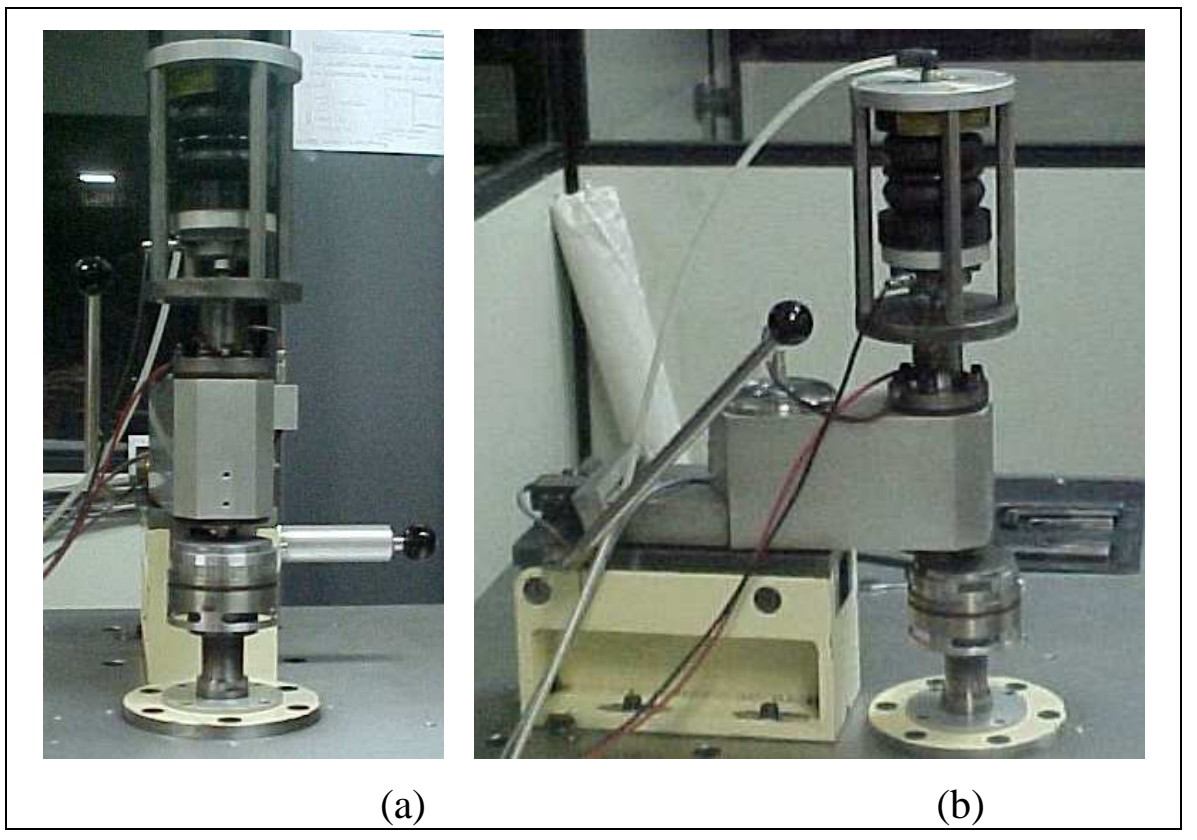

Figura 4.10 - Vista frontal (a) e lateral (b) do tribômetro TE-67.

Das capacidades disponíveis pelo equipamento, a Tabela 4.3 apresenta quais informações foram de interesse nesta pesquisa e quais os sensores utilizados. 
Tabela 4.3 - Informações obtidas no equipamento TE-67.

\begin{tabular}{cc}
\hline Informações & Sensores \\
\hline Força de atrito $(\mathrm{F})$ & Célula de carga (strain gages) \\
Carga normal aplicada $(\mathrm{N})$ & Célula de carga (strain gages) \\
Variação da altura do pino $(\Delta \mathrm{h})$ & Sensor linear de posição (LVDT) \\
Número de rotações & Tacômetro (disco dentado) \\
Temperatura & Termopar (tipo k) \\
\hline
\end{tabular}

Os valores da distância percorrida e da velocidade de deslizamento são obtidos a partir dos dados de número de rotações.

A Figura 4.11 mostra esquematicamente, com uma vista em corte e outra em perspectiva, os principais componentes presentes no cabeçote do equipamento de desgaste.

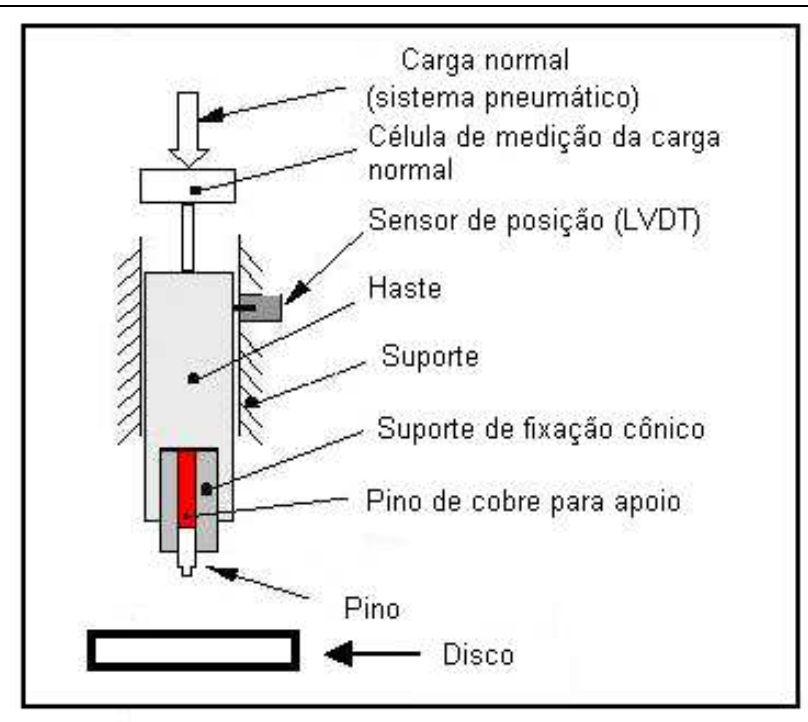

(a)

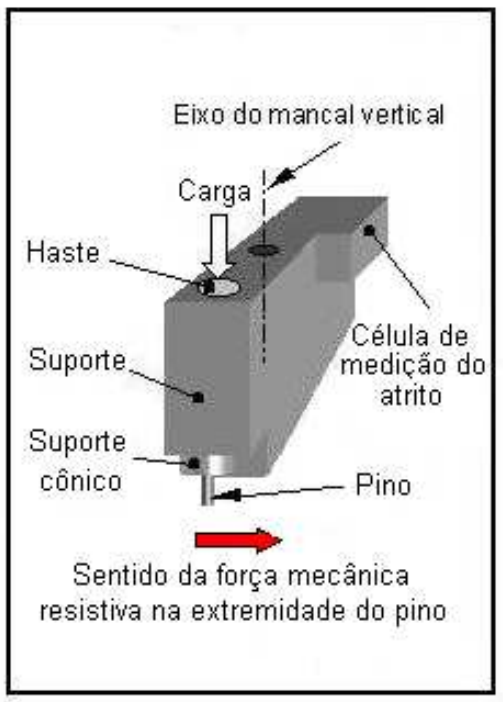

(b)

Figura 4.11 - Desenhos ilustrativos dos principais componentes do sistema pinocontra-disco. Cabeçote de fixação do pino em corte (a) e em perspectiva (b).

\subsubsection{Montagem do ensaio}

Como o próprio nome do ensaio usado nesta pesquisa sugere, a ação tribológica entre corpo (pino polimérico) e contra-corpo (disco), ocorre do contato deslizante de um pino fixo com um disco girante. 
Os pinos são colocados no porta-pino (suporte de fixação cônicos) e estes são roscados na haste fixa do cabeçote do equipamento. A Figura 4.12 mostra fotografia de um suporte de fixação cônico (a) e o suporte já roscado e travado na haste do cabeçote (b).

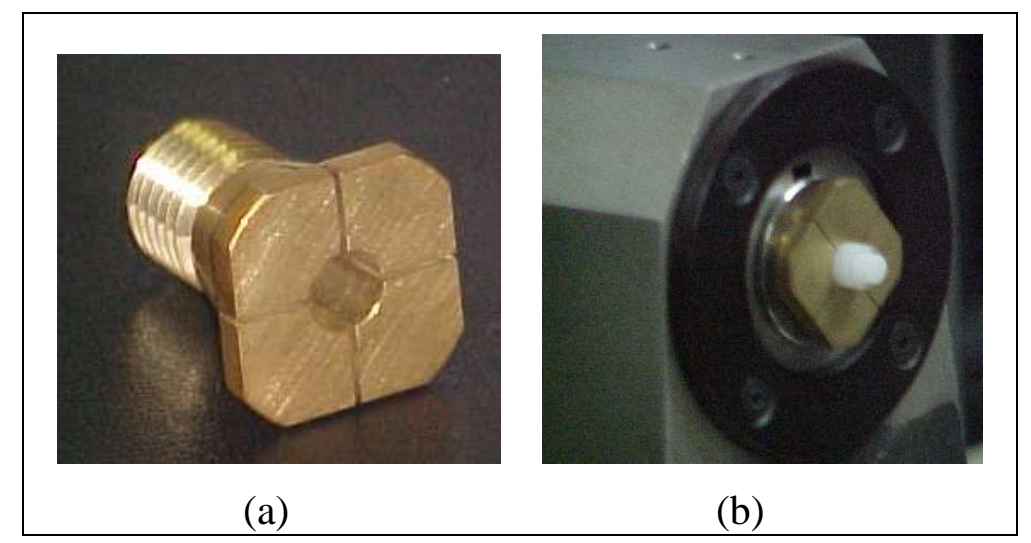

Figura 4.12 - Suporte cônico para fixação do pino na haste do equipamento de desgaste (a). Suporte cônico roscado e pino travado ao equipamento (b).

Tendo fixado pino e disco (Figura 4.13 - a), inicia-se o processo de aplicação da carga normal no pino (atuador pneumático) e motor gira o eixo solidário ao porta-disco (Figura 4.13-b). 


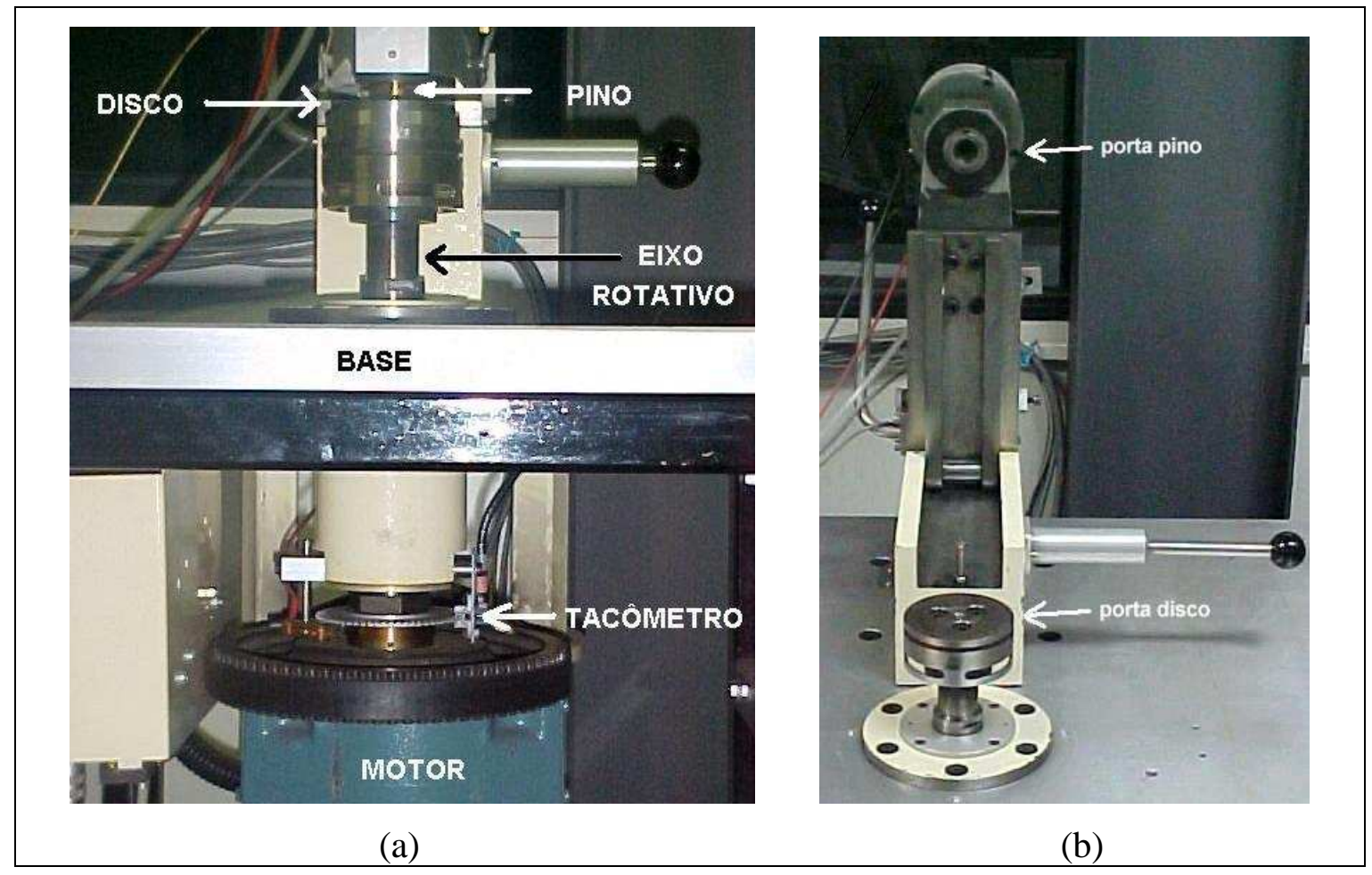

Figura 4.13 - Sistema de movimentação do disco (motor-tacômetro-eixo)-(a). Vista frontal do equipamento mostrando os pontos de fixação de disco e pino (b).

\subsubsection{Coeficiente de atrito e taxa de desgaste}

A taxa de desgaste linear $[\mu \mathrm{m} / \mathrm{m}]$, foi determinada pela medição da variação da altura dos pinos (deslocamento $\Delta \mathrm{h}$ ) durante os ensaios, com a utilização de um sensor linear de posição (LVDT) e pela contagem da distância percorrida (tacômetro) pelo pino sobre o disco.

Os valores de coeficiente de atrito foram determinados mediante a medição tanto da força de atrito entre pino e disco, como da carga normal aplicada a cada instante. Para a medição destes esforços, utilizou-se células de carga (strain-gages), como mostrado na fotografia da Figura 4.14. 


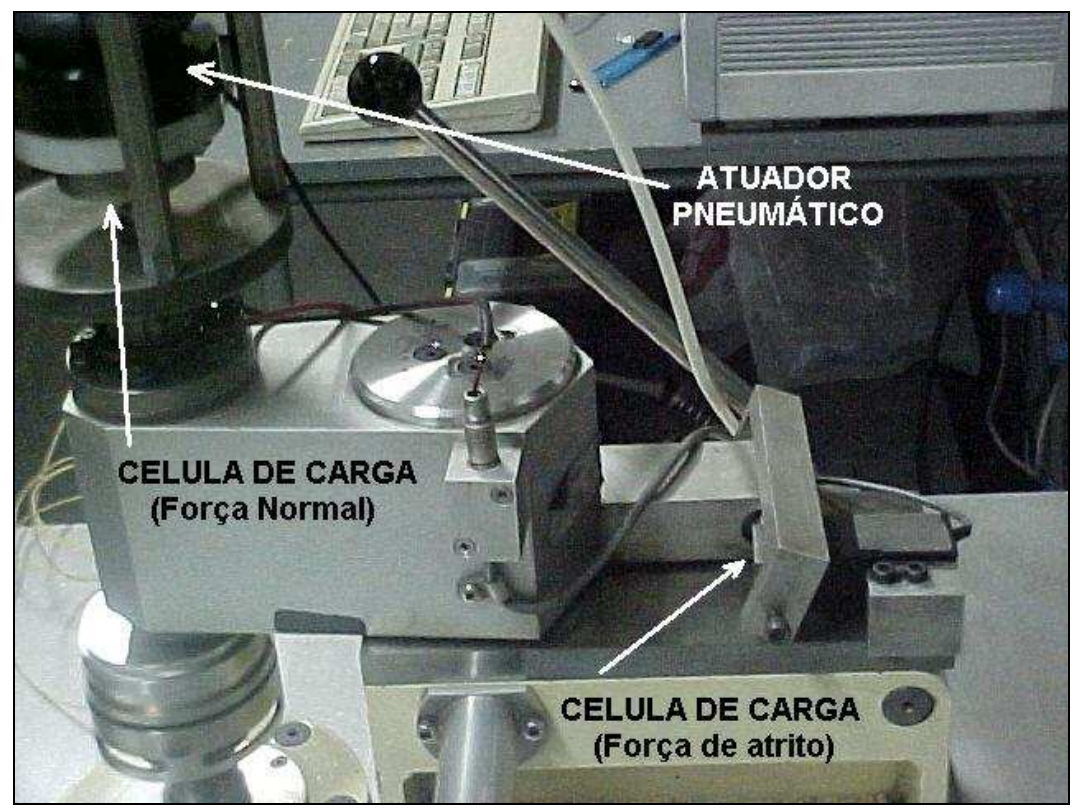

Figura 4.14 - Vista lateral do cabeçote do equipamento de desgaste, mostrando as células de carga responsáveis pela medição da carga normal transmitida pelo atuador pneumático e da força de atrito.

O coeficiente de atrito $(\mu)$ é determinado pela razão entre força de atrito $\left(F_{a}\right)$ e carga normal aplicada (N) (vide Equação 4-1).

$$
\mu=\frac{\mathrm{F}_{\mathrm{a}}}{\mathrm{N}}
$$

Equação 4-1

Os valores de coeficiente de atrito e taxa de desgaste foram determinados após a estabilização dos valores em função da distância percorrida. O período anterior à estabilização dos dados é denominado de running-in.

\subsubsection{Condições de ensaio}

A Tabela 4.4 apresenta os parâmetros de ensaio escolhidos para compreender o comportamento tribológicos dos polímeros em diversas condições PV. Logicamente foram respeitadas as limitações do equipamento juntamente com a integridade físicomecânica dos corpos-de-prova.

Tabela 4.4 - Parâmetros dos ensaios de desgaste

\begin{tabular}{ccc}
\hline $\begin{array}{c}\text { Carga aplicada } \\
{[\mathbf{N}]}\end{array}$ & $\begin{array}{c}\text { Velocidade de deslizamento } \\
{[\mathbf{m} / \mathbf{s}]}\end{array}$ & $\begin{array}{c}\text { Rugosidade dos discos }- \text { Ra } \\
{[\boldsymbol{\mu m}]}\end{array}$ \\
\hline 50 & 0,1 & $0,05<\mathrm{Ra}<0,2$ \\
100 & 0,5 & $0,3<\mathrm{Ra}<0,6$ \\
200 & 1,0 & $1,5<\mathrm{Ra}<2,0$ \\
\hline
\end{tabular}


A Tabela 4.5 apresenta os valores de condição PV usados para os diversos de rugosidade.

Tabela 4.5 - Valores de condição PV para os diversos níveis de carga e velocidade de deslizamento.

\begin{tabular}{|c|c|c|}
\hline $\begin{array}{c}\text { Carga } \\
{[\mathrm{N}]}\end{array}$ & $\begin{array}{c}\text { Velocidade } \\
{[\mathrm{m} / \mathrm{s}]}\end{array}$ & $\begin{array}{c}\text { Condição PV } \\
{\left[\mathrm{kW} / \mathrm{m}^{2}\right]}\end{array}$ \\
\hline 50 & 0,1 & 255 \\
\hline 50 & 0,5 & 1.274 \\
\hline 50 & 1,0 & 2.548 \\
\hline 100 & 0,1 & 510 \\
\hline 100 & 0,5 & 2.548 \\
\hline 100 & 1,0 & 5.096 \\
\hline 200 & 0,1 & 1.019 \\
\hline 200 & 0,5 & 5.096 \\
\hline
\end{tabular}

As taxas de aquisição dos dados obtidos pelo equipamento de desgaste foram de um dado a cada metro de deslizamento, ou seja, $1 \mathrm{~Hz}$ nos ensaios com velocidade de 1 $\mathrm{m} / \mathrm{s}, 0,5 \mathrm{~Hz}$ para a velocidade de $0,5 \mathrm{~m} / \mathrm{s}$ e $0,1 \mathrm{~Hz}$ para $0,1 \mathrm{~m} / \mathrm{s}$.

A umidade relativa do ambiente em que o equipamento de desgaste se encontra foi mantida em $50 \pm 5 \%$ com o uso de um desumidificador de ar modelo 200/110 BR de fabricação ARSEC.

A distância total de deslizamento foi de 3.500 metros.

\subsubsection{Temperatura no contato}

Para a medição da temperatura média da superfície dos pinos durante os ensaios de desgaste foi utilizado o medidor de temperatura interno da máquina de desgaste com um termopar do tipo k (cromel-alumel) ${ }^{101}$. Foram feitos furos de $1 \mathrm{~mm}$ de diâmetro na lateral dos pinos e o termopar foi colocado, sob pressão, em seu interior.

A correção dos valores de temperatura é feita mediante a formulação de ARCHARD $^{102}$ para o contato entre uma superfície circular deslizando contra um plano. A Figura 4.15 apresenta de uma forma esquemática o contato entre um pino de raio $\underline{\mathbf{a}}$ (corpo 1) e uma superfície plana, que neste caso é o disco (corpo 2), além de uma fotografia de um pino montado com o termopar, após a realização de um ensaio. 


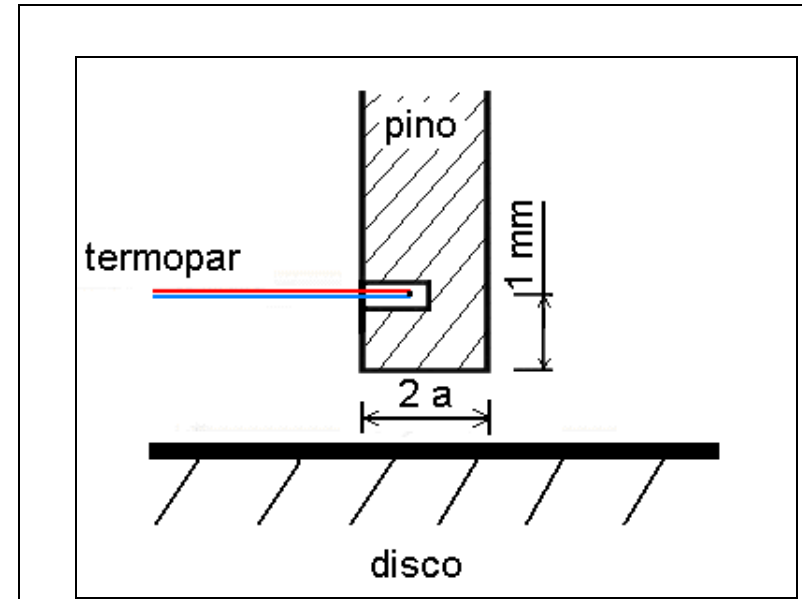

(a)

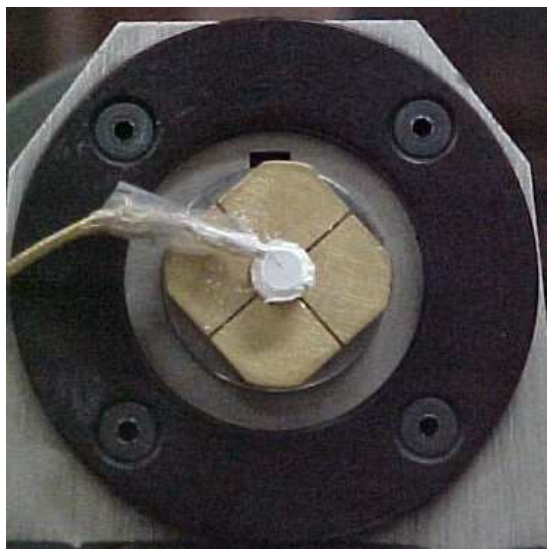

(b)

Figura 4.15 - Esquema mostrando termopar, pino e disco (a). Fotografia de um pino montado com a ponta do termopar em seu interior.

Os parâmetros utilizados nos cálculos de temperatura de contato foram:

(1) Fonte de calor estacionária = pino;

(2) Fonte de calor em movimento = disco;

$\mathrm{N}$ - carga aplicada;

v - velocidade de deslizamento;

a - raio da área de contato $=2,5 \mathrm{~mm}$;

$\mu$ - coeficiente de atrito;

$\lambda$ - condutividade térmica;

D - difusividade térmica.

A temperatura no contato é definida por:

$$
\mathrm{Tc}=\mathrm{Tb}+\mathrm{Tme}
$$

Equação 4-2

onde:

$\mathrm{Tc}=$ Temperatura no contato

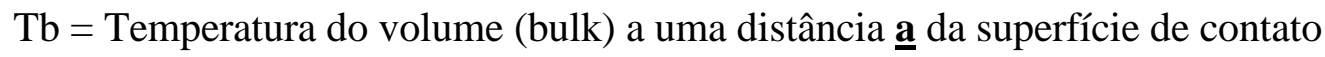

Tme $=$ acréscimo médio de temperatura em relação à $\mathrm{Tb}$

$$
\left(\mathrm{Tme}_{1}=\text { corpo } 1 ; \mathrm{Tme}_{2}=\text { corpo } 2\right)
$$

Para o cálculo da temperatura Tme é necessário calcular um parâmetro denominado número de PECLET (Pe). O número de PECLET ${ }^{102}$ é um adimensional que representa a energia térmica transportada por convecção e é representado por: 


$$
\mathrm{Pe}=\frac{\mathrm{v} \cdot \mathrm{a}}{2 . \mathrm{D}}
$$

sendo que:

- $\quad$ para $\mathrm{Pe}<0,1$

$$
\text { Tme }=\frac{\mu \cdot N \cdot v}{4 \cdot a \cdot \lambda}
$$

- para $\mathrm{Pe}>5$

$$
\text { Tme }=\frac{\mu \cdot \mathrm{N} \cdot \mathrm{v}}{\mathrm{a} \cdot \lambda} \cdot 0,31 \cdot \sqrt{\frac{\mathrm{D}}{\mathrm{v} \cdot \mathrm{a}}}
$$

Para o cálculo da temperatura Tme tem-se que:

$$
\frac{1}{\mathrm{Tme}}=\frac{1}{\mathrm{Tme}_{1}}+\frac{1}{\mathrm{Tme}_{2}}
$$

A Tabela 4.6 apresenta os valores de difusividade térmica dos materiais utilizados como pino e disco.

Tabela 4.6 - Difusividade térmica dos discos e dos pinos. ${ }^{17}{ }^{103}$

\begin{tabular}{ccc}
\hline Elemento & Material & $\mathbf{D}\left[\mathbf{m}^{2} / \mathbf{s}\right]$ \\
\hline Pino & UHMWPE & $2,57 \mathrm{E}-07$ \\
& POM & $1,42 \mathrm{E}-07$ \\
\multirow{2}{*}{ Disco } & Alumina & $7,84 \mathrm{E}-06$ \\
& Aço Inoxidável & $2,21 \mathrm{E}-05$ \\
\hline
\end{tabular}

\subsubsection{Mecanismos de desgaste}

Para a determinação dos mecanismos de desgaste, foi realizado o exame das superfícies de desgaste dos pinos e dos discos mediante a técnica de microscopia eletrônica de varredura (MEV) nos equipamentos STEREOSCAN 240 (marca CAMBRIDGE) e PHILIPS XL30, ambos pertencentes ao Departamento de Engenharia Metalúrgica e de Materiais da EPUSP (PMT-EPUSP). As fotomicrografias foram obtidas utilizando o detector de elétrons secundários (SE) e com tensão de feixe variando de 5 a $15 \mathrm{kV}$.

Devido a característica de não-condutividade dos materiais poliméricos, tanto a superfície dos pinos quanto a dos discos necessitaram de um recobrimento com material condutor (Figura 4.16), este procedimento é conhecido como metalização ${ }^{104}$. A técnica utilizada foi a deposição de íons (sputtering) em atmosfera de argônio e a metalização 
foi feita num equipamento modelo SCD 050 Sputter Coater, marca BALZERS, utilizando ouro com metal condutor.

As condições de deposição de íons utilizadas foram:

- fluxo de argônio de 8 litros/min;

- $\quad$ pressão de 0,06 mbar;

- corrente de $60 \mathrm{~mA}$;

- tempo de exposição de 60 segundos.

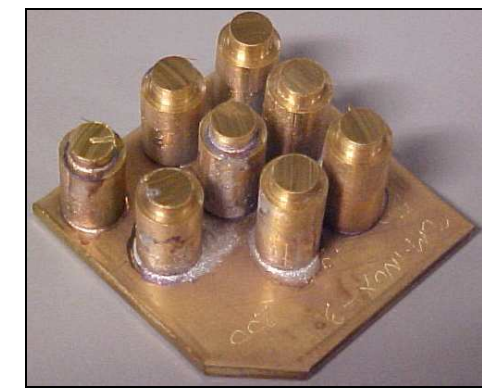

(a)

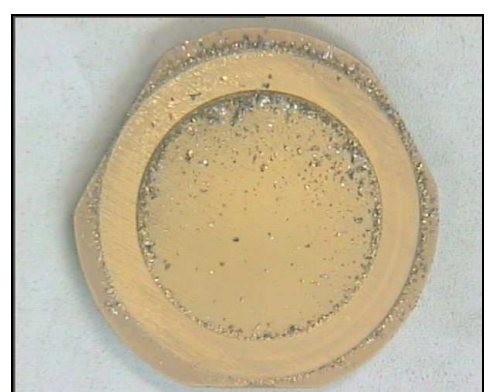

(b)

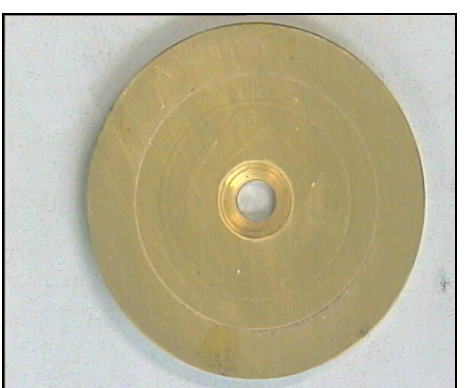

(c)

Figura 4.16 - Corpos-de-prova com recobrimento de ouro para observação em MEV. Pinos (a), discode alumina (b) e disco de aço inoxidável (c).

\subsubsection{Ensaio de fluência}

Para se obter o comportamento quanto à fluência dos materiais poliméricos, utilizou-se o próprio tribômetro como equipamento capaz de aplicar uma força constante e de medir as deformações longitudinais devido a esforços de compressão.

Apesar de não ser um ensaio de fluência normalizado, os resultados obtidos aproximam muito bem as condições em que os polímeros estão sendo submetidos, pois:

- o corpo-de-prova ensaiado é o próprio pino, eliminando desta forma quaisquer influências geométricas;

- o modo de aplicação da carga normal é o mesmo (atuador pneumático);

- o tempo de aplicação da carga é o mesmo em que os pinos tiveram submetidos durante os ensaios de desgaste;

- o sensor de posição (LVDT), o qual indiretamente fornece os valores de taxa de desgaste, é o mesmo que informa qual é a redução da altura dos pino $(\Delta \mathrm{h})$ nos ensaios de fluência. 
Durante a realização dos ensaios de fluência, optou-se por utilizar uma taxa de aquisição de 1 dado a cada 2 segundos, durante as primeiras duas horas, e 1 dado a cada 10 segundos após este tempo. Com isso, a região de transição entre os níveis primário e secundário da fluência, poderia ser melhor analisada.

\subsection{Caracterização dos corpos-de-prova}

\subsubsection{Calorimetria Exploratória Diferencial - DSC}

Para a determinação de informações como temperatura de fusão, entalpia de fusão e grau de cristalinidade, foram realizadas análises térmicas por calorimetria exploratória diferencial (DSC) num equipamento DSC-50, marca SHIMADZU do laboratório de polímeros do Departamento de Engenharia Metalúrgica e de Materiais da Escola Politécnica da USP (PMT-EPUSP).

Segundo Turi ${ }^{105}$, o grau de cristalinidade é obtido por:

$$
\text { grau de cristalinidade }=\frac{\mathrm{H}_{\text {medido }}}{\mathrm{H}_{100 \%}} .100 \quad[\%]
$$

onde:

- $\mathrm{H}_{\text {medido }}=$ entalpia de fusão medida e

- $\mathrm{H}_{100 \%}=$ entalpia de fusão correspondente a $100 \%$ de cristalinidade.

As amostras poliméricas utilizadas nas análises por DSC não excederam $5 \mathrm{mg}$ em massa e as condições utilizadas para a análise foram:

- taxa de aquecimento de $10^{\circ} \mathrm{C} / \mathrm{min}$ e

- vazão de nitrogênio de $20 \mathrm{ml} / \mathrm{min}$.

\subsubsection{Análise Termo-Dinâmico-Mecânica}

Para a determinação das propriedades dinâmico-mecânicas (módulo de armazenamento - E', módulo de perda - E" e tan $\delta$ ) dos polímeros, foram realizadas análises termo-dinâmico-mecânicas num equipamento DMTA da Polymer Laboratories, 
modelo MK II, do laboratório de análises térmicas de polímeros do Departamento de Engenharia de Materiais (DEMA) da Universidade Federal de São Carlos (UFSCar).

As condições das análises DMTA foram:

- cabeçote de flexão em 2 pontos (dual cantilivier);

- distância entre garras de 14 mm;

- deformação transversal de $64 \mu \mathrm{m}$ e

- carga dinâmica aplicada com frequiência de $1 \mathrm{~Hz}$.

A variação de temperatura no cabeçote do equipamento foi conseguida com o uso de nitrogênio líquido (temperaturas abaixo da ambiente) e resistências elétricas (altas temperaturas). A taxa de aquecimento nominal utilizada foi de $3{ }^{\circ} \mathrm{C} / \mathrm{min}$.

A Figura 4.17 mostra as dimensões dos corpos-de-prova poliméricos usados nas análises DMTA.

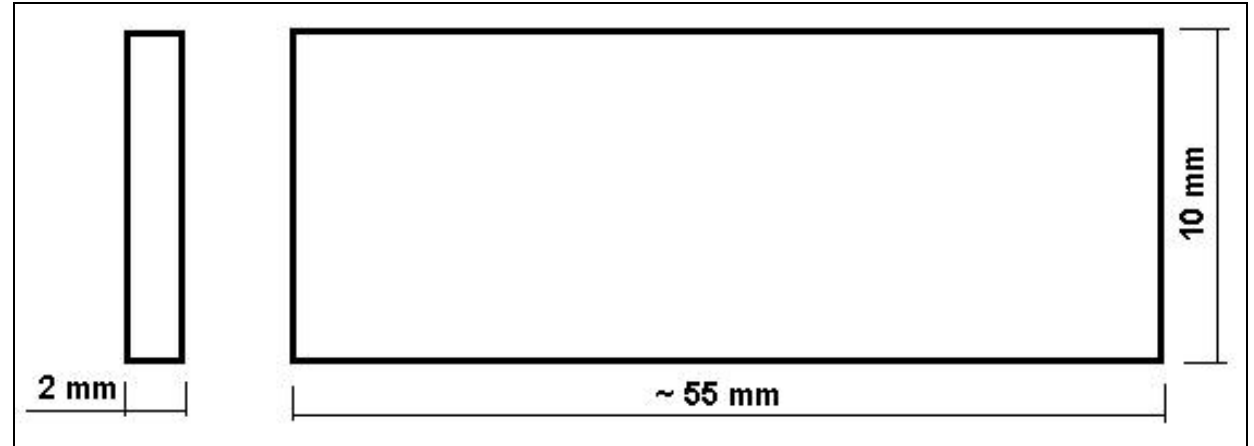

Figura 4.17 - Dimensões dos corpos-de-prova para análises DMTA (sem escala).

\subsubsection{Energia de superfície}

\subsubsection{Método da gota séssil}

O método da gota séssil permite determinar os ângulos de contato de um líquido na superfície de um sólido e mediante a utilização de equações clássicas da físicoquímica de superfícies determina-se a energia de superfície de um sólido. Este método é baseado no balanço entre as forças de superfície e de gravidade ${ }^{106}$. Quando a gota de um líquido é depositada em uma superfície, esta gota forma um ângulo $(\theta)$ na superfície, chamado de ângulo de contato (vide Figura 4.18). 


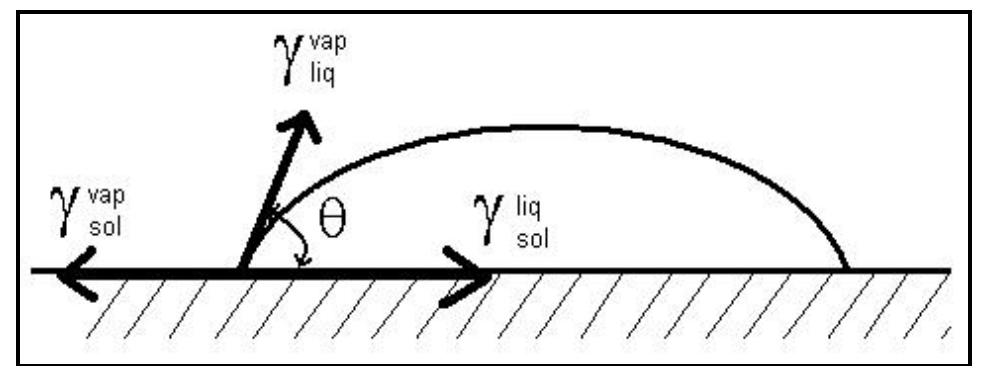

Figura 4.18 - Balanço de forças em uma gota séssil.

Thomas Young, mostrou que em condições de equilíbrio termodinâmico ${ }^{107}$ :

onde:

$$
\gamma_{\text {sol }}^{\text {vap }} \gamma_{\text {liq }}^{\text {sol }}+\gamma^{\text {vap }} \text { liq } \cdot \cos \theta
$$

$$
\begin{aligned}
& \gamma_{\text {sol }}^{\text {vap }}=\text { energia de superfície do sólido; } \\
& \gamma_{\text {liq }}^{\text {sol }} \text { energia interfacial entre sólido e líquido; } \\
& \gamma^{\text {vap }}{ }_{\text {liq }}=\text { energia de superfície do líquido. }
\end{aligned}
$$

Para se determinar as energias de superfícies do POM, UHMWPE, Alumina e aço inoxidável, utiliza-se o método de FOLKES (WU apud FOLKES ${ }^{115}$ ) o qual admite que a energia de superfície dos materiais é composta da somatória de duas componentes:

$$
\begin{aligned}
& \gamma^{\mathrm{d}}=\text { componente de dispersão (não-polar); } \\
& \gamma^{\mathrm{p}}=\text { componente polar. }
\end{aligned}
$$

desta forma, tem-se que:

$$
\gamma=\gamma^{\mathrm{d}}+\gamma^{\mathrm{p}}
$$

Equação 4-9

Para se determinar as componentes $\gamma^{\mathrm{d}}$ e $\gamma^{\mathrm{p}}$, utiliza-se vários líquidos de energia de superfície conhecida. A Tabela 4.7 apresenta os líquidos polar (água destilada) e apolar (diiodometano) utilizados para a determinação das energias de superfície de cada um dos materiais estudados. 
Tabela 4.7- Energia de superfície e as componentes polar e de dispersão a $20^{\circ} \mathrm{C} 108$

\begin{tabular}{cccc}
\hline Líquido & $\begin{array}{c}\boldsymbol{\gamma}^{\mathbf{d}} \\
{[\mathbf{m N} / \mathbf{m}]}\end{array}$ & $\begin{array}{c}\boldsymbol{\gamma}^{\mathbf{p}} \\
{[\mathbf{m N} / \mathbf{m}]}\end{array}$ & $\begin{array}{c}\boldsymbol{\gamma} \\
{[\mathbf{m N} / \mathbf{m}]}\end{array}$ \\
\hline Diiodometano & 44,1 & 6,7 & 50,8 \\
Água destilada & 22,1 & 50,7 & 72,8 \\
\hline
\end{tabular}

A determinação dos ângulos de contato e das componentes polar e de dispersão da energia de superfície dos materiais (polímeros, alumina e aço inoxidável) foi feita num Goniômetro NRL C.A., modelo 100-00, de fabricação RAMÉ-HART INC., do Laboratório de Plasmas e Aplicações do Departamento de Física e Química da UNESP (Campus de Guaratinguetá).

O goniômetro dispõe de um sistema de câmera CCD e um softwear de análise de imagens (Ramehart Imaging 2001), que após aquisição da imagem da gota, processa a medição dos ângulos de contato dos dois lados da gota (direito e esquerdo). A Figura 4.19 mostra um exemplo da determinação e medição dos ângulos de contato feita pelo analisador de imagens.

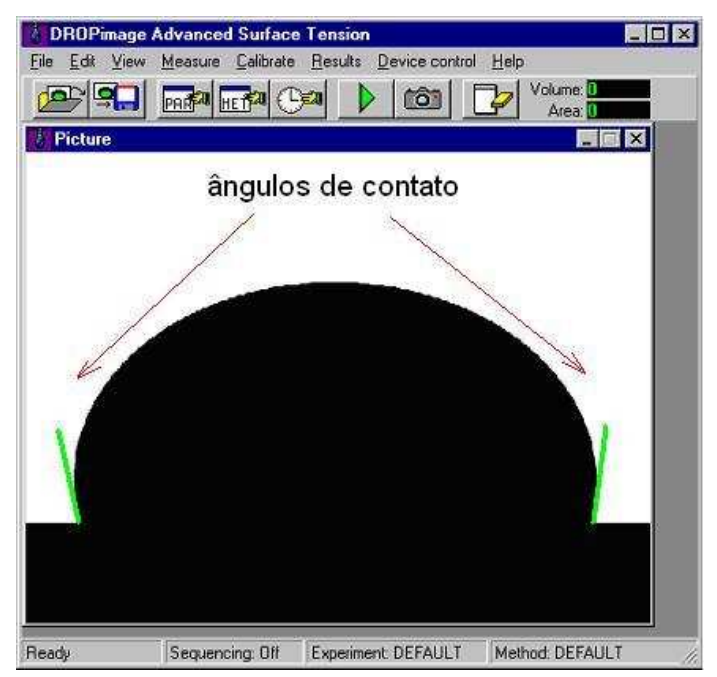

Figura 4.19 - Tela do analisador de imagens mostrando os ângulos de contato da gota com a linha de base dos lados direito e esquerdo.

Para cada um dos materiais estudados foram feitas 3 medidas. Sendo que cada medida apresentada, corresponde à média de 10 aquisições de imagens, e em cada imagem são medidos os ângulos do lado esquerdo e direito da gota. 


\subsubsection{Densidade de energia coesiva}

Para a determinação da densidade de energia coesiva $\left(\varepsilon_{\mathrm{c}}\right)$ foi utilizado o método da contribuição de grupos químicos proposto por SMALL (Equação 4.11), no qual a energia coesiva $\left(E_{c o h}\right)$ de uma substância de baixo ou alto peso molecular, pode ser relacionada com a contribuição energética de cada grupo químico pelo volume molar do mero.

onde:

$$
F=\sqrt{\mathrm{E}_{\mathrm{coh}} \cdot \mathrm{V}(298)}
$$

Equação 4-10

- $F=$ constante de atração molar $\left[\mathrm{J}^{1 / 2} / \mathrm{cm}^{3 / 2}\right]$;

- $\mathrm{V}(298)$ = volume molar do mero da substância à $20^{\circ} \mathrm{C}\left[\mathrm{cm}^{3} / \mathrm{mol}\right]$;

- $\mathrm{E}_{\mathrm{coh}}=$ Energia coesiva $[\mathrm{J} / \mathrm{mol}]$.

O volume molar do mero é dado pela relação:

$$
\rho=\frac{M}{V} \quad \therefore \quad V=\frac{M}{\rho}
$$

Equação 4-11

onde

- $\mathrm{M}=$ massa molar do mero e

- $\rho=$ densidade absoluta da substância.

A Tabela 4.8 apresenta os resultados obtidos por SMALL para a constante de atração molar $F$ dos grupos químicos dos polímeros utilizados nesta pesquisa.

Tabela 4.8 - Contribuições dos grupos químicos para $F^{15}$.

\begin{tabular}{cc}
\hline Grupo & Small $\left[\mathbf{J}^{1 / 2} / \mathbf{c m}^{3 / 2}\right]$ \\
\hline$-\mathrm{CH}_{2^{-}}$ & 272 \\
$-\mathrm{O}-$ & 143 \\
\hline
\end{tabular}

Tendo calculado a energia coesiva $\left(\mathrm{E}_{\mathrm{coh}}\right)$ do polímero, obtém-se a densidade de energia coesiva $\left(\varepsilon_{\mathrm{c}}\right)$ com a equação $4-13$ :

$$
\varepsilon_{\mathrm{c}}=\frac{\mathrm{E}_{\mathrm{coh}}}{\mathrm{V}} \quad\left[\mathrm{J} / \mathrm{cm}^{3}\right]
$$

Equação 4-12

\subsubsection{Rugosidade}

Para a caracterização da superfície dos discos e dos pinos, foi utilizado um rugosímetro com apalpador mecânico SURFCORDER, modelo SE 1700 $\alpha$, de 
fabricação KOSAKALAB. Tanto nas medições nos discos quanto nos pinos, foram utilizados os seguintes parâmetros de medição:

- $\quad$ comprimento de medição $(\mathrm{Lm})=4 \mathrm{~mm}$;

- $\quad$ comprimento de corte $(\mathrm{Lc})=0,8 \mathrm{~mm}$;

- filtro RC (resistivo-capacitivo).

O filtro RC foi utilizado para que possíveis efeitos de ondulação e erros de forma não interferissem nos cálculos dos valores dos parâmetros de rugosidade.

A Figura 4.20 mostra esquematicamente como foram feitas as medidas de rugosidade nos discos e nos pinos.

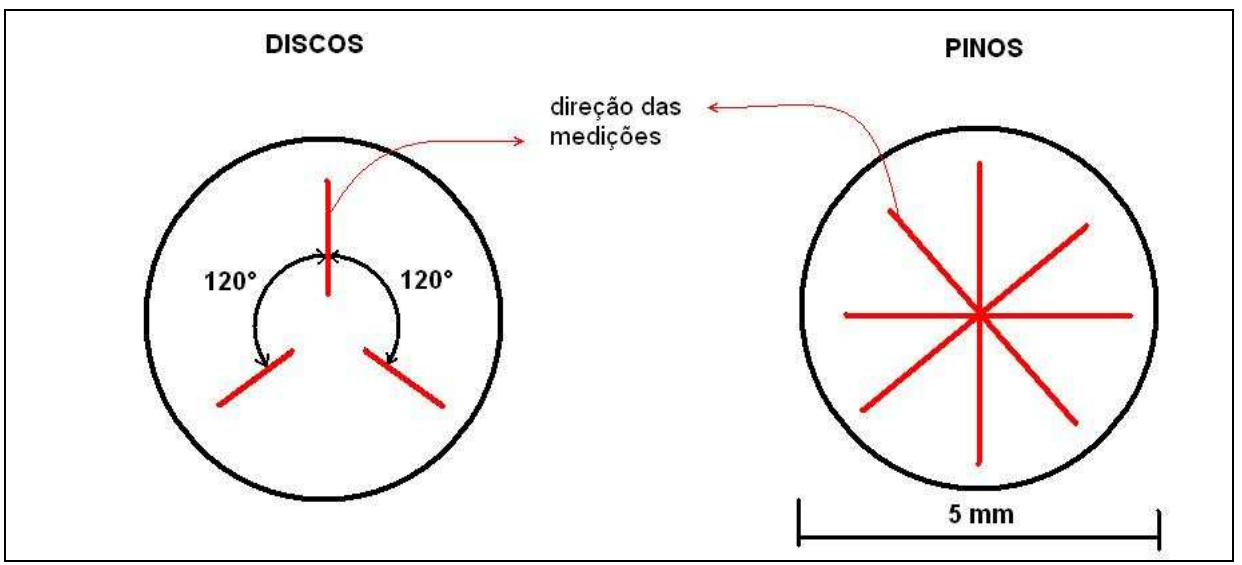

Figura 4.20 - Desenho esquemático dos discos e pinos mostrando as regiões e sentidos de medição da rugosidade.

Nos discos foram feitas cinco medidas de rugosidade em cada uma das três direções apresentadas na Figura 4.20, totalizando 15 medidas em cada disco. Como o processo de preparação das superfícies de contato dos pinos foi o faceamento em torno, optou-se por fazer 7 medições diametrais. Neste caso, as direções das medidas foram aleatórias.

\subsubsection{Ensaio instrumentado de dureza}

Para a determinação do módulo de elasticidade foi utilizado um microdurômetro Modelo Fischerscope HC-100V de fabricação FISCHER do LFS-PME-EPUSP.

No ensaio instrumentado de dureza ${ }^{109}$, o módulo de elasticidade é obtido a partir de um ciclo completo de aplicação e alívio de carga. As profundidades relativas aos estágios de carregamento e descarregamento são mostradas de forma esquemática na Figura 4.21. 


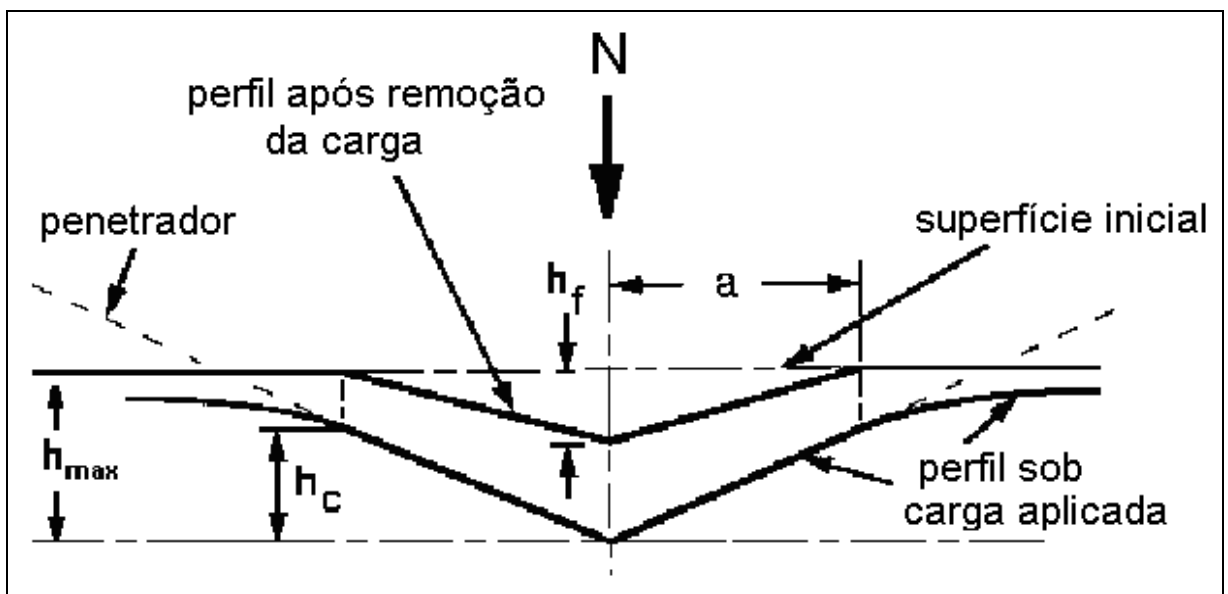

Figura 4.21 - Indicação esquemática dos parâmetros utilizados para cálculo de dureza dinâmica. ${ }^{109}$

Como resultado deste ensaio obtém-se uma curva de carga aplicada por profundidade de penetração. A Figura 4.22 mostra uma curva típica de carregamento e descarregamento.

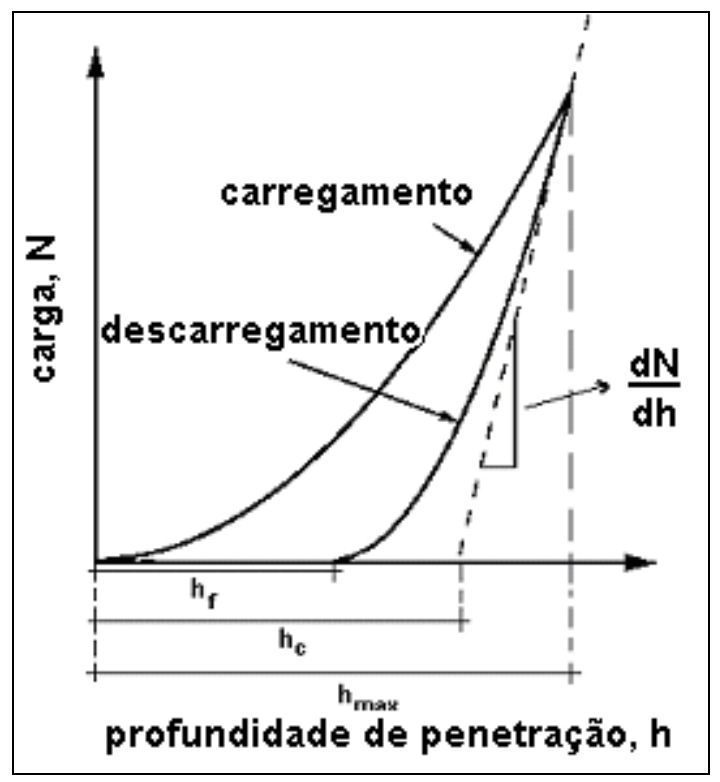

Figura 4.22 - Curva típica de dureza dinâmica. ${ }^{109}$

O método de análise destas curvas, desenvolvido por SNEDDON apud STILWELL; TABOR ${ }^{110}$ considera que o módulo de elasticidade do sistema pode ser determinado através da seguinte relação: 


$$
\mathrm{N}=\frac{2 \mathrm{Ea}}{\left(1-\mathrm{v}^{2}\right)} \mathrm{h}_{\mathrm{c}}
$$

onde:

$$
\begin{aligned}
& \mathrm{E}=\text { módulo de elasticidade; } \\
& \mathrm{N}=\text { carga aplicada } \\
& \mathrm{h}_{\mathrm{c}}=\text { profundidade de penetração; } \\
& \mathrm{v}=\text { coeficiente de Poisson e } \\
& \mathrm{a}=\text { raio da área de contato. }
\end{aligned}
$$

\subsubsection{Composição química do metal}

Os resultados da análise da composição química, obtidos por espectrofotometria de absorção atômica (exceto o carbono que foi feito por combustão) foram realizados pela Divisão de Metalurgia do Instituto de Pesquisas Tecnológicas (IPT).

\subsubsection{Análise metalográfica}

Para o aço inoxidável a caracterização das microestruturas foi realizada com o auxílio de técnicas de microscopia ótica qualitativa e quantitativa.

\subsubsection{Microscopia óptica}

A preparação metalográfica das amostras de aço inoxidável após os tratamentos térmicos, constituiu-se basicamente de uma etapa de lixamento e outra de polimento mecânico em feltros com pasta de diamante, sempre na presença de álcool etílico.

As observações metalográficas foram realizadas utilizando-se microscópio Olympus B60XM, localizado no LFS-PME-EPUSP. O reagente químico utilizado para revelar as microestruturas presentes foi o Vilela.

\subsubsection{Análise Quantitativa}

A Análise quantitativa das fases, ferrita e austenita, foi feita com a utilização de um software analisador de imagens LEICA QWin Standard Versão 2.2, verificando quantidade de fases claras (ferrita) em 5 campos diferentes. 


\subsubsection{Dureza Vickers}

A determinação da dureza Vickers foi realizada no Laboratório de Fenômenos de superfície LFS-PME-EPUSP com um durômetro Vickers de fabricação BUEHLER, modelo VMT7.

Segundo a norma ISO 2039-1 ${ }^{111}$, que define as condições de medição de dureza por penetração para termoplásticos, a carga aplicada foi de $5 \mathrm{kgf}$. Nas amostras de aço inoxidável a carga aplicada foi $10 \mathrm{kgf}$.

O valor da dureza foi calculado segundo a equação:

$$
\mathrm{HV}=1,854 \cdot \frac{\mathrm{N}}{\mathrm{di}^{2}}
$$

onde:

- $\quad \mathrm{HV}=$ Dureza Vickers $\left[\mathrm{kgf} / \mathrm{mm}^{2}\right]$;

- $\mathrm{N}=$ carga aplicada [kgf];

- $\quad \mathrm{di}=$ média do comprimento das diagonais da impressão [mm].

\subsubsection{Densidade absoluta}

Para a determinação da densidade média dos discos de alumina após a sinterização, foi utilizado o método do empuxo ${ }^{58}$, que é dado pela seguinte fórmula:

$$
\mathrm{D}=\left(\frac{\mathrm{Ms}}{\mathrm{Mu}-\mathrm{Mi}}\right) \cdot \rho_{\mathrm{H}_{2} \mathrm{O}}
$$

onde: Ms = Massa da amostra a seco;

$\mathrm{Mu}=$ Massa da amostra úmida;

Mi = Massa da amostra imersa em água destilada;

$\boldsymbol{\rho}_{\mathrm{H}_{2} \mathrm{O}}=$ Densidade da água $\left(=0,998 \mathrm{~g} / \mathrm{cm}^{3}\right.$ a $\left.20{ }^{\circ} \mathrm{C}\right)$

\subsubsection{Difração de raios-X}

A análise de difração de raios-X foi realizada no Laboratório de Cerâmica do Instituto de Pesquisas Tecnológicas e Nucleares - IPEN, nas amostras de alumina.

$\mathrm{O}$ objetivo do uso desta técnica foi o de verificar a presença da fase $\alpha-\mathrm{Al}_{2} \mathrm{O}_{3}$, nas amostras de alumina, o que caracterizaria este material. 
Nesta análise, utilizou-se o difratômetro de Raios-x da marca Philips, Modelo PW 1710, nas seguintes condições: radiação cobre $K \alpha$, no intervalo de $10^{\circ} \leq 2 \theta \leq 90^{\circ}$. A análise foi feita em superfície obtida do corte transversal dos discos cerâmicos. 


\section{RESULTADOS E DISCUSSÃO}

Os resultados desta pesquisa estão apresentados da seguinte maneira:

- Caracterização dos corpos-de-prova;

- Trabalho de adesão;

- Temperatura na região do contato;

- Ensaios de fluência;

- Ensaios de desgaste (taxa e mecanismo de desgaste);

- Período de amaciamento (running-in) e

- Coeficiente de atrito.

\subsection{Caracterização dos corpos-de-prova}

\subsubsection{Polietileno de ultra-alto peso molecular - UHMWPE}

Para a caracterização dos pinos de UHMWPE, foram determinadas:

- propriedades dinâmico-mecânicas;

- dureza Vickers;

- módulo de elasticidade;

- grau de cristalnidade;

- densidade de energia coesiva;

- rugosidade.

Além disso, obteve-se através do fabricante da resina, BRASKEM, diversas propriedades mecânicas, térmicas e físico-químicas (Tabela 5.1). 
Tabela 5.1 - Propriedades físico-químicas, mecânicas e térmicas do UHMWPE ${ }^{112}$.

\begin{tabular}{lcc}
\hline \multicolumn{1}{c}{ Propriedades } & unidade & UHMWPE \\
\hline Peso específico - $\boldsymbol{\rho}$ & $\mathrm{g} / \mathrm{cm}^{3}$ & 0,93 \\
Peso molecular viscosimétrico & $\mathrm{g} / \mathrm{mol}$ & $6 \times 10^{6}$ \\
Absorção de umidade até o equilíbrio a $23^{\circ} \mathrm{C}$ com UR de & $\%$ & 0,01 \\
$50 \%$ (D-570) - $\mathbf{W}_{\mathrm{s}}$ & & \\
\hline Tensão de escoamento a tração - $\boldsymbol{\sigma}_{\mathrm{s}}$ & $\mathrm{MPa}$ & 25 \\
Tensão de ruptura a tração - $\boldsymbol{\sigma}_{\mathbf{r}}$ & $\mathrm{MPa}$ & 35 \\
Alongamento até a ruptura & $\%$ & 467 \\
Dureza Rockwell (Shore D) & - & 63 \\
Resistência ao impacto a 23 $(\mathrm{CHARPY}$ c/ entalhe)) & $\mathrm{kJ} / \mathrm{m}^{2}$ & $>80$ \\
\hline Calor específico a 23 ${ }^{\circ} \mathrm{C}-\mathbf{C p}$ & $\mathrm{J} / \mathrm{Kg} \cdot \mathrm{K}$ & 1675 \\
Condutividade térmica a $23^{\circ} \mathrm{C}-\boldsymbol{\lambda}$ & $\mathrm{W} / \mathrm{K} \cdot \mathrm{m}$ & 0,40 \\
Coeficiente linear de expansão térmica - $\boldsymbol{\alpha}$ & $10^{-6} / \mathrm{K}$ & 150 \\
Temperatura de transição vítrea - Tg & ${ }^{\circ} \mathrm{C}$ & -95 \\
Temp. máxima de uso em curto período & ${ }^{\circ} \mathrm{C}$ & 110 \\
Temperatura mínima e máxima em uso contínuo & ${ }^{\circ} \mathrm{C}$ & -200 \\
& & +100 \\
\hline
\end{tabular}

\subsubsection{Propriedades dinâmico-mecânicas}

As Figuras 5.1, 5.2 e 5.3 apresentam, respectivamente, as curvas do módulo de armazenamento ou recuperação elástica (E'), do módulo de perda (E”) e da tangente de delta ( $\tan \delta=$ E’/E'), em função da temperatura. As Figuras apresentam os resultados de dois ensaios.

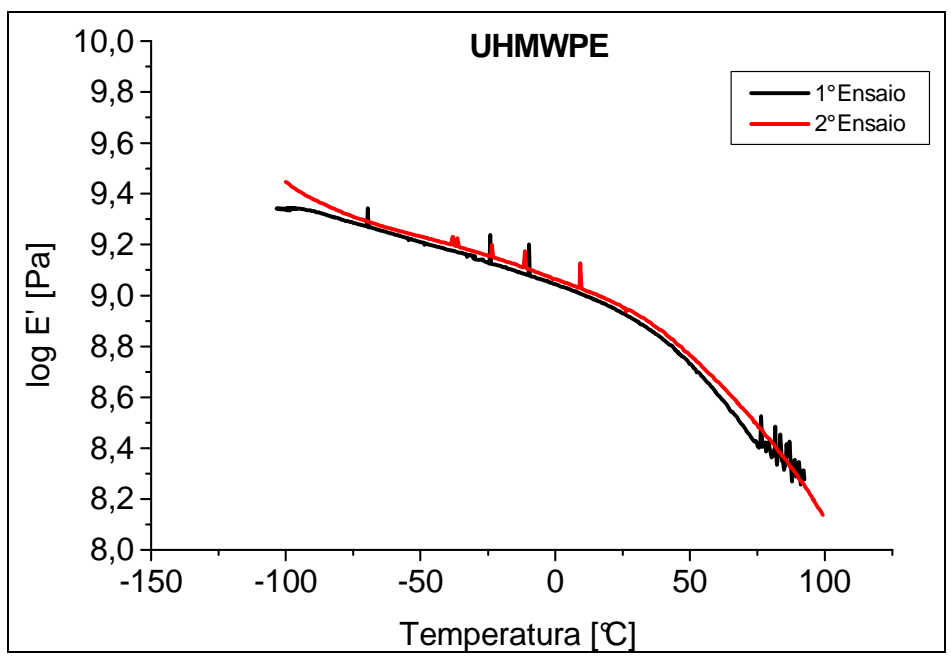

Figura 5.1 - Módulo elástico de armazenamento (E') em função da temperatura. 


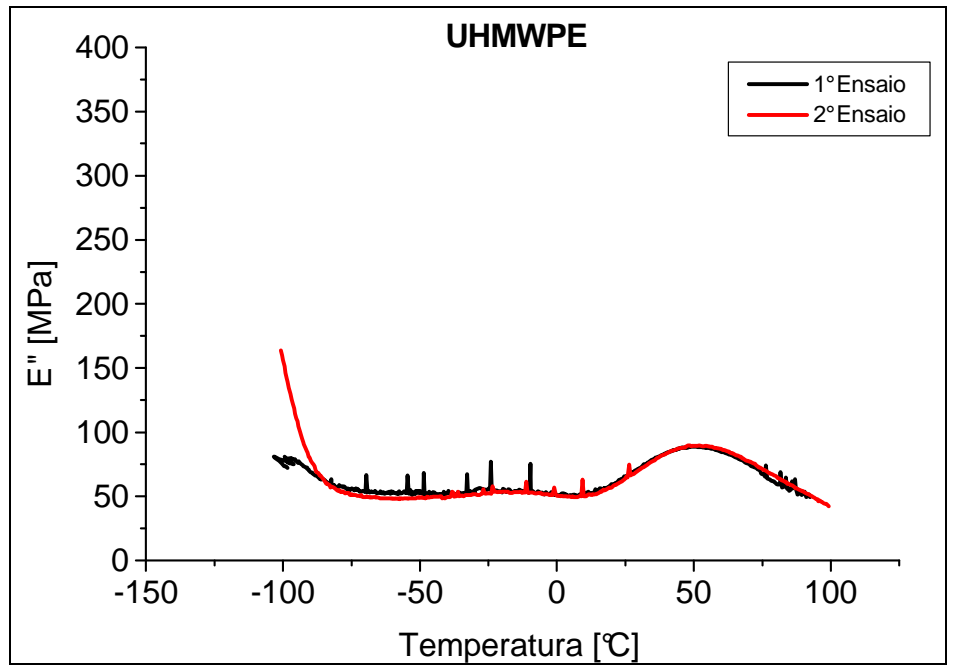

Figura 5.2 - Módulo elástico de perda (E”) em função da temperatura.

Nas Figuras 5.1 e 5.2, alguns picos (spikes) que aparecem nas curvas, não representam mudanças no comportamento do polímero, mas simplesmente um ruído no sinal do equipamento, o qual pode ter uma origem no tratamento eletrônico dos dados ou até na flutuação da tensão proveniente da rede elétrica do laboratório.

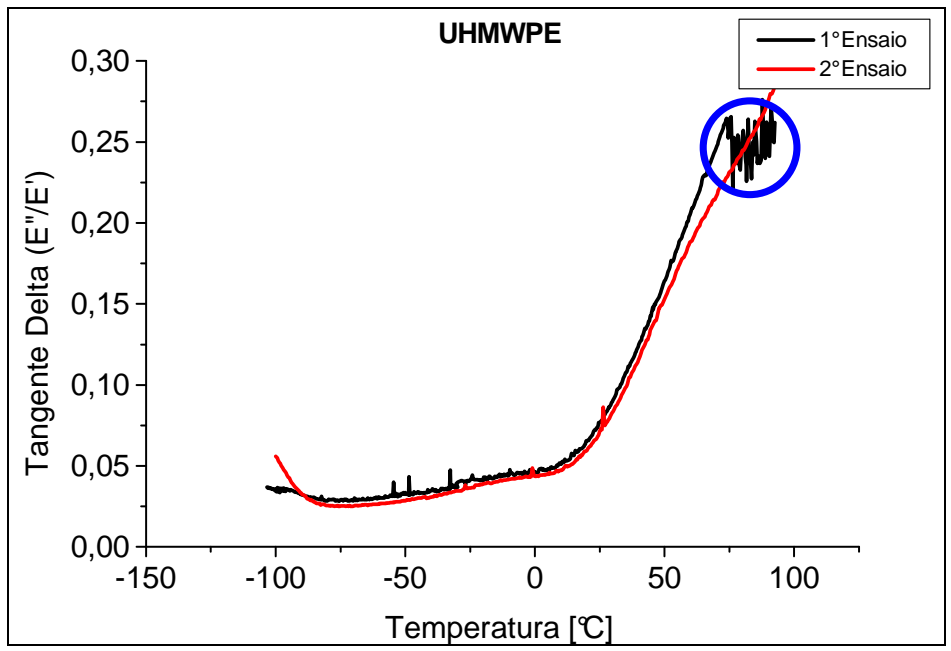

Figura 5.3 - Tangente de delta $(\tan \delta)$ em função da temperatura.

$\mathrm{O}$ círculo da Figura 5.3, mostra que o corpo-de-prova usado no $1^{\circ}$ Ensaio apresentou, por volta dos $75^{\circ} \mathrm{C}$, um comportamento errático, provocado provavelmente por este ter se mantido totalmente fixo ao cabeçote do equipamento com o aumento da temperatura. No entanto, este resultado não interfere no entendimento do comportamento da tangente de delta do UHMWPE, a qual mostra-se crescente entre $25^{\circ}$ e $100^{\circ} \mathrm{C}$. 


\subsubsection{Dureza Vickers}

A Tabela 5.2 apresenta os resultados da determinação da dureza, segundo a norma ISO 2039-1, que define as condições de medição de dureza por penetração para termoplásticos.

Tabela 5.2 - Dureza Vickers do UHMWPE.

\begin{tabular}{ccc}
\hline Medidas & $\begin{array}{c}\text { Diagonal } \\
{[\mathrm{mm}]}\end{array}$ & $\begin{array}{c}\text { Dureza } \\
{\left[\mathrm{kgf} / \mathrm{mm}^{2}\right]}\end{array}$ \\
\hline 1 & 1,14 & 7,16 \\
2 & 1,14 & 7,18 \\
3 & 1,14 & 7,16 \\
4 & 1,17 & 6,82 \\
5 & 1,24 & 6,04 \\
6 & 1,17 & 6,75 \\
7 & 1,17 & 6,77 \\
\hline Média & $\mathbf{1 , 1 7}$ & $\mathbf{6 , 8}$ \\
D. Padrão & $\mathbf{0 , 0 4}$ & $\mathbf{0 , 4}$ \\
\hline
\end{tabular}

\subsubsection{Módulo de elasticidade}

Para a determinação dos valores do módulo de elasticidade, foi utilizada a carga normal de 100 gf, com incremento de 5 gf/s no carregamento e no descarregamento, no procedimento de medição de microdureza dinâmica. O coeficiente de Poisson (v) estimado para o material foi de $0,45^{113}$.

A Tabela 5.3 apresenta os resultados da determinação do módulo de elasticidade do UHMWPE.

Tabela 5.3 - Módulo de elasticidade do UHMWPE.

\begin{tabular}{ccc}
\hline Medidas & $\begin{array}{c}\mathrm{E} /\left(1-\mathrm{v}^{\wedge} 2\right) \\
{[\mathrm{GPa}]}\end{array}$ & $\begin{array}{c}\mathrm{E} \\
{[\mathrm{GPa}]}\end{array}$ \\
\hline 1 & 1,05 & 0,84 \\
2 & 1,03 & 0,82 \\
3 & 1,05 & 0,84 \\
4 & 1,03 & 0,82 \\
5 & 1,03 & 0,82 \\
6 & 1,07 & 0,85 \\
7 & 1,04 & 0,83 \\
\hline Média & $\mathbf{1 , 0 4}$ & $\mathbf{0 , 8 3}$ \\
D. Padrão & $\mathbf{0 , 0 1}$ & $\mathbf{0 , 0 1}$ \\
\hline
\end{tabular}




\subsubsection{Grau de cristalinidade}

A Figura 5.4 apresenta uma curva de compensação de potência DSC em função da temperatura, mostrando o $1^{\circ}$ e único ciclo de aquecimento e resfriamento da amostra de UHMWPE.

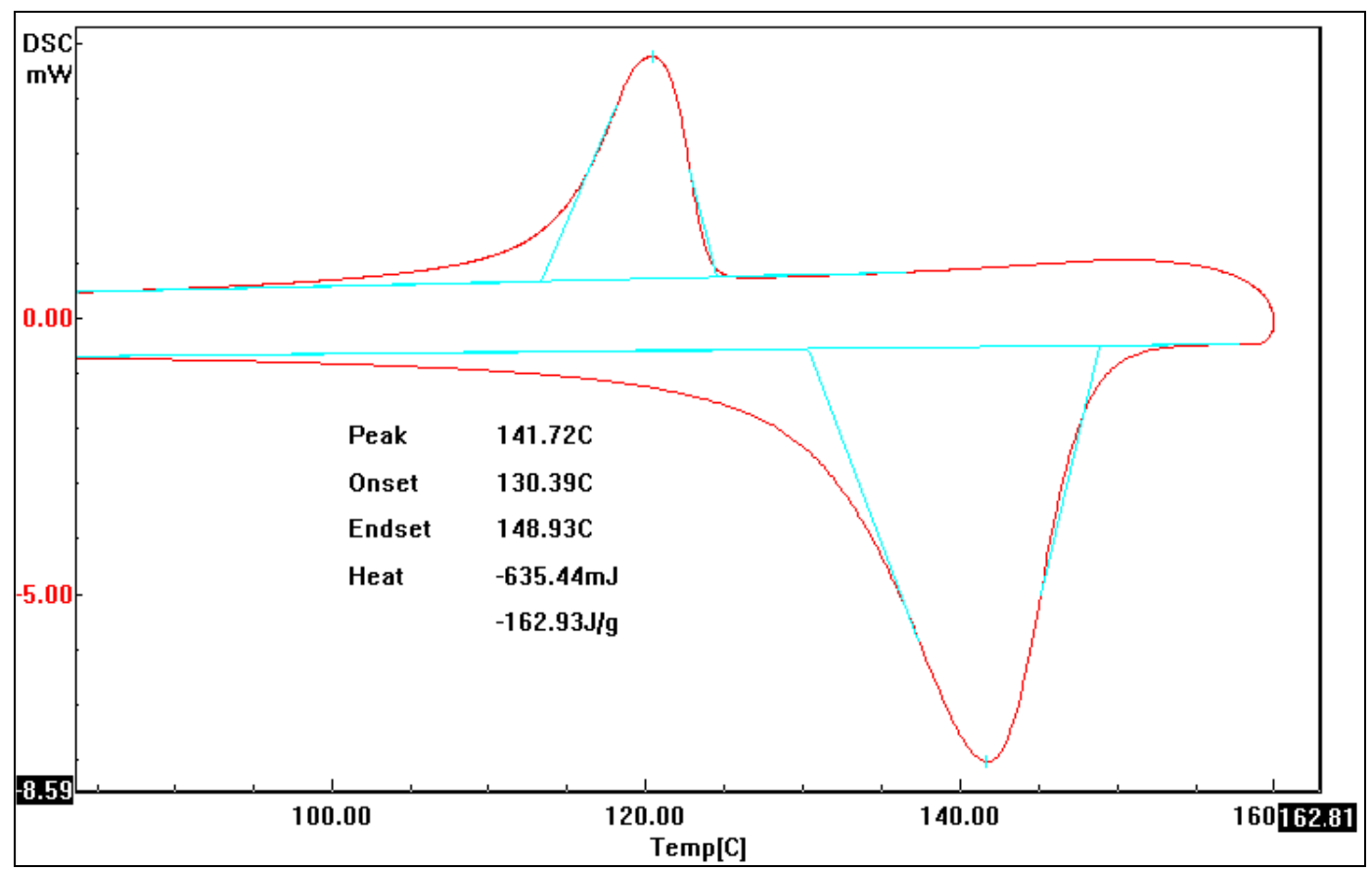

Figura 5.4 - Curva de potência em função da temperatura para o UHMWPE.

Para o cálculo do grau de cristalinidade do UHMWPE, utilizou-se $276[\mathrm{~J} / \mathrm{g}]^{105}$ como valor da entalpia de fusão e os dados da Figura 5.4 para o ciclo de aquecimento. A Tabela 5.4 apresenta alguns resultados da análise térmica por calorimetria exploratória diferencial para o UHMWPE.

Tabela 5.4 - Características Térmicas do UHMWPE.

\begin{tabular}{ccc}
\hline $\begin{array}{c}\text { Temperatura de fusão } \\
{\left[{ }^{\circ} \mathrm{C}\right]}\end{array}$ & $\begin{array}{c}\text { Entalpia de fusão } \\
{[\mathrm{J} / \mathrm{g}]}\end{array}$ & $\begin{array}{c}\text { Grau de cristalinidade } \\
\%\end{array}$ \\
\hline 141,7 & 162,9 & 59,0 \\
\hline
\end{tabular}

\subsubsection{Densidade de energia coesiva}

Para a determinação da densidade de energia coesiva, segundo o método de SMALL ${ }^{15}$, utilizou-se:

- $\quad$ mero do UHMWPE $=-\left[\mathrm{CH}_{2}-\mathrm{CH}_{2}\right]-$; 
- $\quad$ densidade absoluta $=\rho=0,93[\mathrm{~g} / \mathrm{cm} 3]$.

\section{Cálculo da massa molar:}

$$
\begin{aligned}
& M=2 \times C=2 \times 12=24 \\
& 4 \times H=4 \times 1=\frac{4}{28}[\mathrm{~g} / \mathrm{mol}]
\end{aligned}
$$

\section{Cálculo de volume molar:}

$$
\mathrm{V}=\mathrm{M} / \rho=28 / 0,93 \quad \mathrm{~V}=30,1\left[\mathrm{~cm}^{3} / \mathrm{mol}\right]
$$

De acordo com SMALL, o grupo $-\mathrm{CH}_{2}$ - tem parâmetro $F$ de 272; logo

$$
\Sigma F=2 \times-\mathrm{CH}_{2}-=2 \times 272=544
$$

Então, a energia coesiva do UHMWPE é:

$$
\mathrm{E}_{\mathrm{coh}}=F^{2} / \mathrm{V}=(544)^{2} / 30,1 \quad \mathbf{E}_{\mathbf{c o h}}=\mathbf{9 . 8 3 1 , 8}[\mathbf{J} / \mathbf{m o l}]
$$

E a densidade de energia coesiva é:

$$
\varepsilon_{\mathrm{coh}}=\mathrm{E}_{\mathrm{coh}} / \mathrm{V}=9.831,8 / 30,1 \quad \boldsymbol{\varepsilon}_{\text {coh do UHMWPE }}=\mathbf{3 2 6 , 6}\left[\mathbf{J} / \mathbf{c m}^{\mathbf{3}}\right]
$$

\subsubsection{Rugosidade}

A Tabela 5.5 apresenta os resultados de rugosidade da superfície de contato dos pinos de UHMWPE, após o processo de faceamento em torno. 
Tabela 5.5 - Parâmetro de rugosidade da superfície dos pinos de UHMWPE.

\begin{tabular}{ccccc}
\hline Medidas & $\begin{array}{c}\text { Ra } \\
{[\mu \mathrm{m}]}\end{array}$ & $\begin{array}{c}\text { Rq } \\
{[\mu \mathrm{m}]}\end{array}$ & $\begin{array}{c}\text { RzDIN } \\
{[\mu \mathrm{m}]}\end{array}$ & $\begin{array}{c}\text { Sm } \\
{[\mu \mathrm{m}]}\end{array}$ \\
\hline 1 & 1,74 & 2,07 & 160 & 8,80 \\
2 & 1,71 & 2,04 & 215 & 8,37 \\
3 & 1,62 & 1,92 & 165 & 7,49 \\
4 & 1,79 & 2,14 & 175 & 8,96 \\
5 & 2,00 & 2,68 & 155 & 10,28 \\
6 & 2,03 & 2,57 & 160 & 10,82 \\
7 & 1,76 & 2,08 & 154 & 9,27 \\
\hline Média & $\mathbf{1 , 8 1}$ & $\mathbf{2 , 2}$ & $\mathbf{1 6 9}$ & $\mathbf{9 , 1}$ \\
D.Padrão & $\mathbf{0 , 1 5}$ & $\mathbf{0 , 3}$ & $\mathbf{2 1}$ & $\mathbf{1 , 1}$ \\
\hline
\end{tabular}

A Figura 5.5 apresenta um exemplo do perfil de rugosidade dos pinos, obtido durante a medição dos parâmetros de rugosidade. Na ordenada, estão apresentados os dados da variação de altura da ponta do apalpador durante o deslocamento horizontal da haste do rugosímetro, e na abscissa, o comprimento de medição $(\mathrm{lm}=4 \mathrm{~mm})$.

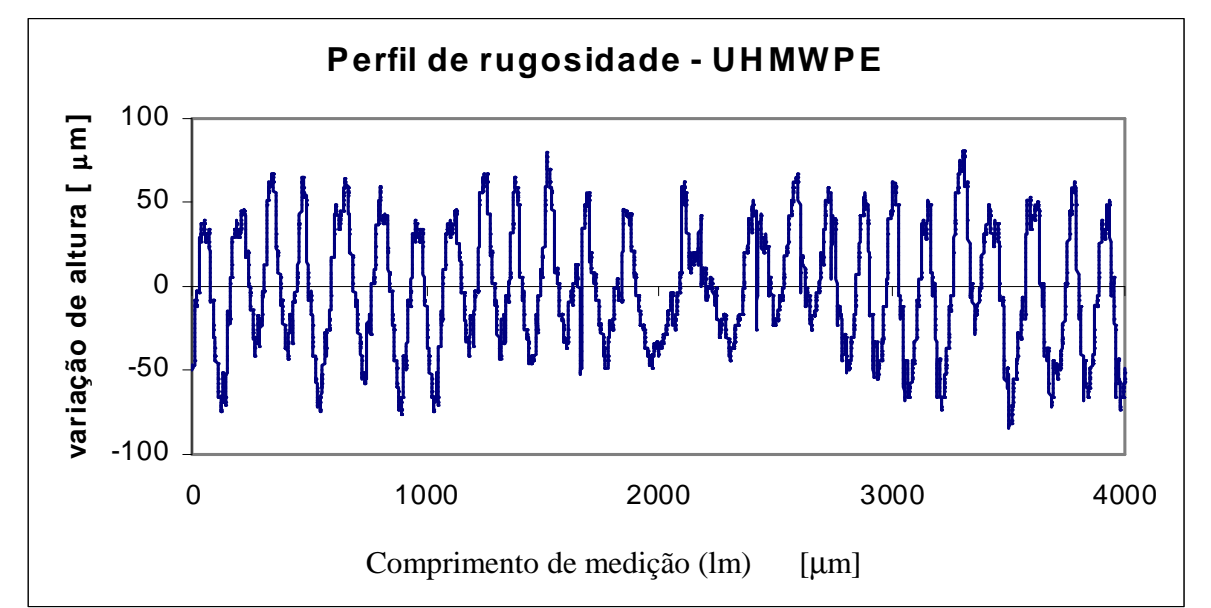

Figura 5.5 - Perfil de rugosidade da superfície dos pinos de UHMWPE.

\subsubsection{Polioximetileno - POM}

Para a caracterização dos pinos de POM, foram determinadas:

- propriedades dinâmico-mecânicas;

- dureza Vickers;

- módulo de elasticidade;

- grau de cristalinidade; 
- densidade de energia coesiva;

- rugosidade.

Para o POM copolímero (Hostaform $\left.{ }^{\circledR}\right)$ obteve-se junto ao fabricante, TICONA, diversas propriedades mecânicas, térmicas e físico-químicas (Tabela 5.6).

Tabela 5.6 - Propriedades físico-químicas, mecânicas e térmicas do POM copolímero $^{17}$.

\begin{tabular}{lcc}
\hline \multicolumn{1}{c}{ Propriedades } & unidade & POM \\
\hline Peso específico - $\boldsymbol{\rho}$ & $\mathrm{g} / \mathrm{cm}^{3}$ & 1,41 \\
Peso molecular viscosimétrico & $\mathrm{g} / \mathrm{mol}$ & $7 \times 10^{4}$ \\
\hline Tensão de escoamento a tração $-\boldsymbol{\sigma}_{\mathrm{s}}$ & $\mathrm{MPa}$ & 66 \\
Tensão de ruptura a tração $-\boldsymbol{\sigma}_{\mathrm{r}}$ & $\mathrm{MPa}$ & 74,3 \\
Alongamento até a ruptura ${ }^{113}-\boldsymbol{\xi}$ & $\%$ & 64,2 \\
Dureza Rockwell (Shore $\mathrm{D})$ & - & 120 \\
Resistência ao impacto a $23^{\circ}(\mathrm{CHARPY}$ c/ entalhe) & $\mathrm{kJ} / \mathrm{m}^{2}$ & $9,3-$ \\
\hline Calor específico a $23^{\circ} \mathrm{C}-\mathbf{C p}^{2}$ & $\mathrm{~J} / \mathrm{K} . \mathrm{g}$ & 1500 \\
Condutividade térmica a $23^{\circ} \mathrm{C}-\boldsymbol{\lambda}$ & $\mathrm{W} / \mathrm{K} . \mathrm{m}$ & 0,30 \\
Coeficiente linear de expansão térmica - $\boldsymbol{\alpha}$ & $10^{-6} / \mathrm{K}$ & 100 \\
Temperatura de transição vítrea - Tg & ${ }^{\circ} \mathrm{C}$ & -65 \\
Temperatura máxima de uso em curto período & ${ }^{\circ} \mathrm{C}$ & 140 \\
Temperatura mínima e máxima em uso contínuo & ${ }^{\circ} \mathrm{C}$ & -30 \\
& & +100 \\
\hline
\end{tabular}

\subsubsection{Propriedades dinâmico-mecânicas}

As Figuras 5.6, 5.7 e 5.8 apresentam, respectivamente, as curvas do módulo de armazenamento ou recuperação elástica (E'), do módulo de perda (E”) e da tangente de delta ( $\tan \delta=$ E'/E') em função da temperatura para o POM. As Figuras apresentam os resultados de duas medições. 


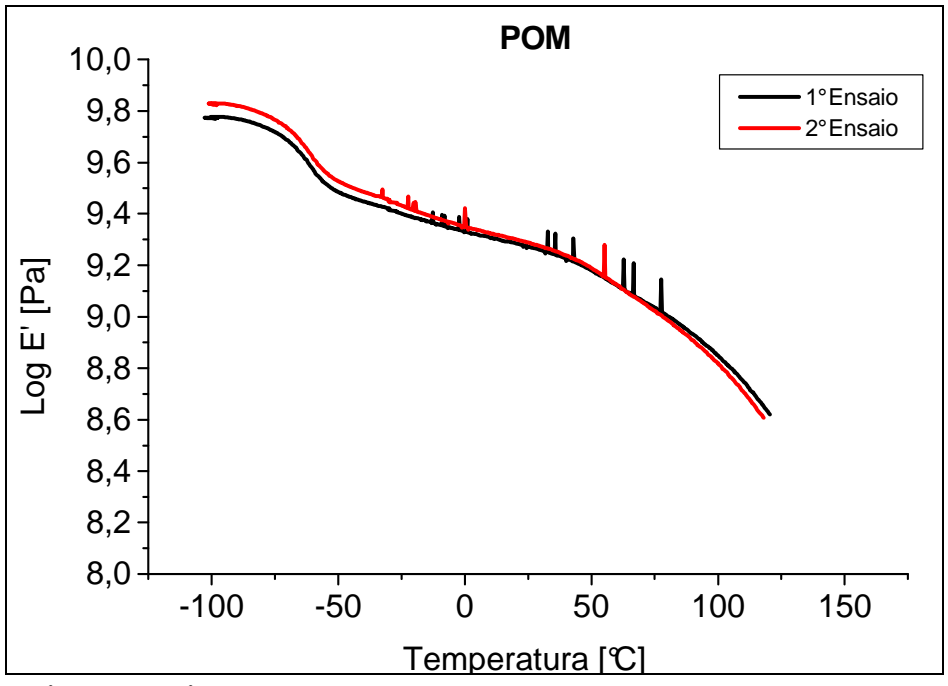

Figura 5.6 - Módulo elástico de armazenamento (E') em função da temperatura para o POM.

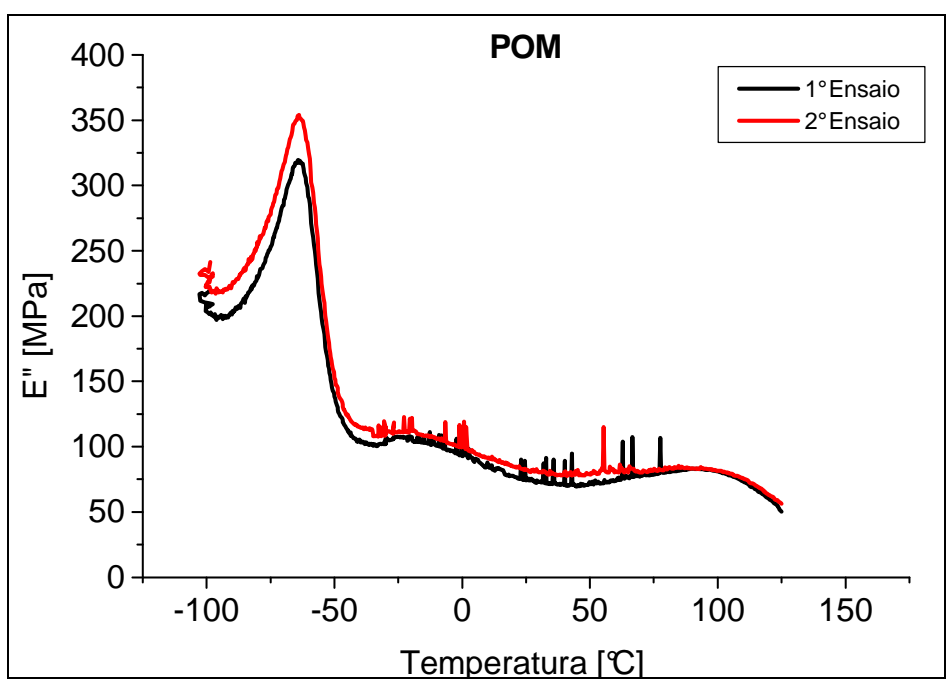

Figura 5.7 - Módulo elástico de perda (E”) em função da temperatura para o POM.

Novamente, pode-se dizer que os picos nas curvas das Figuras 5.6 e 5.7 não representam transições e sim ruídos do sistema de aquisição de dados. 


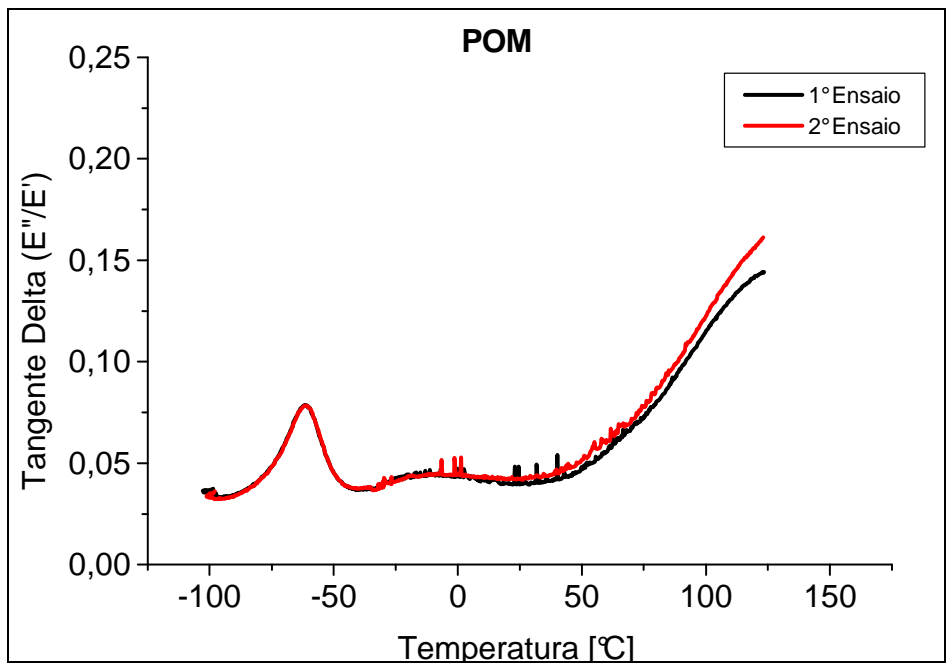

Figura 5.8 - Tangente de delta (tg $\delta$ ) em função da temperatura para o POM.

Além das propriedades dinâmico-mecânicas apresentadas acima, o ensaio de DMTA pode fornecer informações sobre transições de comportamento dos polímeros, as quais estão relacionadas com rotações de segmentos da cadeia polimérica. Na curva de $\operatorname{tg} \delta$ em função da temperatura, pode-se observar um pico na curva referente à transição vítrea. A Figura 5.9 apresenta o pico relacionado com a transição vítrea do POM.

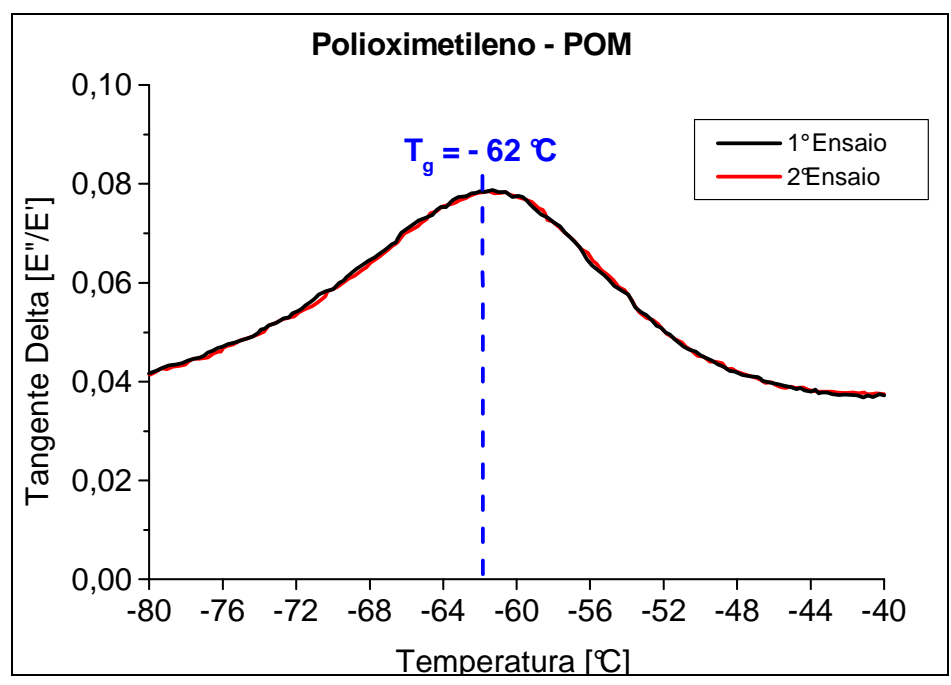

Figura 5.9 - Pico da temperatura de transição vítrea do POM.

\subsubsection{Dureza Vickers}

A Tabela 5.7 apresenta os resultados da determinação da dureza Vickers, segundo a norma ISO 2039-1 ${ }^{111}$, que define as condições de medição de dureza por penetração para termoplásticos. 
Tabela 5.7 - Dureza Vickers do POM.

\begin{tabular}{ccc}
\hline Medidas & $\begin{array}{c}\text { Diagonal } \\
{[\mathrm{mm}]}\end{array}$ & $\begin{array}{c}\text { Dureza } \\
{\left[\mathrm{kgf} / \mathrm{mm}^{2}\right]}\end{array}$ \\
\hline 1 & 0,66 & 21,10 \\
2 & 0,71 & 18,21 \\
3 & 0,69 & 19,40 \\
4 & 0,76 & 16,08 \\
5 & 0,78 & 15,16 \\
6 & 0,79 & 14,74 \\
7 & 0,77 & 15,67 \\
\hline Média & $\mathbf{0 , 7 4}$ & $\mathbf{1 7}$ \\
D. Padrão & $\mathbf{0 , 0 5}$ & $\mathbf{2}$ \\
\hline
\end{tabular}

\subsubsection{Módulo de elasticidade}

Para a determinação dos valores do módulo de elasticidade, foi utilizada a carga normal de $100 \mathrm{gf}$, com incremento de 5 gf/s no carregamento e no descarregamento, utilizando-se a técnica de ensaio instrumentado de dureza. O coeficiente de Poisson (v) estimado para o material foi de $0,38^{17}$.

A Tabela 5.8 apresenta os resultados da determinação do módulo de elasticidade do POM.

Tabela 5.8 - Módulo de elasticidade do UHMWPE.

\begin{tabular}{ccc}
\hline Medidas & $\begin{array}{c}\mathrm{E} /\left(1-\mathrm{v}^{\wedge} 2\right) \\
{[\mathrm{GPa}]}\end{array}$ & $\begin{array}{c}\mathrm{E} \\
{[\mathrm{GPa}]}\end{array}$ \\
\hline 1 & 2,60 & 2,07 \\
2 & 2,68 & 2,14 \\
3 & 2,70 & 2,15 \\
4 & 2,73 & 2,18 \\
5 & 2,80 & 2,23 \\
6 & 2,67 & 2,13 \\
7 & 2,60 & 2,07 \\
\hline Média & $\mathbf{2 , 7}$ & $\mathbf{2 , 1 4}$ \\
D. Padrão & $\mathbf{0 , 1}$ & $\mathbf{0 , 0 6}$ \\
\hline
\end{tabular}

\subsubsection{Grau de cristalinidade}

A Figura 5.10 apresenta uma curva de compensação de potência DSC em função da temperatura, mostrando o $1^{\mathrm{o}}$ e único ciclo de aquecimento e resfriamento da amostra de POM. 


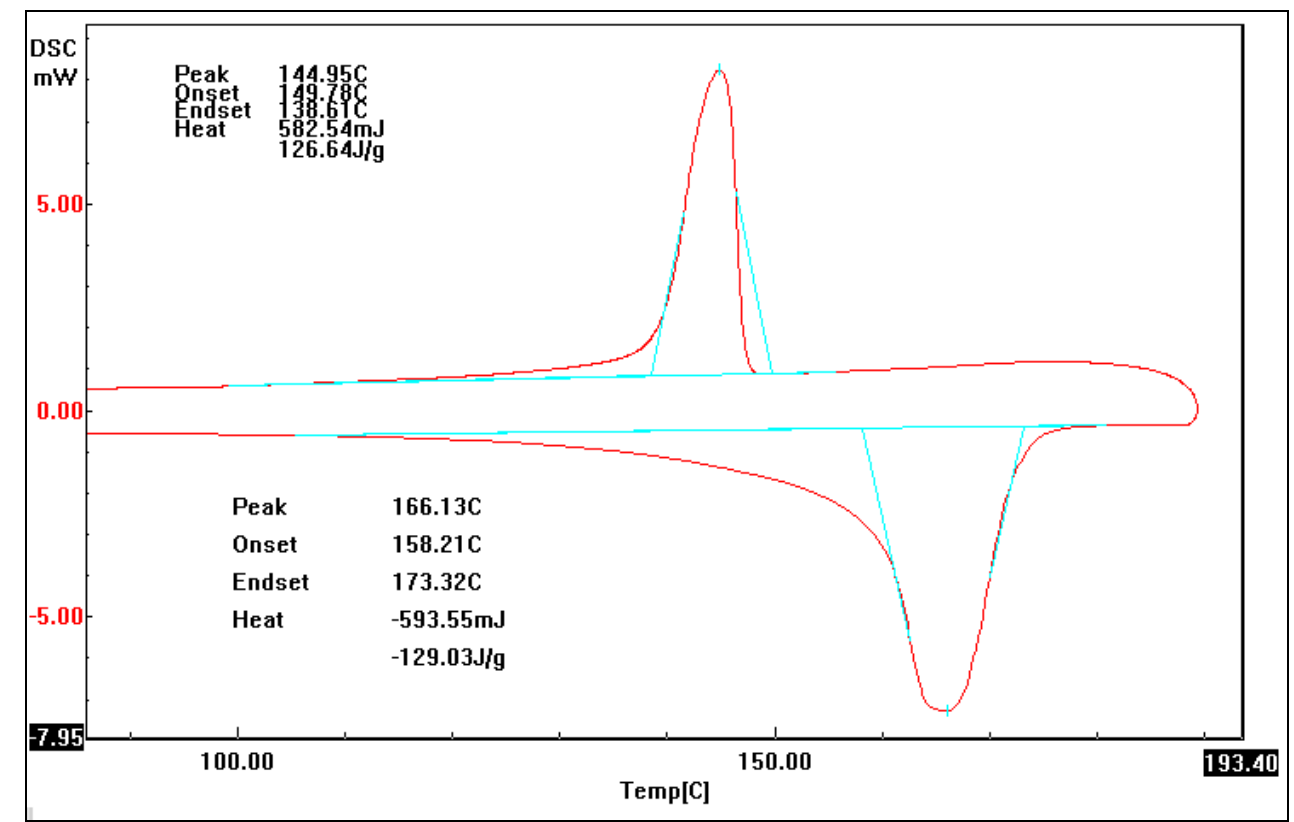

Figura 5.10 - Curva de potência em função da temperatura para o POM.

Para o cálculo do grau de cristalinidade do POM, utilizou-se 186,5 J/g como valor da entalpia de fusão. A Tabela 5.9 apresenta alguns resultados da análise térmica por calorimetria exploratória diferencial para o POM.

Tabela 5.9 - Características térmicas do POM copolímero.

\begin{tabular}{ccc}
\hline $\begin{array}{c}\text { Temperatura de fusão } \\
{\left[{ }^{\circ} \mathrm{C}\right]}\end{array}$ & $\begin{array}{c}\text { Entalpia de fusão } \\
{[\mathrm{J} / \mathrm{g}]}\end{array}$ & $\begin{array}{c}\text { Grau de cristalinidade } \\
\%\end{array}$ \\
\hline 166,1 & 129,03 & 69,2 \\
\hline
\end{tabular}

\subsubsection{Densidade de energia coesiva}

Para a determinação da densidade de energia coesiva, segundo o método de SMALL ${ }^{15}$, utilizou-se:

- mero do $\mathrm{POM}=-\left[\left[-\mathrm{O}-\mathrm{CH}_{2}\right]_{\mathrm{n}}-\mathrm{CH}_{2}\right]_{\mathrm{m}^{-}}$

- $\quad$ sendo $\mathrm{n}=100$ e $\mathrm{m}=1(\text { dados da TICONA })^{95}$

- densidade absoluta $=\rho=1,41\left[\mathrm{~g} / \mathrm{cm}^{3}\right]$;

Cálculo da massa molar:

$$
\begin{aligned}
& \mathrm{M}=101 \times \mathrm{O}=101 \times 16=1.616 \\
& 102 \times \mathrm{C}=102 \times 12=1.224 \\
& 204 \times \mathrm{H}=204 \times 1=\frac{204}{3.044}[\mathrm{~g} / 101 \mathrm{~mol}] \\
& \log \mathrm{M}=30,14[\mathrm{~g} / \mathrm{mol}]
\end{aligned}
$$




\section{Cálculo de volume molar:}

$$
\mathrm{V}=\mathrm{M} / \rho=30,14 / 1,41 \quad \mathrm{~V}=\mathbf{2 1 , 4}\left[\mathrm{cm}^{\mathbf{3}} / \mathbf{m o l}\right]
$$

De acordo com SMALL, os grupos $-\mathrm{CH}_{2}-\mathrm{e}-\mathrm{O}-$ possuem, respectivamente, parâmetros $F$ de 272 e 143 ; logo

$$
\Sigma F=102 \mathrm{x}-\mathrm{CH}_{2}-+101 \mathrm{x}-\mathrm{O}-=27.744+14.443=42.187
$$

Então a energia coesiva do POM é:

$$
\begin{aligned}
& \mathrm{E}_{\mathrm{coh}}=F^{2} / \mathrm{V}=(42.187)^{2} / 2.158,9 \quad \mathrm{E}_{\mathrm{coh}}=824.375[\mathrm{~J} / 101 \mathrm{~mol}] \\
& \operatorname{logo} \mathbf{E}_{\mathbf{c o h}}=\mathbf{8 . 1 6 2 , 1}[\mathbf{J} / \mathbf{1 0 1} \mathbf{~ m o l}]
\end{aligned}
$$

E a densidade de energia coesiva é:

$$
\varepsilon_{\mathrm{coh}}=\mathrm{E}_{\mathrm{coh}} / \mathrm{V}=8.162,1 / 21,4 \quad \boldsymbol{\varepsilon}_{\text {coh do POM }}=\mathbf{3 8 2}\left[\mathrm{J} / \mathrm{cm}^{3}\right]
$$

\subsubsection{Rugosidade}

A Tabela 5.10 apresenta os resultados da determinação da rugosidade da superfície de contato dos pinos de UHMWPE, após o processo de faceamento em torno.

Tabela 5.10 - Parâmetros de rugosidade da superfície dos pinos de POM.

\begin{tabular}{ccccc}
\hline Medidas & $\begin{array}{c}\text { Ra } \\
{[\mu \mathrm{m}]}\end{array}$ & $\begin{array}{c}\text { Rq } \\
{[\mu \mathrm{m}]}\end{array}$ & $\begin{array}{c}\text { RzDIN } \\
{[\mu \mathrm{m}]}\end{array}$ & $\begin{array}{c}\text { Sm } \\
{[\mu \mathrm{m}]}\end{array}$ \\
\hline 1 & 1,67 & 1,94 & 158 & 8,23 \\
2 & 1,60 & 1,90 & 216 & 7,83 \\
3 & 1,52 & 1,80 & 157 & 7,00 \\
4 & 1,68 & 1,99 & 166 & 8,37 \\
5 & 1,87 & 2,50 & 158 & 9,61 \\
6 & 1,90 & 2,40 & 169 & 10,11 \\
7 & 1,64 & 1,95 & 144 & 8,66 \\
\hline Média & $\mathbf{1 , 6 9}$ & $\mathbf{2 , 1}$ & $\mathbf{1 6 7}$ & $\mathbf{8 , 5}$ \\
D.Padrão & $\mathbf{0 , 1 4}$ & $\mathbf{0 , 3}$ & $\mathbf{2 3}$ & $\mathbf{1 , 1}$ \\
\hline
\end{tabular}

A Figura 5.11 apresenta um exemplo do perfil de rugosidade dos pinos, obtido durante a medição dos parâmetros de rugosidade. Na ordenada, estão apresentados os 
dados da variação de altura da ponta do apalpador durante o deslocamento horizontal da haste do rugosímetro, e na abscissa, o comprimento de medição ( $\mathrm{Lm}=4 \mathrm{~mm}$ ).

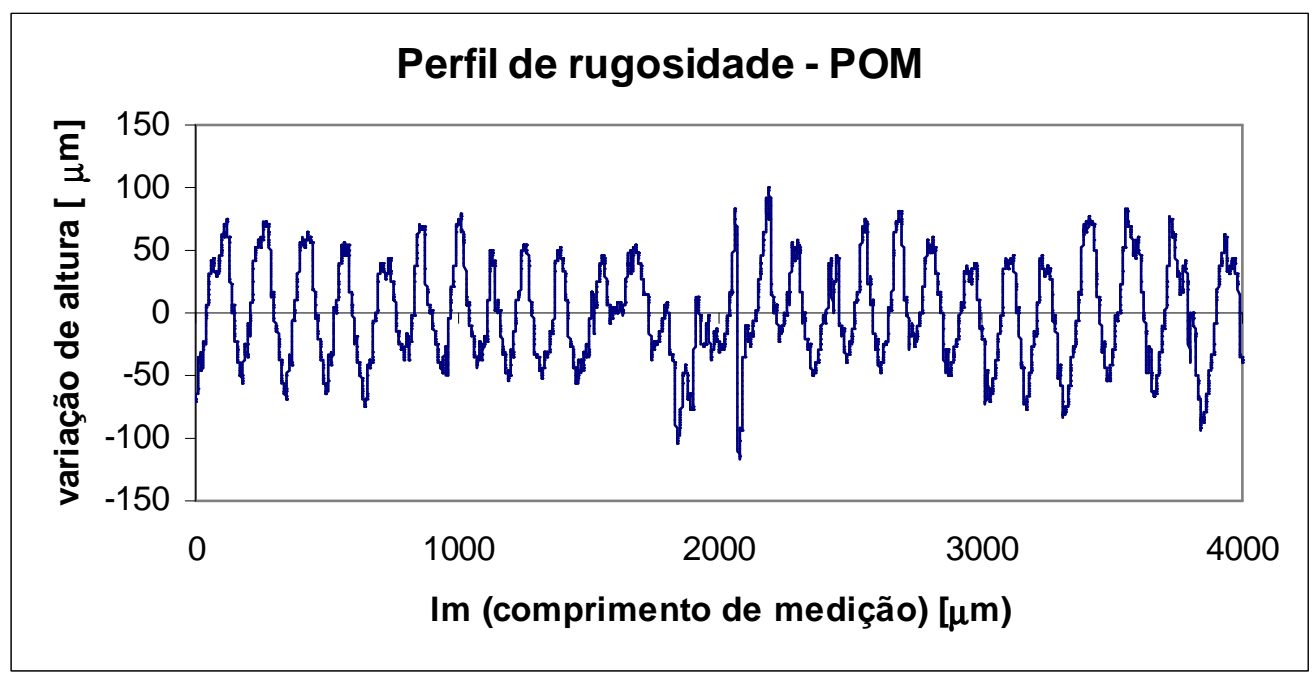

Figura 5.11 - Exemplo de um perfil de rugosidade do POM.

\subsubsection{Aço inoxidável}

Para a caracterização dos discos de aço inoxidável, foram determinadas:

- composição química;

- microestruturas;

- dureza Vickers;

- módulo de elasticidade e

- rugosidade.

\subsubsection{Composição química}

A Tabela 5.11 apresenta os resultados da análise da composição química do aço inoxidável. 
Tabela 5.11 - Composição química do aço inoxidável.

\begin{tabular}{cc}
\hline Elemento & Teor [\%] \\
\hline $\mathbf{C}$ & 0,024 \\
$\mathbf{M n}$ & 11,9 \\
$\mathbf{S i}$ & 0,5 \\
$\mathbf{S}$ & 0,01 \\
$\mathbf{C r}$ & 19,1 \\
$\mathbf{O}$ & $<0,001$ \\
$\mathbf{N}$ & 0,003 \\
\hline
\end{tabular}

Pode-se observar na Tabela acima, que o nível de nitrogênio na liga é bem inferior ao esperado (0,5\% Tabela 4.1), resultando desta forma, não num aço inoxidável austenítico nitrogenado e sim num aço inoxidável duplex (austenítico-ferrítico). No entanto, este fato não é significativo quanto a determinação da propriedades tribológicas dos materiais poliméricos quando deslizando sobre a superfície de um metal.

\subsubsection{Análise metalográfica}

Após o tratamento térmico de solubilização, observou-se que as microestruturas presentes no aço inoxidável são ferrita e austenita. A Figura 5.12 apresenta as microestruturas presentes no aço inoxidável, onde a fase clara é a ferrita e a mais escura a austenita.

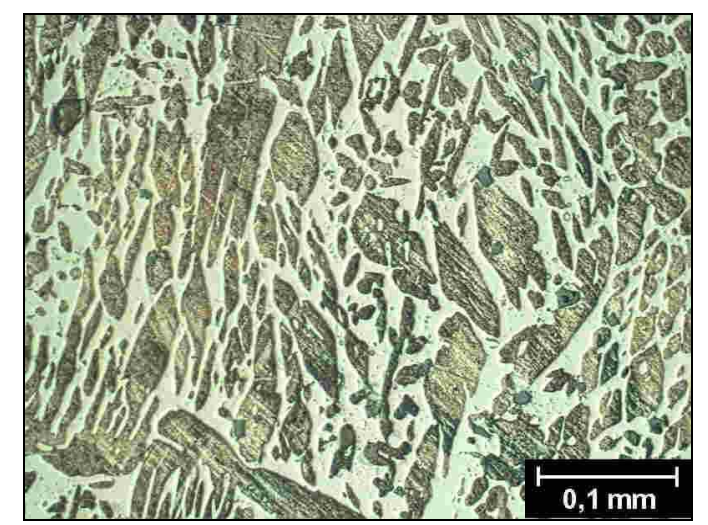

Figura 5.12 - Microestrutura do aço inoxidável mostrando as microestruturas presentes. Ataque Vilela. Ferrita (clara) e austenita (escura).

Com a utilização de um software de análise de imagem, obteve-se a proporção entre austenita e ferrita no aço inoxidável. A Tabela 5.12 apresenta os teores de ferrita em cinco campos diferentes de amostragem. Com isso, pode-se dizer que o aço inoxidável é composto de uma matriz de austenita (58\%) e grãos de ferrita (42\%). 
Tabela 5.12 - Teor de ferrita presente no aço inoxidável.

\begin{tabular}{cc}
\hline CAMPOS & Área de ferrita [\%] \\
\hline 1 & 40,16 \\
2 & 43,63 \\
3 & 39,16 \\
4 & 44,58 \\
5 & 44,92 \\
\hline Média & $\mathbf{4 2}$ \\
D.Padrão & $\mathbf{3}$ \\
\hline
\end{tabular}

\subsubsection{Dureza Vickers}

A Tabela 5.13 apresenta os resultados da medição da dureza Vickers com carga aplicada de $10 \mathrm{kgf}$.

Tabela 5.13 - Dureza Vickers do aço inoxidável.

\begin{tabular}{ccc}
\hline Medidas & $\begin{array}{c}\text { Diagonal } \\
{[\mathrm{mm}]}\end{array}$ & $\begin{array}{c}\text { Dureza } \\
{\left[\mathrm{kgf} / \mathrm{mm}^{2}\right]}\end{array}$ \\
\hline 1 & 0,31 & 96,5 \\
2 & 0,29 & 110,2 \\
3 & 0,32 & 90,5 \\
4 & 0,30 & 103,0 \\
5 & 0,34 & 80,2 \\
6 & 0,30 & 103,0 \\
7 & 0,31 & 96,5 \\
\hline Média & $\mathbf{0 . 3 1}$ & $\mathbf{9 7}$ \\
D. Padrão & $\mathbf{0 . 0 2}$ & $\mathbf{1 0}$ \\
\hline
\end{tabular}

\subsubsection{Módulo de elasticidade}

Para a determinação dos valores de módulo de elasticidade das fases presentes no aço, foi utilizada a carga normal de $1.000 \mathrm{gf}$, com incremento de $10 \mathrm{gf} / \mathrm{s}$ no carregamento e descarregamento, no procedimento de medição de microdureza dinâmica. O coeficiente de Poisson $(v)$ estimado para o material foi de $0,33^{114}$.

A Tabela 5.14 apresenta os resultados da determinação do módulo elasticidade de cada fase, ferrítica e austenítica, do aço inoxidável. 
Tabela 5.14 -Módulo de elasticidade da fase ferrítica.

\begin{tabular}{ccccc} 
& \multicolumn{2}{c}{ Austenita } & \multicolumn{2}{c}{ Ferrita } \\
\hline Medidas & $\begin{array}{c}\mathrm{E} /\left(1-v^{2}\right) \\
{[\mathrm{GPa}]}\end{array}$ & $\begin{array}{c}\mathrm{E} \\
{[\mathrm{GPa}]}\end{array}$ & $\begin{array}{c}\mathrm{E} /\left(1-v^{2}\right) \\
{[\mathrm{GPa}]}\end{array}$ & $\begin{array}{c}\mathrm{E} \\
{[\mathrm{GPa}]}\end{array}$ \\
\hline 1 & 179,40 & 160 & 198,61 & 177 \\
2 & 166,53 & 148 & 203,38 & 181 \\
3 & 185,92 & 166 & 198,46 & 177 \\
4 & 179,99 & 160 & 211,35 & 188 \\
5 & 185,86 & 166 & 202,71 & 181 \\
6 & 179,62 & 160 & 188,78 & 168 \\
7 & 186,26 & 166 & 202,02 & 180 \\
\hline Média & $\mathbf{1 8 1}$ & $\mathbf{1 6 1}$ & $\mathbf{2 0 1}$ & $\mathbf{1 7 9}$ \\
D. Padrão & $\mathbf{7}$ & $\mathbf{6}$ & $\mathbf{7}$ & $\mathbf{6}$ \\
\hline
\end{tabular}

\subsubsection{Rugosidade}

As Tabelas 5.15 e 5.16 apresentam os resultados da rugosidade dos discos de aço inoxidável nos diversos acabamentos superficiais, obtidos em cada faixa de rugosidade prevista.

Tabela 5.15 - Aço Inoxidável - Rugosidade Ra desejada $0,05<$ Ra $<0,2 \mu \mathrm{m}$.

\begin{tabular}{cccccc}
\hline Posição & $\begin{array}{c}\text { Ra } \\
{[\mu \mathrm{m}]}\end{array}$ & $\begin{array}{c}\text { Rq } \\
{[\mu \mathrm{m}]}\end{array}$ & $\begin{array}{c}\text { Ry } \\
{[\mu \mathrm{m}]}\end{array}$ & $\begin{array}{c}\text { RzDIN } \\
{[\mu \mathrm{m}]}\end{array}$ & $\begin{array}{c}\text { Sm } \\
{[\mu \mathrm{m}]}\end{array}$ \\
\hline & 0,11 & 0,18 & 1,17 & 0,73 & 265 \\
$\mathbf{0}^{\circ}$ & 0,13 & 0,17 & 1,07 & 0,52 & 228 \\
& 0,12 & 0,15 & 1,15 & 0,40 & 151 \\
& 0,12 & 0,17 & 1,39 & 0,77 & 253 \\
& 0,15 & 0,20 & 1,37 & 0,86 & 288 \\
\hline & 0,14 & 0,20 & 1,85 & 1,30 & 80 \\
$\mathbf{1 2 0}^{\circ}$ & 0,12 & 0,19 & 1,59 & 0,38 & 75 \\
& 0,14 & 0,21 & 1,65 & 1,13 & 101 \\
& 0,17 & 0,39 & 2,73 & 0,88 & 73 \\
& 0,13 & 0,24 & 1,71 & 1,05 & 138 \\
\hline & 0,15 & 0,22 & 1,73 & 1,41 & 72 \\
$\mathbf{2 4 0}^{\circ}$ & 0,14 & 0,21 & 2,00 & 1,42 & 86 \\
& 0,13 & 0,20 & 1,58 & 1,49 & 101 \\
& 0,14 & 0,20 & 1,90 & 1,34 & 112 \\
& 0,16 & 0,25 & 2,05 & 1,53 & 100 \\
\hline Média & $\mathbf{0 , 1 4}$ & $\mathbf{0 , 2 1}$ & $\mathbf{1 , 6}$ & $\mathbf{1 , 1}$ & $\mathbf{1 4 2}$ \\
D. Padrão & $\mathbf{0 , 0 1}$ & $\mathbf{0 , 0 5}$ & $\mathbf{0 , 6}$ & $\mathbf{0 , 4}$ & $\mathbf{7 7}$ \\
\hline
\end{tabular}


Tabela 5.16 - Aço Inoxidável - Rugosidade Ra desejada $0,3<\operatorname{Ra}<0,6 \mu \mathrm{m}$.

\begin{tabular}{cccccc}
\hline Posição & $\begin{array}{c}\text { Ra } \\
{[\mu \mathrm{m}]}\end{array}$ & $\begin{array}{c}\text { Rq } \\
{[\mu \mathrm{m}]}\end{array}$ & $\begin{array}{c}\text { Ry } \\
{[\mu \mathrm{m}]}\end{array}$ & $\begin{array}{c}\text { RzDIN } \\
{[\mu \mathrm{m}]}\end{array}$ & $\begin{array}{c}\text { Sm } \\
{[\mu \mathrm{m}]}\end{array}$ \\
\hline \multirow{3}{*}{$\mathbf{0}^{\circ}$} & 0,38 & 0,48 & 3,8 & 3,0 & 37 \\
& 0,40 & 0,52 & 3,7 & 3,2 & 31 \\
& 0,36 & 0,48 & 4,1 & 3,1 & 36 \\
& 0,46 & 0,66 & 6,9 & 4,2 & 33 \\
& 0,34 & 0,44 & 3,3 & 2,7 & 32 \\
\hline $\mathbf{1 2 0}^{\circ}$ & 0,34 & 0,42 & 3,3 & 2,7 & 35 \\
& 0,46 & 0,62 & 4,8 & 3,4 & 34 \\
& 0,30 & 0,38 & 3,3 & 2,4 & 31 \\
& 0,42 & 0,54 & 3,5 & 3,3 & 32 \\
& 0,32 & 0,44 & 3,2 & 2,5 & 49 \\
\hline $\mathbf{2 4 0}^{\circ}$ & 0,46 & 0,58 & 4,4 & 3,7 & 44 \\
& 0,42 & 0,60 & 7,6 & 4,3 & 33 \\
& 0,34 & 0,44 & 3,3 & 2,8 & 35 \\
& 0,50 & 0,66 & 4,4 & 4,0 & 29 \\
Média & 0,52 & 0,68 & 7,4 & 4,1 & 33 \\
\hline D. Padrão & $\mathbf{0 , 4 0}$ & $\mathbf{0 , 5 3}$ & $\mathbf{4 , 5}$ & $\mathbf{3 , 3}$ & $\mathbf{3 5}$ \\
\hline
\end{tabular}

\subsubsection{Alumina}

Para a caracterização dos discos de alumina, foram determinadas:

- Composição química (Raios-x);

- densidade absoluta e

- rugosidade.

\subsubsection{Difração de Raios-x}

A Figura 5.13 apresenta o resultado de um difratograma de Raios-x da amostra de alumina. 


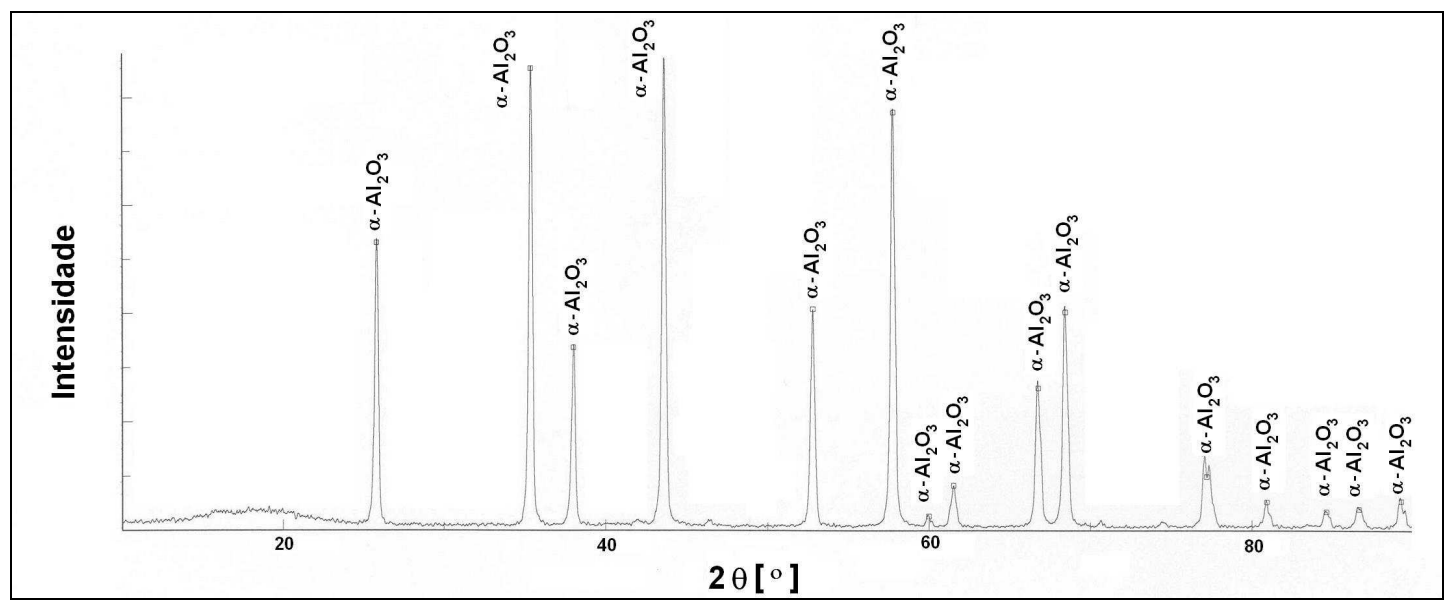

Figura 5.13 - Difratograma de raios-x da alumina.

O difratograma da Figura 5.13 apresenta raias (picos) que permitem identificar a fase $\alpha-\mathrm{Al}_{2} \mathrm{O}_{3}$ na amostra de material cerâmico analisado. Apesar da presença de alguns picos não identificados, pode-se considerar o material analisado como sendo alumina pura.

\subsubsection{Densidade}

Com a compactação dos discos em matriz com 64 mm de diâmetro, a densidade a verde atingiu $55,3 \pm 0,5 \%$ da densidade teórica da alumina $\left(3.980 \mathrm{~kg} / \mathrm{m}^{3}\right)$, passando para 58,8 $\pm 1,3 \%$ após a prensagem hidrostática.

A Tabela 5.17 apresenta os resultados da determinação da densidade da alumina após sinterização e o nível de porosidade.

Tabela 5.17 - Densidade dos discos de alumina e nível de porosidade.

\begin{tabular}{cccccc}
\hline & $\begin{array}{c}\text { Massa úmida } \\
{[\mathrm{g}]}\end{array}$ & $\begin{array}{c}\text { Massa imersa } \\
{[\mathrm{g}]}\end{array}$ & $\begin{array}{c}\text { Massa Seca } \\
{[\mathrm{g}]}\end{array}$ & $\begin{array}{c}\text { Densidade } \\
{\left[\mathrm{g} / \mathrm{cm}^{3}\right]}\end{array}$ & $\begin{array}{c}\text { Porosidade } \\
{[\%]}\end{array}$ \\
\hline 1 & 7,8636 & 5,4340 & 7,2804 & 2,9912 & 0,2484 \\
2 & 7,8626 & 5,4357 & 7,2807 & 2,9946 & 0,2476 \\
3 & 7,8613 & 5,4343 & 7,2808 & 2,9945 & 0,2476 \\
4 & 7,8600 & 5,4346 & 7,2809 & 2,9966 & 0,2471 \\
5 & 7,8614 & 5,4355 & 7,2809 & 2,9959 & 0,2473 \\
\hline Média & $\mathbf{7 , 8 6 1 8}$ & $\mathbf{5 , 4 3 4 8}$ & $\mathbf{7 , 2 8 0 7}$ & $\mathbf{2 , 9 9 5}$ & $\mathbf{0 , 2 4 7 6}$ \\
D. padrão & $\mathbf{0 , 0 0 1 4}$ & $\mathbf{0 , 0 0 0 7}$ & $\mathbf{0 , 0 0 0 2}$ & $\mathbf{0 , 0 0 2}$ & $\mathbf{0 , 0 0 0 5}$ \\
\hline
\end{tabular}




\subsubsection{Rugosidade}

As Tabelas 5.18 e 5.19 apresentam os resultados da rugosidade dos discos de aço inoxidável obtidos em cada faixa de rugosidade prevista.

Tabela 5.18 - Alumina - Rugosidade desejada $0,3<$ Ra $<0,6 \mu \mathrm{m}$.

\begin{tabular}{|c|c|c|c|c|c|}
\hline Posição & $\begin{array}{c}\mathbf{R a} \\
{[\mu \mathrm{m}]}\end{array}$ & $\begin{array}{c}\mathbf{R q} \\
{[\mu \mathrm{m}]}\end{array}$ & $\begin{array}{c}\mathbf{R y} \\
{[\mu \mathrm{m}]}\end{array}$ & $\begin{array}{c}\text { RzDIN } \\
{[\mu \mathrm{m}]}\end{array}$ & $\begin{array}{c}\mathbf{S m} \\
{[\mu \mathrm{m}]}\end{array}$ \\
\hline \multirow{5}{*}{$\mathbf{0}^{\circ}$} & 0,55 & 0,76 & 5,76 & 3,98 & 33 \\
\hline & 0,48 & 0,64 & 4,77 & 3,60 & 28 \\
\hline & 0,43 & 0,56 & 3,56 & 3,17 & 27 \\
\hline & 0,41 & 0,53 & 4,10 & 3,05 & 25 \\
\hline & 0,42 & 0,54 & 3,50 & 3,17 & 30 \\
\hline \multirow{5}{*}{$120^{\circ}$} & 0,35 & 0,44 & 2,96 & 2,42 & 28 \\
\hline & 0,36 & 0,48 & 3,75 & 2,83 & 30 \\
\hline & 0,36 & 0,46 & 3,42 & 2,64 & 27 \\
\hline & 0,42 & 0,61 & 7,19 & 3,77 & 28 \\
\hline & 0,38 & 0,51 & 4,37 & 2,97 & 34 \\
\hline \multirow{5}{*}{$240^{\circ}$} & 0,37 & 0,47 & 2,87 & 2,58 & 59 \\
\hline & 0,39 & 0,51 & 3,93 & 2,75 & 56 \\
\hline & 0,34 & 0,46 & 3,09 & 2,68 & 46 \\
\hline & 0,30 & 0,39 & 2,37 & 2,12 & 61 \\
\hline & 0,31 & 0,39 & 2,64 & 2,10 & 30 \\
\hline Média & $\mathbf{0 , 3 9}$ & 0,52 & 3,9 & 2,9 & 36 \\
\hline D. Padrão & 0,06 & $\mathbf{0 , 1 0}$ & 1,3 & 0,6 & 13 \\
\hline
\end{tabular}

Tabela 5.19 - Alumina - Rugosidade desejada 1,5 $<$ Ra $<2,0 \mu \mathrm{m}$.

\begin{tabular}{cccccc}
\hline Posição & $\begin{array}{c}\text { Ra } \\
{[\mu \mathrm{m}]}\end{array}$ & $\begin{array}{c}\text { Rq } \\
{[\mu \mathrm{m}]}\end{array}$ & $\begin{array}{c}\text { Ry } \\
{[\mu \mathrm{m}]}\end{array}$ & $\begin{array}{c}\text { RzDIN } \\
{[\mu \mathrm{m}]}\end{array}$ & $\begin{array}{c}\text { Sm } \\
{[\mu \mathrm{m}]}\end{array}$ \\
\hline \multirow{3}{*}{$\mathbf{0}^{\circ}$} & 0,93 & 1,37 & 8,93 & 6,98 & 56 \\
& 2,50 & 3,24 & 19,36 & 15,50 & 89 \\
& 1,24 & 1,91 & 14,02 & 8,15 & 66 \\
& 1,31 & 1,96 & 12,11 & 8,88 & 75 \\
& 1,53 & 2,40 & 19,59 & 11,15 & 66 \\
\hline $\mathbf{1 2 0}^{\circ}$ & 2,56 & 3,12 & 16,51 & 12,19 & 127 \\
& 2,39 & 2,97 & 15,48 & 12,64 & 154 \\
& 2,15 & 2,71 & 17,25 & 12,06 & 105 \\
& 2,16 & 2,66 & 14,45 & 11,70 & 127 \\
$\mathbf{2 4 0}^{\circ}$ & 2,28 & 2,78 & 13,57 & 10,94 & 140 \\
\hline & 2,33 & 2,97 & 14,90 & 13,88 & 104 \\
& 1,53 & 1,94 & 10,89 & 7,86 & 96 \\
& 1,52 & 1,92 & 9,78 & 8,23 & 91 \\
Média & 1,33 & 1,76 & 13,06 & 9,32 & 93 \\
D. Padrão $^{*}$ & 1,47 & 1,86 & 10,37 & 8,38 & 112 \\
\hline
\end{tabular}




\subsection{Trabalho de adesão $-W_{a b}$}

Sendo o trabalho de adesão $\left(\mathrm{W}_{\mathrm{ab}}\right)$ uma característica que depende das superfícies do corpo e do contra-corpo, optou-se pela sua apresentação em um item separado. A Tabela 5.20 apresenta os ângulos de contato, medidos com água e com diiodometano, além das componentes polar e dispersiva da energia de superfície.

Tabela 5.20 - Ângulos de contato e energia de superfície dos materiais estudados.

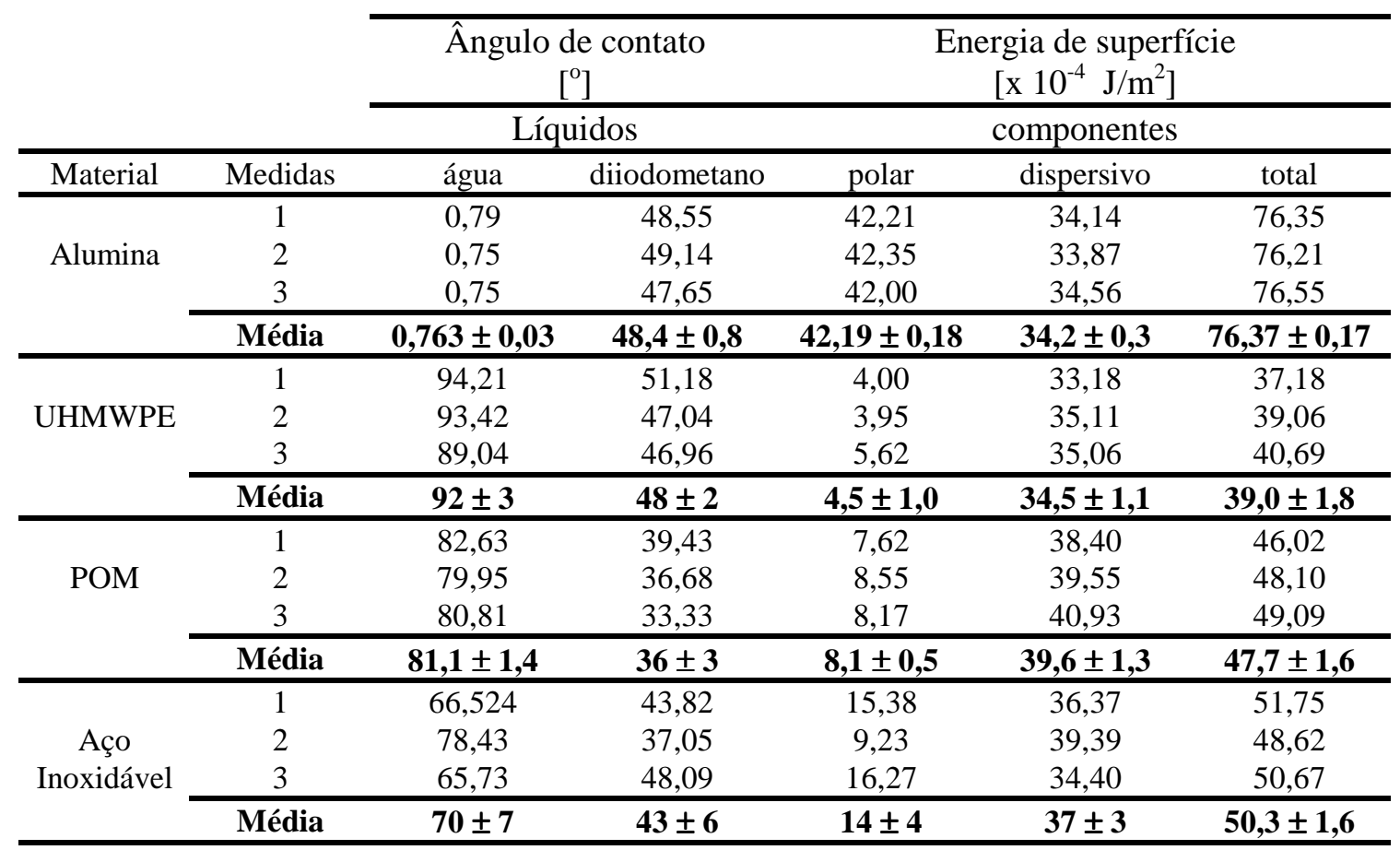

A Tabela 5.21 apresenta os valores do trabalho de adesão dos 4 pares de materiais estudados, calculados a partir dos dados da Tabela 5.20, utilizando a Equação Média Harmônica proposta por WU ${ }^{115}$.

Tabela 5.21 - Trabalho de adesão médio $\left(W_{a b}\right)$ e coeficiente de variação dos pares de materiais estudados.

\begin{tabular}{cccc}
\hline corpo & contra-corpo & $\begin{array}{c}\mathbf{W}_{\mathbf{a b}} \\
{\left[\mathbf{x} \mathbf{1 0}^{-4} \mathbf{J} / \mathbf{m}^{2}\right]}\end{array}$ & $\mathbf{C V ~ [ \% ] ~}$ \\
& & $101 \pm 2$ & 2,2 \\
\multirow{2}{*}{ POM } & Alumina & $96,1 \pm 0,9$ & 0,9 \\
& Aço Inoxidável & $95 \pm 3$ & 3,3 \\
\hline \multirow{3}{*}{ UHMWPE } & POM & $85 \pm 4$ & 4,7 \\
& Alumina & $85 \pm 2$ & 2,5 \\
& Aço Inoxidável & $78 \pm 3$ & 4,5 \\
\hline
\end{tabular}


Na Tabela 5.21, observa-se para o POM que o trabalho de adesão é maior para o par POM-Alumina do que para o par POM-Aço inoxidável, sendo este valor estatisticamente igual a um hipotético par POM-POM. Esses dados indicam uma maior tendência à deposição (transferência) de material do pino de POM sobre a alumina em relação ao aço inoxidável.

Na mesma Tabela, observa-se que os pares UHMWPE-Alumina e UHMWPEAço inoxidável apresentam o mesmo valor de trabalho de adesão, ou seja, a tendência à deposição (transferência) do UHMWPE é semelhante para os dois contra-corpos.

Por fim, verifica-se que o valor de $\mathrm{W}_{\mathrm{ab}}$ do $\mathrm{POM}$ em relação aos dois substratos é maior do que o UHMWPE em relação aos mesmos. Tal fato ocorre devido à cadeia polimérica do POM (- $\left.\mathrm{CH}_{2}-\mathrm{O}-\right)$ ser mais polar e não tão linear quanto ao UHMWPE $\left(-\mathrm{CH}_{2}-\mathrm{CH}_{2}-\right)$. Isto indica uma maior tendência à deposição do POM em relação ao UHMWPE, para cada um dos contra-corpos estudados. Em decorrência disto, se espera que a componente de adesão, integrante do processo de desgaste ${ }^{60}$, seja maior para $o$ POM do que para o UHMWPE, ainda mais pelo fato do $\mathrm{W}_{\mathrm{ab}}$ do hipotético par POM$P O M$ ser maior que do hipotético par UHMWPE-UHMWPE.

\subsection{Medidas de temperatura}

Com o objetivo de se determinar a temperatura próxima à superfície de contato polímero-contra-corpo nas condições PV mais severas, foram realizados ensaios de desgaste com um termopar posicionado a $1 \mathrm{~mm}$ da superfície de contato do pino.

Optou-se por se realizar ensaios de desgaste, com medição de temperatura, cuja condição PV fosse superior a $1.020 \mathrm{~kW} / \mathrm{m}^{2}$, pelo fato de que nos ensaios realizados com condições PV menos severas, o calor gerado na interface dos materiais não provoca um aumento significativo na temperatura, não excedendo $30{ }^{\circ} \mathrm{C}$, conforme experimentos preliminares.

As Tabelas 5.22 e 5.23 apresentam os valores de temperatura medida pelo termopar, após o período de running-in (assentamento das superfícies), em diversas condições de carga, velocidade e acabamento superficial. 
Tabela 5.22 - Temperatura $\left[{ }^{\circ} \mathrm{C}\right]$ próxima à superfície de contato do UHMWPE.

\begin{tabular}{ccccccc}
\hline Carga & $\begin{array}{c}\text { Vel. } \\
{[\mathbf{N}]}\end{array}$ & $\begin{array}{c}\text { Condição PV } \\
{[\mathbf{m} / \mathbf{s}]}\end{array}$ & {$\left[\mathbf{k W} / \mathbf{m}^{2}\right]$} & \multicolumn{4}{c}{ Contra-corpo } \\
\cline { 5 - 7 } & 0,1 & 1.020 & $42,8 \pm 0,6$ & $42,2 \pm 0,5$ & $39,8 \pm 0,6$ & $38,7 \pm 1,1$ \\
200 & 2.550 & - & - & $77,5 \pm 0,6$ & $66,3 \pm 0,6$ \\
50 & 1,0 & 2.550 & $54,8 \pm 0,6$ & $53 \pm 2$ & $78,7 \pm 0,7$ & $74,7 \pm 1,1$ \\
100 & 0,5 & & $\mathbf{I n o x}(\mathbf{R 3})$ & $\mathbf{A l}_{\mathbf{2}} \mathbf{O}_{\mathbf{3}} \mathbf{( R 3 )}$ & $\mathbf{A l}_{\mathbf{2}} \mathbf{O}_{\mathbf{3}}(\mathbf{R 4})$ \\
100 & 1,0 & 5.100 & $65,9 \pm 0,7$ & $80,7 \pm 0,7$ & $106,4 \pm 0,7$ & $99 \pm 2$ \\
200 & 0,5 & 5.100 & $71,0 \pm 0,8$ & $81,7 \pm 0,6$ & - & - \\
\hline
\end{tabular}

Tabela 5.23 - Temperatura $\left[{ }^{\circ} \mathrm{C}\right]$ próxima à superfície de contato do $\mathrm{POM}$.

\begin{tabular}{ccccccc}
\hline Carga & $\begin{array}{c}\text { Vel. } \\
{[\mathbf{N}]}\end{array}$ & $\begin{array}{c}\text { Condição PV } \\
{[\mathbf{m} / \mathbf{s}]}\end{array}$ & {$\left[\mathbf{k W / \mathbf { m } ^ { 2 } ]}\right.$} & \multicolumn{4}{c}{ Contra-corpo } \\
\cline { 5 - 7 } & 0,1 & 1.020 & $52,2 \pm 0,9$ & $54,4 \pm 1,0$ & $66,2 \pm 1,0$ & $58,0 \pm 1,2$ \\
500 & 1,0 & 2.550 & - & - & $73,9 \pm 0,4$ & $109,2 \pm 0,7$ \\
100 & 0,5 & 2.550 & $72,4 \pm 1,2$ & $56,1 \pm 1,1$ & $119,9 \pm 1,3$ & $114,6 \pm 1,5$ \\
100 & 1,0 & 5.100 & $104,5 \pm 0,6$ & $81,6 \pm 1,4$ & $99,6 \pm 1,9$ & $123 \pm 2$ \\
200 & 0,5 & 5.100 & $112,2 \pm 1,3$ & $83,0 \pm 0,5$ & - & - \\
\hline
\end{tabular}

Observa-se nas Tabelas 5.22 e 5.23 que, nos ensaios com a mesma condição PV (2.550 e $5.100 \mathrm{~kW} / \mathrm{m}^{2}$ ), a temperatura sempre foi mais elevada no ensaio com maior carga aplicada. Este fato sugere que o aumento da temperatura possui mais relação com a carga aplicada do que com a velocidade de deslizamento (vide Anexo A). Nota-se também que a elevação de PV levou, como era de se esperar, à elevação da temperatura, exceto no caso do UHMWPE na condição PV $=5.100 \mathrm{~kW} / \mathrm{m}^{2}$ e velocidade de $1,0 \mathrm{~m} / \mathrm{s}$. Este resultado excepcional não pode ser explicado.

Para as análises de taxa de desgaste, os valores de temperatura medidos serão admitidos como os valores médios de temperatura na interface dos materiais. Essa hipótese se justifica, pois:

- correções de temperatura, usando o método de ARCHARD ${ }^{102}$, realizados anteriormente com polímero semelhante (HDPE), indicam que a diferença de temperatura não ultrapassa $5{ }^{\circ} \mathrm{C}$, uma vez que a condutividade térmica e o calor específico são muito semelhantes;

- com o decorrer dos ensaios de desgaste, a superfície de contato do pino se aproxima da ponta do termopar, o que tornaria as correções ainda menores; 
- em algumas condições PV mais elevadas e, portanto, com maiores elevações de temperatura, o ensaio foi interrompido devido ao desgaste do pino levar à ocorrência de contato do termopar com o contra-corpo, indicando assim que as medidas de temperatura nos instantes finais destes ensaios eram feitas na interface.

A determinação das temperaturas muito próximas à superfície de contato do pino permite uma análise das propriedades mecânicas e físico-químicas dos polímeros e, conseqüentemente, da alteração nas respostas tribológicas.

Com as massas moleculares, obtidas das Tabelas 5.1 e 5.6, e as temperaturas atingidas na região de contato, pode-se delimitar aproximadamente a região de trabalho do POM e do UHMWPE durante os ensaios. A Figura 5.14 mostra que o estado físico que os materiais poliméricos apresentam durante a realização dos ensaios é o estado de um plástico rígido com características de deformação viscoelástica.

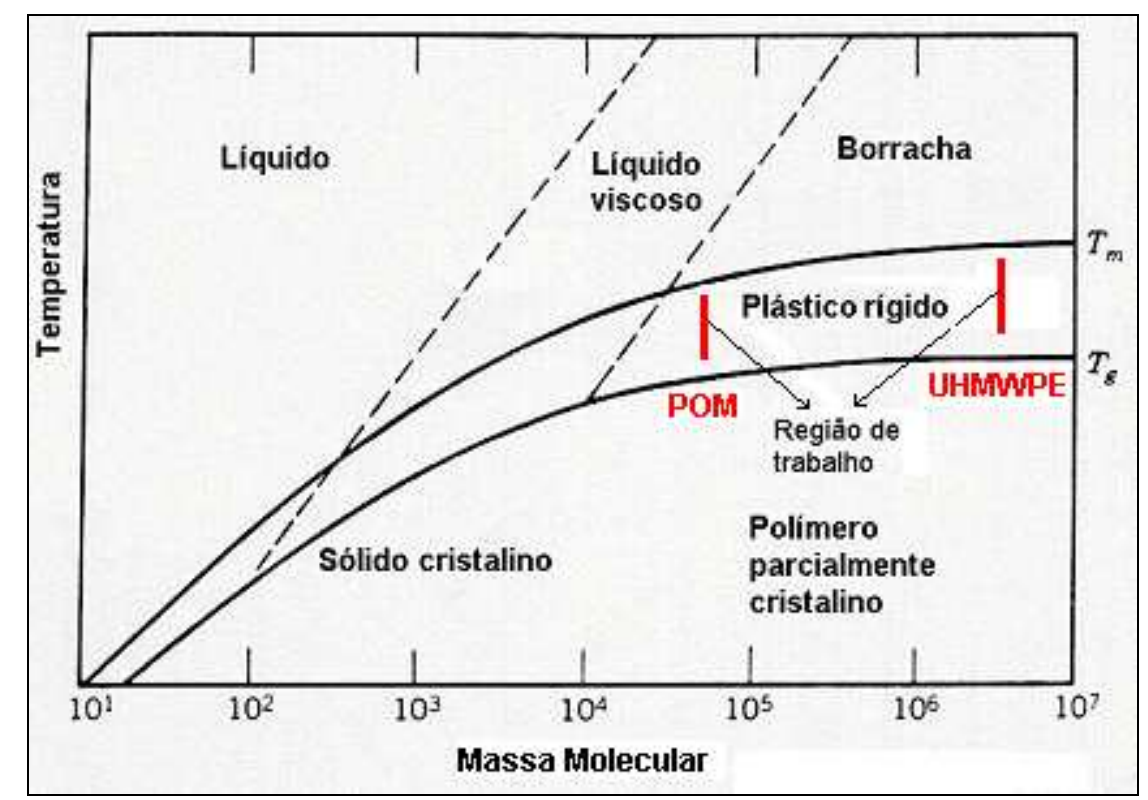

Figura 5.14 - Dependência dos estados físico-mecânicos dos polímeros de acordo com Tm e Tg em função da massa molecular. ${ }^{116}$

A Figura 5.15 apresenta o módulo de armazenamento (E') e o módulo de perda (E”), obtidos por DMTA, em faixas de temperaturas semelhantes às medidas. Nas Figuras, mostram-se os resultados de dois ensaios para cada material. 


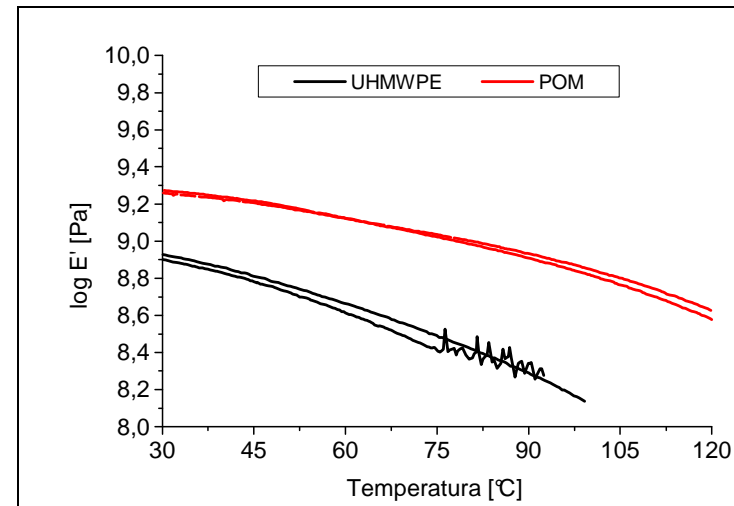

(a)

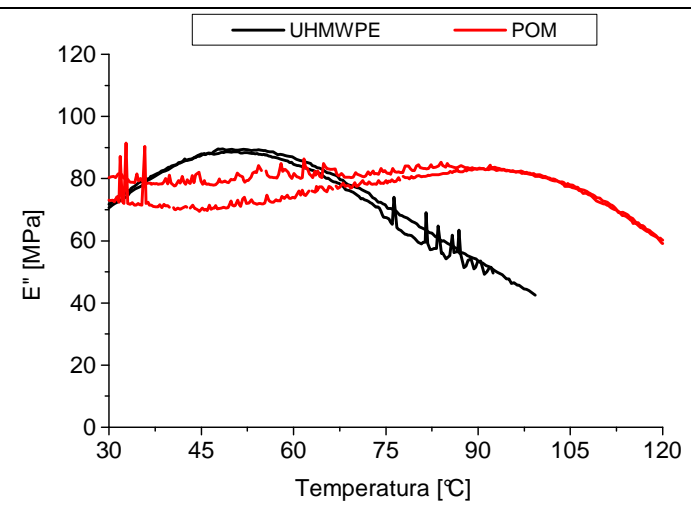

(b)

Figura 5.15 - Módulo de armazenamento - E' (a) e de perda - E”' (b) dos polímeros na faixa de temperaturas atingidas durante $o$ ensaio.

As curvas da Figura 5.15 (a) indicam que o aumento da temperatura na região próxima à superfície de contato reduz o módulo de armazenamento dos dois polímeros e que a repetitibilidade dos ensaios é quase completa. Os picos das curvas do POM são ruídos do sistema de aquisição de dados do equipamento e ocorreram em apenas uma das repetições do ensaio.

A variação absoluta de E' para o POM foi muito maior (1.200 MPa) do que para o UHMWPE (500 MPa), mas a variação percentual desta propriedade ficou em torno de $70 \%$ para ambos os polímeros. Com esta queda de E' nos polímeros, maiores serão as deformações elásticas e elastoplásticas na superfície do pino e, conseqüentemente, maiores serão os danos à superfície.

Nota-se na Figura 5.15 (b) que o módulo de perda do UHMWPE é maior que o E” do POM para temperaturas até próximas a $70{ }^{\circ} \mathrm{C}$. Para o UHMWPE, a variação do módulo de perda, dentro da faixa de temperatura dos ensaios de desgaste, ficou entre 40 e $90 \mathrm{MPa}$, variação esta que pode ser considerada significativa, diante da pequena dispersão dos valores de E" nesta faixa de temperatura. Para o POM, a variação de E" foi menor e com maiores dispersões para as temperaturas mais baixas. Para ambos os materiais, o módulo de perda é cerca de 20 vezes menor do que o módulo de armazenamento. A eventual influência dos módulos de perda e de armazenamento nas propriedades tribológicas dos polímeros será analisada adiante, no entanto sem o aprofundamento que o tema exige.

Além das propriedades E' e E”, as dimensões dos corpos-de-prova são alteradas com a variação da temperatura. Como a variação da altura do pino foi o meio de se 
medir o desgaste dos pinos, será feito a seguir uma análise do efeito da fluência nos resultados de desgaste.

\subsection{Ensaios de fluência}

As Figuras 5.16 e 5.17 apresentam as curvas de fluência, obtidas no equipamento de desgaste, para o UHMWPE e o POM submetidos a cargas de 50, 100 e $200 \mathrm{~N}$ em temperatura ambiente $\left(\sim 25^{\circ} \mathrm{C}\right)$. Como a área da seção transversal do pino é de $19,6 \times 10^{-6}\left[\mathrm{~m}^{2}\right]$, os pinos foram submetidos a tensões compressivas de 2,5; $5,1 \mathrm{e}$ 10,2 MPa.

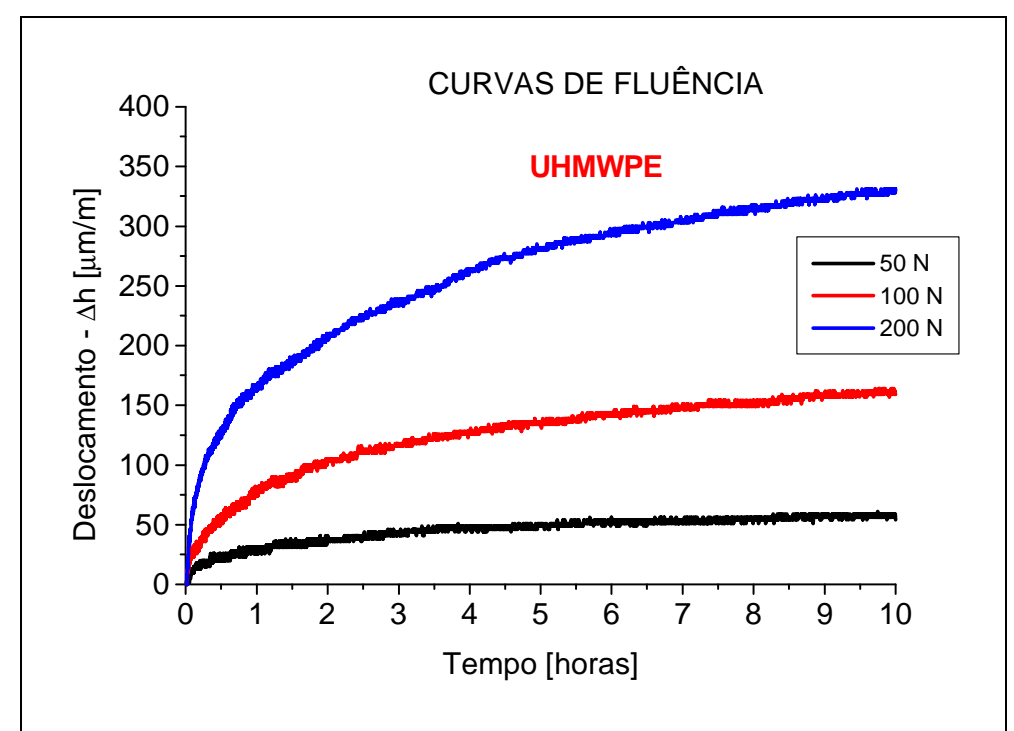

Figura 5.16 - Curvas de fluência do UHMWPE sob carga constante de 50, 100 e $200 N$. 


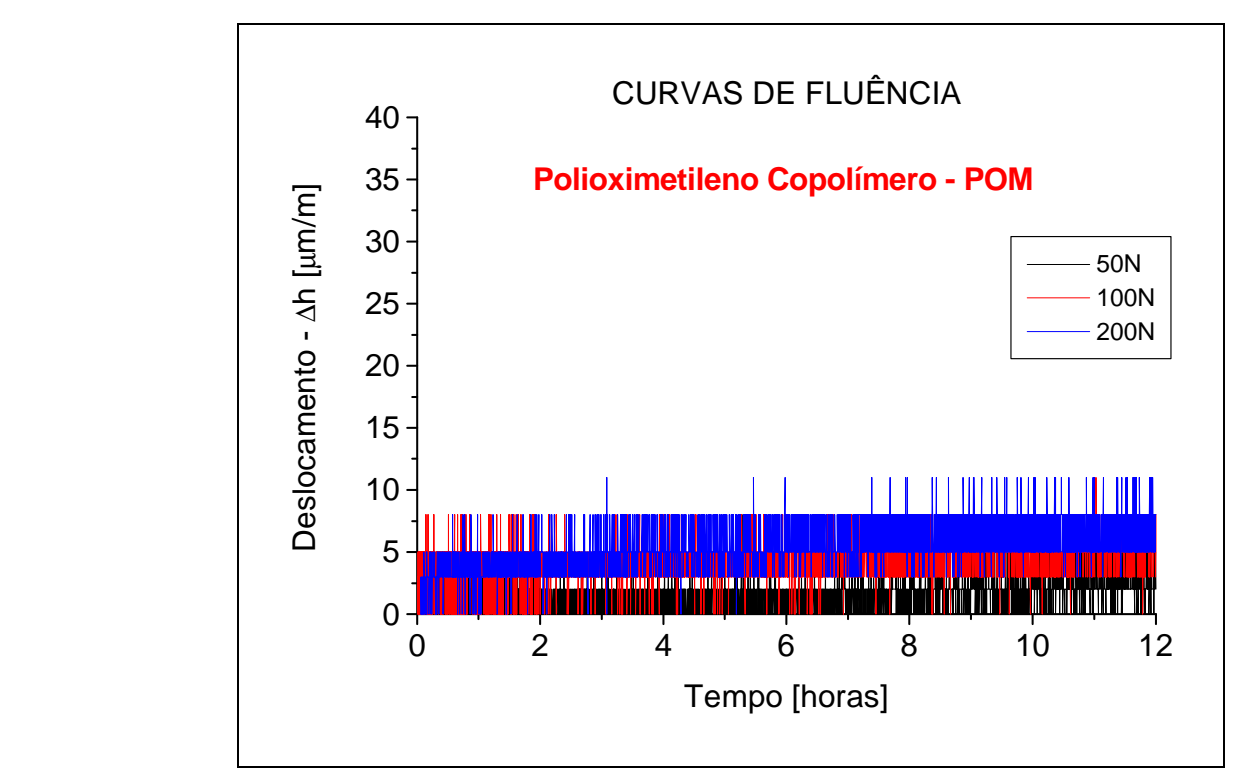

Figura 5.17 - Curvas de fluência do POM sob carga constante de 50, 100 e 200N.

Na Figura 5.16, observa-se que a elevação da carga levou a maiores deslocamentos devido à fluência. Na Figura 5.17, mostram-se os dados brutos de saída do equipamento, permitindo constatar que os deslocamentos do pino de POM são muito menores do que para o UHMWPE e que estes valores estão na faixa de incertezas de medição do sensor de posição linear (LVDT) para os três níveis de carga.

A análise das tendências desses dados mostram que, para os dois polímeros, as deformações devido à fluência se elevam com o tempo e são maiores para cargas maiores.

$\mathrm{O}$ item anterior mostrou claramente a importância da temperatura nas propriedades mecânicas dos polímeros. Logicamente, o mesmo raciocínio se aplica à resistência às deformações por fluência. Para se avaliar quantitativamente o efeito da fluência nas temperaturas dos ensaios, buscou-se dados da literatura para os materiais deste estudo.

A Tabela 5.17 apresenta os resultados de ensaio de fluência por compressão do UHMWPE (UTEC), realizados pela BRASKEM ${ }^{112}$. 
Tabela 5.24 - Deformação específica (\%) por compressão do UHMWPE (UTEC) em função da carga aplicada e da temperatura. ${ }^{112}$

\begin{tabular}{|c|c|c|c|c|c|}
\hline \multirow[b]{2}{*}{$\begin{array}{c}\text { Temperatura } \\
{\left[{ }^{\circ} \mathbf{C}\right]}\end{array}$} & \multirow[b]{2}{*}{$\begin{array}{l}\text { Tensão } \\
\text { [MPa] }\end{array}$} & \multicolumn{4}{|c|}{ Tempo [s] } \\
\hline & & $\begin{array}{c}60 \\
(1 \mathrm{~min})\end{array}$ & $\begin{array}{c}3.600 \\
\text { (1 hora) }\end{array}$ & $\begin{array}{l}86.400 \\
\text { (1 dia) }\end{array}$ & $\begin{array}{r}5.184 .000 \\
(60 \text { dias })\end{array}$ \\
\hline \multirow{5}{*}{20} & 2 & 1,0 & 1,3 & 1,7 & 2,0 \\
\hline & 4 & 2,1 & 2,8 & 3,2 & 4,1 \\
\hline & 6 & 3,2 & 4,2 & 5,1 & 6,2 \\
\hline & 8 & 4,4 & 5,8 & 6,9 & 8,1 \\
\hline & 10 & 5,5 & 7,2 & 8,5 & 10,5 \\
\hline \multirow{5}{*}{50} & 2 & 2,5 & 3,0 & 3,5 & 4,0 \\
\hline & 4 & 5,0 & 5,5 & 6,0 & 8,0 \\
\hline & 6 & 7,5 & 8,5 & 10,0 & 13,0 \\
\hline & 8 & 10,0 & 11,0 & 14,0 & 16,0 \\
\hline & 10 & 12,5 & 14,5 & 16,0 & 20,0 \\
\hline
\end{tabular}

$\mathrm{Na}$ Tabela 5.24, observa-se que para um aumento de 20 para $50{ }^{\circ} \mathrm{C}$ no UHMWPE, as deformações específicas se elevam de aproximadamente $230 \% \mathrm{em}$ média, para todos os níveis de carga. Nota-se que a faixa de carregamento compressivo utilizado é similar aos carregamentos que foram submetidos o POM e o UHMWPE.

Quanto ao POM, obteve-se, em um catálogo técnico da empresa HOECHST ${ }^{117}$, informações sobre o comportamento quanto à fluência do POM da marca Hostaform®. Vale a pena ressaltar que a TICONA, fornecedora do POM utilizado nesta pesquisa, é uma empresa derivada do antigo departamento de plásticos de engenharia da HOESTCH. A marca Hostaform ${ }^{\circledR}$ é usada pela TICONA para denominar o POM em suas fábricas da Europa. Nos EUA, o POM copolímero é chamado de Celcon®.

A Tabela 5.25 apresenta os resultados de ensaios de fluência do POM, submetido a um carregamento de $10 \mathrm{MPa}$, para diversos níveis de temperatura e de tempo de ensaio.

Tabela 5.25 - Deformação específica (\%) do POM (Hostaform®) em função da temperatura e do tempo de ensaio, para carregamento de $10 \mathrm{MPa}$.

\begin{tabular}{cccccc} 
& & \multicolumn{4}{c}{ Tempo $[\mathbf{s}]$} \\
\cline { 2 - 6 } Tensão & Temperatura & $\mathbf{3 6 0}$ & $\mathbf{3 6 0 0}$ & $\mathbf{3 6 0 0 0}$ & $\mathbf{3 6 0 0 0 0}$ \\
{$[\mathbf{M P a}]$} & {$\left[{ }^{\circ} \mathbf{C}\right]$} & $\mathbf{( 0 , 1 \text { hora } )}$ & $(\mathbf{1}$ hora $)$ & $(\mathbf{1 0 ~ h o r a s})$ & $(\mathbf{1 0 0}$ horas $)$ \\
\hline \multirow{2}{*}{10} & 20 & 0,36 & 0,40 & 0,48 & 0,56 \\
& 50 & 0,49 & 0,61 & 0,77 & 0,95 \\
& 80 & 0,77 & 0,91 & 1,05 & 1,18 \\
& 100 & 1,00 & 1,18 & 1,33 & 1,54 \\
\hline
\end{tabular}


Da Tabela 5.25, observa-se que para um aumento de 20 para $100^{\circ} \mathrm{C}$ no $\mathrm{POM}$, as deformações específicas se elevam de aproximadamente $280 \%$ em média, para todos os tempos de ensaio. Nota-se também que a faixa de temperaturas utilizadas é similar às temperaturas encontradas na região de contato dos pinos de POM.

Assim como nos resultados de fluência realizados à temperatura ambiente, também nos dados da literatura, a deformação específica do POM é pelo menos uma ordem de grandeza inferior à do UHMWPE.

Essas informações serão usadas na correção dos dados brutos de taxa de desgaste.

\subsection{Determinação da taxa de desgaste}

Os ensaios de desgaste do tipo pino-contra-disco foram realizados com os sistemas tribológicos apresentados na Tabela 5.26.

Tabela 5.26 - Pares de materiais estudados nesta pesquisa.

\begin{tabular}{ccc}
\hline Polímero & Contra-corpo & Acabamento superficial $[\mu \mathrm{m}]$ \\
\hline \multirow{3}{*}{ POM } & $\mathrm{Al}_{2} \mathrm{O}_{3}$ & $0,3<\mathrm{Ra}<0,6$ \\
\cline { 2 - 3 } & & $1,5<\mathrm{Ra}<2,0$ \\
\cline { 2 - 3 } & Aço inoxidável & $0,3<\mathrm{Ra}<0,6$ \\
\cline { 2 - 3 } & & $0,05<\mathrm{Ra}<0,2$ \\
\hline \multirow{3}{*}{ UHMWPE } & $\mathrm{Al}_{2} \mathrm{O}_{3}$ & $0,3<\mathrm{Ra}<0,6$ \\
\cline { 2 - 3 } & & $1,5<\mathrm{Ra}<2,0$ \\
\cline { 2 - 3 } & Aço inoxidável & $0,3<\mathrm{Ra}<0,6$ \\
\cline { 2 - 3 } & & $0,05<\mathrm{Ra}<0,2$ \\
\hline
\end{tabular}

Inicialmente, para cada família de sistemas tribológicos descritos acima, seriam determinadas 9 condições de ensaio diferentes (3 níveis de cargas versus 3 velocidades de deslizamento), com 3 ensaios repetidos em cada condição, perfazendo assim um total 27 ensaios de desgaste. No entanto, verificou-se que, para a condição de $200 \mathrm{~N}$ de carga aplicada e com $1 \mathrm{~m} / \mathrm{s}$ de velocidade de deslizamento, os dois polímeros fundiam durante o ensaio de desgaste para todos os níveis de acabamento superficial estudados. O mesmo ocorreu nos ensaios com os dois polímeros com carga de $200 \mathrm{~N}$ e velocidade de $0,5 \mathrm{~m} / \mathrm{s}$, para o contra-corpo de $\mathrm{Al}_{2} \mathrm{O}_{3}$, com rugosidade $\mathrm{Ra}$ entre 1,5 e 2,0 $\mu \mathrm{m}$ (R4). A partir destes resultados, pode-se concluir então que o aumento de temperatura, que conduz à fusão, depende não apenas da elevação da condição PV mas, no caso da alumina, também do nível de acabamento superficial. 
Serão apresentados abaixo os valores médios de taxa de desgaste linear, calculados a partir dos resultados de perda de altura dos pinos medidos pelo sensor de posição linear (LVDT), para um total de 186 ensaios. Esses valores serão denominados 'resultados brutos'.

\subsubsection{Resultados brutos de taxa de desgaste}

Os resultados apresentados nas Tabelas 5.27 a 5.30 mostram os valores médios de taxa de desgaste linear $(\mu \mathrm{m} / \mathrm{m})$, obtidos após o período de running-in dos ensaios de desgaste.

Tabela 5.27 - Resultados de taxa de desgaste dos ensaios POM versus $\mathrm{Al}_{2} \mathrm{O}_{3}$.

\begin{tabular}{|c|c|c|c|c|c|c|}
\hline \multirow{2}{*}{$\begin{array}{c}\text { Carga } \\
{[\mathrm{N}]}\end{array}$} & \multirow{2}{*}{$\begin{array}{c}\text { Velocidade } \\
{[\mathrm{m} / \mathrm{s}]}\end{array}$} & \multicolumn{5}{|c|}{ Taxa de desgaste $[\mu \mathrm{m} / \mathrm{m}]$} \\
\hline & & \multicolumn{2}{|c|}{$1,5<\mathrm{Ra}<2,0 \mu \mathrm{m}$} & \multicolumn{3}{|c|}{$0,3<\mathrm{Ra}<0,6 \mu \mathrm{m}$} \\
\hline 50 & 0,1 & 0,065 & 0,003 & 0,013 & \pm & 0,006 \\
\hline 50 & 0,5 & 0,50 & 0,18 & 0,26 & \pm & 0,19 \\
\hline 50 & 1 & 1,0 & 0,4 & 0,57 & \pm & 0,07 \\
\hline 100 & 0,1 & 0,44 & 0,07 & 0,54 & \pm & 0,14 \\
\hline 100 & 0,5 & 2,16 & 0,11 & 1,2 & \pm & 0,7 \\
\hline 100 & 1 & 3,2 & 0,8 & 1,9 & \pm & 0,3 \\
\hline 200 & 0,1 & 0,67 & 0,14 & 1,20 & \pm & 0,09 \\
\hline 200 & 0,5 & \multicolumn{2}{|c|}{ fusão } & 2,7 & \pm & 0,7 \\
\hline
\end{tabular}

Tabela 5.28 - Resultados de taxa de desgaste dos ensaios UHMWPE versus $\mathrm{Al}_{2} \mathrm{O}_{3}$.

\begin{tabular}{|c|c|c|c|c|c|c|}
\hline \multirow{2}{*}{$\begin{array}{c}\text { Carga } \\
{[\mathrm{N}]}\end{array}$} & \multirow{2}{*}{$\begin{array}{c}\text { Velocidade } \\
{[\mathrm{m} / \mathrm{s}]}\end{array}$} & \multicolumn{5}{|c|}{ Taxa de desgaste $[\mu \mathrm{m} / \mathrm{m}]$} \\
\hline & & \multicolumn{2}{|c|}{$1,5<\mathrm{Ra}<2,0 \mu \mathrm{m}$} & \multicolumn{3}{|c|}{$0,3<\mathbf{R a}<0,6 \mu \mathrm{m}$} \\
\hline 50 & 0,1 & 0,29 & $\pm \quad 0,19$ & 0,014 & \pm & 0,002 \\
\hline 50 & 0,5 & 0,6 & 0,3 & 0,022 & \pm & 0,007 \\
\hline 50 & 1 & 0,6 & 0,3 & 0,22 & \pm & 0,16 \\
\hline 100 & 0,1 & 0,5 & 0,4 & 0,029 & \pm & 0,019 \\
\hline 100 & 0,5 & 0,32 & 0,15 & 0,06 & \pm & 0,02 \\
\hline 100 & 1 & 0,6 & 0,2 & 0,36 & \pm & 0,17 \\
\hline 200 & 0,1 & 0,7 & $\pm \quad 0,4$ & 0,15 & \pm & 0,03 \\
\hline 200 & 0,5 & \multicolumn{2}{|c|}{ fusão } & 0,35 & \pm & 0,16 \\
\hline
\end{tabular}


Tabela 5.29 - Resultados de taxa de desgaste dos ensaios UHMWPE versus Aço Inoxidável.

\begin{tabular}{|c|c|c|c|c|c|c|c|}
\hline \multirow{2}{*}{$\begin{array}{c}\text { Carga } \\
{[N]}\end{array}$} & \multirow{2}{*}{$\begin{array}{c}\text { Velocidade } \\
{[\mathrm{m} / \mathrm{s}]}\end{array}$} & \multicolumn{6}{|c|}{ Taxa de desgaste $[\mu \mathrm{m} / \mathrm{m}]$} \\
\hline & & $\mathbf{0 , 3}<\mathrm{R}$ & $a<$ & $\mathbf{0 , 6} \mu \mathrm{m}$ & $0,05<$ & $\mathbf{a}<$ & $0,2 \mu \mathrm{m}$ \\
\hline 50 & 0,1 & 0,016 & \pm & 0,008 & 0,009 & \pm & 0,003 \\
\hline 50 & 0,5 & 0,008 & \pm & 0,003 & 0,008 & \pm & 0,003 \\
\hline 50 & 1 & 0,013 & \pm & 0,005 & 0,007 & \pm & 0,002 \\
\hline 100 & 0,1 & 0,018 & \pm & 0,002 & 0,012 & \pm & 0,001 \\
\hline 100 & 0,5 & 0,029 & \pm & 0,016 & 0,013 & \pm & 0,002 \\
\hline 100 & 1 & 0,029 & \pm & 0,010 & 0,028 & \pm & 0,007 \\
\hline 200 & 0,1 & 0,037 & \pm & 0,001 & 0,020 & \pm & 0,009 \\
\hline 200 & 0,5 & 0,4 & \pm & 0,2 & 0,3 & \pm & 0,2 \\
\hline
\end{tabular}

Tabela 5.30 - Resultados de taxa de desgaste dos ensaios POM versus Aço Inoxidável.

\begin{tabular}{|c|c|c|c|c|c|c|c|}
\hline \multirow{2}{*}{$\begin{array}{c}\text { Carga } \\
{[\mathrm{N}]} \\
\end{array}$} & \multirow{2}{*}{$\begin{array}{c}\text { Velocidade } \\
{[\mathrm{m} / \mathrm{s}]}\end{array}$} & \multicolumn{6}{|c|}{ Taxa de desgaste $[\mu \mathrm{m} / \mathrm{m}]$} \\
\hline & & \multicolumn{3}{|c|}{$\mathbf{0 , 3}<\mathbf{R a}<\mathbf{0 , 6} \mu \mathrm{m}$} & \multicolumn{3}{|c|}{$0,05<\mathrm{Ra}<0,2 \mu \mathrm{m}$} \\
\hline 50 & 0,1 & 0,016 & \pm & 0,003 & 0,008 & \pm & 0,003 \\
\hline 50 & 0,5 & 0,051 & \pm & 0,010 & 0,014 & \pm & 0,005 \\
\hline 50 & 1 & 0,04 & \pm & 0,02 & 0,014 & \pm & 0,009 \\
\hline 100 & 0,1 & 0,014 & \pm & 0,005 & 0,010 & \pm & 0,006 \\
\hline 100 & 0,5 & 0,048 & \pm & 0,011 & 0,024 & \pm & 0,015 \\
\hline 100 & 1 & 0,040 & \pm & 0,012 & 0,007 & \pm & 0,000 \\
\hline 200 & 0,1 & 0,09 & \pm & 0,04 & 0,016 & \pm & 0,007 \\
\hline 200 & 0,5 & 0,07 & \pm & 0,04 & 0,084 & \pm & 0,013 \\
\hline
\end{tabular}

Como os materiais poliméricos apresentam fluência nas temperaturas de ensaio, torna-se necessário fazer uma correção nos 'resultados brutos' de taxa de desgaste, subtraindo destes valores a componente de redução de altura dos pinos devido ao fenômeno de fluência. Estes valores serão denominados então de 'resultados corrigidos' e o modo como foram feitas as correções será apresentado a seguir.

\subsubsection{Correção da taxa de desgaste devido à fluência}

Para fazer a correção dos valores de taxa de desgaste devido à componente de fluência (resultados corrigidos), serão utilizados os resultados dos ensaios de fluência sob compressão, realizados no equipamento de desgaste à temperatura ambiente, além dos dados da literatura, mostrando o efeito da temperatura no comportamento quanto à fluência do UHMWPE e do POM. 


\subsubsection{Correção dos dados do POM}

Como à temperatura ambiente as deformações do POM foram muito pequenas e de difícil visualização, optou-se por utilizar curvas de ajuste para cada carga aplicada. A Figura 5.18 mostra as retas de ajuste para cada nível de carga utilizado, dos resultados dos ensaios de fluência do POM à temperatura ambiente.

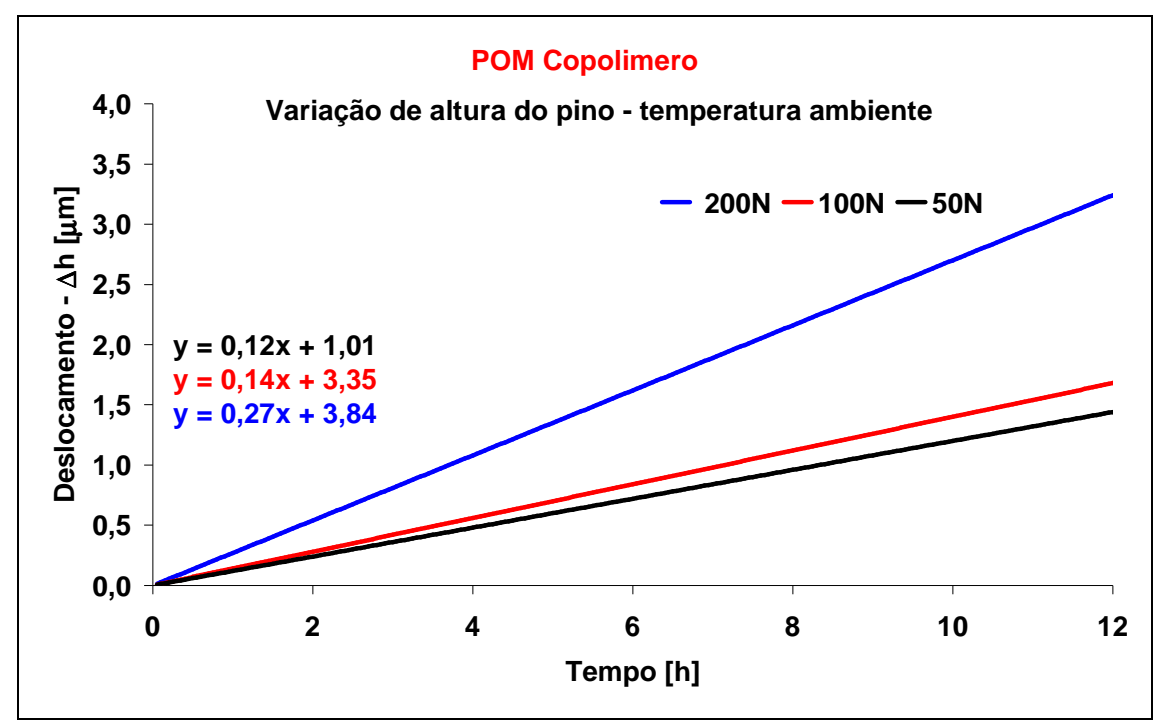

\section{Figura 5.18 - Curvas de ajuste linear dos pontos de fluência do POM à temperatura ambiente $(50,100$ e $200 \mathrm{~N})$.}

A inclinação das retas de ajuste dos dados de fluência do POM, com carga de 50, 100 e $200 \mathrm{~N}$, equivalem às taxas de variação de altura em $\boldsymbol{\mu m} / \mathbf{h}$. Com base nas velocidades de deslizamento utilizadas nos ensaios de desgaste, obtém-se os valores de variação de altura em $\mu \mathbf{m} / \mathbf{m}$, a mesma unidade da taxa de desgaste linear. Os valores de taxa de deformação longitudinal dos pinos para cada condição PV ensaiada, estão apresentados na Tabela 5.31. 
Tabela 5.31 - Taxa de deformação do pino devido a fluência do POM à temperatura ambiente.

\begin{tabular}{ccccc}
\hline & & \multicolumn{3}{c}{ Taxa de deformação $[\mu \mathrm{m} / \mathbf{m}]$} \\
\cline { 3 - 5 } & & \multicolumn{3}{c}{ Carga $[\mathbf{N}]$} \\
\hline $\begin{array}{c}\text { Velocidade } \\
{[\mathbf{m} / \mathbf{s}]}\end{array}$ & $\begin{array}{c}\text { Tempo de } \\
\text { ensaio }[\mathbf{h}]\end{array}$ & $\mathbf{2 0 0}$ & $\mathbf{1 0 0}$ & $\mathbf{5 0}$ \\
\hline 0,1 & 9,72 & 0,00078 & 0,00039 & 0,00033 \\
0,5 & 1,94 & 0,00016 & 0,00008 & 0,00007 \\
1,0 & 0,97 & - & 0,00004 & 0,00003 \\
\hline
\end{tabular}

Dos resultados da influência da temperatura no comportamento quanto à fluência do POM, verificou-se que uma alteração de temperatura de 20 para $100{ }^{\circ} \mathrm{C}$ produz um aumento na deformação do POM de até $280 \%$. Aplicando o fator de proporcionalidade, $\mathbf{k}=\mathbf{2 , 8}$ nos resultados de deslocamento $\Delta \mathrm{h}$, obtidos à temperatura ambiente, para os três níveis de carga, obtêm-se as taxas de variação de altura do pino em função do tempo, para temperatura de $100{ }^{\circ} \mathrm{C}$ como apresentadas na Figura 5.19.

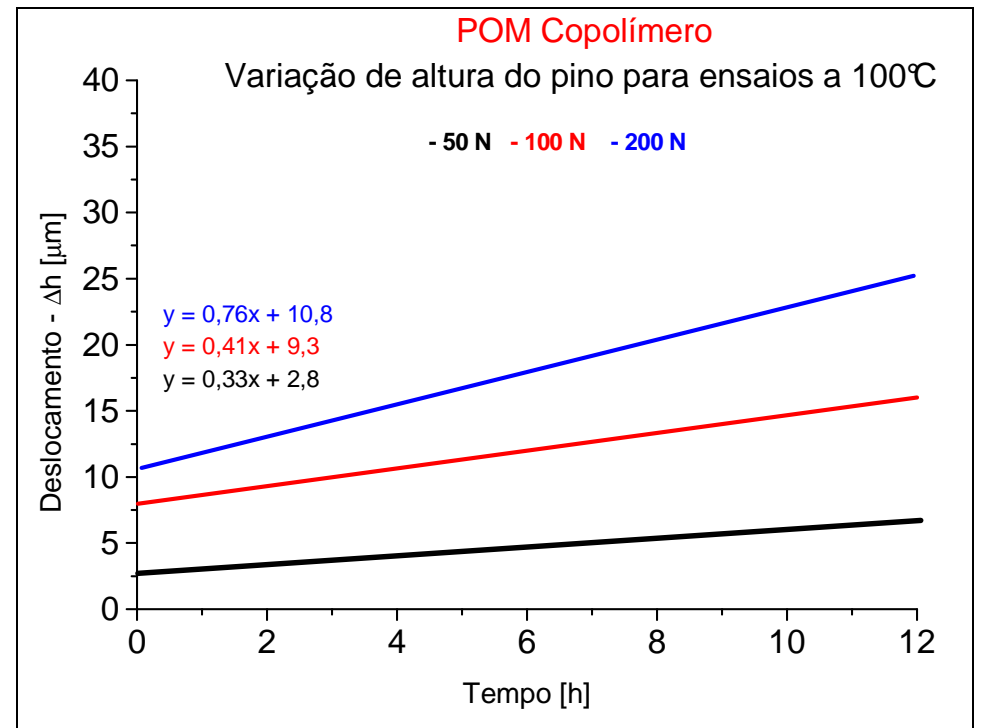

Figura 5.19 - Curvas de ajuste linear dos pontos dos ensaios de fluência do POM, corrigidas para temperatura de $100^{\circ} \mathrm{C}$.

Com a inclinação das curvas de ajuste apresentadas na Figura 5.19, para os três níveis de carregamento, pode-se determinar os valores de correção das taxas de desgaste devido ao fenômeno da fluência. A Tabela 5.32, apresenta os valores de taxa de deformação longitudinal dos pinos, para fluência do POM a $100{ }^{\circ} \mathrm{C}$. 
Tabela 5.32 - Taxa de deformação do pino devido a fluência do POM, a $100{ }^{\circ} \mathrm{C}$.

\begin{tabular}{ccccc}
\hline & & \multicolumn{3}{c}{ Taxa de deformação $[\mu \mathbf{m} / \mathbf{m}]$} \\
\cline { 3 - 5 } & & \multicolumn{3}{c}{ Carga $[\mathbf{N}]$} \\
\hline Velocidade & Tempo de & $\mathbf{2 0 0}$ & $\mathbf{1 0 0}$ & $\mathbf{5 0}$ \\
{$[\mathbf{m} / \mathbf{s}]$} & ensaio $[\mathbf{h}]$ & & & 0,0009 \\
\hline 0,1 & 9,72 & 0,0021 & 0,0011 & 0,0002 \\
0,5 & 1,94 & 0,0004 & 0,0002 & 0,0001 \\
1,0 & 0,97 & - & 0,0001 & \\
\hline
\end{tabular}

Observa-se da Tabela 5.31 e principalmente da Tabela 5.32, que os valores de taxa de deformação dos pinos devido ao fenômeno da fluência são muito baixos, mesmo para temperaturas elevadas $\left(100{ }^{\circ} \mathrm{C}\right)$. E como os erros devido às dispersões dos resultados de taxa de desgaste do POM (Tabela 5.27 e Tabela 5.30) são sempre maiores que $\mathbf{0 , 0 0 3} \mu \mathbf{m} / \mathbf{m}$, não será necessário alterar os valores de taxa de desgaste obtidos para o POM nas diversas condições de ensaio. Cabe ressaltar que as deformações devido à fluência no pino na temperatura de $100{ }^{\circ} \mathrm{C}$ estão super dimensionadas, uma vez que se considerou todo o pino $(25 \mathrm{~mm})$ na temperatura da interface e não apenas aquela região.

\subsubsection{Correção dos dados do UHMWPE}

Com o objetivo de se encontrar qual a parcela devida ao fenômeno da fluência, a mesma deve ser descontada dos valores de taxa de desgaste do UHMWPE (resultados brutos). Um tratamento semelhante ao que foi feito para o POM será também realizado para o UHMWPE.

A Figura 5.20 apresenta as curvas de ajuste dos ensaios de fluência realizados com UHMWPE à temperatura ambiente, para os três níveis de carga estudados. 


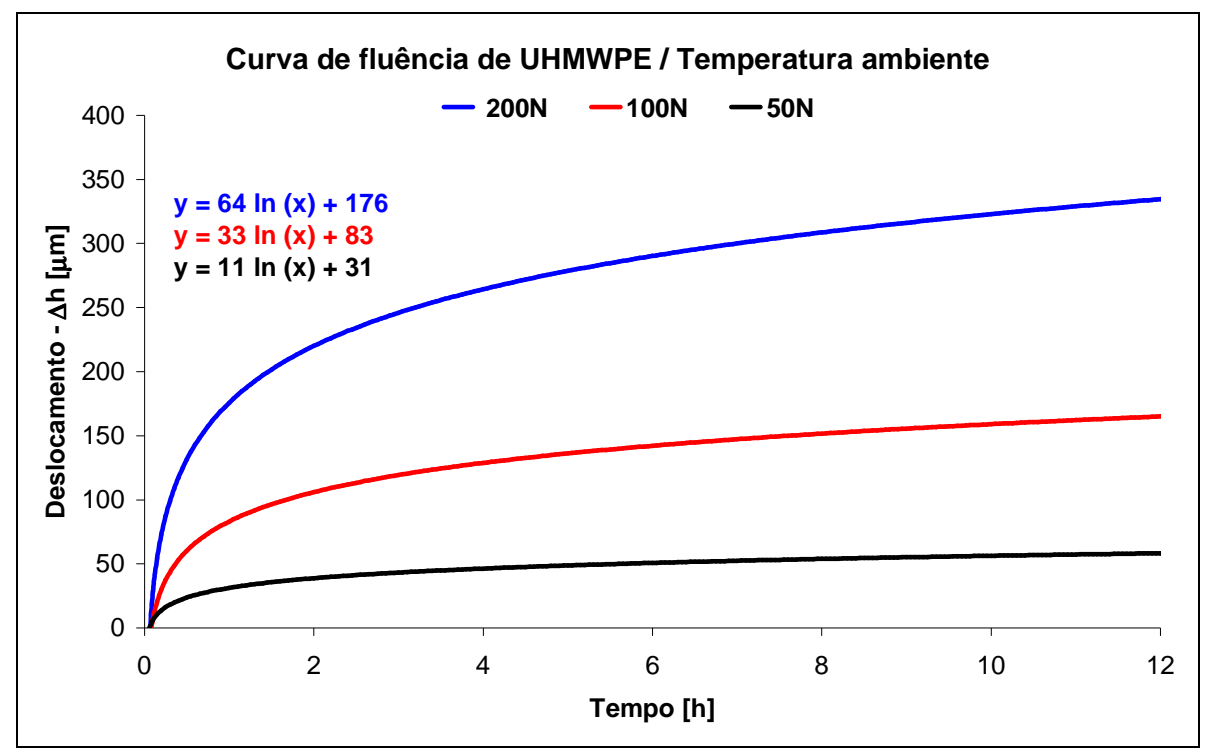

Figura 5.20 - Curvas de ajuste dos ensaios de fluência do UHMWPE realizados à temperatura ambiente, para os três níveis de carga.

Diferentemente dos ensaios com POM, as curvas de fluência do UHMWPE, para os três níveis de carga estudados, apresentaram um comportamento logarítmico, fazendo com que a taxa de deformação, expressa em $\mu \mathrm{m} / \mathrm{h}$, seja uma função não linear do tempo de ensaio.

A Figura 5.21 apresenta a taxa de deformação dos pinos de UHMWPE em função do tempo de ensaio de fluência, realizado à temperatura ambiente, para os três níveis de carga estudados. Nessa Figura, observa-se que a taxa de deformação não se estabiliza ao longo da realização dos ensaios. Este fato indica que a região de fluência secundária do UHMWPE ainda não foi atingida. Dessa forma, será admitido como taxa de deformação o valor da taxa nos instantes finais de cada ensaio de desgaste. Vale a pena ressaltar que a taxa de desgaste obtidas nos ensaios tribológicos é obtida após o período de amaciamento (running-in). Portanto, estaremos comparando valores de taxa de desgaste e taxa de deformação obtidos em critérios semelhantes. 


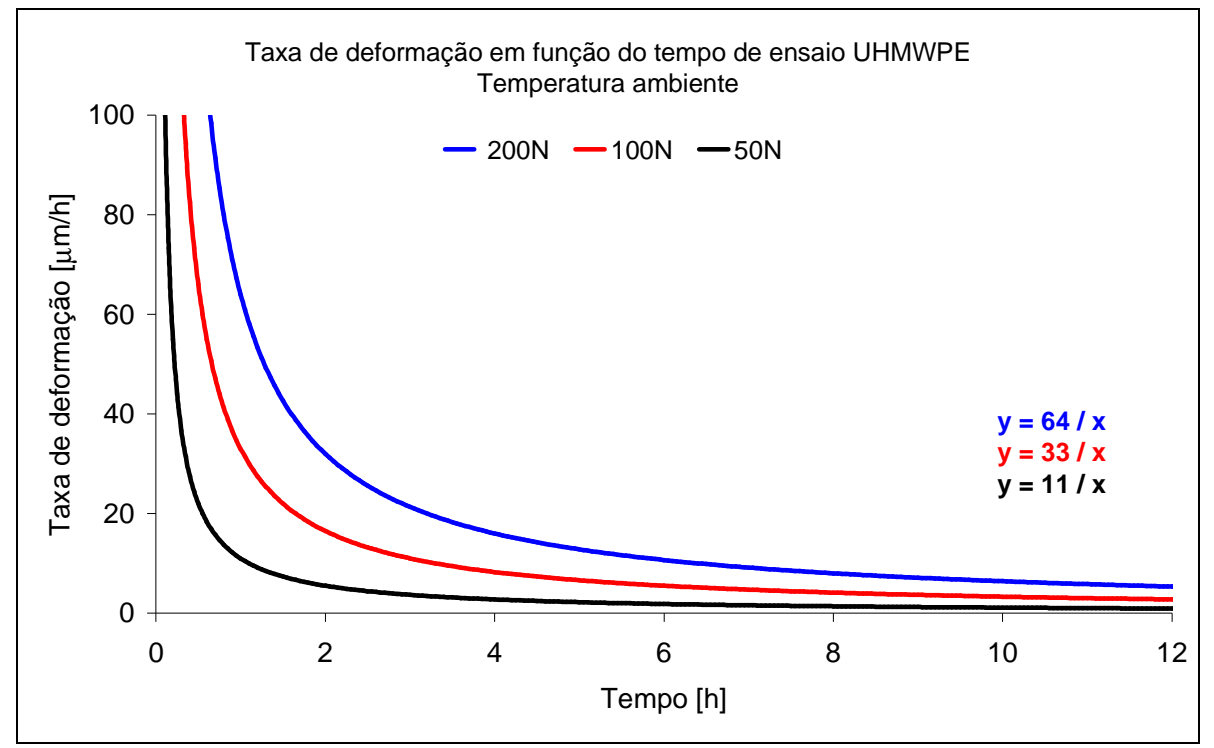

Figura 5.21 - Taxa de deformação em função do tempo de ensaio de fluência para o UHMWPE, para os três níveis de carga, à temperatura ambiente.

A Tabela 5.33 apresenta os valores de taxa de deformação longitudinal, em $\boldsymbol{\mu m} / \mathbf{h}$, do UHMWPE para as 8 condições PV ensaiadas.

Tabela 5.33 - Taxa de variação de altura de pino devido a fluência em relação ao tempo, à temperatura ambiente, do UHMWPE.

\begin{tabular}{ccccc}
\hline & & \multicolumn{3}{c}{ Taxa de deformação $[\mu \mathbf{m} / \mathbf{h}]$} \\
\cline { 3 - 5 } & & \multicolumn{3}{c}{ Carga $[\mathbf{N}]$} \\
\hline $\begin{array}{c}\text { Velocidade } \\
{[\mathbf{m} / \mathbf{s}]}\end{array}$ & $\begin{array}{c}\text { Tempo de } \\
\text { ensaio }[\mathbf{h}]\end{array}$ & $\mathbf{2 0 0}$ & $\mathbf{1 0 0}$ & $\mathbf{5 0}$ \\
\hline 0,1 & 9,72 & 6,6 & 3,4 & 1,1 \\
0,5 & 1,94 & 33,0 & 17,0 & 5,7 \\
1,0 & 0,97 & - & 34,0 & 11,3 \\
\hline
\end{tabular}

Da mesma forma como foi feito para o POM, foram determinadas as componentes da taxa de desgaste, em $\mu \mathbf{m} / \mathbf{m}$, referentes ao fenômeno de fluência ocorrido no UHMWPE. Estes valores de taxa de deformação longitudinal devido à fluência estão apresentados na Tabela 5.34. 
Tabela 5.34 - Taxa de deformação do pino devido a fluência, à temperatura ambiente, do UHMWPE.

\begin{tabular}{ccccc}
\hline & & \multicolumn{3}{c}{ Taxa de deformação $[\mu \mathrm{m} / \mathbf{m}]$} \\
\cline { 3 - 5 } & & \multicolumn{3}{c}{ Carga $[\mathbf{N}]$} \\
\hline $\begin{array}{c}\text { Velocidade } \\
{[\mathbf{m} / \mathbf{s}]}\end{array}$ & Tempo de & $\mathbf{2 0 0}$ & $\mathbf{1 0 0}$ & $\mathbf{5 0}$ \\
\hline 0,1 & ensaio $[\mathbf{h}]$ & & 0,009 & 0,003 \\
0,5 & 9,72 & 0,018 & 0,009 & 0,003 \\
1,0 & 1,94 & 0,018 & 0,009 & 0,003 \\
\hline
\end{tabular}

De acordo com as informações disponibilizadas pelo fabricante do polímero, uma alteração de temperatura de 20 para $50{ }^{\circ} \mathrm{C}$ produz um aumento na deformação do UHMWPE de até $230 \%$. Aplicando o fator de proporcionalidade $\mathbf{k}=\mathbf{2 , 3}$ nos resultados de deslocamento $\Delta \mathrm{h}$, obtidos à temperatura ambiente, para os três níveis de carga, obtêm-se as seguintes curvas de fluência para o UHMWPE a $50{ }^{\circ} \mathrm{C}$ (Figura 5.22 - a) e as suas respectivas taxas de deformação (Figura 5.22 - b).

De posse das taxas de deformação em $\mu \mathbf{m} / \mathbf{h}$, pode-se determinar novamente as taxa de deformação longitudinal dos pinos em $\mu \mathbf{m} / \mathbf{m}$ para o UHMWPE (Tabela 5.35), da mesma maneira utilizada para POM. 


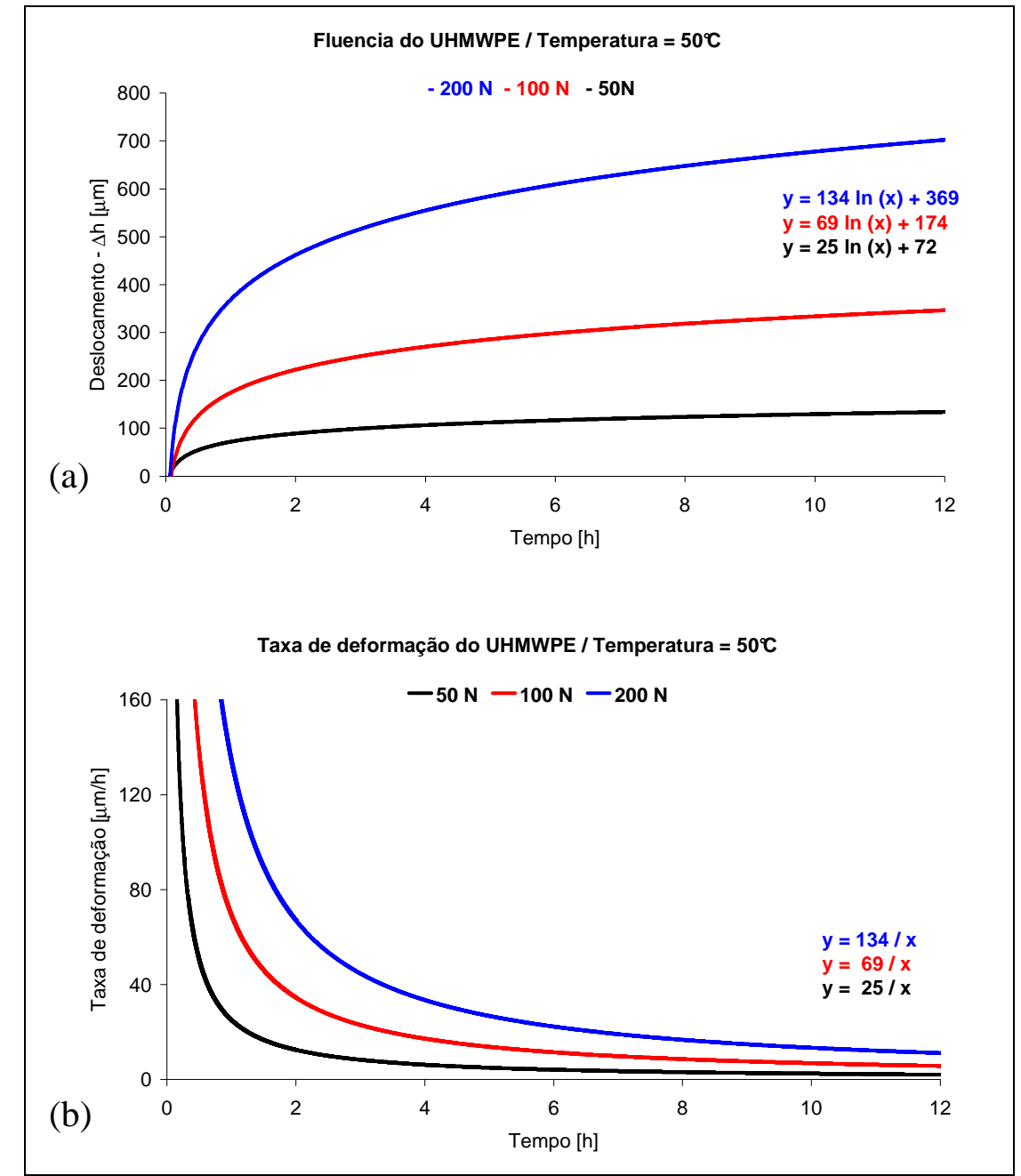

Figura 5.22 - Curvas de fluência para a temperatura de $50^{\circ} \mathrm{C}$ (a), curvas de taxa de deformação para o UHMWPE a $50^{\circ} \mathrm{C}$ (b).

Tabela 5.35 - Taxa de deformação do pino devido a fluência, a $50{ }^{\circ} \mathrm{C}$, do UHMWPE.

\begin{tabular}{ccccc}
\hline & & \multicolumn{3}{c}{ Taxa de deformação $[\mu \mathrm{m} / \mathbf{m}]$} \\
\cline { 3 - 5 } & & \multicolumn{3}{c}{ Carga $[\mathbf{N}]$} \\
\hline $\begin{array}{c}\text { Velocidade } \\
{[\mathbf{m} / \mathbf{s}]}\end{array}$ & $\begin{array}{c}\text { Tempo de } \\
\text { ensaio }[\mathbf{h}]\end{array}$ & $\mathbf{2 0 0}$ & $\mathbf{1 0 0}$ & $\mathbf{5 0}$ \\
\hline 0,1 & 9,72 & 0,038 & 0,020 & 0,007 \\
0,5 & 1,94 & 0,038 & 0,020 & 0,007 \\
1,0 & 0,97 & - & 0,020 & 0,007 \\
\hline
\end{tabular}

Como para o UHMWPE, as taxas de deformação para um dada temperatura dependem somente do carregamento imposto ao material, foi possível encontrar uma relação entre as taxas de deformação do UHMWPE e as temperaturas atingidas no 
contato (Figura 5.23). No entanto, a determinação dessa relação está baseada nas seguintes hipóteses:

- o aumento da taxa de deformação é uma função linear da temperatura do material;

- admitiu-se como $25{ }^{\circ} \mathrm{C}$ a temperatura ambiente do laboratório durante a realização dos ensaios de fluência;

- o comportamento linear da taxa de deformação pode ser extrapolado para temperaturas até $110^{\circ} \mathrm{C}$.

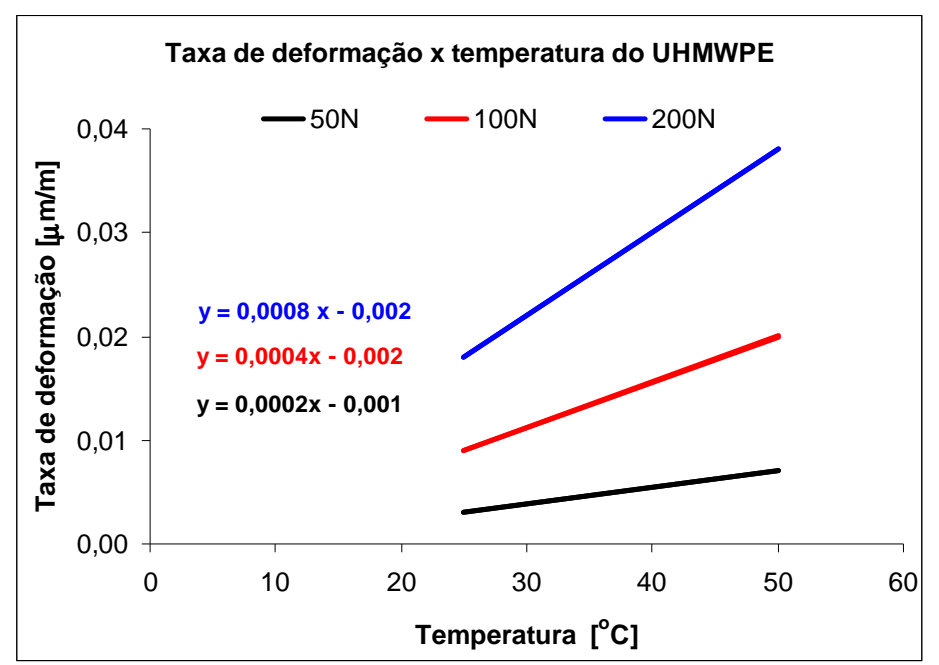

\section{Figura 5.23 - Taxa de deformação devido à fluência em função da temperatura para o UHMWPE.}

De posse das curvas de taxa de deformação em função da temperatura, pode-se determinar as taxas de deformação para cada condição PV ensaiada. No entanto, ainda é necessário considerar que apenas uma região próxima à superfície do pino polimérico ficou submetida a temperaturas elevadas, enquanto que a maior parte do corpo-de-prova permaneceu à temperatura ambiente. Ou seja, é necessário ponderar em qual região dos pinos a temperatura alterou as taxas de deformação devido à fluência.

A Figura 5.24 mostra esquematicamente em que região do pino as taxas de deformação foram influenciadas pelo aumento de temperatura. 


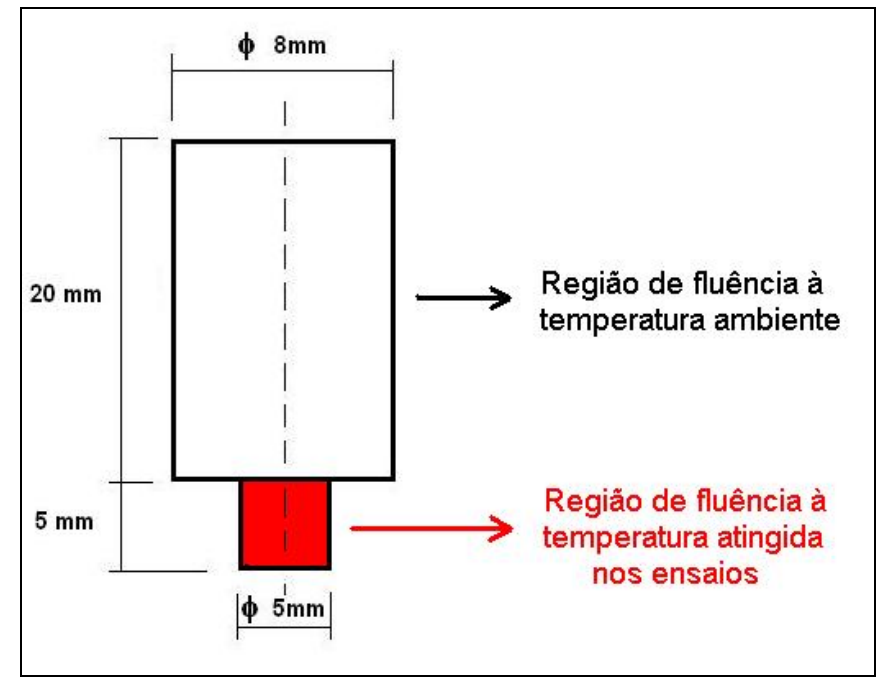

Figura 5.24 - Regiões do corpo-de-prova polimérico com duas regiões de temperatura diferentes durante os ensaios de desgaste.

Admitindo que, dos $25 \mathrm{~mm}$ de comprimento do pino, $20 \mathrm{~mm}$ permaneciam à temperatura ambiente, enquanto que os $5 \mathrm{~mm}$ restantes atingiam a temperatura medida durante a realização dos ensaios, ponderou-se então para o cálculo da taxa de deformação longitudinal total do pino, que $80 \%$ da taxa de deformação do pino se devia à fluência na temperatura ambiente $\left(25^{\circ} \mathrm{C}\right)$ e que os $20 \%$ restantes da taxa de deformação do pino se dava nas temperaturas medidas próximas à região do contato. Vale ressaltar que a hipótese simplificadora de distribuição de temperaturas nos pinos conduz a uma análise muito conservadora, porém a favor da segurança quanto à importância dos dados de fluência

Nas Tabelas de 5.36 a 5.39, apresentam-se os valores de taxa de deformação total para o UHMWPE nos diversos pares de materiais ensaiados.

Tabela 5.36 - Taxa de deformação total dos pinos de UHMWPE nos ensaios contra aço inoxidável R2.

\begin{tabular}{|c|c|c|c|c|c|}
\hline \multirow{2}{*}{$\begin{array}{c}\text { Carga } \\
{[\mathrm{N}]}\end{array}$} & \multirow{2}{*}{$\begin{array}{c}\text { Velocidade } \\
{[\mathrm{m} / \mathrm{s}]}\end{array}$} & \multirow{2}{*}{$\begin{array}{c}\text { Temperatura } \\
\text { do ensaio } \\
{\left[{ }^{\circ} \mathrm{C}\right]}\end{array}$} & \multicolumn{3}{|c|}{ Taxa de deformação $[\mu \mathrm{m} / \mathrm{m}]$} \\
\hline & & & $\begin{array}{c}\text { Temperatura } \\
\text { do ensaio }\end{array}$ & $\begin{array}{c}\text { Temperatura } \\
\text { ambiente }\end{array}$ & TOTAL \\
\hline 50 & 0,1 & 30,0 & 0,004 & 0,003 & 0,003 \\
\hline 50 & 0,5 & 30,0 & 0,004 & 0,003 & 0,003 \\
\hline 50 & 1,0 & 46,0 & 0,008 & 0,003 & 0,004 \\
\hline 100 & 0,1 & 30,0 & 0,011 & 0,009 & 0,009 \\
\hline 100 & 0,5 & 54.8 & 0,024 & 0,009 & 0,012 \\
\hline 100 & 1,0 & 65.9 & 0,029 & 0,009 & 0,013 \\
\hline 200 & 0,1 & 42.8 & 0,380 & 0,018 & 0,090 \\
\hline 200 & 0,5 & 71,0 & 0,634 & 0,018 & 0,141 \\
\hline
\end{tabular}


Tabela 5.37 - Taxa de deformação total dos pinos de UHMWPE nos ensaios contra aço inoxidável R3.

\begin{tabular}{|c|c|c|c|c|c|}
\hline \multirow{2}{*}{$\begin{array}{c}\text { Carga } \\
{[\mathrm{N}]}\end{array}$} & \multirow{2}{*}{$\begin{array}{c}\text { Velocidade } \\
\text { [m/s] }\end{array}$} & \multirow{2}{*}{$\begin{array}{c}\text { Temperatura } \\
\text { do ensaio } \\
{\left[{ }^{\circ} \mathbf{C}\right]} \\
\end{array}$} & \multicolumn{3}{|c|}{ Taxa de deformação $[\mu \mathrm{m} / \mathrm{m}]$} \\
\hline & & & $\begin{array}{c}\text { Temperatura do } \\
\text { ensaio }\end{array}$ & $\begin{array}{c}\text { Temperatura } \\
\text { ambiente }\end{array}$ & TOTAL \\
\hline 50 & 0,1 & 30,0 & 0,004 & 0,003 & 0,003 \\
\hline 50 & 0,5 & 30,0 & 0,004 & 0,003 & 0,003 \\
\hline 50 & 1,0 & 46,0 & 0,008 & 0,003 & 0,004 \\
\hline 100 & 0,1 & 30,0 & 0,011 & 0,009 & 0,009 \\
\hline 100 & 0,5 & 53,0 & 0,023 & 0,009 & 0,012 \\
\hline 100 & 1,0 & 80,7 & 0,036 & 0,009 & 0,014 \\
\hline 200 & 0,1 & 42,2 & 0,374 & 0,018 & 0,089 \\
\hline 200 & 0,5 & 81,7 & 0,730 & 0,018 & 0,160 \\
\hline
\end{tabular}

Tabela 5.38 - Taxa de deformação total dos pinos de UHMWPE nos ensaios contra alumina R3.

\begin{tabular}{|c|c|c|c|c|c|}
\hline \multirow{2}{*}{$\begin{array}{c}\text { Carga } \\
{[\mathrm{N}]} \\
\end{array}$} & \multirow{2}{*}{$\begin{array}{c}\text { Velocidade } \\
{[\mathrm{m} / \mathrm{s}]} \\
\end{array}$} & \multirow{2}{*}{$\begin{array}{c}\text { Temperatura } \\
\text { do ensaio } \\
{\left[{ }^{\circ} \mathbf{C}\right]}\end{array}$} & \multicolumn{3}{|c|}{ Taxa de deformação $[\mu \mathrm{m} / \mathrm{m}]$} \\
\hline & & & $\begin{array}{c}\text { Temperatura } \\
\text { de ensaio }\end{array}$ & $\begin{array}{l}\text { Temperatura } \\
\text { ambiente }\end{array}$ & TOTAL \\
\hline 50 & 0,1 & 30,0 & 0,004 & 0,003 & 0,003 \\
\hline 50 & 0,5 & 30,0 & 0,004 & 0,003 & 0,003 \\
\hline 50 & 1,0 & 77,8 & 0,014 & 0,003 & 0,005 \\
\hline 100 & 0,1 & 30,0 & 0,011 & 0,009 & 0,009 \\
\hline 100 & 0,5 & 78,7 & 0,035 & 0,009 & 0,014 \\
\hline 100 & 1,0 & 106,4 & 0,049 & 0,009 & 0,017 \\
\hline 200 & 0,1 & 39,8 & 0,353 & 0,018 & 0,085 \\
\hline 200 & 0,5 & 110 & 0,985 & 0,018 & 0,211 \\
\hline
\end{tabular}

Tabela 5.39 - Taxa de deformação total dos pinos de UHMWPE nos ensaios contra alumina R4.

\begin{tabular}{cccccc}
\hline $\begin{array}{c}\text { Carga } \\
{[\mathbf{N}]}\end{array}$ & $\begin{array}{c}\text { Velocidade } \\
{[\mathbf{m} / \mathbf{s}]}\end{array}$ & Temperatura & \multicolumn{3}{c}{ Taxa de deformação $[\mu \mathbf{m} / \mathbf{m}]$} \\
\cline { 4 - 6 } & & do ensaio $\left[{ }^{\circ} \mathbf{C}\right]$ & $\begin{array}{c}\text { Temperatura de } \\
\text { ensaio }\end{array}$ & $\begin{array}{c}\text { Temperatura } \\
\text { ambiente }\end{array}$ & TOTAL \\
\hline 50 & 0,1 & 30,0 & 0,004 & 0,003 & 0,003 \\
50 & 0,5 & 30,0 & 0,004 & 0,003 & 0,003 \\
50 & 1,0 & 66,3 & 0,012 & 0,003 & 0,005 \\
100 & 0,1 & 30,0 & 0,011 & 0,009 & 0,009 \\
100 & 0,5 & 74,7 & 0,033 & 0,009 & 0,014 \\
100 & 1,0 & 99,0 & 0,046 & 0,009 & 0,016 \\
200 & 0,1 & 38,7 & 0,343 & 0,018 & 0,083 \\
\hline
\end{tabular}

De posse dos valores da componente de desgaste devido à fluência (Tabela 5.36 a 5.39), foi possível corrigir os valores de taxa de desgaste anteriormente denominados de 'resultados brutos' para o UHMWPE. Estes resultados, doravante denominados de “resultados corrigidos", serão apresentados a seguir. 


\subsubsection{Resultados corrigidos de taxa de desgaste}

As Tabelas 5.40 a 5.43 apresentam os resultados corrigidos de taxa de desgaste dos polímeros nos tribossistemas estudados (denominada de taxa de desgaste final). Os valores apresentados em vermelho enfatizam os resultados onde a fluência foi considerada relevante.

Tabela 5.40 - Taxa de desgaste final dos ensaios $\mathrm{POM}$ versus $\mathrm{Al}_{2} \mathrm{O}_{3}$.

\begin{tabular}{ccrllrll}
\hline Carga & Velocidade & \multicolumn{6}{c}{ Taxa de desgaste $[\boldsymbol{\mu m} / \mathbf{m}]$} \\
\cline { 3 - 8 }$[\mathbf{N}]$ & {$[\mathbf{m} / \mathbf{s}]$} & \multicolumn{1}{c}{$\mathbf{1 , 5}<\mathbf{R a}<\mathbf{2 , 0} \boldsymbol{\mu} \mathbf{m}$} & $\mathbf{0 , 3}<\mathbf{R a}<\mathbf{0 , 6} \boldsymbol{\mu m}$ \\
\hline 50 & 0,1 & 0,065 & \pm & 0,003 & 0,013 & \pm & 0,006 \\
50 & 0,5 & 0,50 & \pm & 0,18 & 0,26 & \pm & 0,19 \\
50 & 1 & 1,0 & \pm & 0,4 & 0,57 & \pm & 0,07 \\
100 & 0,1 & 0,44 & \pm & 0,07 & 0,54 & \pm & 0,14 \\
100 & 0,5 & 2,16 & \pm & 0,11 & 1,2 & \pm & 0,7 \\
100 & 1 & 3,2 & \pm & 0,8 & 1,9 & \pm & 0,3 \\
200 & 0,1 & 0,67 & \pm & 0,14 & 1,20 & \pm & 0,09 \\
200 & 0,5 & & & & 2,7 & \pm & 0,7 \\
\hline
\end{tabular}

Tabela 5.41 - Taxa de desgaste final dos ensaios POM versus Aço inoxidável.

\begin{tabular}{cccccccc}
\hline Carga & Velocidade & \multicolumn{6}{c}{ Taxa de desgaste $[\boldsymbol{\mu m} / \mathbf{m}]$} \\
\cline { 3 - 8 }$[\mathbf{N}]$ & {$[\mathbf{m} / \mathbf{s}]$} & \multicolumn{0}{c}{$\mathbf{0 , 3}<\mathbf{R a}<\mathbf{0 , 6} \boldsymbol{\mu m}$} & $\mathbf{0 , 0 5}<\mathbf{R a}<\mathbf{0 , 2} \boldsymbol{\mu m}$ \\
\hline 50 & 0,1 & 0,016 & \pm & 0,003 & 0,008 & \pm & 0,003 \\
50 & 0,5 & 0,051 & \pm & 0,010 & 0,014 & \pm & 0,005 \\
50 & 1 & 0,04 & \pm & 0,02 & 0,014 & \pm & 0,009 \\
100 & 0,1 & 0,014 & \pm & 0,005 & 0,010 & \pm & 0,006 \\
100 & 0,5 & 0,048 & \pm & 0,011 & 0,024 & \pm & 0,015 \\
100 & 1 & 0,040 & \pm & 0,012 & 0,007 & \pm & 0,000 \\
200 & 0,1 & 0,09 & \pm & 0,04 & 0,016 & \pm & 0,007 \\
200 & 0,5 & 0,07 & \pm & 0,04 & 0,084 & \pm & 0,013 \\
\hline
\end{tabular}

Destaca-se que não foi necessário efetuar correções nos valores de taxa de desgaste dos ensaios com POM, devido ao efeito da fluência ter-se apresentado numericamente inferior às variações dos resultados. 
Tabela 5.42 - Taxa de desgaste final dos ensaios UHMWPE versus $\mathrm{Al}_{2} \mathrm{O}_{3}$

\begin{tabular}{|c|c|c|c|c|c|c|c|}
\hline \multirow{2}{*}{$\begin{array}{c}\text { Carga } \\
{[\mathrm{N}]} \\
\end{array}$} & \multirow{2}{*}{$\begin{array}{c}\text { Velocidade } \\
{[\mathrm{m} / \mathrm{s}]}\end{array}$} & \multicolumn{6}{|c|}{ Taxa de desgaste $[\mu \mathrm{m} / \mathrm{m}]$} \\
\hline & & $1,5<R$ & $a<$ & $2,0 \mu \mathrm{m}$ & $0,3<$ & $1<$ & $0,6 \mu \mathrm{m}$ \\
\hline 50 & 0,1 & 0,29 & \pm & 0,19 & 0,011 & \pm & 0,002 \\
\hline 50 & 0,5 & 0,6 & \pm & 0,3 & 0,022 & \pm & 0,007 \\
\hline 50 & 1 & 0,6 & \pm & 0,3 & 0,22 & \pm & 0,16 \\
\hline 100 & 0,1 & 0,5 & \pm & 0,4 & 0,029 & \pm & 0,019 \\
\hline 100 & 0,5 & 0,32 & \pm & 0,15 & 0,06 & \pm & 0,02 \\
\hline 100 & 1 & 0,6 & \pm & 0,2 & 0,36 & \pm & 0,17 \\
\hline 200 & 0,1 & 0,7 & \pm & 0,4 & 0,15 & \pm & 0,03 \\
\hline 200 & 0,5 & & & & 0,35 & \pm & 0,16 \\
\hline
\end{tabular}

Para o UHMWPE deslizando sobre $\mathrm{Al}_{2} \mathrm{O}_{3}$, devido às suas taxa de desgaste apresentarem-se mais elevadas, o efeito da fluência na variação de altura do pino foi notado apenas em uma condição de ensaio, a de menor condição PV e com temperatura no contato inferior a $30^{\circ} \mathrm{C}$.

Tabela 5.43 - Taxa de desgaste final dos ensaios UHMWPE versus aço inoxidável.

\begin{tabular}{|c|c|c|c|c|c|c|c|}
\hline \multirow{2}{*}{$\begin{array}{l}\text { Carga } \\
{[\mathbf{N}]} \\
\end{array}$} & \multirow{2}{*}{$\begin{array}{c}\text { Velocidade } \\
{[\mathrm{m} / \mathrm{s}]}\end{array}$} & \multicolumn{6}{|c|}{ Taxa de desgaste $[\mu \mathrm{m} / \mathrm{m}]$} \\
\hline & & $\mathbf{0 , 3}<\mathbf{F}$ & $\mathbf{a}<$ & $0,6 \mu \mathrm{m}$ & $0,05<$ & $\mathbf{a}<$ & $0,2 \mu \mathrm{m}$ \\
\hline 50 & 0,1 & 0,016 & \pm & 0,008 & 0,009 & \pm & 0,003 \\
\hline 50 & 0,5 & 0,008 & \pm & 0,003 & 0,008 & \pm & 0,003 \\
\hline 50 & 1 & 0,013 & \pm & 0,005 & 0,003 & \pm & 0,002 \\
\hline 100 & 0,1 & 0,009 & \pm & 0,002 & 0,003 & \pm & 0,001 \\
\hline 100 & 0,5 & 0,029 & \pm & 0,016 & 0,002 & \pm & $\mathbf{0 , 0 0 2}$ \\
\hline 100 & 1 & 0,015 & \pm & 0,010 & 0,015 & \pm & 0,007 \\
\hline 200 & 0,1 & & & & & & \\
\hline 200 & 0,5 & 0,4 & \pm & 0,2 & 0,3 & \pm & 0,2 \\
\hline
\end{tabular}

Devido às reduzidas taxas de desgaste do UHMWPE quando deslizando sobre aço inoxidável, a fluência teve uma maior importância nos resultados de taxa de desgaste, como visto na Tabela 5.43. Para este sistema tribológico, foi necessário até eliminar os resultados de uma das condições de ensaio (200 N e $0,1 \mathrm{~m} / \mathrm{s})$, uma vez que as taxas de fluência foram superiores aos valores médios da taxa de desgaste.

De posse dos valores finais de taxa de desgaste, pode-se verificar a dispersão dos resultados obtidos calculando o coeficiente de variação das medidas. A Tabela 5.44 apresenta os valores médios do coeficiente de variação $\left(\mathrm{CV}_{\mathrm{m}}\right)$ dos resultados de taxa de desgaste para os 4 tribossistemas estudados. 
Tabela 5.44 - Coeficiente de variação médio $\left(C V_{m}\right)$ dos resultados finais de taxa de desgaste para os 4 tribossistemas estudados.

\begin{tabular}{|c|c|c|c|c|c|}
\hline Polímero & Contra-corpo & $\mathrm{CV}_{\mathrm{m}}[\%]$ & Polímero & Contra-corpo & $\mathrm{CV}_{\mathrm{m}}[\%]$ \\
\hline \multirow{5}{*}{ UHMWPE } & Alumina R4 & 57 & \multirow{5}{*}{ POM } & Alumina R4 & 21 \\
\hline & Alumina R3 & 42 & & Alumina R3 & 33 \\
\hline & Aço Inox R3 & 46 & & Aço Inox R3 & 37 \\
\hline & Aço Inox R2 & 45 & & Aço Inox R2 & 42 \\
\hline & Média & $47 \pm 7$ & & Média & $33 \pm 9$ \\
\hline
\end{tabular}

Na Tabela 5.44, observa-se que os coeficientes de variação dos ensaios com UHMWPE apresentaram-se superiores, quando comparados com os valores obtidos para o POM. No entanto, dispersões de resultados na ordem de 30 a $50 \%$ são resultados comumente encontrados na literatura, tanto para ensaios tribológicos de metais, quanto para polímeros $^{118}$.

\subsection{Análise dos resultados de taxa de desgaste}

De posse dos valores de taxa de desgaste finais apresentados pelos materiais poliméricos (determinados na seção 5.5.3) será possível analisar as influências das variáveis estudadas (carga aplicada, velocidade de deslizamento, acabamento superficial e material do contra-corpo) na resistência ao desgaste desses materiais.

Para o estudo do comportamento tribológico de qualquer sistema, é imprescindível que se obtenha, mediante medições, os valores de coeficiente de atrito, taxa de desgaste e temperatura no contato. No entanto, uma outra ferramenta de extrema importância em uma pesquisa tribológica é a observação das superfícies de desgaste dos corpos-de-prova ensaiados, bem como das partículas de desgaste (debris) geradas durante o deslizamento. Com base nestas informações, é possível identificar, mesmo que qualitativamente, os mecanismos de desgaste que atuaram nos sistemas durante os ensaios.

Com o objetivo de verificar como a influência da severidade das condições de contato na taxa de desgaste dos materiais poliméricos, as análises dos resultados serão feitas para cada par tribológico, verificando as relações entre a taxa de desgaste e a condição PV, a temperatura no contato, o acabamento superficial e os mecanismos de desgaste.

Com o objetivo de compreender o comportamento dos materiais poliméricos em algumas condições de ensaio específicas, também serão realizadas comparações entre 
médias utilizando a análise de variância. O resultados destas análises estatísticas estarão apresentados no Anexo B.

Devido à grande quantidade de resultados, optou-se por primeiramente realizar análises segmentadas das influências de cada variável nos sistemas tribológicos e caminhando progressivamente para análises mais globais. A Figura 5.25 apresenta de forma esquemática como foi organizada as seções a seguir.

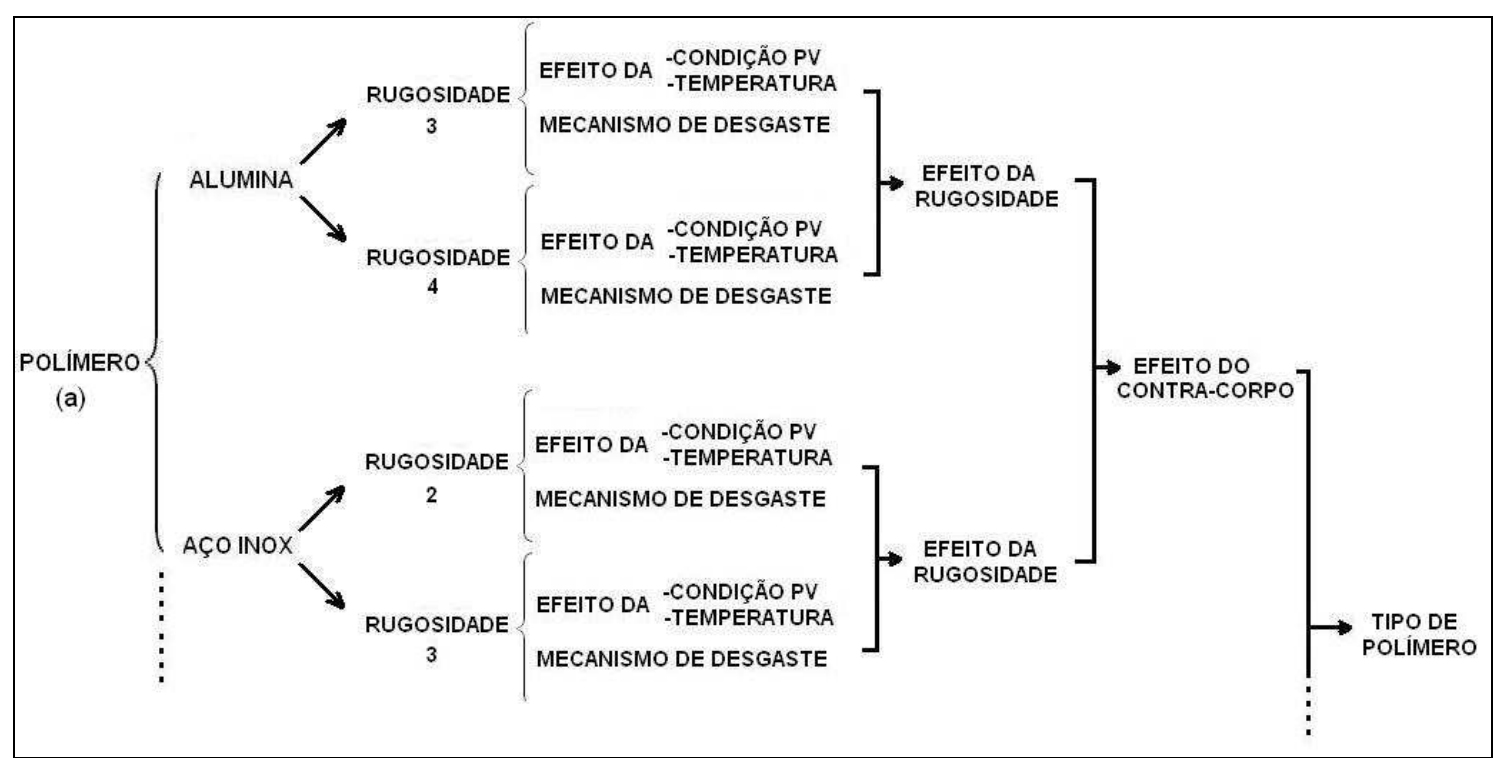

Figura 5.25 - Diagrama esquemático das análises da taxa de desgaste em função da condição PV, da temperatura no contato, do acabamento superficial e dos materiais do contra-corpo e do polímero.

Vale ressaltar que as temperaturas medidas próxima à interface pino-disco não são variáveis do sistema, como a condição PV e a rugosidade. Na verdade a temperatura é uma resposta (variável dependente) do sistema. No entanto observar como se comportam as taxas de desgaste a uma dada temperatura, em muitos casos, torna-se uma informação muito importante.

A Tabela 5.45, apresenta os códigos referentes aos níveis de acabamento superficial dos discos e o parâmetro combinado proposto por GUIMARÃES ${ }^{93}$. 
Tabela 5.45 - Código de acabamento superficial e parâmetro de rugosidade combinado das superfícies dos discos de alumina e aço inoxidável.

\begin{tabular}{lcccc}
\hline \multicolumn{1}{c}{ Polímero } & Contra-corpo & Acabamento & Código & LnRz/lnSm \\
\hline \multirow{2}{*}{ POM ou } & $\mathrm{Al}_{\mathbf{2}} \mathbf{O}_{\mathbf{3}}$ & $1,5<\mathrm{Ra}<2,0 \mu \mathrm{m}$ & $\mathbf{R 4}$ & $\mathbf{0 , 5 7 3}$ \\
UHMWPE & & $0,3<\mathrm{Ra}<0,6 \mu \mathrm{m}$ & $\mathbf{R 3}$ & $\mathbf{0 , 2 9 7}$ \\
& \multirow{2}{*}{ Aço Inoxidável } & $0,3<\mathrm{Ra}<0,6 \mu \mathrm{m}$ & $\mathbf{R 3}$ & $\mathbf{0 , 3 3 6}$ \\
& & $0,05<\mathrm{Ra}<0,2 \mu \mathrm{m}$ & $\mathbf{R 2}$ & $\mathbf{0 , 0 1 9}$ \\
\hline
\end{tabular}

\subsubsection{Desgaste do POM}

A seguir, serão apresentadas as análises dos ensaios de desgaste realizados com o pino de polioximetileno (POM), além disto, será apresentado para o primeiro par , POM x Alumina R3, uma análise sobre os aspectos geométricos e de formação das partículas de desgaste, os quais poderão ser estendidos aos demais pares.

\subsubsection{POM x Alumina R3}

A Figura 5.26 apresenta os resultados de taxa média de desgaste do POM deslizando contra alumina com acabamento superficial R3 em função da condição PV, mostrando uma tendência de crescimento.

Observa-se que ajustes dos resultados de desgaste por curvas de regressão linear, polinomial, exponencial e logarítmica foram examinados, obtendo-se sempre coeficientes de correlação inferiores a $\mathbf{0 , 7 5}$. Foi observado também que, na maioria dos resultados que se apresentam a seguir, as correlações foram ainda piores. Assim sendo, procedeu-se às análises do desgaste observando-se apenas as tendências globais. 


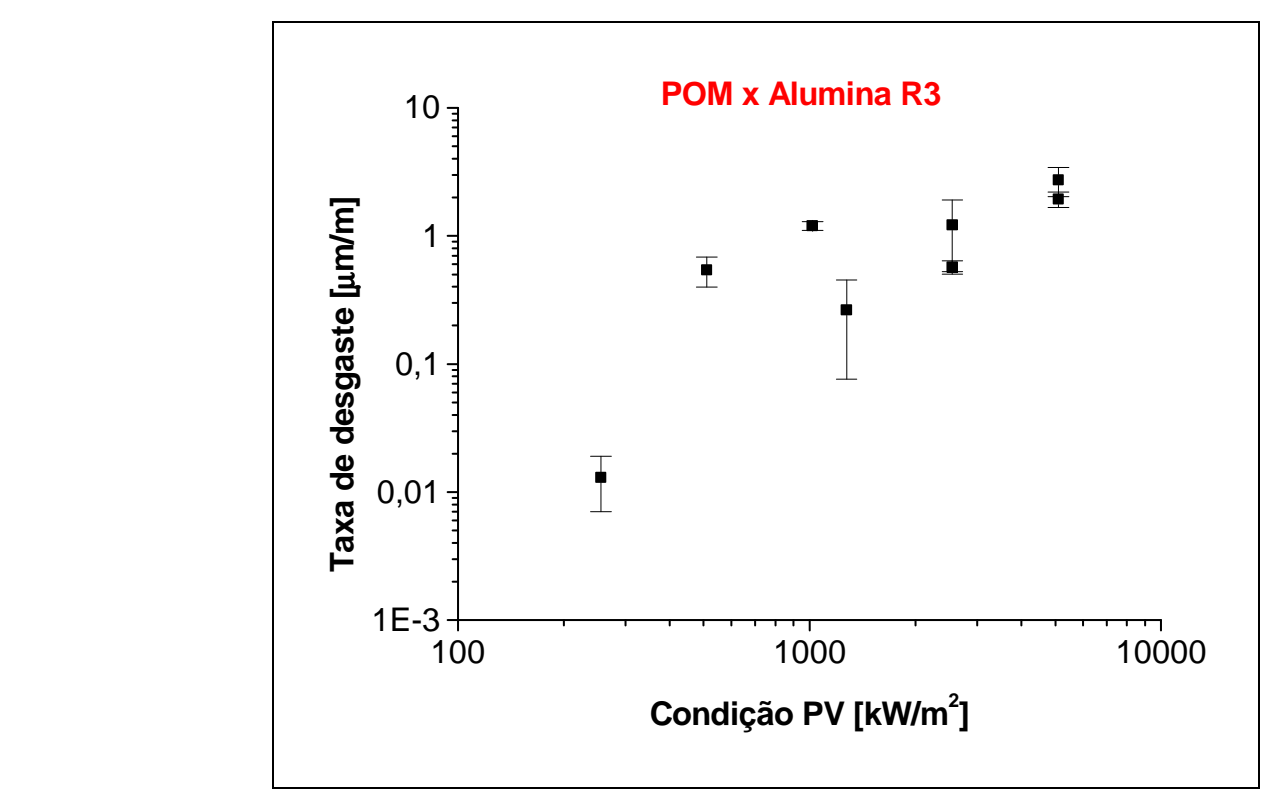

Figura 5.26 - Taxa média de desgaste e seus respectivos desvios padrões em função da condição $\mathrm{PV}$ dos ensaios com o par $\mathrm{POM} \times \mathrm{Al}_{2} \mathrm{O}_{3} \mathbf{R 3}$.

A Figura 5.27 apresenta os mesmos resultados de taxa de desgaste do POM em função da temperatura medida no pino.

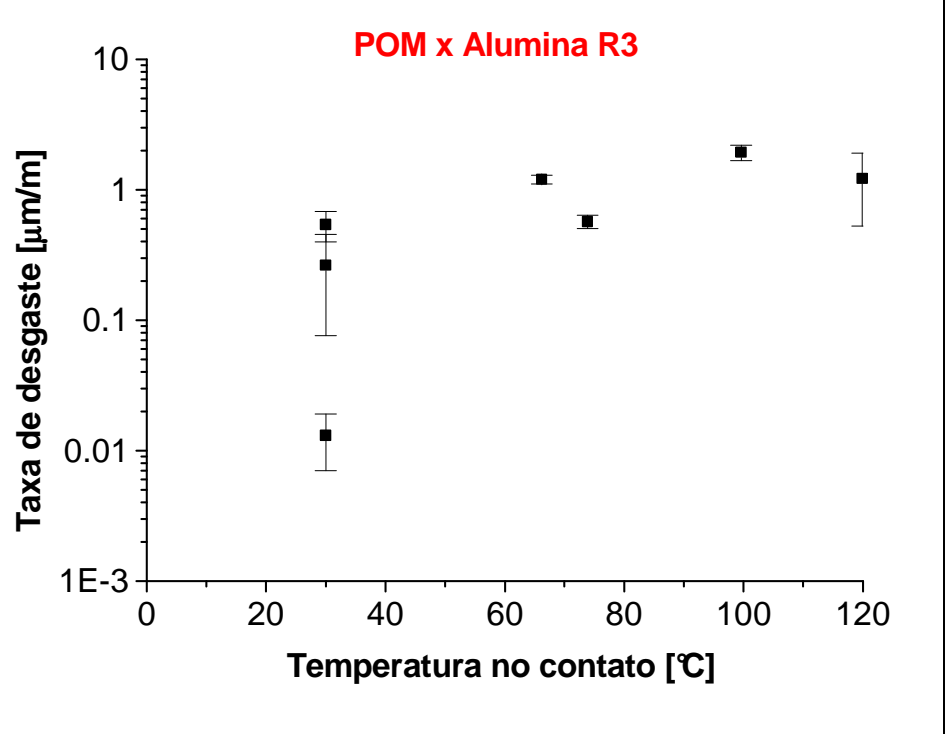

Figura 5.27 - Taxa média de desgaste e seus respectivos desvios padrões em função da temperatura medida no pino, par $\mathrm{POM} \times \mathrm{Al}_{2} \mathrm{O}_{3} \mathrm{R3}$.

Observando a disposição dos resultados nessa Figura, nota-se que, excluindo a menor condição PV, correspondente ao ponto de menor taxa de desgaste, uma elevação da temperatura de 30 para $120{ }^{\circ} \mathrm{C}$ provocou uma elevação na taxa de desgaste de 
0,26 até $2,7 \mu \mathrm{m} / \mathrm{m}$, o que sugere uma correspondência do aumento do desgaste com o aumento da temperatura. No entanto, vale salientar que a análise por curvas de regressão desses mesmos pontos mostrou coeficientes de correlação sempre menores que 0,7 , indicando uma correlação deficiente entre a temperatura e a taxa de desgaste.

Por outro lado, notou-se que a observação de aumento da taxa de desgaste com temperaturas mais elevadas se repetiu em todos os ensaios realizados com discos de alumina; com exceção da condição UHMWPE R4.

Nos ensaios de desgaste, tanto com POM quanto com UHMWPE, as temperaturas mais elevadas não ultrapassaram $75 \%$ da temperatura de fusão do polímero. Mesmo não ocorrendo fusão completa, observa-se que esse aumento da temperatura provoca quedas significativas nas propriedades mecânicas (Figura 2.5 e Figura 5.15) e mudanças em algumas propriedades físico-químicas (como o trabalho de adesão $-\mathrm{W}_{\mathrm{ab}}{ }^{18}$, volume específico ${ }^{7}$ e condutividade térmica ${ }^{18}$ ), todas potencialmente importantes quanto ao desgaste de polímeros. Sendo as propriedades mecânicas reduzidas, maiores serão as deformações e mais 'eficiente' será a atuação danosa dos mecanismos de desgaste.

Observando a superfície dos pinos, pode-se dizer que ocorreu uma mudança na morfologia da superfície de desgaste com o aumento da severidade das condições no contato. Nas condições PV menos severas, foram notados riscos provocados pelas asperezas do contra-corpo (Figura 5.28). É possível que tais riscos tenham sido originados do mecanismo de abrasão a dois corpos. 


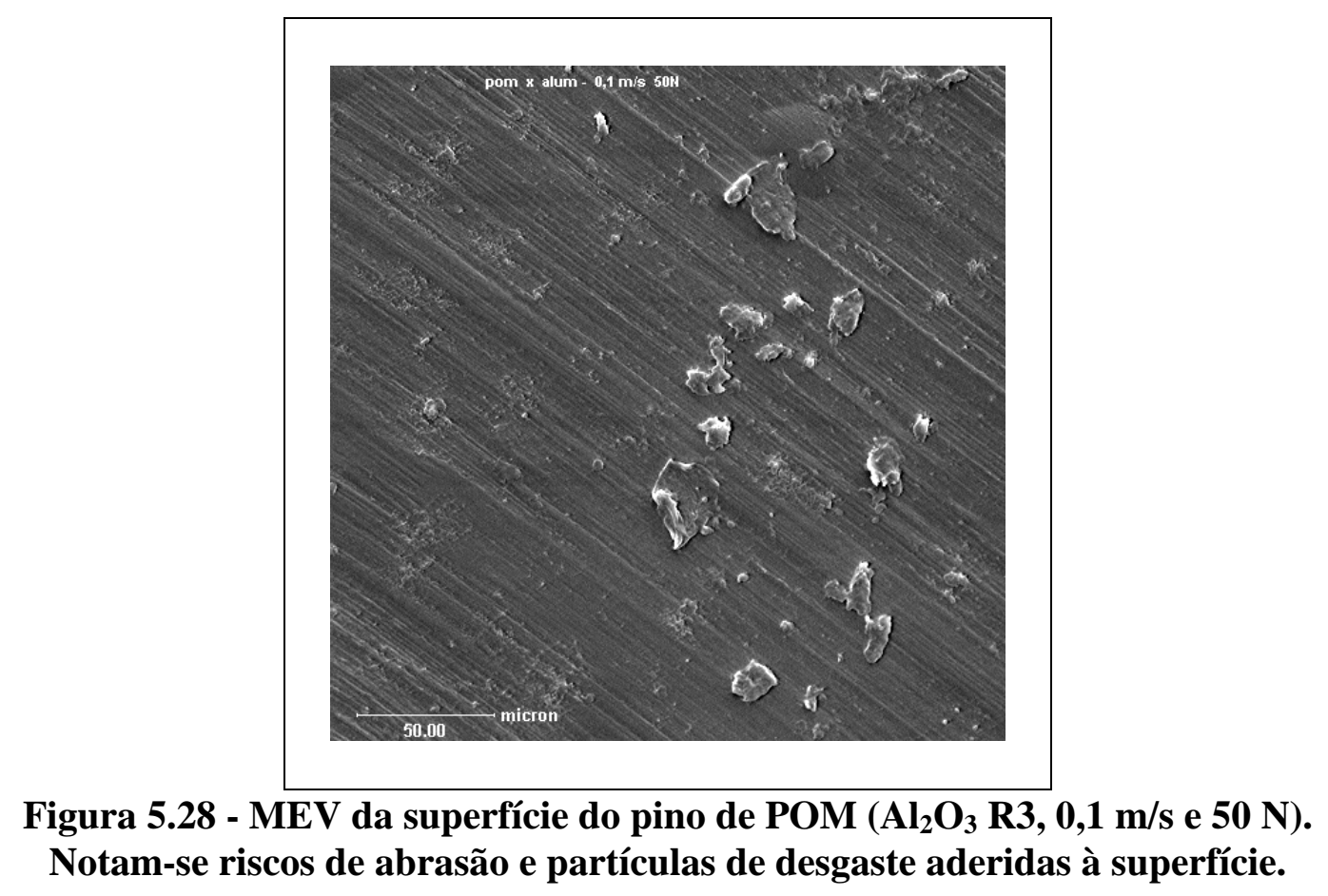

Por outro lado, com o aumento da condição PV, além dos riscos, também observou-se a morfologia de ondas (mostrado na Figura 5.29), passando a ser o fenômeno preponderante. A literatura ${ }^{22}$ tem relacionado essa morfologia de desgaste com mecanismos de fadiga. A ocorrência desse mecanismo estaria relacionada à atuação cíclica das asperezas do contra-corpo, que provocaria uma deformação intensa na superfície do polímero, conduzindo à nucleação e propagação de trincas e, conseqüentemente, produzindo na superfície a morfologia de ondas. 


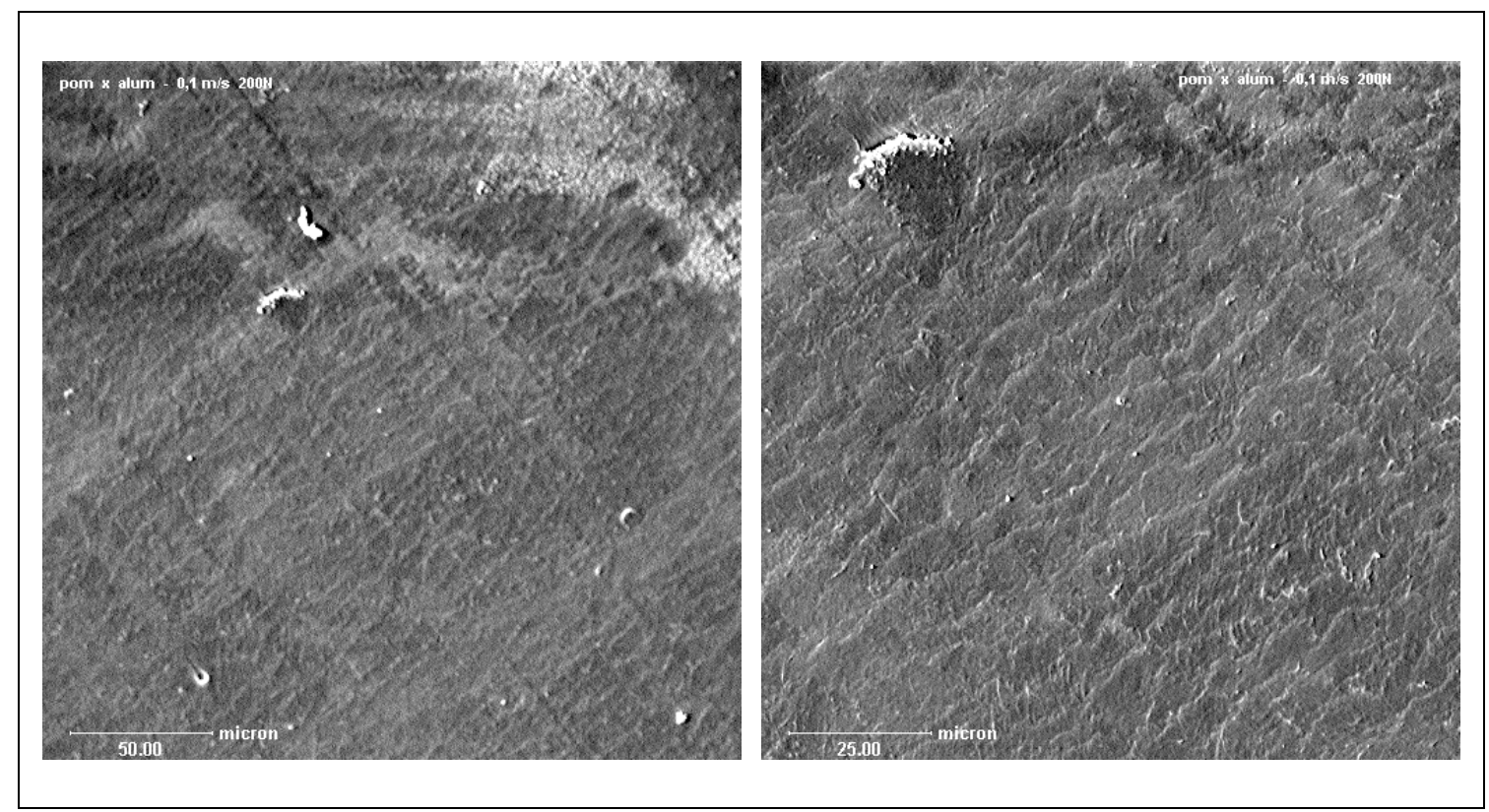

Figura 5.29 - MEV da superfície de pino de $\mathrm{POM}\left(\mathrm{Al}_{2} \mathrm{O}_{3} \mathrm{R3}, 0,1 \mathrm{~m} / \mathrm{s}\right.$ e $\left.200 \mathrm{~N}\right)$. Notam-se riscos de abrasão e formação de ondas.

Em termos dos prováveis mecanismos abrasivos que causaram os riscos observados, sabe-se da literatura ${ }^{26}$ que a remoção de material da superfície na abrasão a dois corpos pode ser dividida em quatro micromecanismos (microcorte, microssulcamento, microlascamento e microfadiga de baixo ciclo). No entanto, não foi possível identificar, além do microcorte e microssulcamento, a ocorrência de microfadiga.

A observação de uma superfície desgastada do pino com maior ampliação mostrou um aspecto fragmentado e quebradiço nas bordas dos riscos (Figura 5.30). Essa evidência sugere a ocorrência de ruptura frágil ( nessas regiões, indicando a possibilidade de ocorrência do microlascamento, ainda que de forma limitada. No entanto, vale ressaltar que não se observou tal fenômeno nos ensaios com condições PV mais severas, sendo o mesmo também ausente nos pinos de UHMWPE. Possivelmente, com o aumento da temperatura no contato devido ao aumento da condição PV, deve haver uma conseqüente queda nas propriedades mecânicas do polímero, ocasionando possibilidades para ocorrência de fratura dúctil nessas condições.

Devido à ação simultânea dos micromecanismos abrasivos acima descritos, será adotada somente a denominação abrasão quando da ocorrência de riscos nas superfícies dos pinos. 


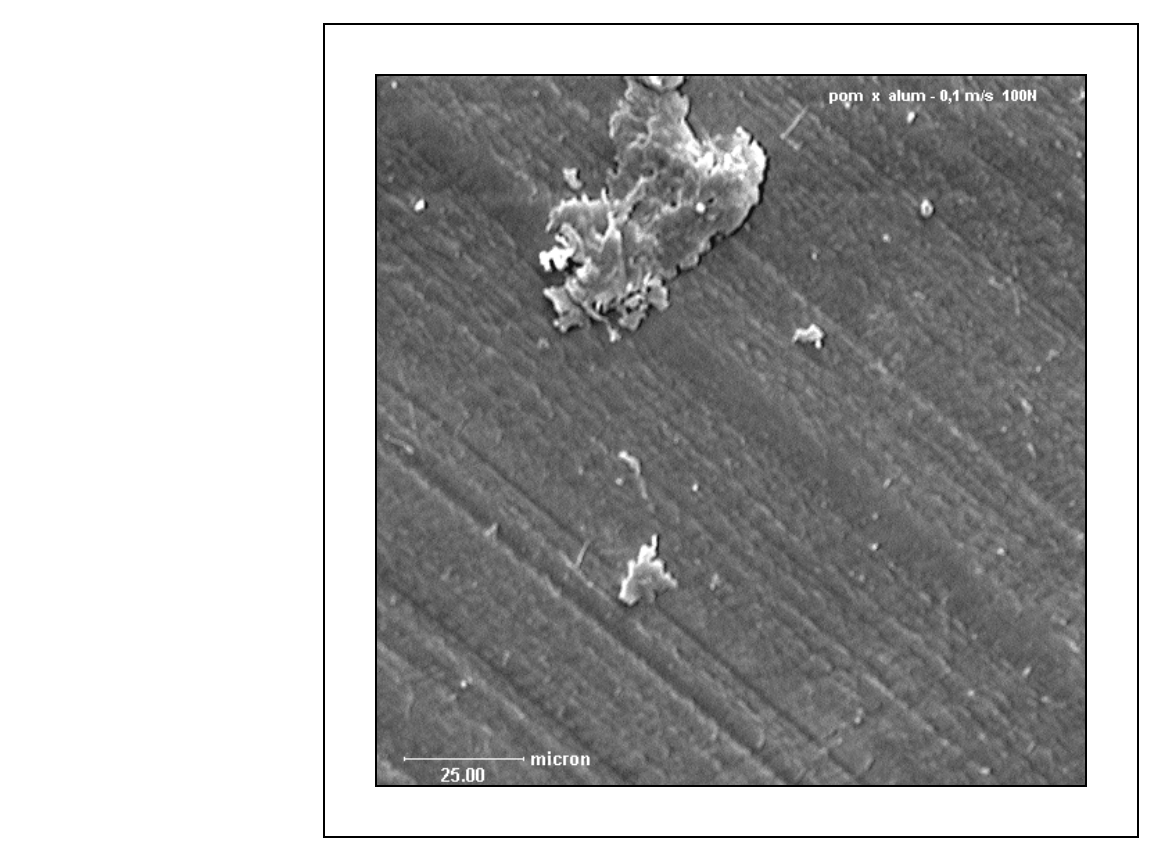

Figura 5.30 - MEV da superfície de pino de $\mathrm{POM}\left(\mathrm{Al}_{2} \mathrm{O}_{3} \mathrm{R3}, 0,1 \mathrm{~m} / \mathrm{s}\right.$ e $\left.100 \mathrm{~N}\right)$. Nota-se um aspecto fragmentado da bordas dos riscos e partículas aglomeradas.

Na Figura 5.31 (a), observa-se partículas de desgaste de diversos tamanhos, apresentando formato de lâminas (flocos ou placas) e bastões. Tanto os bastões quanto as lâminas são formados por partículas de desgaste menores, que se aglomeram enquanto são pressionadas pelo pino contra o disco. Estas partículas que se aglomeram podem ser provenientes da ação danosa de algum mecanismo de desgaste que atuou em um dado momento do ensaio, ou são partículas que retornaram à pista de contato após se desprenderem do pino e terem permanecido ao lado da pista de desgaste.

Na Figura 5.31 (b), fica mais evidente que, com o decorrer do processo de desgaste, as partículas tendem a se acumular em uma mesma região, formando uma placa heterogênea (lâminas), composta por pequenas partículas esmagadas (laminadas). 


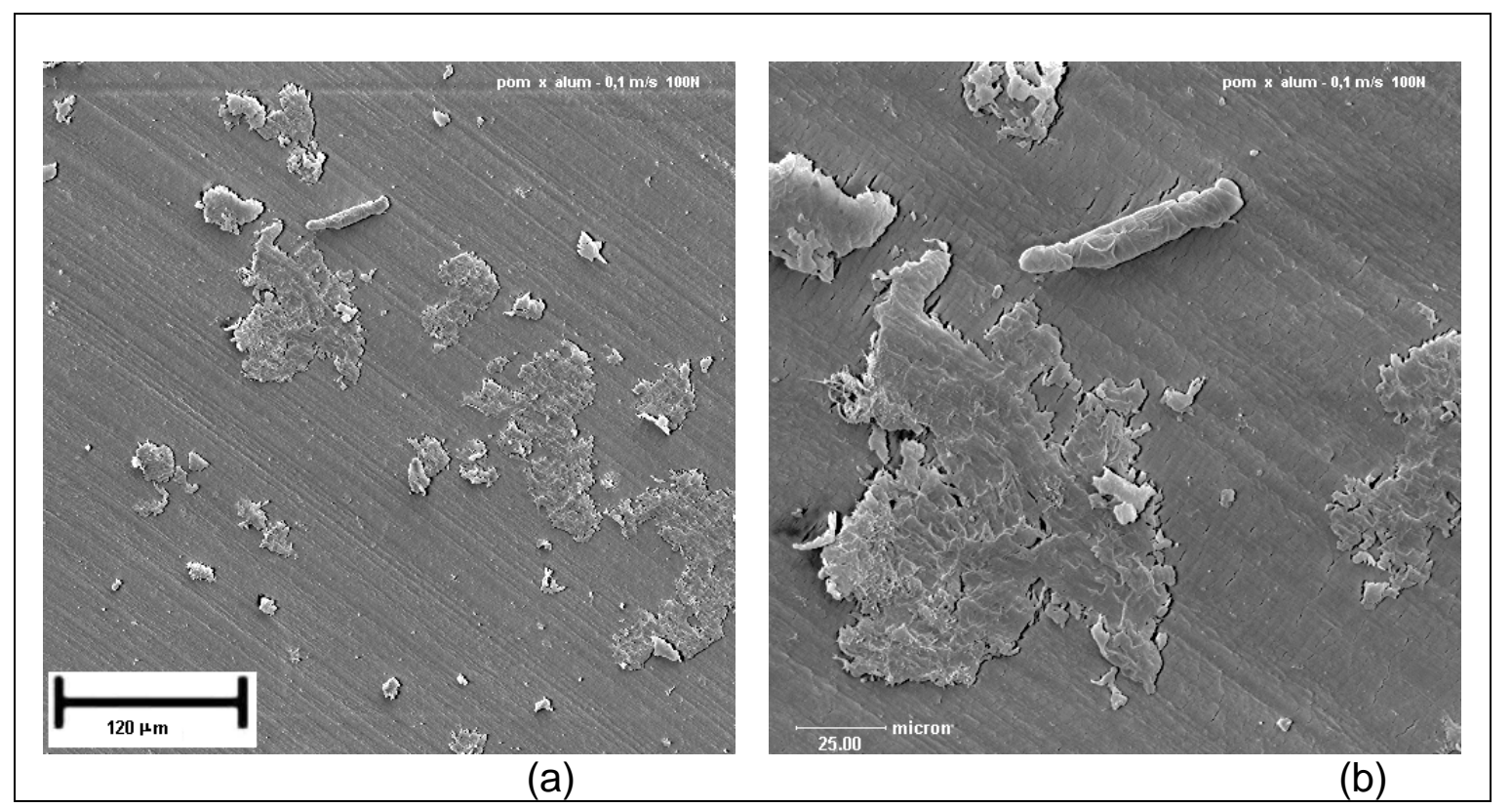

Figura 5.31 - MEV da superfície de pino de $\mathrm{POM}\left(\mathrm{Al}_{2} \mathrm{O}_{3} \mathrm{R3}, 0,1 \mathrm{~m} / \mathrm{s}\right.$ e $\left.100 \mathrm{~N}\right)$ Partículas c/ diversos tamanhos e formas (a) aglomeração de partículas (b).

Além da superfície dos pinos, as superfícies dos discos e as partículas de desgaste também foram observadas. A Figura 5.32 mostra a superfície de um disco de alumina, com partículas de desgaste presentes na pista de desgaste e também ao lado desta. Esse fato se repete na maioria das condições PV ensaiadas, tanto nos ensaios com POM, quanto com UHMWPE, e principalmente contra o disco de alumina, com o que se observou os maiores valores de taxa de desgaste.

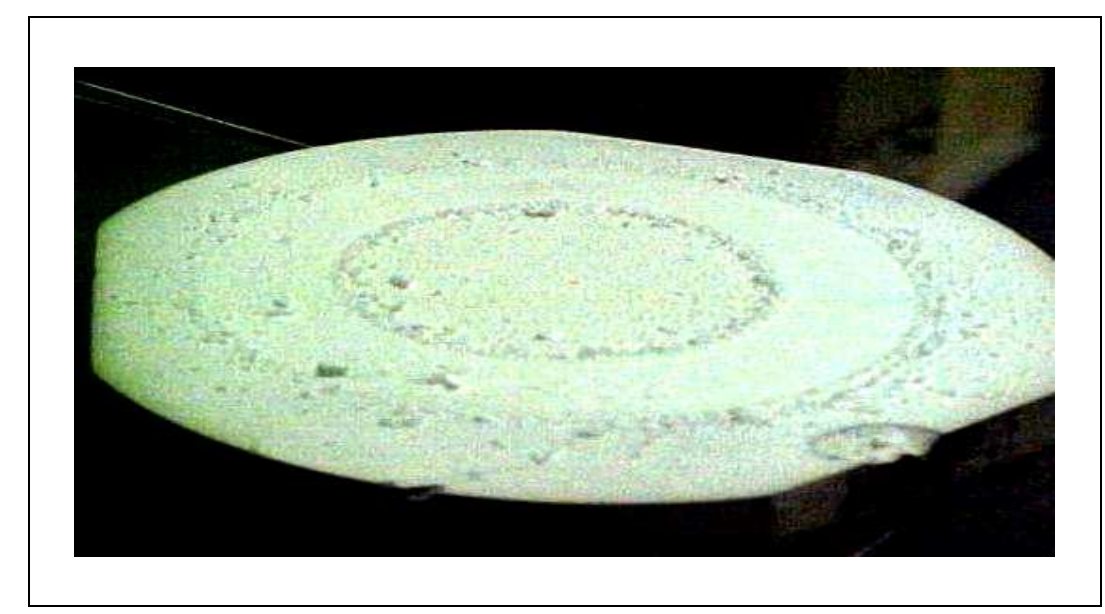

Figura 5.32 - Disco de alumina após a realização do ensaio de desgaste contra POM.

A presença de material polimérico aderido à superfície dos discos, na região da pista de contato, pode ser explicada da seguinte forma: 
$1^{\circ}$ ) As partículas de desgaste que foram removidas da superfície do pino por algum mecanismo de desgaste permanecem na pista de contato. Posteriores deslizamentos do pino sobre essas partículas provocam o amassamento (laminação) destas sobre as pistas e a sua consequiente adesão. Durante esse processo, as novas partículas podem se aglomerar às primeiras e, com isso, provocar um aumento gradual do tamanho da região com material aderido, formando placas, chegando, no limite, a formar um filme em toda a pista de contato. Com o decorrer dos ensaios, as placas de material aderido são removidas da pista, saindo para as laterais ou sendo transferidas para o próprio pino;

$2^{\circ}$ ) As partículas que se encontravam ao lado da pista de contato (Figura 5.32) retornam à mesma, principalmente nos ensaios com velocidade mais elevada, por efeito de força centrífuga. A sequiência de remoção de material, amassamento, saída da pista de contato, retorno à pista, novo amassamento, aglomeração e adesão à pista de contato, faz com que as grandes placas de material aderido apresentem um aspecto superficial com elevada deformação. Além disso, assim como a superfície desgastada, também é observado riscamento na direção do deslizamento no material aderido;

$3^{\circ}$ ) E, por fim, como hipótese, acredita-se que parte do material presente na superfície dos discos possa ter sido depositado pelos mecanismos tradicionais de transferência de filme polimérico (transferência 'normal' e transferência lamelar) ${ }^{36}$. Como só foi possível observar a superfície dos discos após os ensaios, não se conseguiu evidências contundentes da ocorrência de tais mecanismos.

Em termos da observação do fenômeno de adesão do polímero no contra-corpo, ressalta-se que, apesar da dificuldade em quantificar o volume de material depositado nos discos, pode-se dizer que os ensaios com alumina apresentaram sempre uma maior quantidade de material transferido em relação aos ensaios com aço inoxidável. Esse fato esteve em correspondência com os valores de trabalho de adesão - $\mathrm{W}_{\mathrm{ab}}$ (Tabela 5.21) para os dois pares de materiais poliméricos estudados.

Das análises microscópicas realizadas nas partículas de desgaste de POM e de UHMWPE nas mais diversas condições de carregamento e de acabamento superficial, pode-se dizer que: 
- As partículas de desgaste podem apresentar formatos desde plaquetas lisas, passando por morfologias do tipo escamas, flocos, podendo se deformar até a formação de bastões e de filmes;

- A aglomeração de partículas pode ocorrer devido a aspectos mecânicos (partículas esmagadas contra outras) ou por aspectos térmicos (partículas que se encontram em uma temperatura elevada aderem às outras por estarem em contato);

- O tamanho das partículas foi um aspecto que teve grande variação em um mesmo ensaio, independentemente dos materiais utilizados e das condições de ensaio;

- Houve tendência de uma maior quantidade de partículas nos ensaios com condição PV mais elevada, principalmente nos ensaios com POM.

A Figura 5.33 apresenta de uma forma esquemática o processo de gênese das partículas de desgaste, a partir dos mecanismos de desgaste atuantes (risco, ondas e transferência de filme). Aspectos característicos também são descritos, tantos das partículas de desgaste que saíram da pista de contato, quanto daquelas que permaneceram (ou retornaram) na pista de contato, aderindo-se ao pino ou ao disco durante o ensaio. Em resumo, essa Figura tenta mostrar, de forma generalizada, os possíveis fenômenos que ocorreram na região do contato. Considera-se que os fenômenos descritos estiveram presentes em maior ou menor grau, em todos os pares de materiais ensaiados. As eventuais diferenças serão apresentadas durante a discussão dos resultados de cada par estudado, quando necessário. 


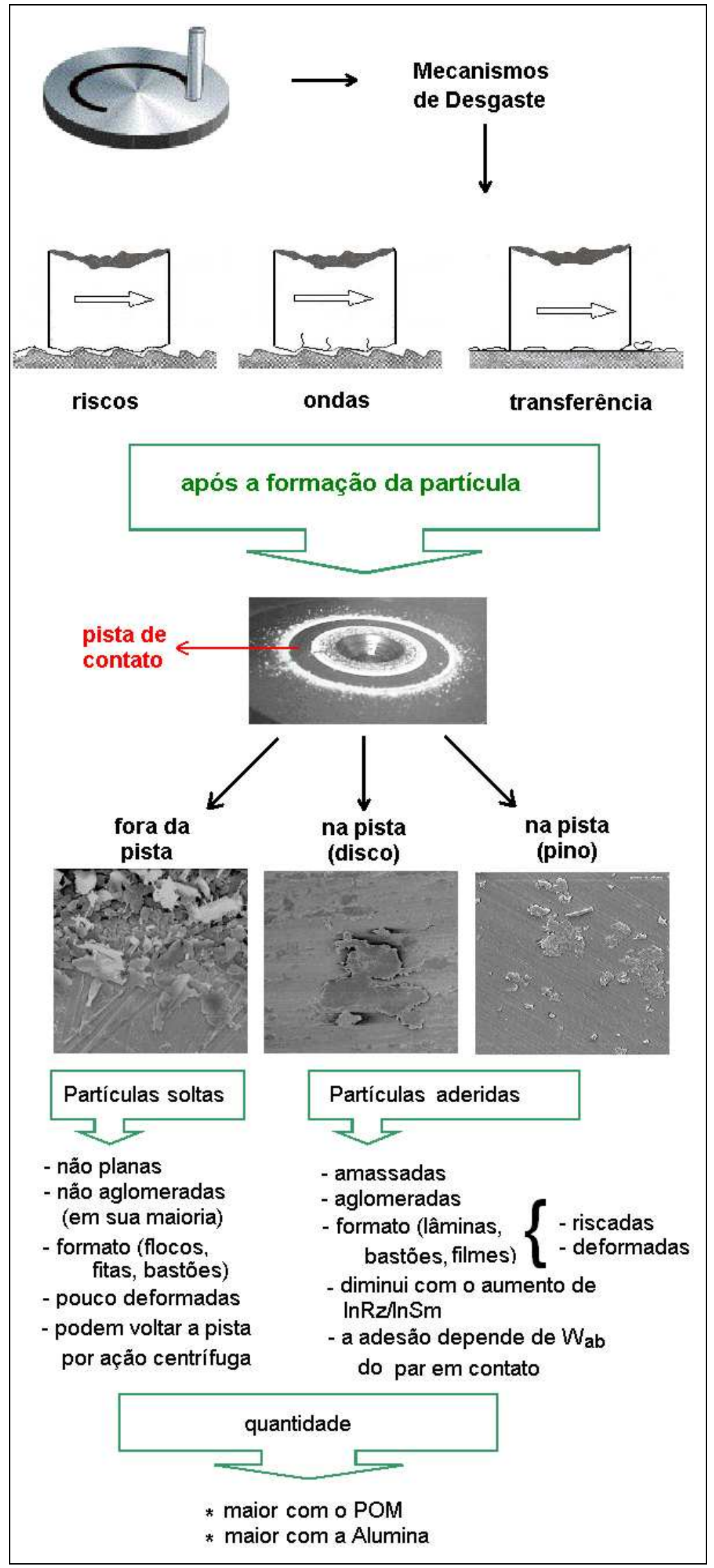

Figura 5.33 - Gênese e características das partículas originadas pelo desgaste. 


\subsubsection{POM x Alumina R4}

A Figura 5.34 apresenta os resultados de taxa de desgaste dos pinos de POM deslizando contra discos de alumina, com acabamento superficial R4, em função da condição PV.

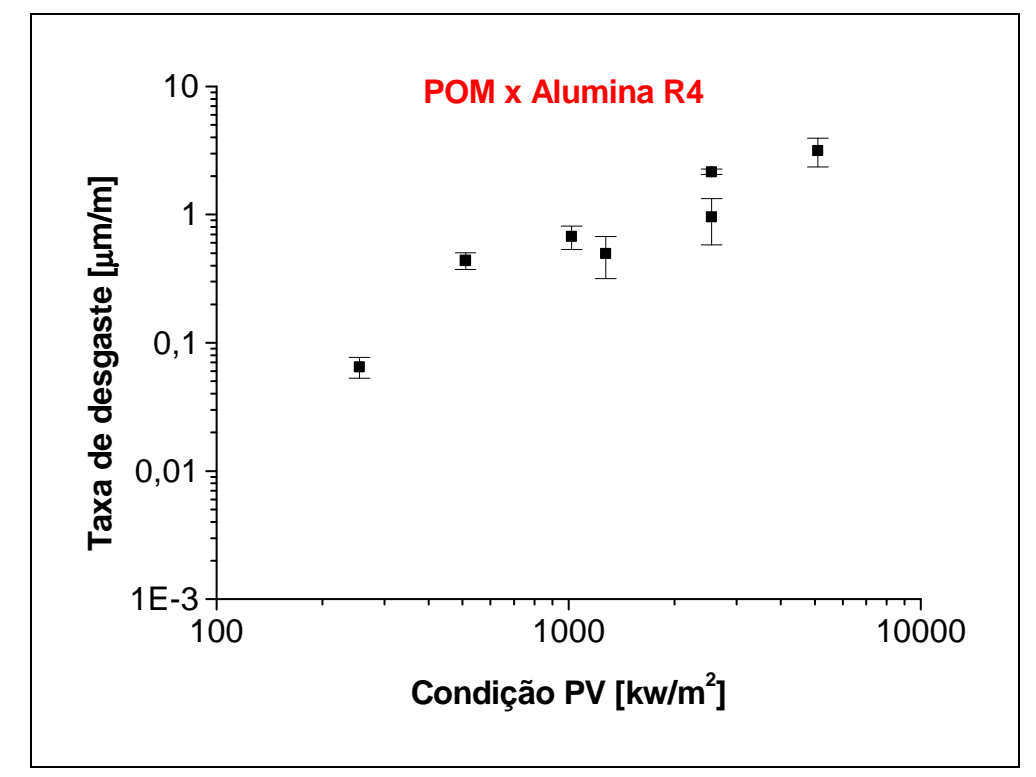

Figura 5.34 - Taxa média de desgaste e seus respectivos desvios padrões em função da condição $\mathrm{PV}$ dos ensaios com o par $\mathrm{POM} \times \mathrm{Al}_{2} \mathrm{O}_{3} \mathbf{R 4}$.

Analisando a Figura 5.34, observa-se uma clara tendência da taxa de desgaste apresentar valores mais elevados nos ensaios com maior condição PV. Essa tendência de crescimento também é bastante nítida na Figura 5.35, a qual apresenta o comportamento da taxa de desgaste com a temperatura próxima ao contato. Nos três ensaios de desgaste que apresentaram as maiores temperaturas, uma variação de temperatura de $10{ }^{\circ} \mathrm{C}$ resultou em aumentos expressivos na taxa de desgaste. Considerase que tal fato esteve relacionado com uma queda significativa nas propriedades mecânicas do POM com o aumento da temperatura. Vale ressaltar que, por volta de 120 ${ }^{\circ} \mathrm{C}$ (Figura 5.10), parte da estrutura cristalina do POM desaparece devido à fusão dos cristalitos, mudando seu estado de borrachoso para viscoso (Figura 2.4). 


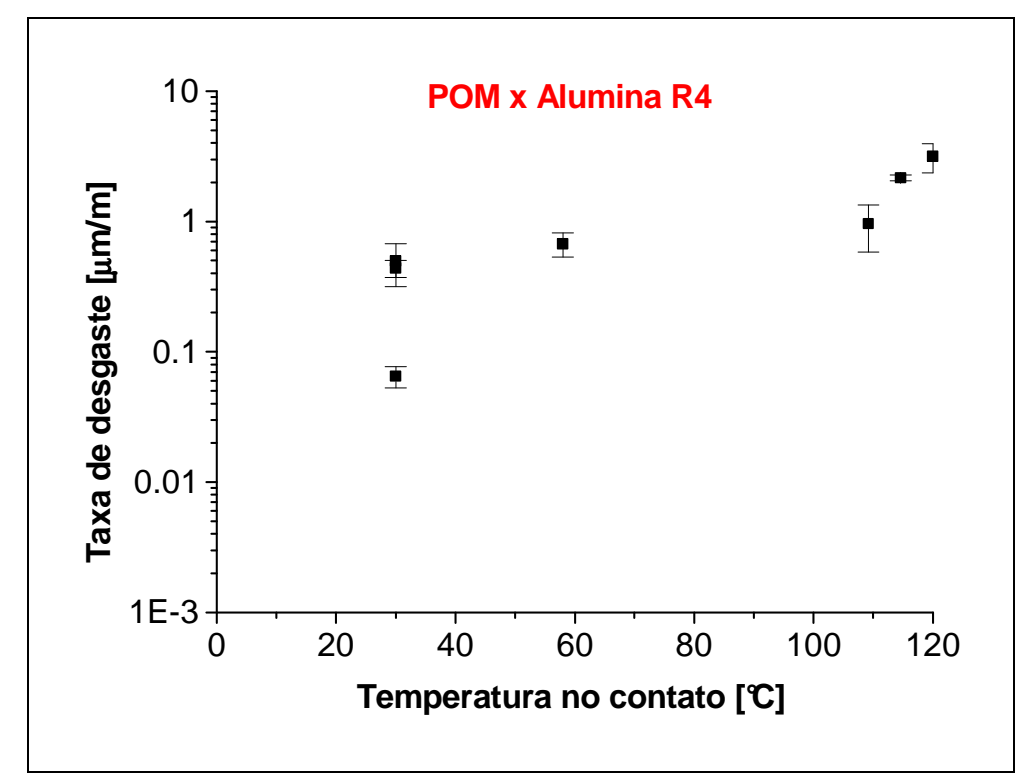

Figura 5.35 - Taxa média de desgaste e seus respectivos desvios padrões em função da temperatura medida no pino dos ensaios com o par $\mathrm{POM} \times \mathrm{Al}_{2} \mathrm{O}_{3} \mathbf{R 4}$.

Observando a superfície resultante dos pinos na Figura 5.36, nota-se que a presença de material aderido foi muito pequena, em comparação com a superfície ensaiada com a rugosidade R3 (vide Figura 5.28). É possível que o aumento da rugosidade dos discos tenha diminuído a tendência à ocorrência da adesão.

\section{Figura 5.36 - MEV da superfície do pino de $\mathrm{POM}\left(\mathrm{Al}_{2} \mathrm{O}_{3} \mathrm{R4}, 0,5 \mathrm{~m} / \mathrm{s}\right.$ e $\left.50 \mathrm{~N}\right)$} Observa-se riscos e poucas partículas depositadas.

Além da presença de partículas com formato de lâminas deformadas e aglomeradas na superfície do pino, observou-se também (Figura 5.37 a e b) algumas 
partículas com aspecto mais geométrico, denotando uma característica frágil. Essa evidência sugere que, com o aumento da magnitude das asperezas do disco de alumina, a ocorrência de mecanismos abrasivos do tipo microfratura torna-se mais provável.

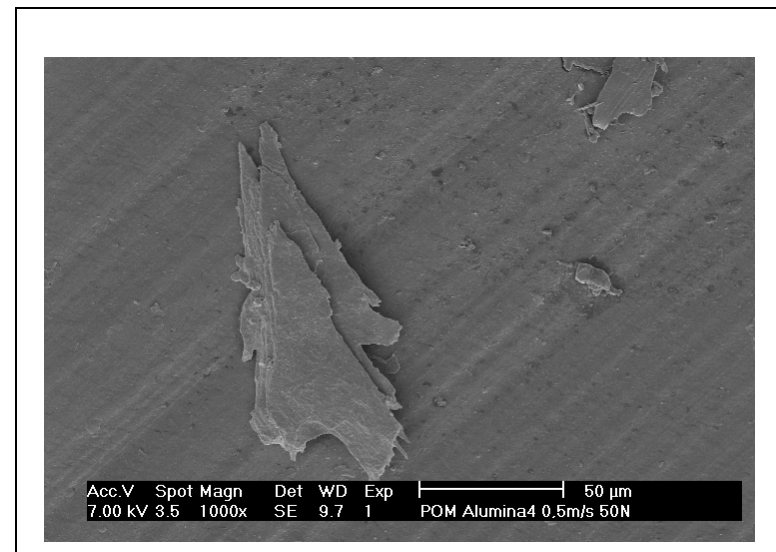

(a)

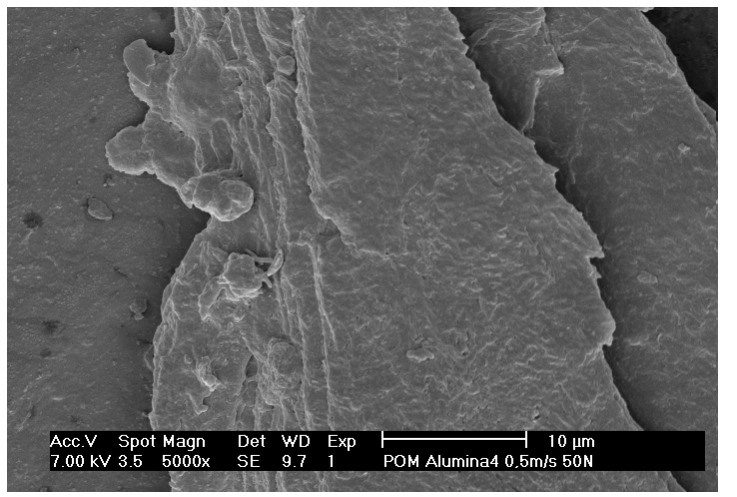

(b)

Figura 5.37 - MEV da superfície do pino de $\mathrm{POM}\left(\mathrm{Al}_{2} \mathrm{O}_{3} \mathrm{R4}, 0,5 \mathrm{~m} / \mathrm{s}\right.$ e $\left.50 \mathrm{~N}\right)$. Partículas com aspecto frágil (quebradiço / geométrico).

$\mathrm{Na}$ Figura 5.38, observa-se que as poucas partículas de desgaste que retornaram à superfície do pino estão fortemente aderidas a este, apresentado um aspecto de incorporação ao material original.

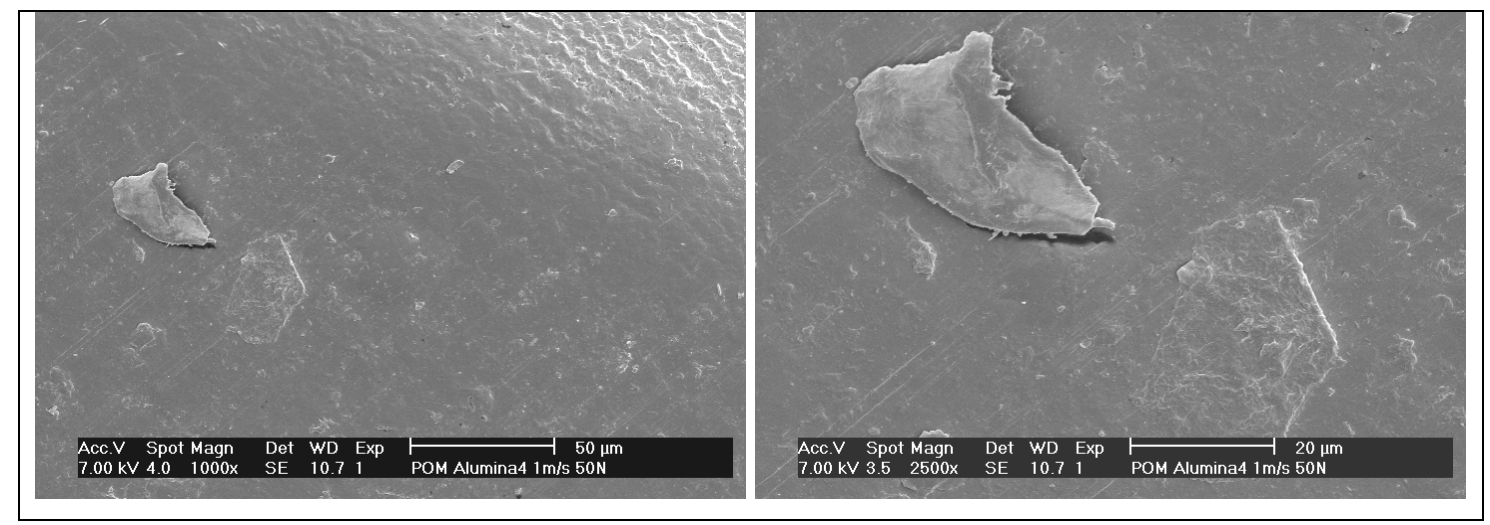

Figura 5.38 - MEV da superfície do pino de $\mathrm{POM}\left(\mathrm{Al}_{2} \mathrm{O}_{3} \mathrm{R4}, 1 \mathrm{~m} / \mathrm{s}\right.$ e $\left.50 \mathrm{~N}\right)$. Partículas fortemente aderidas ao pino e morfologia tipo ondas.

Como observado nos resultados dos ensaios com alumina R3, uma mudança dos mecanismos de desgaste também ocorre nesse nível de rugosidade quando há aumento da severidade da condição de ensaio. Nas condições PV menos severas, observou-se somente a presença de riscos provocados pelas asperezas do contra-corpo (Figura 5.36). 
No entanto, com o aumento da condição PV, além dos riscos, também houve a formação de ondas (Figura 5.39).

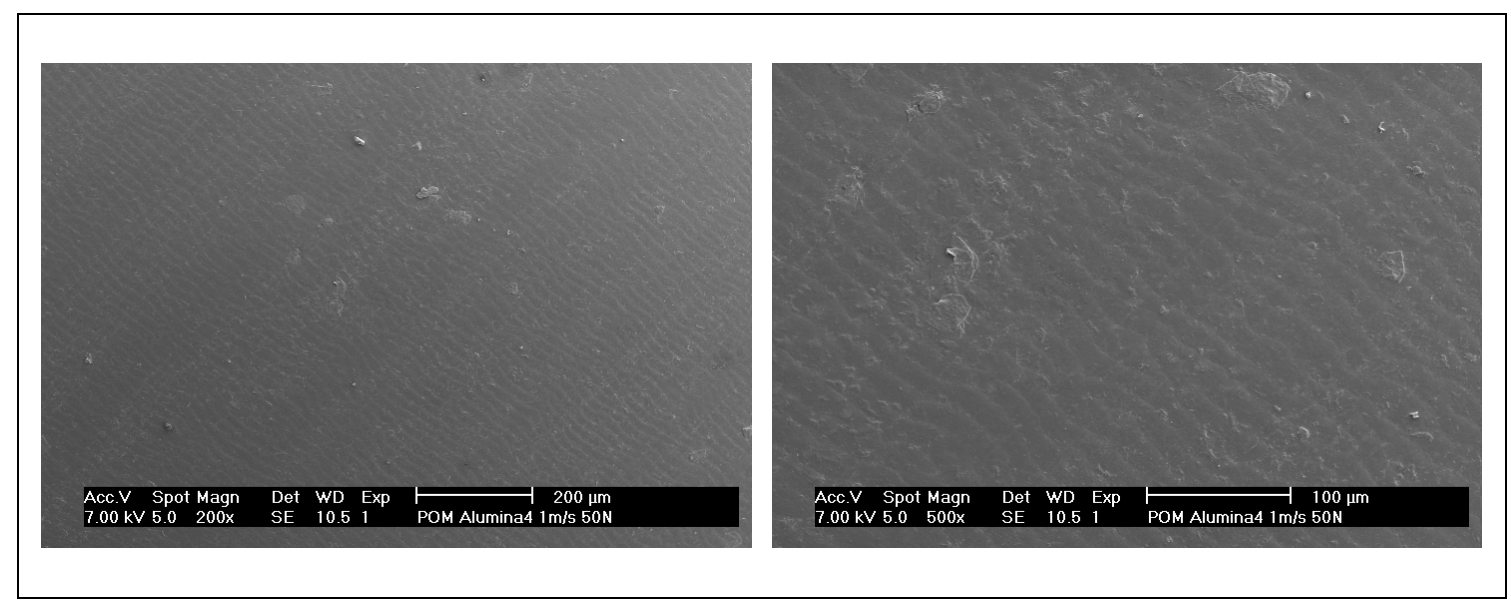

Figura 5.39 - MEV da superfície de pino de $\mathrm{POM}\left(\mathrm{Al}_{2} \mathrm{O}_{3} \mathrm{R4}, 1 \mathrm{~m} / \mathrm{s}\right.$ e $\left.50 \mathrm{~N}\right)$. Mecanismo de formação de ondas e partículas aderidas ao pino, apresentando a mesma morfologia de desgaste da superfície do pino.

Após a identificação dos mecanismos de desgaste e do efeito da condição PV e da temperatura no contato do par POM-Alumina, analisaremos o efeito do acabamento superficial na taxa de desgaste desse par.

\subsubsection{Efeito do acabamento superficial no desgaste de POM $x$ Alumina}

A Figura 5.40 apresenta os resultados de taxa de desgaste dos pinos de POM deslizando contra discos de alumina, com os dois níveis de acabamento superficial. 


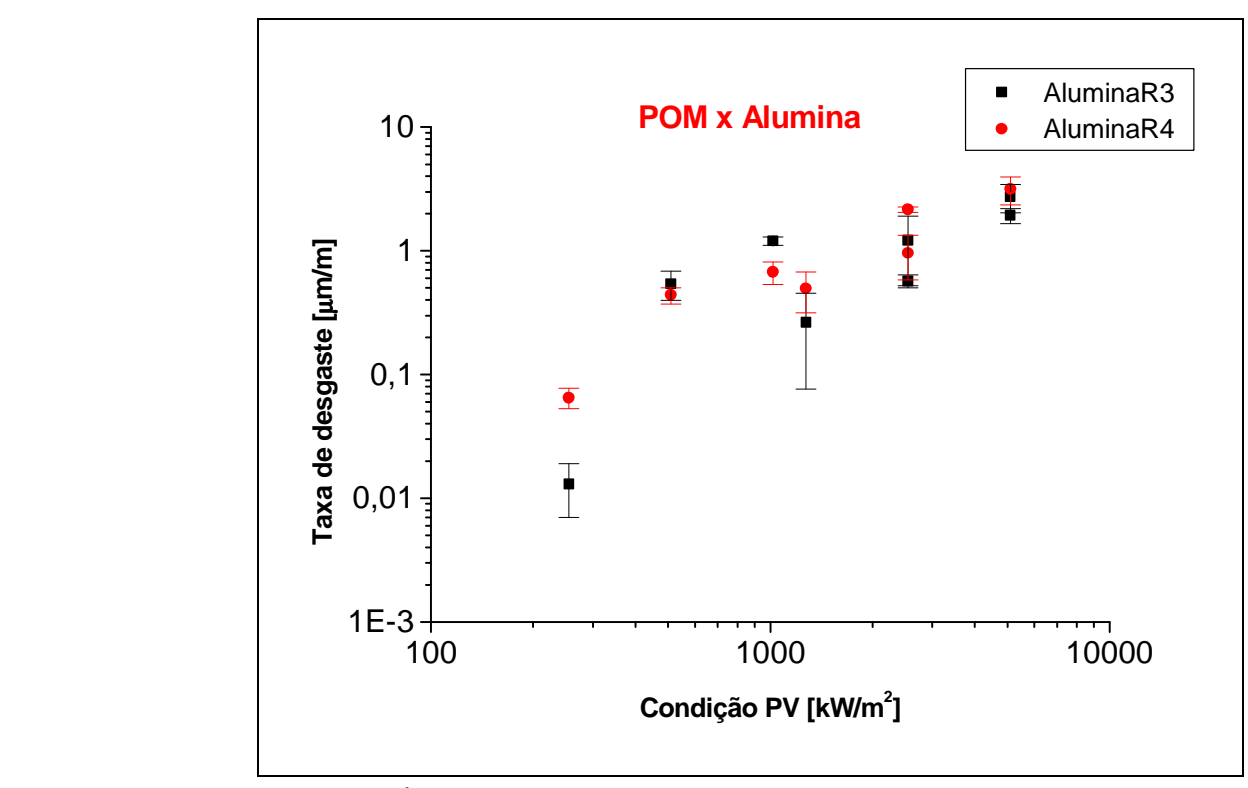

Figura 5.40 - Taxa média de desgaste e seus respectivos desvios padrões em função da condição $\mathrm{PV}$, par $\mathrm{POM} \times \mathrm{Al}_{2} \mathrm{O}_{3}$.

Nota-se na Figura 5.40 que, excluindo os resultados de desgaste resultantes da menor condição PV, na qual o contra-corpo mais rugoso provocou uma maior taxa de desgaste no POM, não houve diferença significativa entre os valores de taxa de desgaste com a mudança de acabamento superficial dos discos de alumina. Como esperado, a taxa de desgaste mostrou tendência de crescimento para condições PV mais severas.

Com a Figura 5.41, pode-se analisar o efeito do acabamento superficial no comportamento da taxa de desgaste em função da temperatura atingida no contato durante o ensaio. Novamente, verifica-se uma tendência de crescimento da taxa de desgaste com o aumento da temperatura, não importando os níveis de acabamento superficial. 


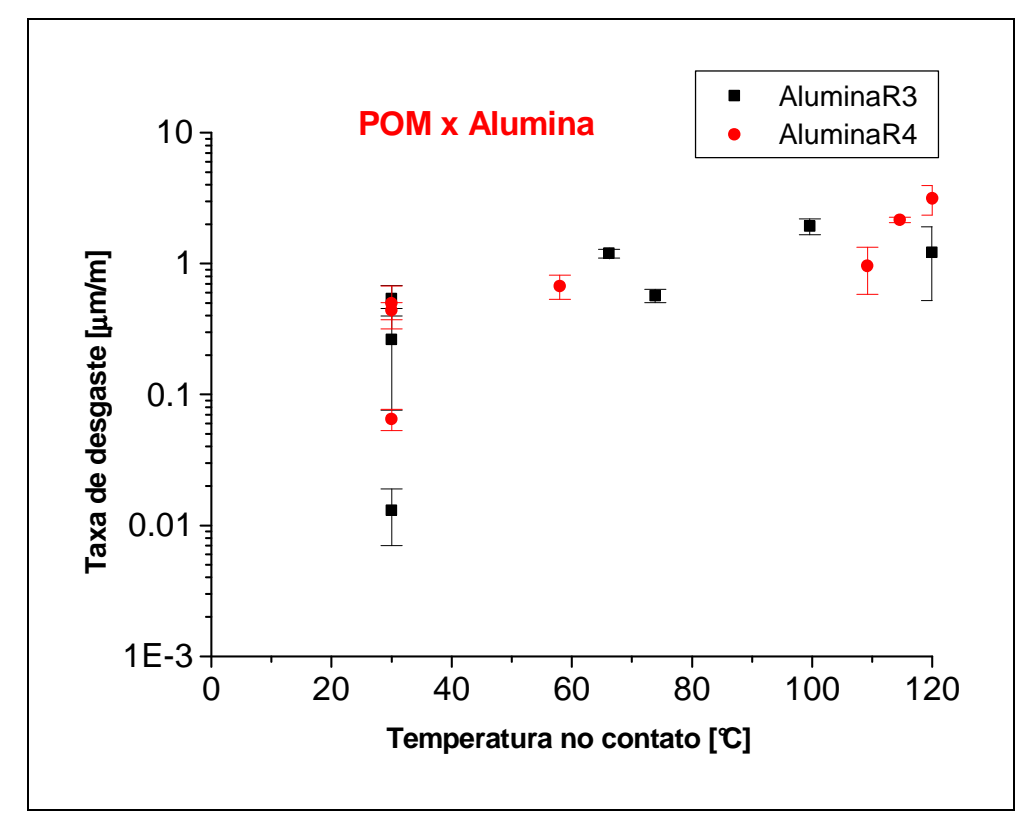

Figura 5.41 - Taxa média de desgaste e seus respectivos desvios padrões em função da temperatura no contato dos ensaios com o par $\mathrm{POM} \times \mathrm{Al}_{2} \mathrm{O}_{3}$.

Em termos do efeito do acabamento superficial dos discos de alumina na taxa de desgaste do POM, a Figura 5.42 e principalmente a Tabela 5.40, mostram que, quando se analisa globalmente os dois grupos de resultados os valores da taxa de desgaste, ou são estatisticamente iguais, ou se elevam para rugosidades mais elevadas. Observando os resultados em função da condição de ensaio, houve uma exceção significativa, referente à condição com carga de $200 \mathrm{~N}$ e velocidade de deslizamento de $0,1 \mathrm{~m} / \mathrm{s}$, onde o acabamento mais rugoso provocou uma taxa de rugosidade menor. Vale ressaltar que este foi o único caso de exceção em todas as séries de ensaios da presente pesquisa. 


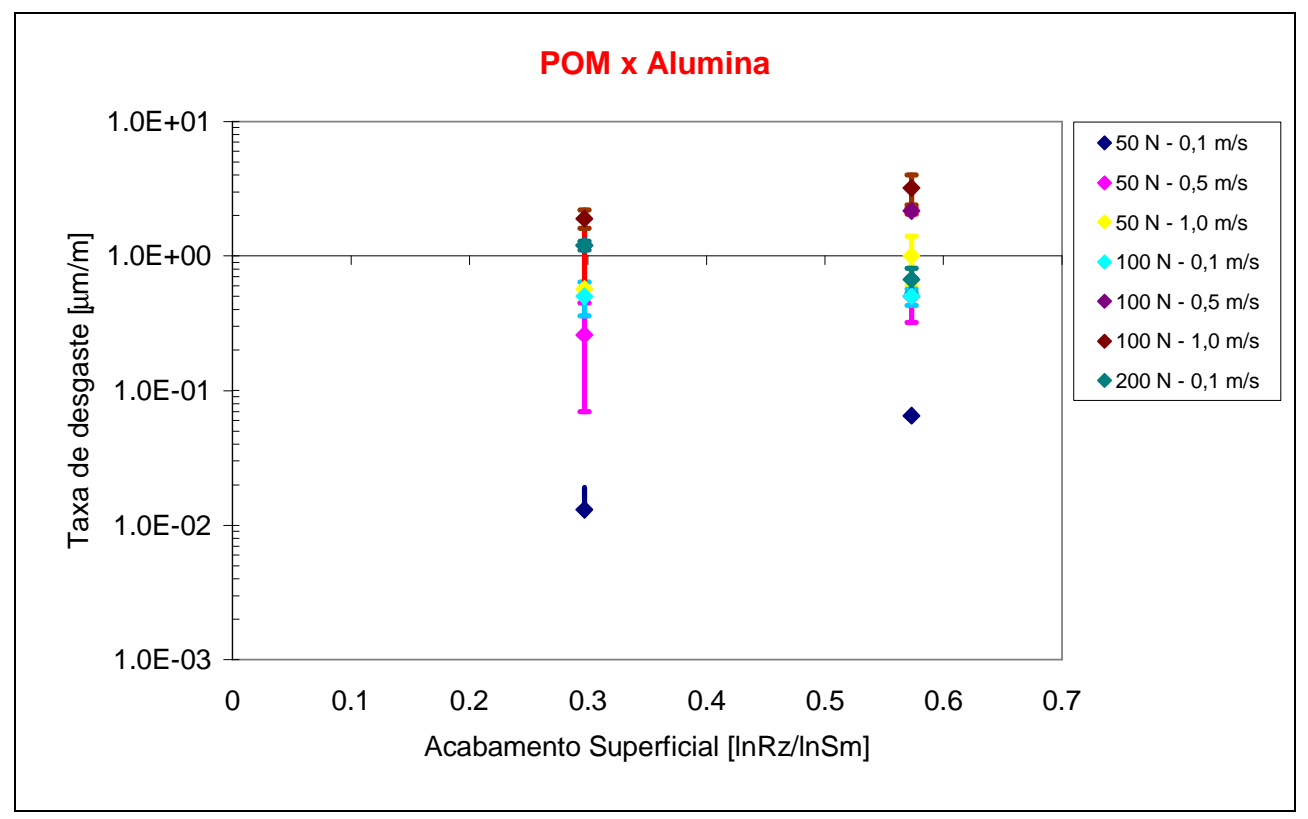

Figura 5.42 - Taxa média de desgaste em função do acabamento superficial dos ensaios com o par $\mathrm{POM} \times \mathrm{Al}_{2} \mathrm{O}_{3}$.

\subsubsection{POM x Aço Inox R2}

A Figura 5.43 apresenta os resultados de taxa de desgaste dos pinos de POM deslizando contra discos de aço inoxidável, com acabamento superficial R2, em função da condição PV.

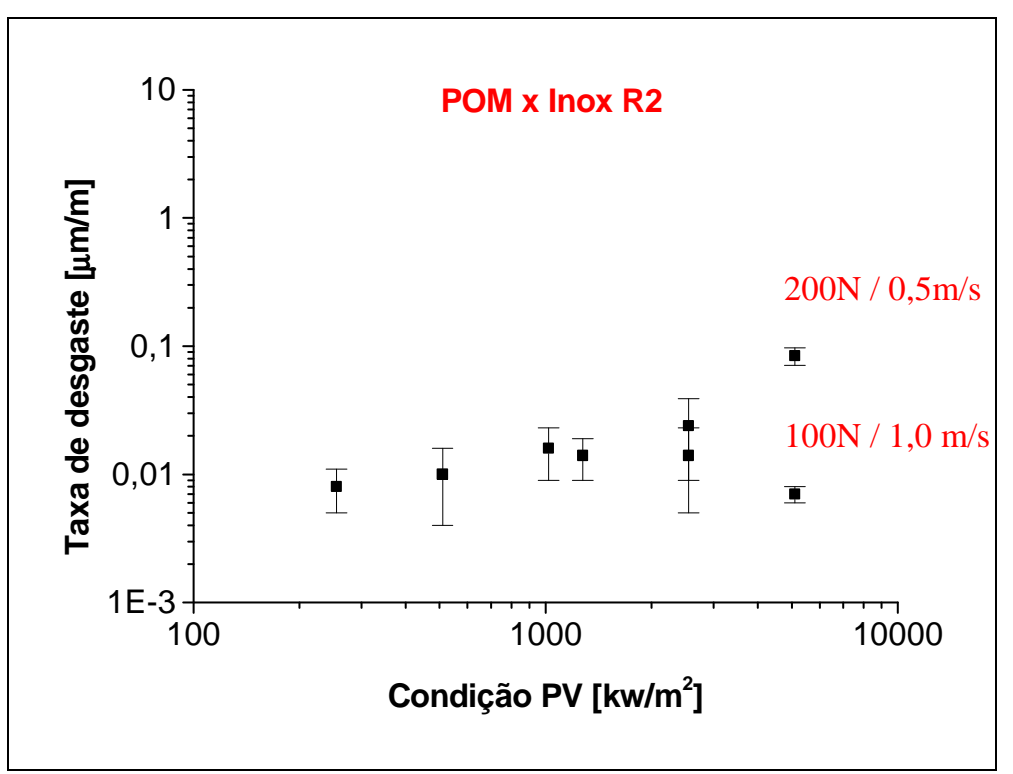

Figura 5.43 - Taxa média de desgaste e seus respectivos desvios padrões em função da condição PV dos ensaios com o par POM x Aço inox R2. 
Nota-se que os valores médios das taxas de desgaste indicaram alguma tendência de crescimento com o aumento da condição PV; entretanto, a elevada dispersão dos resultados torna essa constatação imprecisa.

Analisando as Tabelas de 5.40 a 5.43 que mostram os resultados finais de taxa de desgaste dos pares ensaiados, pode-se dizer que a taxa de desgaste em ensaios realizados sob as mesmas condições PV (vide Anexo A) foi sempre mais elevada quando a carga era maior. Pode ser visto pela Figura 5.43 que a diferença nos valores foi intensamente acentuada com o par POM contra aço Inoxidável R2.

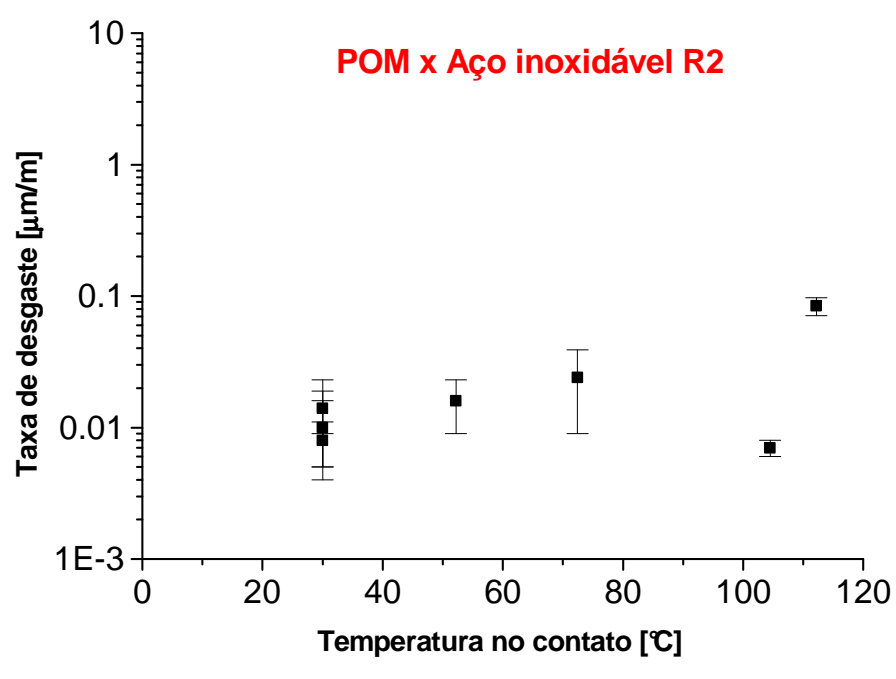

Figura 5.44 - Taxa média de desgaste e seus respectivos desvios padrões em função da temperatura medida no pino dos ensaios com o par POM x Aço Inox R2.

A Figura 5.44 mostra o efeito da temperatura próxima à região do contato na taxa de desgaste do POM deslizando contra aço inoxidável R2. Observa-se nessa Figura que a temperatura no contato praticamente não influenciou nos valores de taxa de desgaste medidos, ao menos no intervalo de 30 a $105{ }^{\circ} \mathrm{C}$. Diferentemente dos resultados com alumina, nos quais houve elevação da taxa de desgaste com a condição PV e com a temperatura, com aço inoxidável não se observou tal efeito.

Observando a superfície dos pinos, pode-se dizer que, assim como nos ensaios de POM x Alumina, aqui também ocorreu uma mudança na atuação dos mecanismos de desgaste com o aumento da severidade do ensaio. Nas condições PV menos severas, ocorreu riscamento (Figura 5.45) e, com o aumento da condição PV, além dos riscos, houve também a formação de ondas (Figura 5.46). 


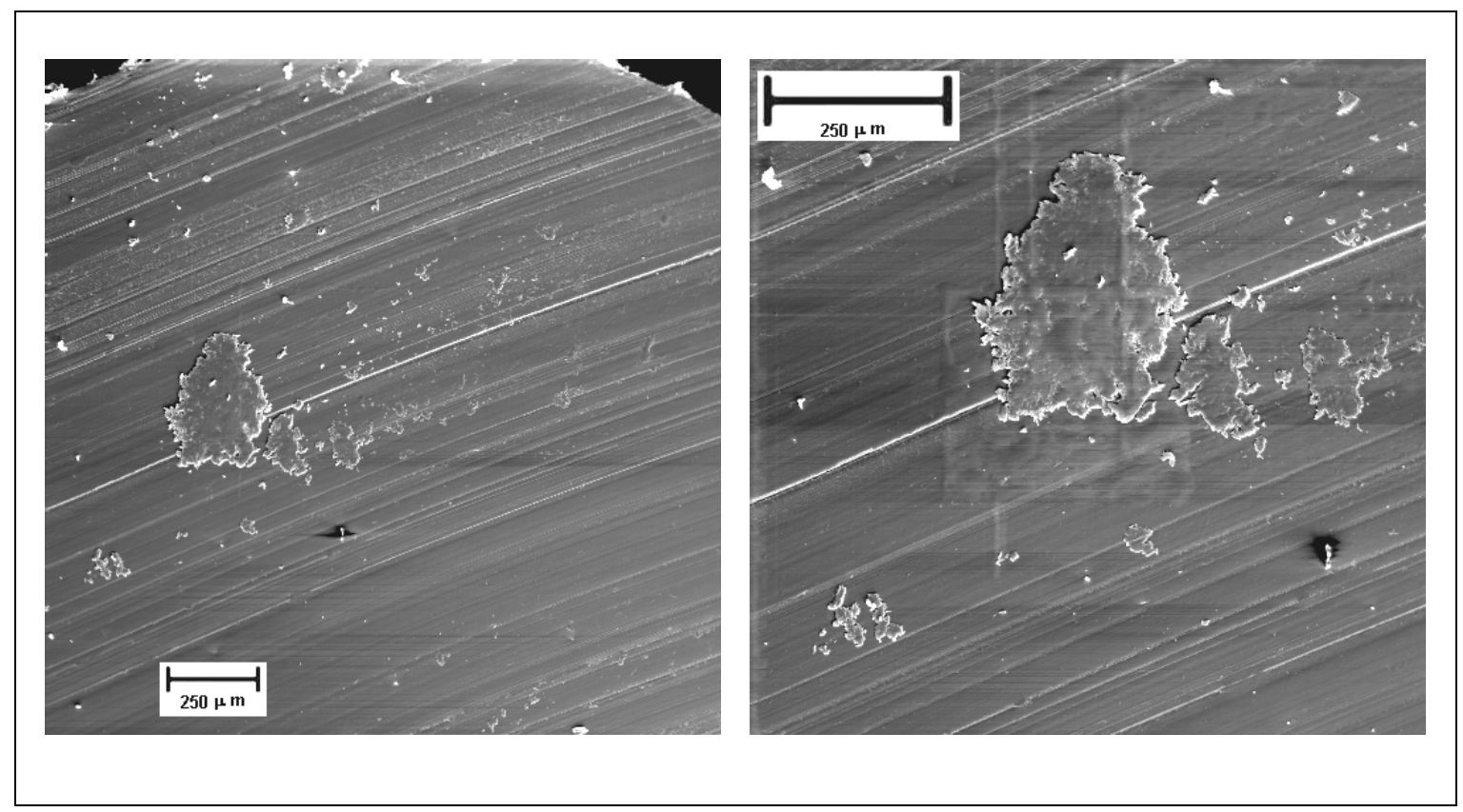

Figura 5.45 - MEV da superfície de pino de POM (Aço Inox R2, 0,5 m/s e 50 N). Observa-se presença de riscos e partículas aderidas e aglomeradas.

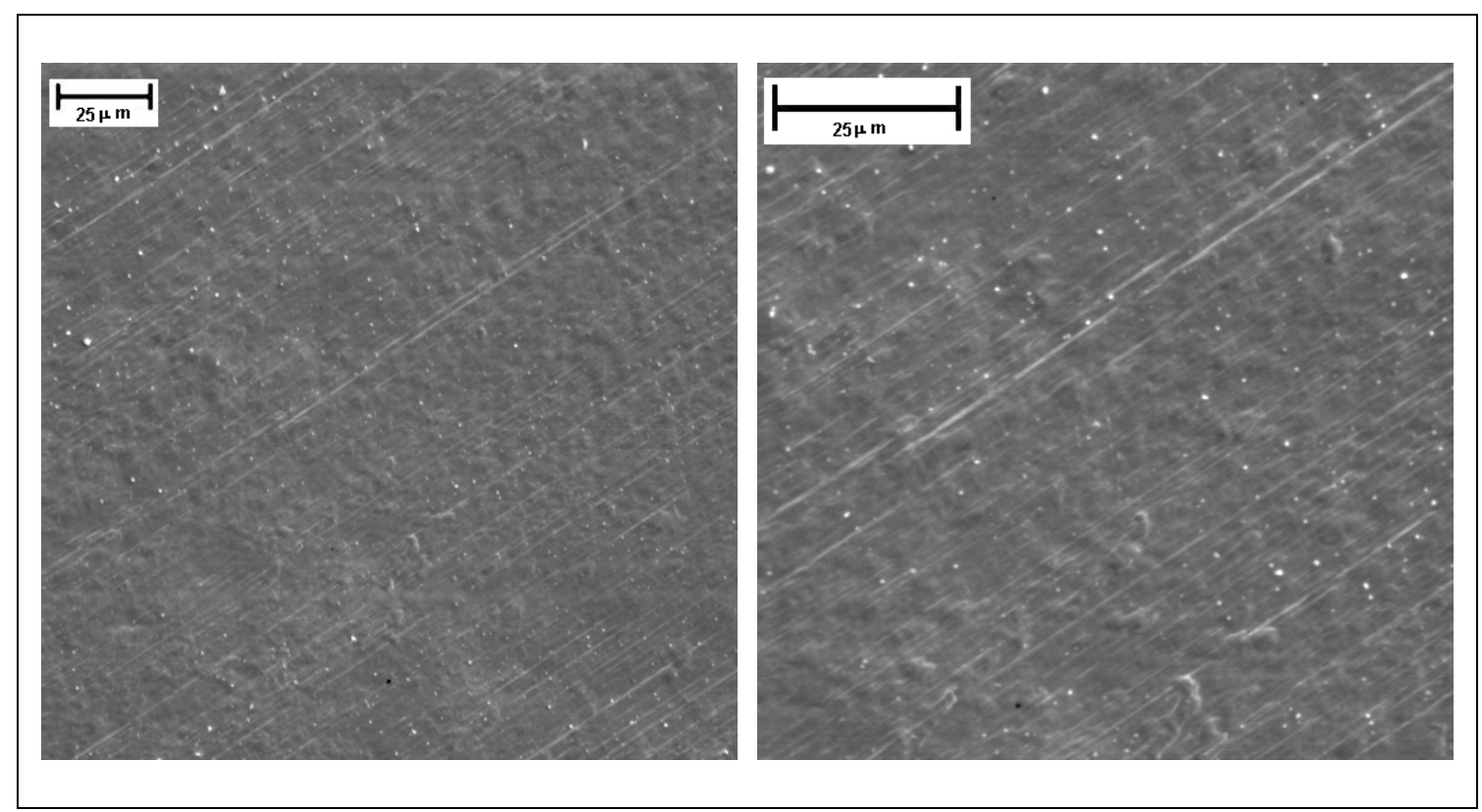

Figura 5.46 - MEV da superfície de pino de POM (Aço Inox R2, 0,1 m/s e 100 N). Observa-se presença simultânea de riscos e de ondas.

Da mesma forma como ocorreu nos ensaios contra alumina, os riscos causados pelas asperezas do contra-corpo presentes na superfície dos pinos apresentaram um aspecto frágil nas bordas dos riscos (Figura 5.47). Convém informar que esse tipo de fenômeno não foi identificado nas análises dos pinos de UHMWPE. 


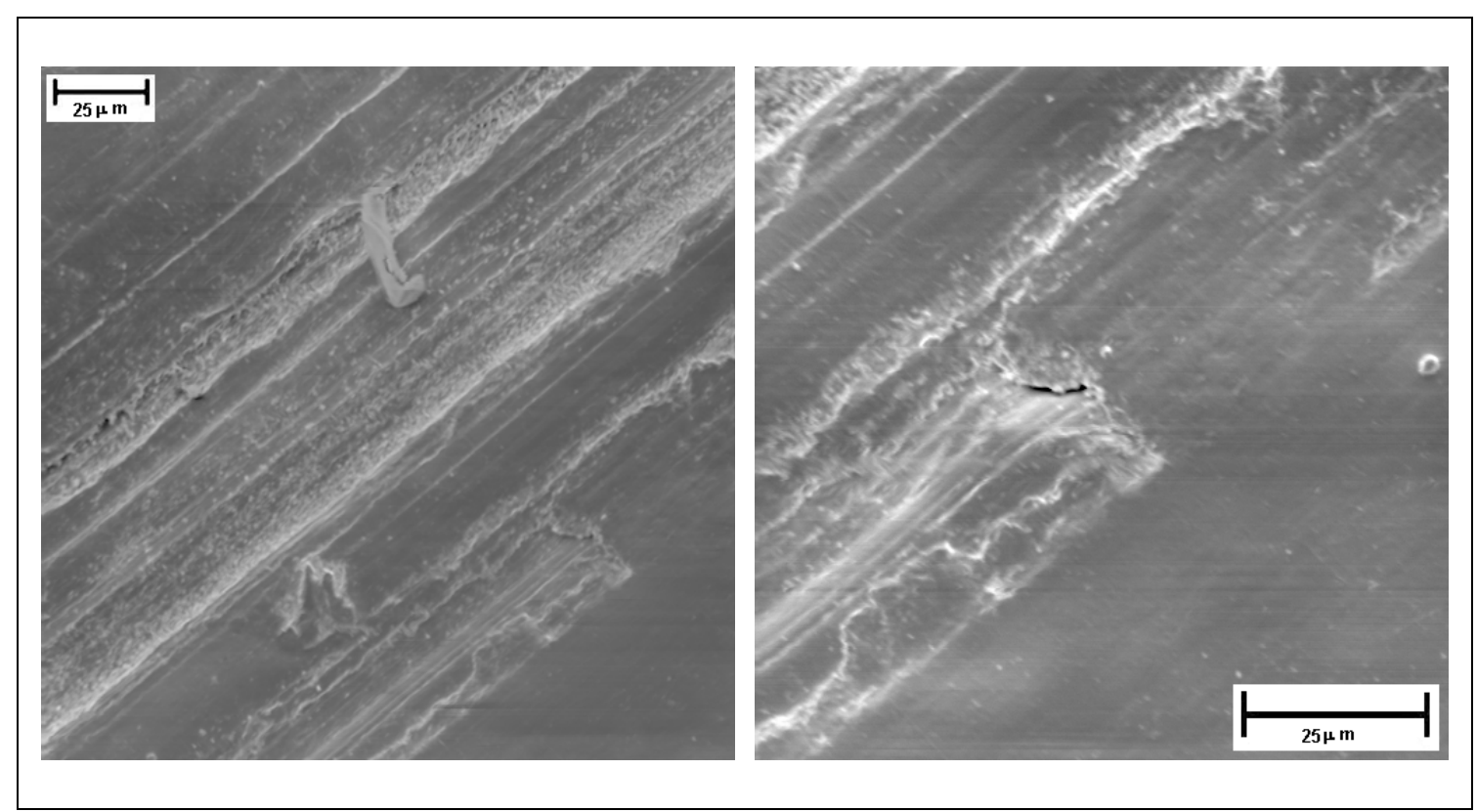

Figura 5.47 - MEV da superfície do pino de POM (Aço Inox R2, 0,1 m/s e 100 N). Observação de um aspecto frágil nas bordas dos riscos.

A Figura 5.48 mostra a formação de um filme polimérico na superfície do pino nos ensaios com condições PV baixas (em geral inferiores a $2.550\left[\mathrm{~kW} / \mathrm{m}^{2}\right]$ ). Nota-se que esse filme apresenta um aspecto fragmentado e quebradiço e, além disso, com riscos de abrasão. É possível que a formação do filme polimérico na superfície do pino deva ter atuado como uma camada protetiva, visto que os valores de taxa de desgaste nesses ensaios foram muitos baixos. A formação dessa camada será analisada em maior profundidade nas seções 5.6.2 e 5.7. Na Figura 5.48, também observa-se que a superfície inicial do pino ainda não foi completamente desgastada; ou seja, nesses ensaios, ainda não se superou o período de running-in. 


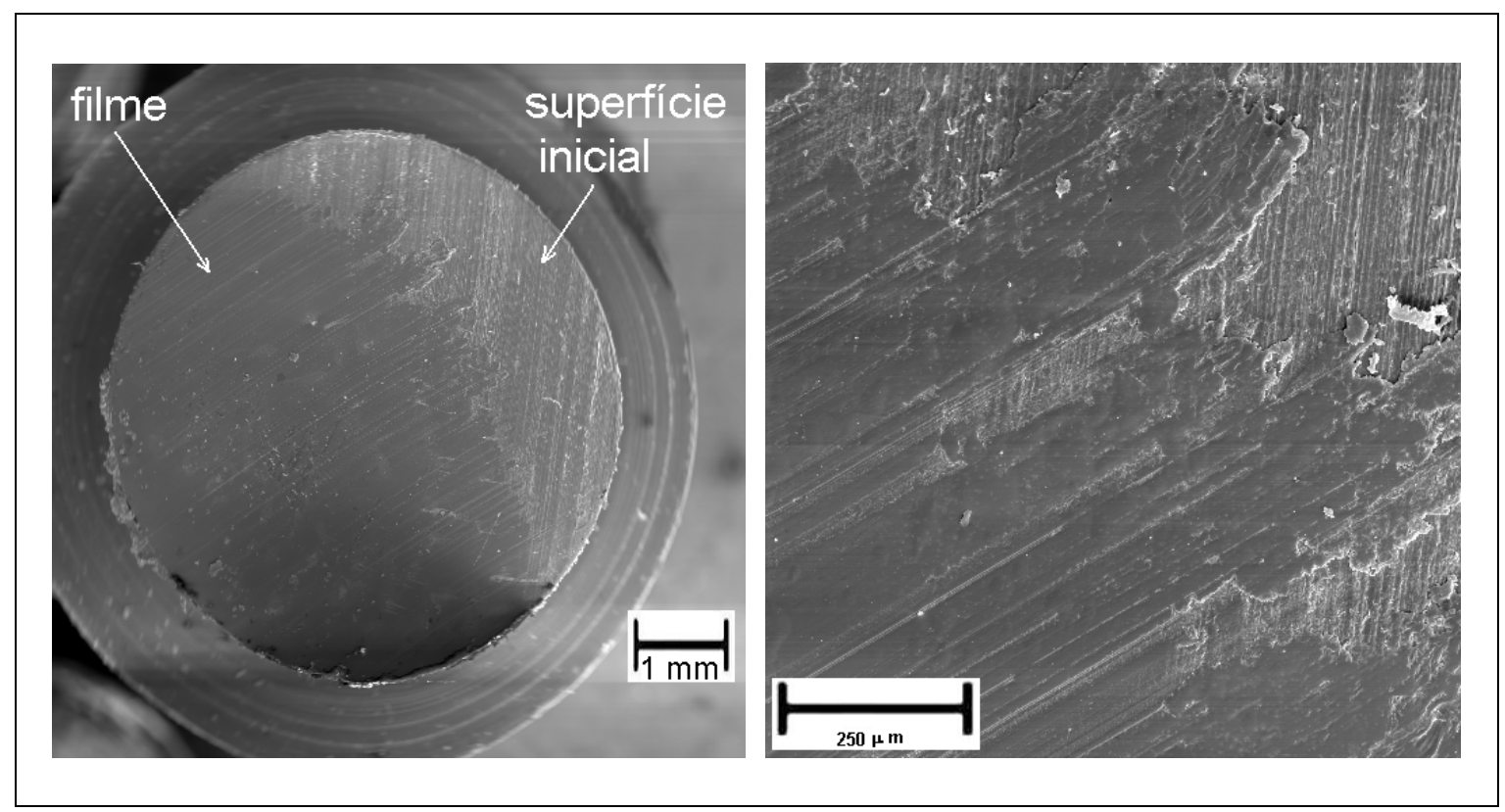

Figura 5.48 - MEV da superfície do pino de POM (Aço Inox R2, 1 m/s e 50 N). Observação de filme recobrindo grande extensão da área de contato.

\subsubsection{POM x Aço Inox R3}

A Figura 5.49 apresenta os resultados de taxa de desgaste dos pinos de POM deslizando contra discos de aço inoxidável, com acabamento superficial R3, em função da condição PV.

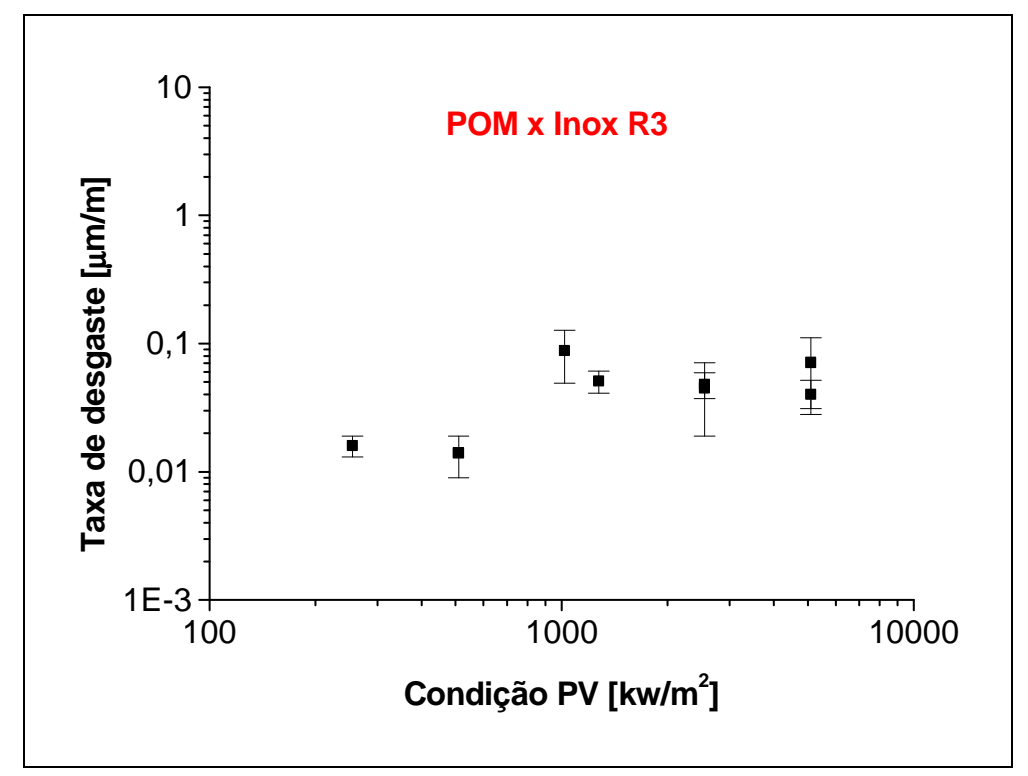

Figura 5.49 - Taxa média de desgaste e seus respectivos desvios padrões em função da condição PV dos ensaios do par POM x Aço inox R3. 
Utilizando o método de análise de variância para amostras de mesmo tamanho $^{120}$, verificou-se que os valores de taxa de desgaste obtidos nos ensaios com condição PV acima de 1.000 [kW/m2] podem ser considerados iguais, ao nível de $5 \%$ de significância. Assim, apesar dos resultados apresentarem uma tendência de crescimento quando tratados somente como valores médios, o que se observa é que, acima de $1.000[\mathrm{~kW} / \mathrm{m} 2]$, não há influência significativa nos valores de taxa de desgaste. Abaixo desse patamar de severidade, a taxa de desgaste apresenta valores inferiores aos observados nas altas condições PV. O mesmo comportamento foi observado para o par POM x aço inoxidável R2.

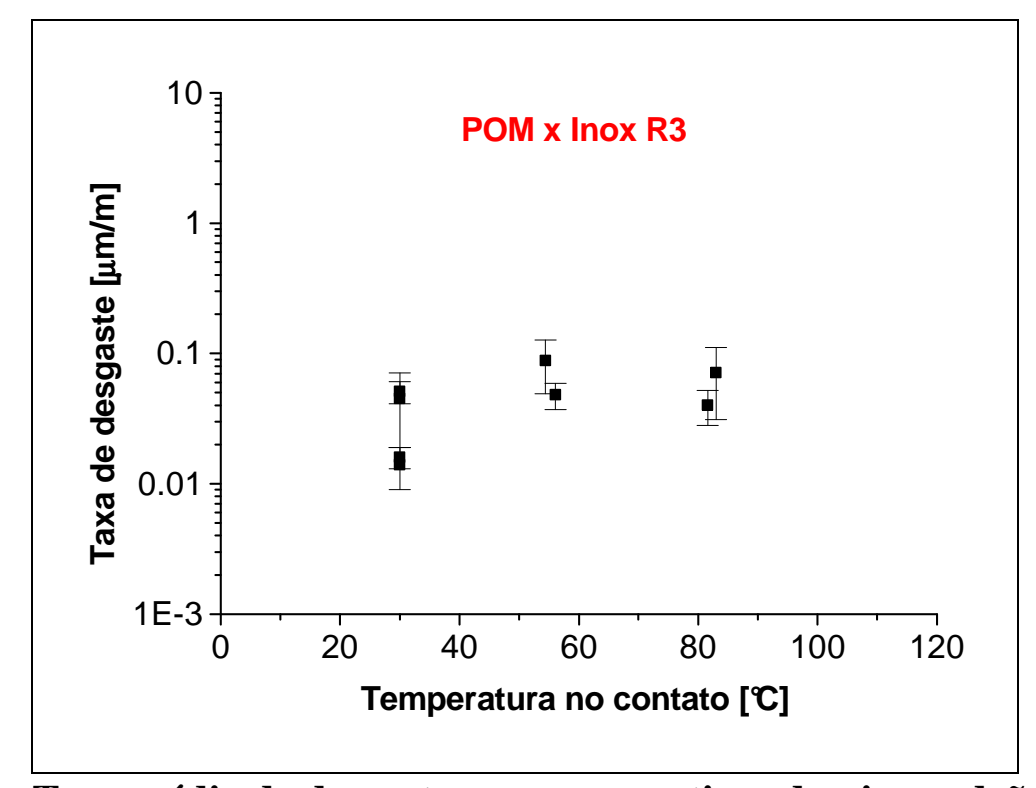

\section{Figura 5.50 - Taxa média de desgaste e seus respectivos desvios padrões em função da temperatura medida no pino dos ensaios do par POM x Aço inox R3.}

A Figura 5.50 mostra a taxa de desgaste em função da temperatura medida no pino. Observa-se que a variação da temperatura no intervalo de 30 a $90{ }^{\circ} \mathrm{C}$ não alterou os valores de taxa de desgaste.

Quanto às aparências das superfícies desgastadas, observou-se que não houve mudança significativa em termos de aspecto morfológico, comparado com o POM com os demais pares tribológicos apresentados anteriormente. No entanto, vale salientar que:

- Não se observou a presença do filme na superfície dos pinos; ou seja, em todos os ensaios com o acabamento superficial R3, o período de running-in foi ultrapassado; 
- Nota-se a formação de ondas acompanhando a direção dos riscos; porém, não se observou o mecanismo de fadiga em grandes regiões da superfície do pino, como foi observado nos demais pares tribológicos com POM (Figura $5.51)$.

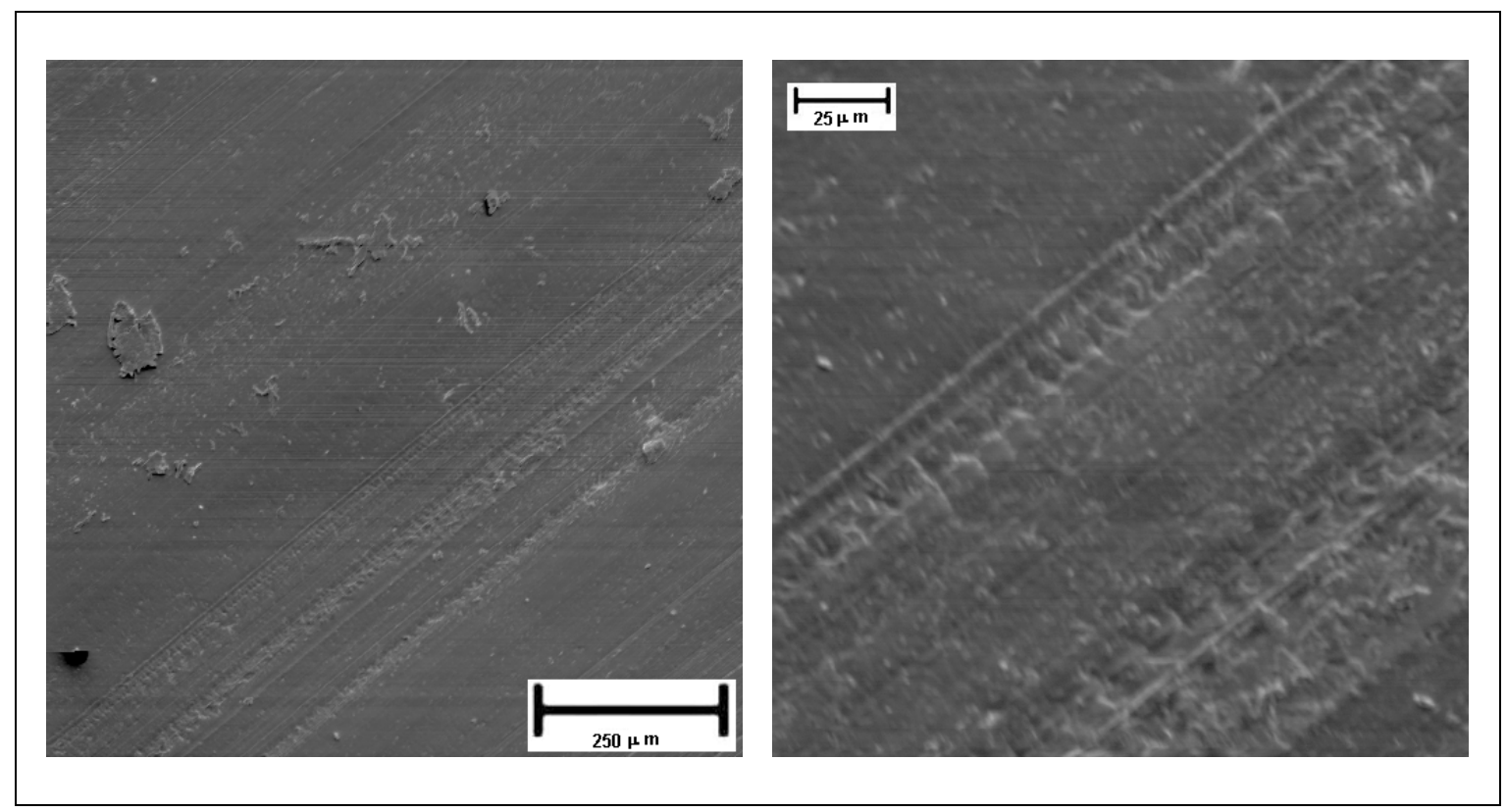

Figura 5.51 - MEV da superfície do pino de POM (Aço Inox R3, 1 m/s e 100 N). Mecanismo de formação de ondas acompanhando os riscos de abrasão.

Após a identificação dos mecanismos de desgaste e do efeito da condição PV e da temperatura próxima ao contato do par POM - Aço Inoxidável, analisaremos o efeito do acabamento superficial na taxa de desgaste desse par.

\subsubsection{Efeito do acabamento superficial no desgaste de POM x Aço Inoxidável}

A Figura 5.52 apresenta os resultados de taxa de desgaste em função da condição PV para os ensaios de POM deslizando sobre aço inoxidável. 


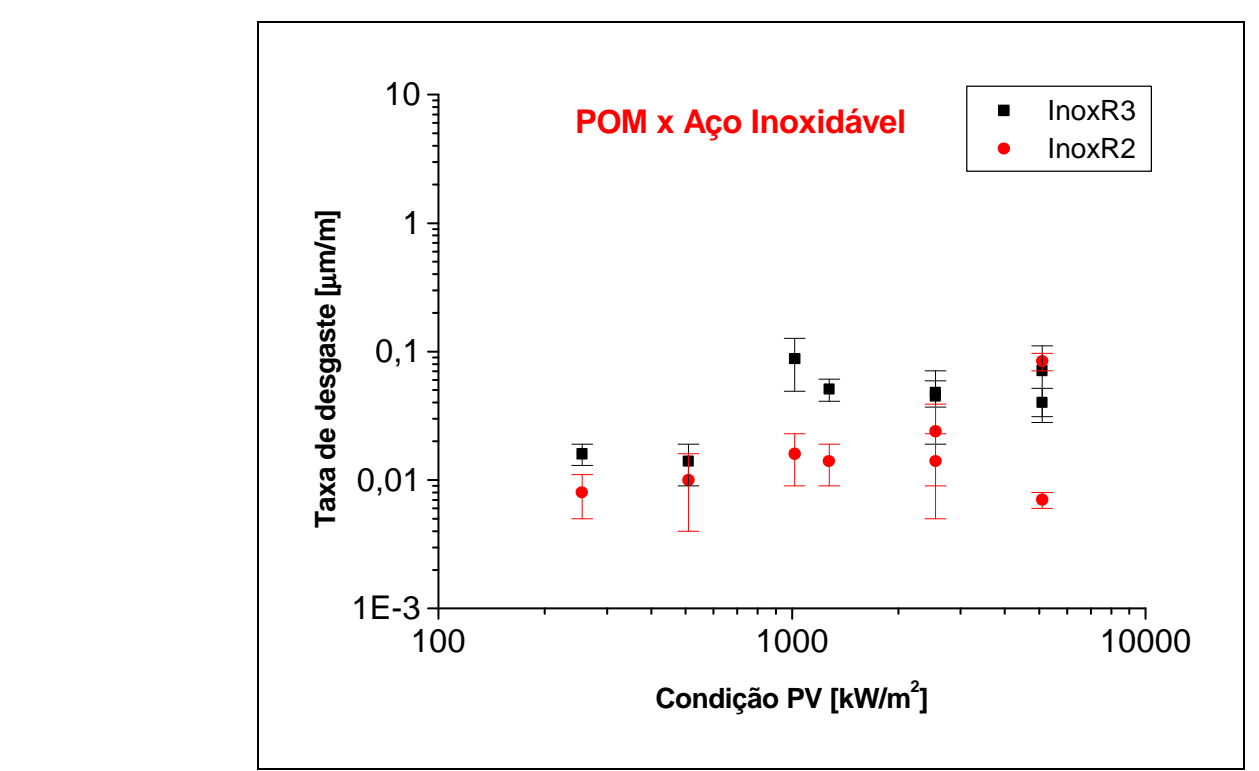

Figura 5.52 - Taxa média de desgaste e seus respectivos desvios padrões em função da condição PV dos ensaios com o par POM x Aço Inox.

Apesar das grandes dispersões de resultados nessa Figura, nota-se que os ensaios realizados nos discos com acabamento superficial menos severo (R2) apresentaram, na maioria dos casos, menores taxas de desgaste.

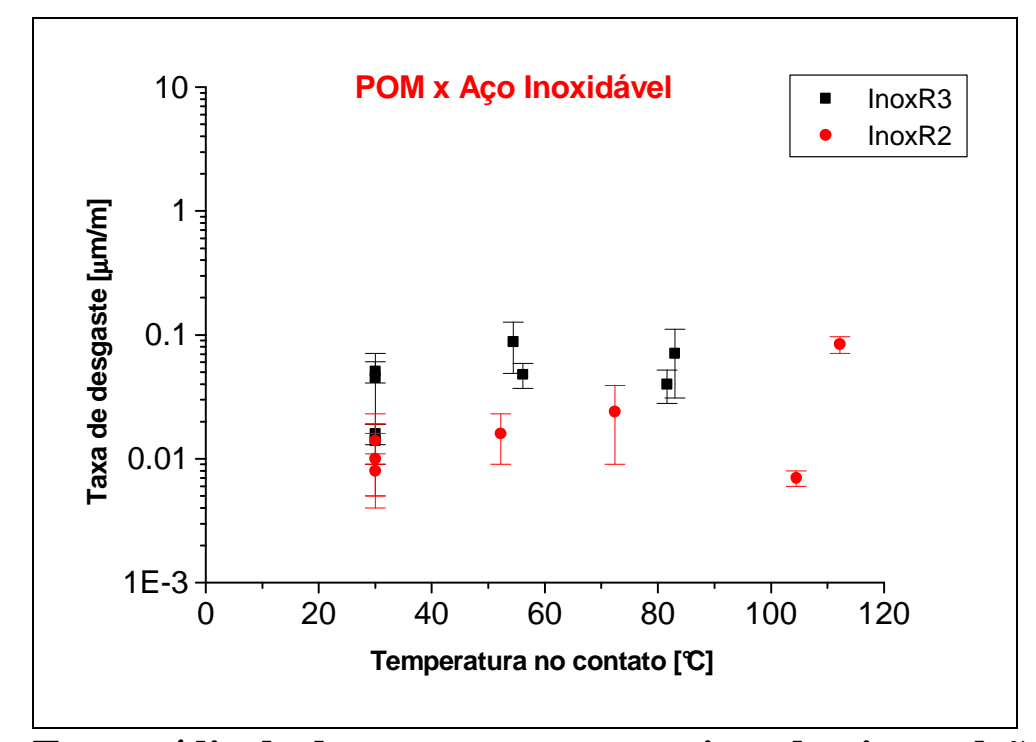

Figura 5.53 - Taxa média de desgaste e seus respectivos desvios padrões em função da temperatura no contato dos ensaios com o par POM x Aço Inox.

A Figura 5.53 apresenta os resultados de taxa de desgaste em função da temperatura próxima ao contato para os ensaios de POM deslizando sobre aço inoxidável. Observa-se que os ensaios com acabamento R2, a temperatura atingiu até 
$115^{\circ} \mathrm{C}$, enquanto que nos ensaios com acabamento $\mathrm{R} 3$, a temperatura não ultrapassou $85{ }^{\circ} \mathrm{C}$.

A análise dos resultados da taxa de desgaste de POM deslizando sobre aço inoxidável nos dois acabamentos superficiais (Figura 5.54 e principalmente a Tabela 5.41) mostrou uma tendência de crescimento da taxa de desgaste média com o aumento da rugosidade do contra-corpo. No entanto, o crescimento não pode ser considerado significativo, devido à elevada dispersão dos resultados.

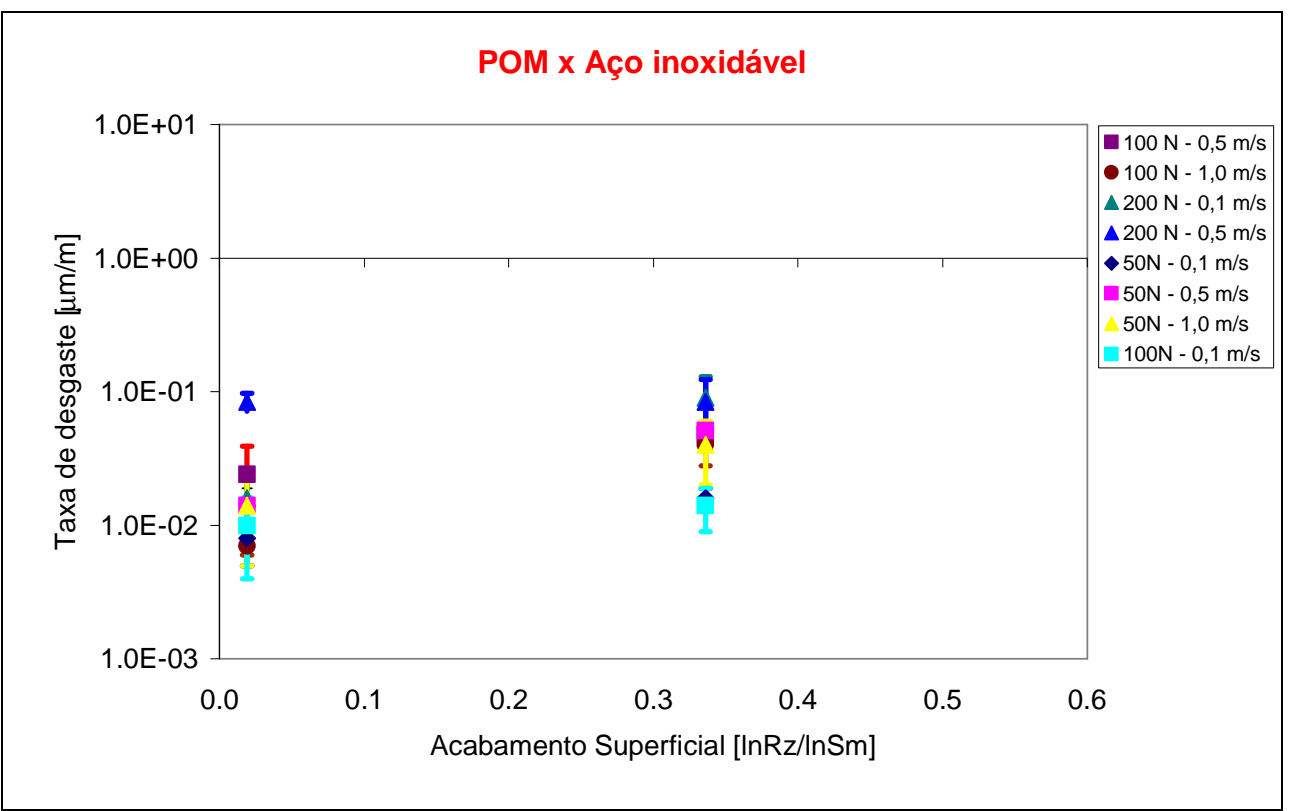

Figura 5.54 - Taxa média de desgaste em função do acabamento superficial dos ensaios de POM x Aço Inox.

Tendo concluído as análises do efeito da condição PV, da temperatura próxima ao contato e do acabamento superficial nos ensaios com POM, verificaremos a seguir o efeito do contra-corpo (alumina e aço inoxidável) na taxa de desgaste.

\subsubsection{Efeito do contra-corpo na taxa de desgaste do POM}

Nos itens anteriores à seção 5.6.1, foram analisados os efeitos da condição PV, da temperatura próxima ao contato e do acabamento superficial para os pares POM $\mathrm{x}$ Alumina e POM x Aço inoxidável. Mostra-se a seguir, os resultados de taxa de desgaste em função do contra-corpo. 


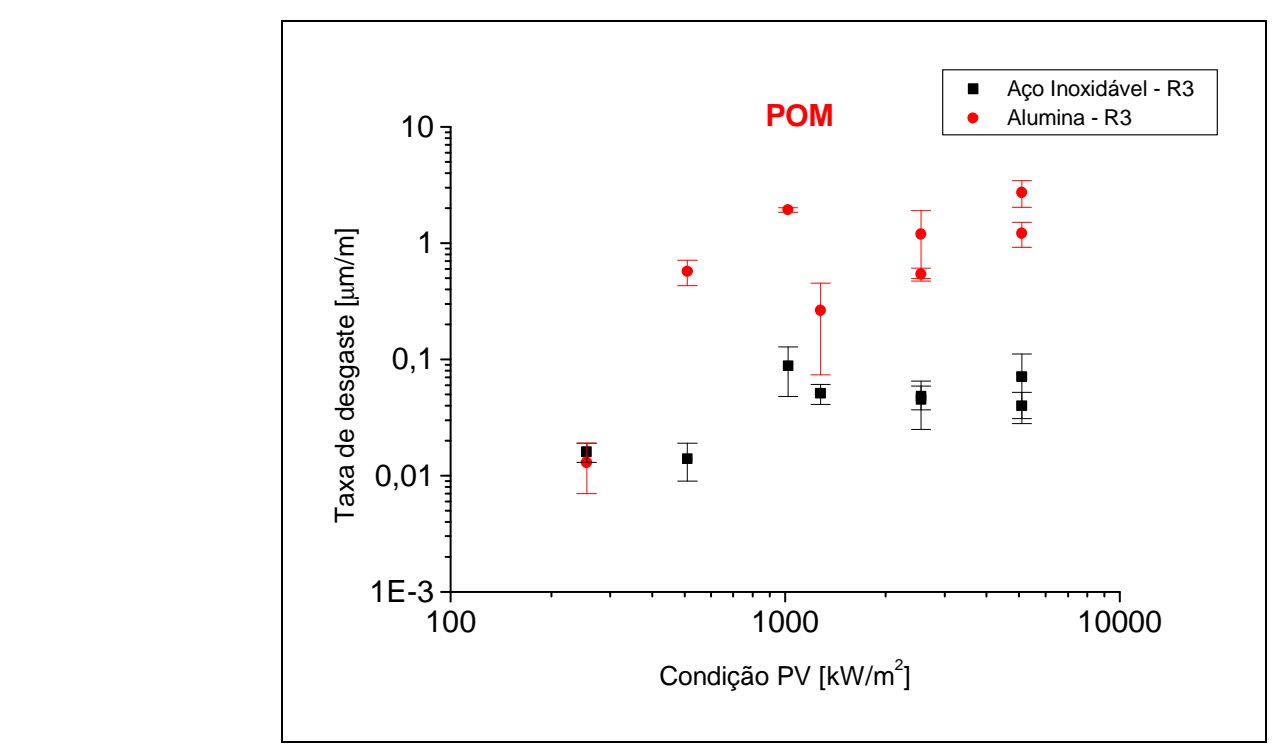

Figura 5.55 - Taxa média de desgaste e seus respectivos desvios padrões em função da condição PV dos ensaios com POM (rugosidade R3).

A Figura 5.55 mostra o efeito do contra corpo em relação à condição PV para os ensaios com rugosidade R3. Já a Figura 5.56 mostra o mesmo efeito com todas as amostras de POM.

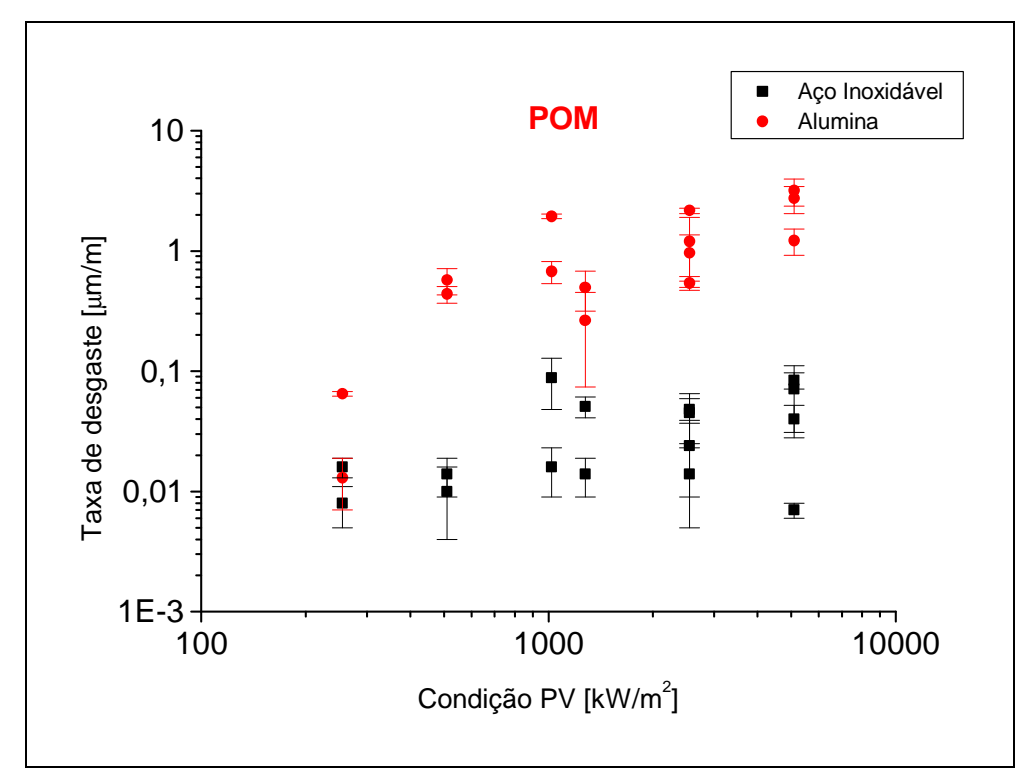

Figura 5.56 - Taxa média de desgaste e seus respectivos desvios padrões em função da condição PV dos ensaios com POM.

Observando a Figura 5.56, nota-se que o efeito do tipo de contra-corpo fica mais evidente. No entanto, com o objetivo de comparar o efeito do material do contra-corpo, somente os resultados da Figura 5.55 podem ser utilizados, pois dessa forma, a variável acabamento superficial mantém-se inalterada. 
A Figura 5.55 mostra que, com o aumento da condição PV, mais clara fica a tendência dos valores de taxa de desgaste dos ensaios realizados com alumina apresentarem-se mais elevados do que aqueles obtidos nos ensaios com aço inoxidável. A Tabela 5.21 mostra que o trabalho de adesão do par POM $x$ Alumina é significativamente maior que o par POM x Aço inoxidável. Haveria portanto, uma maior afinidade para a formação de ligações fracas na interface dos dois materiais, característica dos mecanismos adesivos, no par com alumina. No entanto, somente esse fato não explica a diferença de comportamento do desgaste do POM com ambos os materiais de disco, visto ainda que os mecanismos de desgaste mais evidentes estiveram relacionados com fenômenos abrasivos.

A Figura 5.57 mostra o efeito do tipo contra-corpo em relação à temperatura próxima ao contato para os ensaios com discos com rugosidade R3. Já a Figura 5.58 mostra o mesmo efeito para todas as amostras de POM.

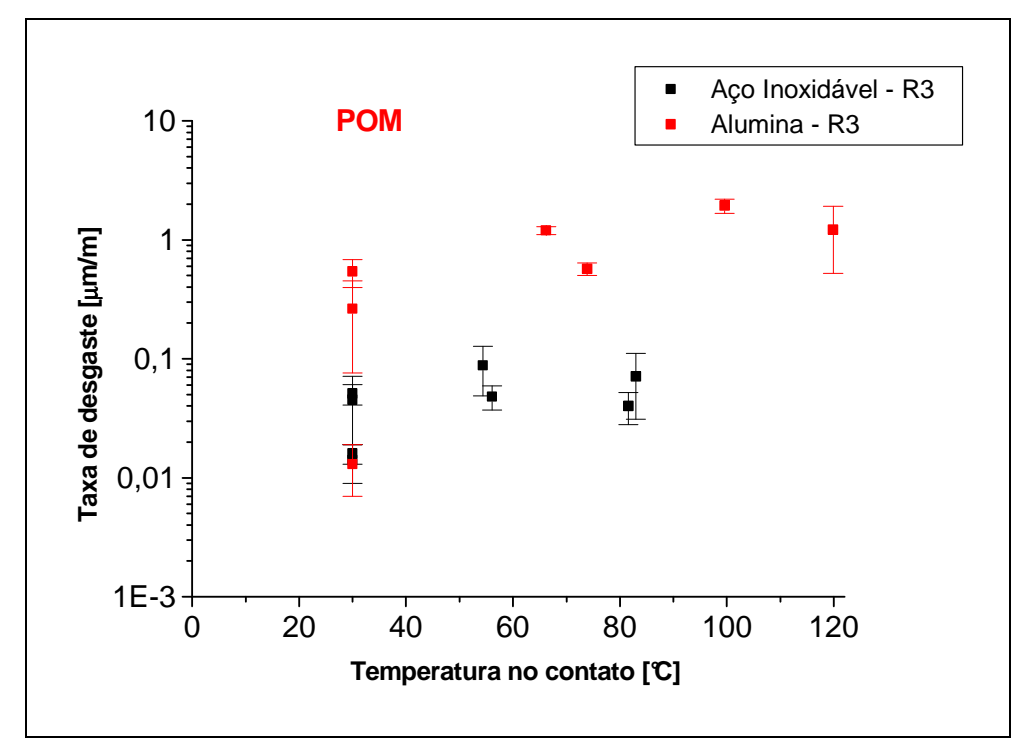

Figura 5.57 - Taxa média de desgaste e seus desvios padrões em função da temperatura no contato dos ensaios com POM (rugosidade R3). 


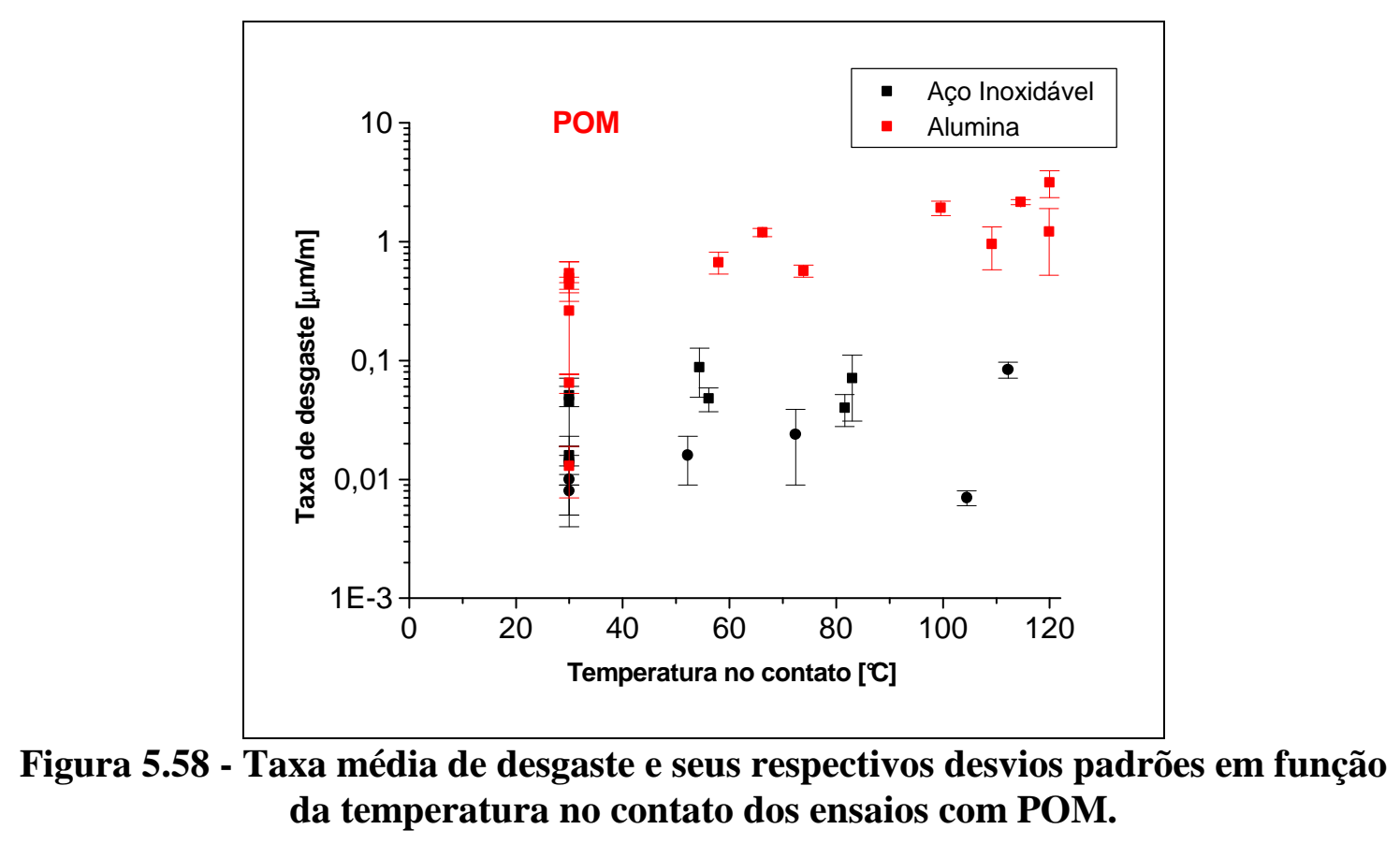

Nota-se nas Figuras 5.57 e 5.58, que, para os mesmos níveis de temperatura, a taxa de desgaste do par POM x Alumina tendeu a ser maior, comparada à taxa do par POM x Aço Inoxidável, mostrando novamente a importância do tipo de contra-corpo na taxa de desgaste.

A Figura 5.59, confirma o comportamento com desgaste mais severo da alumina em relação ao aço inoxidável nos ensaios com POM. A observação microscópica da superfície de desgaste dos pinos de POM, cujos valores de taxa de desgaste na Figura 5.59 estão marcados com um círculo, mostrou apenas a morfologia de desgaste com riscos; evidenciando que somente o mecanismo de abrasão esteve atuando nestes ensaios. 


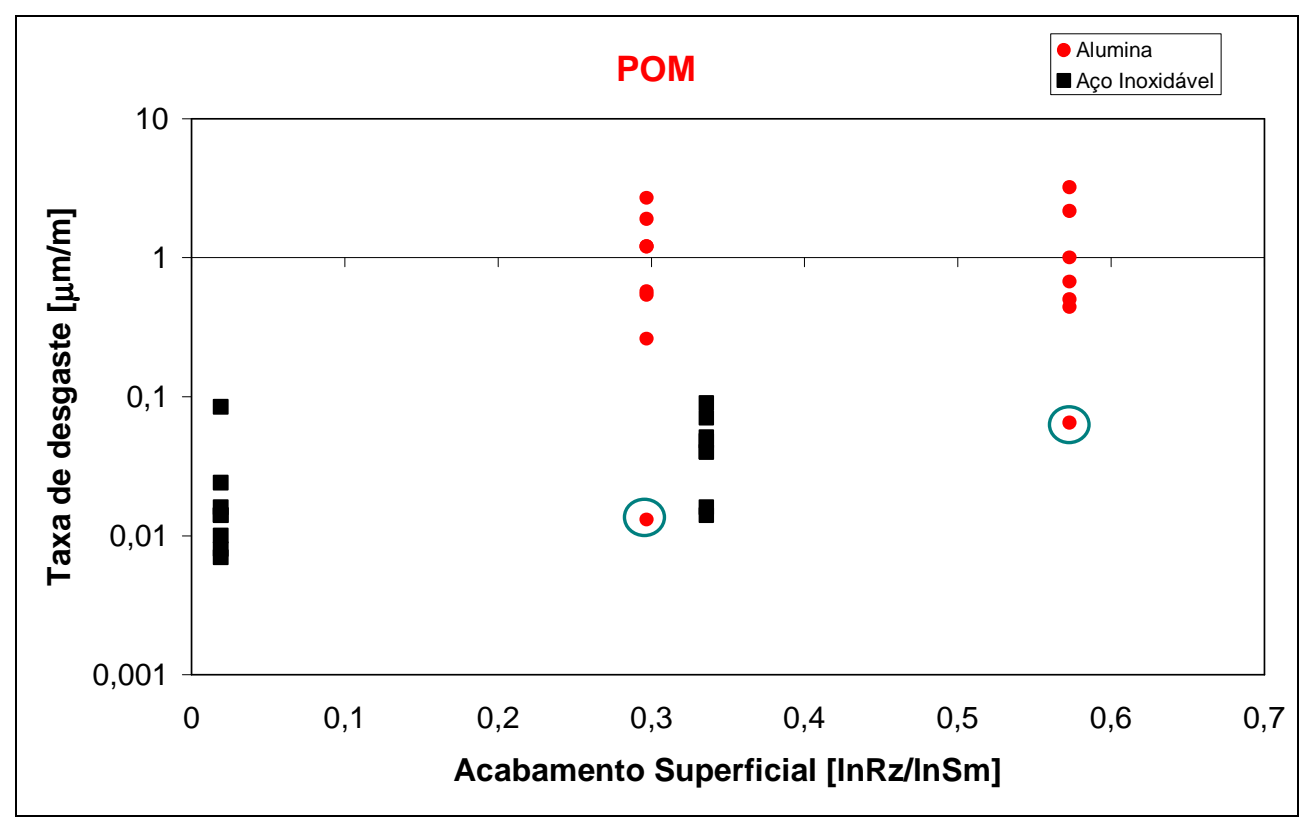

Figura 5.59 - Taxa média de desgaste em função do acabamento superficial dos ensaios com POM.

Para análises do desgaste em termos mais globais, propõe-se um parâmetro relacionado à severidade das condições de contato, no qual três parcelas são consideradas. A primeira parcela é referente às condições dinâmicas de cada ensaio, representada pela condição PV; a segunda é representada pela agressividade do acabamento superficial do contra-corpo $(\operatorname{lnRz} / \mathrm{lnSm})$ e a terceira parcela é referente à capacidade de dissipação de calor da região de contato, representada pela difusividade térmica dos materiais em contato.

Sendo assim, uma maneira mais adequada de se analisar os resultados da taxa de desgaste em função das diversas variáveis estudadas seria através de uma variável composta, chamada de severidade global, a qual seria diretamente proporcional aos fatores dinâmicos e rugosos presentes no contato e indiretamente proporcional à capacidade de dissipação de calor dos materiais. Dessa forma, tem-se:

$$
\text { severidade global }=\frac{\text { PVR }}{D_{p} D_{d}}\left[\mathrm{~kg} . \mathrm{s} / \mathrm{m}^{4}\right]
$$

onde:

$$
\begin{aligned}
& \mathrm{P}=\text { pressão de contato }[\mathrm{Pa}] \\
& \mathrm{V}=\text { velocidade }[\mathrm{m} / \mathrm{s}]
\end{aligned}
$$


$\mathrm{R}=\mathrm{LnRz} / \operatorname{LnSm}[-]$

$\mathrm{D}_{\mathrm{p}}=$ difusividade térmica do pino $\left[\mathrm{m}^{2} / \mathrm{s}\right]$

$\mathrm{D}_{\mathrm{d}}=$ difusividade térmica do disco $\left[\mathrm{m}^{2} / \mathrm{s}\right]$

Observação: o parâmetro presente no denominador da severidade global $\left(\mathrm{D}_{\mathrm{p}} \mathrm{D}_{\mathrm{d}}\right)$ representa a difusividade térmica combinada dos materiais em contato.

A Figura 5.60 apresenta os resultados da taxa de desgaste em função da severidade global (PVR/DD) nos ensaios com POM deslizando sobre aço inoxidável e alumina. Optou-se por não apresentar no gráfico os desvios padrões dos valores médios, para se obter uma melhor visualização das tendências de comportamento.

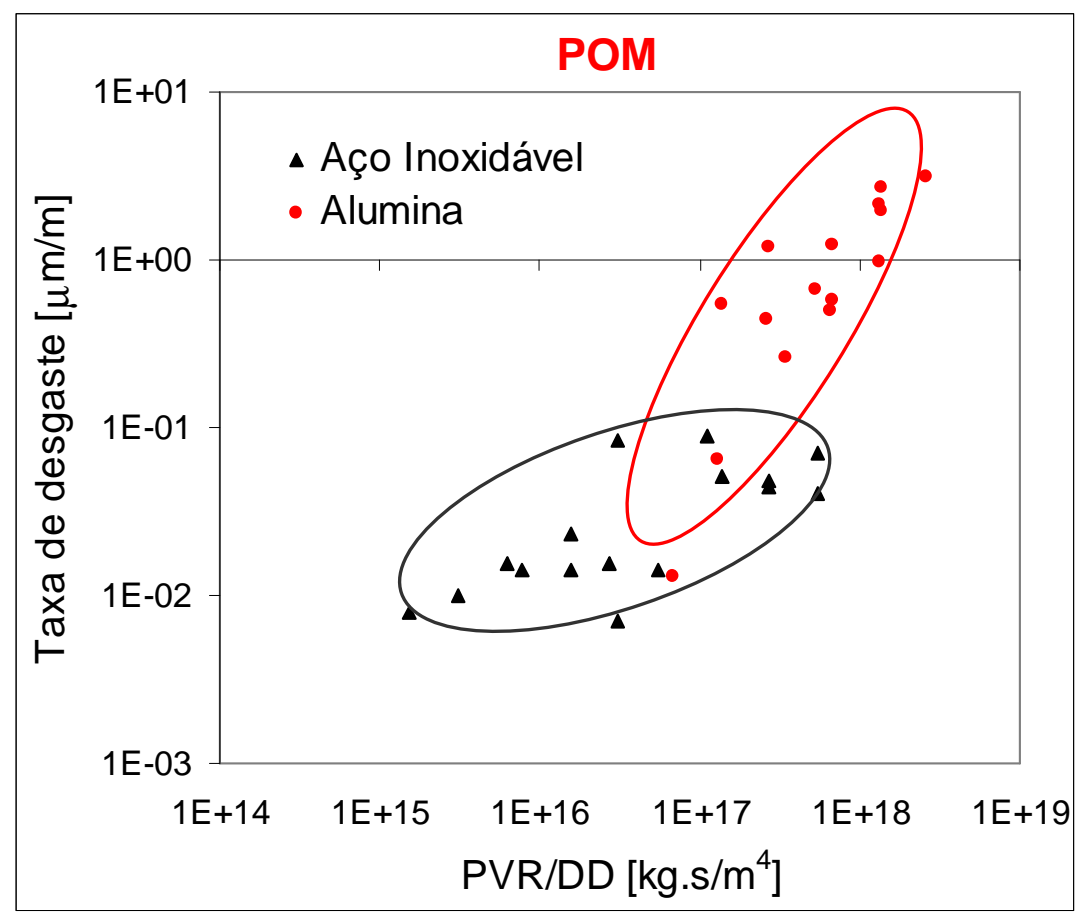

Figura 5.60 - Taxa média de desgaste em função da severidade global dos ensaios de POM contra alumina e aço inoxidável.

Observa-se na Figura 5.60 que, além de o par POM x Alumina apresentar valores mais elevados da taxa de desgaste, também, analisando a tendência da nuvem de pontos, a elevação da taxa de desgaste com o aumento da severidade global foi mais acentuada nos ensaios com alumina, comparado aos resultados com aço inoxidável. 


\subsubsection{Desgaste do UHMWPE}

A seguir serão apresentados os resultados dos ensaios de desgaste realizados com o UHMWPE como material do pino.

\subsubsection{UHMWPE $x$ Alumina $R 3$}

A Figura 5.61 apresenta os resultados de taxa de desgaste dos pinos de UHMWPE deslizando contra discos de alumina, com acabamento superficial R3, em função da condição PV.

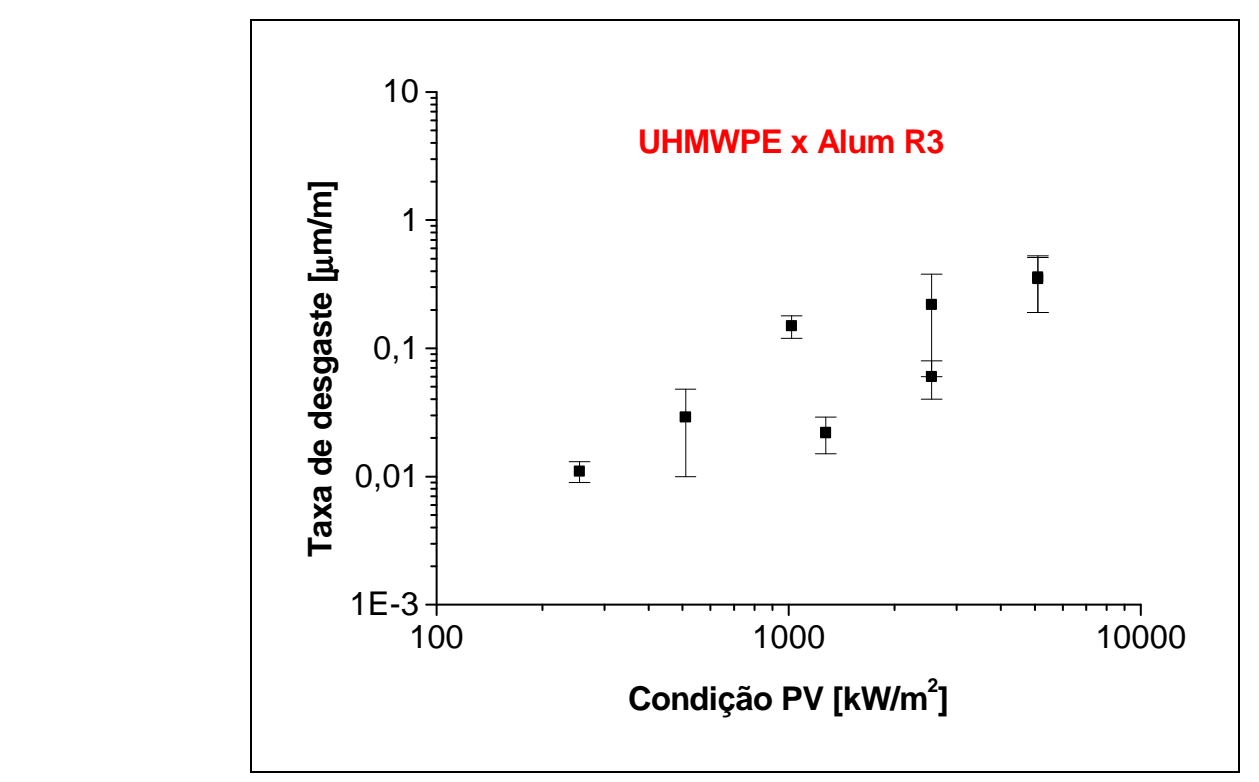

Figura 5.61 - Taxa média de desgaste e seus respectivos desvios padrões em função da condição PV dos ensaios com UHMWPE $x \mathrm{Al}_{2} \mathrm{O}_{3} \mathrm{R3}$.

A Figura 5.61 mostra uma tendência de aumento da taxa de desgaste do UHMWPE para condições PV mais elevadas.

Ao analisar a Figura 5.62, onde se apresenta a influência da temperatura na taxa de desgaste, observa-se que, acima de $30^{\circ} \mathrm{C}$, a variação na temperatura não afetou significativamente os valores de taxa de desgaste. Tal fato é confirmado pela análise de variância das médias, com 95\% de confiança (Anexo B). 


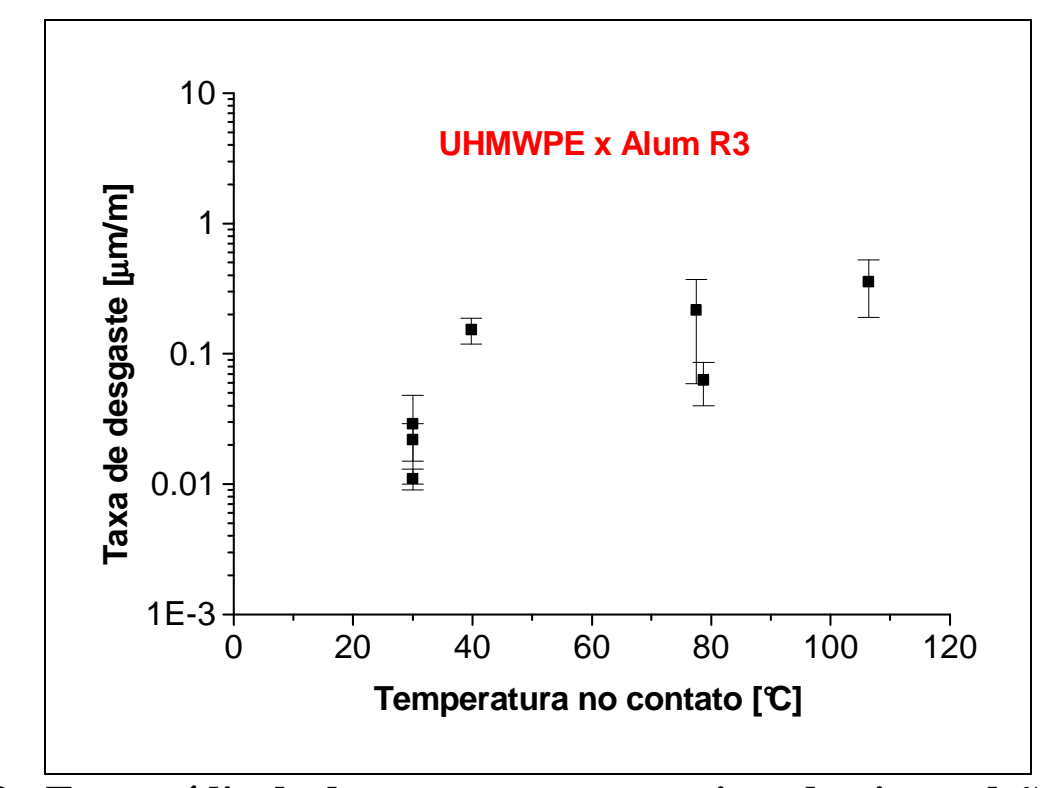

\section{Figura 5.62 - Taxa média de desgaste e seus respectivos desvios padrões em função da temperatura próxima ao contato dos ensaios com UHMWPE $\times \mathrm{Al}_{2} \mathrm{O}_{3} \mathrm{R3}$.}

Observando a superfície dos pinos, verificou-se que uma leve diferença em relação ao que ocorreu com o POM. Com UHMWPE, os mecanismos de abrasão e de formação de ondas atuaram conjuntamente desde as condições PV menos severas, porém houve uma mudança na intensidade dos mecanismos. O desgaste por abrasão se sobressaiu nas condições com menor severidade (Figura 5.63) e, com o aumento da condição PV, a formação de ondas cresceu em intensidade (Figura 5.64). A Figura 5.63 (b) mostra uma região com uma camada depositada na superfície do pino mais homogênea do que aquelas encontradas nos pinos de POM e com ondas. Essas camadas mais homogêneas acabam protegendo a superfície do pino durante um período de tempo; no entanto, com o decorrer do ensaio, o material depositado na superfície do pino também é arrancado. Nota-se ainda que as bordas dos riscos de abrasão apresentaram um aspecto mais dúctil, em comparação com os riscos no POM. 


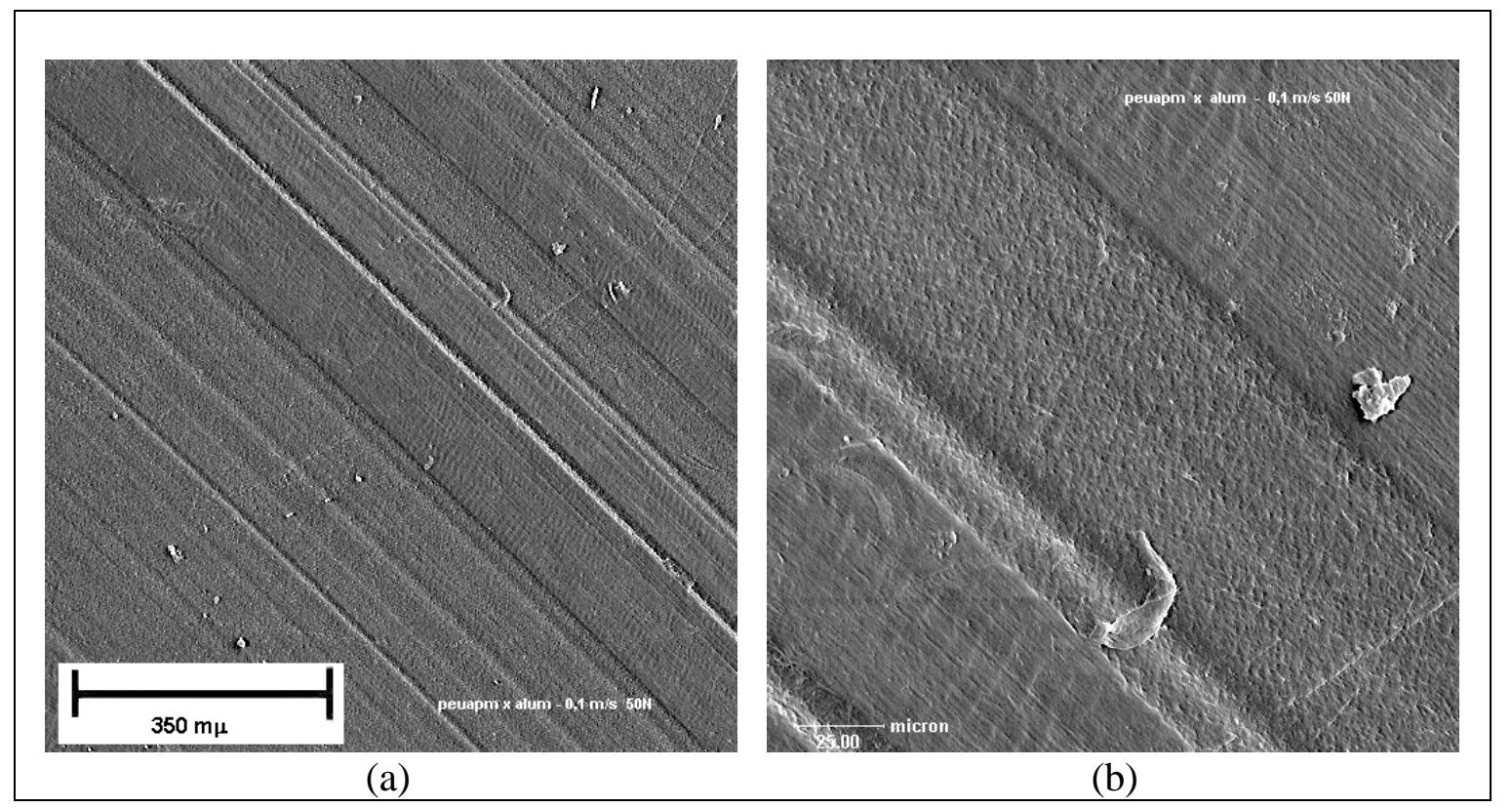

Figura 5.63 - MEV da superfície do pino de UHMWPE $\left(\mathrm{Al}_{2} \mathrm{O}_{3} \mathrm{R3}, 0,1 \mathrm{~m} / \mathrm{s}\right.$ e $\left.50 \mathrm{~N}\right)$. Observam-se riscos de abrasão e formação de ondas, e partículas se destacando.

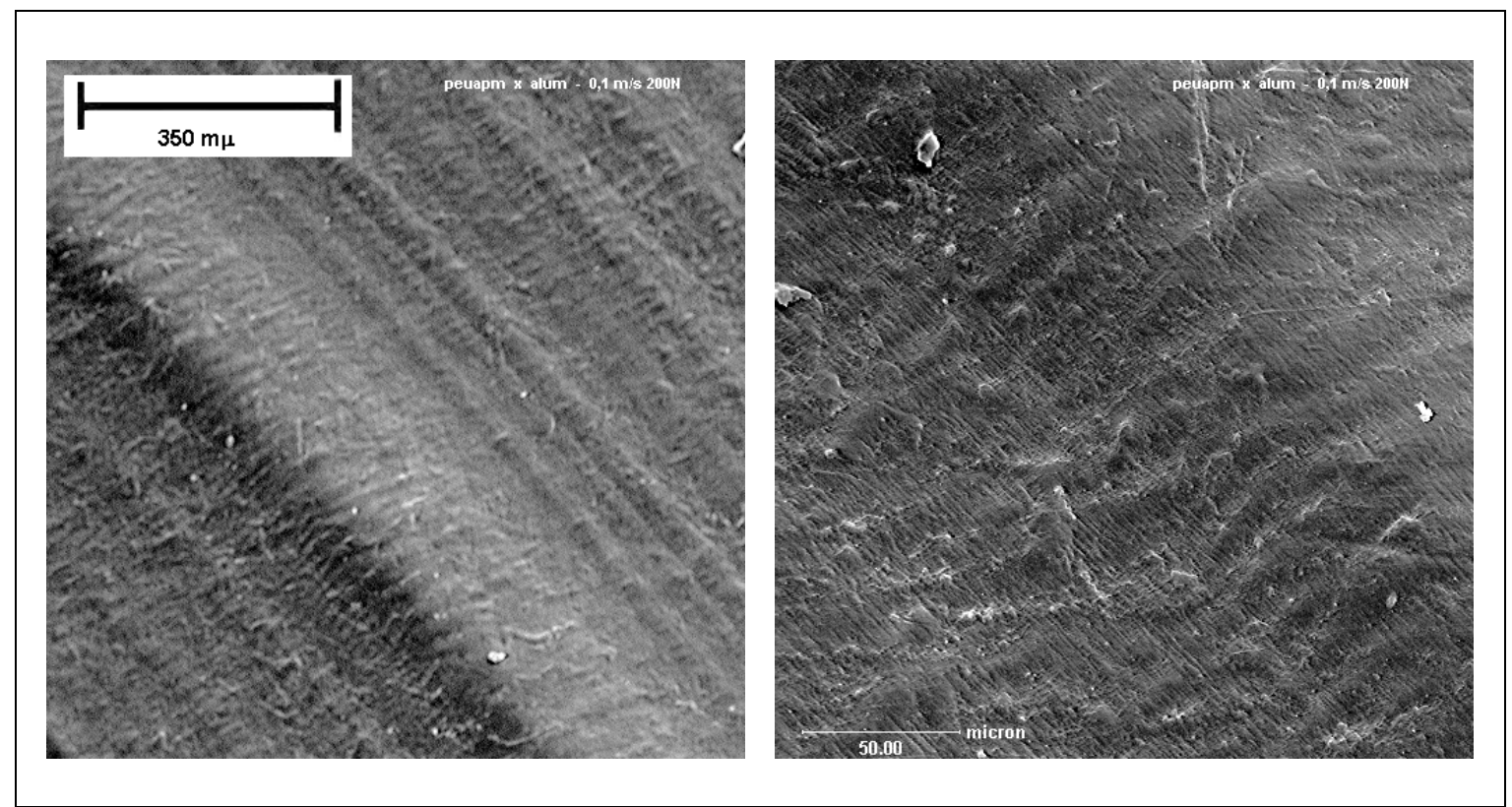

Figura 5.64 - MEV da superfície do pino de UHMWPE $\left(\mathrm{Al}_{2} \mathrm{O}_{3} \mathrm{R3}, 0,1 \mathrm{~m} / \mathrm{s}\right.$ e $\left.200 \mathrm{~N}\right)$. A formação de ondas é mais intensa e o riscamento acompanha o formato das ondas.

Na Figura 5.65, observa-se que as partículas de desgaste aderidas à superfície do pino apresentam uma morfologia de grandes placas de material aglomerado e esmagado. 
Comparado com resultados com os pinos de POM, a quantidade de material aderido foi maior, como se vê nas Figuras 5.28 e 5.31.

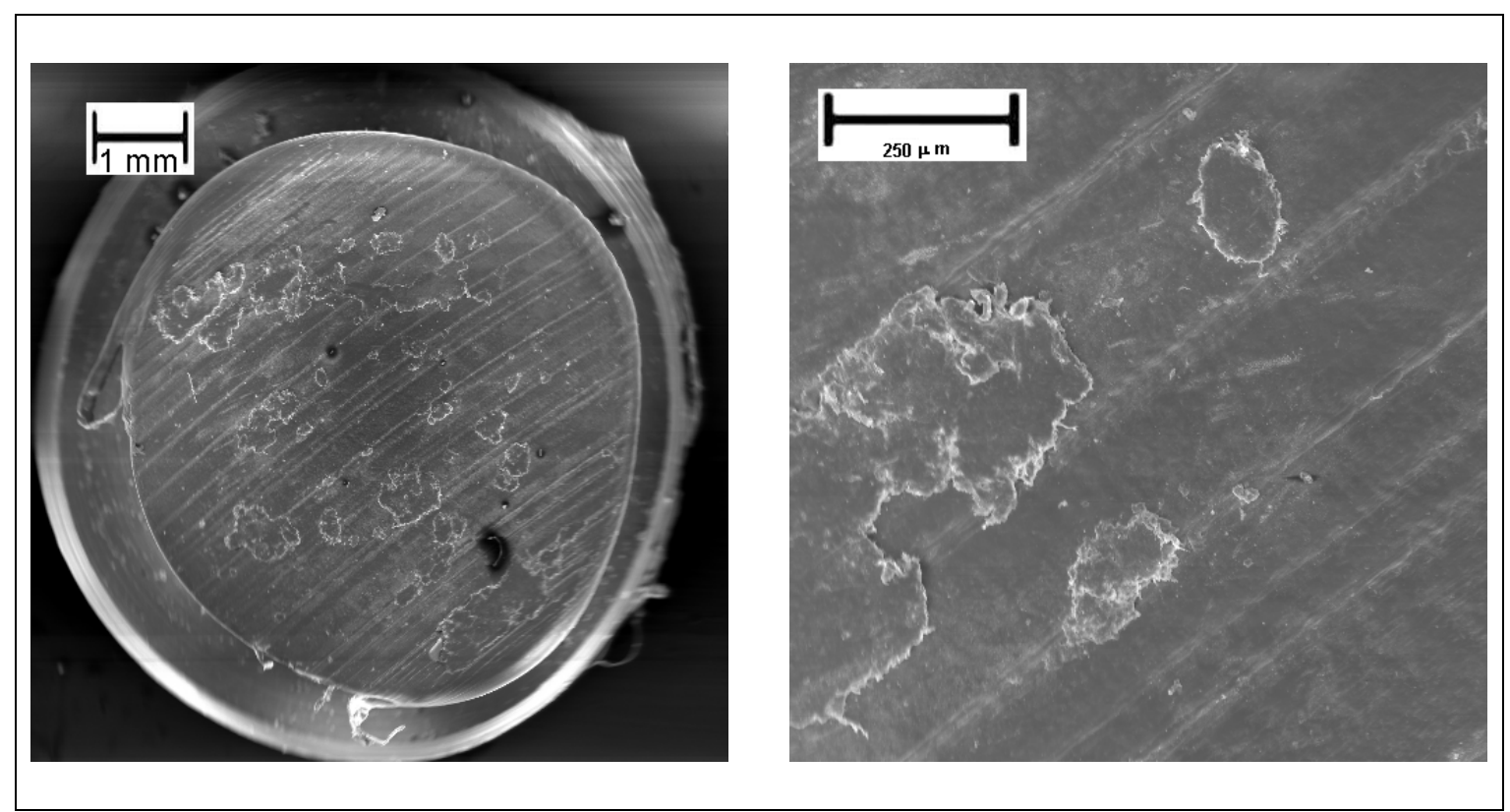

Figura 5.65 - MEV da superfície do pino de UHMWPE $\left(\mathrm{Al}_{2} \mathrm{O}_{3} \mathrm{R3}\right.$, de $1 \mathrm{~m} / \mathrm{s}$ e $50 \mathrm{~N}$. Presença de grandes placas de material polimérico aderidas à superfície do pino.

Quanto ao aspecto morfológico da superfície de desgaste mostrada na Figura 5.65, é possível que o material depositado na superfície do pino tivesse inicialmente sido arrancado da superfície do mesmo pela ação de um mecanismo de desgaste. Como estas partículas devem permanecer na pista de contato ou então retornam a ela após subseqüentes passagens do pino pela pista, este material adere-se então à superfície do pino e é então esmagado devido ao esforço mecânico no contato.

No entanto, a permanência de material no pino, ou mesmo a formação de uma camada protetiva homogênea por toda a superfície, depende tanto das condições de deslizamento, quanto do acabamento superficial do contra-corpo. É intuitivo que acabamentos do disco com maior rugosidade devam arrancar esta camada. Os resultados com maior rugosidade do disco estão apresentados a seguir.

\subsubsection{UHMWPE x Alumina R4}

As Figuras 5.66 e 5.67 apresentam os resultados de taxa de desgaste dos pinos de UHMWPE deslizando contra discos de alumina, com acabamento superficial R4, em 
função das condições PV de cada ensaio e da temperatura na região de contato, respectivamente. Em termos do desgaste, a comparação entre as médias das taxas de desgaste, realizada por análise de variância, mostrou que não houve diferença significativa (95\% de confiança) entre os valores de taxa de desgaste de UHMWPE deslizando sobre alumina R4 (Anexo B).

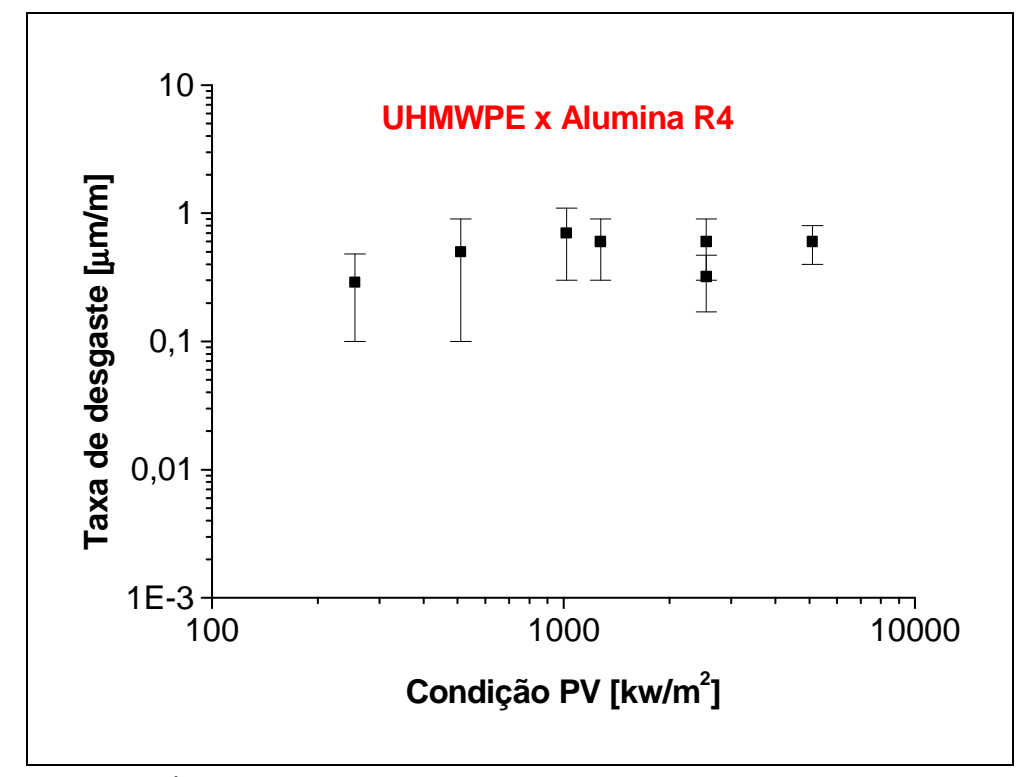

Figura 5.66 - Taxa média de desgaste e seus respectivos desvios padrões em função
da condição PV dos ensaios com UHMWPE $x \mathrm{Al}_{2} \mathrm{O}_{3} \mathrm{R4}$.

As Figuras 5.71 e 5.72 mostram que tanto a condição PV como a temperatura desenvolvida no contato tiveram pouca influência no comportamento tribológico quanto a resistência ao desgaste do UHMWPE contra alumina R4. Vale lembrar que, nos demais ensaios realizados contra alumina, tanto com o POM quanto com o UHMWPE, foi observado que a taxa de desgaste tendia a crescer com o aumento da condição PV do ensaio, notando-se também que, nas condições de ensaio menos severas, as taxas de desgaste foram da ordem de centésimos de micrometros por metro. Já nos ensaios com o par UHMWPE $\times \mathrm{Al}_{2} \mathrm{O}_{3} \mathrm{R} 4$, os resultados mantiveram-se em um patamar constante, bem maior, com taxa de desgaste por volta de $0,52 \mu \mathrm{m} / \mathrm{m}$. Este fato indica a importância da interação entre o acabamento superficial e o tipo de material do contra-corpo na análise do desgaste. 


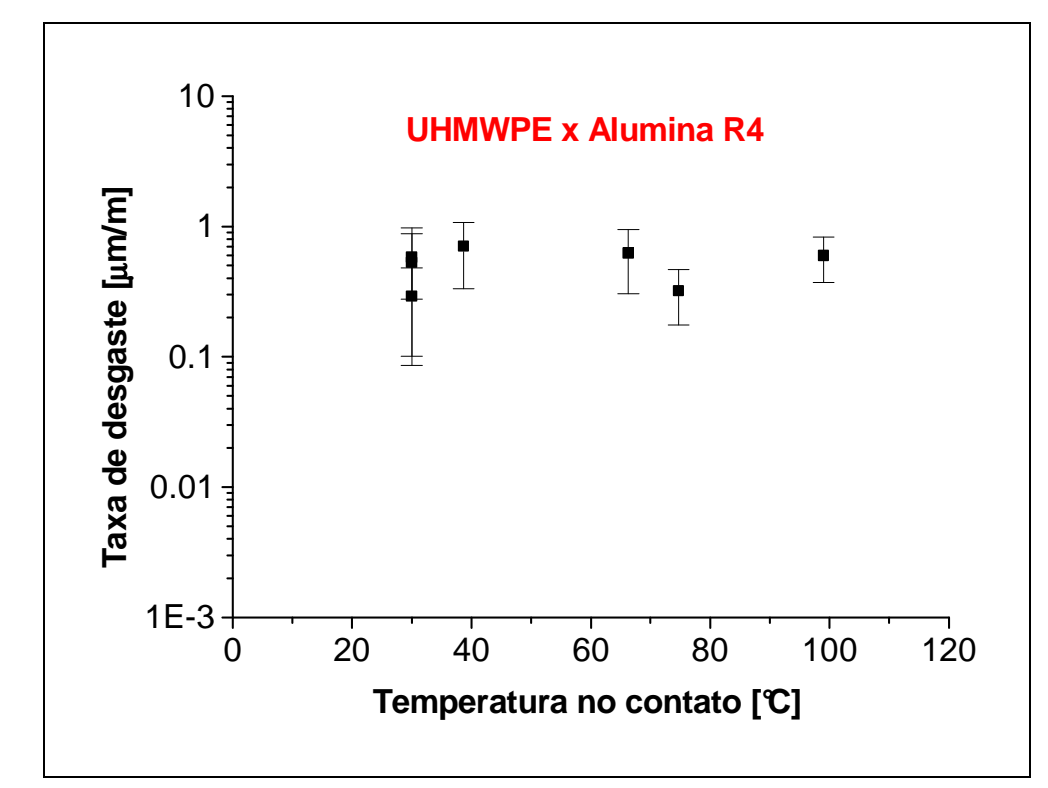

Figura 5.67 - Taxa média de desgaste e seus respectivos desvios padrões em função da temperatura próxima ao contato dos ensaios com UHMWPE $\times \mathrm{Al}_{2} \mathrm{O}_{3} \mathrm{R4}$.

Observando a superfície desgastada dos pinos de UHMWPE, da mesma maneira como ocorreu nos ensaios com POM, houve uma mudança na intensidade de atuação dos mecanismos de desgaste. Inicialmente, ocorreu somente abrasão (Figura 5.68), e com o aumento da condição PV, o mecanismo de formação de ondas também começou a atuar (Figura 5.69).

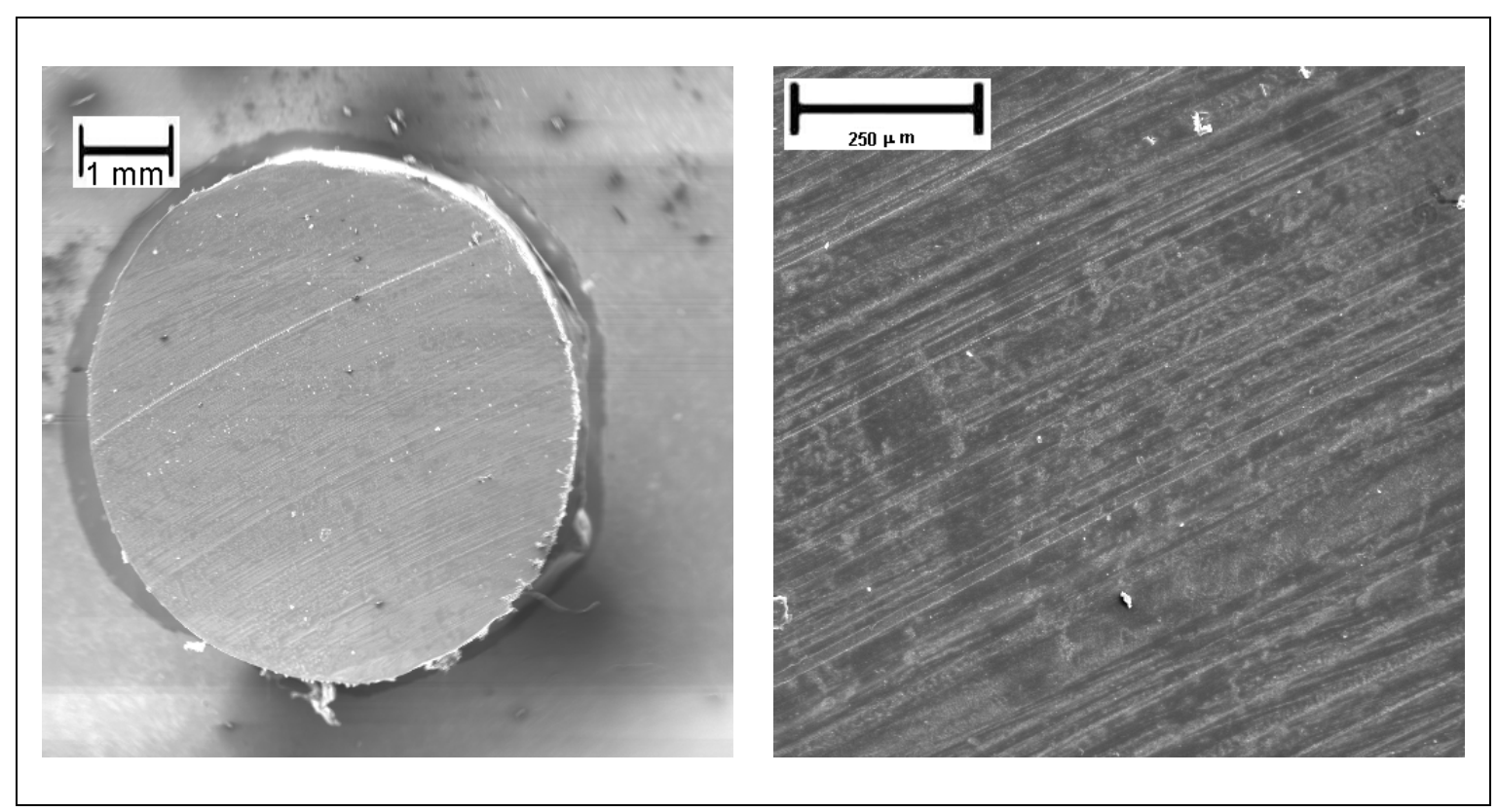

Figura 5.68 - MEV da superfície do pino de UHMWPE $\left(\mathrm{Al}_{2} \mathrm{O}_{3} \mathrm{R4}, 0,5 \mathrm{~m} / \mathrm{s}\right.$ e $50 \mathrm{N0}$. Nota-se mecanismo de abrasão e pouca presença de material depositado no pino. 
Quase não se nota material aderido na superfície do pino, em comparação com a superfície resultante dos ensaios com alumina R3. Com o aumento da rugosidade, houve uma aparente preponderância de fenômenos abrasivos, em detrimento dos adesivos. A ação abrasiva da superfície do disco pareceu ter inibido o crescimento de uma camada protetiva na superfície dos pinos de UHMWPE, conduzindo assim a valores bem mais altos de taxa de desgaste, mesmo nas condições PV menos severas.
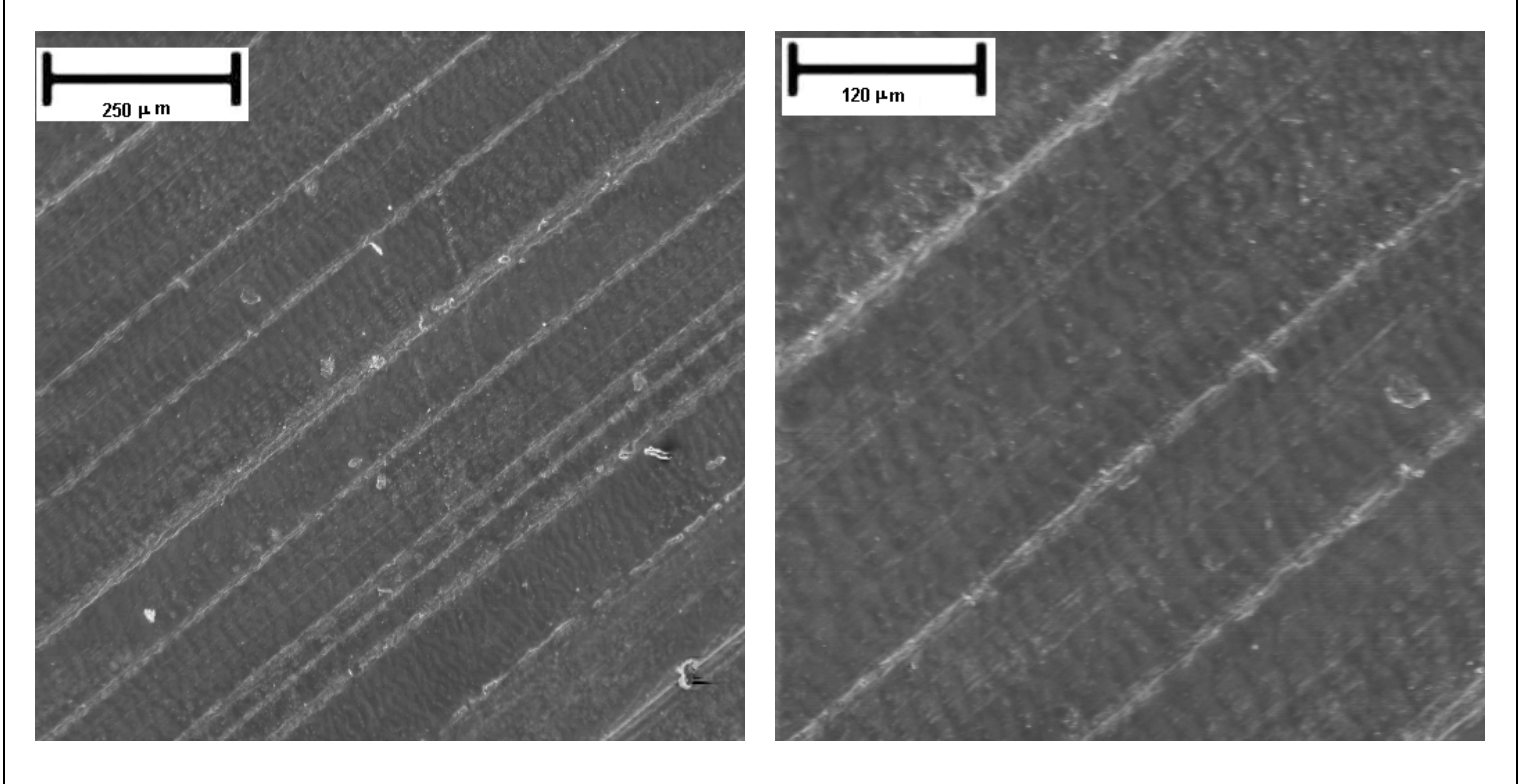

Figura 5.69 - MEV da superfície de pino de UHMWPE $\left(\mathrm{Al}_{2} \mathrm{O}_{3} \mathrm{R4}, 0,5 \mathrm{~m} / \mathrm{s} \mathrm{e} 100 \mathrm{~N}\right)$. Atuação concomitante dos mecanismos de abrasão e de formação de ondas.

Após a identificação dos mecanismos de desgaste e do efeito da condição PV e da temperatura próxima ao contato do par UHMWPE x Alumina, analisaremos o efeito do acabamento superficial na taxa de desgaste deste par.

\subsubsection{Efeito do acabamento superficial no desgaste de UHMWPE $x$}

\section{Alumina}

A Figura 5.70 apresenta os resultados de taxa de desgaste dos pinos de UHMWPE deslizando contra discos de alumina, com os dois tipos de acabamento superficial. Nessa Figura, observa-se que a taxa de desgaste do UHMWPE nos ensaios com acabamento superficial R4 foi mais elevada do que nos ensaios com R3, para as mesmas condições PV. No entanto, com o aumento da condição PV, as taxas de 
desgaste das duas condições de acabamento superficial tenderam a apresentar os mesmos valores, indicando dessa forma que, para condições PV muito elevadas, o efeito do acabamento superficial tornou-se menos relevante.

Comparando com a Figura 5.40, nota-se que a influência da rugosidade no comportamento do desgaste do polímero por toda a faixa de condições PV foi mais clara com o UHMWPE.

Uma análise de correlação da capacidade de dissipação de calor do polímero com o efeito da rugosidade do disco leva a evidenciar que, como UHMWPE dissipa melhor o calor, a intensificação dos fenômenos abrasivos com o aumento da rugosidade pode ser identificada, nas condições PV menos severas. Porém, para condições PV mais elevadas, a elevação de temperatura torna-se mais relevante do que o aumento da rugosidade. Os efeitos térmicos nas propriedades dos materiais reduzem tanto a resistência aos mecanismos de desgaste atuantes, que a maior amplitude das asperezas não eleva significativamente sua capacidade de provocar dano à superfície do UHMWPE. Este fato reforça a idéia da capacidade de dissipação de calor ser um fator importante na resistência ao desgaste desses polímeros.

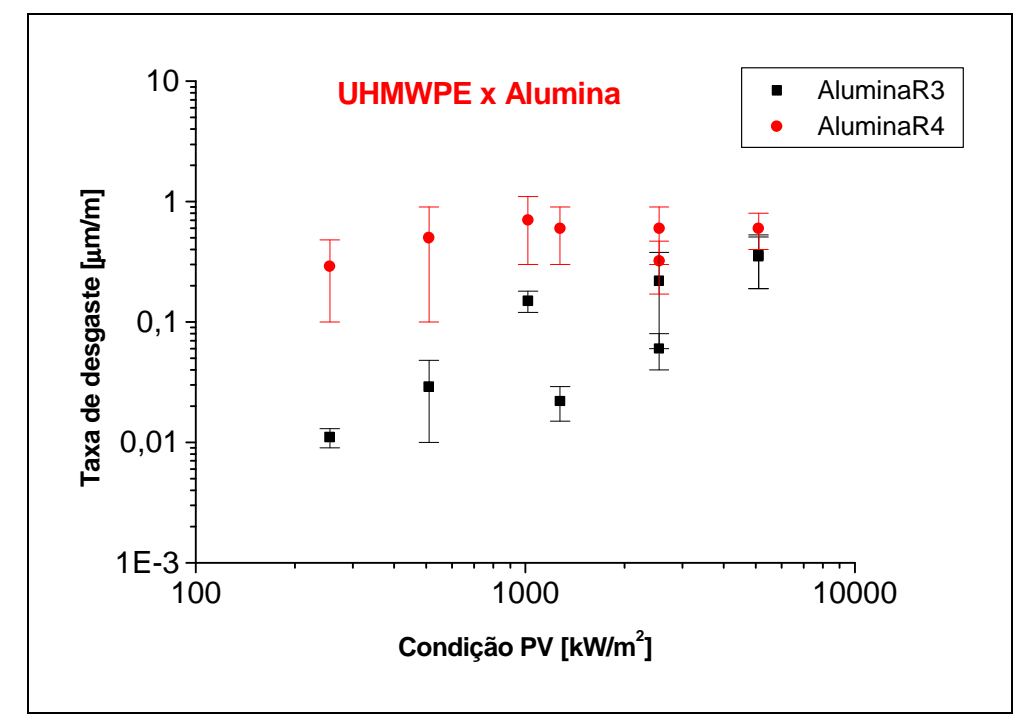

Figura 5.70 - Taxa média de desgaste e seus respectivos desvios padrões em função da condição PV dos ensaios com o par UHMWPE x $\mathrm{Al}_{2} \mathrm{O}_{3}$.

Na Figura 5.71, é mostrado o efeito da temperatura na região de contato na taxa de desgaste com os dois acabamentos superficiais. As temperaturas nos ensaios com rugosidade R4 foram, em média, sempre superiores à dos ensaios com rugosidade R3. No entanto, com o aumento da temperatura, o efeito do acabamento foi menos influente. 


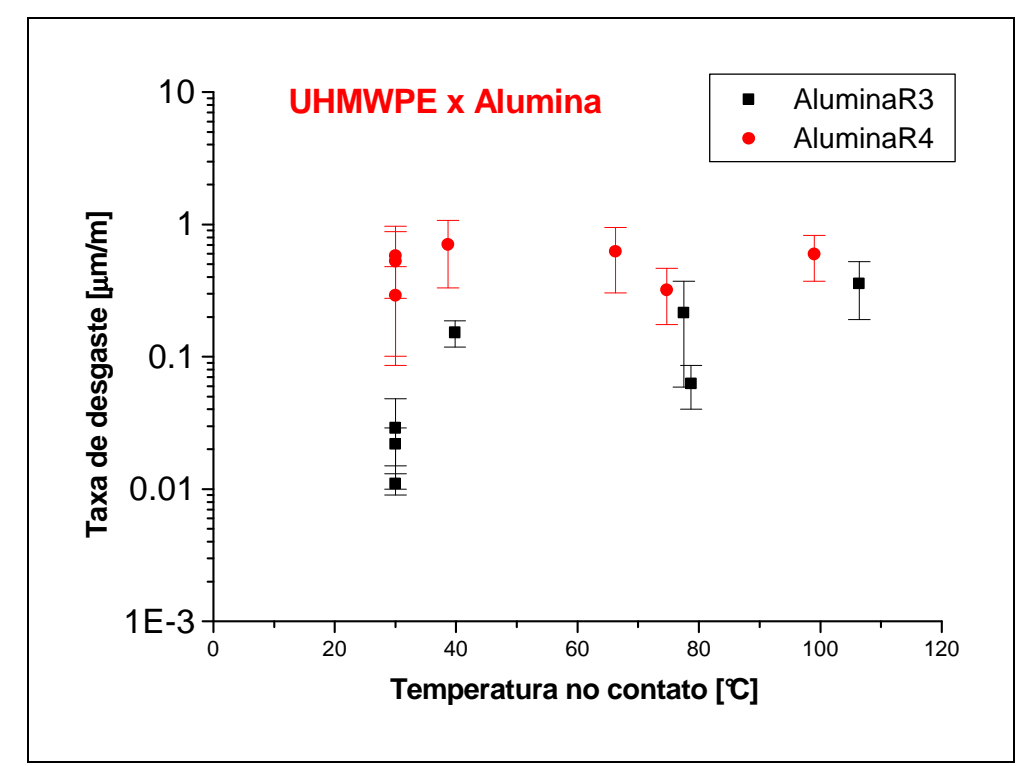

Figura 5.71 - Taxa média de desgaste e seus respectivos desvios padrões em função da temperatura próxima ao contato dos ensaios com o par UHMWPE $x \mathrm{Al}_{2} \mathrm{O}_{3}$.

A análise dos resultados da taxa de desgaste de UHMWPE contra alumina com os dois acabamentos superficiais (Figura 5.72) mostrou que, apesar das altas dispersões dos resultados, existiu uma tendência de aumento no desgaste do polímero, quando se eleva a rugosidade do contra-corpo nos níveis apresentados. Porém, o aumento da taxa de desgaste foi menor nas condições mais severas, com explicado anteriormente.

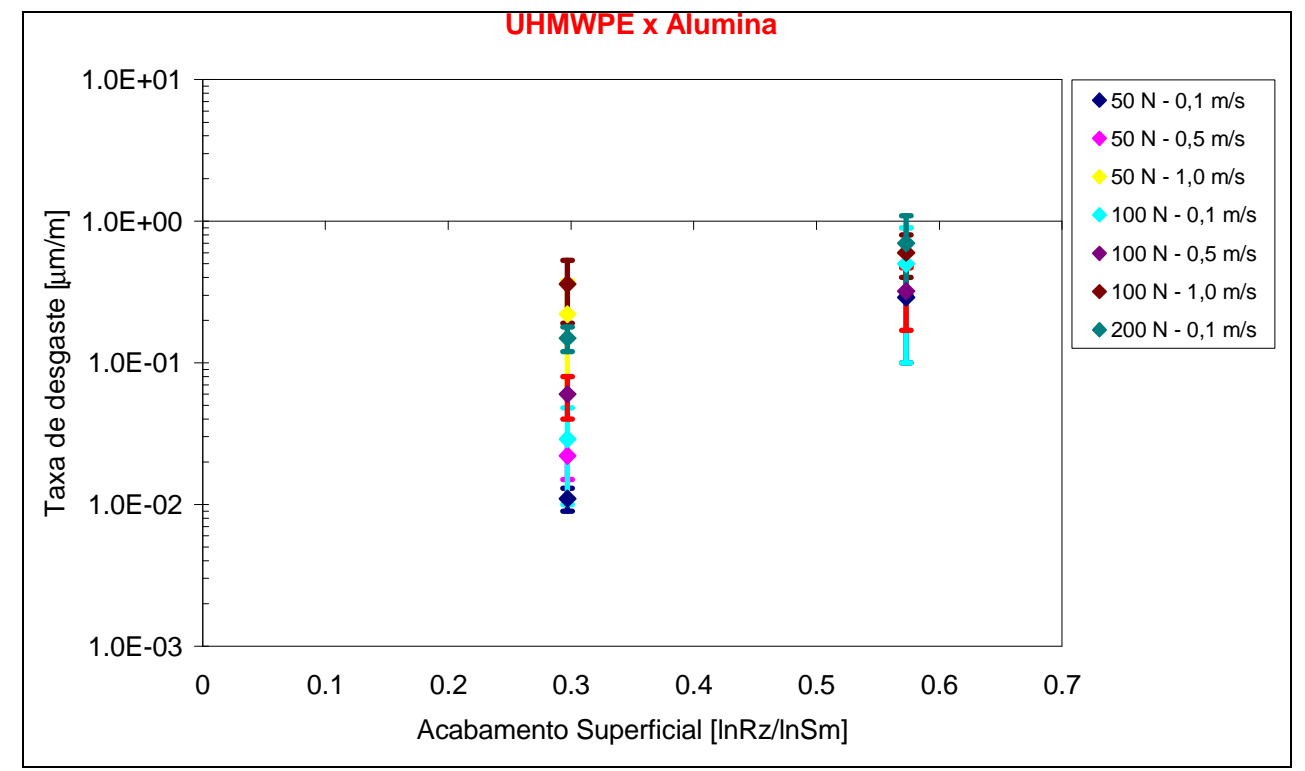

Figura 5.72 - Taxa média de desgaste em função do acabamento superficial dos ensaios de UHMWPE $\times \mathrm{Al}_{2} \mathrm{O}_{3}$. 
A seguir apresentaremos as análises dos resultados de taxa de desgaste do par UHMWPE x Aço Inoxidável em função dos diversos parâmetros de ensaio.

\subsubsection{UHMWPE x Aço Inox R2}

A Figura 5.73 apresenta os resultados de taxa de desgaste dos pinos de UHMWPE deslizando contra alumina, com acabamento superficial R2, em função da condição PV.

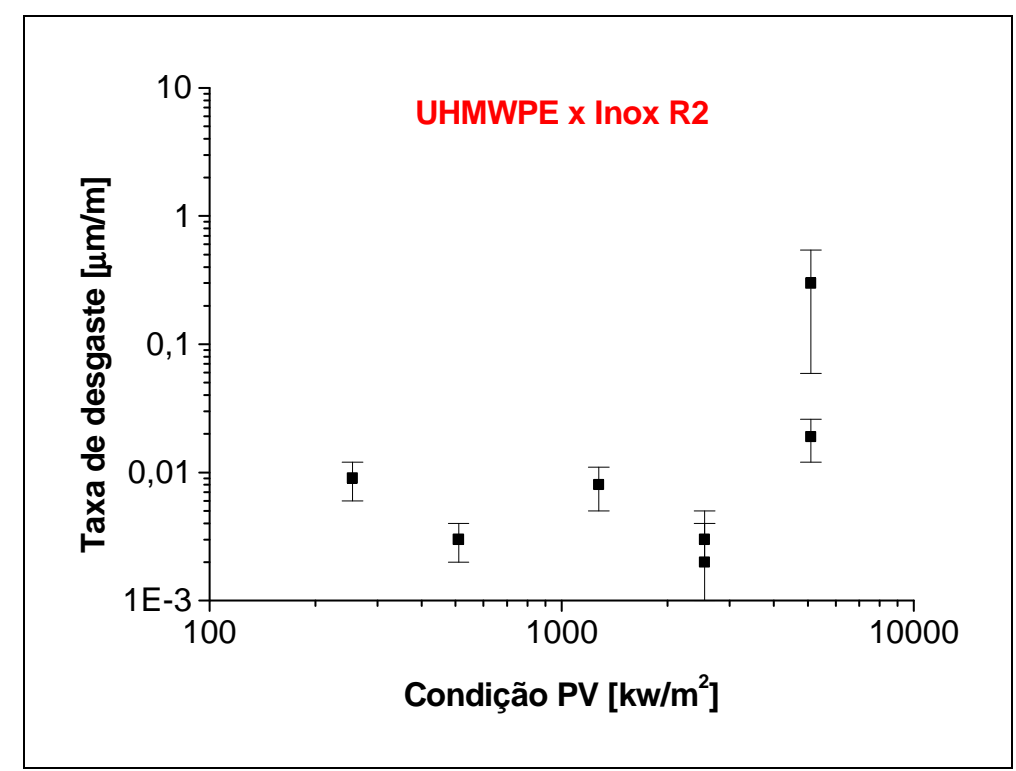

Figura 5.73 - Taxa média de desgaste e seus respectivos desvios padrões em função da condição PV dos ensaios com o par UHMWPE x Aço Inox R2.

Pela Figura 5.73, exceto para a condição PV mais severa $(0,5 \mathrm{~m} / \mathrm{s}$ e $200 \mathrm{~N})$, onde a taxa de desgaste foi de uma ordem de grandeza superior às demais, o aumento da condição PV não influenciou significativamente (95\% de confiança) nos resultados de taxa de desgaste. Além disso, observa-se na mesma Figura a ocorrência de taxas de desgaste com valores muito baixos, inferiores a $0,010 \mu \mathrm{m} / \mathrm{m}$ para diversas condições PV e com dispersões de resultados da ordem dos valores médios. Tal fato pode ser explicado pela influência de dois fatores: a baixa intensidade de atuação dos mecanismos de desgaste, principalmente do abrasivo e a correção dos dados devido aos efeitos da fluência.

Sendo o acabamento superficial R2 o menos agressivo do ponto de vista dos danos provocados pelas asperezas do contra-corpo, era esperado que os níveis de taxa desgaste não fossem elevados, principalmente nas condições PV menos severas. No entanto, observou-se que a influência dos efeitos de fluência foi de maneira geral 
acentuada com esse par de materiais. Sendo assim, para algumas amostras, as taxas de desgaste foram muito pequenas e tiveram que ser corrigidas, pois o deslocamento vertical do pino $(\Delta \mathrm{h})$ devido à fluência foi da mesma ordem de grandeza que o desgaste (Tabela 5.43).

A Figura 5.74 apresenta os mesmos resultados de taxa de desgaste dos pinos de UHMWPE, em função das temperaturas desenvolvidas no contato.

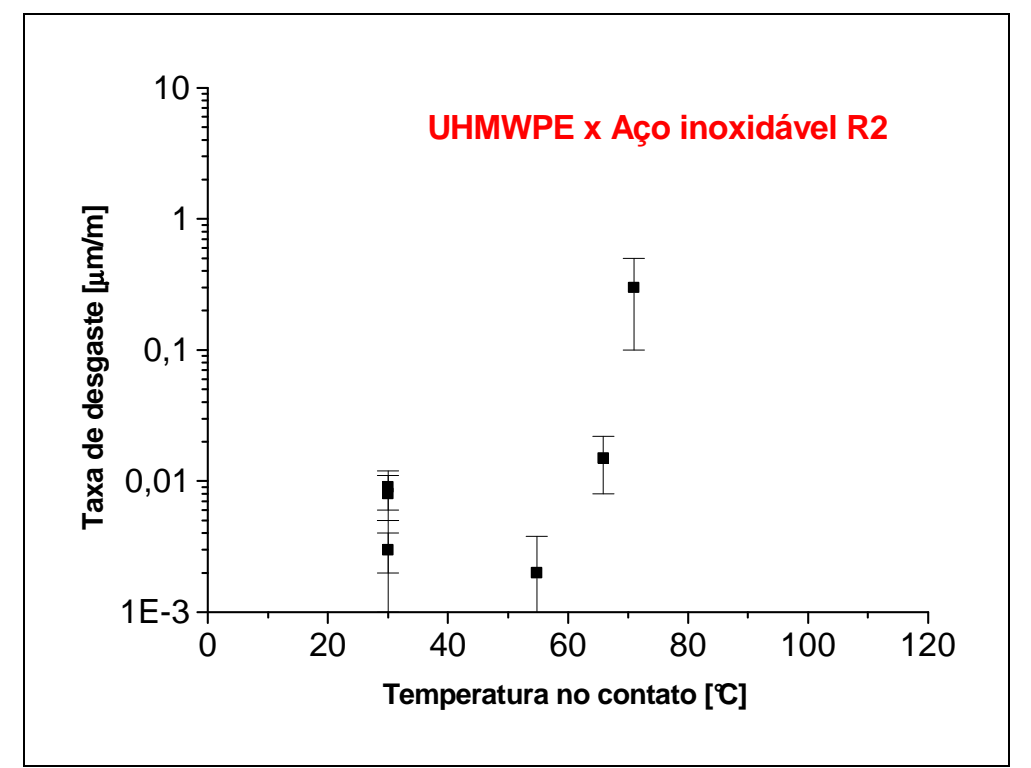

Figura 5.74 - Taxa média de desgaste e seus respectivos desvios padrões em função da temperatura no contato dos ensaios com o par UHMWPE x Aço Inox R2.

Comparando com as temperaturas desenvolvidas em todos os outros pares tribológicos, a Figura 5.74 mostra que, nesse caso, as temperaturas atingiram valores menores, ou seja, houve menor geração de calor, o que também pode ter influenciado as pequenas taxa de desgaste. Por outro lado, o pino que apresentou a maior taxa de desgaste foi aquele que atingiu a maior temperatura na região de contato, o que mostra mais uma vez a importância dos parâmetros térmicos na resistência ao desgaste de materiais poliméricos.

Observando a superfície dos pinos de UHMWPE resultantes desses ensaios, pode-se dizer que alguns ensaios não ultrapassaram o período de running-in, pois ainda se percebia a presença das marcas de usinagem da superfície do pino (Figura 5.76). Essa fato foi observado, apesar das curvas de deslocamento do pino em função da distância percorrida sugerirem que a taxa de desgaste já se tinha se estabilizado (Figura 5.75). No decorrer do ensaio, as variações de altura dos pinos se tornaram tão pequenas, que os 
resultados se aproximavam das incertezas de medição do equipamento, tornando difícil verificar se o período de running-in tinha sido ultrapassado.

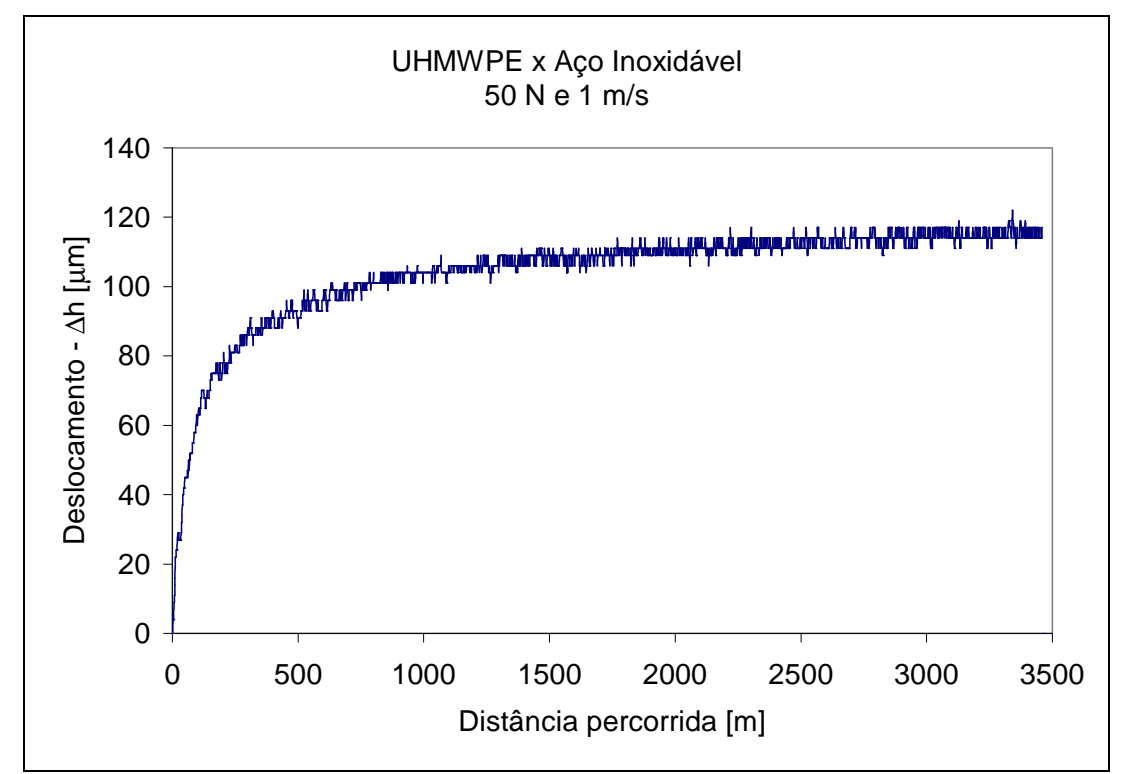

Figura 5.75 - Curva de deslocamento do pino em função da distância percorrida, para o par UHMWPE x Aço Inox R2 ( $50 \mathrm{~N}$ e 1,0 m/s).

A micrografia da Figura 5.76 mostra a presença de um filme aderido à superfície do pino, semelhante ao da Figura 5.48, que pareceu proteger a superfície do pino, apresentando alguns riscos de abrasão. Acredita-se que esse filme tenha sido formado pelas intensas deformações plásticas que teriam ocorrido na superfície do pino no início dos ensaios de desgaste.

Conhece-se que a área real de contato é muito menor que a área aparente ${ }^{46,60}$, assim sendo, desenvolve-se na superfície do pino tensões de compressão extremamente elevadas. Somando-se a isto o fato dos corpos estarem em movimento relativo, o material deformado plasticamente é amassado no sentido contrário ao deslizamento do pino. Este mecanismo é descrito com mais detalhes na seção 5.7. 


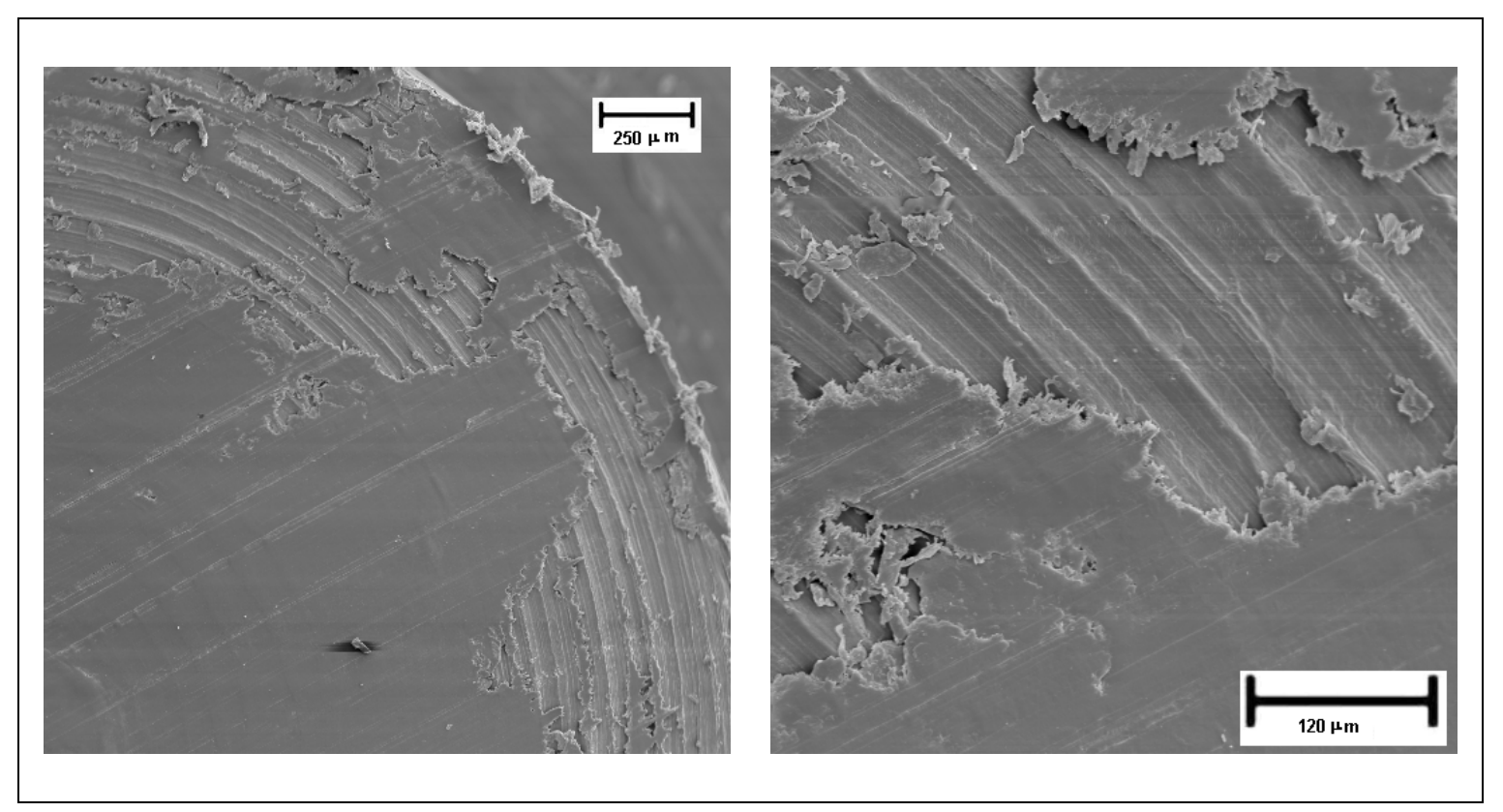

Figura 5.76 -MEV da superfície de pino de UHMWPE (Aço Inox R2, 1 m/s e 50 N). Filme homogêneo e compacto formado em uma grande região, com alguns riscos.

Ainda sobre o filme formado na superfície dos pinos, pode-se dizer que onde ocorre a formação de filme na superfície do pino, não foi constatada a ocorrência de mecanismos de fadiga (formação de ondas).

É razoável sugerir que este filme tenha tido uma atuação protetiva durante o período de running-in e, assim, provavelmente pode ter contribuído para que este período fosse mais extenso que o esperado. No entanto, com o decorrer do ensaio, o próprio filme pode sofrer as ações danosas das asperezas do contra-corpo, sendo então removido. Esse período de formação e remoção de filme se dá até toda a superfície do pino se assentar na do disco, tornando a área real de contato próxima à área aparente de contato, quando então os mecanismos de desgaste, já mencionados anteriormente, atuaram formando novas partículas de desgaste e a taxa de desgaste se estabilizará.

Em alguns ensaios onde o período de running-in foi ultrapassado, observou-se o fenômeno de formação de partículas com formato de bastões, que foram aderidas à superfície do pino e intensamente deformadas. Esta morfologia de desgaste é chamada na literatura de rolled-up wear particules ${ }^{119}$ (Figura 5.77). 


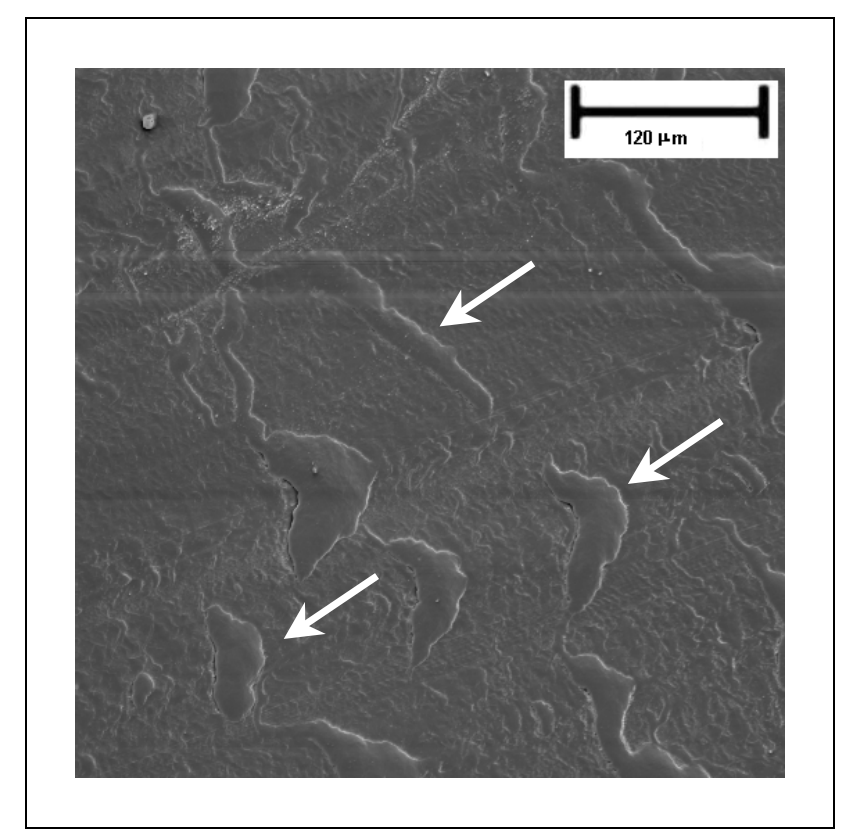

Figura 5.77 -MEV da superfície de pino de UHMWPE (Aço Inox R2, 1 m/s e $100 \mathrm{~N}$ ). Observa-se o mecanismo de desgaste do tipo rolled-up wear particules. ${ }^{119}$

\subsubsection{UHMWPE $x$ Inox $R 3$}

As Figuras 5.78 e 5.79 apresentam os resultados de taxa de desgaste dos pinos de UHMWPE contra aço inoxidável, com acabamento superficial R3, em função da condição PV e da temperatura próxima ao contato, respectivamente.

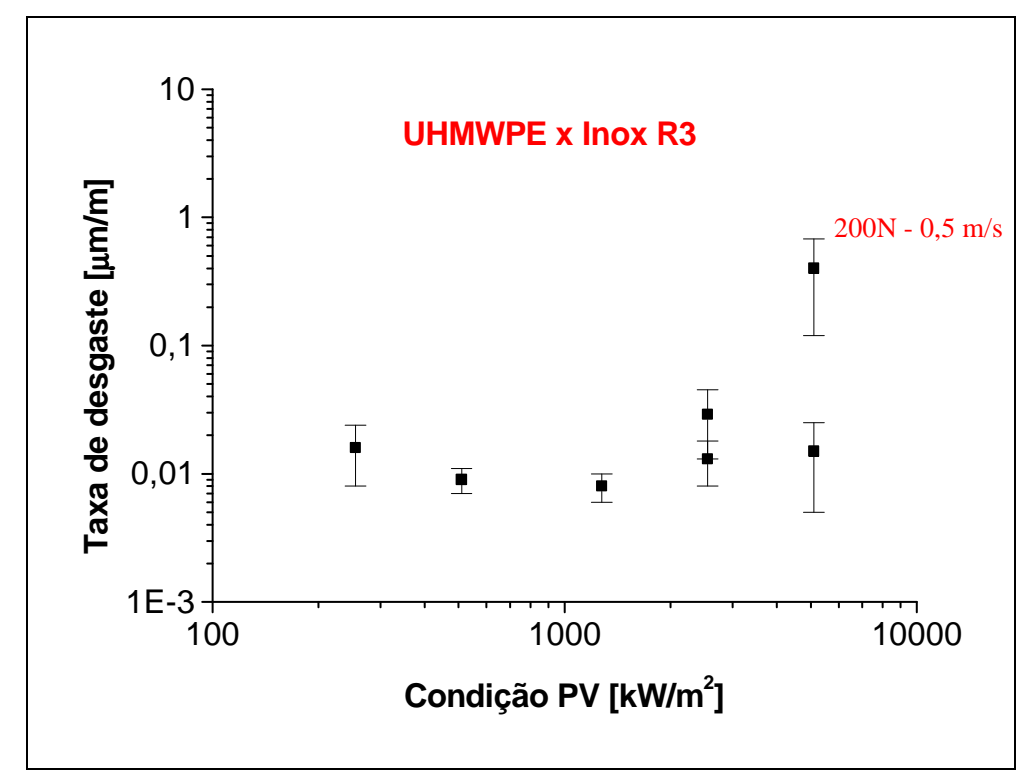

Figura 5.78 - Taxa média de desgaste e seus respectivos desvios padrões em função da condição PV dos ensaios com o par UHMWPE x Aço Inox R3. 
As Figuras 5.78 e 5.79 mostram que, excetuando o ensaio com carga de $200 \mathrm{~N} \mathrm{e}$ velocidade de $0,5 \mathrm{~m} / \mathrm{s}$, tanto a condição PV quanto os níveis de temperatura na região do contato não influenciaram os valores de taxa de desgaste do UHMWPE; foi verificado, com $95 \%$ de confiança, que não houve diferença significativa nesses resultados.

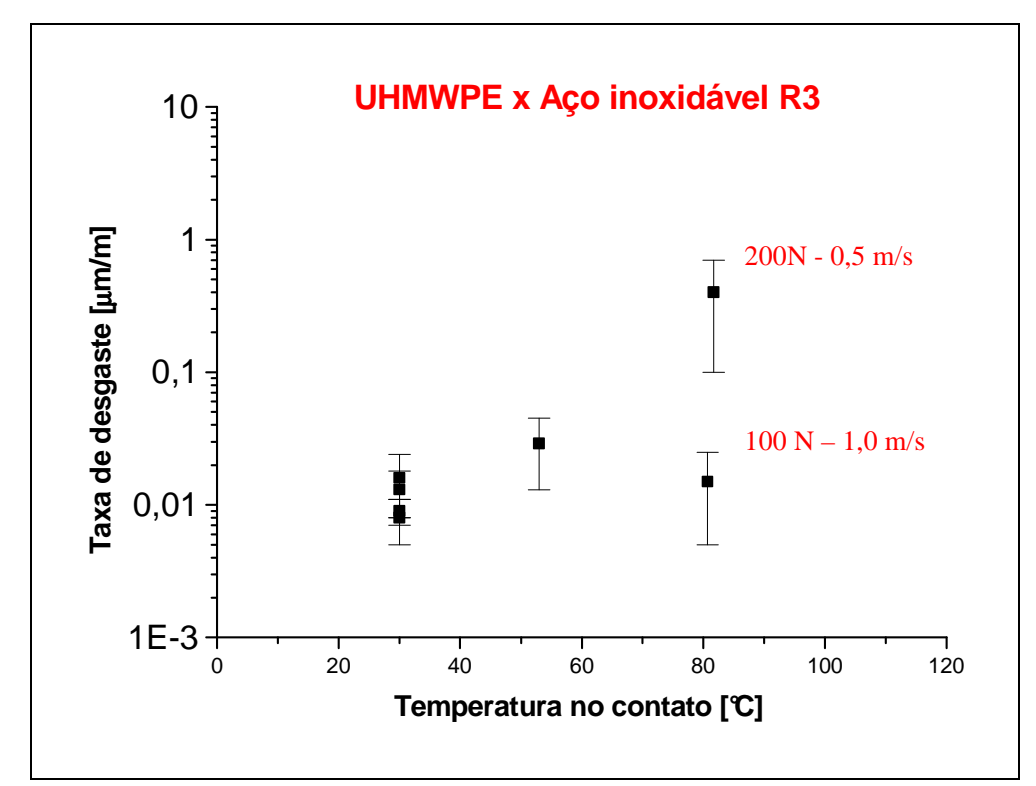

Figura 5.79 - Taxa média de desgaste e respectivos desvios padrões em função da temperatura próxima ao contato dos ensaios com UHMWPE contra Aço Inox R3.

Aparentemente, existe um outro fator relevante nessas análises de desgaste que não está sendo contemplado, pois os ensaios de desgaste realizados com a condição PV de $5.100 \mathrm{~kW} / \mathrm{m}^{2}$ atingiram temperaturas semelhantes na região do contato e, no entanto, o ensaio com a carga mais elevada $(200 \mathrm{~N}$ e $0,5 \mathrm{~m} / \mathrm{s})$ apresenta uma taxa de desgaste uma ordem de grandeza superior ao ensaio com carga de $100 \mathrm{~N}$ e 1,0 m/s. Na realidade, para todos os ensaios realizados nas mesmas condições PV $\left(2.550\right.$ e $\left.5.100 \mathrm{~kW} / \mathrm{m}^{2}\right)$ as maiores taxas de desgaste estiveram, em 100\% dos casos, relacionados com os ensaios com maior carga.

Observando a superfície dos pinos, pode-se dizer que, assim como aconteceu nos ensaios realizados contra aço inoxidável com acabamento superficial R2, novamente ocorreu a formação de um filme homogêneo sobre os sulcos de usinagem da superfície do pino (Figura 5.80). 


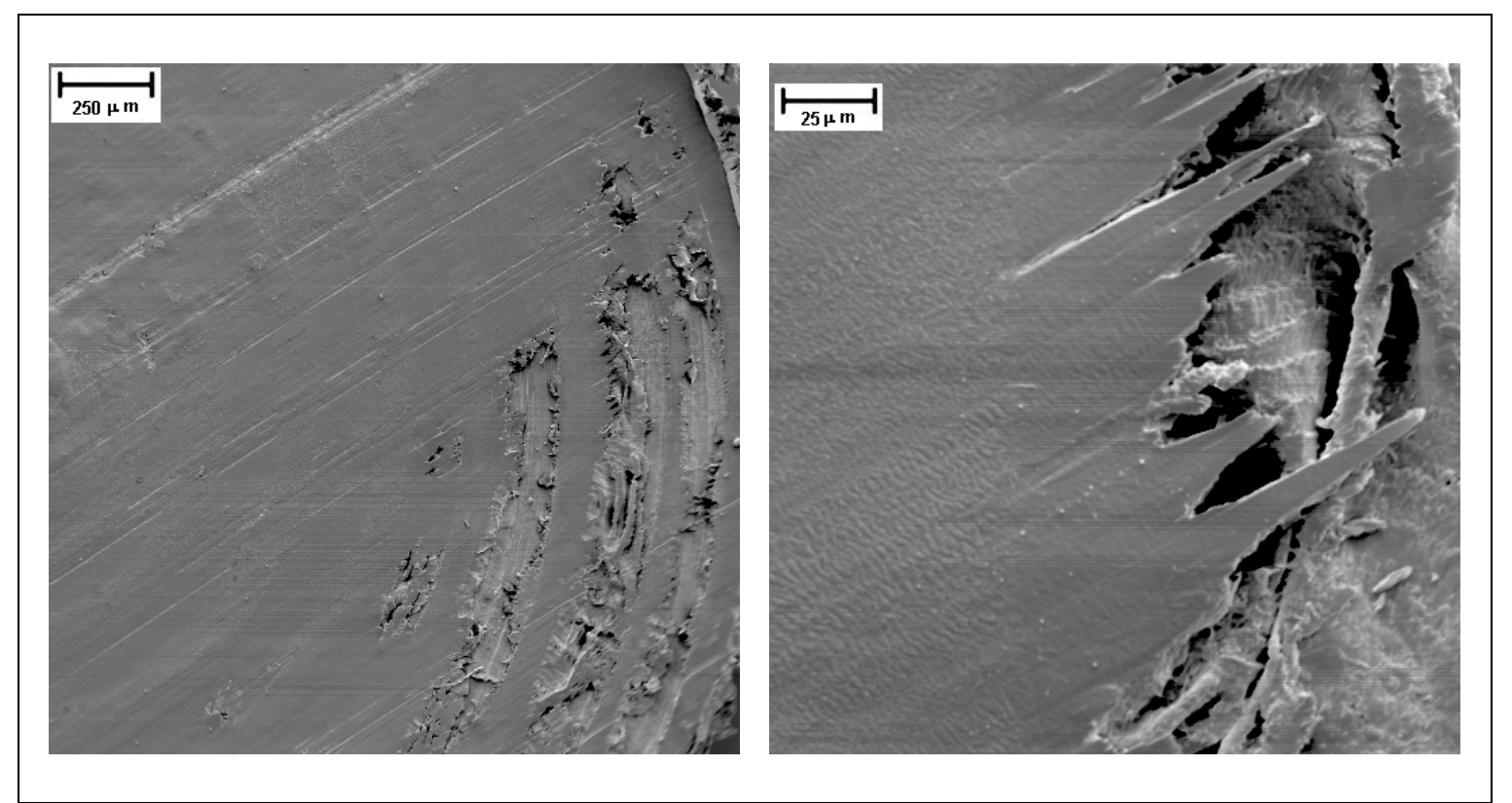

Figura 5.80 - MEV da superfície de pino de UHMWPE (Aço Inox R3, 0,5 m/s e 100 N). Presença de mecanismo de desgaste por abrasão no filme polimérico.

Diferentemente do que havia acontecido com a rugosidade R2, nesse caso, observou-se a presença de mecanismos de fadiga (formação de ondas) nos ensaios com baixa condição PV. Na realidade, os mecanismos de desgaste são observados nos filmes. A atuação desse mecanismo de desgaste nestes níveis de severidade reafirma a relação entre rugosidade e mecanismo de fadiga. Da mesma forma como havia ocorrido para os demais pares, nos ensaios com condições PV mais elevadas, intensifica-se o mecanismo de desgaste por fadiga (formação de ondas).

Após a identificação dos mecanismos de desgaste e do efeito da condição PV e da temperatura no contato do par UHMWPE x Aço Inoxidável, analisaremos o efeito do acabamento superficial na taxa de desgaste deste par.

\subsubsection{Efeito do acabamento superficial no desgaste de UHMWPE $x$ Aço Inoxidável}

As Figuras 5.81 e 5.82 apresentam os resultados de taxa de desgaste dos pinos de UHMWPE contra discos de aço inoxidável em função da condição PV e da temperatura próxima ao contato, comparando os dois níveis de acabamento superficial. 


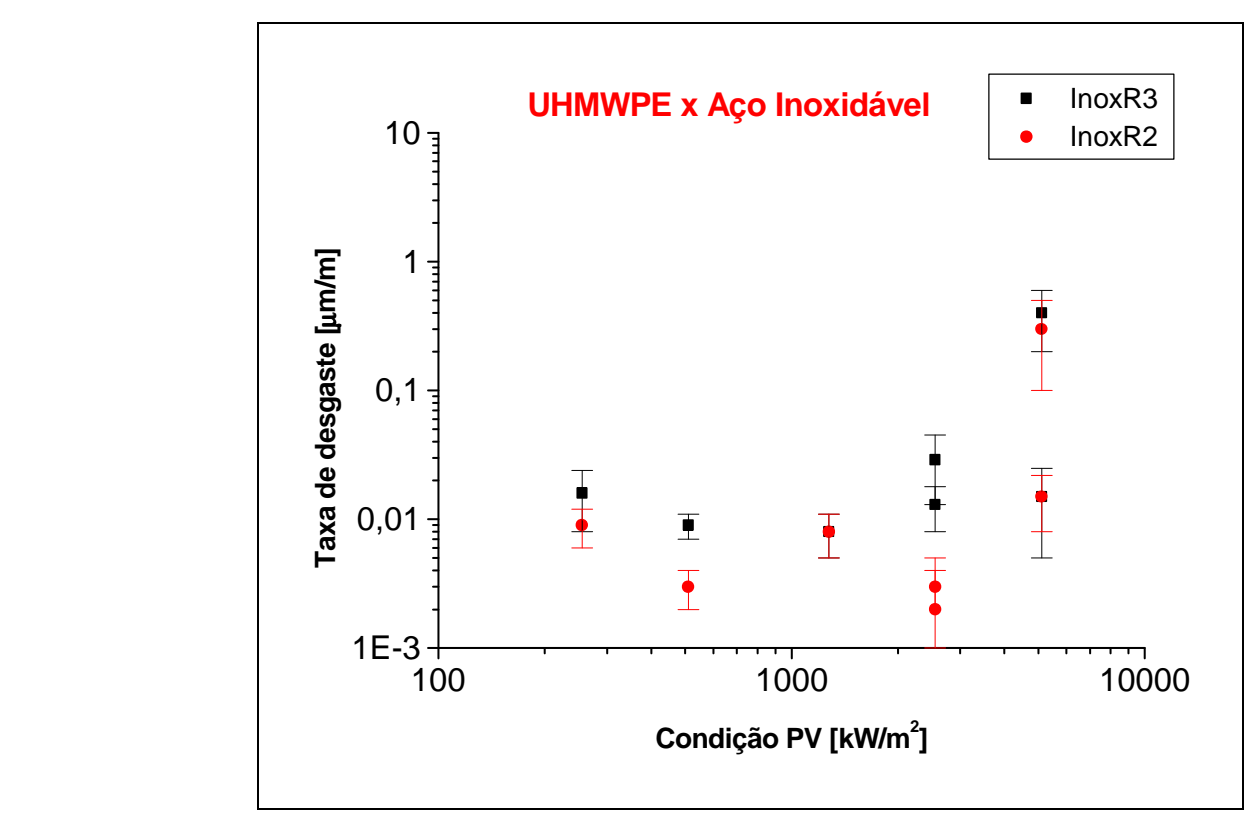

Figura 5.81 - Taxa média de desgaste e seus respectivos desvios padrões em função da condição PV dos ensaios do par UHMWPE x Aço Inox.

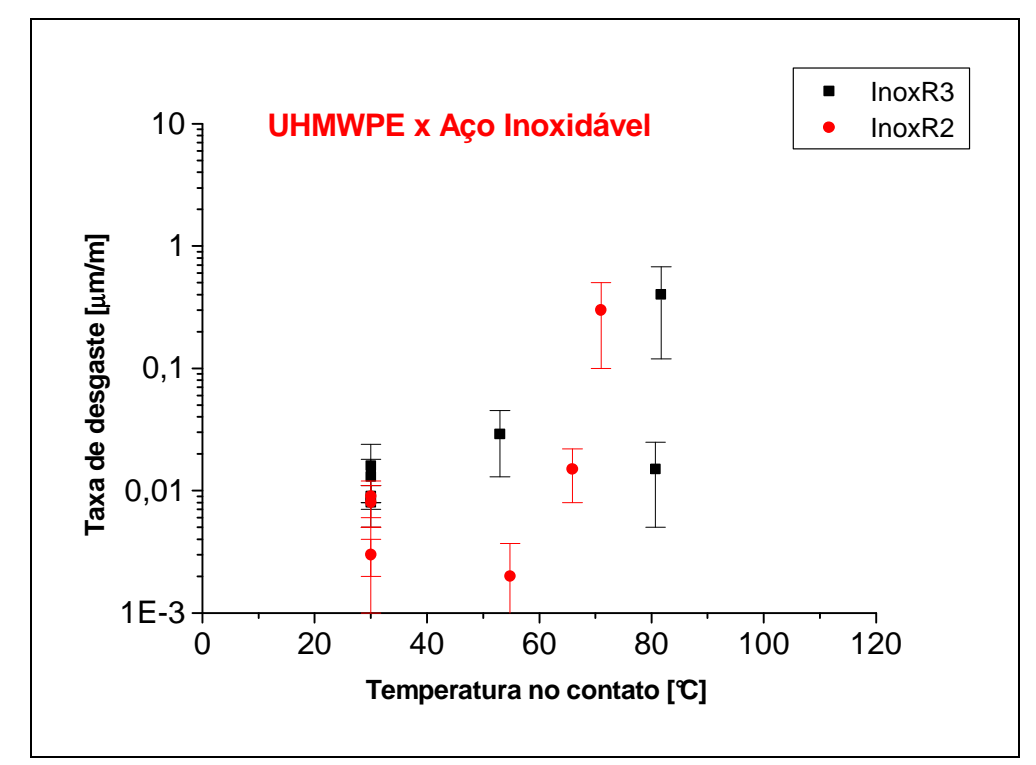

Figura 5.82 - Taxa média de desgaste e seus respectivos desvios padrões em função da temperatura próxima ao contato dos ensaios do par UHMWPE x Aço Inox.

Aparentemente, não se nota um efeito claro da variação do acabamento superficial no comportamento da taxa de desgaste nas diversas faixas de PV (Figura 5.81); também não se notam diferenças claras nas tendências das temperaturas atingidas (Figura 5.82). Vale recordar que o mesmo resultado foi obtido nos ensaios de POM $\mathrm{x}$ Aço Inoxidável. 
Apesar dos resultados apresentados na Figura 5.83 e também na Tabela 5.43, mostrarem que os valores médios da taxa de desgaste tenderam a ser maiores com o aumento da rugosidade, a dispersão dos resultados indicam que, na realidade, não houve diferença significativa. A análise de variância realizada para comparar os resultados médios da taxa de desgaste dos ensaios realizados com UHMWPE com os dois níveis de acabamento superficial confirma a impressão passada pela Figura 5.83, na qual não há diferença significativa (95\% de confiança) entre esses resultados. Estas análises indicam que a rugosidade dos discos de aço inoxidável não interferiu nos resultados de desgaste do UHMWPE, dentro das faixas estudadas.

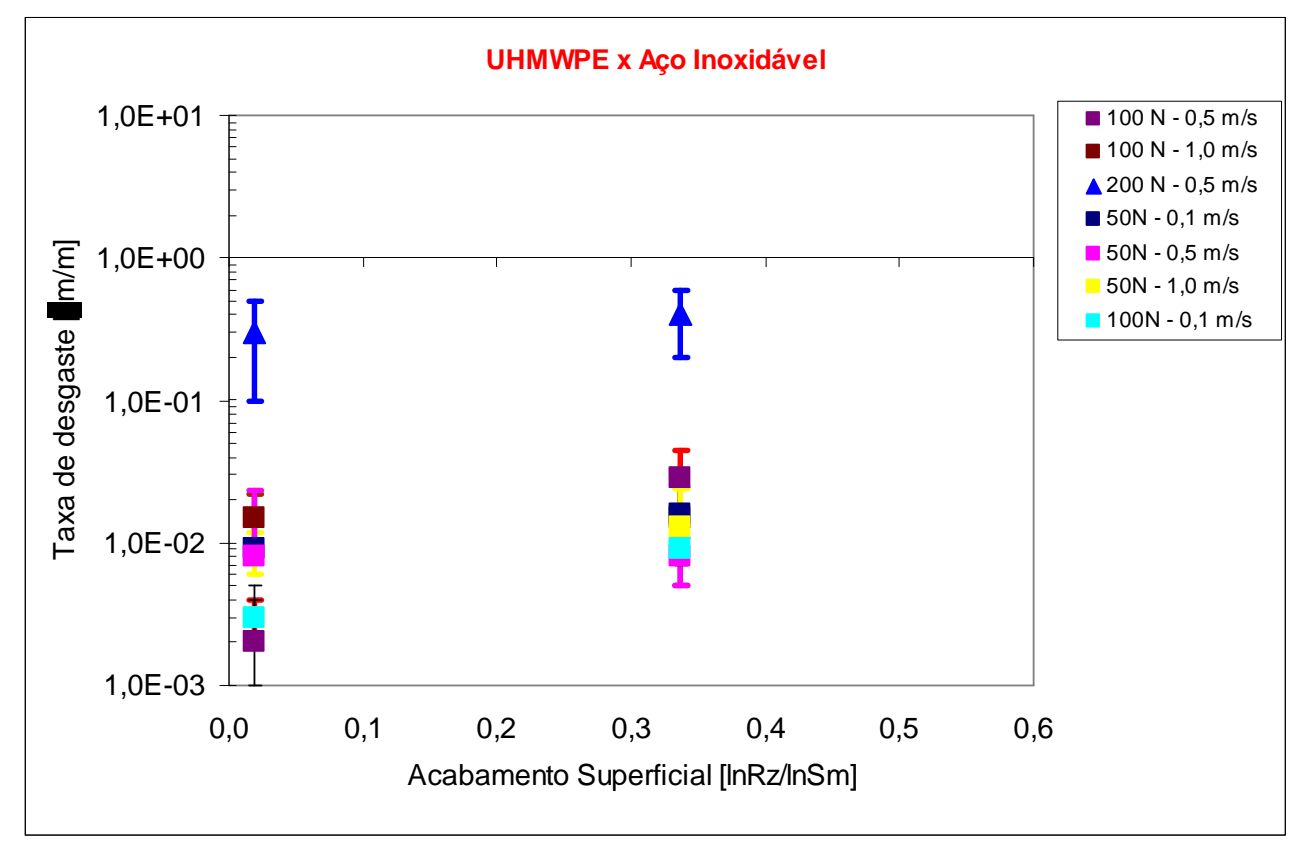

Figura 5.83 - Taxa média de desgaste em função do acabamento superficial dos ensaios de UHMWPE contra aço inoxidável.

Tendo concluído as análises do efeito da condição PV, da temperatura próxima ao contato e do acabamento superficial nos ensaios com UHMWPE, verificaremos a seguir o efeito do contra-corpo (alumina e aço inoxidável) na taxa de desgaste.

\subsubsection{Efeito do contra-corpo na taxa de desgaste do UHMWPE}

As Figuras 5.84 e 5.85 mostram o comportamento da taxa de desgaste em relação ao contra-corpo utilizado: alumina e aço inoxidável. Com o objetivo de manter o 
parâmetro acabamento superficial fora das análises comparativas, serão utilizados somente os resultados dos ensaios com acabamento tipo R3.

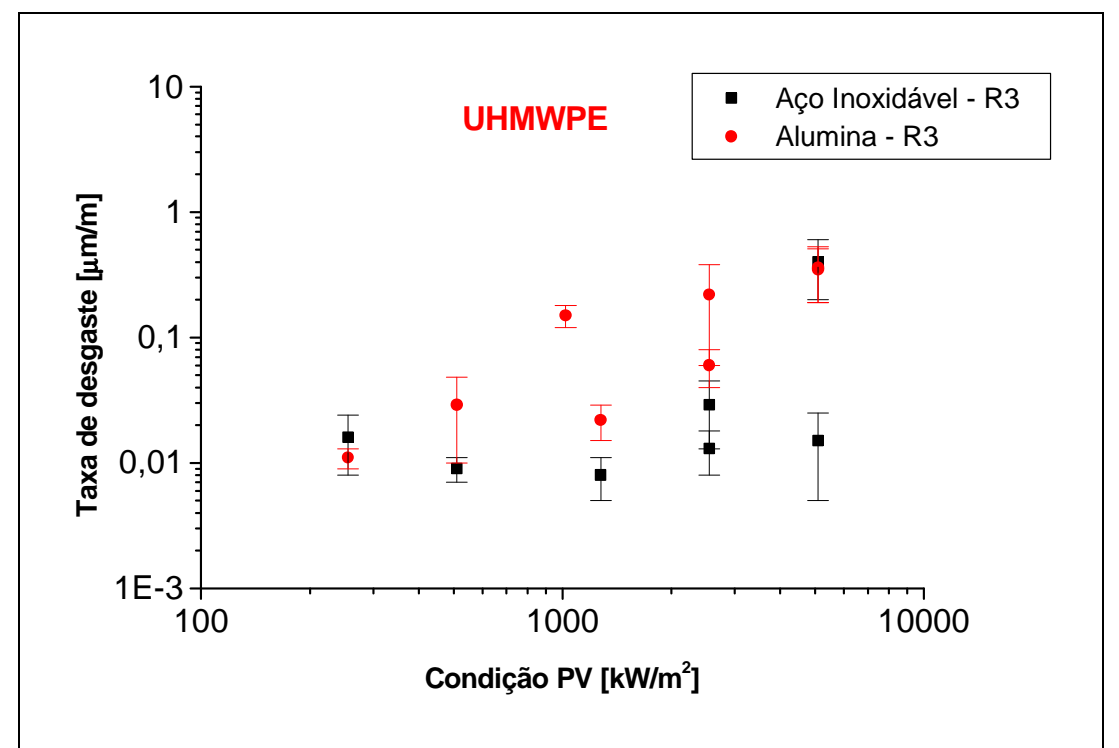

Figura 5.84- Taxa média de desgaste e seus respectivos desvios padrões em função da condição PV dos ensaios com UHMWPE (rugosidade R3).

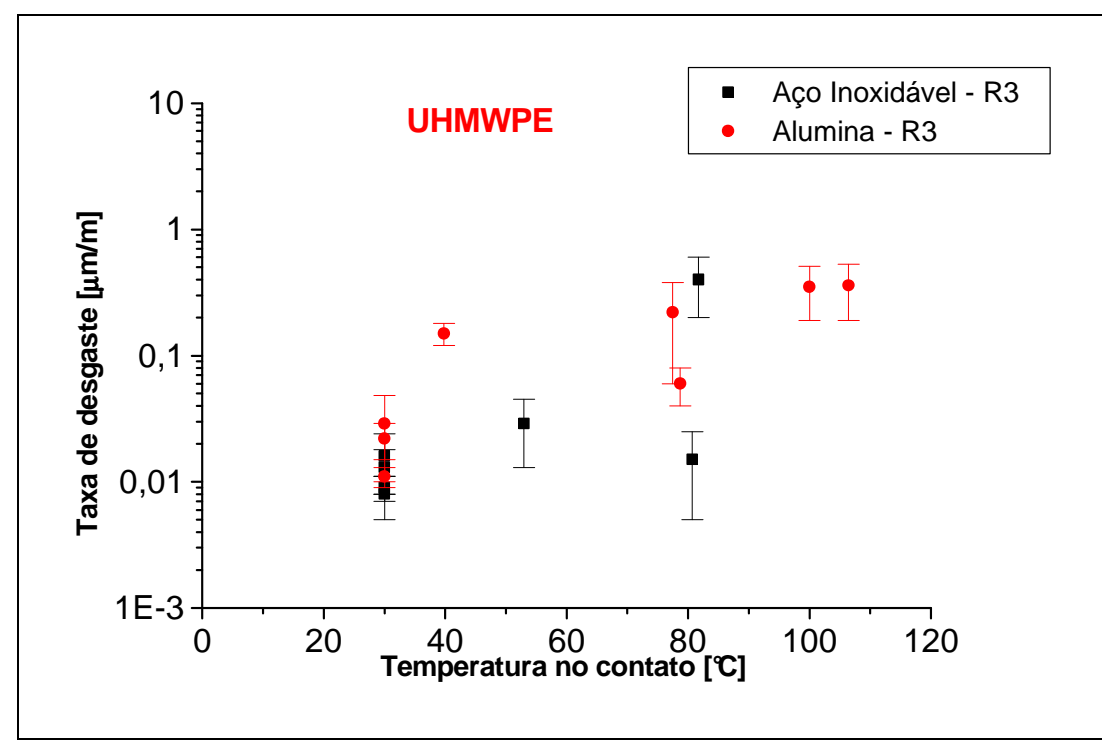

Figura 5.85 - Taxa média de desgaste e seus respectivos desvios padrões em função da temperatura próxima ao contato dos ensaios com UHMWPE (rugosidade R3).

Em termos das temperaturas atingidas, observa-se um comportamento muito próximo da taxa de desgaste com os dois materiais de disco em relação à condição PV (Figura 5.84), observa-se que as taxas de desgaste dos ensaios do UHMWPE contra alumina mostraram-se superiores nas condições PV intermediárias. Nas condições PV 
limite inferior e superior, não se observou o efeito do material do contra-corpo. No caso dos ensaios com POM (Figura 5.55), a alumina mostrou-se mais agressiva do que o aço inoxidável .

Vale ressaltar que o valor do trabalho de adesão entre o UHMWPE e o aço inoxidável ou a alumina é o mesmo $\left(8,5 \mathrm{~mJ} / \mathrm{m}^{2}\right)$, pelo menos à temperatura ambiente ${ }^{18}$. Portanto, para desgaste do UHMWPE, não foram os efeitos adesivos os principais responsáveis pela maior agressividade da alumina em relação ao aço inoxidável. Para o POM, o trabalho de adesão deste em contato com a alumina é maior que com o Aço Inoxidável, o que pode caracterizar a maior severidade do contato com a alumina naquele caso, conduzindo assim, a taxas de desgaste mais elevadas.

A Figura 5.86, que apresenta o efeito de todos os acabamentos superficiais na taxa de desgaste do UHMWPE, indica que, aparentemente, houve uma tendência do desgaste se elevar com o aumento do parâmetro de acabamento superficial $\operatorname{lnRZ} / \operatorname{lnSm}$, um pouco mais evidente nos ensaios com alumina. Nos ensaios com POM, a influência do acabamento superficial (vide Figura 5.59) foi mais nítida do que aqui.

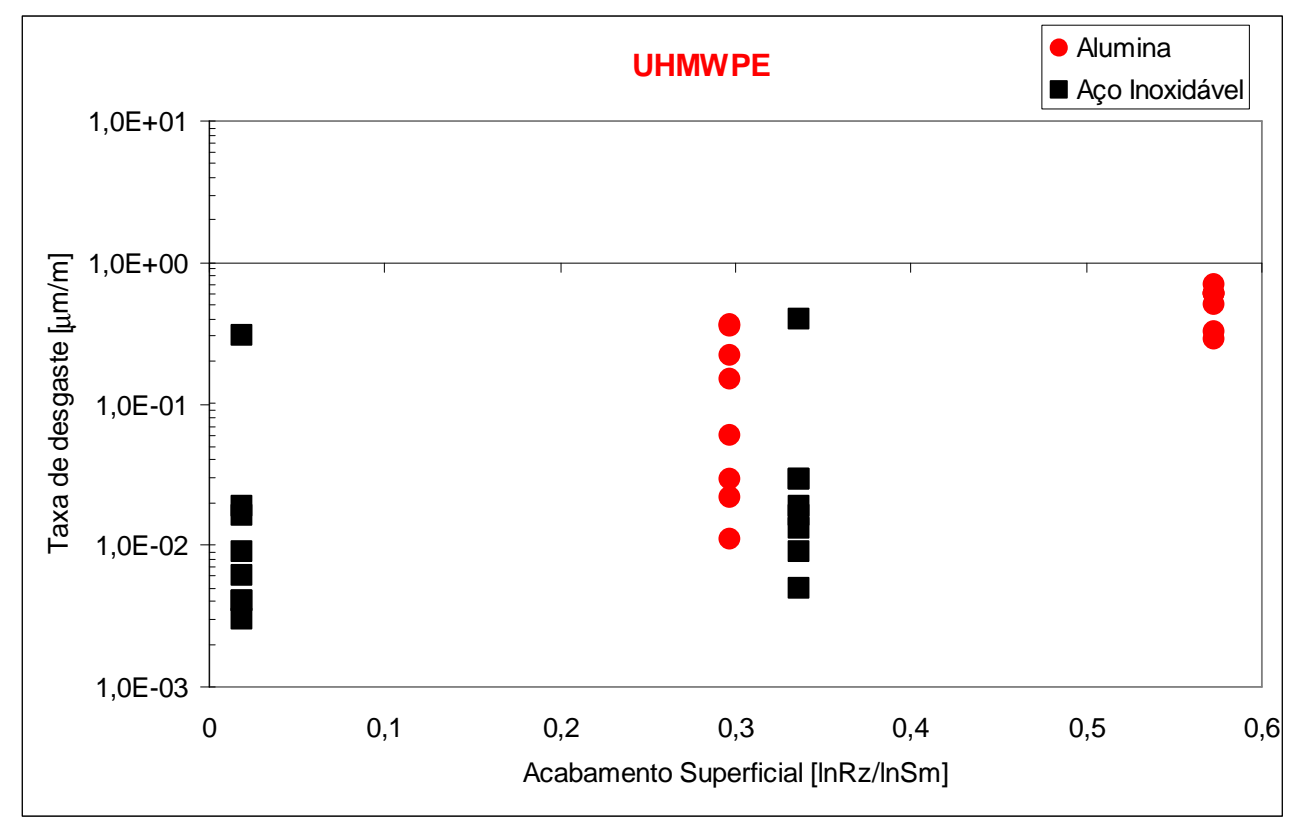

Figura 5.86 - Taxa média de desgaste em função do acabamento superficial dos ensaios com UHMWPE.

Novamente, com o intuito de organizar os dados de uma maneira mais global, a Figura 5.87 apresenta os resultados de taxa de desgaste em função da severidade global (PVR/DD) dos ensaios com UHMWPE. 


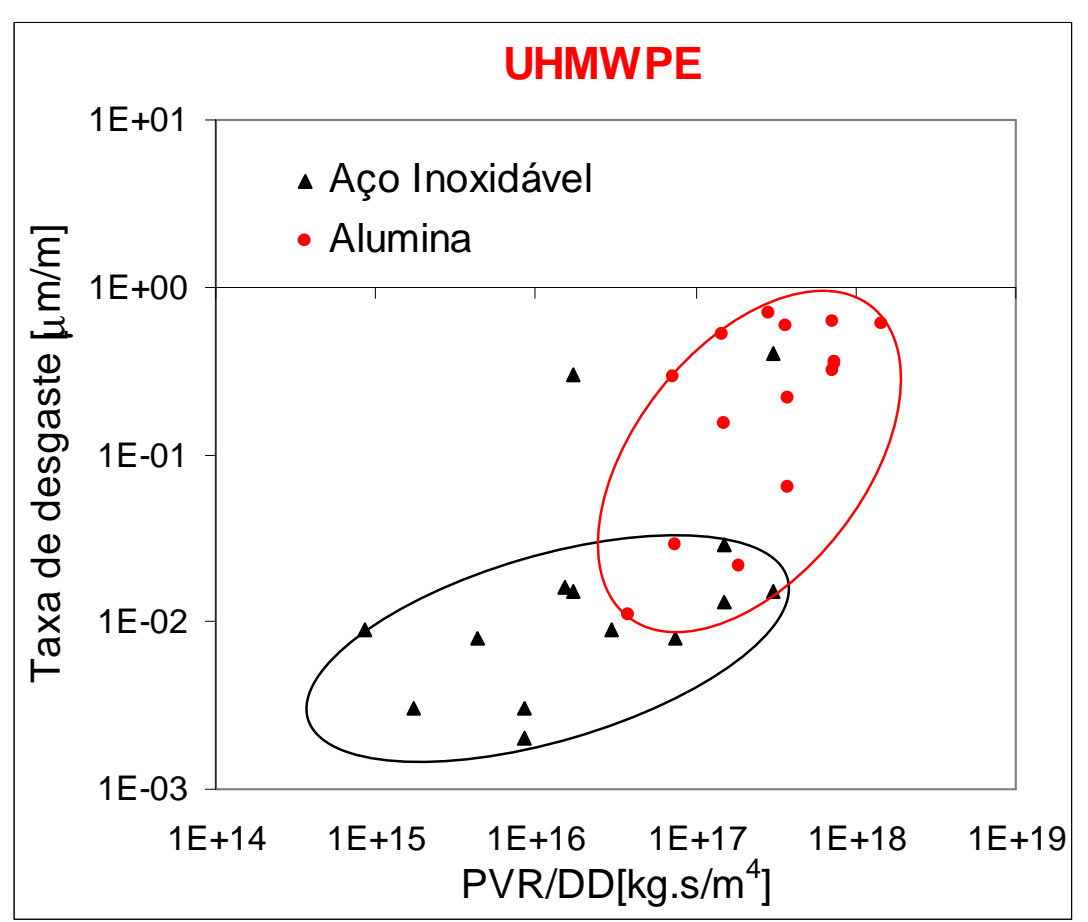

Figura 5.87 - Taxa média de desgaste em função da severidade global dos ensaios com UHMWPE contra alumina e aço inoxidável.

Assim como ocorreu nas análises de POM em função da severidade global (vide Figura 5.60), também com UHMWPE, verifica-se com maior nitidez a tendência dos ensaios com alumina terem apresentado valores de taxa de desgaste, em geral, superiores à do aço inoxidável. Com exceção dos resultados com carga de $200 \mathrm{~N}$ e velocidade de $0,5 \mathrm{~m} / \mathrm{s}$ (condições extremas), a nuvem de tendências dos resultados de desgaste contra aço inoxidável apresentou-se abaixo dos resultados contra alumina, e também com uma tendência de crescimento menos acentuada em função de PVR/DD.

As análises dos resultados de taxa de desgaste realizadas até este ponto procuraram verificar como se comportam os materiais poliméricos (POM e UHMWPE), quanto à taxa de desgaste, quando se altera a condição de ensaio no sentido de torná-las mais agressivas do ponto de vista dinâmico-mecânico. Para tal, verificou-se a influência da condição PV, da temperatura no contato e do nível de acabamento superficial na taxa de desgaste de diversos pares de polímero x contra-corpo rígido. A seguir, será apresentada uma comparação da taxa de desgaste do POM e do UHMWPE nas diversas condições de ensaio estudadas. 


\subsubsection{Comparação de resultados: POM $x$ UHMWPE}

A Figura 5.88 apresenta a influência da condição PV na taxa de desgaste dos dois polímeros estudados. As Figuras de 5.88 a 5.91 não mostram as barras de incerteza das medidas de taxa de desgaste, para que se possa visualizar as tendências de comportamento com maior clareza.

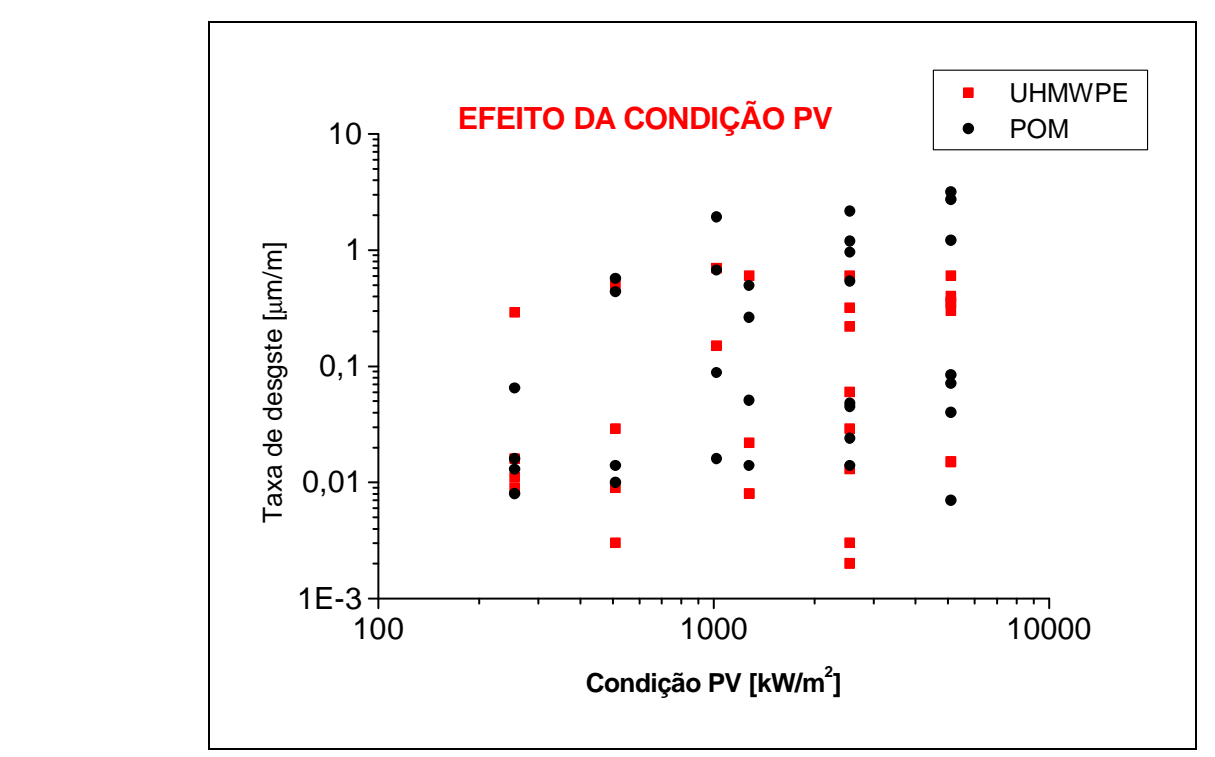

\section{Figura 5.88 - Taxa média de desgaste do POM e do UHMWPE em função da condição PV.}

Quando foram realizadas análises localizadas para verificar a influência da condição PV na taxa de desgaste dos dois polímeros, foi possível identificar algumas tendências de comportamento com cada tribossistema. No entanto, quando analisados em conjunto, a observação da Figura 5.88 mostra não ser possível identificar diferenças no comportamento tribológico dos dois polímeros.

Quando analisamos a influência da temperatura atingida na região do contato na taxa de desgaste dos dois polímeros estudados (Figura 5.89 - a), novamente não se consegue identificar uma clara diferença de comportamento. No entanto, se o foco de comparação for alterado, como na Figura 5.89(b), onde as taxas de desgaste são apresentadas em relação ao tipo de contra-corpo, é possível identificar que os ensaios realizados com alumina tenderam a apresentar maiores taxas de desgaste em toda a faixa de temperaturas atingidas. Somente dois resultados com UHMWPE contra aço inoxidável apresentaram taxas de desgaste superiores ao patamar de $0,1 \mu \mathrm{m} / \mathrm{m}$; no entanto, apesar da temperatura atingida no contato para estas condições não poderem ser 
consideradas elevadas, as condições PV destes ensaios foram as mais severas que este material foi submetido nos dois níveis de acabamento superficial.

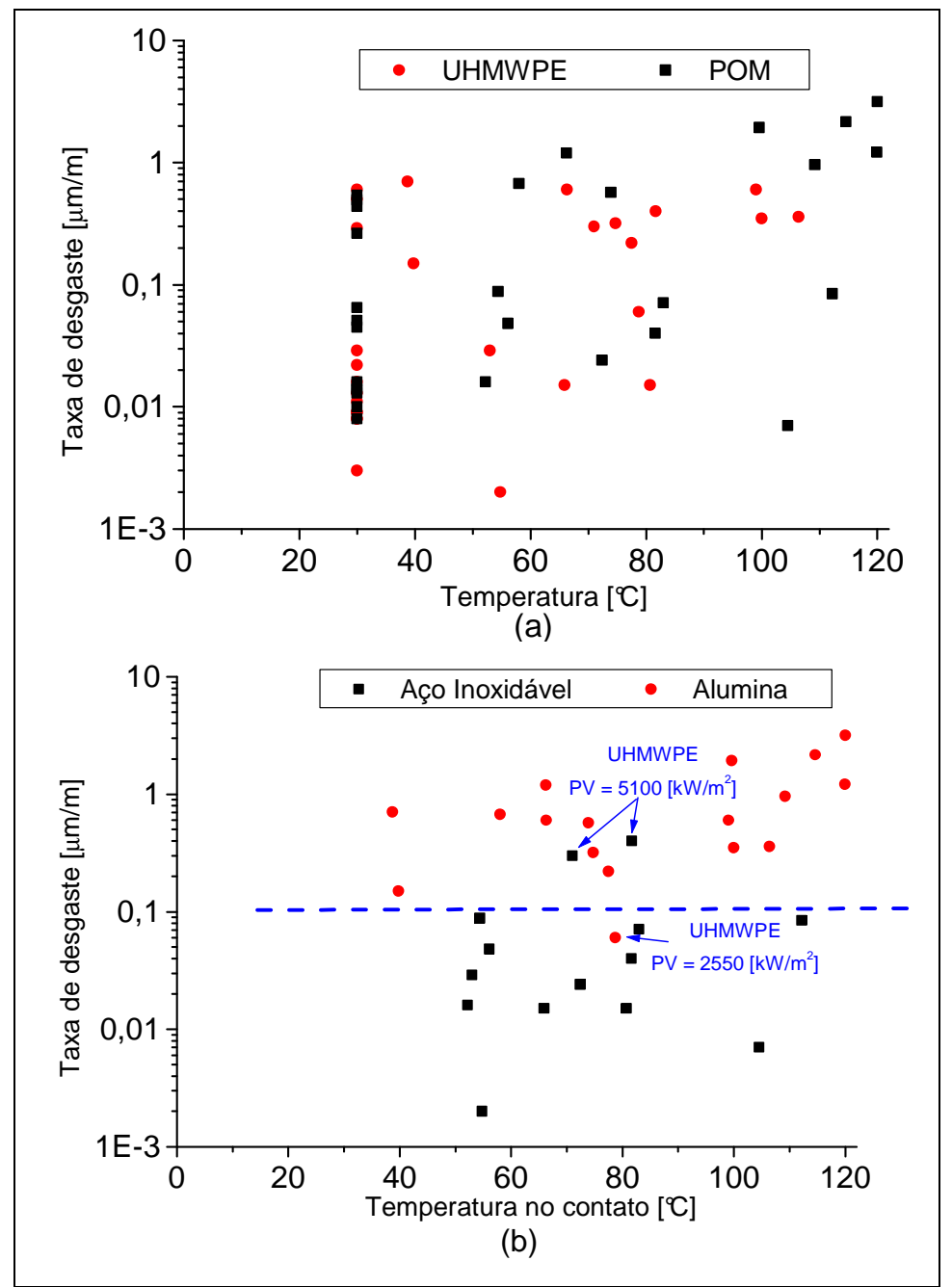

Figura 5.89 - Taxa média de desgaste em função da temperatura no contato. Todos os resultados com POM e UHMWPE (a), separados pelo tipo de contra-corpo (b).

Uma observação quanto à Figura 5.89(b) é que, com o intuito de analisar com clareza o efeito de um aumento significativo na temperatura de contato, estão apresentados somente os valores da taxa de desgaste dos ensaios com temperaturas atingidas superiores a $30{ }^{\circ} \mathrm{C}$.

Sendo assim, pode-se dizer que, quanto ao efeito da temperatura, o fator que tem maior relevância não é exatamente o polímero que está sendo ensaiado e sim as características térmicas do contra-corpo, como difusividade e condutividade térmica.

No entanto, apesar da troca de enfoque, descrevendo o desgaste não em termos do polímero, mas do material contra-corpo, propiciar a observação de tendências diferenciadas de comportamento do desgaste em termos dos tribossistemas formados, 
ainda não foi possível compreender como se comportam os dois polímeros quando se modificam as condições de severidade 'térmica' do ensaio.

Esta mudança de enfoque também foi feita para os resultados da taxa de desgaste em função da condição PV e do acabamento superficial, porém, nestes casos, nenhuma tendência ou informação relevante foi verificada. A Figura 5.90 apresenta a influência do nível de acabamento superficial na taxa de desgaste dos dois polímeros estudados.

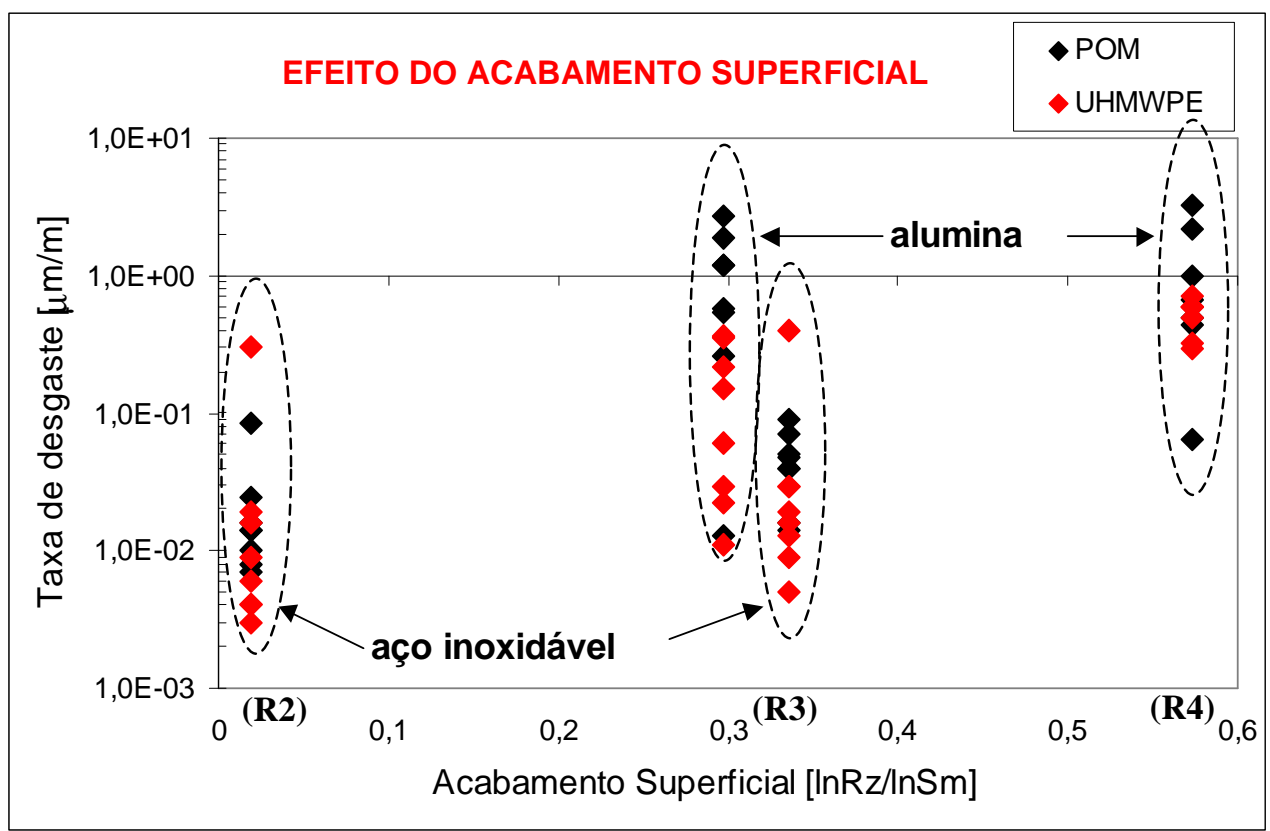

Figura 5.90 - Taxa média de desgaste do POM e do UHMWPE em função do acabamento superficial.

Como mencionado anteriormente, não é possível observar que um polímero apresentou maior resistência ao desgaste do que o outro quando submetidos à contracorpos mais rugosos. No entanto, pode-se dizer que:

- Para níveis de rugosidade semelhantes (acabamento superficial R3), onde o parâmetro $\operatorname{lnRz} / \operatorname{lnSm}$ manteve-se próximo a 0,3, o UHMWPE tendeu a apresentar maior resistência ao desgaste que o POM;

- Analisando somente os resultados contra alumina, o UHMWPE também tendeu a apresentar menor taxa de desgaste que POM;

- Já analisando somente os resultados contra aço inoxidável, o desgaste de ambos os polímeros foi muito similar, tanto para rugosidade $\mathrm{R} 2$ como para R3. 
O comportamento do desgaste de ambos os polímeros também foi analisado quanto ao parâmetro de severidade global, PVR/DD, e os resultados estão mostrados na Figura 5.91.

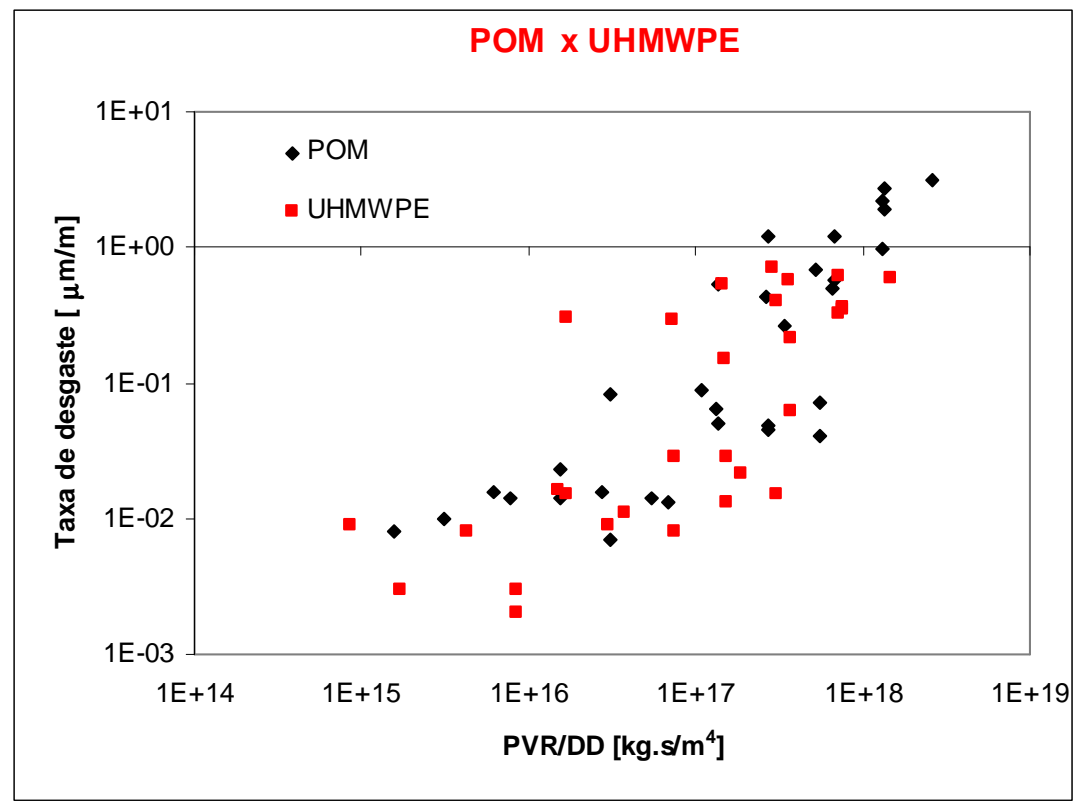

\section{Figura 5.91 - Taxa média de desgaste do POM e do UHMWPE em função da severidade global (PVR/DD).}

Ao observar todos os valores de taxa de desgaste tomando como base somente o material polimérico ensaiado em função da severidade global (Figura 5.91) nota-se a impossibilidade de se verificar quaisquer tendências dos resultados. Por outro lado, organizando os resultados da Figura 5.91 em função dos 4 pares estudados, é possível distinguir diferenças de tendências no comportamento de cada par, como mostrado na Figura 5.92. 


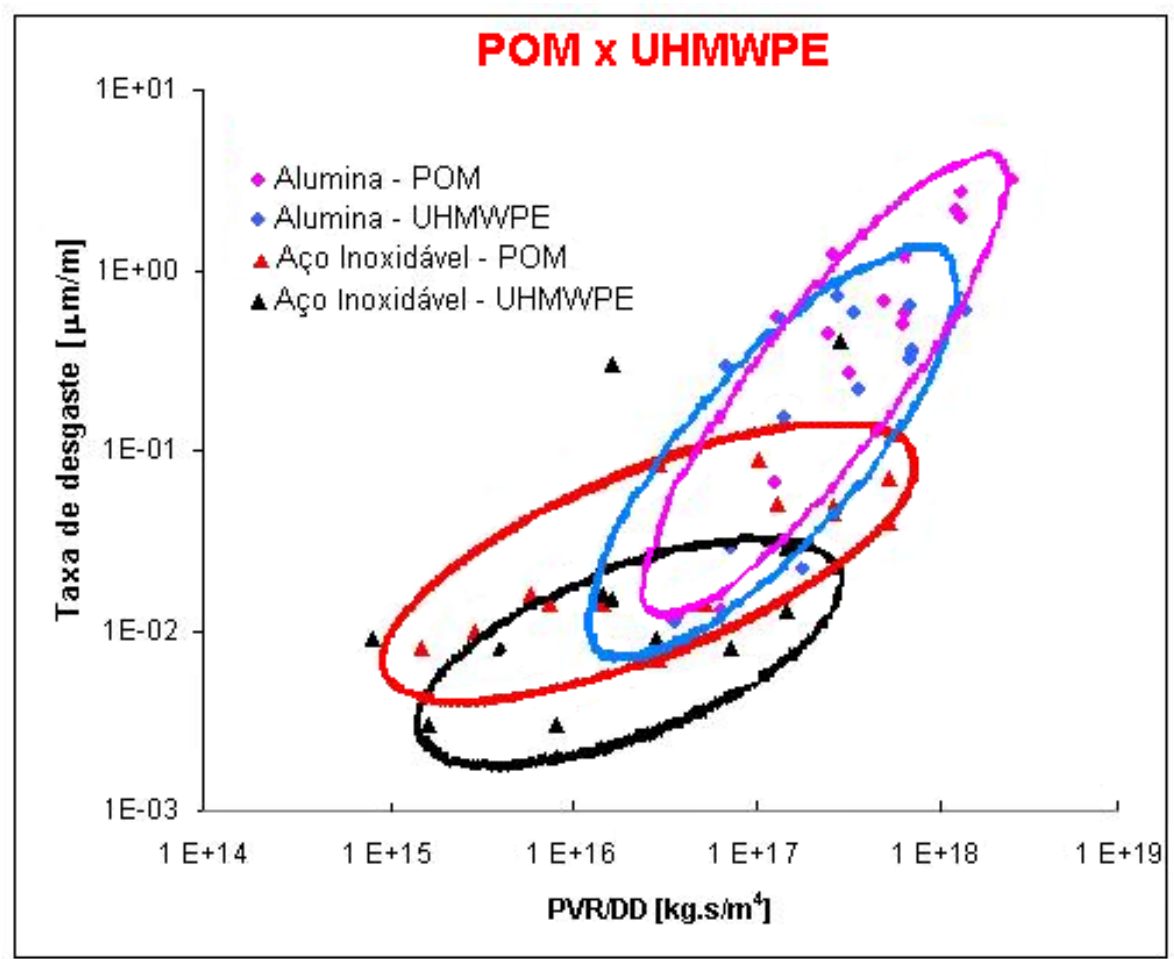

Figura 5.92 - Taxa média de desgaste em função da severidade global (PVR/DD) dos pares estudados (nuvens de tendência).

A Figura 5.92 mostra que, tanto para o POM quanto para o UHMWPE, o tipo de contra-corpo resulta em uma influência nítida no comportamento tribológico do polímero, onde os ensaios com alumina mostraram-se mais agressivos aos polímeros. Também se observa nos ensaios com alumina que há um aumento mais acentuado da taxa de desgaste à medida que a severidade global aumenta. Por outro lado, é possível observar que, em termos do polímero, de maneira geral, o UHMWPE mostrou-se um material um pouco mais resistente ao desgaste, tanto contra o aço inoxidável quanto contra a alumina.

Ainda observando a Figura 5.92 pode-se dizer que, mais do que as condições de severidade no contato (condição PV, temperatura e nível de acabamento superficial), os tipos de materiais envolvidos, tanto do pino mas principalmente do disco, é que determinam o nível de desgaste o tribossistema irá apresentar.

\subsection{Período de amaciamento (running-in)}

As análises microscópicas das superfícies de desgaste dos pinos poliméricos mostraram que, em algumas condições de cargas, velocidade e acabamento superficial, a 
distância de deslizamento de 3.500 metros não foi suficientemente longa para que se ultrapassa-se o período de amaciamento (running-in) destes ensaios. Apesar dos resultados sugerirem uma estacionariedade quanto aos valores de taxa de desgaste e/ou de coeficiente de atrito (ver Figura 5.93), na realidade, as condições de contato estavam mudando continuamente durante este período de avaliação.

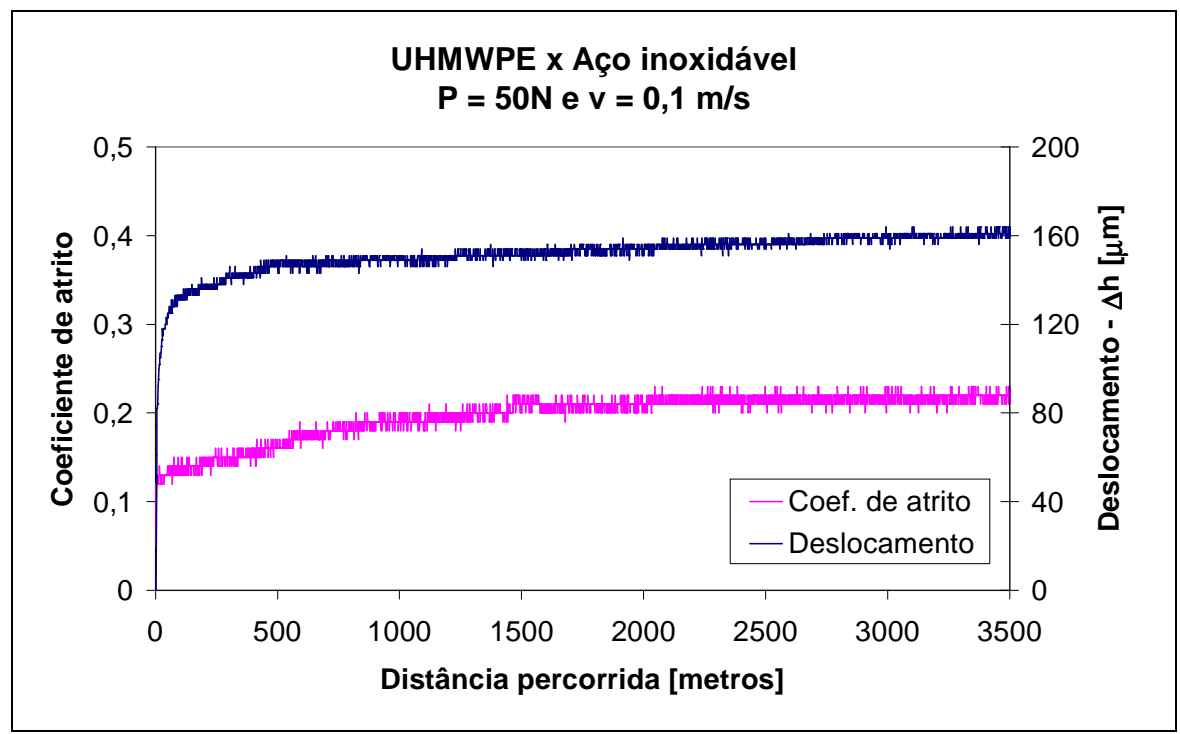

Figura 5.93 - Curvas de coeficiente de atrito e deslocamento do pino em função da distância, para o UHMWPE x Aço Inoxidável R2, com $P=50 \mathrm{~N}$ e v = 0,1 m/s.

As alterações nas condições de contato estão basicamente relacionadas com o aumento paulatino da área real de contato durante a realização do ensaio. Como foi visto no Capítulo 4 (Materiais e Métodos), a superfície de contato dos pinos foi preparada por meio de torneamento (faceamento) com avanço de $0,16[\mathrm{~mm} / \mathrm{rot}]$, conduzindo desta forma, a um acabamento, até certo ponto, grosseiro na superfície do pino. No entanto, nos ensaios com condições mais severas, tanto as deformações plásticas iniciais quanto a intensa remoção de material pelos diversos mecanismos de desgaste, tornavam menos importantes o acabamento superficial da superfície de contato do pino.

Analisando estaticamente as condições de carregamento, pode-se dizer que as cargas de 50, 100 e 200 N, não são suficientemente altas para provocarem escoamento e deformação plástica na superfície do pino, pois, nominalmente, para um pino com diâmetro de $5 \mathrm{~mm}$, as tensões normais médias de contato são de 2,55; 5,10 e 10,20 [MPa], respectivamente para as carga de 50, 100 e $200 \mathrm{~N}$, e as tensões normais de escoamento são 25 e $66 \mathrm{MPa}$, para o UHMWPE e o POM, respectivamente. 
No entanto, no início dos ensaios, a área real de contato é muito menor que a área aparente, este fato faz com que as tensões nas pontas das asperezas da superfície dos pinos sejam muito maiores que a tensão de escoamento do material. A Figura 5.94, mostra esquematicamente o contato entre a superfície do pino e a do disco.

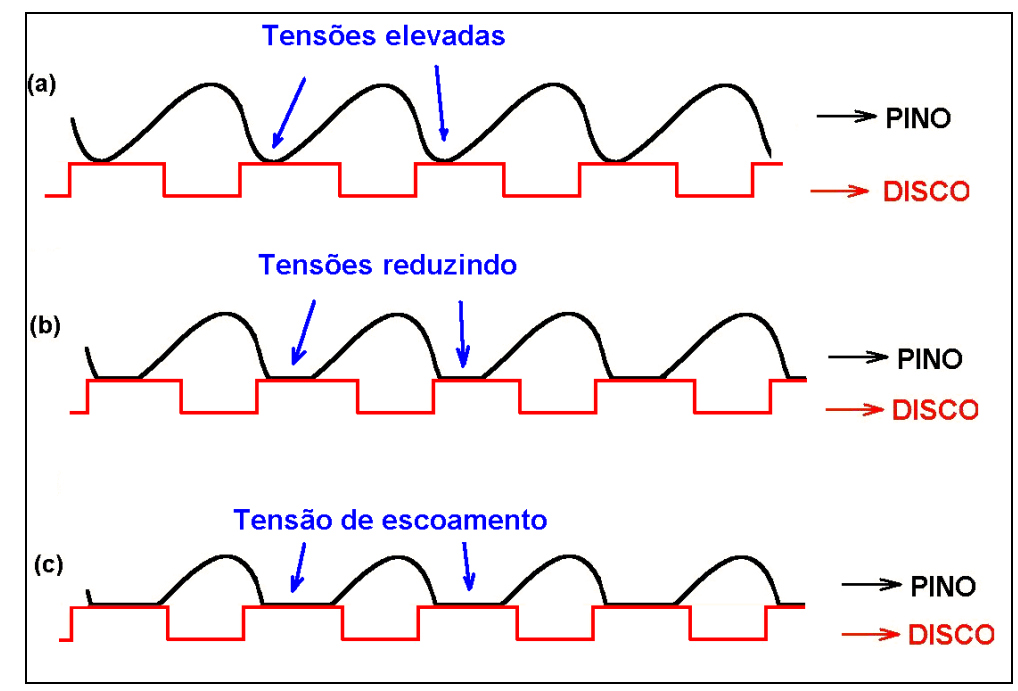

Figura 5.94 - Desenho esquemático do aumento da área real de contato com a carga aplicada.

A Figura 5.94-a mostra que quando há o contato entre as duas superfícies, a área real de contato é muito pequena e mesmo uma carga baixa (50N, por exemplo) induz tensões elevadas nos cumes das asperezas. A medida que o material começa a escoar, a área real de contato vai aumentando e as tensões vão reduzindo (Figura 5.94 -b). A partir de um certo nível de deformação, o aumento da área real de contato estabiliza o valor da tensão nos pontos de contato, próximo ao valor da tensão de escoamento (Figura 5.94-c). Logicamente que com o movimento relativo entre pino e disco, os níveis de deformação plástica se acentuam, pois tensões cisalhantes devido aos esforços de atrito também começam a atuar. Para o caso do UHMWPE, a tensão de escoamento seria atingida para uma área real de contato 90\% menor que a área aparente; já para o POM, este valor seria de, aproximadamente, $96 \%$.

Para condições de ensaio mais severas, os fenômenos mencionados na Figura 5.94 ocorrem da mesma forma (e até com mais intensidade); no entanto, como o período de running-in é ultrapassado, o aumento da área real de contato e as deformações plásticas iniciais, perdem sua importância. Já nos ensaios onde se verificou que após os 3500 metros de deslizamento, o par tribológico continuava no período de amaciamento, 
as deformações plásticas assumem papel importante quanto ao aspecto morfológico da superfície de desgaste do pino.

A Figura 5.95 apresenta uma proposta de formação do filme polimérico, em forma de lâminas sobrepostas, presente na superfície destes pinos e apresentadas na seção 5.6.

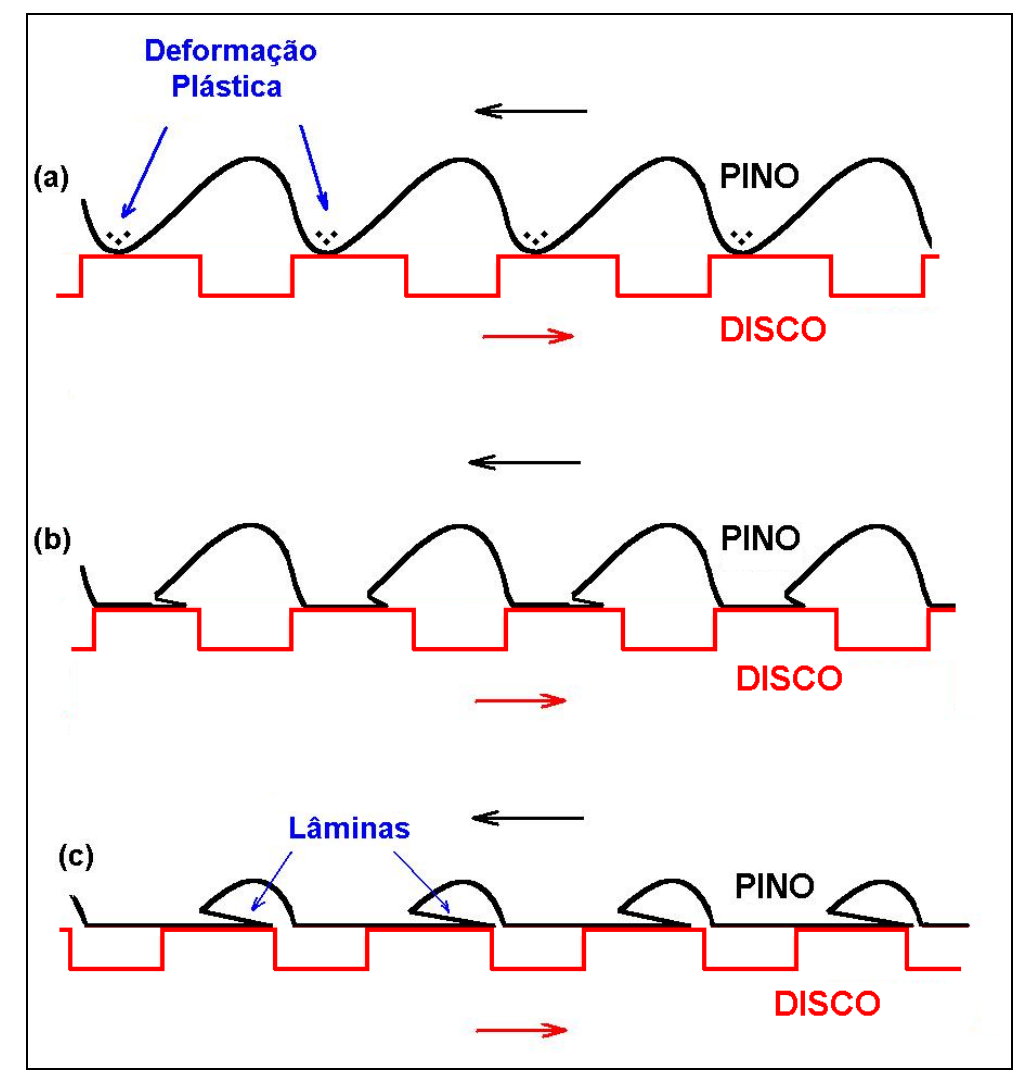

Figura 5.95 - Desenho esquemático da formação das lâminas presentes na superfície dos pinos durante o deslizamento no período de running-in.

Do desenho esquemático do processo de formação de lâminas, apresentado na Figura 5.95 pode-se dizer que:

(a) como no cume das marcas de usinagem da superfície do pino a área real de contato é muito pequena, ocorre deformação plástica intensa nestas regiões;

(b) com o movimento relativo entre pino e disco, esta porção de matéria que está sendo deformada plasticamente é amassada e empurrada na forma de lâminas de espessuras muito finas, na direção contrária ao movimento relativo do pino;

(c) com o transcorrer do ensaio, estas lâminas vão crescendo, se espalhando e preenchendo toda a superfície do pino. Como durante este período do 
ensaio, os mecanismos de desgaste tipo formação de ondas e abrasão continuam atuando, estas lâminas também podem ser removidas da superfície do pino.

A Figura 5.96 mostra a superfície de um pino de UHMWPE, após deslizamento sobre aço inoxidável R3, com velocidade $0,1 \mathrm{~m} / \mathrm{s}$ e carga de $100 \mathrm{~N}$. Nota-se que os cumes das marcas de usinagem estão intensamente deformados e que o filme apresenta mecanismos de abrasão e fadiga.

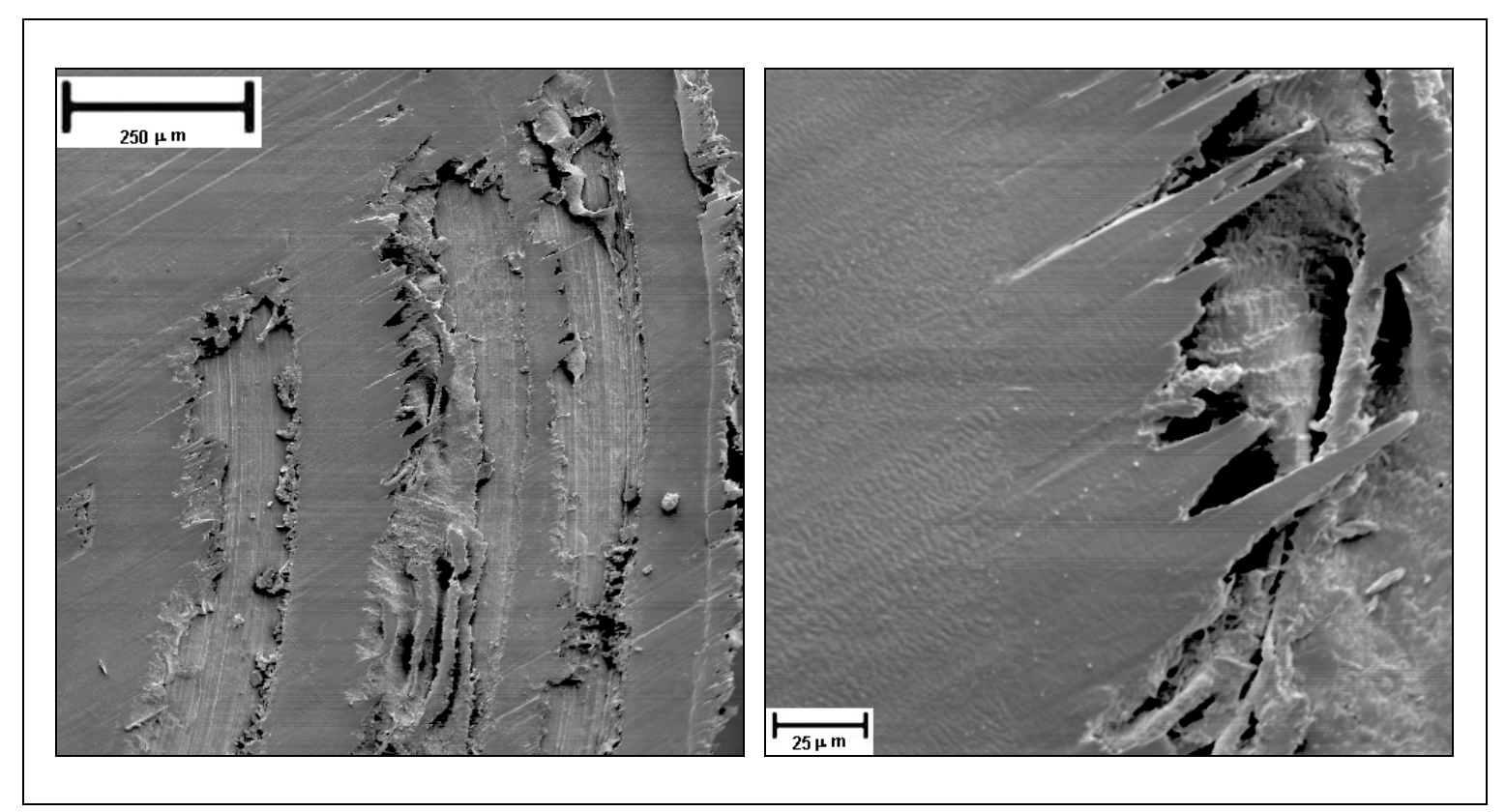

Figura 5.96 - MEV da superfície de pino de UHMWPE.(Aço Inox R3, v = 0,5 m/s e 100 N). Presença do mecanismo de desgaste por fadiga + abrasão.

A Figura 5.97 apresenta uma sugestão da formação do filme homogêneo na superfície do pino (detalhe), que é composto por diversas lâminas sobrepostas que vão sendo amassadas (laminadas) durante o ensaio de desgaste. 


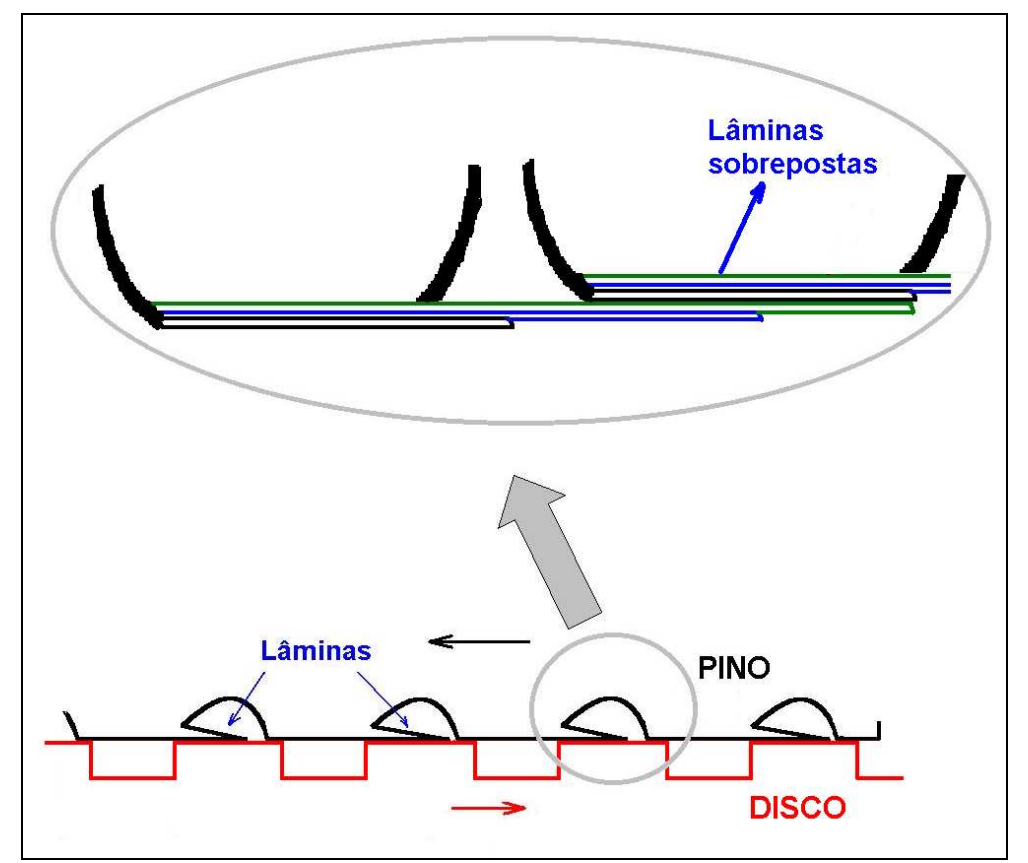

Figura 5.97 - Detalhe da superfície do pino mostrando que o filme polimérico presente na superfície do pino é formado por várias lâminas sobrepostas.

Com o transcorrer do ensaio, novas áreas dos cumes das marcas de usinagem são deformadas plasticamente, formando novas lâminas, as quais serão sobrepostas às lâminas formadas anteriormente, formando um filme, a principio homogêneo, porém composto por diversas lâminas sobrepostas.

A Figura 5.98 apresenta a superfície de um pino de UHMWPE, onde o filme polimérico cobre toda a área de contato. Sendo o filme formado por seguidas camadas de material altamente deformadas com espessuras muito finas, é possível prever que com o decorrer do ensaio estas camadas sejam removidas. A Figura 5.98 mostra uma lâmina se destacando do filme polimérico. 


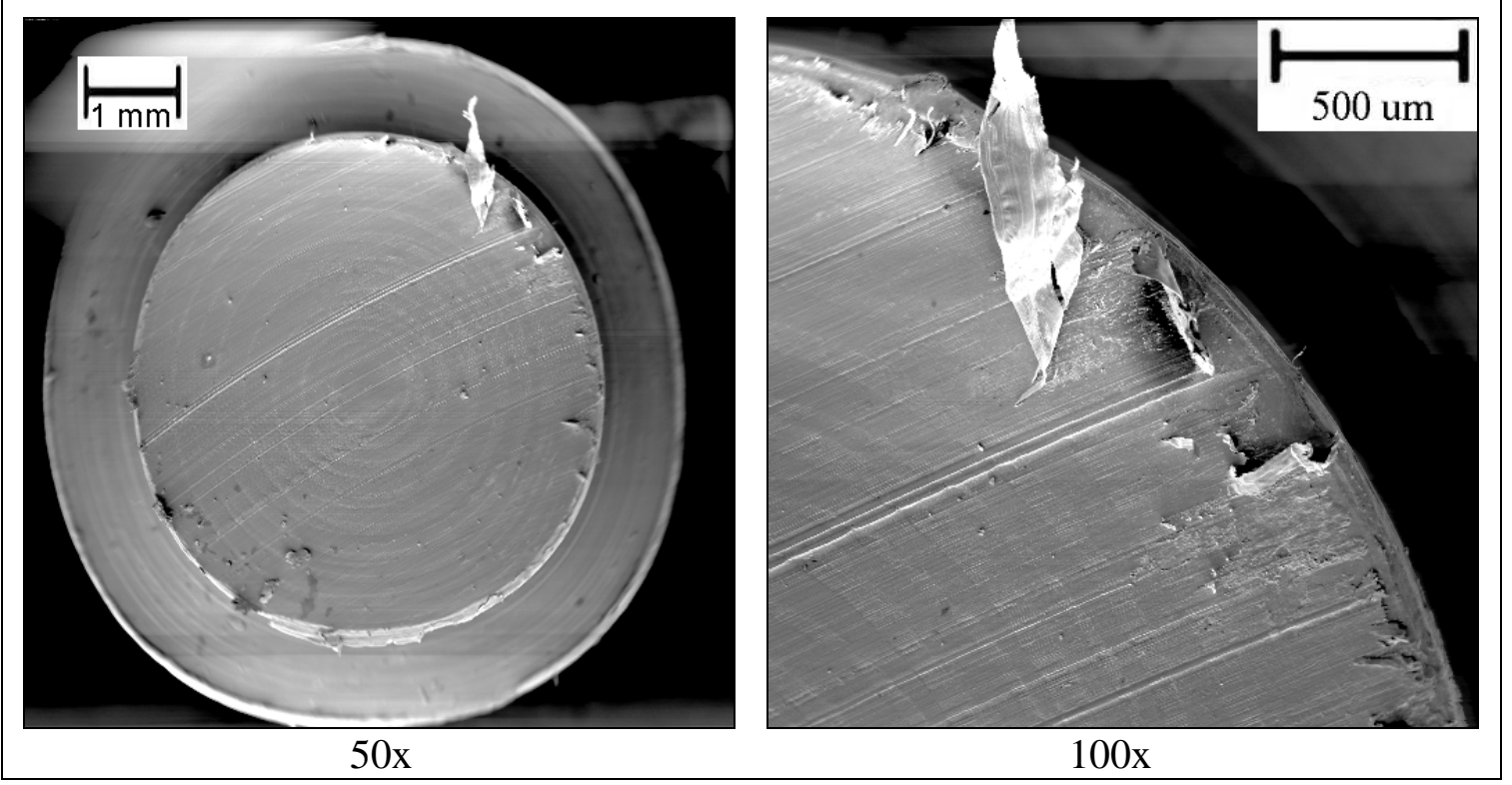

Figura 5.98 - MEV da superfície de pino de UHMWPE (Aço Inox R3, 0,1 m/s e 50 N). Filme formado de camadas mostrando o destacamento de uma lâmina.

O final do período de running-in nos ensaios de desgaste pode ser definido como o momento em que:

- devido a remoção de material da superfície do pino, toda a área de contato entre pino e disco, se iguala à área aparente; ou seja, o desgaste ocorrido na superfície do pino foi suficientemente elevado ao ponto de remover todas as marcas de usinagem e

- os valores de coeficiente de atrito e de taxa de desgaste tenham se estabilizado.

A Figura 5.99 mostra a superfície de um pino de UHMWPE, cujas marcas de usinagem estão quase todas removidas pelo processo de desgaste. Ou seja, para este par, nas condições de contato, o final do período de amaciamento esteve próximo. 


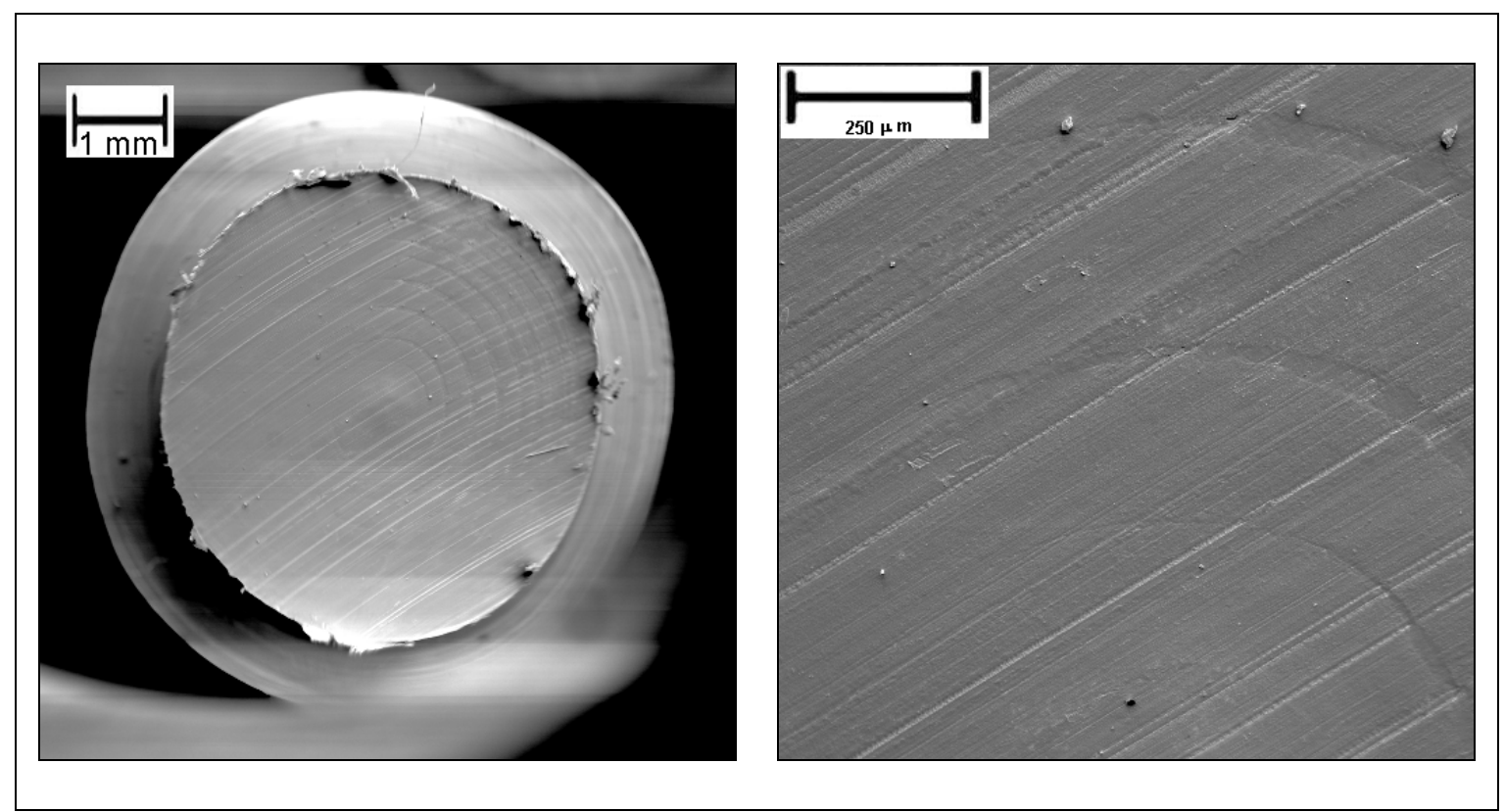

Figura 5.99 - MEV da superfície de pino de UHMWPE (Aço Inox R3, 0,1 m/s e 100 $\mathrm{N})$. Quase todas as marcas de usinagem foram removidas.

\subsection{Coeficiente de atrito}

Os resultados sobre o coeficiente de atrito dos pares estudados serão analisados em duas partes:

- valores médios finais e tendência de comportamento;

- relação coeficiente de atrito severidade global.

Uma breve análise do comportamento do coeficiente de atrito durante os ensaios, englobando período de running-in e estado estacionário está apresentado no Anexo C. No entanto não foi possível até o momento avançar na compreensão dos fenômenos envolvidos.

Observação: No transcorrer das discussões sobre atrito, o termo 'coeficiente de atrito' será relacionado ao coeficiente de atrito cinético e não ao estático.

\subsubsection{Análise dos resultados de coeficiente de atrito}

Os resultados apresentados nas Tabelas 5.46 a 5.49 mostram os valores médios de coeficiente de atrito, obtidos após o período de running-in dos ensaios de desgaste. 
Tabela 5.46 - Resultados de coeficiente de atrito dos ensaios $\mathrm{POM}$ versus $\mathrm{Al}_{2} \mathrm{O}_{3}$

\begin{tabular}{cccccccc}
\hline Carga & Velocidade & \multicolumn{5}{c}{ Coeficiente de atrito } \\
\cline { 3 - 7 }$[\mathbf{N}]$ & {$[\mathbf{m} / \mathbf{s}]$} & \multicolumn{1}{c}{$\mathbf{1 , 5}<\mathbf{R a}<\mathbf{2 , 0} \boldsymbol{\mu \mathbf { m }}$} & $\mathbf{0 , 3}<\mathbf{R a}<\mathbf{0 , 6} \boldsymbol{\mu m}$ \\
\hline 50 & 0,1 & 0,385 & \pm & 0,018 & 0,24 & \pm & 0,03 \\
50 & 0,5 & 0,44 & \pm & 0,10 & 0,48 & \pm & 0,12 \\
50 & 1,0 & 0,47 & \pm & 0,07 & 0,53 & \pm & 0,15 \\
100 & 0,1 & 0,40 & \pm & 0,03 & 0,43 & \pm & 0,07 \\
100 & 0,5 & 0,43 & \pm & 0,05 & 0,47 & \pm & 0,10 \\
100 & 1,0 & 0,40 & \pm & 0,05 & 0,386 & \pm & 0,011 \\
200 & 0,1 & 0,35 & \pm & 0,05 & 0,325 & \pm & 0,004 \\
200 & 0,5 & & & & 0,35 & \pm & 0,06 \\
\hline
\end{tabular}

Tabela 5.47 - Resultados de coeficiente de atrito dos ensaios POM versus Inox

\begin{tabular}{|c|c|c|c|c|c|c|c|}
\hline \multirow{3}{*}{$\begin{array}{c}\text { Carga } \\
{[\mathbf{N}]} \\
50\end{array}$} & \multirow{3}{*}{$\begin{array}{c}\begin{array}{c}\text { Velocidade } \\
{[\mathbf{m} / \mathbf{s}]}\end{array} \\
0,1\end{array}$} & \multicolumn{6}{|c|}{ Coeficiente de atrito } \\
\hline & & \multicolumn{3}{|c|}{$\mathbf{0 , 3}<\mathbf{R a}<0,6 \mu \mathrm{m}$} & \multicolumn{3}{|c|}{$0,05<\mathrm{Ra}<0,2 \mu \mathrm{m}$} \\
\hline & & 0,54 & \pm & 0,03 & 0,34 & \pm & 0,07 \\
\hline 50 & 0,5 & 0,46 & \pm & 0,02 & 0,50 & \pm & 0,14 \\
\hline 50 & 1,0 & 0,328 & \pm & 0,017 & 0,36 & \pm & 0,03 \\
\hline 100 & 0,1 & 0,43 & \pm & 0,07 & 0,36 & \pm & 0,04 \\
\hline 100 & 0,5 & 0,264 & \pm & 0,014 & 0,317 & \pm & 0,013 \\
\hline 100 & 1,0 & 0,24 & \pm & 0,02 & 0,28 & \pm & 0,05 \\
\hline 200 & 0,1 & 0,326 & \pm & 0,017 & 0,375 & \pm & 0,018 \\
\hline 200 & 0,5 & 0,194 & \pm & 0,016 & 0,292 & \pm & 0,007 \\
\hline
\end{tabular}


Tabela 5.48 - Resultados de coeficiente de atrito dos ensaios UHMWPE versus $\mathrm{Al}_{2} \mathbf{O}_{3}$.

\begin{tabular}{ccrccccc}
\hline Carga & Velocidade & \multicolumn{7}{c}{ Coeficiente de atrito } \\
\cline { 3 - 7 }$[\mathbf{N}]$ & {$[\mathbf{m} / \mathbf{s}]$} & \multicolumn{1}{c}{$\mathbf{1 , 5}<\mathbf{R a}<\mathbf{2 , 0} \boldsymbol{\mu m}$} & $\mathbf{0 , 3}<\mathbf{R a}<\mathbf{0 , 6} \boldsymbol{\mu m}$ \\
\hline 50 & 0,1 & 0,27 & \pm & 0,04 & 0,15 & \pm & 0,03 \\
50 & 0,5 & 0,31 & \pm & 0,03 & 0,23 & \pm & 0,03 \\
50 & 1,0 & 0,26 & \pm & 0,02 & 0,29 & \pm & 0,04 \\
100 & 0,1 & 0,28 & \pm & 0,07 & 0,178 & \pm & 0,019 \\
100 & 0,5 & 0,29 & \pm & 0,04 & 0,28 & \pm & 0,10 \\
100 & 1,0 & 0,269 & \pm & 0,015 & 0,32 & \pm & 0,12 \\
200 & 0,1 & 0,24 & \pm & 0,05 & 0,24 & \pm & 0,03 \\
200 & 0,5 & & & & 0,24 & \pm & 0,04 \\
\hline
\end{tabular}

Tabela 5.49 - Resultados de coeficiente de atrito dos ensaios UHMWPE versus Inox.

\begin{tabular}{ccrlllll}
\hline Carga & Velocidade & \multicolumn{9}{c}{ Coeficiente de atrito } \\
\cline { 3 - 7 }$[\mathbf{N}]$ & {$[\mathbf{m} / \mathbf{s}]$} & \multicolumn{0}{c}{$\mathbf{0 , 3}<\mathbf{R a}<$} & $\mathbf{0 , 6} \boldsymbol{\mu m}$ & $\mathbf{0 , 0 5}<\mathbf{R a}<\mathbf{0 , 2} \boldsymbol{\mu m}$ \\
\hline 50 & 0,1 & 0,12 & \pm & 0,05 & 0,21 & \pm & 0,03 \\
50 & 0,5 & 0,081 & \pm & 0,013 & 0,16 & \pm & 0,03 \\
50 & 1,0 & 0,128 & \pm & 0,005 & 0,17 & \pm & 0,09 \\
100 & 0,1 & 0,14 & \pm & 0,03 & 0,20 & \pm & 0,04 \\
100 & 0,5 & 0,174 & \pm & 0,008 & 0,21 & \pm & 0,04 \\
100 & 1,0 & 0,190 & \pm & 0,018 & 0,244 & \pm & 0,015 \\
200 & 0,1 & 0,152 & \pm & 0,018 & 0,177 & \pm & 0,008 \\
200 & 0,5 & 0,20 & \pm & 0,02 & 0,20 & \pm & 0,03 \\
\hline
\end{tabular}

A Tabela 5.50 apresenta os valores médios do coeficiente de variação (CV) dos resultados de coeficiente de atrito para os tribossistemas estudados. 
Tabela 5.50 - Coeficiente de variação médio(CV) dos resultados de coeficiente de atrito para os tribossistemas estudados.

\begin{tabular}{|c|c|c|c|c|c|}
\hline Polímero & Contra-corpo & $\mathrm{CV}[\%]$ & Polímero & Contra-corpo & $\mathrm{CV}[\%]$ \\
\hline \multirow{4}{*}{ UHMWPE } & Alumina R4 & 13,4 & \multirow{4}{*}{ POM } & Alumina R4 & 12,7 \\
\hline & Alumina R3 & 19,2 & & Alumina R3 & 15,4 \\
\hline & Aço Inox R3 & 14,7 & & Aço Inox R3 & 7,3 \\
\hline & Aço Inox R2 & 19,2 & & Aço Inox R2 & 11,8 \\
\hline
\end{tabular}

Da Tabela 5.50 observa-se que a dispersão dos resultados de coeficiente de atrito não ultrapassou 20\%. Levando-se em conta a variedade de comportamento do coeficiente de atrito e a variabilidade inerente às propriedades tribológicas, pode-se dizer que os resultados finais médios são satisfatórios do ponto de vista da repetibilidade dos valores em torno de uma média.

É comum a tentativa de correlacionar os valores (e também o comportamento) de coeficiente de atrito com as taxas de desgaste em cada ensaio, no entanto não foi possível, no âmbito deste trabalho, procurar tais correlações e/ou explicações para comportamento semelhantes ou antagônicos entre atrito e desgaste.

A seguir serão apresentados os resultados de coeficiente de atrito em função das condições PV e das temperaturas desenvolvidas na região do contato.

\subsubsection{POM x Alumina}

A Figura 5.100 apresenta os resultados de coeficiente de atrito do POM deslizando contra alumina com acabamento superficial R3 e R4, em função das condições PV de cada ensaio e da temperatura desenvolvida na região de contato. 


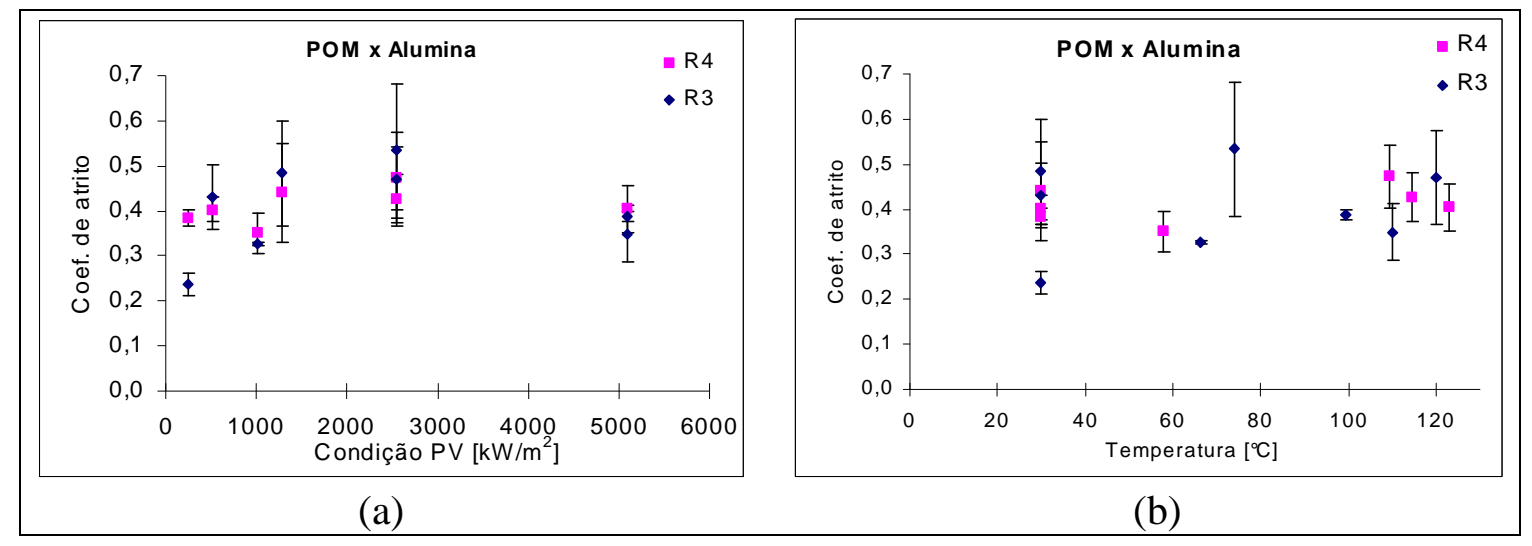

Figura 5.100 - Coeficiente de atrito em função das condições PV (a) e da temperatura no contato (b). (POM x Alumina)

Observa-se na Figura 5.100 (a) que o coeficiente de atrito apresenta uma tendência, não muita clara, de crescimento com a condição PV até $2550 \mathrm{~kW} / \mathrm{m}^{2}$. Para condições mais severas observa-se uma queda no atrito, independentemente do acabamento superficial.

Esta queda no coeficiente de atrito poderia relacionar-se com a elevação da temperatura no contato, no entanto, a Figura 5.100 (b) não apresenta claramente uma relação entre a temperatura e o coeficiente de atrito. $\mathrm{Na}$ realidade, os valores de coeficiente de atrito mostram-se pouco afetados pelos valores de temperatura nos dois níveis de acabamento superficial.

Por fim, pode-se dizer que a Figura 5.100 mostra que a variação no acabamento superficial dos discos de alumina não afetou significativamente os valores de coeficiente de atrito.

\subsubsection{POM x Aço Inoxidável}

A Figura 5.101 apresenta os resultados de coeficiente de atrito do POM deslizando contra aço inoxidável com acabamento superficial R2 e R3, em função das condições PV de cada ensaio e da temperatura no contato. 


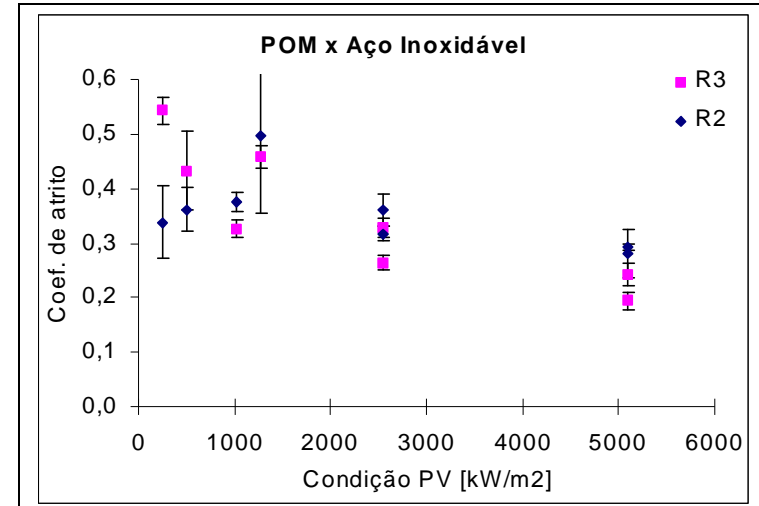

(a)

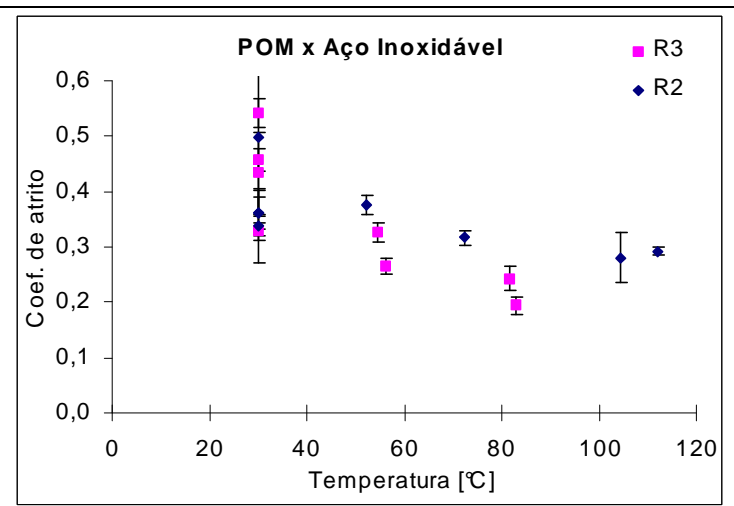

(b)

Figura 5.101 - Coeficiente de atrito em função das condições PV e da temperatura no contato (POM x Aço Inoxidável).

Na Figura 5.101 (a) observa-se uma redução nos valores de coeficiente de atrito com o aumento da condição PV, principalmente nos ensaios com acabamento superficial R3. O mesmo comportamento do coeficiente de atrito se dá com relação à temperatura no contato (Figura 5.101 - b). Desta forma, pode-se dizer que para o par POM x Aço Inoxidável, existe uma relação entre o aumento da temperatura desenvolvida no contato e a queda nos valores de coeficiente de atrito. Ainda sobre a Figura 5.101 (b), observa-se que o acabamento menos agressivo (R2) conduziu a maiores temperaturas na ponta do pino para as mesmas condições PV. Tal fato sugere que com a diminuição da rugosidade, a atuação de mecanismos adesivos se eleva acarretando em um aumento na temperatura no contato. Pode-se dizer também que não houve influência significativa do tipo de acabamento superficial, R2 ou R3, nos valores médios de coeficiente de atrito para este par.

\subsubsection{UHMWPE $x$ Alumina}

A Figura 5.102 apresenta os resultados de coeficiente de atrito do UHMWPE deslizando contra alumina com acabamento superficial R3 e R4, em função das condições PV de cada ensaio e da temperatura no de contato. 


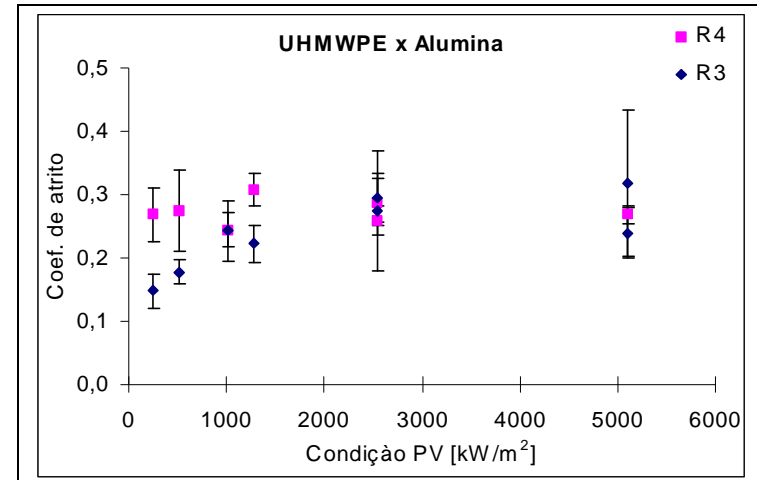

(a)

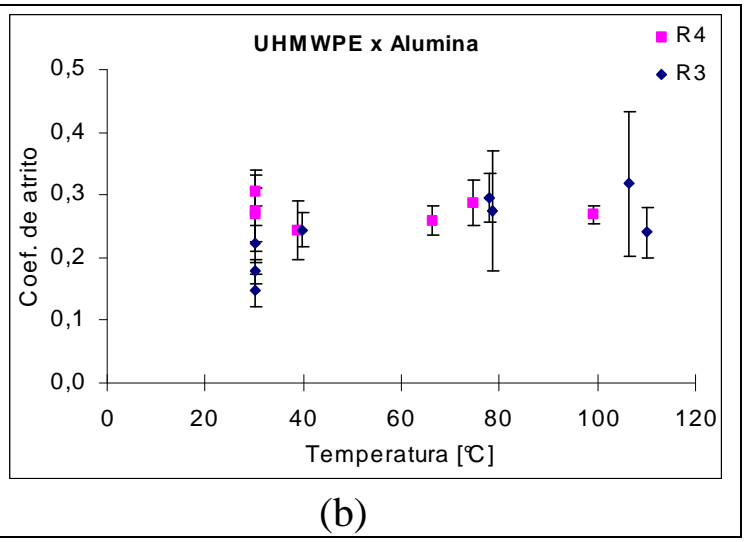

Figura 5.102 - Coeficiente de atrito em função das condições PV e da temperatura no contato (UHMWPE $x$ Alumina).

A análise de variância dos resultados de coeficiente de atrito de UHMWPE $\mathrm{x}$ Alumina mostra que não há diferencia significativa a um nível de confiança de $95 \%$, para todos os ensaios com acabamento R4 e nos ensaios com condição PV acima de 510 $\mathrm{kW} / \mathrm{m}^{2}$, para acabamento superficial tipo R3 (Figura 5.102-a). Ainda sobre a Figura 5.102 (a), nota-se que nas condições PV mais baixas, é possível perceber que o acabamento R3 apresenta menores coeficiente de atrito em comparação com R4.

$\mathrm{Na}$ Figura 5.102 (b), observa-se que o acabamento menos agressivo (R3) conduziu a maiores temperaturas na ponta do pino para condições PV mais severas. Tal fato sugere que com a diminuição da rugosidade, a atuação de mecanismos adesivos se eleva acarretando em um aumento na temperatura no contato para a mesma condição PV. Vale ressaltar que o mesmo efeito ocorreu para o par POM x Aço Inoxidável.

\subsubsection{UHMWPE x Aço Inoxidável}

A Figura 5.103 apresenta os resultados de coeficiente de atrito do UHMWPE deslizando contra aço inoxidável com acabamento superficial R2 e R3, em função das condições PV de cada ensaio e da temperatura desenvolvida próxima à região de contato. 


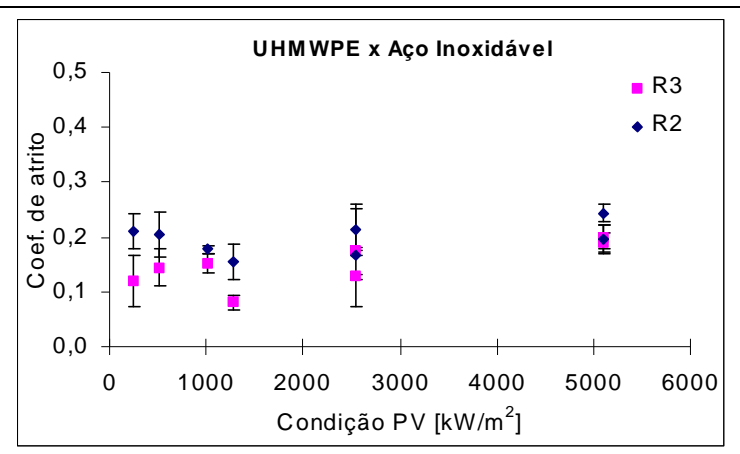

(a)

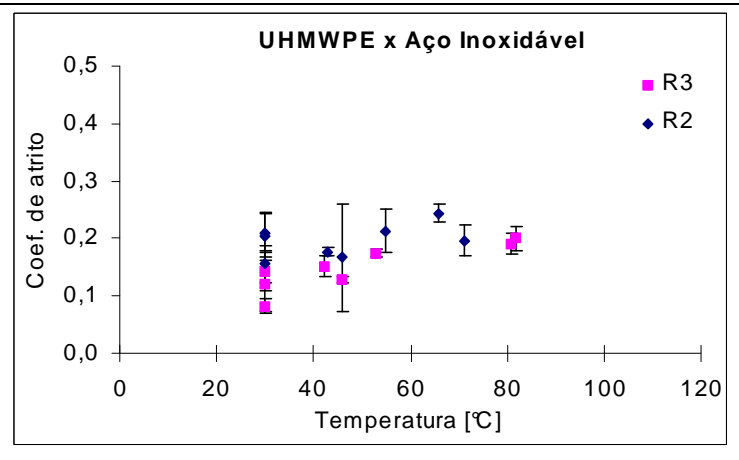

(b)

Figura 5.103 - Coeficiente de atrito em função das condições PV e da temperatura no contato do par UHMWPE $x$ Aço Inoxidável, nos dois níveis de acabamentos superficiais estudados.

A análise de variância dos resultados de coeficiente de atrito de UHMWPE x Aço inoxidável mostra que não há diferencia significativa a um nível de confiança de 95\%, para todos os ensaios com acabamento R2. Ou seja, alterações nas condições PV e as temperaturas desenvolvidas na região de contato não influenciam nos resultados de coeficiente de atrito deste par.

Quanto aos resultados de UHMWPE x Aço Inoxidável com acabamento R3, nota-se uma leve tendência de aumento do atrito com a elevação das condições PV dos ensaios (Figura $5.103-$ a).

Comparando os resultados de atrito em relação ao acabamento superficial nas Figura 5.103 (a) e (b), também fica claro que nos níveis de rugosidade estudados, não há influencia do acabamento superficial no coeficiente de atrito.

Com base nas análises globais discutidas acima sobre a influência das condições PV, das temperaturas desenvolvidas na região de contato e dos acabamentos superficiais no coeficiente de atrito dos 4 sistemas tribológicos, não é possível identificar um comportamento padrão do coeficiente de atrito em função deste conjunto de variáveis. Sabe-se da importância de uma caracterização pormenorizada desta propriedade tribológica, no entanto, esta atividade de análise mais aprofundada dos resultados de coeficiente de atrito, supera os objetivos iniciais desta pesquisa. 


\subsubsection{Severidade global}

A Figura 5.104 apresenta os valores finais médios de coeficiente de atrito em função do parâmetro PVR/DD (severidade global) para todos os ensaios.

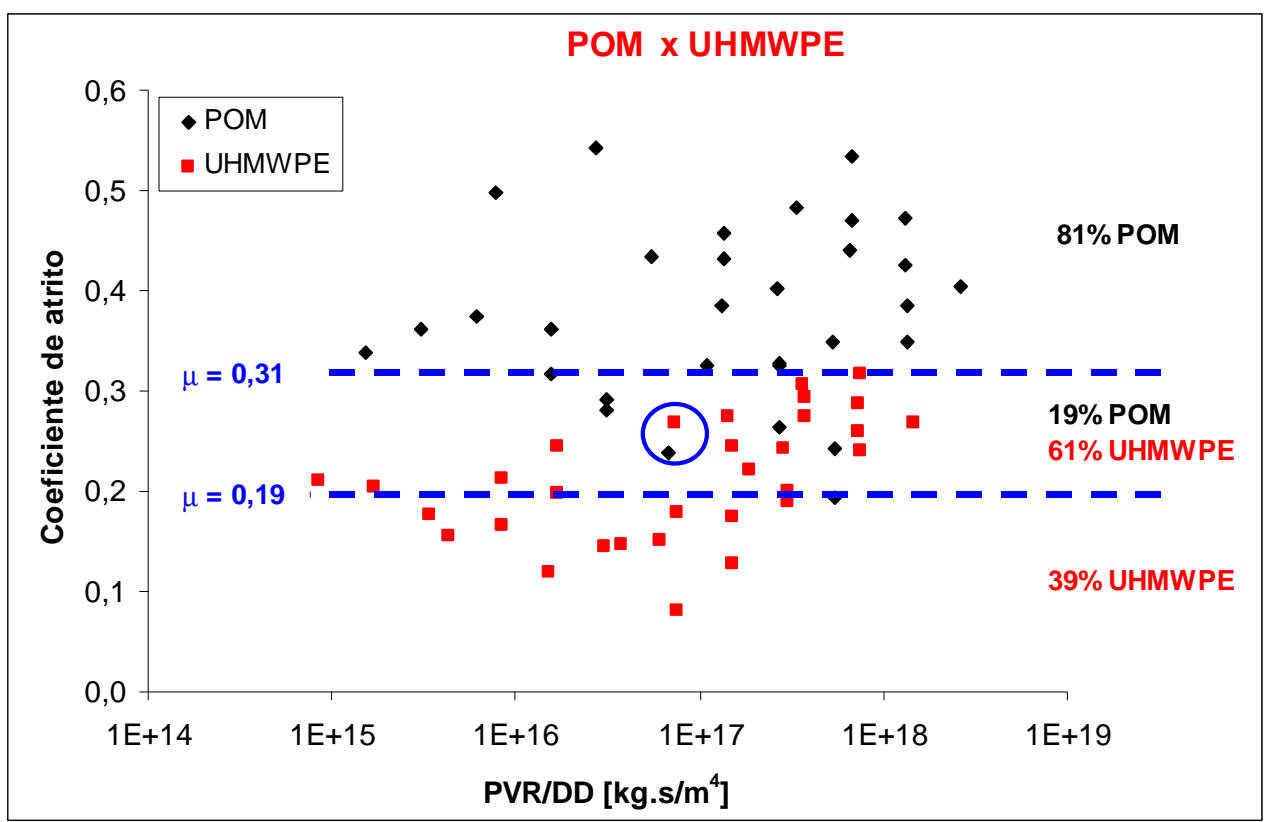

Figura 5.104 - Coeficiente de atrito em função da severidade global - PVR/DD.

A Figura 5.104 apresenta uma tendência dos coeficientes de atrito do POM serem mais elevados que os do UHMWPE, em geral. Pode-se dizer então que há uma transição de valores de coeficientes de atrito dependendo do polímero ensaiado:

- $\mu<0,19 \rightarrow 39 \%$ dos ensaios com UHMWPE;

- $\mathbf{0 , 1 9}<\boldsymbol{\mu}<\mathbf{0 , 3 1} \rightarrow 19 \%$ dos ensaios de POM e 61\% dos de UHMWPE;

- $\boldsymbol{\mu}>\mathbf{0 , 3 1} \rightarrow 81 \%$ dos ensaios com POM.

Analisando individualmente cada condição PVR/DD, pode-se dizer que o POM apresenta maiores valores de coeficiente de atrito, com exceção dos pontos marcado pelo circulo azul (Figura 5.104) onde o UHMWPE $\left(\mathrm{Al}_{2} \mathrm{O}_{3}, \mathrm{R} 3,50 \mathrm{~N}\right.$ e $\left.0,1 \mathrm{~m} / \mathrm{s}\right)$ apresentou um valor mais elevado de coeficiente de atrito. Como as temperaturas no contato dos pinos de POM, para as mesmas condições PV, sempre foram iguais ou superiores às do UHMWPE, pode-se dizer, ao menos globalmente, que temperaturas mais elevadas conduzem a maiores coeficientes de atrito.

Ainda na Figura 5.104, observa-se que o aumento da severidade no contato não conduz a uma efetiva alteração do coeficiente, ou seja, os resultados indicam que o 
coeficiente de atrito depende muito mais do tipo de polímero ensaiado, do que das diversas alterações nas condições de contato. Convém salientar que quanto ao desgaste, o componente do sistema tribológico mais relevante foi o material do contra-corpo.

\subsection{Consolidação dos fenômenos relacionados ao desgaste}

O conhecimento das propriedades dos materiais tem sido um fator importante para esclarecer o comportamento tribológico de um sistema. Com a finalidade de auxiliar a discussão dos resultados de desgaste, a Tabela 5.51 apresenta um resumo das propriedades térmicas, mecânicas e físico-químicas dos materiais ensaiados.

\section{Tabela 5.51 - Propriedades térmicas, mecânicas e características físico-químicas} dos materiais estudados.

\begin{tabular}{|c|c|c|}
\hline PROPRIEDADES & UHMWPE & POM \\
\hline Temperatura de fusão $-\operatorname{Tm}\left[{ }^{\circ} \mathrm{C}\right]$ & 143 & 166 \\
\hline Temperatura de transição vítrae $-\mathrm{Tg}\left[{ }^{\circ} \mathrm{C}\right]$ & -95 & -65 \\
\hline $\mathrm{k}=$ condutividade térmica $\left(23^{\circ} \mathrm{C}\right)[\mathrm{W} / \mathrm{m} \mathrm{K}]$ & 0,40 & 0,30 \\
\hline $\begin{array}{l}\mathrm{Cp}=\text { calor específico }\left(23^{\circ} \mathrm{C}\right)[\mathrm{J} / \mathrm{kg} \mathrm{K}] \\
\mathrm{D}=\text { difusividade térmica }\left[\mathrm{m}^{2} / \mathrm{s}\right]\end{array}$ & $\begin{array}{c}1675 \\
2,57 \times 10^{-4}\end{array}$ & $\begin{array}{c}1500 \\
1,42 \times 10^{-4}\end{array}$ \\
\hline $\begin{array}{l}\mathrm{H}=\text { dureza }[\mathrm{MPa}]-\text { tendência à fadiga } \\
\tau_{\mathrm{e}}=\text { tensão de escoamento por tração }[\mathrm{MPa}]\end{array}$ & $\begin{array}{c}68,7 \\
25\end{array}$ & $\begin{array}{c}166,8 \\
66\end{array}$ \\
\hline $\begin{array}{l}\mathrm{E}=\text { módulo de elasticidade }[\mathrm{MPa}] \\
\mathrm{E} / \tau_{\mathrm{e}}=\text { tendência à adesão }[-]\end{array}$ & $\begin{array}{l}832 \\
33,3\end{array}$ & $\begin{array}{l}2300 \\
34,8\end{array}$ \\
\hline $\begin{array}{l}\phi=\text { Alongamento até a ruptura }[\%] \\
\tau_{\mathrm{r}}=\text { tensão de ruptura por tração[MPa] }\end{array}$ & $\begin{array}{c}467,4 \\
30,4\end{array}$ & $\begin{array}{l}64,2 \\
63,0\end{array}$ \\
\hline$\tau_{\mathrm{r}} . \phi=$ resistência a abrasão $[\mathrm{MPa}]$ & 142,1 & 40,5 \\
\hline$v=$ Coeficiente de Poisson $[-]$ & 0,45 & 0,38 \\
\hline Resistência ao Impacto CHARPY $\left(23^{\circ} \mathrm{C}\right)\left[\mathrm{kJ} / \mathrm{m}^{2}\right]$ & 80 & 9,3 \\
\hline$\varepsilon_{\mathrm{c}}=$ densidade de energia coesiva $\left[\mathrm{J} / \mathrm{cm}^{3}\right]$ & 320 & 382 \\
\hline$\rho=$ densidade $\left[\mathrm{kg} / \mathrm{m}^{3}\right]$ & 0,93 & 1,41 \\
\hline Peso molecular viscosimétrico $[\mathrm{g} / \mathrm{mol}]$ & $6 \times 10^{6}$ & $7 \times 10^{4}$ \\
\hline Grau de cristalinidade $[\%]$ & 59,9 & 69,2 \\
\hline $\mathrm{Wab}=$ trabalho de adesão $\left[\mathrm{mJ} / \mathrm{m}^{2}\right]-$ Alumina & 8,5 & 10,1 \\
\hline - Inoxidável & 8,5 & 9,6 \\
\hline - ele mesmo & 7,8 & 9,5 \\
\hline
\end{tabular}

Tendo em vista as propriedades descritas nessa Tabela, correlacionando-as com os resultados e toda a discussão já realizada acerca dos aspectos analisados nesta pesquisa, pode-se dizer que, em termos de: 
$\left.1^{\circ}\right)$ Mecanismos de desgaste

- As análises das superfícies de desgaste dos pinos, dos discos e a observação da morfologia das partículas de desgaste, mostraram basicamente que os 3 mecanismos de desgaste que atuaram durante a realização dos ensaios de deslizamento foram: a abrasão (riscamento), a fadiga (formação de ondas) e a adesão (transferência de filme). Foi verificada uma maior evidência de atuação dos dois primeiros, ou seja, houve preponderância de um caráter mais abrasivo do que adesivo;

- O POM apresentou um aspecto mais frágil (menor resistência ao impacto) quando comparado ao UHMWPE, e mostrou uma maior tendência de sofrer desgaste (provavelmente devido ao efeito da maior dureza) ${ }^{22}$. Além disso, tendeu a perder mais massa quando submetido às superfícies mais rugosas (concordando com a sua menor resistência à abrasão $\left.-\tau_{\mathrm{r}} . \phi\right)^{68}$;

- Tanto para o POM, mas principalmente para o UHMWPE, a transferência de material para a superfície do disco reduz a possibilidade de atuação de mecanismos adesivos no próprio polímero, pois o trabalho de adesão do polímero quando em contato com ele mesmo (neste caso, com o filme depositado) é menor do que em contato com a superfície dos contra-corpos.

$2^{\circ}$ ) Propriedades dos polímeros

- A curva do módulo de armazenamento elástico E' (Figura 5.15) indica que, dentro do intervalo de variação da temperatura na região do contato, as propriedades elásticas dos dois materiais poliméricos são reduzidas em $70 \%$. $\mathrm{Na}$ realidade, o aumento da temperatura provoca uma redução também na dureza e na tensão de escoamento (Figura 2.5). Em termos do desgaste, tais reduções nas propriedades mecânicas podem acentuar a ação danosa, principalmente dos mecanismos abrasivos;

- As propriedades elásticas do UHMWPE $\left(E / \tau_{\mathrm{e}}\right)$ confere a este material uma tendência a sofrer uma maior ação de fenômenos adesivos, em comparação com o POM. No entanto, a ocorrência de fenômenos adesivos também está intimamente ligada ao trabalho de adesão dos pares em contato $\left(\mathrm{W}_{\mathrm{ab}}\right)$. Assim, os pares com POM mostram-se mais capazes de formar ligações 
fracas, responsáveis pelos fenômenos de adesão, do que aqueles pares formados pelo UHMWPE;

- O aumento da temperatura na região do contato modifica a capacidade de amortecimento dos materiais poliméricos. No entanto, a própria literatura ${ }^{85}$ mostra que a busca de relações da resistência ao desgaste de polímeros com o módulo de perda (ou mesmo com as demais propriedades dinâmicomecânicas dos polímeros) ainda necessita de um maior aprofundamento nas investigações quanto ao comportamento das propriedades dos materiais poliméricos frente às variações dinâmico-mecânicas, principalmente em relação aos materiais semicristalino sob contato deslizante;

- Tanto a densidade de energia coesiva $\left(\boldsymbol{\varepsilon}_{\mathbf{c}}\right)$ quanto a massa molecular (MM) são propriedades físico-químicas dos polímeros que interferem no seu comportamento tribológico. A densidade de energia coesiva tem se mostrado mais importante quando somente fenômenos adesivos ocorrem, porém nesta pesquisa o que se observou foi uma predominância dos mecanismos abrasivos. Sabe-se que o aumento da massa molecular para um dado material conduz a um aumento de sua resistência ao desgaste ${ }^{14}$, no entanto ainda não se encontrou um patamar, ou um limite de valores de MM, onde a partir do qual o aumento da massa molecular deixa de ser representativa no seu comportamento ao desgaste. Sendo assim, não foi possível obter correlações conclusivas entre estas propriedades físico-químicas e as taxas de desgaste dos polímeros estudados.

$3^{\circ}$ ) Rugosidade do contra-corpo

- Os ensaios de desgaste mostraram que, em geral, a taxa de desgaste se eleva com ao aumento da rugosidade. A literatura ${ }^{22}$ indica que, em ensaios contra corpos rígidos, os principais mecanismos de desgaste que atuariam no polímero seriam a fadiga e a abrasão e, quanto mais altas as asperezas do corpo rígido, maior seria a intensidade destes mecanismos. $\mathrm{Na}$ análise das superfícies de desgaste dos materiais ensaiados, verificou-se que os mecanismos de desgaste atuantes foram a fadiga (formação de ondas) e a abrasão. Porém vale salientar que, para todos os tribossistemas, mas 
principalmente nos ensaios contra alumina, mecanismos de desgaste tipicamente adesivos, como transferência de filme, puderam ser identificados, embora não tenham sido quantificados em relação à variação da rugosidade do contra-corpo;

$4^{\circ}$ ) Variação de temperatura

- O material POM apresenta um maior grau de cristalinidade, o que the conferiria uma maior capacidade de manter suas propriedades mecânicas em temperaturas elevadas por mais tempo ${ }^{18}$. Nos ensaios realizados, foi observado que as temperaturas atingidas foram mais elevadas com o POM do que com o UHMWPE, para as mesmas condições de ensaio. Nesse caso, o fato da difusividade térmica do UHMWPE ser superior à do POM deve ter contribuído para que o calor gerado na interface dos corpos não conduza a um aumento indesejado de temperatura.

- A capacidade de dissipação de calor do par tribológico mostrou ser o fator mais relevante quanto às temperaturas desenvolvidas.

$\left.5^{\circ}\right)$ Severidade global (PVR/DD)

- Os resultados finais mostraram que há uma tendência de crescimento da taxa de desgaste com o aumento da severidade global do ensaio para cada par estudado. No entanto, foi verificado que, apesar da utilização de um parâmetro mais geral (PVR/DD) fornecer uma visão mais ampla do comportamento do desgaste dos polímeros, há ainda outros aspectos referentes aos tribossistemas, tais como o efeito das cargas dinâmicas no contato, a mecânica de formação e remoção dos filmes de transferência e o comportamento do coeficiente de atrito, que também influenciam no comportamento quanto ao desgaste dos polímeros e que não são contemplados pelo parâmetro PVR/DD.

Com base nas discussões apresentadas acima, buscou-se a implementação de um modelo matemático que considerasse as condições de contato e as propriedades mecânicas e físico-químicas dos polímeros, além das características do contra-corpo, 
como o acabamento superficial, a difusividade térmica e o trabalho de adesão. Contudo, com o modelo desenvolvido (Anexo C) não foi possível evidenciar uma correlação clara entre as suas variáveis e os valores de taxa de desgaste, visto que as dispersões dos resultados atingiram valores de até $120 \%$ e sabendo que um bom modelo tribológico não deveria ultrapassar uma dispersão de $30 \%{ }^{118}$.

Ao analisar cada variável independente dos ensaios com os pares tribológicos estudados, foi possível organizá-las seqüencialmente quanto ao grau de influência em relação à taxa de desgaste dos polímeros. A Figura 5.105 mostra que mais importante que as condições dinâmicas de ensaio, que o tipo de polímero e que o nível de acabamento superficial dos discos, é a natureza do contra-corpo que mostrou-se o parâmetro mais influente nos resultados de desgaste dos polímeros.

\begin{tabular}{|c|c|c|c|}
\hline \multicolumn{2}{|c|}{ 1- Material do contra-corpo } & \multicolumn{2}{|l|}{ 2- Acabamento superficial do contra-corpo } \\
\hline $\begin{array}{l}\text { Alumina }>\text { Aço Inoxidável } \\
\text { Alumina }=\text { Aço Inoxidável } \\
\text { Alumina }<\text { Aço Inoxidável }\end{array}$ & $\begin{array}{r}69 \% \\
31 \% \\
0 \%\end{array}$ & $\begin{array}{l}\uparrow \text { rugosidade } \rightarrow \text { aumento na taxas de desgaste } \\
\uparrow \text { rugosidade } \rightarrow \text { taxa de desgaste constante } \\
\uparrow_{\text {rugosidade }} \rightarrow \text { diminuição na taxa de desgaste }\end{array}$ & $\begin{array}{r}55,2 \% \\
41,4 \% \\
3,4 \%\end{array}$ \\
\hline \multicolumn{2}{|l|}{ 3-T po depolimero } & \multicolumn{2}{|l|}{ 4- Condição PV } \\
\hline $\begin{array}{l}\mathrm{POM}>\mathrm{UHMWPE} \\
\mathrm{POM}=\mathrm{UHMWPE} \\
\mathrm{POM}<\mathrm{UHMWPE}\end{array}$ & $\begin{array}{l}45 \% \\
45 \% \\
10 \% \\
\end{array}$ & $\begin{array}{l}\text { A taxa de desgaste se el eva com a condição PV } \\
\text { A taxa de desgaste independe da condição PV } \\
\text { A taxa de desgaste diminui com a condição PV }\end{array}$ & $\begin{array}{l}37,5 \% \\
62,5 \% \\
0,0 \% \\
\end{array}$ \\
\hline
\end{tabular}

Figura 5.105 - Quadro resumo dos resultados de desgaste dos polímeros, evidenciando as influências em termos percentuais de cada variável estudada.

Considerando que, durante os ensaios tribológicos de pares polímero x contracorpo rígido, verificou-se que a variação de altura do pino $(\Delta \mathbf{h})$, utilizada para mensurar a degradação dos polímeros, ocorre não somente devido ao desgaste propriamente e à atuação de mecanismos de desgaste (abrasão, fadiga e transferência), mas também devido à fluência do polímero e ao fenômeno da fusão. É evidente que a intensidade de cada um desses fenômenos (desgaste, fluência e fusão) possui uma forte dependência com a temperatura dos corpos e com a severidade das condições do ensaio. Portanto, é possível organizar os resultados dos ensaios de desgaste, salientando as regiões onde estes fenômenos atuaram, em função da severidade global para cada tipo de polímero estudado. As Figuras 5.106 e 5.107 mostram as regiões onde os fenômenos de desgaste, 
fluência e fusão atuaram, além da tendência de comportamento da variação de altura, de cada par tribológico estudado, em função da severidade global (PVR/DD).

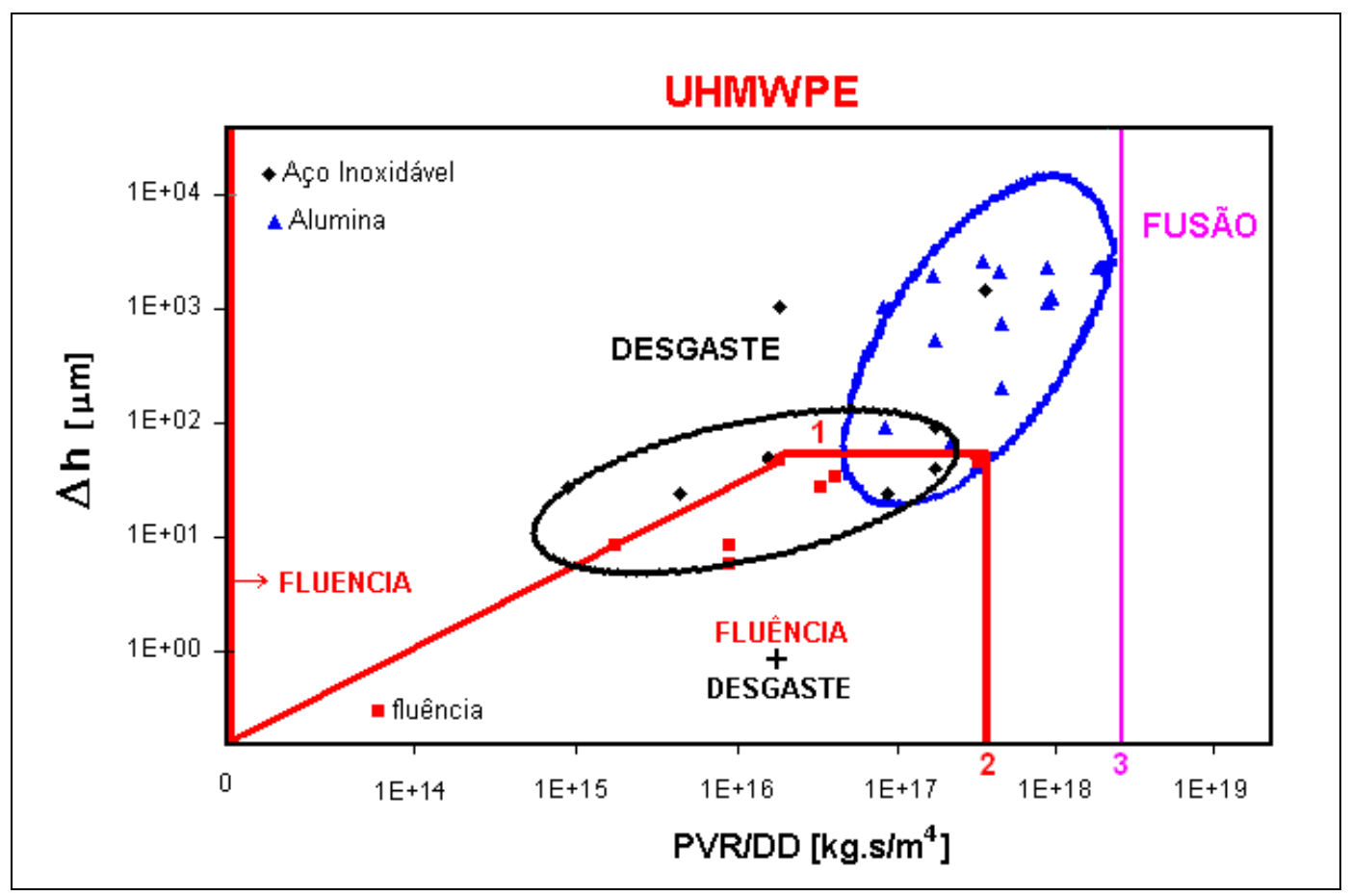

Figura 5.106 - Mapa do comportamento do UHMWPE.

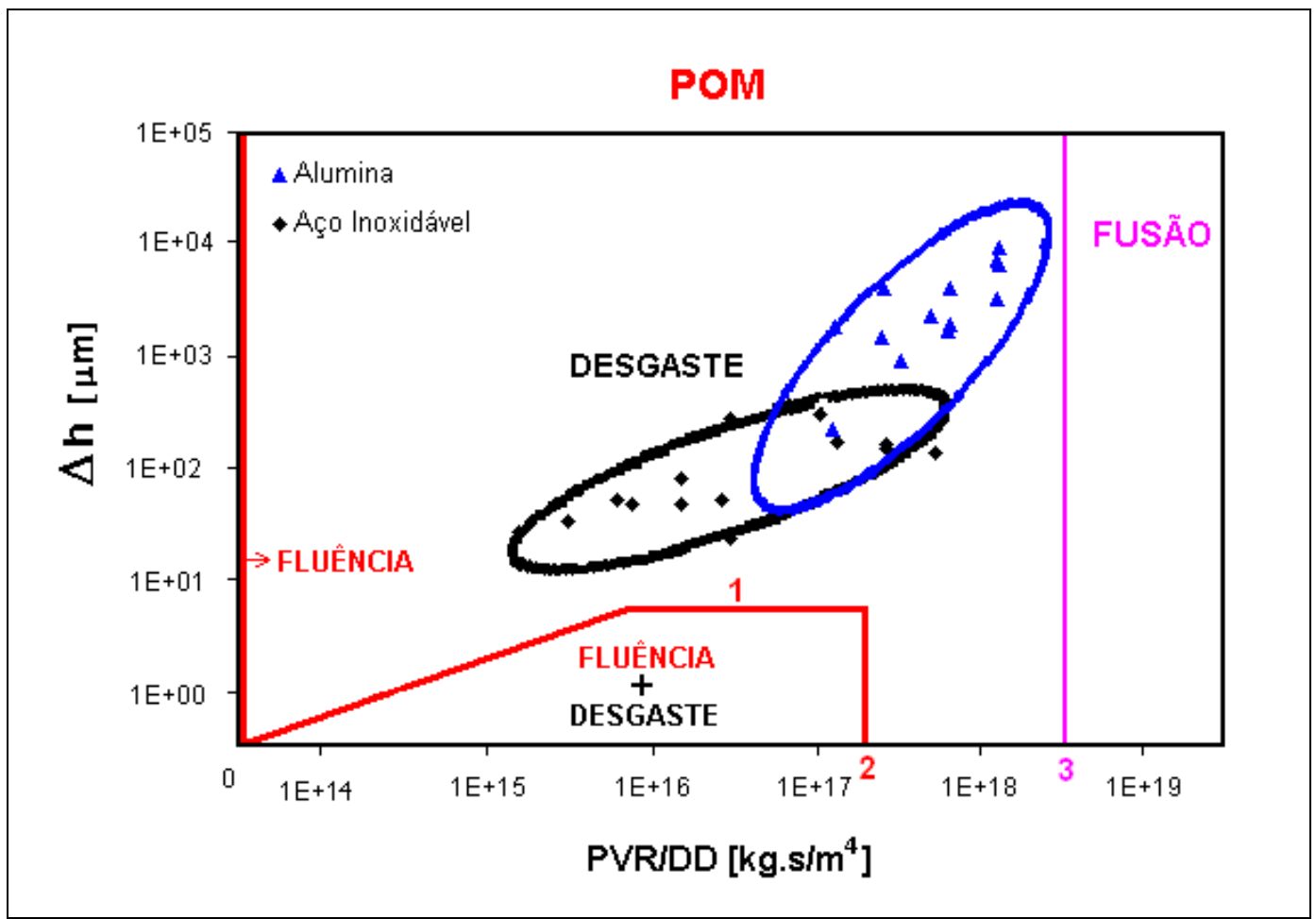

Figura 5.107 - Mapa do comportamento do POM. 
Analisando os mapas de comportamento do POM e do UHMWPE apresentados nas Figuras acima, tem-se que:

- A linha vertical vermelha onde ocorreu somente o fenômeno da fluência está relacionada à severidade tribológica zero, pois esta condição se dá com velocidade nula;

- A fluência atuou nos polímeros em todos os níveis de severidade, no entanto sua importância diminuiu com o aumento da severidade pois, nesse caso, as taxas de desgaste tornam-se tão altas, de modo que aquelas regiões deformadas por fluência são removidas pela ação dos mecanismos de desgaste;

- A região onde tanto os fenômenos de fluência quanto os de desgaste são representativos, é delimitada pelas retas 1 e 2 . A posição destas retas dependerá de cada sistema tribológico analisado. Para o mapa de comportamento do POM, as retas 1 e 2 são apenas representativas (extrapolações), pois como se verificou nesta pesquisa, a maior rigidez do POM fez com que a região Fluência + Desgaste não pudesse ser observada nas condições de ensaio utilizadas;

- Na região onde ocorreram ambos os fenômenos de desgaste e fluência, que refere-se aos valores de desgaste dos ensaios com UHMWPE, foi necessário realizar a correção do desgaste quanto à fluência, visto que a variação de altura do pino deu-se pela ação simultânea destes dois fenômenos;

- A maior estabilidade dimensional do POM faz com que a região onde atuam tanto a fluência como o desgaste seja bem menor do que a região observada com o UHMWPE e não superpõe com a nuvem de resultados de desgaste;

- Assim como os limites da região para a ocorrência da fluência simultaneamente ao desgaste dependem tanto do polímero quanto do material do contra corpo, os limites da região para a ocorrência de fusão nos polímeros também dependem do par ensaiado. Sendo que nos mapas de comportamento este limite é a linha vertical 3. Para o UHMWPE o ponto 3 corresponde a um parâmetro de severidade (PVR/DD) da ordem de 2,9 x $10^{18}\left[\mathrm{~kg} . \mathrm{s} / \mathrm{m}^{4}\right]$ e de $5,2 \times 10^{18}\left[\mathrm{~kg} . \mathrm{s} / \mathrm{m}^{4}\right]$ no mapa de comportamento do POM; 
- Os mapas das Figuras 5.106 e 5.107 mostram que, mais do que o tipo de polímero ou as condições de ensaio empregadas, a natureza do contra-corpo possui papel fundamental quanto à resistência ao desgaste do material polimérico. 


\section{Conclusões}

No âmbito do trabalho experimental realizado, as seguintes conclusões foram obtidas:

1. Fenômenos observados:

1.1 Fusão: para um dado par tribológico, a fusão do material polimérico foi uma função da condição PV e do acabamento superficial do contra-corpo.

1.2 Abrasão: o mecanismo de desgaste por abrasão atuou nos polímeros em todas as condições PV ensaiadas e sua ação danosa tornou-se mais efetiva com a elevação da rugosidade e da temperatura.

1.3 Formação de ondas: A formação de ondas na superfície desgastada dos polímeros, apontada na literatura como sendo relacionada ao mecanismo de desgaste por fadiga, não ocorre para as condições PV mais brandas e tornase mais evidente com o aumento da condição PV e da rugosidade.

1.4 Adesão: a transferência de filme, causada por ocorrência do fenômeno de adesão, foi o mecanismo de degradação menos danoso em termos de desgaste dos polímeros.

1.5 Fluência: a maior rigidez do POM em relação ao UHMWPE foi a razão pelo fenômeno de fluência só ser significativo na degradação do UHMWPE na faixa das condições de ensaio estudadas.

2. Mapas de comportamento:

2.1 - A degradação dos materiais poliméricos POM e UHMWPE foi sistematizada na forma de mapas de comportamento. Nos mapas foi utilizado o parâmetro de severidade global dos ensaios e a variação de altura do pino, a qual representa a degradação do polímero.

2.2 O parâmetro de severidade global (PVR/DD), desenvolvido nesta pesquisa para conseguir obter melhores relações entre a taxa de desgaste apresentada pelo polímeros e os diversos parâmetros do sistema tribológico, mostrou-se 
bastante adequado pois considera os três principais fatores relacionados às condições de severidade no contato: a condição de carregamento do ensaio, representada pela condição de velocidade e pressão (PV), a agressividade do acabamento superficial do contra-corpo, representada pelo parâmetro combinado de rugosidade $\operatorname{lnRz} / \operatorname{lnSm}(\mathrm{R})$ e a capacidade de dissipação de calor da região do contato, representada pela difusividade térmicas dos materiais em contato (DD).

2.3 - Com os mapas de degradação em função da severidade global, foi possível identificar as tendências de ocorrência do desgaste, da fluência e da fusão dos polímeros ensaiados contra cerâmica e metal.

3. A temperatura é o principal fator intensificador dos mecanismos de desgaste, uma vez que esta é uma função de PVR/DD. Em decorrência disto, a taxa de desgaste dos polímeros foi, em geral, maior quando contra a alumina e maior no POM em comparação ao UHMWPE.

4. Os valores de coeficiente de atrito nos ensaios com POM foram superiores aos com UHMWPE. As condições experimentais não permitiram avaliar outras correlações. 


\section{Sugestões para trabalhos futuros}

1. Compreender os mecanismos de desgaste em condições PVR/DD menos severas realizando ensaios de desgaste mais longos.

2. Investigar as relações entre taxa de desgaste e mudanças microestruturais dos polímeros (grau de cristalinidade, tamanho dos esferulitos, recristalização, etc.).

3. Buscar compreender os fenômenos de atrito e desgaste utilizando a análise térmica de calorimetria exploratória diferencial (DSC) de amostras retiradas das superfícies dos pinos ensaiados e também das partículas de desgaste. Investigar os mecanismos de desgaste de transferência de filme medindo a espessura dos filmes e buscando verificar uma possível orientação das macromoléculas.

4. Estudar o comportamento do coeficiente de atrito dos materiais poliméricos realizando ensaios interrompidos.

5. Utilizar técnicas de redes neurais para o modelamento matemático do comportamento quanto ao atrito e ao desgaste de materiais poliméricos.

6. Estudar o comportamento tribológico do POM e do UHMWPE formando blendas entre si e com outros termoplásticos, além de compósitos destes polímeros com fibras de vidro, fibras celulósicas, etc..

7. Aprofundar o estudo dos mecanismos de desgaste do materiais poliméricos. 


\section{ANEXO A \\ ENSAIOS COM A MESMA CONDIÇÃO PV}

Nos ensaios realizados nesta pesquisa, dois pares de condições PV foram repetidos para todos os sistemas pino/disco/acabamento superficial estudados. A Tabela A.1 mostra os valores dos parâmetros de ensaio que apresentam a mesma condição PV.

Tabela A.1 - Parâmetros do ensaio de desgaste com a mesma condição PV.

\begin{tabular}{ccc}
\hline $\begin{array}{c}\text { Carga } \\
{[\mathrm{N}]}\end{array}$ & $\begin{array}{c}\text { Velocidade } \\
{[\mathrm{m} / \mathrm{s}]}\end{array}$ & $\begin{array}{c}\text { Condição PV } \\
{\left[\mathrm{kW} / \mathrm{m}^{2}\right]}\end{array}$ \\
\hline 50 & 1,0 & 2.550 \\
100 & 0,5 & 2.550 \\
100 & 1,0 & 5.100 \\
200 & 0,5 & 5.100 \\
\hline
\end{tabular}

A Tabela A.2 mostra uma comparação qualitativa do comportamento do coeficiente de atrito $(\mu)$ e taxa de desgaste (D) em função das variações de velocidade de deslizamento (V) e carga aplicada (N) nos ensaios com a mesma condição PV.

Tabela A.2 - Relação entre velocidade, taxa de desgaste e coeficiente de atrito nos ensaios com a mesma condição $P V$.

\begin{tabular}{|c|c|c|c|c|}
\hline Par tribológico & $\begin{array}{c}\text { Condição PV } \\
{\left[\mathrm{kW} / \mathrm{m}^{2}\right]}\end{array}$ & $\begin{array}{c}\text { Velocidade } \\
{[\mathrm{m} / \mathrm{s}]}\end{array}$ & $\begin{array}{c}\text { Desgaste } \\
{[\mu \mathbf{m} / \mathbf{m}]}\end{array}$ & $\begin{array}{c}\text { Coef. de } \\
\text { atrito }\end{array}$ \\
\hline \multirow[t]{2}{*}{ PE x Aço Inox R2 } & 2550 & $\uparrow$ & - & $\downarrow$ \\
\hline & 5100 & $\uparrow$ & $\downarrow$ & $\uparrow$ \\
\hline \multirow[t]{2}{*}{ PE x Aço Inox R3 } & 2550 & $\uparrow$ & $\downarrow$ & $\downarrow$ \\
\hline & 5100 & $\uparrow$ & $\downarrow$ & - \\
\hline \multirow[t]{2}{*}{$\mathrm{PE} \times \mathrm{Al}_{2} \mathrm{O}_{3} \mathrm{R} 3$} & 2550 & $\uparrow$ & $\uparrow$ & $\uparrow$ \\
\hline & 5100 & $\uparrow$ & - & $\uparrow$ \\
\hline $\mathrm{PE} \times \mathrm{Al}_{2} \mathrm{O}_{3} \mathrm{R} 4$ & 2550 & $\uparrow$ & - & $\downarrow$ \\
\hline \multirow[t]{2}{*}{ POM x AçoInox R2 } & 2550 & $\uparrow$ & $\downarrow$ & $\uparrow$ \\
\hline & 5100 & $\uparrow$ & $\downarrow$ & - \\
\hline \multirow[t]{2}{*}{ POM x Aço Inox R3 } & 2550 & $\uparrow$ & - & $\uparrow$ \\
\hline & 5100 & $\uparrow$ & $\downarrow$ & $\uparrow$ \\
\hline \multirow[t]{2}{*}{$\mathrm{POM} \times \mathrm{Al}_{2} \mathrm{O}_{3} \mathrm{R} 3$} & 2550 & $\uparrow$ & $\downarrow$ & $\uparrow$ \\
\hline & 5100 & $\uparrow$ & $\downarrow$ & $\uparrow$ \\
\hline POM x A12O3 R4 & 2550 & $\uparrow$ & $\downarrow$ & $\uparrow$ \\
\hline
\end{tabular}

Analisando os resultados da Tabela A.2 observa-se: 
- para todos $\mathbf{( 1 0 0 \% )}$ ) os ensaios com POM verificou-se que para a mesma condição PV, quanto menor a carga aplicada menor é a taxa de desgaste $(\downarrow \mathbf{N}$ produz $\downarrow \mathbf{D})$ e quanto maior a velocidade de deslizamento maior o coeficiente de atrito $(\uparrow \mathbf{V}$ produz $\uparrow \mu)$;

- para $75 \%$ dos ensaios com PE verificou-se que para a mesma condição PV, quanto menor a carga aplicada menor é a taxa de desgaste $(\downarrow \mathbf{N}$ produz $\downarrow$ D) e em $50 \%$ dos casos, quanto maior a velocidade de deslizamento maior o coeficiente de atrito $(\uparrow \mathbf{V}$ produz $\uparrow \boldsymbol{\mu})$;

- a partir dos resultados apresentados acima, pode-se dizer que existe uma relação mais forte entre os pares carga aplicada e taxa de desgaste $(\mathbf{N}$ e D) e velocidade de deslizamento e coeficiente de atrito $(\mathbf{V}$ e $\boldsymbol{\mu})$.

Para alguns ensaios com a mesma condição PV foi feita a medição da temperatura próxima à superfície de contato. Em $100 \%$ dos casos, para a mesma condição PV, uma carga maior conduz a uma temperatura mais elevada. ( $\uparrow \mathbf{N}$ produz $\uparrow$ Temperatura). O que por analogia relaciona temperatura com taxa de desgaste, como sendo respostas do sistema tribológico com comportamento proporcional ( $\uparrow$ Temperatura conduz $\uparrow \mathbf{D})$. 


\section{ANEXO B}

\section{ANÁLISE DE VARIÂNCIA}

A principal e mais importante técnica para a solução de problemas de comparação de várias médias é a análise de variância. A análise de variância é um método capaz de identificar diferenças entre as médias populacionais devidas a várias causas atuando simultaneamente sobre os elementos da população. O método ${ }^{120}$ apresentado a seguir se aplica para amostras de mesmo tamanho onde:

$$
\begin{aligned}
& \mathrm{k}=\text { número de amostras; } \\
& \mathrm{n}=\text { tamanho de amostras; } \\
& \alpha=\text { nível de significância. }
\end{aligned}
$$

Neste método, tem-se duas hipóteses:

$$
\begin{aligned}
& \mathrm{H}_{0}=\mu_{1}=\mu_{2}=\ldots=\mu_{\mathrm{k}} \text { (todas as médias são iguais) } \\
& \mathrm{H}_{1}=\text { pelo menos uma das médias populacionais é diferente }
\end{aligned}
$$

$\mathrm{H}_{0}$ será aceita se $\mathbf{F}<\mathbf{F}_{\mathrm{k}-1}, \mathrm{k}(\mathrm{n}-1), \alpha$ ou se $\mathrm{F}<1$

onde $\mathbf{F}$ são os pontos de porcentagem da distribuição $\mathbf{F}$ (FICHER) de SNEDECOR $^{120}$, a qual relaciona os valores da população com os seus respectivos erros.

A notação matemática usada foi: 
$\mathrm{x}_{\mathrm{ij}}(\mathrm{i}=1,2, . ., \mathrm{k} ; \mathrm{j}=1,2, . \mathrm{n})=\mathrm{j}$ - ésimo valor da $\mathrm{i}-$ ésima amostra de $\mathrm{n}$ elementos $\mathrm{T}_{\mathrm{i}}=\sum_{\mathrm{j}=1}^{\mathrm{n}} \mathrm{x}_{\mathrm{ij}}=$ soma dos valores da $\mathrm{i}-$ ésima amostra $\mathrm{Q}_{\mathrm{i}}=\sum_{\mathrm{j}=1}^{\mathrm{n}} \mathrm{x}_{\mathrm{ij}}^{2}=$ soma dos quadrados dos valores da $\mathrm{i}$ - ésima amostra $\mathrm{T}=\sum_{\mathrm{i}=1}^{\mathrm{k}} \mathrm{T}_{\mathrm{i}}=$ soma total dos valores $\mathrm{Q}=\sum_{\mathrm{i}=1}^{\mathrm{k}} \mathrm{Q}_{\mathrm{i}}=$ soma total dos quadrados dos valores

$\overline{\mathrm{x}_{\mathrm{i}}}=\frac{\mathrm{T}_{\mathrm{i}}}{\mathrm{n}}=$ média da $\mathrm{i}-$ ésima amostra

$\overline{\mathrm{x}}=\frac{\mathrm{T}}{\mathrm{n} \mathrm{k}}=$ média de todos os valores

Existem 3 formas de se estimar a variância $\left(\sigma^{2}\right)$ : estimativa total $\left(\mathrm{s}_{\mathrm{T}}{ }^{2}\right)$, estimativa entre amostras $\left(\mathrm{s}_{\mathrm{E}}^{2}\right)$ e estimativa residual $\left(\mathrm{s}_{\mathrm{R}}^{2}\right)$.

$\mathrm{s}_{\mathrm{T}}^{2}=\frac{\mathrm{Q}-\left[\mathrm{T}^{2} /(\mathrm{nk})\right]}{\mathrm{nk}-1} ; \quad \mathrm{s}_{\mathrm{E}}^{2}=\frac{\sum_{\mathrm{i}=1}^{\mathrm{k}}\left(\mathrm{T}_{\mathrm{i}}^{2} / \mathrm{n}\right)-\left(\mathrm{T}^{2} / \mathrm{nk}\right)}{\mathrm{k}-1} ; \quad \mathrm{s}_{\mathrm{R}}^{2}=\frac{\mathrm{Q}-\sum_{\mathrm{i}=1}^{\mathrm{k}}\left(\mathrm{T}^{2} / \mathrm{n}\right)}{\mathrm{k}(\mathrm{n}-1)}$

Os numeradores das estimativas total, entre amostras e residual são denominados respectivamente, de: soma de quadrados total ou SQT, soma de quadrados entre amostras ou SQE e soma dos quadrados residual ou SQR.

Para aplicação do método, é usual e recomendável dispor os valores segundo o chamado "quadro" de análise de variância. A Tabela 7.1 apresenta este quadro esquemático, para a obtenção do parâmetro $\mathrm{F}$ dos seus dados, o qual será comparado com $\mathrm{F}_{\mathrm{k}-1, \mathrm{k}(\mathrm{n}-1)}, \alpha$. de Snedecor ${ }^{120}$.

Tabela 7.1 - Disposição prática dos dados para a análise de variância.

\begin{tabular}{|c|c|c|c|c|c|}
\hline $\begin{array}{l}\text { Fonte de } \\
\text { variação }\end{array}$ & $\begin{array}{c}\text { Soma de } \\
\text { Quadrados }\end{array}$ & $\begin{array}{c}\text { Graus de } \\
\text { Liberdade }\end{array}$ & $\begin{array}{c}\text { Quadrado } \\
\text { Médio }\end{array}$ & $\mathbf{F}$ & $F_{k-1,1, k(n-1)}, \alpha$ \\
\hline Entre amostras & SQE & $\mathrm{k}-1$ & SQE/k-1 & $\mathrm{S}_{\mathrm{E}}^{2} / \mathrm{s}_{\mathrm{R}}^{2}$ & \\
\hline Residual & SQR & $\mathrm{k}(\mathrm{n}-1)$ & $\mathrm{SQR} / \mathrm{k}(\mathrm{n}-1)$ & & \\
\hline Total & SQT & $\mathrm{nk}-1$ & & & \\
\hline
\end{tabular}




\section{RESULTADOS DE ANÁLISE DE VARIÂNCIA}

Análise de Variância dos resultados de desgaste para diversos sistemas tribológicos. A Tabela B.1 mostra a disposição prática dos dados para a análise de variância com $95 \%$ de confiança.

Tabela B.1 - Disposição prática dos dados para a análise de variância.

\begin{tabular}{lccccc}
\hline $\begin{array}{c}\text { Fonte de } \\
\text { Variação }\end{array}$ & $\begin{array}{c}\text { Soma de } \\
\text { Quadrados }\end{array}$ & $\begin{array}{c}\text { Graus de } \\
\text { Liberdade }\end{array}$ & $\begin{array}{c}\text { Quadrado } \\
\text { Médio }\end{array}$ & $\mathrm{F}$ & $\mathrm{F}_{\mathrm{k}-1, \mathrm{k}(\mathrm{n}-1), \alpha}$ \\
\hline Entre amostras & $\mathrm{SQE}$ & $\mathrm{k}-1$ & $\mathrm{SQE} / \mathrm{k}-1$ & $\mathrm{~s}_{\mathrm{E}}{ }^{2} / \mathrm{s}_{\mathrm{R}}{ }^{2}$ & \\
\hline Residual & $\mathrm{SQR}$ & $\mathrm{k}(\mathrm{n}-1)$ & $\mathrm{SQR} / \mathrm{k}(\mathrm{n}-1)$ & \\
\hline Total & $\mathrm{SQT}$ & $\mathrm{nk}-1$ & & \\
\hline
\end{tabular}

\section{B.1 - POM x Aço Inoxidável R2}

A Figura B.1 apresenta o resultado de taxa de desgaste em função da condição PV para o POM deslizando sobre aço Inoxidável com acabamento superficial tipo R2.

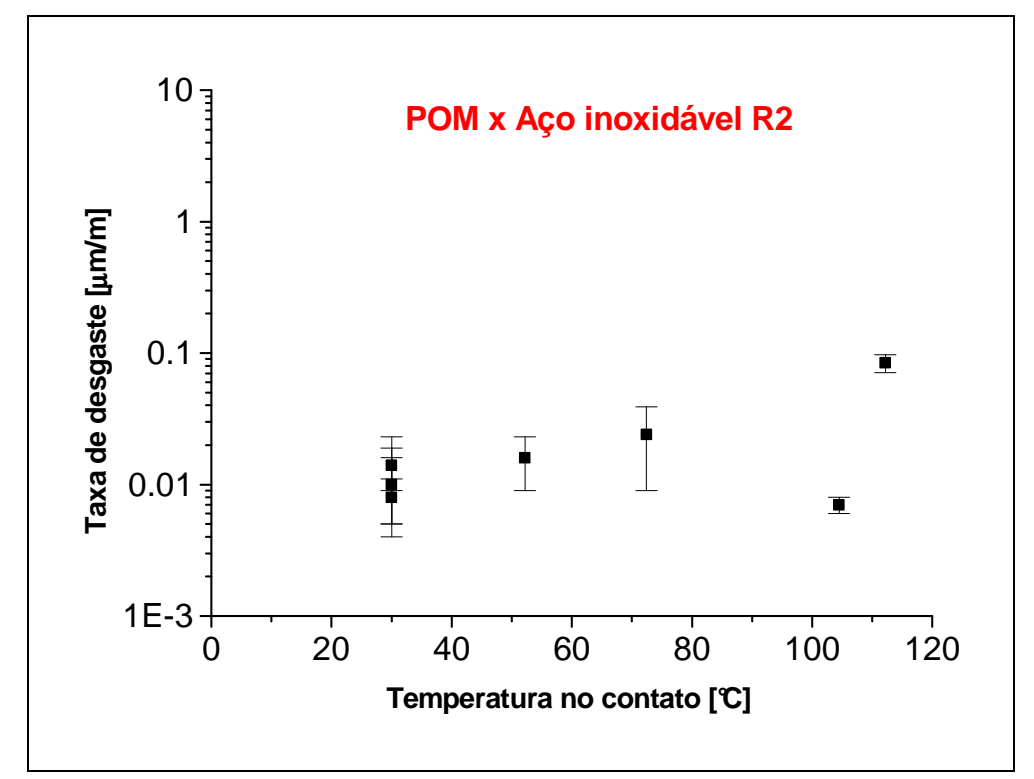

Figura B.1 - Taxa média de desgaste e seus respectivos desvios padrões em função da temperatura no contato dos ensaios de POM x Aço Inox R2. 
Tabela B.2 - Disposição prática dos dados para a análise de variância para os resultados de POM x Aço Inox R2.

\begin{tabular}{|l|c|c|c|c|c|}
\hline \multicolumn{7}{|c|}{ POM x Aço Inox R2 } \\
\hline $\begin{array}{l}\text { Fonte de } \\
\text { variação }\end{array}$ & $\begin{array}{c}\text { Soma de } \\
\text { Quadrados }\end{array}$ & $\begin{array}{c}\text { Graus de } \\
\text { Liberdade }\end{array}$ & $\begin{array}{c}\text { Quadrado } \\
\text { Médio }\end{array}$ & $\mathrm{F}$ & $\mathrm{F} \alpha(95 \%)$ \\
\hline Entre amostras & 0,0003 & 6 & 0,00005 & 0,59 & 2,85 \\
Residual & 0,0011 & 14 & 0,00008 & & \\
Total & 0,0014 & 20 & & & \\
\cline { 5 - 7 } & & &
\end{tabular}

\section{B.2 - POM x Aço Inoxidável R2}

A Figura B.2 apresenta o resultado de taxa de desgaste em função da condição PV para o POM deslizando sobre aço Inoxidável com acabamento superficial tipo R3.

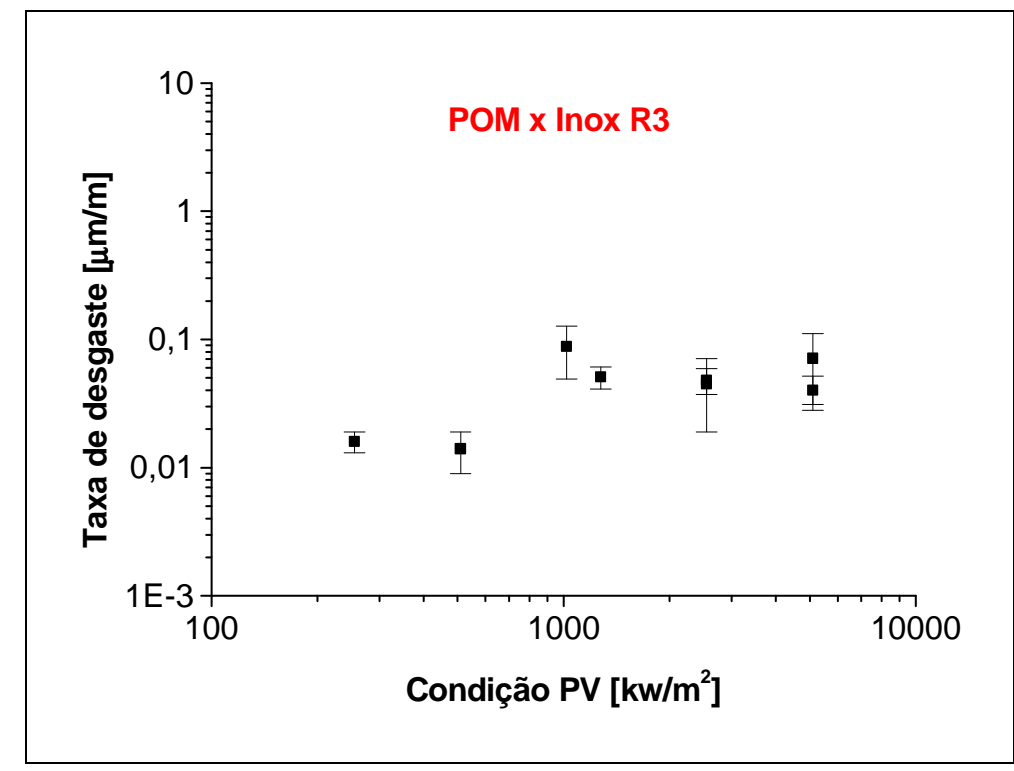

Figura B.2 - Taxa média de desgaste e seus respectivos desvios padrões em função da condição PV dos ensaios de POM x Aço inox R3. 
Tabela B.3 - Disposição prática dos dados para a análise de variância para os resultados de POM x Aço Inox R3.

POM x Aço Inox R3

\begin{tabular}{|l|c|c|c|c|r|}
\hline $\begin{array}{c}\text { Fonte de } \\
\text { variação }\end{array}$ & $\begin{array}{c}\text { Soma de } \\
\text { Quadrados }\end{array}$ & $\begin{array}{c}\text { Graus de } \\
\text { Liberdade }\end{array}$ & $\begin{array}{c}\text { Quadrado } \\
\text { Médio }\end{array}$ & $F$ & $F \alpha(95 \%)$ \\
\hline Entre amostras & 0,0099 & 5 & 0,00198 & 2,60 & 3,11 \\
Residual & 0,0091 & 12 & 0,00076 & & \\
Total & 0,0191 & 17 & \multicolumn{3}{|l}{} \\
\cline { 5 - 7 } & & &
\end{tabular}

\section{B.3 - UHMWPE x Alumina R4}

A Figura B.3 apresenta o resultado de taxa de desgaste em função da condição PV para o UHMWPE deslizando sobre alumina com acabamento superficial tipo R4.

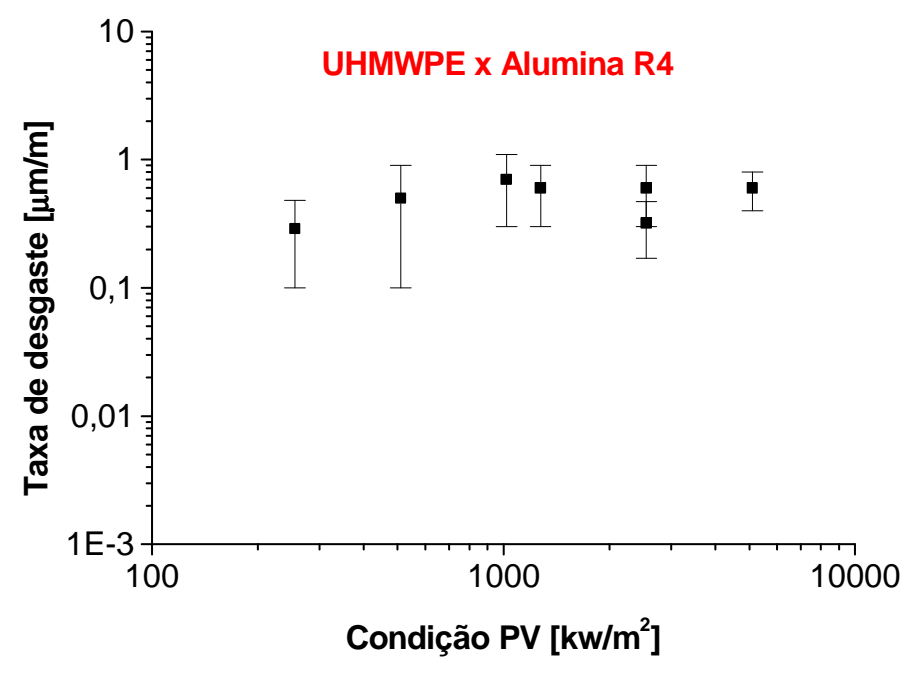

Figura B.3 - Taxa média de desgaste e seus respectivos desvios padrões em função da condição PV dos ensaios com UHMWPE x $\mathrm{Al}_{2} \mathrm{O}_{3} \mathbf{R 4}$.

Tabela B.4 - Disposição prática dos dados para a análise de variância para os resultados de UHMWPE x Alumina R4.

\begin{tabular}{|c|c|c|c|c|c|}
\hline \multicolumn{6}{|c|}{ UHMWPE X Alumina R4 } \\
\hline $\begin{array}{l}\text { Fonte de } \\
\text { variação }\end{array}$ & $\begin{array}{l}\text { Soma de } \\
\text { Quadrados }\end{array}$ & $\begin{array}{l}\text { Graus de } \\
\text { Liberdade }\end{array}$ & $\begin{array}{c}\text { Quadrado } \\
\text { Médio }\end{array}$ & $\mathrm{F}$ & $\mathrm{F} \alpha(95 \%)$ \\
\hline Entre amostras & 0,4495 & 6 & 0,07491 & 0,81 & 2,85 \\
\hline Residual & 1,3018 & 14 & 0,09298 & & \\
\hline Total & 1,7512 & 20 & & & \\
\hline
\end{tabular}




\section{B.4 - UHMWPE e POM x Aço Inoxidável}

A Figura B.4 apresenta o resultado de taxa de desgaste em função da condição PV para o UHMWPE e POM deslizando sobre aço inoxidável.

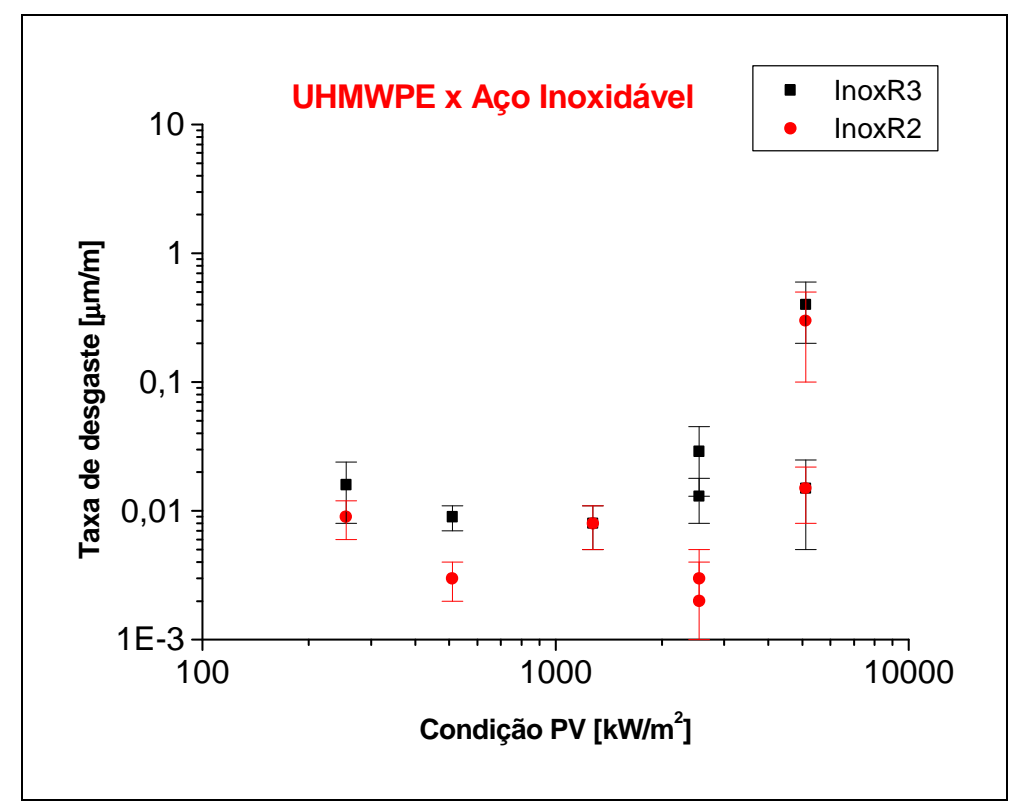

Figura B.4 - Taxa média de desgaste e seus respectivos desvios padrões em função da condição PV dos ensaios de UHMWPE x Aço Inox.

Tabela B.5 - Disposição prática dos dados para a análise de variância para os resultados de UHMWPE e POM x Aço inoxidável.

\begin{tabular}{|c|c|c|c|c|c|}
\hline \multicolumn{6}{|c|}{ UHMWPE x Aço Inox (R2 e R3) } \\
\hline $\begin{array}{l}\text { Fonte de } \\
\text { variação }\end{array}$ & $\begin{array}{l}\text { Soma de } \\
\text { Quadrados }\end{array}$ & $\begin{array}{l}\text { Graus de } \\
\text { Liberdade }\end{array}$ & $\begin{array}{l}\text { Quadrado } \\
\text { Médio }\end{array}$ & $\mathrm{F}$ & $\mathrm{F} \alpha(95 \%)$ \\
\hline Entre amostras & 0,0016 & 1 & 0,00161 & 0,10 & 3,11 \\
\hline Residual & 0,2012 & 12 & 0,01677 & & \\
\hline Total & 0,2028 & 13 & & & \\
\hline
\end{tabular}




\section{ANEXO C MODELO DE DESGASTE}

\section{C.1 - Modelamento matemático e a tribologia}

O modelamento é dito como a arte de criar descrições matemáticas para fenômenos reais. Estas descrições podem ser relativamente simples, porém precisas o suficiente para servir aos propósitos de quem está modelando. É importante reconhecer que existem diferentes modelos que descrevem partes de uma mesma realidade, dependendo do ponto de vista de quem está trabalhando o modelo e de qual parte da realidade quer-se descrever.

Os modelos podem representar um fenômeno dinâmico no aspecto comportamental sem especificar sua evolução. Um modelo pode ser uma fórmula, uma relação quantitativa, uma tabela de dados empíricos ou uma equação ${ }^{121}$.

O objetivo do modelamento em tribologia, não é produzir uma cópia exata do sistema tribológico, mas tentar reproduzir certas características específicas, ou mais relevantes, do sistema. Devido às aproximações feitas para se obter o modelo, entendese que este é uma representação imperfeita do sistema.

Há diferentes tipos de modelos que podem ser usados para descrever sistemas dinâmicos, pode-se citar:

- Modelo em escala: permite examinar processos físicos e são construídos a partir de estudos em escala reduzida dos processos reais;

- Modelos matemáticos: a dinâmica dos sistemas é descrita por equações diferenciais lineares ou não-lineares. Estes modelos podem se divididos em estáticos, dinâmicos contínuos ou dinâmicos discretos.

- Modelos verbais: As relações básicas que descrevem estes sistemas são tão complexas e tão pouco conhecidas, que fica quase impossível propor um modelo. A sociologia é psicologia são áreas do conhecimento que trabalham com este tipo de modelo.

Para o estudo do comportamento tribológico dos materiais, deve-se considerar as propriedades físicas de todo o sistema. A literatura apresenta basicamente, três tipos de modelos físicos, que são: 
Um modelo fundamental descreve as propriedades e o comportamento de um sistema a partir de hipóteses ou princípios físicos básicos. Estes modelos são freqüentemente usados para se obter constantes ou informações para serem utilizadas em cálculos mais gerais ou menos rigorosos. Um objetivo importante deste modelo é o desenvolvimento de modelos computacionais com faixas de validade bem definidas.

\section{b) MODELO FENOMENOLÓGICO}

Um modelo fenomenológico é baseado na percepção ou na fórmula que representa o entendimento intuitivo e qualitativo de uma situação física particular, podendo ser calibrado com outras teorias básicas (comportamento mecânico dos materiais, termodinâmica, dinâmica dos fluidos, etc.) ou novos experimentos.

Estes modelos se baseiam em teorias simples, que modelam o fenômeno apenas aproximadamente.

\section{c) MODELO EMPÍRICO}

Os modelos empíricos são obtidos de dados de uma fórmula matemática ou retirados diretamente de tabelas. O importante é que os dados sejam obtidos de experimentos. Mas com freqüência estes dados apresentam efeitos inesperados, interferência entre medidas ou erros de calibração dos equipamentos.

Estes modelos podem ser usados para interpolação e nunca para extrapolação. Este fato ocorre devido à dois fatores: parâmetros físicos da faixa em que o modelo é valido e condições ambientais particulares para o qual este é utilizado. No caso de modelos tribológicos, a influência dos parâmetros do sistema assume papel altamente relevante quanto a determinação da faixa de validade do modelo empírico.

Para o modelamento matemático da taxa de desgaste e do coeficiente de atrito a literatura tem mostrado uma opção pelas seguintes técnicas:

- Modelos fenomenológico = modelamento mecânico tradicional enfatizando parâmetros de superfície);

- Modelos empíricos = utilizando o método da análise dimensional ou técnicas de inteligência artificial (Redes Neurais).

A seguir serão apresentados alguns métodos e exemplos de modelamento matemático do comportamento tribológico de materiais poliméricos e uma discussão 
sobre a importancia da caracterização e utilização de parâmetros de superfície adequados 'a problemas tribológicos.

\section{C.1.1 - Modelo fenomenológico tradicional enfatizando parâmetros de superfície}

Para o desenvolvimento deste tipo de modelo matemático utiliza-se, no caso do coeficiente de atrito, a definição tradicional de Da Vinci:

$$
\mu=\frac{\mathrm{F}_{\mathrm{a}}}{\mathrm{N}}
$$

Para o caso do desgaste é comum a utilização de teorias de fratura, mecânica do contínuo, equações de fadiga e resistência dos materiais.

O passo fundamental neste tipo de análise é conseguir representar as condições (mesoscópicas) do contato, ou seja, determinação de parâmetros adequados de rugosidade e informações sobre raio de curvatura de asperezas, função distribuição de alturas de asperezas, etc..

\section{Modelo de coeficiente de atrito segundo BASSANI et all ${ }^{122}$}

Durante o desenvolvimento deste modelo probabilístico de coeficiente de atrito foram ponderadas as seguintes considerações:

- necessidade de uma análise estatística geométrica de uma superfície isotrópica gaussiana;

- o comportamento tribológico dos polímeros depende muito dos raios dos picos das asperezas;

- o contato deve ser considerado quase elástico.

O modelo mecânico de superfície utilizado no desenvolvimento do modelo de atrito, está apresentado na Figura C.1. 


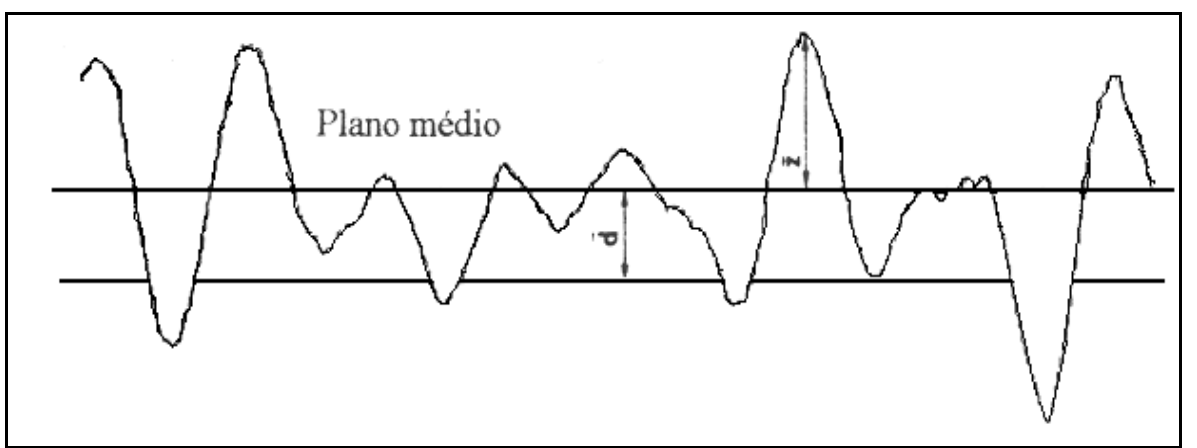

Figura C.7.1 - Contato entre uma superfície rugosa e um plano elástico (polímero) ${ }^{122}$.

As forças envolvidas no modelo mecânico apresentado são:

$$
\mathbf{F}=\mathbf{F s}+\mathbf{F p}
$$

onde:

$\mathrm{F}=$ força de atrito

Fs = componente de cisalhamento (devido à adesão)

$\mathrm{Fp}=$ componente de sulcamento (devido à deformação)

$\mathrm{N}=$ carga normal aplicada

Sabe-se que o coeficiente de atrito é definido por:

$$
\mu=\frac{\mathrm{F}_{\mathrm{a}}}{\mathrm{N}}
$$

Da análise estatística da superfície rugosa, tem-se:

$$
\begin{gathered}
\mathrm{N}=0,04 \cdot \mathrm{D} \cdot \frac{\mathrm{m}_{\mathrm{o}}^{3 / 4} \cdot \mathrm{m}_{4}^{3 / 4}}{\mathrm{~m}_{2}} \cdot \int_{\mathrm{d}}^{\infty} \mathrm{p}_{1}(\mathrm{z}) \mathrm{dz} \cdot \int_{\mathrm{d}}^{\infty} \mathrm{dz} \cdot \int_{-\infty}^{\mathrm{o}} \frac{(\mathrm{z}-\mathrm{d})^{3 / 2}}{\mathrm{k}_{\mathrm{e}}{ }^{1 / 2}} \cdot \mathrm{p}_{1}\left(\mathrm{z}, \mathrm{k}_{\mathrm{e}}\right) \mathrm{dz} \\
\mathrm{Fs}=0,19 \cdot \tau_{\mathrm{e}} \cdot \frac{\mathrm{m}_{\mathrm{o}}^{1 / 2} \cdot \mathrm{m}_{4}^{1 / 2}}{\mathrm{~m}_{2}} \cdot \int_{\mathrm{d}}^{\infty} \mathrm{p}_{1}(\mathrm{z}) \mathrm{dz} \cdot \int_{\mathrm{d}}^{\infty} \mathrm{dz} \cdot \int_{-\infty}^{\mathrm{o}} \frac{(\mathrm{z}-\mathrm{d})}{\mathrm{k}_{\mathrm{e}}} \cdot \mathrm{p}_{1}\left(\mathrm{z}, \mathrm{k}_{\mathrm{e}}\right) \mathrm{dz} \\
\mathrm{F}_{\mathrm{p}}=0,03 \cdot \mathrm{D} \cdot \frac{\mathrm{m}_{\mathrm{o}} \cdot \mathrm{m}_{4}}{\mathrm{~m}_{2}} \cdot \int_{\mathrm{d}}^{\infty} \mathrm{p}_{1}(\mathrm{z}) \mathrm{dz} \cdot \int_{\mathrm{d}}^{\infty} \mathrm{dz} \cdot \int_{-\infty}^{\mathrm{o}}(\mathrm{z}-\mathrm{d})^{2} \cdot \mathrm{p}_{1}\left(\mathrm{z}, \mathrm{k}_{\mathrm{e}}\right) \mathrm{dz} . \\
\mathrm{D}=\frac{\mathrm{E}}{1-\mathrm{v}_{\mathrm{p}}^{2}}
\end{gathered}
$$

onde: E - módulo de elasticidade do polímero

v - coeficiente de Poisson do polímero

$\tau_{\mathrm{e}}$ - resistência ao cisalhamento do polímero

z, d e k $\mathrm{k}_{\mathrm{e}}$ - parâmetros de contado (ver Figura C.1) 
$\mathrm{m}_{\mathrm{o}}=\mathrm{E}\left(\mathrm{z}^{2}\right)-$ momento espectral zero do perfil

$\mathrm{m}_{2}=\mathrm{E}\left\{\left(\frac{\mathrm{dz}}{\mathrm{dx}}\right)^{2}\right\}-$ segundo momento espectral do perfil

$\mathrm{m}_{4}=\mathrm{E}\left\{\left(\frac{\mathrm{d}^{2} \mathrm{z}}{\mathrm{dx}^{2}}\right)^{2}\right\}$ - terceiro momento espectral do perfil

$\mathrm{E}\{\}=$ valor da esperança matemática.

Os valores de mo, $\mathrm{m}_{2}$ e $\mathrm{m}_{4}$ são equivalentes à média quadrática da altura, inclinação e derivada segunda do perfil de distribuição das alturas das asperezas em uma direção arbitrária, respectivamente. ${ }^{123}$

Combinando as equações temos:

$$
\mathrm{N}=\mathrm{B}_{\mathrm{n}} \cdot \frac{\sigma_{\mathrm{dp}}}{\beta_{\mathrm{d}}}, \quad \mathrm{F}_{\mathrm{p}}=\mathrm{B}_{\mathrm{p}} \cdot \frac{\sigma_{\mathrm{dp}}{ }^{2}}{\beta_{\mathrm{d}}{ }^{2}} \quad \text { e } \quad \mathrm{F}_{\mathrm{s}}=\mathrm{B}_{\mathrm{s}}
$$

onde:

$\beta d$ - fator de autocorrelação de decaimento

$\sigma_{\mathrm{dp}}$ - desvio-padrão

$\mathrm{Bn}$, Bs e Bp - constantes que dependem das características mecânicas dos polímeros e das condições de contato.

Assim, o modelo de coeficiente de atrito proposto é:

$$
\mu=\mu_{s}+\mu_{p}=\frac{F_{s}}{N}+\frac{F_{p}}{N} \longrightarrow \mu=\frac{B_{s}}{B_{n}} \cdot \frac{\beta_{d}}{\sigma_{d p}}+\frac{B_{p}}{B_{n}} \cdot \frac{\sigma_{d p}}{\beta_{d}}
$$

\section{Modelo de desgaste segundo JAIN; BAHADUR ${ }^{124}$}

Para a determinação deste modelo, o desgaste foi considerado um fenômeno complexo que depende das condições de deslizamento, propriedades dos materiais e topografia das superfícies.

Para o caso dos polímeros, considerou-se a dureza como uma propriedade sem sentido, devido à fluência e a relaxação de tensão sofrida por estes materiais à temperatura ambiente (lê-se comportamento viscoelástico). 
Condições de contorno utilizadas para o modelamento:

- A altura das asperezas das duas superfícies variam aleatoriamente;

- As asperezas apresentam uma forma esférica;

- As asperezas de uma superfície são alinhadas com as asperezas da outra superfície e possuem a mesma inclinação na direção de deslizamento;

- As deformações na zona de contato são de natureza elástica;

- As zonas de contato são suficientemente separadas para agir independentemente uma das outras.

Utilizando a tensão de tração responsável pela fadiga segundo HAMILTON;

GOODMANN temos o seguinte modelo:

$$
\mathrm{V}=\frac{\mathrm{K}_{1} \cdot \mathrm{P} \cdot \mathrm{L} \cdot \eta_{\mathrm{L}} \cdot \mathrm{v}_{\mathrm{p}}}{2 \cdot \mathrm{S}_{\mathrm{o}}} \cdot\left[\mathrm{f} \cdot\left(\frac{4+v}{8}\right) \cdot \pi+\frac{1-2 v}{3}\right]
$$

sendo:

$$
\mathrm{K}_{1}=\left(\frac{2 \cdot \mathrm{k}_{1} \cdot \mathrm{E}^{\prime}}{\pi \cdot \mathrm{S}_{\mathrm{o}}}\right) \cdot\left(\frac{1}{\beta}\right)^{\frac{\mathrm{t}+1}{2}} \cdot \sigma^{\left(\frac{\mathrm{t}-3}{2}\right)} \cdot\left[\frac{\mathrm{F}_{3 / 2}(\mathrm{~h})}{\mathrm{F}_{1}(\mathrm{~h})}\right]^{\mathrm{t}-1} \cdot \frac{\mathrm{F}_{\mathrm{o}}(\mathrm{h})}{\mathrm{F}_{1}(\mathrm{~h})}
$$

onde:

$\mathrm{V}$ - volume de material desgastado

$\mathrm{P}$ - tensão aplicada

L - distância percorrida

$v$ - coeficiente de Poisson

$\mathrm{k}_{1}$ - constante dependente do Poisson

f - coeficiente de atrito

E'- módulo de elasticidade $\mathrm{v}_{\mathrm{p}}$ - volume médio da partícula de desgaste

$\mathrm{t}$ - constante de fadiga do material

$\eta_{L}$ - densidade linear das asperezas

$S_{o}$ - constante de resistência à fadiga do material

$\beta$ - raio de curvatura das asperezas

$\alpha$ - desvio padrão da distribuição das alturas das asperezas

$\phi(z)$ - função distribuição das alturas das asperezas 


$$
\begin{aligned}
& F_{0}(h)=\int_{d}^{\infty} \phi(z) \cdot d z \\
& F_{1}(h)=\int_{d}^{\infty}(z-d) \cdot \phi(z) \cdot d z \\
& F_{3 / 2}(h)=\int_{d}^{\infty}(z-d)^{3 / 2} \phi(z) \cdot d z
\end{aligned}
$$

\section{C.1.2 - Modelos empíricos}

\section{Modelamento por análise dimensional}

Para o desenvolvimento de modelos matemáticos tribológicos utilizando técnicas de análise dimensional necessita-se inicialmente que se defina que fatores do sistema tribológico em estudo estarão influenciando os resultados de atrito e de desgaste. Estes fatores consistirão nos parâmetros do modelo.

Pode-se definir os parâmetros do modelo tribológico, para materiais poliméricos, segundo a seguinte família de fatores:

- meio ambiente;

$$
\begin{aligned}
& \Rightarrow \text { umidade relativa } \\
& \Rightarrow \text { temperatura } \\
& \Rightarrow \text { atmosfera (gases, camadas, lubrificantes, etc..) }
\end{aligned}
$$

- propriedades dos materiais;

$$
\begin{array}{ll}
\Rightarrow & \text { mecânicas } \\
& -\quad \text { módulo de elasticidade } \\
& -\quad \text { dureza } \\
& -\quad \text { resistência ao cisalhamento } \\
\Rightarrow & \text { térmicas } \\
& -\quad \text { coeficiente de dilatação térmica } \\
& -\quad \text { condutibilidade térmima } \\
& -\quad \text { calor específico } \\
\Rightarrow & \text { físico-químicas } \\
& -\quad \text { energia de superfície }
\end{array}
$$


- densidade de energia coesiva

- parâmetros de contato

$\Rightarrow$ acabamento superficial (parâmetros de rugosidade, dimensão fractal, raio de curvatura de asperezas, distribuição de altura de asperezas, etc..)

$\Rightarrow$ área real de contato

- parâmetros dinâmicos

$\Rightarrow$ Carga aplicada

$\Rightarrow$ Velocidade de deslizamento

$\Rightarrow$ Tempo de contato (ou distância percorrida em contato)

Definidos os parâmetros do modelo, aplica-se o Teorema П e obtêm-se os grupos adimensionais que o modelo organizará, de acordo com a propriedade tribológica a ser investigada. 


\section{Modelo de coeficiente de atrito segundo MADAKSON ${ }^{125}$}

Este modelo de atrito sugere que a força de atrito resulta da adesão, do sulcamento e do intertravamento de asperezas, a qual é governada pela energia superficial além da natureza e magnitude da deformação superficial.

Os grupos adimensionais encontrados foram:

$$
\mathrm{F}=\phi\left(\mathrm{N}, \frac{\rho \cdot \mathrm{V}^{2} \cdot \mathrm{A}}{\mathrm{P}}, \frac{\gamma}{\mathrm{H} \cdot \mathrm{V}^{2}}, \frac{\mathrm{E}_{\mathrm{d}}}{\mathrm{P}} \cdot \frac{\mathrm{Q}}{\mathrm{A} \cdot \mathrm{r}}\right) \cdot \mathrm{C}
$$

Separando a componente da força de atrito pela carga aplicada, obtém-se o modelo de coeficiente de atrito:

$$
\mu=\frac{F}{N}=C \cdot\left(\frac{\rho \cdot A \cdot v^{2}}{N}\right)^{x} \cdot\left(\frac{\gamma}{H \cdot V^{2}}\right)^{y} \cdot\left(\frac{E_{d} \cdot Q}{N \cdot A \cdot r}\right)^{z}
$$

onde:

$$
\begin{array}{ll}
\rho \text { - densidade } & \mathrm{Q} \text { - área deformada } \\
\text { v - velocidade de deslizamento } & \mathrm{r} \text { - rugosidade } \\
\mathrm{A} \text { - área real de contato } & \mathrm{x} \text { - coeficiente do fator de adesão } \\
\mathrm{N} \text { - carga normal aplicada } & \mathrm{y} \text { - coeficiente do fator de energia superficial } \\
\gamma \text { - energia superficial } & \mathrm{z} \text { - coeficiente do fator de energia de deformação } \\
\mathrm{H} \text { - dureza } & \mathrm{C} \text { - constante dependente da temperatura, meio } \\
\text { Ed - energia de deformação } & \text { ambiente e sistema tribológico }
\end{array}
$$

\section{Modelo de desgaste segundo VISWANATH; BELLOW ${ }^{126}$}

Para obter o modelo de desgaste de polímeros foi utilizado um equipamento para ensaio de desgaste tipo pino-contra-disco e o método de análise dimensional seguindo o Teorema $\Pi$ de Buckingham.

Esta equação também considera o efeito da rugosidade do contra-corpo e a aplicação para um número maior de polímeros, tais como o polioximetileno (POM), o policloreto de vinila (PVC), polietileno de alta densidade (PEAD) e o polierafluoro etileno (PTFE).

Para tal, foram obtidos os seguintes termos adimensionais: 


$$
\begin{aligned}
& \left(\frac{\mathrm{E}^{3} \cdot \mathrm{V}}{\gamma^{3}}\right),\left(\frac{\mathrm{W} \cdot \mathrm{E}}{\gamma^{2}}\right),\left(\frac{\mathrm{E} \cdot \alpha}{\gamma}\right),\left(\frac{\gamma \cdot \mathrm{C} p}{\mathrm{v} \cdot \mathrm{k}}\right),\left(\frac{\mathrm{v} \cdot \mathrm{T} \cdot \mathrm{E}}{\gamma}\right) \\
& \Downarrow \quad \Downarrow \quad \Downarrow \quad \Downarrow \quad \Downarrow \\
& \text { adesão deformação rugosidade térmico distância }
\end{aligned}
$$

Uma equação linear não considera as propriedades dos materiais poliméricos, com isso obtemos uma equação com menor sensibilidade e maiores erros.

\section{玉 Equação linear}

$$
\mathrm{V}=\mathrm{K}_{\mathrm{w}} \cdot \frac{\mathrm{W} \cdot \mathrm{v} \cdot \mathrm{T} \cdot \alpha}{\gamma}
$$

Para a determinação de uma equação não-linear são colocados os expoentes p,q,r,s e $\mathrm{Kw}$ como coeficiente de desgaste adimensional, além de obter melhores resultados, esta equação confirma a influência das propriedades dos materiais.

\section{モ Equação não-linear}

$$
\mathrm{V}=\mathrm{K}_{\mathrm{w}} \cdot \mathrm{W}^{\mathrm{p}} \cdot \mathrm{v}^{\mathrm{q}} \cdot \mathrm{T}^{\mathrm{r}} \cdot \alpha^{\mathrm{s}} \cdot \mathrm{E}^{-3+\mathrm{p}+\mathrm{r}+\mathrm{s}} \cdot \gamma^{3-2 \mathrm{p}-\mathrm{q}-\mathrm{s}} \cdot\left(\frac{\mathrm{C}_{\mathrm{p}}}{\mathrm{k}}\right)^{\mathrm{r}-\mathrm{q}}
$$

onde:

Cp - calor específico

E - módulo de elasticidade

$\mathrm{Kw}$ - coeficiente de desgaste

$\mathrm{T}$ - tempo de deslizamento

v - velocidade de deslizamento

$\mathrm{V}$ - volume de material desgastado
W - tensão de contato

$\alpha$ - rugosidade do contra-corpo

$\gamma$ - energia livre de superfície

$\mu$ - coeficiente de atrito

p,q,r,s - parâmetros experimentais.

\section{C.1.3 - Técnicas de inteligência artificial (Redes Neurais)}

Uma outra maneira de se obter um modelo empírico para o comportamento tribológico de polímeros é a utilização de técnicas de inteligência artificial, como as 
redes neurais. No entanto, não se encontrou exemplo de utilização desta técnica no modelamento do coeficiente de atrito.

JONES et all $^{127}$ acreditam que a utilização das redes neural poderá além de reduzir o tempo de realização de ensaios tribológicos também eliminar custos associados à realização destes ensaios. Logicamente deve-se atentar para o fato da representatividade dos resultados perante o comportamento real dos materiais em uso e de uma eventual mudança de mecanismo que os ensaios acelerados podem provocar em alguns sistemas tribológicos.

VELTEN et all ${ }^{128}$ afirma que uma das mais reconhecidas características da análise quantitativa de experimentos complexos como os ensaios tribológicos, é a dependência não-linear de variáveis que descrevem o comportamento dos materiais e as condições experimentais.

Para a implementação de uma rede neural com o objetivo de caracterizar um comportamento tribológico de um determinado sistema, são duas as questões capitais a se resolver: qual a topologia (arquitetura) a se implementar e quais os algoritmos de treinamento e minimização mais eficazes.

As redes neurais mais utilizada na modelagem dos comportamentos tribológicos de materiais são aquelas com topologia de múltiplas camadas (Multilayer Feedforward Network), geralmente com três camadas (a $1^{\mathrm{a}}$ camada para entrada dos dados, uma camada culta, além da camada de saídas dos dados) sendo que somente as duas últimas camadas é que processam os dados. Da mesma forma o algoritmo de aprendizagem mais utilizado é o de retro-alimentação (backpropagation), obtido do método de otimização do gradiente descendente.

\section{C.1.4 - A Topografia da superfície}

Um fator de grande importância no modelamento do atrito e do desgaste de sistemas tribológicos é o acabamento superficial dos materiais em contato. A literatura tem mostrado que os tradicionais parâmetros de superfície, que são baseados no desvio do perfil em relação a uma linha média, como o Ra, Rq ou Rz, não são suficientemente representativos, no que tange uma correlação com fenômenos físicos que ocorrem na região de contato durante o deslizamento. 
Utilizando os parâmetros de rugosidade convencionais, TANAKA; NAGAI ${ }^{129} \mathrm{e}$ HUTCHINGS $^{60}$ mostram que tanto o coeficiente de atrito quanto a taxa de desgaste de um material polimérico decaem com a diminuição destes parâmetros no contra-corpo. Porém existe um ponto de inflexão onde este comportamento se inverte. Sugerindo uma mudança de mecanismos de abrasão (deformação) para adesão.

EISS; MILLOY ${ }^{94}$ mostram que informações sobre a distribuição de altura das asperezas e a curvatura do raio dos picos das superfícies, são de grande importância quanto aos mecanismos de desgaste de polímeros.

A caracterização do acabamento ou da rugosidade de uma superfície está vinculada aos seguintes fatores:

- processo de fabricação,

- instrumento de medida e

- métodos de análise empregados.

RAMACHANDRA; OVAERT ${ }^{91}$ verificaram que os sulcos provocados por um processo de usinagem, podem influenciar a ocorrência de desgaste em polímeros, dependendo da direção de deslizamento entre os corpos.

Um modelo matemático que explicite a importância de uma melhor caracterização das superfícies e utilize parâmetros de superfície mais adequados do que os tradicionais $\mathrm{Ra}, \mathrm{Rq}$ ou $\mathrm{Ry}$, possivelmente conseguirá representar melhor o comportamento quanto ao atrito e ao desgaste de sistemas tribológicos. Talvez a utilização de parâmetros tradicionais combinados de rugosidade, informações mais detalhadas do perfil (raio e inclinação das asperezas e distribuição de alturas) e/ou a determinação de um outro parâmetro característico de uma superfície, como a dimensão fractal (STUPAK et all ${ }^{92}$ ), possa apresentar melhores resultados.

\section{C.2 - Modelamento matemático}

\section{C.2.1 - Método da análise dimensional}

Este método pode ser considerado como híbrido, pois apesar da técnica ser estritamente mecânica, uma etapa importante é a escolha dos parâmetros que pertenceram ao mesmo grupo adimensional, onde a compreensão dos aspectos 
fenomenológicos do sistema tribológico assume papel de relevância para a adequação do modelo.

O método da análise dimensional consiste em organizar uma série de parâmetros do sistema tribológico estudado, em grupos adimensionais, utilizando quaisquer tipos de técnicas de análise dimensional, como por exemplo, o Teorema П (Teorema dos Пs de Buckingham) com o sistema de unidades SI (Sistema Internacional).

\section{Teorema $\Pi$}

Seja um problema físico envolvendo n grandezas. Seja $\mathbf{m} \leq \mathbf{n}$, o número mínimo de dimensões fundamentais (independentes entre si) necessárias para se denotar as dimensões das $\mathbf{n}$ grandezas $\left(\mathbf{a}_{1}, \mathbf{a}_{2}, \mathbf{a}_{3}, \ldots . . . \mathbf{a}_{\mathbf{n}}\right)$. Essas dimensões fundamentais são denotadas por $\mathbf{A}_{\mathbf{1}}, \mathbf{A}_{\mathbf{2}}, \mathbf{A}_{\mathbf{3}}, \ldots . . \mathbf{A}_{\mathbf{m}}$.

Uma matriz dimensional $\left\{\mathbf{e}_{\mathbf{i j}}\right\}, \mathbf{m} \mathbf{x} \mathbf{n}$, pode ser formada escrevendo na linha i (i $=\mathbf{1}, \mathbf{2}, \ldots \mathbf{m})$ e na coluna $\mathrm{j}(\mathbf{j}=\mathbf{1}, \mathbf{2}, \ldots \mathbf{n})$ o expoente $\mathbf{e}_{\mathbf{i j}}$ referente a dimensão fundamental $\mathbf{A}_{\mathbf{1}}$ contido na dimensão da grandeza $\mathbf{a}_{\mathbf{j}}$.

\begin{tabular}{|l|c|c|c|c|c|}
\hline & & $\mathrm{a}_{1}$ & $\mathrm{a}_{2}$ & $\cdots$ & $\mathrm{a}_{\mathrm{n}}$ \\
\hline & $\mathrm{A} 1$ & $\mathrm{e} 11$ & $\mathrm{e} 12$ & $\cdots$ & $\mathrm{e} 1 \mathrm{n}$ \\
\hline Matriz Dimensional $=\left\{\mathrm{e}_{\mathrm{ij}}\right\}=$ & $\mathrm{A}_{2}$ & $\mathrm{e}_{21}$ & $\mathrm{e}_{22}$ & $\cdots$ & $\mathrm{e}_{2 \mathrm{n}}$ \\
\hline & $\cdot$ & $\cdot$ & $\cdot$ & $\cdots$ & $\cdot$ \\
\hline & $\mathrm{A}_{\mathrm{m}}$ & $\mathrm{e}_{\mathrm{m} 1}$ & $\mathrm{e}_{\mathrm{m} 2}$ & $\cdots$ & $\mathrm{e}_{\mathrm{mn}}$ \\
\hline
\end{tabular}

onde:

$$
\begin{aligned}
& {\left[a_{1}\right]=A_{1}{ }^{e 11} \cdot A_{1}{ }^{e 21} \ldots A_{m}{ }^{e m 1}} \\
& {\left[a_{j}\right]=A_{1}{ }^{e 1 j} \cdot A_{1}{ }^{e 2 j} \ldots A_{m}{ }^{e m j}}
\end{aligned}
$$

Seja $\mathbf{r} \leq \mathbf{m}$ a dimensão (ordem) da maior sub-matriz quadrada formada a partir de $\left\{\mathbf{e}_{\mathbf{i j}}\right\}$ cujo determinante é não nulo. Desta forma $\mathbf{r}$ é chamada característica da matriz dimensional.

Teorema П: O problema físico em questão pode ser escrito em termos de um conjunto de $\mathbf{n}-\mathbf{r}$ parâmetros adimensionais dimensionalmente independentes. 


\section{Base de grandezas}

Em um problema físico onde $\mathrm{r}$ é a característica da matriz dimensional, qualquer conjunto de $r$ grandezas associadas a uma sub-matriz $\mathbf{r} \mathbf{x} \mathbf{r}$ de determinante não nulo forma uma base para a resolução de problemas pelo Teorema $\Pi$.

Uma base é sempre um conjunto formado pelo maior número possível de grandezas cujas dimensões são independentes entre si.

\section{Determinação dos parâmetros $\Pi$.}

Inicialmente é necessário escolher uma base conveniente para o modelamento tribológico. Talvez seja esta a etapa mais importante quanto a obtenção de um modelo que tenha uma representação fenomenológica em seus grupos adimensionais.

Como critérios práticos para a escolha da base podemos citar:

- Procurar não incluir na base grandezas consideradas dependentes, isto é, aquelas que se deseja estudar em função das demais;

- Quando se suspeitar que determinada grandeza pode ter pouca influencia na propriedade tribológica, evite inclui-la na base;

- Procurar incluir na base grandezas que podem ser melhor controladas nos ensaios tribológicos;

- Procure incluir as grandezas que melhor caracterizam o problema em seus aspectos geométricos, cineticos, dinâmicos e físico-químicos.

Para cada grandeza restante (fora da base) escreve-se um parâmetro $\Pi$ como sendo o produto desta grandeza pelas grandezas da base elevadas a expoentes incógnitos. A determinação destes expoentes é feita de maneira a tornar $\Pi$ adimensional.

\section{C.2.2 - Modelamento matemático da taxa de desgaste}

A busca de um modelo matemático das taxas de desgaste de materiais poliméricos submetidos a movimento deslizante sobre um contra-corpo rígido será apresentada da seguinte forma:

- Correção dos dados (período de running-in);

- Desenvolvimento dos modelos; 
- Determinação das constantes dos modelos;

- Apresentação dos resultados.

Antes, porém, a análise dos mecanismos de desgaste apresentados pelos polímeros, a qual foi discutida com maior profundidade, mostrou que alguns resultados de taxa de desgaste foram obtidos com o sistema tribológico atuando ainda no período de running-in. Desta forma, será necessário que estes resultados sejam descartados, quando do desenvolvimento do modelo. A Tabela C.2 apresenta quais resultados de taxa de desgaste não serão considerados na obtenção dos parâmetros característicos do modelo.

Tabela C.2 - Tribossistemas e condições de ensaios descartados pelo fato dos ensaios de desgaste não atingirem o regime permanente.

\begin{tabular}{ccc}
\hline & TRIBOSSISTEMAS & \\
\hline UHMWPE x INOX R2 & UHMWPE x INOX R3 & POM x INOX R2 \\
\hline & ENSAIOS & \\
\hline CARGA & Velocidade & Condição PV \\
{$[\mathrm{N}]$} & {$[\mathrm{m} / \mathrm{s}]$} & 255 \\
\hline 50 & 0,1 & 1274 \\
50 & 0,5 & 2548 \\
50 & 1 & 510 \\
100 & 0,1 & 1019 \\
\hline
\end{tabular}

\section{C.2.2.1 - Desenvolvimento do modelo matemáticos por análise dimensional}

O modelo de taxa de desgaste apresentado a seguir foi desenvolvidos com a metodologia utilizada por MADAKSON ${ }^{125}$, RHEE $^{130}$ e VISWANATH; BELOW ${ }^{126}$, a qual utiliza a técnica dos parâmetro $\Pi$ para a obtenção dos grupos adimensionais do modelo.

Para a formação dos grupos adimensionais, primeiramente é necessário escolher os parâmetros do sistema tribológico que sejam os mais representativos, do ponto de vista do comportamento dos materiais envolvidos. É nesta fase que toda a discussão sobre os mecanismos de desgaste atuantes e os efeitos das condições PV, do acabamento superficial e das propriedades dos materiais; fornece um embasamento para uma escolha mais criteriosa dos parâmetros do modelo. 
A Tabela C.3 apresenta quais os parâmetros dos sistemas tribológicos foram analisados para fazer parte do modelo de taxa de desgaste.

Tabela C.3 - Parâmetros dos sistemas tribológicos.

\begin{tabular}{lll}
\hline CARACTERÍSTICAS & PARÂMETROS & UNIDADES \\
\hline \multirow{3}{*}{ Variáveis do } & $\mathrm{h}=$ altura de desgaste & {$[\mathrm{m}]$} \\
Sistema tribológico & $\mathrm{d}=$ distância de deslizamento & {$[\mathrm{m}]$} \\
& $\mathrm{N}=$ carga aplicada & {$[\mathrm{N}]$} \\
& $\mathrm{A}=$ área aparente de contato & {$\left[\mathrm{m}^{2}\right]$} \\
& $\mathrm{v}=$ velocidade de deslizamento & {$[\mathrm{m} / \mathrm{s}]$} \\
& lnRz/lnSm = parâmetro de rugosidade & {$[-]$} \\
\hline & $\tau_{\mathrm{r}}=$ tensão de ruptura por tração & {$[\mathrm{Pa}]$} \\
& $\phi=$ alongamento até a ruptura & {$[\%]$} \\
Propriedades mecânicas & $\mathrm{E}=$ Módulo de elasticidade (Young) & {$[\mathrm{Pa}]$} \\
& $\tau_{\mathrm{e}}=$ tensão de escoamento por tração & {$[\mathrm{Pa}]$} \\
& $\mathrm{H}=$ Dureza & {$[\mathrm{Pa}]$} \\
& $\mathrm{E}=$ Módulo elástico de perda & {$[\mathrm{Pa}]$} \\
\hline Propriedades térmicas & $\mathrm{C}_{\mathrm{p}}=$ Calor específico à pressão constante & {$[\mathrm{J} / \mathrm{kg} \mathrm{K}]$} \\
& $\lambda=$ condutividade térmica & {$[\mathrm{W} / \mathrm{m} \mathrm{K}]$} \\
\hline \multirow{3}{*}{ Propriedades } & $\mathrm{W}_{\mathrm{ab}}=$ trabalho de adesão & {$\left[\mathrm{J} / \mathrm{m}^{2}\right]$} \\
físico-químicas & $\rho=$ densidade absoluta do polímero & {$\left[\mathrm{kg} / \mathrm{m}^{3}\right]$} \\
& $\varepsilon_{\mathrm{c}}=$ densidade de energia coesiva & {$\left[\mathrm{J} / \mathrm{m}^{3}\right]$} \\
& $\mathrm{MM}=$ massa molecular & {$[\mathrm{g} / \mathrm{mol}]$} \\
\hline
\end{tabular}

Além da escolha dos parâmetros dos sistemas tribológicos, é necessário compreender qual a sua função nos grupos adimensionais e como este parâmetro responde aos dados experimentais. Quanto à escolha dos parâmetros apresentados na, pode-se dizer:

1) Variáveis do sistema tribológico:

- a altura de desgaste (h) e a distância de deslizamento (d) fazem parte do grupo adimensional representativo da taxa de desgaste, apresentado como a redução da altura do pino em micrometros de desgaste por metro deslizado $[\mu \mathrm{m} / \mathrm{m}]$

- a carga aplicada (N), a velocidade de deslizamento (V) e o acabamento superficial (lnRZ/InSm) são as variáveis dos tribossistemas (variáveis independentes);

- a área aparente de contato (A) representa uma característica geométrica do contato e é diretamente responsável, juntamente com a carga $(\mathbf{N})$, pela intensidade dos esforços de compressão; 
- o parâmetro $\ln \mathbf{R z} / \mathbf{l n S m}$, refere-se à condição de acabamento da superfície. Este parâmetro foi proposto por GUIMARÃES ${ }^{93}$ e expressa de uma forma combinada, os efeitos de amplitude da rugosidade (parâmetros escalares de altura) com efeitos de comprimento (parâmetros de separação). Além de representar a severidade da condição da superfície muito bem, este parâmetro apresentou uma boa correlação com a dimensão fractal da superfície. Mostrando que no futuro, será possível utilizar a dimensão fractal como um parâmetro representativo das condições da superfície, para fins de comportamento tribológico.

\section{2) Propriedades Mecânicas}

- O produto da tensão de ruptura pelo alongamento $\left(\tau_{\mathbf{r}} \cdot \phi\right)$, em um ensaio de tração, o qual representa a energia aplicada ao material e responsável pela seu rompimento em um ensaio de tração, tem sido correlacionado, com êxito, com a resistência à abrasão dos polímeros por diversos pesquisadores ${ }^{68}$. Pode-se dizer que este parâmetro está relacionado com a tenacidade do material, que traduz a capacidade de absorver energia na região das deformações plásticas provocadas pela tensão de contato (P/A). Sendo a micro-abrasão um dos principais mecanismos de desgaste presentes nos ensaios, optou-se por utilizar estas propriedades mecânicas no modelo de desgaste;

- Apesar da presença constante de material na interface dos dois corpos, acredita-se que os fenômenos abrasivos responsáveis pela remoção de material da superfície do pino ocorrem devido à ação (de corte e/ou deformação) das asperezas do contra-corpo (abrasão a dois corpos) do que pela presença de um terceiro corpo entre os materiais;

- As propriedades comumente relacionadas com a resistência à fadiga são a tensão de escoamento e o módulo de elasticidade $\left(\tau_{\mathrm{e}} / \mathbf{E}\right)$. Apesar da importância do módulo de elasticidade (E) no comportamento mecânico dos polímeros, principalmente nos fenômenos adesivos, a literatura tem relacionado a resistência à fadiga com o comportamento frágil do material, utilizando a resistência ao impacto e dureza como propriedades relacionadas 
com a resistência à fadiga. Sendo assim, optou-se por selecionar como parâmetro do modelo a dureza $(\mathbf{H})$ do polímero.

- A utilização de propriedades dinâmico-mecânicas (E', E” e tan $\delta$ ) como parâmetro nos modelos matemáticos de desgaste de polímeros ainda não conseguiu ser implementada. O fato é que ainda não se conseguiu compreender exatamente o papel de cada propriedade na resistência ao desgaste dos polímeros. Apesar do crescimento do número de trabalhos científicos, principalmente sobre polímeros amorfos e elastômeros submetidos a processos de erosão, pouco se tem feito no sentido de compreender o comportamento de polímeros semicristalinos em contato deslizante. Por esta razão, optou-se por não utilizar as propriedades dinâmico-mecânicas como parâmetros do modelo de taxa de desgaste;

\section{3) Propriedades Térmicas}

- Sendo os polímeros materiais viscoelásticos, com comportamento mecânico e físico-químico, fortemente dependente da temperatura, a utilização das propriedades térmicas destes materiais nos modelos de desgaste tem sido uma constante na literatura ${ }^{131},{ }^{126}$. O modelo de taxa de desgaste proposto a seguir utiliza as tradicionais propriedades de condutividade térmica e calor específico, além da densidade absoluta dos polímeros. O parâmetro $\left[\lambda /\left(\rho . C_{p}\right)\right]$, também chamado de difusividade térmica, representa a capacidade de dissipação de calor de uma certa substancia. Desta forma, quanto maior a difusividade térmica, menor será a temperatura na interface de contato, reduzindo a queda nas propriedades mecânicas e, consequientemente, menores serão as taxas de desgaste.

4) Propriedades físico-químicas

- Sendo a adesão (transferência de filme) um dos mecanismos de desgaste atuantes durante os ensaios realizados, optou-se pela escolha do trabalho de adesão $\left(\mathbf{W}_{\mathbf{a b}}\right)$ como um parâmetro representativo dos fenômenos adesivos. Apesar da importância deste parâmetro ter sido ressaltada por RABINOWICZ deste a década de 60 do século XX, até o momento, os 
modelos de desgaste, e mesmo os de coeficiente de atrito, utilizam a energia de superfície $(\boldsymbol{\gamma})$ como parâmetro representativo dos mecanismos de adesão, desprezando assim, a interação energética que há quando do contato entre duas superfície $\left(\mathbf{W}_{\mathbf{a b}}=\boldsymbol{\gamma}_{\mathrm{a}}+\boldsymbol{\gamma}_{\mathrm{b}}-\boldsymbol{\gamma}_{\mathrm{ab}}\right)$;

- Sendo a estrutura molecular um fator determinante nas características e magnitudes das forças intermoleculares dos materiais poliméricos ${ }^{70}$, é coerente utilizar propriedades físico-químicas para explicar a resistência ao desgaste destes materiais. Tanto a densidade de energia coesiva $\left(\boldsymbol{\varepsilon}_{\mathbf{c}}\right)$ quanto a massa molecular (MM) são propriedades físico-químicas dos polímeros que interferem no seu comportamento tribológico e que, infelizmente, ainda não se conhece exatamente qual o seu papel. A densidade de energia coesiva tem se mostrado mais importante quando somente fenômenos adesivos ocorrem. Sabe-se que o aumento da massa molecular para um dado material conduz a um aumento de sua resistência ao desgaste ${ }^{14}$, no entanto ainda não se encontrou um patamar, ou um limite de valores de MM, onde a partir do qual o aumento da massa molecular deixa de ser representativa no seu comportamento ao desgaste. E neste caso, justamente o UHMWPE tem sido exemplo de aumento da massa molecular e nenhuma mudança na resistência ao desgaste. Sendo assim, optou-se por não incluir a massa molecular e a densidade de energia coesiva como parâmetros do modelo.

Como durante a etapa de análise dos resultados de desgaste, verificou-se que a taxa de desgaste possuía uma melhor correlação com a energia adicionada ao sistema, representada pela condição PV, do que com a carga aplicada e a velocidade de deslizamento, analisadas separadamente, optou-se por utilizar a condição PV como uma segunda variável representativa dos sistemas tribológicos estudados.

Após a seleção dos parâmetros mais representativos para a elaboração do modelo matemático é necessário obter os grupos adimensionais que representem os fenômenos envolvidos no processo de desgaste. Assim, aplicando o Teorema $\Pi$ nos parâmetros escolhidos, foram obtidos dois grupos adimensionais. Um constituído pelo acabamento superficial como variável do sistema e um segundo grande grupo que utiliza a condição PV como variável independente. 


$$
\left(\frac{\mathrm{d}}{\mathrm{h}} \cdot \frac{\ln \mathrm{Rz}}{\ln \mathrm{Sm}} \cdot \frac{\mathrm{H}}{\tau_{\mathrm{e}}}\right)\left(\frac{\rho \cdot \mathrm{C}_{\mathrm{p}} \cdot \mathrm{W}_{\mathrm{ab}}}{\tau_{\mathrm{r}} \cdot \phi \cdot \mathrm{E} \cdot \lambda} \cdot \frac{\mathrm{Nv}}{\mathrm{A}}\right)
$$

O grande grupo adimensional que segue o comportamento da condição PV pode ser dividido em três sub-grupos, da seguinte forma:

$$
\left[\left(\frac{\mathrm{N}}{\mathrm{A} \cdot \tau_{\mathrm{r}} \cdot \phi}\right) \cdot\left(\frac{\mathrm{v}^{1 / 2} \cdot \rho \cdot \mathrm{C}_{\mathrm{p}}}{\lambda}\right) \cdot\left(\frac{\mathrm{v}^{1 / 2} \cdot \mathrm{W}_{\mathrm{ab}}}{\mathrm{E}}\right)\right]
$$

Admitindo o valor da taxa de desgaste $(\mathbf{Q})$ como sendo a altura de desgaste pela distância percorrida durante os ensaios, temos que:

$$
\mathrm{Q}=\left(\frac{\mathrm{h}}{\mathrm{d}}\right)
$$

Desta forma, pode-se dizer que a taxa de desgaste é uma função de diversos parâmetros do sistema tribológico estudado, das propriedades mecânicas e térmicas mais relevantes, além de algumas propriedades físico-químicas.

$$
\mathrm{Q}=\mathrm{f}\left(\left(\frac{\ln \mathrm{Rz}}{\ln \mathrm{Sm}} \cdot \frac{\mathrm{H}}{\tau_{\mathrm{e}}}\right),\left(\frac{\mathrm{N}}{\mathrm{A} \cdot \tau_{\mathrm{r}} \cdot \phi}\right),\left(\frac{\mathrm{v}^{1 / 2} \cdot \rho \cdot \mathrm{C}_{\mathrm{p}}}{\lambda}\right),\left(\frac{\mathrm{v}^{1 / 2} \cdot \mathrm{W}_{\mathrm{ab}}}{\mathrm{E}}\right)\right)
$$

Re-arranjando os grupos adimensionais de uma maneira didática e acrescentando os coeficientes $\mathbf{x}$ e $\mathbf{y}$, referentes à influência do acabamento superficial e da condição $\mathrm{PV}$, respectivamente, o modelo matemático da taxa de desgaste dos sistemas tribológicos estudados, será dado por:

$$
\mathrm{Q}=\operatorname{Dd} \cdot\left(\frac{\ln \mathrm{Rz}}{\ln \mathrm{Sm}} \cdot \frac{\mathrm{H}}{\tau_{\mathrm{e}}}\right)^{\mathrm{x}} \cdot\left(\frac{\mathrm{N}}{\mathrm{A} \cdot \tau_{\mathrm{r}} \cdot \phi}\right)^{\mathrm{y}} \cdot\left(\frac{\mathrm{v}^{1 / 2} \cdot \rho \cdot \mathrm{C}_{\mathrm{p}}}{\lambda}\right)^{\mathrm{y}} \cdot\left(\frac{\mathrm{v}^{1 / 2} \cdot \mathrm{W}_{\mathrm{ab}}}{\mathrm{E}}\right)^{\mathrm{y}}
$$

onde Dd é chamado de constante de desgaste.

No modelo de taxa de desgaste da equação acima, é possível identificar o que cada grupo adimensional representa quanto aos fenômenos que provocam dano à 
superfície do polímero. Os grupos adimensionais representativos dos fenômenos de fadiga, abrasão, adesão e dissipação térmica estão apresentados abaixo.

$$
\begin{aligned}
& \left(\frac{\ln \mathrm{Rz}}{\ln \mathrm{Sm}} \cdot \frac{\mathrm{H}}{\tau_{\mathrm{e}}}\right) \quad\left(\frac{\mathrm{N}}{\mathrm{A} \cdot \tau_{\mathrm{r}} \cdot \phi}\right) \quad\left(\frac{\mathrm{v}^{1 / 2} \cdot \rho \cdot \mathrm{C}_{\mathrm{p}}}{\lambda}\right) \quad\left(\frac{\mathrm{v}^{1 / 2} \cdot \mathrm{W}_{\mathrm{ab}}}{\mathrm{E}}\right) \\
& \Downarrow \quad \Downarrow \quad \Downarrow \quad \Downarrow \\
& \text { fadiga abrasão térmico adesão }
\end{aligned}
$$

\section{C.2.2.2 - Determinação das constantes dos modelos}

Para a determinação dos índices $\mathbf{x}$ e $\mathbf{y}$ do modelo matemático, é necessário recorrer aos índices das funções de ajuste de pontos dos resultados de taxa de desgaste em função do acabamento superficial e das condições PV. A inclinação média das curvas obtidas representa os expoentes correspondentes aos grupos a que a rugosidade e a condição PV pertencem. Assim como nos modelos de desgaste para polímeros propostos por VISWANATH e BELOW ${ }^{126}$, para a determinação dos expoentes dos grupos adimensionais, optou-se por utilizar um ajuste exponencial em gráficos di-log, onde a inclinação da curva é representada pelo expoente da variável independente.

A Figura C.1, mostra um exemplo de uma equação de ajuste exponencial dos dados de POM x Alumina R4. Nesta equação de ajuste, a inclinação da reta é representada pelo expoente de PV $(\mathrm{y}=1,1556)$.

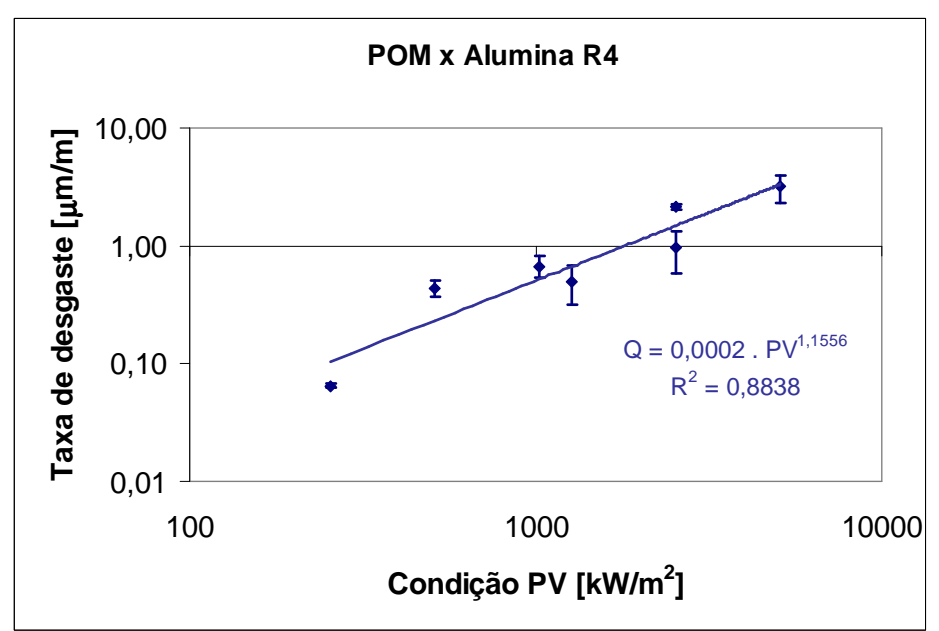

Figura C.1 - Taxa de desgaste em função da condição PV, para os ensaios de POM $x$ Alumina R4, mostrando a curva de juste exponencial. 
As Tabelas C.4 e C.5 apresentam os valores médios dos expoentes dos grupos adimensionais referentes ao acabamento superficial $(\mathbf{x})$ e à condição PV (y).

Tabela C.4 - Índices médios " $x$ " das curvas exponenciais de ajuste para os ensaios de desgaste variando o acabamento superficial e o coeficiente de variação (CV).

\begin{tabular}{cccc}
\hline Corpo & contra-corpo & $\mathbf{x}$ & $\mathbf{C V}[\%]$ \\
\hline POM & Alumina & $1,20 \pm 0,70$ & 59 \\
& Aço Inoxidável & $0,48 \pm 0.21$ & 43 \\
\hline UHMWPE & Alumina & $3,08 \pm 1.71$ & 56 \\
& Aço Inoxidável & $0,33 \pm 0.27$ & 81 \\
\hline
\end{tabular}

Tabela C.5 - Índices médios "y" das curvas exponenciais de ajuste para os ensaios de desgaste variando a condição $P V$ e o coeficiente de variação $(C V)$.

\begin{tabular}{cccc}
\hline Corpo & contra-corpo & $\mathbf{y}$ & CV [\%] \\
\hline POM & Alumina & $1,23 \pm 0,29$ & 24 \\
& Aço Inoxidável & $0,33 \pm 0,30$ & 91 \\
\hline UHMWPE & Alumina & $0,60 \pm 0,21$ & 35 \\
& Aço Inoxidável & $3,28 \pm 1,22$ & 37 \\
\hline
\end{tabular}

Substituindo os índices médios $\mathbf{x}$ e $\mathbf{y}$, no modelo matemático e utilizando os resultados de taxa de desgaste obtidos dos ensaios tribológicos, calcula-se a constante de desgaste média (Dd) para cada um dos 4 tribossistemas. A Tabela C.6 apresenta os valores das constantes de desgaste média obtidas dos modelos matemáticos.

Tabela C.6 - Constante de desgaste média (D) dos modelos matemáticos de taxa de desgaste e o coeficiente de variação $(\mathrm{CV})$.

\begin{tabular}{cccc}
\hline corpo & contra-corpo & D & CV [\%] \\
\hline POM & Alumina & $(2,28 \pm 2,90) \times 10^{4}$ & 127 \\
& Aço Inoxidável & $(4,80 \pm 3,20) \times 10^{-5}$ & 67 \\
\hline UHMWPE & Alumina & $(1,83 \pm 1,65) \times 10^{-2}$ & 90 \\
& Aço Inoxidável & $(4,77 \pm 5,24) \times 10^{4}$ & 110 \\
\hline
\end{tabular}

Observação: Com o objetivo de ressaltar a dispersão dos resultados obtidos no cálculo dos índices x e y e da constante de desgaste (Dd), optou-se por apresentar os valores médios calculados juntamente com os seus respectivos desvios-padrão, sem considerar as regras de apresentação de algarismos significativos. 


\section{C.2.2.3 Apresentação e discussão dos resultados do modelo}

A Figura C.3 apresenta uma comparação dos resultados de taxa de desgaste obtidos durante os ensaios e as taxas de desgaste calculadas pelos modelos matemáticos apresentados acima. Nestes gráficos a taxa de desgaste está apresentada em metros desgastados por metro deslizados $[\mathrm{m} / \mathrm{m}]$ e a severidade das condições de ensaio está representada pelo parâmetro PVR (Pressão x Velocidade $\mathrm{x}$ Rugosidade), onde $\mathrm{R}=$ $\operatorname{lnRz} / \operatorname{lnSM}$.

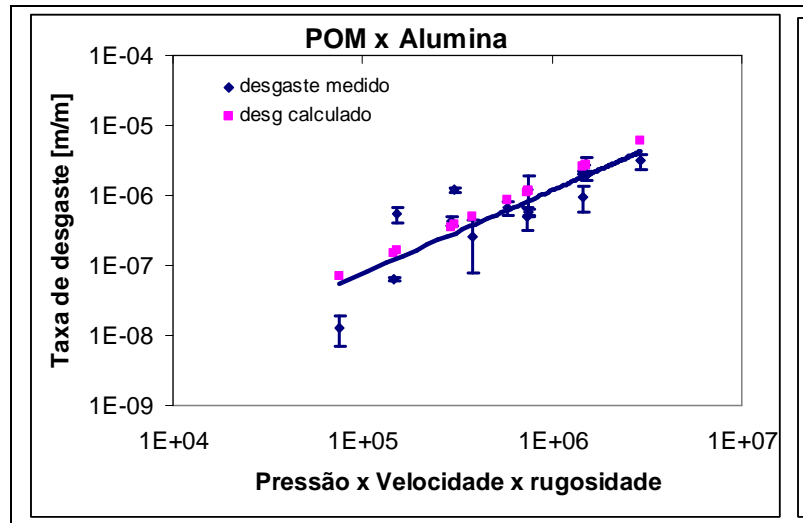

(a)

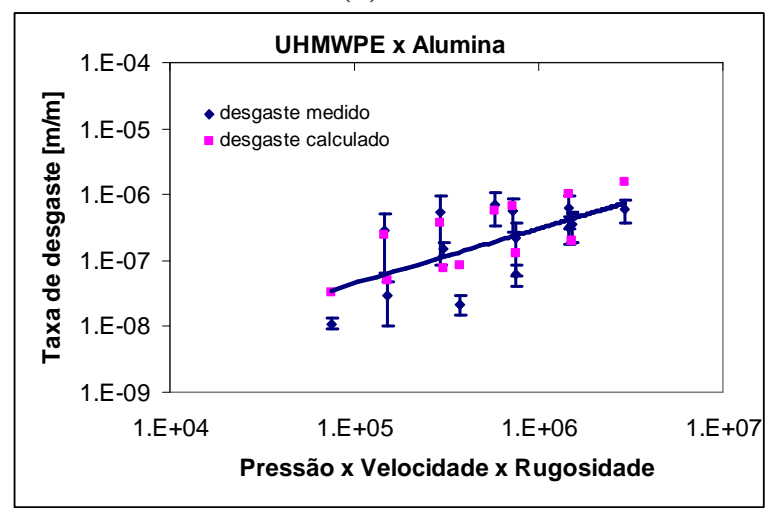

(c)

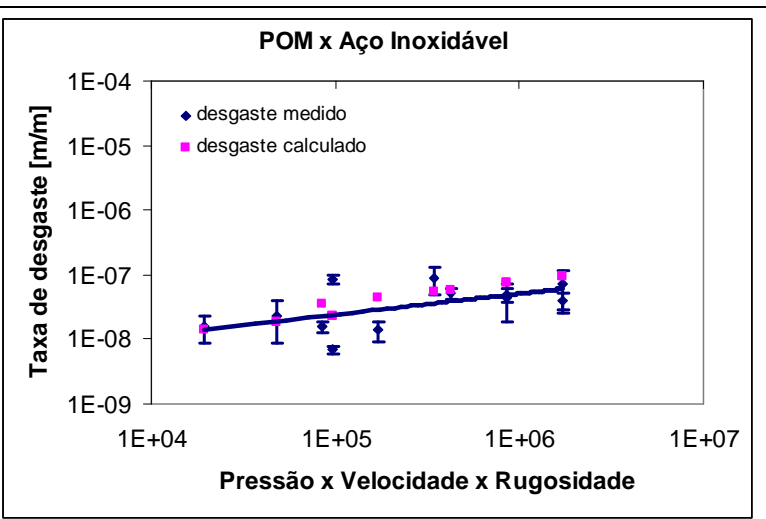

(b)

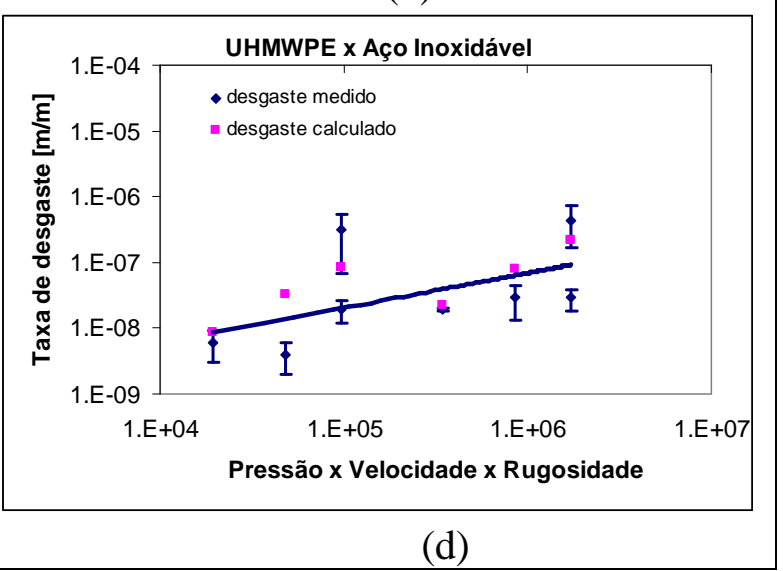

(d)

Figura C.3 - Comparação entre as taxas de desgaste medidas e as calculadas pelo modelo matemático. A reta em azul é a curva de ajuste exponencial dos resultados medidos durante os ensaios de desgaste. (a) POM x Alumina, (b) POM x Aço Inoxidável, (c) UHMWPE x Alumina e (d) UHMWPE x Aço inoxidável.

Analisando os valores dos índices $\mathbf{x}$ e $\mathbf{y}$ (Tabelas C.4 e C.5) e da constante de desgaste Dd (Tabela C.6) observamos que a dispersão dos resultados é excessivamente alta, chegando ao limite do coeficiente de variação $(\mathbf{C V})$ da constante de desgaste dos ensaios de UHMWPE x Aço Inoxidável atingir $122 \%$. No entanto, substituindo os valores médios de $\mathbf{x}, \mathbf{y}$ e $\mathbf{D}$ nos modelos matemáticos propostos e comparando os 
resultados de taxa de desgaste medida com a taxa calculada em função da severidade dos ensaios tribológicos (Pressão x Velocidade x Rugosidade), observa-se que os valores calculados apresentam uma tendência de comportamento muito próxima à dos dados medidos, principalmente nos ensaios com POM.

Desta forma, pode-se dizer que os modelos de taxa de desgaste desenvolvidos podem ser considerados quantitativamente poucos 'seguros', no entanto, ao observar a Figura C.3, verifica-se que a proposição de parâmetros representativos dos sistemas (materiais) estudados e a aplicação correta de uma técnica de modelamento tradicional, conduz, qualitativamente, a bons resultados. 


\section{ANEXO D \\ COMPORTAMENTO DO COEFICIENTE DE ATRITO}

No transcorrer dos ensaios de desgaste, foi possível determinar os valores de coeficiente de atrito pela medição da força de atrito e da carga normal aplicada, com aquisição destes valores a cada 1 segundo. Sendo assim, obtem-se o comportamento do coeficiente de atrito durante todo o percurso de 3500 metros.

Analisando os resultados de todos os ensaios realizados nesta pesquisa, verificou-se que o coeficiente de atrito em função do tempo de ensaio e/ou da distância percorrida apresentou três tendências (tipos) de comportamento, conforme mostrado a Figura D.1.

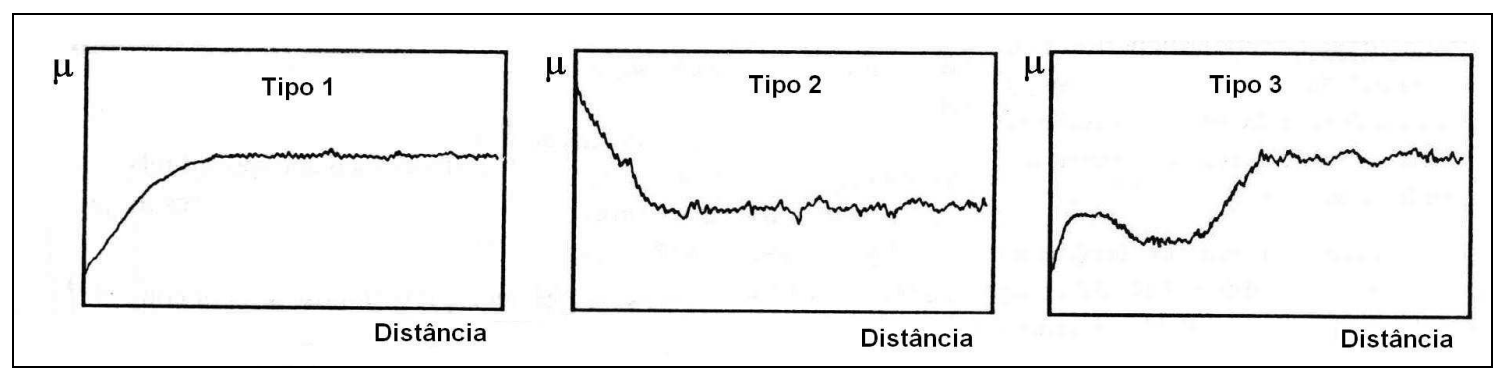

Figura D.1 - Tendências de comportamento apresentadas pelo coeficiente de atrito em função do tempo de ensaio, para os dois polímeros estudados.

No comportamento Tipo 1, o coeficiente de atrito se eleva durante o período de running-in (amaciamento) e atinge a região de estado estacionário após um dado período de tempo. Verificou-se que nos ensaios com comportamento Tipo 1, este período de running-in pode variar desde 100 até 2500 metros, ou seja, a taxa de elevação do coeficiente de atrito nem sempre se comporta da mesma maneira. A Figura D.2, apresenta um exemplo de comportamento Tipo 1, para o UHMWPE deslizando sobre aço inoxidável com acabamento superficial tipo R2. 


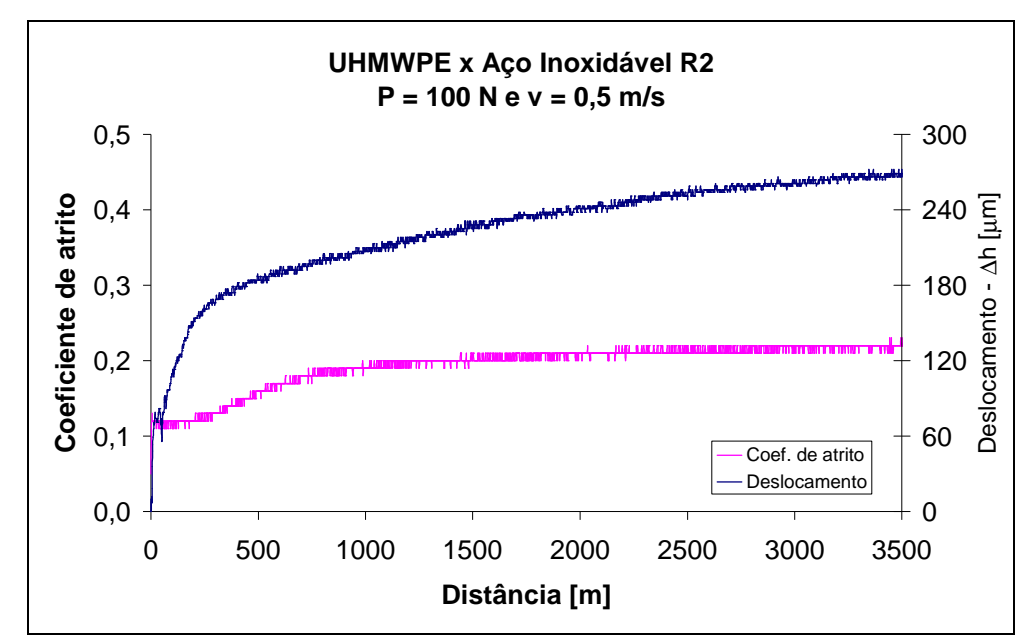

Figura D.2 - Coeficiente de atrito e deslocamento do pino em função da distância de deslizamento (UHMWPE x Aço inoxidável R2 - F = $100 \mathrm{~N} \mathrm{e} \mathrm{v} \mathrm{=} \mathrm{0,5} \mathrm{m/s).}$

Inversamente ao que ocorre no comportamento Tipo 1, no Tipo 2, o coeficiente de atrito reduz com o decorrer do ensaio, até atingir o patamar de estado estacionário. A literatura $^{60,62}$ sugere que este tipo de comportamento ocorre quando da formação de um filme de transferência na superfície do contra-corpo. A presença deste filme com cadeias orientadas na direção do deslizamento, reduz o atrito entre os corpos, além disto, para polímeros de cadeia molecular linear e apolar (UHMWPE, HDPE e PTFE), o contato polímero-polímero reduz a componente de adesão do atrito, pois estes materiais (que já tem baixa energia de superfície) em contato com si próprio apresentam valores de trabalho de adesão ainda menores. Novamente aqui, verifica-se que o período de running-in pode terminar nos primeiros metros de deslizamento, ou se estender até 2500 metros. A Figura D.3, apresenta um exemplo de comportamento Tipo 2, para o POM deslizando sobre aço inoxidável com acabamento superficial tipo R3. 


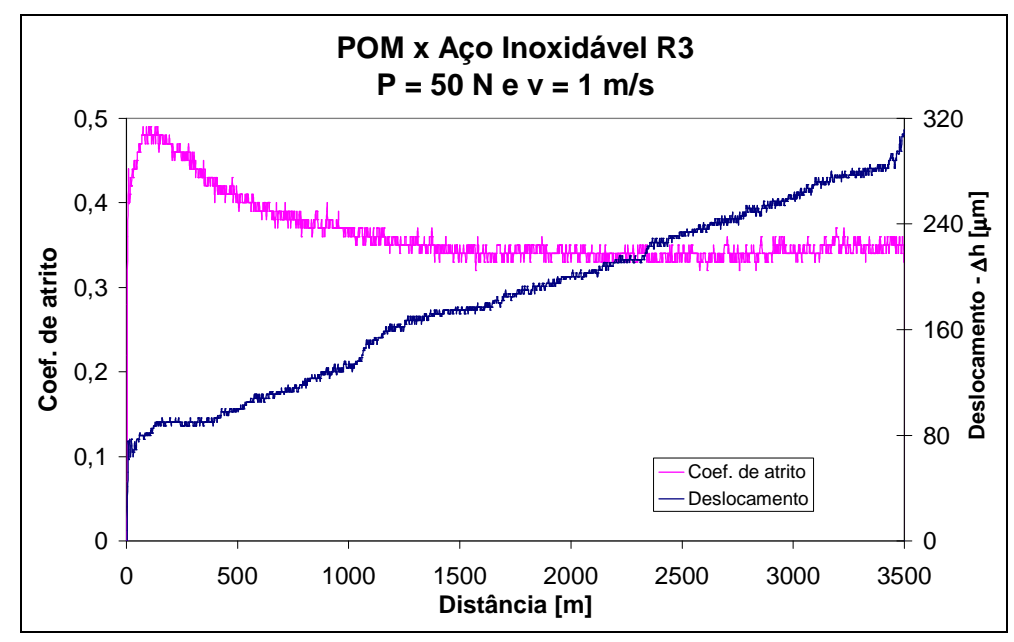

Figura D.3 - Coeficiente de atrito e deslocamento do pino em função da distância de deslizamento. (POM x Aço Inoxidável R3 - F = 50 N e v = 1,0 m/s).

O comportamento do coeficiente de atrito em função da distância de deslizamento do Tipo 3, foi aquele que menos ocorreu durante a realização desta pesquisa. A literatura ${ }^{132}$ explica este tipo de comportamento da seguinte maneira:

- um período de running-in curto até alcançar um primeiro patamar de estado estacionário;

- predominância inicial de um mecanismo de atrito (e/ou desgaste);

- após um período de tempo, mudanças nas condições de contato, ou até mesmo de características (propriedades) dos materiais, provocam uma transição de mecanismo;

- coeficiente de atrito mantém-se estável em um segundo patamar de estado estacionário.

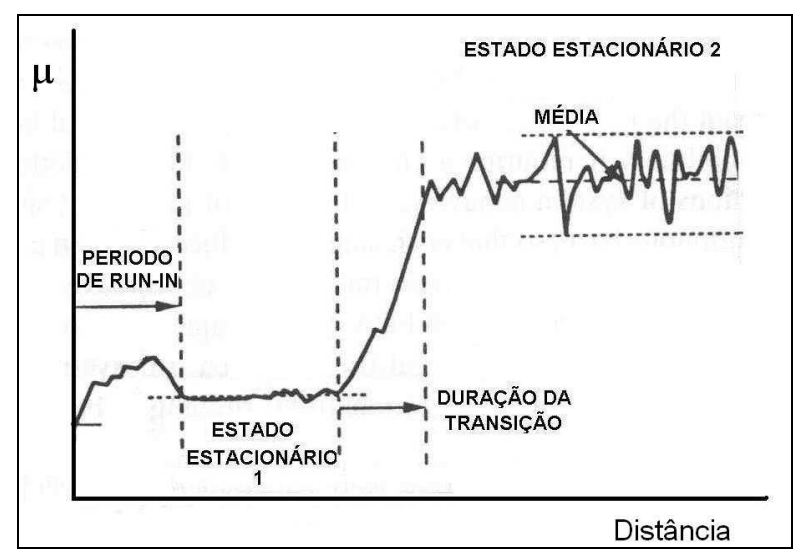

Figura D.4 - Comportamento do atrito em função da distância (ou tempo) ${ }^{132}$. 
Na Figura D.4, a região de baixo coeficiente de atrito (estado estacionário 1) pode estar relacionada com a formação de um filme de transferência na superfície do disco. Sucessivas passagens do pino pela superfície do disco, provocam a formação e a remoção continua deste filme polimérico, até um momento em que não ocorre uma transferência de material para a superfície do disco em quantidade suficiente para manter o coeficiente de atrito em valores baixos, ocorrendo a partir deste momento, uma transição de comportamento do coeficiente de atrito, para uma estabilização de seus valores em um patamar mais elevado (estado estacionário 2). A Figura D.5, apresenta um exemplo de comportamento Tipo 3, para o POM deslizando sobre alumina com acabamento superficial tipo R4.

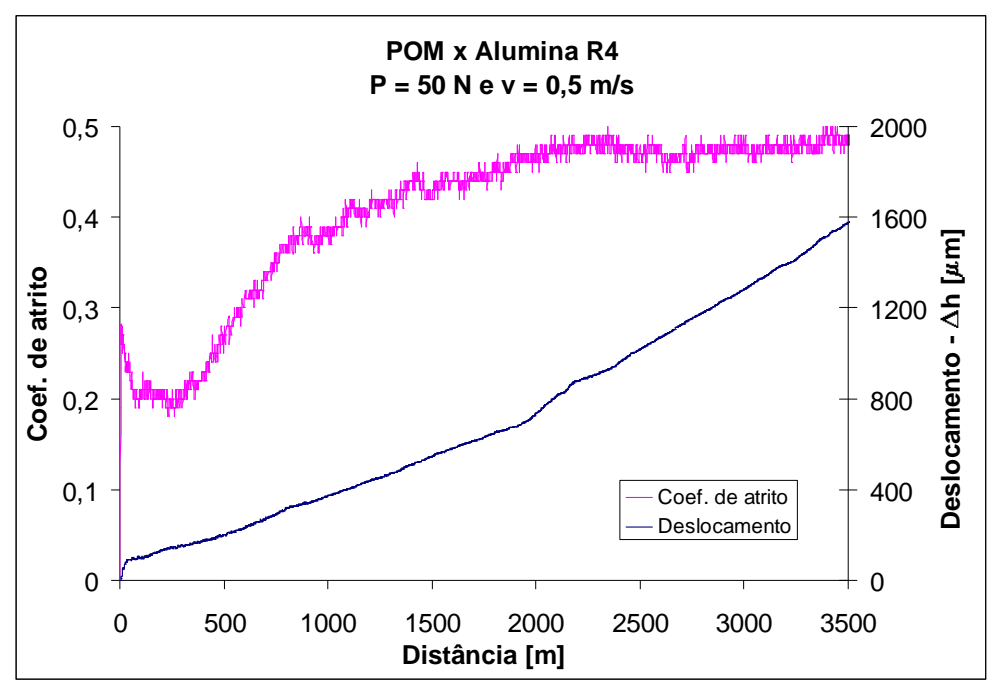

Figura D.5 - Coeficiente de atrito e deslocamento do pino em função da distância de deslizamento. (POM x Alumina R3 - F = 50 N e v = 0,5 m/s).

Não por acaso, as Figuras D.2. D3 e D.5, mostram os comportamentos do coeficiente de atrito, para quaisquer tipos de pares em contato e nas mais diversas condições de carga e velocidade. Na realidade, não foi possível identificar uma relação clara de como os tipos de comportamento do coeficiente de atrito se relacionam com as demais variáveis dos ensaios. A Tabela D.1, mostra uma consolidação da ocorrência de cada tipo de comportamento do atrito para as condições de ensaio estudadas. 
Tabela D.1 - Tipos de comportamento do coeficiente de atrito em função dos pares em contato e das condições de ensaio.

\begin{tabular}{|c|c|c|c|c|c|}
\hline Pino & Disco & Acabamento & Tipo & Quantidade & Comentários \\
\hline & & $\mathrm{R} 2$ & 1 & $88 \%$ & Para todas as condições de ensaio \\
\hline \multirow{7}{*}{ UHMW } & Aço Inox & & 3 & $12 \%$ & Para todas as condições de ensaio \\
\hline & & R3 & 1 & $92 \%$ & Para todas as condições de ensaio \\
\hline & & & 3 & $8 \%$ & $200 \mathrm{~N}$ e $0,5 \mathrm{~m} / \mathrm{s}-50 \mathrm{Ne} 1,0 \mathrm{~m} / \mathrm{s}$ \\
\hline & & R3 & 1 & $42 \%$ & Para todas as condições de ensaio \\
\hline & Alumina & & 2 & $58 \%$ & Para todas as condições de ensaio \\
\hline & & $\mathrm{R} 4$ & 1 & $58 \%$ & Para todas as condições de ensaio \\
\hline & & & 2 & $42 \%$ & Para todas as condições de ensaio \\
\hline \multirow{10}{*}{ POM } & & $\mathrm{R} 2$ & 1 & $88 \%$ & Para todas as condições de ensaio \\
\hline & & & 3 & $12 \%$ & Somente com $\mathrm{v}=0,1 \mathrm{~m} / \mathrm{s}$ \\
\hline & Aço Inox & & 1 & $33 \%$ & Somente com $\mathrm{v}=0,1 \mathrm{~m} / \mathrm{s}$ \\
\hline & & R3 & 2 & $63 \%$ & Todos com $\mathrm{v}=0,5$ e $1,0 \mathrm{~m} / \mathrm{s}$ \\
\hline & & & 3 & $4 \%$ & $P=200 \mathrm{Ne} \mathrm{v}=0,1 \mathrm{~m} / \mathrm{s}$ \\
\hline & & R3 & 1 & $92 \%$ & Para todas as condições de ensaio \\
\hline & & & 2 & $8 \%$ & $50 \mathrm{~N}$ e $0,1 \mathrm{~m} / \mathrm{s}-100 \mathrm{~N}$ e $0,5 \mathrm{~m} / \mathrm{s}$ \\
\hline & Alumina & & 1 & $75 \%$ & Para todas as condições de ensaio \\
\hline & & $\mathrm{R} 4$ & 2 & $20 \%$ & Para todas as condições de ensaio \\
\hline & & & 3 & $5 \%$ & $\mathrm{P}=50 \mathrm{Ne} \mathrm{v}=0,5 \mathrm{~m} / \mathrm{s}$ \\
\hline
\end{tabular}

Analisando os dados da Tabela D.1, pode-se dizer que:

- a ocorrência dos comportamentos Tipos 1, 2 e 3, se deu em maior quantidade para o Tipo 1, seguidos do Tipo 2 e Tipo 3, respectivamente;

- o comportamento Tipo 1 ocorreu para o todos os pares ensaiados, independentemente das condições de ensaio;

- o comportamento Tipo 2, esteve presente somente nos ensaios com acabamento superficial R3 e R4;

- o comportamento Tipo 3 não apresentou nenhuma relação com os pares ensaiados, tão pouco com as condições de carga, velocidade e acabamento superficial; 
- as informações obtidas sobre o comportamento do coeficiente de atrito em função da distância percorrida não foram capazes de sugerir uma tendência de comportamento, tão pouco mostrar uma maior influência de uma variável específica nesta propriedade tribológica.

Apesar de conhecer, segundo a segundo, o comportamento do coeficiente de atrito no transcorrer de cada ensaio de desgaste, não teria sido este, inicialmente o objetivo desta pesquisa, o de estudar os diversos comportamentos do coeficiente de atrito e compreender suas relações com os pares em contato, com o acabamento superficial e com as condições dinâmicas de ensaio. Sendo assim, não se cogitou fazer ensaios interrompidos, a cada 500 metros de deslizamento, por exemplo, para analisar os aspectos morfológicos das superfícies de desgaste do pino e do disco. Possivelmente, o acompanhamento mais detalhado ao longo dos ensaios poderia explicar como de dá a evolução dos valores de coeficiente de atrito.

Das análises das superfícies de desgaste dos pinos e dos discos, apresentadas anteriormente, sabe-se da ocorrência de transferência de filme polimérico para a trilha de contato no disco, sabe-se que as partículas depositadas durante uma passagem do pino sobre a pista, poderiam se arrancadas nas passagens seguintes, ou até, servirem como 'ilhas' de material aderido, capazes de modificar o comportamento do coeficiente de atrito durante os ensaios. Sabe-se que, principalmente, no caso do UHMWPE, o filme depositado tem suas moléculas orientadas na direção de deslizamento e que este fato conduz a uma redução no coeficiente de atrito. Provavelmente estes fatos tenham ocorrido nos Tipos 2 e 3 de comportamento do coeficiente de atrito. No entanto, isto não quer dizer que não houve transferência de filme quando o Tipo 1 esteve atuando. Somente as informações obtidas das superfícies de desgaste após a realização dos ensaios, não nos permitem atacar em maior profundidade o comportamento do atrito durante os ensaios. 


\section{8 - Referências bibliográficas}

1 CAPUTO, R. \& ABRAMO, L. Perfil da Indústria do plástico no Brasil. ABIPLAST - p.19, 1997

2 FERRAROLLI, F. Plásticos de Engenharia no contexto do mercado de termoplásticos: um desafio para vencer. Polímeros Ciência e Tecnologia, vol. 13, n 1, p. E4 - E8, 2003

3 ESCHBACH, L. Nonresorbable polymers in bone surgery. INJURY. International Journal of the Care Injured, Vol. 31, p. D22 - D27, 2000

4 MANO, E. B. \& MENDES, L. C. Identificação de plásticos, borrachas e fibras. Editora Edgard Blucher LTDA, $1{ }^{\text {a }}$ Edição, p. 1-58, 2000

5 ASHBY, M. \& JONES, D.R.H. Engineering Materials: An Introduction to Microstruture, Processing and Design. Vol. 2, Pergamon Press, p.201-239, 1995

6 HERTZBERG, R. W. Deformation and Fracture Mechanics of Engineering Materials. Third Edition. John Wiley \& Sons, Chap. 6, p. 193-236, 1989

7 Canevarolo, Jr. S. V. Ciência dos Polímeros. Um texto básico para tecnólogos e engenheiros. Artliber Editora, p.33-146, 2002

8 MANO, E. B. Introdução a polímeros. Editora Edgard Blücher Ltda., p. 12-29, 1994

9 NEWEY, C. \& WEAVER, G. Materials principals and practice. Butterworth-Heinemann Ltd, p. 293-340, 1990

10 CALLISTER JR., W. D. Materials science and engineering - An introduction. 3a Edição, John Wiley \& Sons., p. 444-507, 1994

11 DIETER, G. E. Mechanical Metallurgy - SI Metric Edition. Mc Graw-Hill Book Company, Chap. 8, p. $268-289,1988$

12 BAER, E. Advanced polymers. Scientific American, Vol. 255, nº 4, p. 146-155, 1986

13 VAN VLACK, L. H. Princípios de ciência dos materiais. São Paulo, Edgard Blucher, Cap. 7, p.164-198, 1977 
14 ANDERSON J. C.,Tribology International, p. 43-47, 1982

15 VAN KREVElen, D. W. Properties of Polymers. Their correlation with chemical strutucture; their numerical estimation an predition from additive group contribuitions. $3^{\text {a }}$ Ed. Elsevier, p. 189-241, 1990

16 BAHADUR, S. The development of transfer layers and their role im polymer trybology. Wear, Vol. 245, p. 92-99, 2000

17 TICONA - Technical Literatura Library (version 1.0), CD-ROM, 2001

18 SPERLING, L. H. Introduction o Physical Polymer Science. John Wiley \& Sons, p. 97422,1985

19 CALCOTE, L. R. Introduction to Continuum Mechanics. Princetown, D. Van Nostrand Company, Inc., p. 15-211, 1968

20 WETTON, R. E.. Development in Polymer Characterisation Vol. 5. Chap. 5. Editado por Dalkins, J. V, Elsevier Apllied Science Publishers, p. 179-221, 1986

21 CANEVAROLO, Jr. S. V. Análise Dinâmico-Mecânica para Sistemas Poliméricos. Parte 1 O Amortecimento (tan $\delta$ ) Polímero: Ciência e Tecnologia. ABPol, p. 36-40, 1991

22 BARTENEVEV, G. M. \& LAVRENTEV, V. V. Friction and Wear of polymers, Tribology Series, ${ }^{\circ}{ }^{6}$. Elsevier Scientific Publishing Company, p. 10-260, 1981

23 MOORE, D. F. Principles and aplications of tribology. Pergamon Press, $1^{\text {a }}$ Ed., p. 1-86, 1975

24 FARIAS, M. C. M. Desgaste por deslizamento de aços inoxidáveis austeníticos. Dissertação de Mestrado, Escola Politécnica da USP, 128p, 1999

25 YAMAGUSHI, Y. Tribology of plastic materials - Their characteristics and applications to sliding componentes. Tribology series, $n^{\circ} 16$, Elsevier Science Publishers, $p$. 93-143, 1990

26 ZUM-GAHR, K. H. Microstruture and Wear of Materials - Tribology Series, $\mathrm{n}^{\circ} .10$ Elsevier Science Publishers, p. 437-447, 1987 
27 BRISCOE, B,. J. \& TABOR, F. R. S. Friction and wear of polymers. Cap. I, John Wiley \& Son, p.1-46, 1978

28 BRISCOE, B. Wear of polymers: an essay on fundamental aspects. Tribology International, p.231-243, 1981

29 BUDINSKI, K. G. Friction in machine design. Tribological Modeling for Mechanical Designers ASTM, STP 1105, p. 89-125, 1991

30 STEIJN, R. P.Friction and wear of plastics. Metals Engeneering Quartely. ASM, p.9-21, 1967

31 SANTNER, E. \& CZICHOS, H. Tribology of polymers. Tribology International, vol 22, $\mathrm{n}^{\mathrm{o}}$ 2, p 103-109, 1989

32 ZHANG, S. W. State-of-the-art of polymer tribology. Tribology International, vol 31, $\mathrm{n}^{\text {os }}$ 1-3, p.49-60, 1998

33 TEWARI, U. S., SHARMA, S. K. \& VASUdEVAN P. Polymer Tribology. Rev. Macromolecules Chem. Phys, C29(1), p.1-38, 1989

34 LUDEMA, K. C. \&TABOR, D. The friction and the visco-elastic properties of polymeric solids. Wear, Vol. 9, p. 329-348,1966

35 LANCASTER, J. K. Material specific wear mechanisms: relevance to wear modelling. Wear, Vol. 141, p. 159-183, 1990

36 BRISCOE, B.J. Material aspects of polymer wear. Scripta Mettalurgica et Materialia. Vol. 24, p. 839-844, 1990

37 RABINOWICZ, E. Influence of surface energy os friction and wear phenomena. Journal of Applied Physics, Vol. 32, nº, p. 14401445, 1961

38 RABINOWICZ, E. Pratical uses of the surface energy criterion. Wear, Vol. 7, p. 9-22, 1964

39 RABINOWICZ, E. Friction and wear of metals. Metals Engineering Quartely. ASM, p. 48,1967 
40 LEE, L-H. Effect of surface energetics on polymer friction and wear. ASTM-STP. p. 3168,1974

41 Ma, K-X., HO, C-H., ZHU, F. \& CHUNG, T-S. Investigation of surface energy for organic light emiting polymers and indium tin oxide. Thin Solid Films, Vol. 371, p. 140-147, 2000

42 CZICHOS, H. Influence of adhesive and abrasive mechanisms on the tribological behaviour of thermoplastics polymers. Wear, Vol. 88, p. 27-43, 1983

43 ERHARD, G. Sliding friction behavior of polymer-polymer material combinations. Wear, Vol. 84, p. 167-181, 1983

44 ADAMSON, A. W. Physical Chemistry of Surfaces, p.179-308, 1996

45 BELY, V. A., SAVKIN, V. G. \& SVIRIDYONOK, A. I. Effect of struture on polymer friction. Wear, Vol. 18, p. 11-18, 1971

46 GREENWOOD, J.A. \& WILIAMSOM, J. B. P. Contact of nominally flat rough surface. Proceedings Royal Society London, A295, p. 300-319, 1966

47 TANAKA, K.\& YAMADA, Y.Effect of sliding speed on transfer and wear of semicrystalline polymers sliding against smooth steel surface. Wear of Materials, p. 617-624

48 MCLAREN, K. G. \& TABOR, D. Friction of polymers at engineering speeds: influence of speed, temperature and lubricants. Wear, Vol. 8, p. 79-83, 1965

49 BELLOW, D. G. \& VISWANATH, N. S. An analysis of the wear of polymers. Wear, Volumes162-164, p. 1048-1053, 1993

50 RHEE, S. H. \& LUDEMA, K. C. Mechanism of formation of polymeric transfer films. Wear, Vol. 46, p. 231-240, 1978

51 BRENTNALL, A. B. \& LANCASTER, J. K. The friction and wear behaviour of a composite, dry-bearing linear sliding against itself. Wear of Materials, Vol. 2, p. 596-603, 1989

52 CLERICO, M. A study of the friction and wear of poliamida against metal. Wear, Vol.13, p. 183-197, 1969 
53 VINOGRADOV, G. V., MUSTAFAEV, V. A. \& PODOLSKY, Y. Y. A study of heavy metal-to-plastic friction duties and of the wear of hardened steel in the presence of polymers, Wear, Vol. 8, p. 358-373, 1965

54 MALAY, K. K. \& BAHADUR, S. An investigation of the temperature rise in polymer-metal sliding. Wear, Vol. 82, p. 81-92, 1982

55 WANG, Q., KONG, X. ZHU, L. \& FAN, Y. A study on the tribological behavior os polyethylene. II. Effects of operating conditios on the friction behavior of polyethylene. Journal Applied Polymer Science, Vol. 58, p. 903-910, 1995

56 LANCASTER, K. K. A Review of the influence of enviroment humidity and water on friction, lubrication and wear Tribology International, Vol. 23, nº 6 , p. 371389, 1990

57 MCNICOL, A., DOWSON, D. \& DAVIES, M. The effect of humidity and eletrical fields upon the wear of high density polyethylene and polytetrafluoroethylene. Wear, Vol. 181-183, p.603-612, 1995

58 FERREIRA, V. Processamento, caracterização mecânica e tribológica do compósito $\mathbf{A l}_{2} \mathbf{O}_{3}$-NbC. Dissertação de mestrado. IPEN/SP, 2001

59 SILVA. C. H., TANAKA, D. K. \& SINATORA, A. Friction coefficient between high density polyethylene on galvanized steel - preliminary results” Wear, Vol. 225-229, parte I, p. $339-342,1999$

60 HUTCHINGS, I. M. Tribology: Friction and Wear of Engineering Materials. Edward Arnold / London, p.51-57, 1992

61 TANAKA, K. Transfer of semycristalline polymers sliding against a smooth steel surface. Wear, Vol. 75, p. 183-199, 1982

62 STACHOWIAK, G. W \& BATCHELOR, A. W. Engineering Tribology, $2^{\mathrm{a}}$ Edição, Butterworth-Heinemann, p. 619-668, 2001

63 SPEERSCHNEIDER, C. J. \& LI, C. H. - Some onbservations on structure of PTFE. Journal of Applied Physics, Vol. 33, nº 5, p. 1871-1874, 1962 
64 TANAKA, K., OCHIYAMA, Y. \& TOYOOKA, S. - The mecanism of wear of PTFE. Wear, Vol. 23, p. 153-172, 1973

65 MAKINSOM, K. R. \& TABOR, D. The friction and transfer of PTFE. Proceedings Royal Society London, Ser A, Vol. 281, p. 49-61, 1964

66 KONG, H. \& ASHBY, M.F. Wear mechanism in brittle solids - Acta Mettalurgica et Materialia , Vol. 40, n. 11, p. 2907-2920, 1992

67 SUH, N. P. \& TURNER, A. L. Elements of Mechanical Behavior Solids. Scripta Book Company / Washigton, p 293-361, 1980

68 LANCASTER, J. K. Abrasive wear of polymers. Wear, Vol. 14, p. 223-239, 1969

69 SILVA, C. H. ; TANAKA, D.K. \& SINATORA, A. Mecanismos de desgaste do polietileno de alta densidade. 53 $^{\circ}$ Congresso Anual da ABM, BH/MG, 1998

70 RYMUZA, Z. Predicting wear in miniature steel-polymer journal bearing. Wear, vol 137, p. 211-249, 1990

71 GILTRON, J. P. A relationship between abrasive wear and the cohesive energy of materials. Wear, Vol. 15, p. 71-78, 1970

72 OMAR, M. K., ATKINS, ${ }^{a}$ G. \& LANCASTER, J. K. The role of crack resistance parameters in polymer wear. Journal of Applied Physics, Vol .19, p. 177-195, 1986

73 PLESKACHEVSKY, Y. M. , ZAITSEV, A. L.\& SMIRNOV, V. V. Oxidation and its influence on low pressure polyethylene wear. Wear, Vol. 181-183, p.222-226, 1995

74 BRISCOE B. J., EVANS, P. D., PELILLO, E. \& SINHA, S. K. Scrathing maps for polymers. Wear, Vol. 200, p. 137-147, 1996

75 BARRET, T.S.; STACHOWIAK, G. W \& BATCHELOR, A. W. Effect of roughness and sliding speed on the wear and friction of ultra-high molecular weight polyethylene. Wear, Vol. 153 , p. 331-350, 1992 
76 WANG, A.; ESSNER, A.; POLINENI, V.K.; STARK, C. \& DUMBLETON, J. H. Lubrication and wear of ultra-high molecular weight polyrthylene in total joint replacements Tribology International, Vol. 31, ${ }^{\text {os }} 1-3$, p. 17-33, 1998

77 WILLIAMS, J. A. Engineering Tribology, Oxford Univerty Press, p.132-135, 1991

78 SCHALLAMACH, A. How does rubber slide? Wear, Vol. 17, p. 301-312, 1971

79 RUBEM, G. C., BLANCHET, T. A. \& KENNEDY, F. E., Formation of UHMWPE polymeric transfer on sliding glass counterface: early and steady-state studied by transmission electron microscopy . Journal of Materials Sciense , 28, p. 1045-1058, 1993

80 ARGAWAL, V.R., PILlAI, U.T.S. \& SETHURAMIAH, A. New observation on PTFE wear mechanism. Wear of Materials, p. 501-506, 1989

81 MARCUS, K. , BALL, A \& ALLEN, C. - The effect of the grinding direction on the nature of the transfer film formed during the sliding wear of UHMWPE against stainless steel . Wear, Vol. 151, p. 323-336, 1981

82 BELYI, V. A.; SVIRIDYONOK, A. I.; SMURUGOV, V. A. \& NEVZOROV, V.V. Adhesive wear of polymer friction. Journal of Lubrication Technology, Vol. 109, p. 396400, 1997

83 SOOM, A. \& KIM, C. Interactions between dynamic normal and frictional forces during unlubricated sliding. Transactions of the ASME, Journal of Lubrication Technology, Vol. 105, p.221-9, 1983

84 FARIAS, M.C.M., MARU, M.M., SANTOS, J.F. \& PADOVESE, L. R. Estudo da força de atrito dinâmica em ensaio de desgaste por deslizamento a seco.Congresso Nacional de Engenharia Mecânica - CONEM'2000, Natal / RN, CD-Rom, 2000

85 CAIS, R-. E.;NOZOMI, M.; KAWAI, M. \& MIYAKE, A. Antiplasticization and abrasion resistance of policarbonates in the charges-transport layer of an organic photoconductor. Macromolecules, Vol. 25, p. 4588-4596, 1992

86 WEICK, B. L. \& BRUSHAN, B. The tribological and dynamic behavior of alternative magnetic tape substrates. Wear, Vol. 190, p. 28-43, 1995 
87 WEICK, B. L. \& BRUSHAN, B. The relationship between dynamic mechanical behavior, transverse curvature and wear of magnetic tapes. Wear, Vol. 202 , p. 17-29,1996

88 COOPER, J.R., DOWSON, D. \& FISHER, J Macroscopic and microscopic wear mechanism in UHMWPE. Wear, Vol. 162-164, p. 378-384, 1993

89 SOUNG, J. \& EHRESTEINS, G. W. Effecty of sliding velocity on the wear effect of timetemperature equivalence. Wear, Vol. 162-164, p. 662-668, 1993

90 SILVA, C. H.; GUIMARÃES, M. S.; TANAKA, D. K. \& SINATORA,A. Influência do estado superficial no atrito do polietileno de alta densidade. Congresso Nacional de Engenharia Mecânica - CONEM'2000, Natal/ RN, CD-Rom., 2000

91 RAMACHANDRA, S. AND OVAERT, T. C. "The effect of controlled surface topographical features on the unlubricated transfer and wear of PEEK", Wear, Vol. 206, p.9499, 1997

92 STUPAK, P. R. , KANG, J. H. AND DONOVAN, J. A., "Fractal characteristics of rubber wear surfaces as a function of load and velocity", Wear, Vol. 141, p. 73-84, 1990

93 GUIMARAES, M. S. Geometria fractal aplicada à caracterização de rugosidade de superfícies lixadas ou submetidas a tração e corrosão. Anais do $2^{\circ}$ Workshop "Qualificação de chapas para a indústria automobilística” EPUSP, S.P., p.155-167, 1999

94 EISS, JR. N. S. AND MILLOY, S. C. The effect os asperity curvature on polymer wear.”, Conference of Wear of materials, ASME, New York, p. 650-656, 1985

95 CALliS. P. F. B. Novas versões do poliacetal copolímero. Polímeros Ciência e Tecnologia, Vol. 13, n 1, E8 - E16, 2003

96 ELCHISON, B. Modern Plastic Enciclopedia, p. B1-B4, 2001

97 COUTINHO, F.M.B.; MELlO, I.L.SANTA MARI, L.C. Polietileno, principais tipos, proprieddes e aplicações. Polímeros Ciência e Tecnologia, Vol. 13, n¹, p.1-13, 2003

98 MILLER, R.C. Modern Plastic Enciclopedia, p. 34-35, 2001 
99 SILVA Jr. W. C.- Estudo de um aço inoxidável austenítico de alto teor de nitrogênio para utilização em implantes cirúrgicos. Dissertação de mestrado. PMT-EPUSP, 2000

100 ASTM G 99-90 Standard test method for wear testing with a pin-on-disk apparatus Metals test methods and analytical procedure. Vol. 03.02 - Wear and erosion; metal corrosion. section 3, p. 387-391, 1992

101 RAY, M. S. Engineering Experimentation. Ideas, Techniques and Presentation. McGrsw-Hill Book Company, p. 124-153, 1988

102 ARCHARD, J. F. The temperature of rubbing surfaces. Wear, Vol. 2, p.439-455, 1959

103 www.brasken.com.br - Produtos e Serviços; Polietileno de ultra-alto peso molecular (UHMWPE); UTEC 6540/6541. julho de 2003

104 KESTENBACH, H-J; BOTTA FO, W. J. Microscopia Eletrônica: Transmissão e Varredura, São Paulo, ABM, p. 17 - 101,1994

105 TURI, E. A. Thermal Characterization of Polymeric Materials, p. 235-270, 1981

106 ADAMSON, A. W. Physical Chemistry of Surfaces, p.1-43, 1996

107 DEMARQUETE, N. R. Tensão interfacial entre polímeros. Tese de livre-docência PMTEPUSP, p. 47-59, 1999

108 SHIMIZU, R. N. \& DEMARQUETE, N. R. Evaluation of surface energy of solid polymers using different models. Journal of Applied Polymer Science, Vol.. 76, 1831-1845, 2000

109 PINTAÚDE, G.; SINATORA, A. Avaliação da dureza como critério para determinação do regime de desgaste abrasivo In. $5^{\circ}$ CONGRESSO ANUAL DA ABM, CD-Rom, 2000

110 STILWELL, N.A. \& TABOR, D., Elastic recovery of conical indentations, Procedings of Physical Society of London, Vol. 78, p.169-179, 1961

111 ISO International Standard. Plastics - Determination of Hardness. ISO 2039-1 (E) part 1,. p 1-3, 1997

112 www.brasken.com.br - Produtos e Serviços; Boletins Técnicos - BOLETIM Técnico n ${ }^{\circ}$ 4.03 (Revisão 1 / agosto de 2002) - julho de 2003 
113 BOHM, H. ;BETZ, S \& BALL, A. The wear resistance of polymer. Tribology International, Vol. 23, n ${ }^{\circ}$ 6, p. 399-406, 1990

114 WARREN, R.Ceramic-Matrix Composites, Chapman and Hall, Inc. New York, 1992

115 WU, S. Calculation of interfacial tension in polymer systems. Journal of Polymer Science, Vol. 34, p. 19-30, 1071

116 BILlMEYER, F. W. Textbook of Polimer Science. 3rd Edition. Jonh Wiley \& Sons, Inc., p. 345-355, 1984

117 HOESCHT, Kunststoffe Hoescht, Hostaform®, p. 10 - 38

118 BARBER, J. B. Is modeling a useful activity? Tribological Modeling for Mechanical Desiners, ASTM STP 1105, p. 165-172, 1991

119 UETZ, H., RICHTER, K \& WIEDEMEYER, J. System temperature and tribological behaviour of polymer-metal sliding ccouples in pin-on-disc model testing. Wear, Vol. 88, p. $103-114,1983$

120 COSTA NETO, P. L. O. Estatística. Editora Edgard Blucher, p.152-174, 1977

121 BOSCH, P.P. J. \& KLAUW, Modeling. Identification and Simulation of Dinamical Systems. CRC Press INC., 1994

122 BASSINI, R., DI PASQUALE, E. \& VITALI, C. Probabilistic model for metal-polymer friction. Wear, Vol 95, p. 177-191,1984

$123 \mathrm{McCOOL}$, J. I. Comparison of models for the contatct of rough surfaces. Wear, Vol. 107, p. $37-60,1986$

124 JAIN, V. K. \& BAHADUR, S. Development of wear equation for polymer-metal sliding in terms of the fatigue and topography sliding surfaces. Wear, Vol 9, p. 329-348, 1966

125 MADAKSON, P. B. - The friction behaviour of materials. Wear, Vol 87, p. 191-206,1983

126 VISWANATH, N. \& BELLOW, D. G. Development of an equation for the wear of polymers. Wear, Vol 181-183, p. 42-49,1995 
127 JONES, S.P., JANSEN R \& FUSARO, R. L. Preliminary investigation of neural network techniques to predict tribological properties. Tribology Transactions, Vol. 40 (2), p. 312-320, 1997

128 VELTEN, K., REINICKE, R.; FRIEDRICH. K. Wear volume prediction with artificial neural networks. Tribology International, Vol. 33, p. 731-736, 2000.

129 TANAKA, K. and NAGAI, T., 1985, "Effect of counterface on the friction and wear of polytetrafluoroethylene and polyethylene" Conference of Wear of Materials, ASME, New York, p. 397- 404, 1985

130RHEE, S. K. Wear equation for polymer sliding against metal surface. Wear, Vol. 16, p.431-445, 1970

131 KAR, M. K. \& BAHADUR, S. The wear equation for unfilled and filled polyoxymethylene. Wear, Vol. 30, p. 337-348, 1974

132 BLAU, P. J. Friction Science and Technology, Marcell Dekker Inc., p. 251-284, 1996 